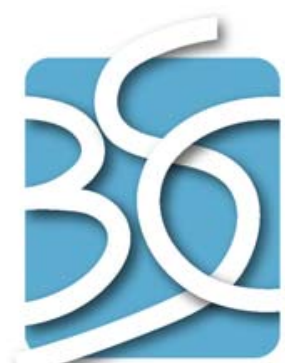

BECHTEL SAIC COMPANYLC
QA: QA

MDL-NBS-HS-000015 REV 01

September 2004

\title{
Drift-Scale Coupled Processes (DST and TH Seepage) Models
}

Prepared for:

U.S. Department of Energy

Office of Civilian Radioactive Waste Management

Office of Repository Development

1551 Hillshire Drive

Las Vegas, Nevada 89134-6321

Prepared by:

Bechtel SAIC Company, LLC

1180 Town Center Drive

Las Vegas, Nevada 89144

Under Contract Number

DE-AC28-01RW12101 


\section{DISCLAIMER}

This report was prepared as an account of work sponsored by an agency of the United States Government. Neither the United States Government nor any agency thereof, nor any of their employees, nor any of their contractors, subcontractors or their employees, makes any warranty, express or implied, or assumes any legal liability or responsibility for the accuracy, completeness, or any third party's use or the results of such use of any information, apparatus, product, or process disclosed, or represents that its use would not infringe privately owned rights. Reference herein to any specific commercial product, process, or service by trade name, trademark, manufacturer, or otherwise, does not necessarily constitute or imply its endorsement, recommendation, or favoring by the United States Government or any agency thereof or its contractors or subcontractors. The views and opinions of authors expressed herein do not necessarily state or reflect those of the United States Government or any agency thereof. 
QA: QA

Drift-Scale Coupled Processes (DST and TH Seepage) Models MDL-NBS-HS-000015 REV 01

September 2004 


\begin{tabular}{|l|l|l|}
\hline OCRWM & MOdel SignatURe PAge/ChANGE History & Page iii \\
\cline { 3 - 3 } & 1. Total Pages: 384 \\
\hline
\end{tabular}

2. Type of Mathematical Model

$\triangle$ Process Model $\quad \square$ Abstraction Mode! $\square$ System Model

Describe Intended Use of Model

Thermal Hydrological (TH) Seepage Model is used to simulate the fluid flow down to the drift and to calculate transient seepage rates into the drift.

3. Title

Drift-Scale Coupled Processes (DST and TH Seepage) Models

4. DI (including Rev. No., if applicable):

MDL-NBS-HS-000015 REV 01

5. Total Appendices

6. No. of Pages in Each Appendix

Eight (8)

A-4, B-4, C-18, D-4, E-4; F-6; G-8; H-4

\begin{tabular}{|c|c|c|c|}
\hline & Printed Name & Signature & Date \\
\hline 7. Originator & $\begin{array}{l}\text { J.T. Birkholzer/ } \\
\text { S. Mukhopadhyay }\end{array}$ & & $\begin{array}{l}9 / 28 / 04 \\
04 / 28 / 2004\end{array}$ \\
\hline $\begin{array}{l}\text { 8. Independent Technical } \\
\text { Reviewer }\end{array}$ & R. Andrews & & $9 / 29 / 04$ \\
\hline 9. Checker & Y. Seol & & $9 / 28 / 04$ \\
\hline 10. QER & K. Gilkerson & & itzes \\
\hline 11. Responsible Manager/Lead & C. Howard & & $9 / 29 / 04$ \\
\hline 12. Responsible Manager & E. Hardin & & $9 / 29 / 04$ \\
\hline
\end{tabular}

13. Remarks

Y.T. Tsang also contributed to the development of Section 7.

Change History

\begin{tabular}{|l|l|}
\hline \multicolumn{1}{|c|}{ 14. Revision No. } & \multicolumn{1}{|c|}{ 15. Description of Change } \\
\hline REV 00 & Not issued. Draft REV00G was renumbered as Draft REV01A. \\
\hline REV 01 & Initial Issue. This report addresses the closure of CR-20S0(B), and TBV-5768. \\
\hline
\end{tabular}




\section{INTENTIONALLY LEFT BLANK}




\section{CONTENTS}

Page

ACRONYMS AND ABBREVIATIONS ....................................................................... xix

1. PURPOSE ............................................................................................................... 1

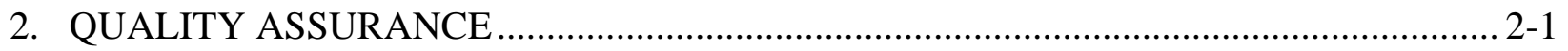

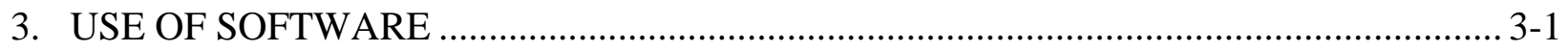

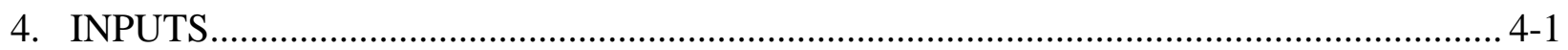

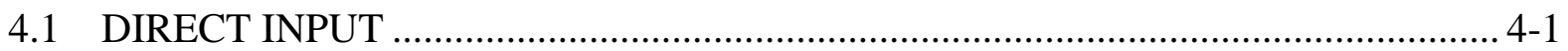

4.1.1 Direct Input Data for TH Seepage Model .................................................. 4-1

4.1.1.1 Hydrological and Thermal Properties of Fractured Rock .............. 4-1

4.1.1.2 Model Boundary Conditions ..................................................... 4-4

4.1.1.3 Thermal Load and Ventilation Efficiency...................................4-6

4.1.1.4 Percolation Fluxes .................................................................... 4-8

4.1.1.5 Grid Design Data................................................................ 4-9

4.1.1.6 In-Drift Geometry and Properties .......................................... 4-11

4.1.2 Input Data for DST TH Model ............................................................ 4-12

4.1.2.1 Hydrological and Thermal Properties ........................................ 4-12

4.1.2.2 Model Boundary Conditions .................................................... 4-13

4.1.2.3 Heat Input .......................................................................... 4-13

4.1.2.4 Borehole and Sensor Location Data.......................................... 4-13

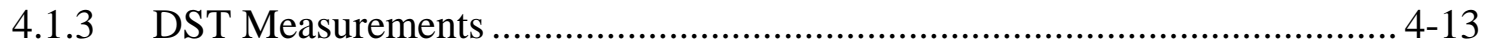

4.1.3.1 Temperature Measurements ...................................................... 4-14

4.1.3.2 Ground-Penetrating Radar Data ............................................... 4-14

4.1.3.3 Air-Permeability Measurements ............................................. 4-14

4.1.3.4 Water Sampling Data .......................................................... 4-14

4.1.4 Input Data for DTN: LB0402THRMLPRP.001 .................................... 4-14

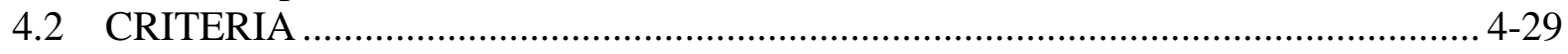

4.3 CODES, STANDARDS, AND REGULATIONS .............................................. 4-36

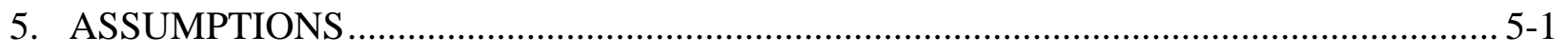

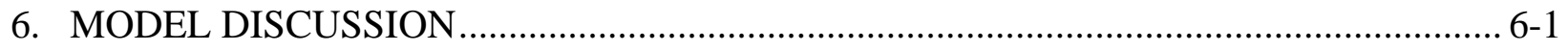

6.1 COUPLED TH PROCESSES AND THERMAL SEEPAGE ................................ 6-3

6.1.1 Heat Transfer and Moisture Redistribution .............................................. 6-3

6.1.2 Thermal Seepage ............................................................................... 6-5

6.2 TH SEEPAGE MODEL ............................................................................ 6-7

6.2.1 TH Model Description.................................................................. 6-7

6.2.1.1 Conceptual Model and Mathematical Formulation.......................6-7

6.2.1.2 Model Dimensionality, Model Domain and Numerical Grid ...... 6-15

6.2.1.3 Model Boundary Conditions, Initial Conditions, and Thermal

Load............................................................................... 6-22

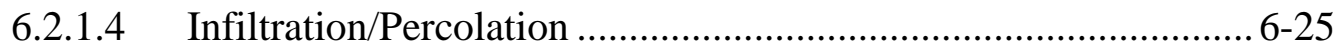




\section{CONTENTS (CONTINUED)}

Page

6.2.1.5 Properties of Fractured Rock and In-Drift Properties . 6-26

6.2.1.6 Overview of Simulation Cases Studied with the TH Seepage Model ........................................................................................... 6-28

6.2.2 Simulation Results for the Tptpmn Submodel .......................................... 6-34

6.2.2.1 Drift-Scale Thermal-Hydrological Behavior and Sensitivities .... 6-34

6.2.2.2 Thermal Seepage .................................................................... 6-58

6.2.3 Simulation Results for the Tptpll Submodel ........................................... 6-77

6.2.3.1 Drift-Scale Thermal-Hydrological Behavior............................. 6-77

6.2.3.2 Thermal Seepage .................................................................... 6-82

6.2.4 Discussion of TH Seepage Model Results ............................................ 6-87

6.2.4.1 Recommendations for Thermal Seepage Abstraction .................. 6-89

6.2.4.2 Sensitivity Studies for Thermal Seepage Abstraction.................. 6-90

6.2.5 TH Conditions in Collapsed Drifts......................................................... 6-113

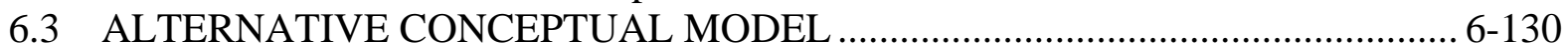

6.3.1 Modeling Procedure and Conceptual Model............................................ 6-133

6.3.1.1 Modeling Procedure ............................................................ 6-133

6.3.1.2 Characteristics of Episodic Preferential Flow and Conceptual

Flow Model .............................................................................. 6-133

6.3.1.3 Water Penetration into Superheated Rock .............................. 6-138

6.3.2 ACM Application for the Tptpmn Unit................................................ 6-139

6.3.2.1 Results for Cases 1 and 2 (Mean Cases) ................................. 6-139

6.3.2.2 Sensitivity Cases ............................................................. 6-147

6.3.3 Application for the Tptpll Unit...................................................... 6-151

6.3.4 Discussion of THMEFF Results.......................................................... 6-153

6.3.5 Discussion of Other Alternative Numerical Approaches .......................... 6-154

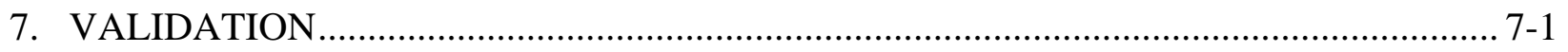

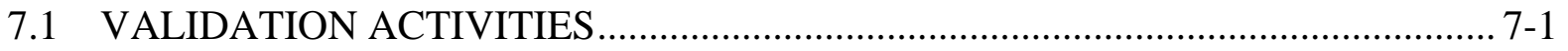

7.1.1 Confidence Building During Model Development to Establish Scientific

Basis and Accuracy for Intended Use ....................................................... 7-1

7.1.2 Confidence Building After Model Development to Support the Scientific

Basis of the Model...................................................................................... 7-3

7.1.3 Corroboration of Model Results with Experimental Data............................. 7-4

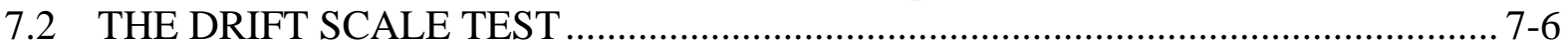

7.2.1 Design and Geometry .................................................................... 7-6

7.2.2 Measurements to Probe the Coupled Processes .......................................... 7-8

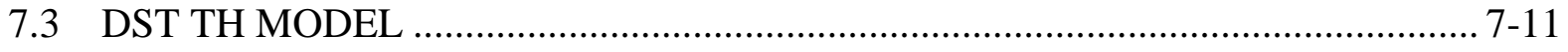

7.3.1 Stages of Model Development .......................................................... 7-11

7.3.2 Conceptual Model and Mathematical Formulation..................................... 7-13

7.3.3 Model Domain and Numerical Grid................................................... 7-13

7.3.4 Model Boundary and Initial Conditions ............................................... 7-16

7.3.5 Model Parameters and Rock Properties ................................................. 7-18

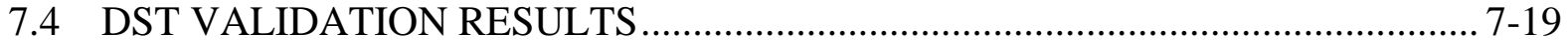




\section{CONTENTS (CONTINUED)}

\section{Page}

7.4.1 DST Data Used for Validation and Validation Criteria .............................. 7-19

7.4.2 Statistical Measures for Temperature Evaluation ...................................... 7-22

7.4.3 Comparative Analysis of Measurements and Results from Simulations with Site-Specific Property Set

7.4.3.1 Temperature ........................................................................ 7-23

7.4.3.2 Water Redistribution: Matrix Saturation.................................... 7-34

7.4.3.3 Water Redistribution: Fracture Saturation ............................... 7-39

7.4.4 Comparative Analysis of the Site-Specific Property and the Calibrated Property Set

$7-52$

7.4.4.1 Temperature ................................................................. 7-52

7.4.4.2 Water Redistribution: Matrix Saturation.................................. 7-57

7.4.4.3 Water Redistribution: Fracture Saturation and Water Flux......... 7-59

7.5 DISCUSSION OF VALIDATION ACTIVITIES ........................................... 7-61

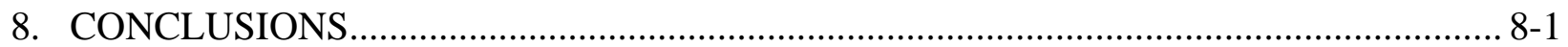

8.1 SUMMARY AND CONCLUSIONS ….............................................................. 8-1

8.2 IMPLICATIONS FOR ABSTRACTION OF THERMAL SEEPAGE IN INTACT

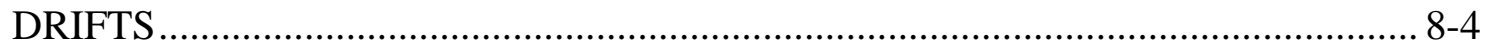

8.3 MODEL VALIDATION AND UNCERTAINTIES ….......................................... 8-5

8.4 HOW THE APPLICABLE ACCEPTANCE CRITERIA ARE ADDRESSED........... 8-7

8.5 OUTPUT DTNS ................................................................................. 8-13

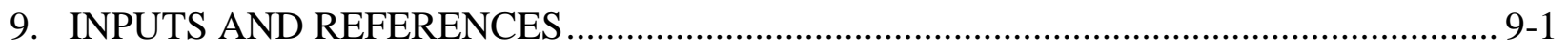

9.1 DOCUMENTS CITED ................................................................................ 9-1

9.2 CODES, STANDARDS, REGULATIONS, AND PROCEDURES ........................ 9-11

9.3 SOURCE DATA, LISTED BY DATA TRACKING NUMBER ............................ 9-12

9.4 OUTPUT DATA, LISTED BY DATA TRACKING NUMBER ...........................9-15

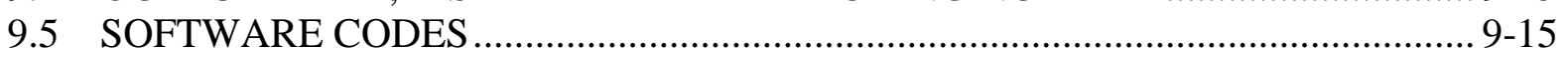

APPENDIX A - RANDOM PERMEABILITY FIELDS GENERATED WITH EXCEL ........ A-1 APPENDIX B - ARITHMETIC AVERAGE FOR INFILTRATION VALUES .......................B-1 APPENDIX C - SENSITIVITY TO REVISED MATRIX POROSITY AND THERMAL PROPERTIES .................................................................................

APPENDIX D - TOP AND BOTTOM MODEL BOUNDARY CONDITIONS .................... D-1 APPENDIX E - EXTRACTION OF CONTACT ELEVATION FROM THREE-DIMENSIONAL UZ NUMERICAL GRIDS ...............................E-1

APPENDIX F - DERIVATION OF THERMAL PROPERTIES FOR UZ MODEL LAYERS IN DTN: LB0402THRMLPRP.001 …......................................................F-1 


\section{CONTENTS (CONTINUED)}

Page

APPENDIX G - QUALIFICATION OF DATA FROM DTN: SN9908T0872799.004 FOR INTENDED USE IN THIS REPORT..................................................... G-1

APPENDIX H - DATA QUALIFICATION PLAN FOR QUALIFICATION OF VENTILATION EFFICIENCY VALUE ....................................................... $\mathrm{H}-1$ 


\section{FIGURES}

\section{Page}

6.1-1. Schematic of TH Processes at the Drift Scale and the Mountain Scale................. 6-6

6.2.1.2-1. Tptpmn Submodel Mesh with Close-Up View of Drift Vicinity ......................... 6-19

6.2.1.2-2. Discretization Inside of the Drift and of the Immediate Drift Vicinity in the Tptpmn Submodel and the Tptpll Submodel .................................................... 6-20

6.2.1.2-3. Tptpll Submodel Mesh with Close-Up View of Drift Vicinity .......................... 6-21

6.2.1.6-1. Overview of Simulation Cases for the Tptpmn Submodel ................................. 6-29

6.2.1.6-2. Overview of Simulation Cases for the Tptpll Submodel .................................. 6-30

6.2.2.1-1. Rock Temperature at the Drift Crown for Tptpmn Submodel (Simulation

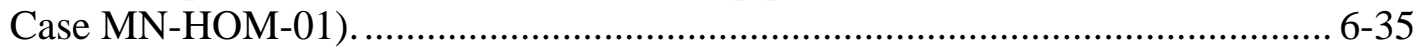

6.2.2.1-2. (a) Matrix Saturation and (b) Fracture Saturation at the Drift Crown for Tptpmn Submodel (Simulation Case MN-HOM-01) ....................................... 6-37

6.2.2.1-3. Matrix Saturation and Temperature for Tptpmn Submodel (Simulation Case MN-HOM-01) at (a) 100 Years and (b) 500 Years after Emplacement ............... 6-38

6.2.2.1-4. Matrix Saturation and Temperature for Tptpmn Submodel (Simulation Case MN-HOM-01) at (a) 1,000 Years and (b) 2,000 Years after Emplacement ......... 6-39

6.2.2.1-5. Fracture Saturation and Liquid Flux for Tptpmn Submodel (Simulation Case MN-HOM-01) at (a) 100 Years and (b) 500 Years after Waste Emplacement .... 6-41

6.2.2.1-6. Fracture Saturation and Liquid Flux for Tptpmn Submodel (Simulation Case MN-HOM-01) at (a) 1,000 Years and (b) 2,000 Years after Waste Emplacement.

6.2.2.1-7. (a) Fracture Saturation and (b) Vertical Liquid Flux in a Vertical Cross Section above Drift Crown for Tptpmn Submodel (Simulation Case MN-HOM-01).

6.2.2.1-8. Rock Temperature at the Drift Crown for Tptpmn Submodel with Different Infiltration Scenarios.

6.2.2.1-9. (a) Matrix Saturation and (b) Fracture Saturation at the Drift Crown for Tptpmn Submodel with Different Infiltration Scenarios

6.2.2.1-10. (a) Fracture Saturation and (b) Vertical Liquid Flux in a Vertical Cross Section above Drift Crown, for Tptpmn Submodel with a Flux Multiplication Factor of 5 (Simulation Case MN-HOM-02).....

6.2.2.1-11. (a) Fracture Saturation and (b) Vertical Liquid Flux in a Vertical Cross Section above Drift Crown, for a Tptpmn Submodel with a Flux Multiplication Factor of 10 (Simulation Case MN-HOM-03)...

6.2.2.1-12. Rock Temperature at the Drift Crown for Tptpmn Submodel with Different Thermal Loads ....

6.2.2.1-13. (a) Matrix Saturation and (b) Fracture Saturation at the Drift Crown for Tptpmn Submodel with Different Thermal Loads.

6.2.2.1-14. (a) Fracture Saturation and (b) Vertical Liquid Flux in a Vertical Cross Section above Drift Crown for Tptpmn Submodel with High-Temp Mode (Simulation Case MN-HOM-04)....

6.2.2.1-15. (a) Fracture Saturation and (b) Vertical Liquid Flux in a Vertical Cross Section above Drift Crown for Tptpmn Submodel with Low-Temp Mode (Simulation Case MN-HOM-05). $6-53$ 


\section{FIGURES (CONTINUED)}

Page

6.2.2.1-16. Matrix Saturation and Temperature at 500 Years after Emplacement for Tptpmn Submodel with SCM Capillary-Strength Parameter (Simulation Case MN-HOM-06)

6.2.2.1-17. Fracture Saturation and Liquid Flux at 500 Years after Emplacement for Tptpmn Submodel with SCM Capillary-Strength Parameter (Simulation Case MN-HOM-06).

6.2.2.1-18. (a) Fracture Saturation and (b) Vertical Liquid Flux in a Vertical Cross Section above Drift Crown for Tptpmn Submodel with SCM CapillaryStrength Parameter (Simulation Case MN-HOM-06)

6.2.2.2-1. Fracture Permeability Distribution in $\log (\mathrm{k})$ for Heterogeneous Realization

6.2.2.2-2. (a) Fracture Temperature and (b) Fracture Saturation at the Drift Crown for Tptpmn Submodel with Heterogeneous Permeability Field (Simulation Case MN-HET-01, Realization 1), in Comparison with Homogeneous Simulation Run (Simulation Case MN-HOM-06) ....

6.2.2.2-3. Fracture Saturation and Liquid Flux for Tptpmn Submodel with Heterogeneous Permeability Field (Simulation Case MN-HET-01, Realization 1) at (a) 100 Years and (b) 500 Years after Waste Emplacement ..... 6-66

6.2.2.2-4. Fracture Saturation and Liquid Flux for Tptpmn Submodel with Heterogeneous Permeability Field (Simulation Case MN-HET-01, Realization 1) at (a) 1,000 Years and (b) 2,000 Years after Waste Emplacement. 6-67

6.2.2.2-5. Rock Temperature along Drift Periphery for Tptpmn Submodel with Different Infiltration Scenarios .... 6-68

6.2.2.2-6. TH Conditions for Tptpmn Submodel with Flux Multiplication Factor 5 (Simulation Case MN-HET-02, Realization 1)...

6.2.2.2-7. TH Conditions for Tptpmn Submodel with Flux Multiplication Factor 10 (Simulation Case MN-HET-03, Realization 1)...

6.2.2.2-8. TH Conditions for Tptpmn Submodel with Flux Multiplication Factor 5 (Simulation Case MN-HET-02, Realization 2)...

6.2.2.2-9. TH Conditions for Tptpmn Submodel with Flux Multiplication Factor 10 (Simulation Case MN-HET-03, Realization 2) .... 6-74

6.2.2.2-10. Fracture Saturation for Tptpmn Submodel with Flux Multiplication Factor 5 (Simulation Case MN-HET-02, Realization 3) ...

6.2.2.2-11. TH Conditions for Simulation Run with Flux Multiplication Factor 10 (Simulation Case MN-HET-03, Realization 3) ... 6-76

6.2.3.1-1. Rock Temperature at the Drift Crown for Tptpll Submodel (Simulation Case LL-HOM-01) Compared to Tptpmn Submodel (Simulation Case MN-HOM01).

6.2.3.1-2. Matrix Saturation (a) and Fracture Saturation (b) at the Drift Crown for Tptpll Submodel (Simulation Case LL-HOM-01) Compared to Tptpmn Submodel (Simulation Case MN-HOM-01). 


\section{FIGURES (CONTINUED)}

Page

6.2.3.1-3. Fracture Saturation (a) and Vertical Liquid Flux (b) in a Vertical Cross Section above Drift Crown for Tptpll Submodel (Simulation Case LL-HOM-01) $6-81$

6.2.3.2-1. Fracture Saturation for Tptpll Submodel with Flux Multiplication Factor 5 (Simulation Case LL-HET-01, Realization 1).

6.2.3.2-2. TH Conditions for Tptpll Submodel with Flux Multiplication Factor 10 (Simulation Case LL-HET-02, Realization 1) $6-86$

6.2.4.1-1. Possible Abstraction Model for Thermal Seepage Percentage as a Function of Time after Waste Emplacement

6.2.4.2-1. Rock Temperature for Tptpmn Submodel with Different Flux Multiplication Factors and Reference Mode Thermal Load

6.2.4.2-2. $\quad$ Rock Temperature for Tptpmn Submodel with Different Heat Loads and Flux Multiplication Factor 10.

6.2.4.2-3. Seepage Percentage for Tptpmn Submodel with Different Heat Loads and Flux Multiplication Factor 10 Showing Results from Thermal Run and from Long-Term Ambient Runs

6.2.4.2-4. Seepage Percentage for Tptpmn Submodel with Different Heat Loads and Flux Multiplication Factor 20, Showing Results from Thermal Run and from Long-Term Ambient Runs.

6.2.4.2-5. Rock Temperature for Tptpmn Submodel with Flux Multiplication Factor of 100 and Reference Mode Thermal Load

6.2.4.2-6. Seepage Percentage for Tptpmn Submodel with Flux Multiplication Factor 100 and Reference Mode Thermal Load Showing Results from Thermal Run and from Long-Term Ambient Runs.

6.2.4.2-7. Seepage Percentage for Tptpmn Submodel with a Fracture CapillaryStrength Parameter of $1 / \alpha=400 \mathrm{~Pa}$, Showing Results from Thermal Run and from Long-Term Ambient Runs

6.2.4.2-8. $\quad$ Rock Temperature Evolution at the Drift Wall for Tptpmn Submodel Showing Different Fracture Permeability Simulations for Reference Thermal Mode Using Percolation Flux Scenario with Multiplication Factor 10

6.2.4.2-9. Seepage Percentage for Tptpmn Submodel for Reference Thermal Mode Using Percolation Flux Scenario with Multiplication Factor 10

6.2.4.2-10. Rock Temperature Evolution at the Drift Wall for Tptpmn Submodel Showing Different Thermal Conductivity Simulations for Reference Thermal Mode Using Percolation Flux Scenario with Multiplication Factor 10

6.2.4.2-11. Seepage Percentage for Tptpmn Submodel Showing Different Thermal Conductivity Simulations for Reference Thermal Mode Using Percolation Flux Scenario with Multiplication Factor 10.

6.2.4.2-12. Seepage Percentage Tptpmn Submodel Using a Standard Dual-Permeability Method, Showing Results from Thermal Run and from Long-Term Ambient Runs 


\section{FIGURES (CONTINUED)}

Page

6.2.4.2-13. Temperature at Drift Crown from Two Different Approaches Adopted for Calculating the Fracture Continuum Thermal Conductivities

6.2.4.2-14. Fracture Saturation at Drift Crown from Two Different Approaches Adopted for Calculating the Fracture Continuum Thermal Conductivities

6.2.4.2-15. Temperatures in the Fractures at the Drift Crown for Two Alternative Conceptualizations of Fracture-Matrix Interface Thermal Conductivity ........... 6-105

6.2.4.2-16. Fracture Saturation at the Drift Crown for Two Alternative Conceptualizations of Fracture-Matrix Interface Thermal Conductivity 6-106

6.2.4.2-17 Predicted Seepage Percentage for Two Alternative Conceptualizations of Fracture-Matrix Interface Thermal Conductivity

6.2.4.2-18. Temperatures in the Fractures at the Drift Wall for Two Alternative Thermal Conductivity Values Assigned to In-Drift Open-Cavity Elements.

6.2.4.2-19. Fracture Saturations at the Drift Wall for Two Alternative Thermal Conductivity Values Assigned to In-Drift Open-Cavity Elements.

6.2.4.2-20. Predicted Thermal Seepage Percentage for Two Alternative Thermal Conductivity Values Assigned to In-Drift Open-Cavity Elements.

6.2.4.2-21. Temperatures in the Fractures at the Drift Wall for Two Alternative Thermal Property Sets Assigned to Waste Package Elements.

6.2.4.2-22. Fracture Saturations at the Drift Wall for Two Alternative Thermal Property Sets Assigned to Waste Package Elements.

6.2.4.2-23. Predicted Thermal Seepage Percentage for Two Alternative Thermal Property Sets Assigned to Waste Package Elements ....

6.2.5-1. Schematic of TH Differences between an Open Non-Collapsed Drift and a Rubble-Filled Collapsed Drift.

6.2.5-2. Close-Up View of the Collapsed Drift Discretization and Properties Assignment

6.2.5-3. Rock Temperature Evolution for Base Case and 50\%-Contact Area Case at Three Representative Locations within and Close to Collapsed Drift....

6.2.5-4. Saturation and Temperature at 100 Years after Emplacement, for Fragmented Rock Blocks (within Collapsed Drift) and Matrix Rock (Outside of Collapsed Drift)

6.2.5-5. Saturation and Liquid Fluxes at 100 Years after Emplacement, for Void Space (within Collapsed Drift) and Fractures (Outside of Collapsed Drift) ...... 6-122

6.2.5-6. Saturation and Temperature at 1000 Years after Emplacement, for Fragmented Rock Blocks (within Collapsed Drift) and Matrix Rock (Outside of Collapsed Drift)

6.2.5-7. Saturation and Liquid Fluxes at 1,000 Years after Emplacement, for Void Space (within Collapsed Drift) and Fractures (Outside of Collapsed Drift) ...... 6-123

6.2.5-8. Saturation and Temperature at 2,000 Years after Emplacement, for Fragmented Rock Blocks (within Collapsed Drift) and Matrix Rock (Outside of Collapsed Drift)

6.2.5-9. Saturation and Liquid Fluxes at 2,000 Years after Emplacement, for Void Space (within Collapsed Drift) and Fractures (Outside of Collapsed Drift) ...... 6-124 


\section{FIGURES (CONTINUED)}

Page

6.2.5-10. Saturation and Temperature at 10,000 Years after Emplacement, for Fragmented Rock Blocks (within Collapsed Drift) and Matrix Rock (Outside of Collapsed Drift)

6.2.5-11. Saturation and Liquid Fluxes at 10,000 Years after Emplacement, for Void Space (within Collapsed Drift) and Fractures (Outside of Collapsed Drift) ...... 6-125

6.2.5-12. Downward Flux in the Fractures/Voids along a Vertical Line through the Center of the Collapsed Drift for Base Case Simulation

6.2.5-13. Downward Flux in the Fractures/Voids along a Vertical Line through the Center of the Collapsed Drift for Simulation with Limited Contact Area (50\% Contact Area)

6.2.5-14. Evolution of Relative Humidity in the Rubble Material Immediately Above the Drip Shield, for Base Case and 50\%-Contact Area Case

6.2.5-15. Rock Temperature Evolution for Percolation Flux Scenario with Multiplication Factor of 10 Compared to Base Case at Three Representative Locations within and Close to Collapsed Drift.

6.2.5-16. Downward Flux in the Fractures/Voids Along a Vertical Line through the Center of the Collapsed Drift, for Percolation Flux Scenario with a Multiplication Factor of 10

6.3-1. (a) Schematic Illustration of Conceptual Model for Finger Flow in a Vertical Fracture above a Drift with Heat Conduction from the Adjacent Rock, and (b) Episodic Finger Flow in Unsaturated Fractured Rock in the Vicinity of Waste Emplacement Drifts

6.3.2.1-1. Maximum Penetration of Tip of Finger versus Time at 550 Years of Heating for Case 1 and Case 2 (Tptpmn Unit).

6.3.2.1-2. Total Water Mass Breakthrough at Location z at 550 Years of Heating for Case 1 and Case 2 (Tptpmn Unit)

6.3.2.1-3. $\quad$ Predicted Wall Temperature History in and Extent of Superheated Rock above Waste Emplacement Drifts for Tptpmn Unit

6.3.2.1-4. Maximum Penetration and Percentage of Water Mass Arriving at Drift Crown for Case 1 (Tptpmn Unit)

6.3.2.1-5. Ratio of Thermally Perturbed Vertical Flux and Ambient Percolation for Case 1 (Tptpmn Unit), at Fourteen Different Time Steps after Waste Emplacement.

6.3.2.1-6. Maximum Penetration and Percentage of Water Mass Arriving at Drift Crown for Case 2 (Tptpmn Unit)

6.3.2.1-7. Ratio of Thermally Perturbed Vertical Flux and Ambient Percolation for Case 2 (Tptpmn Unit)

6.3.2.2-1. Ratio of Thermally Perturbed Vertical Flux and Ambient Percolation, Showing Sensitivity of Model Results to (a) Fracture Aperture (Cases 1, 1a, 1b) and (b) Initial Water Volume (Cases 1, 1c, 1d)....

6.3.2.2-2. Ratio of Thermally Perturbed Vertical Flux and Ambient Percolation, Showing Sensitivity of Model Results to (a) Fracture Aperture (Case 2, 2a, 2b) and (b) Initial Water Volume (Case 2, 2c, 2d) 6-150 


\section{FIGURES (CONTINUED)}

Page

6.3.3-1. $\quad$ Predicted Wall Temperature History in and Extent of Superheated Rock above Waste Emplacement Drifts for Tptpll Unit....

6.3.3-2. Maximum Penetration and Percentage of Water Mass Arriving at Drift Crown for Case 1 (Tptpll Unit).

6.3.3-3. Ratio of Thermally Perturbed Vertical Flux and Ambient Percolation for Case 1 (Tptpll Unit) .

7.2.1-1. $\quad$ Plan View of DST Area .

7.2.1-2. Three-Dimensional Perspective of the As-Built Borehole Configuration of the DST

7.2.2-1. Three-Dimensional Perspective of Wing Heaters and Temperature Boreholes in the DST. $7-10$

7.2.2-2. Three-Dimensional Perspective of Wing Heaters and Hydrology Boreholes in the DST

7.2.2-3. Three-Dimensional Perspective of Wing Heaters and Boreholes for Geophysical Measurements (GPR and Neutron Logging) in the DST ................ 7-11

7.3.3-1. Vertical Cross Section of DST Numerical Grid ............................................ 7-14

7.3.3-2. Detailed View of Vertical Cross Section of DST Numerical Grid through Plane Containing Temperature Boreholes 158 to 165. 7-15

7.3.3-3. Detailed View of Vertical Cross Section of DST Numerical Grid through Plane Containing Hydrology Boreholes 57 to 61

7.4.3.1-1. Measured and Simulated Temperature Profile in Boreholes 158, 159, and 160 at Different Times of Heating: (a) 12 months, (b) 24 months, (c) 36, and (d) 48 months .

7.4.3.1-2 Measured and Simulated Temperature Profile at 5 Months of Cooling in Boreholes 158, 159, and 160.

7.4.3.1-3. Temporal Evolution of Temperature in Selected Sensors of Boreholes (a) 160, (b) 59, and (c) 60 .

7.4.3.2-1 Change in Matrix Saturation from Preheat Saturation (a) Measured GPR Results in Boreholes 49 to 51 in January 1999 (Approximately 14 Months of Heating) and (b) Simulated Results at 12 Months of Heating....

7.4.3.2-2. Change in Matrix Saturation from Preheat Saturation (a) Measured GPR Data in Boreholes 49 to 51 in October 1999 (Approximately 23 Months of Heating) and (b) Simulated Results at 24 Months of Heating.....

7.4.3.2-3. Change in Matrix Saturation from Preheat Saturation (a) Measured GPR Data in Boreholes 49 to 51 in January 2002 (Near the End of Heating) and

(b) Simulated Results at End of Heating Phase...

7.4.3.3-1. S Simulated Contours of Fracture Saturation in Hydrology Boreholes 57 to 61 at Different Times of Heating (a) 12 Months, (b) 18 Months, (c) 24 Months, and (d) at End of Heating Period

7.4.3.3-2. $\quad$ Measured and Simulated Air-Permeability Ratios in Hydrology Boreholes

(a) 59, (b) 60, and (c) 61 7-45

7.4.3.3-3. Contours of Change in Fracture Saturation from End of Heating to 6 Months of Cooling 


\section{FIGURES (CONTINUED)}

Page

7.4.3.3-4. Simulated Fracture Saturation in Borehole Intervals (a) 59-2, (b) 59-3, (c) 59-4, (d) 60-2, (e) 60-3, (f) 76-2, (g) 76-3, and (h) 186-3

7.4.4.1-1. Comparison of Simulated Temperature Profiles in Boreholes 158, 159, and 160 Using the Site-Specific and DS/AFM-UZ02-Mean Property Sets at (a) 24 Months of Heating and at (b) the End of the Heating Period

7.4.4.1-2. Comparison of Simulated Temporal Evolution of Temperature Using the Site-Specific and DS/AFM-UZ02-Mean Property Sets for Selected Sensors of (a) Borehole 160, (b) Hydrology Borehole 59, and (c) Hydrology Borehole 60

7.4.4.2-1. Simulated Contours of Matrix Liquid Saturation at End of Heating Using (a) the DS/AFM-UZ02-Mean Property Set and (b) the Site-Specific Property Set

7.4.4.3-1. Simulated Contours of Fracture Saturation and Fracture Flux at 12 Months of Heating Using (a) the DS/AFM-UZ02-Mean Property Set and (b) the Site-Specific Property Set

C-1. $\quad$ Evolution of Rock Temperature at the Drift Crown for Tptpmn Submodel, Comparing New vs. Previous Thermal Properties (Simulation Cases MN HOM-NEW-01 vs. MN HOM-01).

C-2. Evolution of Matrix Saturation at the Drift Crown for Tptpmn Submodel, Comparing New vs. Previous Thermal Properties (Simulation Cases MN HOM-NEW-01 vs. MN HOM-01)...

C-3. Evolution of Fracture Saturation at the Drift Crown for Tptpmn Submodel, Comparing New vs. Previous Thermal Properties (Simulation Cases MN HOM-NEW-01 vs. MN HOM-01)....

C-4. $\quad$ (a) Fracture Saturation and (b) Vertical Liquid Flux in a Vertical Cross Section above Drift Crown for Tptpmn Submodel, Comparing New vs. Previous Thermal Properties (Simulation Cases MN HOM-NEW-01 vs. MN HOM-01) ..C-10

C-5. Evolution of Rock Temperature for Tptpmn Submodel with Flux Multiplication Factor 1 (Realization 1), Comparing New vs. Previous Thermal Properties (Simulation Cases MN HET-NEW-01 vs. MN HET-01) ......C-11

C-6. Evolution of Fracture Saturation for Tptpmn Submodel with Flux Multiplication Factor 1 (Realization 1), Comparing New vs. Previous Thermal Properties (Simulation Cases MN HET-NEW-01 vs. MN HET-01) .....C-11

C-7. Evolution of Rock Temperature for Tptpmn Submodel with Flux Multiplication Factor 5 (Realization 1), Comparing New vs. Previous Thermal Properties (Simulation Cases MN HET-NEW-02 vs. MN HET-02) ......C-12

C-8. Evolution of Fracture Saturation for Tptpmn Submodel with Flux Multiplication Factor 5 (Realization 1), Comparing New vs. Previous Thermal Properties (Simulation Cases MN HET-NEW-02 vs. MN HET-02).....C-12 C-9. Evolution of Thermal Seepage for Tptpmn Submodel with Flux Multiplication Factor 5 (Realization 1), Comparing New vs. Previous Thermal Properties (Simulation Cases MN HET-NEW-02 vs. MN HET-02).....C-13 


\section{FIGURES (CONTINUED)}

Page

C-10. Evolution of Thermal Seepage for Tptpmn Submodel with Flux Multiplication Factor 10 (Realization 1), Comparing New vs. Previous Thermal Properties (Simulation Cases MN HET-NEW-03 vs. MN HET-03) .....C-13

C-11. Evolution of Thermal Seepage for Tptpmn Submodel with Flux Multiplication Factor 10 (Realization 1), Comparing New vs. Previous Thermal Properties (Simulation Cases MN HET-NEW-03 vs. MN HET-03) .....C-14

C-12. Evolution of Rock Temperature at the Drift Crown for Tptpll Submodel, Comparing New vs. Previous Thermal Properties (Simulation Cases LL HOM-NEW-01 vs. LL HOM-01).

C-13. Evolution of Matrix Saturation at the Drift Crown for Tptpll Submodel, Comparing New vs. Previous Thermal Properties (Simulation Cases LL HOM-NEW-01 vs. LL HOM-01) ...................................................................... 15

C-14. Evolution of Fracture Saturation at the Drift Crown for Tptpll Submodel, Comparing New vs. Previous Thermal Properties (Simulation Cases LL HOM-NEW-01 vs. LL HOM-01)

C-15. (a) Fracture Saturation and (b) Vertical Liquid Flux in a Vertical Cross Section above Drift Crown for Tptpll Submodel, Comparing New vs. Previous Thermal Properties (Simulation) 


\section{TABLES}

Page

3-1. Qualified Software Used in This Report....................................................... 3-2

4.1-1. Direct Input Data to the TH Seepage Model ................................................. 4-16

4.1-2. Summary of Hydrological and Thermal Properties of Geologic Units Tptpul, Tptpmn, and Tptpll ........................................................................................ 4-17

4.1-3. Summary Statistics of Estimated Capillary-Strength Parameter for Lower Lithophysal Zone and Middle Nonlithophysal Zone from Seepage

Calibration Model ....

4.1-4. Intermediate-Scale Variability Statistics of Estimated Capillary-Strength

Parameter over Repository Rock Block, Using Different Calculation

Methods

4.1-5. Mean and Standard Deviation of Log-Air-Permeability Values of Disturbed

Zones (Post-Excavation) from Niches and Systematic Testing Boreholes

SYBT-ECRB-LA\#2.

4.1-6. $\quad$ Top and Bottom Boundary Conditions for the Tptpmn and Tptpll

Submodels.

4.1-7. Statistics of Percolation Flux Distributions at the PTn/TSw Interface.

4.1-8. Comparison of Adopted and Revised Values of Elevation and Thickness of

Stratigraphic Layers for the Tptpmn Submodel..

4.1-9. Comparison of Adopted and Revised Values of Elevation and Thickness of

Stratigraphic Layers for the Tptpll Submodel ....

4.1-10. In-Drift Geometry and Property Choices for TH Seepage Model ....................... 4-24

4.1-11. Input Data for DST TH Model (Corroborative Information) ............................. 4-27

4.1-12. Measured Data Used for Model Validation (Corroborative Information)............ 4-28

4.1-13. Input Data for LB0402THRMLPRP.001.................................................... 4-29

4.2-1. $\quad$ Project Requirements and YMRP Acceptance Criteria Applicable to This

Report........................................................................................... 4-29

6-1. $\quad$ Scientific Notebooks Used in This Report................................................... 6-2

6-2. $\quad$ FEPs Addressed in This Report ................................................................. 6-2

6.2.1.3-1. TH Seepage Model Boundary Conditions ..................................................... 6-23

6.2.1.4-1. Infiltration Boundary Condition for the TH Seepage Model............................. 6-26

6.2.1.6-1. List of Simulation Cases for the Tptpmn Submodel and Tptpll Submodel.......... 6-31

6.2.2.2-1. Seepage Percentage from Steady-State Simulation Runs Performed with the

Tptpmn Submodel, Using Different Infiltration Scenarios and Different

Realizations.

6.2.3.2-1. Seepage Percentage from Steady-State Simulation Runs Performed with the

Tptpll Submodel (Realization 1), Using Different Infiltration Scenarios and

Two Different Fracture Capillary-Strength Parameter Values

6.3.1.2-1. Suite of Episodic Flow Events Analyzed with the TH Model for Episodic

Finger Flow ...................................................................................... 6-137

7.3.4-1. Total Average Heater Power at Various Times of Heating in the DST............... 7-18

7.4.3.1-1. Statistical Comparison of Measured and Simulated Temperatures ..................... 7-33

B-1. $\quad$ Average Infiltration Values for Different Climate Periods...................................

C-1. $\quad$ Summary of Revised and Original Rock Matrix Properties ..................................3 


\section{TABLES (Continued)}

Page

C-2. $\quad$ List of Simulation Cases Using Revised Properties .............................................4

F-1. $\quad$ Matrix Thermal Properties for the UZ Model Layers............................................3

F-2. $\quad$ Bulk Thermal Conductivities of Repository Model Layers.................................F-4

F-3. $\quad$ Fault Thermal Properties.............................................................................F-4

G-1. Parameters and Values from DTN: SN9908T0872799.004 [DIRS 108437]

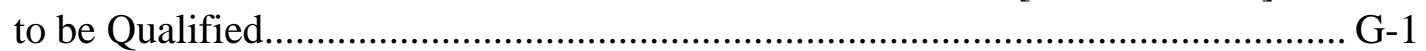

G- 2. In-Drift Geometry and Property Choices for TH Seepage Model....................... G-3 


\section{ACRONYMS AND ABBREVIATIONS}

\begin{tabular}{|c|c|}
\hline $\begin{array}{l}\text { ACM } \\
\text { AFM }\end{array}$ & $\begin{array}{l}\text { alternative conceptual model } \\
\text { active fracture model }\end{array}$ \\
\hline DFNM & discrete-fracture network method \\
\hline DKM & dual-permeability method/model \\
\hline DST & Drift Scale Test \\
\hline DTN & data tracking number \\
\hline ECRB & Enhanced Characterization of Repository Block \\
\hline ERT & electrical resistivity tomography \\
\hline ESF & Exploratory Studies Facility \\
\hline FEPs & features, events, and processes \\
\hline GFM & geologic framework model \\
\hline GPR & ground penetrating radar \\
\hline НТОМ & high-temperature thermal operating mode \\
\hline IED & information exchange drawing \\
\hline LA & license application \\
\hline LBT & Large Block Test \\
\hline PA & performance assessment \\
\hline QA & quality assurance \\
\hline SCM & seepage calibration model \\
\hline SHT & Single Heater Test \\
\hline SMPA & seepage model for performance assessment \\
\hline SSPA & $\begin{array}{l}\text { FY } 01 \text { Supplemental Science and Performance Analyses, Volume 1: Scientific } \\
\text { Bases and Analyses }\end{array}$ \\
\hline TDMS & Technical Data Management System \\
\hline $\mathrm{TH}$ & thermal-hydrological \\
\hline THC & thermal-hydrological-chemical \\
\hline THM & thermal-hydrological-mechanical \\
\hline THMEFF & TH model for episodic finger flow \\
\hline Tptpul & Topopah Spring Tuff upper lithophysal unit \\
\hline Tptpmn & Topopah Spring Tuff middle Nonlithophysal unit \\
\hline Tptpll & Topopah Spring Tuff lower lithophysal unit \\
\hline Tptpln & Topopah Spring Tuff lower nonlithophysal unit \\
\hline TSPA & total system performance assessment \\
\hline TWP & technical work plan \\
\hline
\end{tabular}




\section{ACRONYMS AND ABBREVIATIONS (Continued)}

UZ unsaturated zone

YMP Yucca Mountain Project

YMRP Yucca Mountain Review Plan, Final Report 


\section{PURPOSE}

The purpose of this report is to document drift-scale modeling work performed to evaluate the thermal-hydrological (TH) behavior in Yucca Mountain fractured rock close to waste emplacement drifts. The heat generated by the decay of radioactive waste results in rock temperatures elevated from ambient for thousands of years after emplacement. Depending on the thermal load, these temperatures are high enough to cause boiling conditions in the rock, giving rise to water redistribution and altered flow paths. The predictive simulations described in this report are intended to investigate fluid flow in the vicinity of an emplacement drift for a range of thermal loads. Understanding the $\mathrm{TH}$ coupled processes is important for the performance of the repository because the thermally driven water saturation changes affect the potential seepage of water into waste emplacement drifts. Seepage of water is important because if enough water gets into the emplacement drifts and comes into contact with any exposed radionuclides, it may then be possible for the radionuclides to be transported out of the drifts and to the groundwater below the drifts.

For above-boiling rock temperatures, vaporization of percolating water in the fractured rock overlying the repository can provide an important barrier capability that greatly reduces (and possibly eliminates) the potential of water seeping into the emplacement drifts. In addition to this thermal process, water is inhibited from entering the drift opening by capillary forces, which occur under both ambient and thermal conditions (capillary barrier). The combined barrier capability of vaporization processes and capillary forces in the near-field rock during the thermal period of the repository is analyzed and discussed in this report.

There are two outputs from this model report. The first output is the thermal properties of the unsaturated zone (UZ) model layers. These thermal properties can be found in DTN: LB0402THRMLPRP.001. The methodologies involved in developing the thermal properties (as found in DTN: LB0402THRMPLPRP.001) are described in Section 4.1 .4 and Appendix F. Aside from these thermal properties, the main model output from this report is the amount of thermal seepage into emplacement drifts. Thermal seepage refers to the seepage of water into drifts during the time period that water flow processes in the drift vicinity are perturbed from heating of the rock. The amount and temporal evolution of thermal seepage is evaluated in predictive simulations for a variety of simulation cases. The model results (see Sections 6.2.2 through 6.2.5) demonstrate that, due to capillary and vaporization barriers (note that, although related, these barriers are specific to the discussion in this report and are not to be construed as synonymous with specific individual barriers intended to limit exposure to radiological waste, as discussed in 10 CFR 63.114 [DIRS 156605]), water is prevented from entering drifts as long as the fractured rock near the drift wall is at above-boiling temperature. At later times, when the near-field fractured rock gradually cools and resaturates, the amount of thermal seepage is bounded by the respective long-term ambient seepage rate. (In other words, the flux perturbation caused by heating does not enhance seepage compared to ambient conditions.) It is shown in Sections 6.2.1 through 6.2.4 that these important qualitative findings hold for a wide range of rock properties, boundary conditions, and conceptual model choices. Based on these findings, an abstraction methodology for thermal seepage is developed in Abstraction of Drift Seepage (BSC 2004 [DIRS 169131], Sections 6.5 .2 and 6.5.3) for further use in the total system performance assessment (TSPA). Recommendations for the thermal seepage abstraction are provided in Section 6.2.4.1 of this report. 
The TH simulations in this report also provide the conceptual basis for process models intended to evaluate thermal-hydrological-chemical (THC) and thermal-hydrological-mechanical (THM) behavior in the drift vicinity. Consistency among the different models-with respect to the conceptual model and TH properties-allows this report to focus on TH processes and sensitivity of thermal seepage to relevant parameters, while leaving the THM and THC model reports to concentrate on respective chemical and mechanical processes and their related sensitivities. Note that the focus of this TH model report, as well as the related THM and THC reports, is on the near-field rock conditions, not on the in-drift environment. For these studies, the in-drift environment can be simulated in a simplified manner, only to the detail that is required to provide the proper boundary conditions for the near-field rock. Predictions of the in-drift TH or THC conditions relevant for TSPA are given in other reports. For example, the future temperature and relative humidity condition close to the waste packages can be found in Multiscale Thermohydrologic Model (BSC 2004 [DIRS 169565], Section 6.3).

The analyses documented in this report were initially conducted under the technical work plan (TWP) Technical Work Plan for: Performance Assessment Unsaturated Zone (BSC 2004 [DIRS 167969]). The relevant TWP sections for this work were Section 1.12.5, entitled “Thermal Seepage Process Model” (Work Package AUZM08), and Attachment I, entitled "Model Validation Plans” (Section I-3-2). Note that this report acquired a new analysis/model report number, U0240 (it was previously identified as N0000 within the TWP). In accordance with the TWP (BSC 2004 [DIRS 167969]), the work scope of this report included:

- Development of an improved methodology for estimating seepage during the thermal period, using a drift-scale TH process model

- Application of the TH process model for a number of simulation cases to provide input to the seepage abstraction for the TSPA

- Validation of the TH process model against measurements from the ongoing Drift Scale Test (DST)

- Development and application of an alternative conceptual model (ACM) for thermal seepage.

The report has been further modified according to activities described in the more recent Technical Work Plan for: Near-Field Environment and Transport: Near-Field Coupled Processes (TH Seepage and THM) Model Report Integration (BSC 2004 [DIRS 170236]). The modifications include editing, partial rewriting, and reformatting to incorporate Regulatory Integration Team Phase 1 comments. The primary tasks associated with these modifications for this report are given in Section 1.2.1 of the current TWP (BSC 2004 [DIRS 170236]). There have also been changes in the model validation strategy compared to that given in the previous TWP (BSC 2004 [DIRS 167969]), which will be explained later in this report (Sections 6.3 and 7). The details of the model validation plan and rationale for selecting the model validation for this report can be found in Section 2.2.1 of the current TWP (BSC 2004 [DIRS 170236]). Note that some deviations from the technical work plan (BSC 2004 [DIRS 170236]) have occurred in this document. This is REV 01 of this document instead of being REV 00, as planned in the TWP (BSC 2004 [DIRS 170236], Section 1.1). Thermal properties of the UZ model layers 
(DTN: LB0402THRMLPRP.001) are one of the technical product outputs of this document (see Section 4.1.4 and Appendix F). This was not planned in the TWP (BSC 2004 [DIRS 170236]). Deviations from the planned acceptance criteria in the TWP (BSC 2004 [DIRS 170236], Section 3.2.1) are discussed in Sections 4.2 and 8.4. Discussion on deviations from the FEPs list in the TWP (BSC 2004 [DIRS 170236], Section 2.1.6, Table 3) can be found in Section 6.

The drift-scale process model used for predictive simulation of TH conditions and for evaluating thermal seepage as input to seepage abstraction and TSPA is the TH seepage model, which incorporates relevant $\mathrm{TH}$ coupled processes in the fractured rock. The TH seepage model is applied to explicitly simulate fluid flow down to the drift and to directly calculate transient seepage rates during the period of thermally enhanced temperatures. The conceptual framework for seepage under thermal conditions is consistent with the modeling framework used for ambient seepage in the seepage model for performance assessment (SMPA), as described in Seepage Model for PA Including Drift Collapse (BSC 2004 [DIRS 167652], Section 6.3). Namely, the TH seepage model uses a stochastic representation of the fracture permeability field in the drift vicinity, applies fracture capillary properties estimated from niche liquid release tests, and represents the capillary barrier at the drift wall with a specific boundary condition developed for the SMPA. The new methodology for estimating thermal seepage is significantly improved from the approach used for the Site Recommendation, as documented in Total System Performance Assessment for the Site Recommendation (CRWMS M\&O 2000 [DIRS 153246], Section 3.3.3.2.3) and FY01 Supplemental Science and Performance Analyses, Volume 2: Performance Analyses (BSC 2001 [DIRS 154659], Section 3.2.2.6). For Site Recommendation, thermal seepage was estimated from abstraction results of an isothermal (ambient temperature) seepage process model applying predicted thermally perturbed percolation fluxes at $5 \mathrm{~m}$ above the drift crown as upper-boundary conditions to the ambient model.

Predictive simulations from the TH seepage model are performed in two-dimensional vertical cross sections perpendicular to the axis of a representative waste emplacement drift. Different cross sections (submodels) are studied, depending on the location of the drifts. The Tptpmn submodel has the emplacement drift located in the Topopah Spring Tuff middle nonlithophysal unit (Tptpmn). The Tptpll submodel has the emplacement drift located in the Topopah Spring Tuff lower lithophysal unit (Tptpll). Two main suites of simulation cases are studied for each of these submodels. The first suite of cases addresses the relevant thermal-hydrological conditions in the drift vicinity, mainly for informative purposes. The second suite of cases focuses specifically on the potential of thermal seepage for further use in seepage abstraction and TSPA, applying the specific modeling framework for seepage that was outlined above. While most simulation runs and sensitivity cases are conducted for intact, non-degraded drifts (Sections 6.2.2, 6.2.3, and 6.2.4), a subset of additional simulations is devoted to understanding the TH conditions for collapsed drifts (Section 6.2.5).

Sensitivity analyses are conducted with the TH seepage model primarily for factors known to impact thermal seepage-thermal-operating mode, percolation flux, and drift-scale rock properties-in order to cover the expected range of uncertainty and variability related to these factors. Temperature conditions, for example, are expected to vary considerably in the repository, arising from heat output variation between individual waste packages, emplacement-time differences between repository sections, and three-dimensional edge effects. The "reference mode" in this report considers a thermal load representative of the average 
thermal conditions for the current repository design, resulting in maximum rock temperatures above the boiling point of water for several hundred years, close to the emplacement drifts. Three other thermal-operating modes are studied as sensitivity cases, resulting in rock temperature conditions that can be as high as $140^{\circ} \mathrm{C}$ (for the so-called "high-temp" mode), that will feature a relatively short boiling period and maximum temperatures just above boiling (for the so-called "additional heat mode"), and that will never exceed boiling temperature (for the so-called "low-temp mode"). The rate of seepage in the low-temp mode is expected to be similar to that for ambient conditions, because the vaporization barrier only becomes effective for rock temperature above boiling. Additional sensitivity analyses include use of different fracture flow conceptual models (active fracture model and dual-permeability method), transient versus steady-state seepage modeling, and testing of different conceptual model choices.

Relevant simulation results from the TH seepage model are given in Section 6.2. Section 6.2.1.6 provides an overview of the suite of simulation cases conducted in this report. Transient seepage rates during the period of elevated temperatures are presented for several simulation cases chosen to represent the variability range of seepage-affecting parameters required in TSPA. Based on these results, possible abstraction methods for thermal seepage are discussed in Section 6.2.4.1.

Measured data from the Drift Scale Test (DST) are used to evaluate and validate the conceptual and numerical models of the TH coupled processes predicted with the TH seepage model. The geometry of the DST heated drift is consistent with the current design of the repository. Heating in the DST was initiated on December 3, 1997, and continued for slightly more than four years. The heaters were turned off on January 14, 2002. The DST rock block has been cooling since then. The simulation model used for investigating the TH processes in the DST-the DST TH model-shares the same model conceptualization as the TH seepage model. The DST-TH model uses a three-dimensional numerical grid that represents the test geometry and dimensions as realistically as possible. Validation criteria and results are provided in Section 7.

Conceptual model uncertainty is addressed using an ACM for the movement of water in unsaturated fractures. This ACM is only used to corroborate the main prediction model for thermal seepage; results from this ACM are not carried forward to TSPA. The ACM assumes that the downward flow toward the heated emplacement drifts occurs in preferential flow paths (fingers) that intermittently carry water at flow rates much larger than that of average percolation. Such flow conditions can promote the potential of water arrival at waste emplacement drifts during the thermal period, because the water may penetrate far into the hot rock despite vigorous vaporization. The TH model for episodic finger flow (THMEFF) is applied to simulate the complex flow processes of episodic finger-flow events in the heated fractured rock. Results from the alternative conceptual model are given in Section 6.3.

Potential limitations of the TH seepage model can be summarized as follows:

- The limitations of the TH seepage model, as for all predictive models, are defined by the conceptual model as presented in Section 6.2.1.1.

- Because modeling of coupled processes is so computationally intensive, the TH seepage model is conducted in two-dimensional vertical sections rather than with a 
three-dimensional representation. For the same reason, it is not feasible to conduct systematic sensitivity studies by variation of many input parameters over a wide range of values. Rather, a small number of parameters known to be important for seepage have been carefully selected for the sensitivity studies (see Section 6.2.1.6).

- The three heater experiments that are available for model validation are located in the Tptpmn horizon at Yucca Mountain. No heater test was conducted in the Tptpll or other repository units (see Section 7.1.3). Nevertheless, the TH processes for the Tptpll are well captured by the model.

- The DST offers no seepage data (observed seepage rates) that can be used directly for thermal-seepage validation purposes (see Section 7.1). However, the DST data are used to validate the TH Seepage process model and are used to predict thermal seepage response (supplemented by other confidence building measures).

It will be demonstrated in this report that, despite these limitations, the TH seepage model is sufficiently accurate and adequate for the intended application (see Section 7).

Various model efforts and other analyses provide input to this thermal seepage model report (see Section 4.1). The main input sources are Calibrated Properties Model (BSC 2004 [DIRS 169857]), Seepage Calibration Model and Seepage Testing Data (BSC 2004 [DIRS 171764]), and UZ Flow Models and Submodels (BSC 2004 [DIRS 169861]). 


\section{INTENTIONALLY LEFT BLANK}




\section{QUALITY ASSURANCE}

Development of this report on drift-scale TH processes and the supporting modeling activities have been determined to be subject to the Yucca Mountain Project's quality assurance (QA) program as documented in the technical work plan (TWP) (BSC 2004 [DIRS 170236], Section 8.1, Work Package ARTM02). Approved QA procedures identified in Section 4 of the TWP (BSC 2004 [DIRS 170236]) have been used to conduct and document the activities described in this report. Electronic management of information was evaluated in accordance with AP-SV.1Q, Control of the Electronic Management of Information, and controlled under YMP-LBNL-QIP-SV.0, Management of YMP-LBNL Electronic Data, as planned in the TWP (BSC 2004 [DIRS 170236], Section 8.4).

This report examines the properties of natural barriers that are classified in the Q-List (BSC 2004 [DIRS 168361]) as "Safety Category" because they are important to waste isolation, as defined in AP-2.22Q, Classification Analyses and Maintenance of the Q-List. The report contributes to the analysis and modeling data used to support performance assessment (PA). The conclusions of this report do not affect the repository design or engineered features important to safety, as defined in AP-2.22Q. 


\section{INTENTIONALLY LEFT BLANK}




\section{USE OF SOFTWARE}

The computer code used for the simulation of coupled TH processes is TOUGH2 V1.6 (LBNL 2003 [DIRS 161491]). This code is applied for the TH seepage model as well as for the sensitivity studies performed with DST TH model. For consistency with previous DST modeling work, the three-dimensional DST simulations using the site-specific (DKM-TT99) property set are performed with TOUGH2V1.3MEOS4 V1.0 (LBNL 1999 [DIRS 147569]). The computer code used for the alternative conceptual model (ACM) is TH_PULSE.F V1.0 (LBNL 2002 [DIRS 160767]). Other software used in this report primarily serves for preparation of input data for and analysis of output data from simulation runs. A list of software codes and routines is given in Table 3-1. The computer codes and routines have been baselined in accordance with LP-SI.11Q, Software Management. All software used is considered appropriate for the intended use, has been applied in the range of the validation, and was obtained from Software Configuration Management.

Standard, off-the-shelf visual-display graphics programs (Tecplot Versions 8.0 and 9.0) were used to plot data and illustrate information generated from the numerical simulation results. Information needed to reproduce the graphical display of data generated from model results is included in this report and the scientific notebooks listed in Table 6-1. Standard, off-the-shelf software Excel 97 SR-1 was used to generate random numbers for production of heterogeneous permeability fields. Information relevant to these calculations is given in Appendix A, and the respective Excel data files were submitted to the Technical Data Management System (TDMS). Appendix B lists another Excel file used for calculating the arithmetic mean of infiltration values (see Section 4.1.1.5). 


\begin{tabular}{|c|c|c|c|c|c|c|c|c|}
\hline $\begin{array}{l}\text { Item } \\
\text { No. }\end{array}$ & Software Name & Version & \begin{tabular}{|c|} 
Software \\
Tracking Number \\
(STN)
\end{tabular} & Platform & $\begin{array}{l}\text { Operating } \\
\text { System }\end{array}$ & Range of Use & Brief Description & DIRS \\
\hline 1 & TOUGH2 & 1.6 & 10007-1.6-01 & Alpha System & OSF1 V4.0 & $\begin{array}{l}\text { TOUGH2 should be used for } \\
\text { applications where } \\
\text { temperature }(\mathrm{T}) \text { is in the } \\
\text { range } 0<\mathrm{T}<360^{\circ} \mathrm{C} \text {. }\end{array}$ & $\begin{array}{l}\text { Used as an integral } \\
\text { finite difference } \\
\text { numerical simulator for } \\
\text { nonisothermal flows of } \\
\text { multicomponent, } \\
\text { multiphase fluids in } \\
\text { porous and fractured } \\
\text { media. }\end{array}$ & 161491 \\
\hline 2 & $\begin{array}{l}\text { TOUGH2V1.3MEO } \\
\text { S4 }\end{array}$ & $\begin{array}{l}\text { 1.3MEOS4 } \\
\text { V1.0 }\end{array}$ & $\begin{array}{l}\text { 10062- } \\
1.3 \mathrm{MEOS} 4 \mathrm{~V} 1.0- \\
00\end{array}$ & Alpha System & OSF1 V4.0 & $\begin{array}{l}\text { TOUGH2V1.3MEOS4 } \\
\text { should be used for } \\
\text { applications where } \\
\text { temperature }(\mathrm{T}) \text { is in the } \\
\text { range } 0<\mathrm{T}<360^{\circ} \mathrm{C} \text {. Active } \\
\text { fracture model }(\mathrm{AFM}) \\
\text { concepts not available in } \\
\text { TOUGH2V1.3MESO4. }\end{array}$ & $\begin{array}{l}\text { TOUGH2V1.3MEOS4 } \\
\text { is a general purpose } \\
\text { integral finite-difference } \\
\text { software for simulating } \\
\text { isothermal or } \\
\text { nonisothermal } \\
\text { multiphase flow and } \\
\text { transport in porous and } \\
\text { fractured rock. }\end{array}$ & 147569 \\
\hline 3 & TH_PULSE.F & 1.0 & 10851-1.0-00 & Sun UltraSparc & SunOS 5.5.1 & $\begin{array}{l}\text { The semi-analytical solution } \\
\text { provided by this software is } \\
\text { most accurate when the } \\
\text { thermal perturbation in the } \\
\text { rock is nearly uniform across } \\
\text { the width of the liquid finger, } \\
\text { see Equation 6.3.1.3-2. }\end{array}$ & $\begin{array}{l}\text { Calculates the } \\
\text { penetration depth and } \\
\text { mass flow of episodic } \\
\text { liquid fingers infiltrating } \\
\text { into superheated rock, } \\
\text { using a front tracking } \\
\text { algorithm. This } \\
\text { software will be used to } \\
\text { investigate thermal } \\
\text { seepage with episodic } \\
\text { flow events. }\end{array}$ & 160767 \\
\hline 4 & mk_rect.f & 1.0 & 10228-1.0-00 & Sun UltraSparc & SunOS 5.5.1 & $\begin{array}{l}\text { The grid is generated for } \\
\text { use with the TOUGH2 family } \\
\text { of codes only. }\end{array}$ & $\begin{array}{l}\text { Generates rectangular } \\
\text { grid elements. }\end{array}$ & 148351 \\
\hline
\end{tabular}


Table 3-1. Qualified Software Used in This Report (Continued)

\begin{tabular}{|c|c|c|c|c|c|c|c|c|}
\hline $\begin{array}{l}\text { Item } \\
\text { No. }\end{array}$ & Software Name & Version & \begin{tabular}{|c|} 
Software \\
Tracking Number \\
(STN)
\end{tabular} & Platform & $\begin{array}{l}\text { Operating } \\
\text { System }\end{array}$ & Range of Use & Brief Description & DIRS \\
\hline 5 & mk_circ.f & 1.0 & $10229-1.0-00$ & Sun UltraSparc & SunOS 5.5.1 & $\begin{array}{l}\text { The grid is generated for } \\
\text { use with the TOUGH2 family } \\
\text { of codes only. }\end{array}$ & $\begin{array}{l}\text { Generates radial grid } \\
\text { elements. }\end{array}$ & 148349 \\
\hline 6 & merggrid.f & 1.0 & 10230-1.0-00 & Sun UltraSparc & SunOS 5.5.1 & $\begin{array}{l}\text { The grid is generated for } \\
\text { use with the TOUGH2 family } \\
\text { of codes only. }\end{array}$ & $\begin{array}{l}\text { Merges rectangular } \\
\text { and circular grid } \\
\text { elements. The output }\end{array}$ & 148352 \\
\hline 7 & mk_grav2d.f & 1.0 & $10231-1.0-00$ & Sun UltraSparc & SunOS 5.5.1 & $\begin{array}{l}\text { To be used only for grid } \\
\text { generation in the DST TH } \\
\text { model (Section 7.3.3) }\end{array}$ & $\begin{array}{l}\text { Generates a two- } \\
\text { dimensional vertical } \\
\text { grid for the DST TH } \\
\text { model using the output } \\
\text { from AMESH V1.0 (see } \\
\text { item } 26 \text { in this table). } \\
\end{array}$ & 147538 \\
\hline 8 & mk_3dslize.f & 1.0 & $10232-1.0-00$ & Sun UltraSparc & SunOS 5.5.1 & For DST TH model use only. & \begin{tabular}{|l|} 
Prepares a three- \\
dimensional numerical \\
grid for the three- \\
dimensional DST TH \\
model. \\
\end{tabular} & 147539 \\
\hline 9 & mk_grav3d.f & 1.0 & 10233-1.0-00 & Sun UltraSparc & SunOS 5.5.1 & For DST TH model use only. & $\begin{array}{l}\text { Converts files for the } \\
\text { three-dimensional drift- } \\
\text { scale model }\end{array}$ & 147540 \\
\hline 10 & mk_gener.f & 1.0 & $10234-1.0-00$ & Sun UltraSparc & SunOS 5.5.1 & For DST TH model use only. & $\begin{array}{l}\text { Assigns heating power } \\
\text { to selected elements of } \\
\text { the TOUGH2 mesh. }\end{array}$ & 147542 \\
\hline 11 & mk_observ.f & 1.0 & $10235-1.0-00$ & Sun UltraSparc & SunOS 5.5.1 & For DST TH model use only. & $\begin{array}{l}\text { Determines the } \\
\text { elements in the MESH } \\
\text { that are closest to the } \\
\text { actual sensors } \\
\text { locations in hydrology } \\
\text { holes 57-61, 74-78, } \\
\text { and 185-186. }\end{array}$ & 147543 \\
\hline 12 & mk_dual.f & 1.0 & $10236-1.0-00$ & Sun UltraSparc & SunOS 5.5.1 & For DST TH model use only. & $\begin{array}{l}\text { Generates a mesh for } \\
\text { three-dimensional dual } \\
\text { permeability } \\
\text { simulations. }\end{array}$ & 147544 \\
\hline
\end{tabular}




\begin{tabular}{|c|c|c|c|c|c|c|c|c|}
\hline & & & Table 3-1. & Qualified Softw & re Used in Th & Report (Continued) & & \\
\hline $\begin{array}{l}\text { Item } \\
\text { No. }\end{array}$ & Software Name & Version & $\begin{array}{c}\text { Software } \\
\text { Tracking Number } \\
\text { (STN) }\end{array}$ & Platform & $\begin{array}{l}\text { Operating } \\
\text { System }\end{array}$ & Range of Use & Brief Description & DIRS \\
\hline 13 & mk_time*.f & 1.0 & 10237-1.0-00 & Sun UltraSparc & SunOS 5.5.1 & $\begin{array}{l}\text { For DST TH model use } \\
\text { only. }\end{array}$ & $\begin{array}{l}\text { Reads temperature } \\
\text { history data collected by } \\
\text { a LLNL system and } \\
\text { produces output files } \\
\text { that can be plotted with } \\
\text { Tecplot. } \\
\end{array}$ & 147545 \\
\hline 14 & mk_obs3d.f & 1.0 & 10238-1.0-00 & Sun UltraSparc & SunOS 5.5.1 & $\begin{array}{l}\text { For DST TH model use } \\
\text { only. }\end{array}$ & $\begin{array}{l}\text { process data for } \\
\text { TOUGH2 drift-scale } \\
\text { modeling }\end{array}$ & 147546 \\
\hline 15 & mk_tec ${ }^{*} . f$ & 1.0 & |10239-1.0-00 & Sun UltraSparc & SunOS 5.5.1 & $\begin{array}{l}\text { For DST TH model use } \\
\text { only. }\end{array}$ & $\begin{array}{l}\text { Process data for } \\
\text { TOUGH2 drift-scale } \\
\text { modeling }\end{array}$ & 147547 \\
\hline 16 & mk_cluster ${ }^{\star} . f$ & 1.0 & 10240-1.0-00 & Sun UltraSparc & SunOS 5.5.1 & $\begin{array}{l}\text { For DST TH model use } \\
\text { only. }\end{array}$ & $\begin{array}{l}\text { Calculates elements in } \\
\text { TOUGH2 numerical grid } \\
\text { aligned along the radial } \\
\text { lines of the RTD holes } \\
158-165 .\end{array}$ & 147548 \\
\hline 17 & mk_3dinter*.f & 1.0 & |10241-1.0-00 & Sun UltraSparc & SunOS 5.5.1 & $\begin{array}{l}\text { For DST TH model use } \\
\text { only. }\end{array}$ & $\begin{array}{l}\text { Calculates interpolated } \\
\text { simulated temperatures } \\
\text { at all sensor locations in } \\
\text { borehole } \# 133 \text { at a } \\
\text { given time. }\end{array}$ & 147550 \\
\hline 18 & mk_temp3d_all.f & 1.0 & 10242-1.0-00 & Sun UltraSparc & SunOS 5.5.1 & $\begin{array}{l}\text { For DST TH model use } \\
\text { only. }\end{array}$ & $\begin{array}{l}\text { Reads a TOUGH2 } \\
\text { output file and filters } \\
\text { only the element names } \\
\text { and temperatures at } \\
\text { those elements at a } \\
\text { given time. }\end{array}$ & 147551 \\
\hline 19 & mk_evaluate_*.f & 1.0 & 10243-1.0-00 & Sun UltraSparc & SunOS 5.5.1 & $\begin{array}{l}\text { For DST TH model use } \\
\text { only. }\end{array}$ & $\begin{array}{l}\text { Calculates statistical } \\
\text { measures of the } \\
\text { goodness of simulated } \\
\text { temperatures as } \\
\text { compared against } \\
\text { measured temperatures. }\end{array}$ & 147552 \\
\hline
\end{tabular}


Table 3-1. Qualified Software Used in This Report (Continued)

\begin{tabular}{|c|c|c|c|c|c|c|c|c|}
\hline $\begin{array}{c}\text { Item } \\
\text { No. }\end{array}$ & Software Name & Version & $\begin{array}{c}\text { Software } \\
\text { Tracking Number } \\
\text { (STN) }\end{array}$ & Platform & $\begin{array}{l}\text { Operating } \\
\text { System }\end{array}$ & Range of Use & Brief Description & DIRS \\
\hline 20 & 2kgridv1.f & 1.0 & $10244-1.0-00$ & Sun UltraSparc & SunOS 5.5.1 & For DST TH model use only. & $\begin{array}{l}\text { Process data for } \\
\text { TOUGH2 drift-scale } \\
\text { modeling }\end{array}$ & 147553 \\
\hline 21 & mk_ysw_eleme.f & 1.0 & $10245-1.0-00$ & Sun UltraSparc & SunOS 5.5.1 & For DST TH model use only. & $\begin{array}{l}\text { Reads the element } \\
\text { names in files } \\
\text { produced by 2kgridv1.f, } \\
\text { renames them and } \\
\text { assigns appropriate } \\
\text { rock names. }\end{array}$ & 147554 \\
\hline 22 & mk_ysw_conne.f & 1.0 & $10246-1.0-00$ & Sun UltraSparc & SunOS 5.5.1 & For DST TH model use only. & $\begin{array}{l}\text { The names of the } \\
\text { elements in CONNE } \\
\text { file produced by } \\
2 \text { kgridv1.f are copied to } \\
\text { the names of the } \\
\text { elements in a three- } \\
\text { dimensional dual } \\
\text { permeability mesh, } \\
\text { keeping the rest of the } \\
\text { information. }\end{array}$ & 147556 \\
\hline 23 & mk_can_power.f & 1.0 & $10247-1.0-00$ & Sun UltraSparc & SunOS 5.5.1 & For DST TH model use only. & $\begin{array}{l}\text { Calculates the average } \\
\text { of total canister heater } \\
\text { power over a given } \\
\text { period of time. }\end{array}$ & 147557 \\
\hline 24 & mk_wing_power.f & 1.0 & $10248-1.0-00$ & Sun UltraSparc & SunOS 5.5.1 & For DST TH model use only. & $\begin{array}{l}\text { Calculates the average } \\
\text { of total wing heater } \\
\text { power over a given } \\
\text { period of time. }\end{array}$ & 147558 \\
\hline 25 & mk_incon_3d_dual.f & 1.0 & $10250-1.0-00$ & Sun UltraSparc & SunOS 5.5.1 & For DST TH model use only. & $\begin{array}{l}\text { Generates a TOUGH2 } \\
\text { INCON file for a three- } \\
\text { dimensional dual } \\
\text { permeability mesh. }\end{array}$ & 147560 \\
\hline
\end{tabular}


Table 3-1. Qualified Software Used in This Report (Continued)

\begin{tabular}{|c|c|c|c|c|c|c|c|c|}
\hline $\begin{array}{l}\text { Item } \\
\text { No. }\end{array}$ & Software Name & Version & $\begin{array}{c}\text { Software } \\
\text { Tracking Number } \\
\text { (STN) }\end{array}$ & Platform & $\begin{array}{l}\text { Operating } \\
\text { System }\end{array}$ & Range of Use & Brief Description & DIRS \\
\hline 26 & AMESH & 1.0 & $10045-1.0-00$ & Sun UltraSparc & SunOS 5.5.1 & $\begin{array}{l}\text { To be used only with } \\
\text { TOUGH2 family of codes. }\end{array}$ & $\begin{array}{l}\text { Generates discrete } \\
\text { one-dimensional, two- } \\
\text { dimensional or three- } \\
\text { dimensional grids for } \\
\text { numerical modeling of } \\
\text { flow and transport } \\
\text { problems in which the } \\
\text { formulation is based on } \\
\text { the integral finite } \\
\text { difference method. }\end{array}$ & 147561 \\
\hline 27 & EXT & 1.1 & 10005-1.1-00 & Sun UltraSparc & UNIX $^{1}$ & $\begin{array}{l}\text { To be used only with } \\
\text { TOUGH2 family of codes. }\end{array}$ & $\begin{array}{l}\text { The EXT code extracts } \\
\text { data from TOUGH2 } \\
\text { output files for plotting }\end{array}$ & 160768 \\
\hline 28 & EXT & 1.0 & $10047-1.0-00$ & Sun UltraSparc & SunOS 5.5.1 & $\begin{array}{l}\text { To be used only with } \\
\text { TOUGH2 family of codes. }\end{array}$ & $\begin{array}{l}\text { The EXT code extracts } \\
\text { data from TOUGH2 } \\
\text { output files for plotting }\end{array}$ & 147562 \\
\hline 29 & exclude.f & 1.0 & $10316-1.0-00$ & Sun UltraSparc & SunOS 5.5.1 & $\begin{array}{l}\text { To be used only with } \\
\text { TOUGH2 family of codes. }\end{array}$ & $\begin{array}{l}\text { Used to exclude points } \\
\text { outside a specified } \\
\text { radius so that points } \\
\text { will not overlap when } \\
\text { output is merged using } \\
\text { merggrid.f V1.0 for two- } \\
\text { dimensional THC } \\
\text { Seepage model. } \\
\end{array}$ & 153089 \\
\hline 30 & assign.f & 1.0 & $10315-1.0-00$ & Sun UltraSparc & SunOS 5.5.1 & $\begin{array}{l}\text { To be used only with } \\
\text { TOUGH2 family of codes. }\end{array}$ & $\begin{array}{l}\text { Used to assign a } \\
\text { geologic name to all } \\
\text { TOUGH elements } \\
\text { according to their } \\
\text { location in the Z- } \\
\text { direction for two- } \\
\text { dimensional THC } \\
\text { Seepage model. }\end{array}$ & 153090 \\
\hline
\end{tabular}

\footnotetext{
${ }^{1}$ UNIX as in SunOS 5.5.1
} 
Table 3-1. Qualified Software Used in This Report (Continued)

\begin{tabular}{|c|c|c|c|c|c|c|c|c|}
\hline $\begin{array}{l}\text { Item } \\
\text { No. }\end{array}$ & Software Name & Version & $\begin{array}{c}\text { Software } \\
\text { Tracking Number } \\
\text { (STN) }\end{array}$ & Platform & $\begin{array}{l}\text { Operating } \\
\text { System }\end{array}$ & Range of Use & Brief Description & DIRS \\
\hline 31 & mk_grav2.f & 1.0 & 10379-1.0-00 & Sun UltraSparc & SunOS 5.5.1 & $\begin{array}{l}\text { To be used only with } \\
\text { TOUGH2 family of codes. }\end{array}$ & $\begin{array}{l}\text { Reads AMESH V1.0 } \\
\text { output files and creates } \\
\text { TOUGH2 V1.4 mesh } \\
\text { input file data, namely } \\
\text { the gravity vector data } \\
\text { and grid block labeling } \\
\text { data }\end{array}$ & 153068 \\
\hline 32 & 2kgridv1a.for & 1.0 & 10382-1.0-00 & PC & DOS Emulation & $\begin{array}{l}\text { To be used only with } \\
\text { TOUGH2 family of codes. }\end{array}$ & $\begin{array}{l}\text { Generates dual- } \\
\text { permeability grids for } \\
\text { the TOUGH2 family of } \\
\text { codes. }\end{array}$ & 153067 \\
\hline 33 & mrgdrift.f & 1.0 & 10380-1.0-00 & Sun UltraSparc & SunOS 5.5.1 & $\begin{array}{l}\text { To be used only with } \\
\text { TOUGH2 family of codes. }\end{array}$ & $\begin{array}{l}\text { Merges the geologic } \\
\text { mesh with the drift } \\
\text { mesh for TOUGH2 and } \\
\text { TOUGHREACT } \\
\text { simulations. }\end{array}$ & 153082 \\
\hline
\end{tabular}




\section{INTENTIONALLY LEFT BLANK}




\section{INPUTS}

\subsection{DIRECT INPUT}

This section provides documentation for all inputs to the report. Because this report documents simulation of coupled TH phenomena, a variety of input information is required. Inputs to the report are referred to by data tracking number (DTN) or by reference. Inputs are organized into several data-type categories, described in the following subsections. Section 4.1.1 provides input references to the predictive $\mathrm{TH}$ seepage model (listed in Table 4.1-1), Section 4.1.2 provides input references to the DST TH model used as corroborative information for model validation (listed in Table 4.1-11), and Section 4.1.3 summarizes measured data from the DST heater test used as corroborative information for model validation (listed in Table 4.1-12). Tables 4.1-1 and 4.1-11 further categorize each input data set into data from the Technical Data Management System (TDMS), data from design documents, and output from approved analyses/model reports. Directly used inputs are listed in Table 4.1-1 and parameter values are given in Tables 4.1-2 through 4.1-9. Data sources that provide information for making conceptual model choices for in-drift properties are given in Table 4.1-10. Data sources used in sensitivity studies or in model validation are listed in Tables 4.1-2, 4.1-11, 4.1-12. Inputs used in developing thermal properties of the UZ model layers (DTN: LB0402THRMLPRP.001) are discussed in Section 4.1.4 and are listed in Table 4.1-13. The status of all inputs is shown in the Document Input Reference System (DIRS) database.

Note that this report uses the nomenclature for lithostratigraphic units defined in Geologic Framework Model (BSC 2004 [DIRS 170029]), while some DTNs refer to the same lithostratigraphic units using the nomenclature of the UZ model reports. The relationship between these is given in several model reports (e.g., in BSC 2004 [DIRS 169855], Table 6-5).

\subsubsection{Direct Input Data for TH Seepage Model}

The data presented in this subsection are used as input to the predictive TH seepage model. These data are considered direct input data to the model unless otherwise noted.

\subsubsection{Hydrological and Thermal Properties of Fractured Rock}

Hydrological properties (such as permeability, van Genuchten parameters, residual saturation for both the fractures and the matrix, and the active fracture parameter for the fractures) used in the TH seepage model are excerpted from the UZ drift-scale calibrated property set for the mean infiltration scenario (DTN: LB0208UZDSCPMI.002 [DIRS 161243]). The calibration model used to develop these properties is described in Calibrated Properties Model (BSC 2004 [DIRS 169857], Section 6.3.2). Other hydrological properties such as fracture porosity, frequency, aperture, and interface areas are obtained from DTN: LB0205REVUZPRP.001 [DIRS 159525]. These hydrological properties (along with the thermal properties; see next paragraph) will be referred to as the DS/AFM-UZ02-Mean property set in this report. These hydrological properties represent the repository-wide averages for the various stratigraphic layers in the UZ at Yucca Mountain. The same property sets are used in most, if not all, other reports that simulate various aspects of flow and transport in the unsaturated zone at Yucca Mountain. Source DTNs for the hydrological properties are given in Table 4.1-1. For quick reference, values of the 
hydrological properties are listed in Table 4.1-2 for the main repository units, the Topopah Spring Tuff middle nonlithophysal (Tptpmn or tsw34) and lower lithophysal (Tptpll or tsw35) stratigraphic units. For the sake of completeness, properties for the upper lithophysal (Tptpul or tsw33) unit are also provided. In the Tptpmn submodel, the base of the Tptpul unit is at $18 \mathrm{~m}$ above the drift centerline. This unit is thus potentially important for drift-scale TH behavior, especially for the Tptpmn submodel. However, because the Tptpll or tsw35 is more than $100 \mathrm{~m}$ thick, the lower nonlithophysal (Tptpln or tsw36) is situated far away from the source of heat for both the Tptpmn and Tptpll submodel. As a result, the (thermal and hydrological) properties of the Tptpln or tsw36 unit have little impact on the drift-scale TH behavior (when the emplacement drifts are located in either the Tptpmn or Tptpll units). The properties of the Tptpln or tsw36 unit are thus not listed in Table 4.1-2 (though they are included in the numerical model and can be found in DTN: LB0205REVUZPRP.001 [DIRS 159525], DTN: LB0208UZDSCPMI.002 [DIRS 161243], and DTN: LB0210THRMLPRP.001 [DIRS 160799]). Note also that the thermal and hydrological properties of the upper lithophysal (Tptpul) unit are similar to those of the lower lithophysal (Tptpll) unit. The same is also true between the middle nonlithophysal (Tptpmn) and lower nonlithophysal (Tptpln) units. Consequently, it is not considered necessary to perform elaborate modeling with the heat source in the Tptpul or Tptpln, even though a small part of the repository may be located in the Tptpln unit. The modeling predictions from the Tptpmn and Tptpll submodels should adequately represent TH conditions in the Tptpln and Tptpul units, respectively, had the emplacement drifts been located in those two units.

The DS/AFM-UZ02-Mean property set, in addition to the hydrological properties described above, also includes thermal properties from DTN: LB0210THRMLPRP.001 [DIRS 160799] of the UZ model layers. This DTN is listed in Table 4.1-1 as direct input to the TH seepage model, and it provides input data for wet and dry thermal conductivities, heat capacity, grain density and porosity of the matrix component of all UZ model layers. For reference purposes, thermal properties of the tsw33, tsw34, and tsw35 model layers are given in Table 4.1-2 (note that wet and dry thermal conductivities for these layers are the bulk thermal conductivities, which include the effect of the lithophysal porosities). Thermal properties of the UZ model layer have since been updated (with revised values for the nonrepository layers), and a more recent data source (DTN: LB0402THRMLPRP.001) for them is currently available (see Section 4.1 .4 and Appendix F). Sensitivity analyses have been carried out to determine the impact on the TH simulations in this model report arising out of using thermal properties from DTN: LB0210THRMLPRP.001 [DIRS 160799] instead of using the recent values from DTN: LB0402THRMLPRP.001. These sensitivity analyses can be found in Appendix C. It is shown that the differences between simulation results conducted with the revised thermal properties versus the original thermal properties are very small, in most cases almost undetectable. There is no impact on the main results from this report, i.e., the conclusions drawn from the thermal seepage study that are used as a basis for seepage abstraction remain unchanged (Appendix C, Section C.5).

Note that the tortuosity parameter is not based on data specific to Yucca Mountain. The tortuosity parameter is used for calculating vapor-air diffusion processes. These processes are of minor importance for the modeling results, as their impact on the TH conditions in the rock is very small compared to conductive and convective processes. Thus, exact quantification or even calibration of this parameter is not needed; instead, appropriate tortuosity values are taken from 
the literature. From the range of values ( 0.1 for clay to 0.7 for sand) given in de Marsily (1986 [DIRS 100439], p. 233), a value of 0.2 is selected for the rock matrix. This value is on the lower end of the given values, because the tuff rock matrix is fairly tight. Tortuosities for single fractures are set to 0.7. This value corresponds to the highest tortuosity given by de Marsily (1986 [DIRS 100439], p. 233), with the rationale that paths are less tortuous within fractures than in the matrix.

For simulation runs with focus on thermal seepage, the modeling framework for seepage (see Section 6.2.1.1.2) requires certain modifications to the DS/AFM-UZ-02-Mean properties. For example, the fracture capillary-strength parameter $1 / \alpha$ in the drift vicinity is taken from calibration results in Seepage Calibration Model and Seepage Testing Data (BSC 2004 [DIRS 171764], Section 6.6.4, Table 6-8), instead of the DS/AFM-UZ02-Mean value of the respective host rock unit. The seepage calibration model (SCM) conducts calibration to niche and Enhanced Characterization of the Repository Block (ECRB) liquid-release data to derive specific $1 / \alpha$-values that match the niche test results. A summary of all calibrated capillary-strength values is provided in Table 4.1-3 (DTN: LB0302SCMREV02.002 [DIRS 162273]; also given in BSC 2004 [DIRS 171764], Section 6.6.4, Table 6-8). Data from six test intervals are available in the lower lithophysal zone: four intervals in boreholes located above the ECRB Cross-Drift, and two intervals in boreholes above Niche 1620. Four intervals in the middle nonlithophysal zone have been analyzed, one interval in a borehole above Niche 3107 and three intervals in boreholes above Niche 4788. Based on these data, the spatial variability of the capillary-strength parameter over the repository is described in Abstraction of Drift Seepage (BSC 2004 [DIRS 169131], Section 6.6.2). The abstraction report indicates uniform probability distributions to cover the variability of this parameter, with distribution statistics given in Table 4.1-4 (DTN: LB0310AMRU0120.001 [DIRS 166409]; also given in BSC 2004 [DIRS 169131], Table 6.6-2). Four different methods to develop these statistics are discussed in the abstraction, all of which lead to similar overall seepage results (BSC 2004 [DIRS 169131], Section 6.8.2).

The fracture capillary-strength parameter used in the TH seepage model represents the range of values defined by the above spatial variability statistics (Table 4.1-4). Using Method A from Abstraction of Drift Seepage (BSC 2004 [DIRS 169131], Table 6.6-2), the mean of the calibrated values over all Tptpmn and Tptpll sample locations is $591 \mathrm{~Pa}$; the standard deviation is $109 \mathrm{~Pa}$. All other methods in Table 6.6-2 of Abstraction of Drift Seepage (BSC 2004 [DIRS 169131], Methods B through D) give larger capillary-strength values; using these larger values will reduce the potential for seepage. A uniform probability distribution is developed based on these data that ranges from 402 to780 Pa (BSC 2004 [DIRS 169131], Figure 6.6-2), with a mean of $591 \mathrm{~Pa}$. Based on these data (see paragraph immediately above), the TH seepage model applies a basecase value of $589 \mathrm{~Pa}$ for most simulation cases that address thermal seepage. To cover the range of possible values, a sensitivity case is studied with a small capillary-strength of $400 \mathrm{~Pa}$, which leads to increased overall ambient and thermal seepage (Section 6.2.4.2.2). The small difference between the mean values of 589 and $591 \mathrm{~Pa}$ is not relevant for the seepage predictions. Earlier versions of Seepage Calibration Model and Seepage Testing Data (CRWMS M\&O 2001 [DIRS 153045], Section 6) had suggested a calibrated value of 589 Pa for the Tptpmn; a value that was the starting point of the thermal seepage analyses and was not updated because of the negligible difference. 
The modeling framework for thermal seepage (see Section 6.2.1.1.2) also calls for representation of small-scale fracture permeability heterogeneity in the drift vicinity. The structure of the heterogeneous fracture permeability fields used in this report is based on small-scale air-permeability test data. The most appropriate information on small-scale fracture permeability stems from the air-injection testing conducted in the inside niches of the Exploratory Studies Facility (ESF), as displayed, for example, in Figure 6.6-1 of Abstraction of Drift Seepage (BSC 2004 [DIRS 169131]). Typically, such tests were performed by isolating a short section of the boreholes $(1 \mathrm{foot}[0.3 \mathrm{~m}]$ in niches, $6 \mathrm{ft}[1.8 \mathrm{~m}]$ in systematic testing borehole SYBT-ECRBLA\#2), using an inflatable packer system, and then injecting compressed air at a constant rate into the isolated injection interval. Using the pressure response as input, the air-permeability value of the tested interval was calculated based on a commonly used analytical solution (BSC 2004 [DIRS 170004], Section 6.1.2.1; LeCain 1995 [DIRS 101700], p. 10, Equation 15). With the exception of the systematic testing boreholes, which were constructed after excavation of the drift, air-permeability values are available both before and after excavation. The boreholes above Niches 3107, 3566, 3650, 4788, and 1620 had been drilled and tested prior to niche construction. Except for Niche 3566, testing was repeated using the same testing methodology and identical packer setup after excavation. (Note: Niches are named after construction station. For example, the niche at construction station 31+07 is referred to as Niche 3107.) For the evaluation of drift seepage, the fracture heterogeneity distribution AFTER excavation is relevant (i.e., disturbed-zone permeability).

For the Tptpmn unit, disturbed zone data are available from Niches 3107, 3650, and 4788 in the ESF. For the Tptpll unit, data from Niche 1620 and from borehole SYBT-ECRB-LA\#2 in the ECRB Cross-Drift are used. The appropriateness of using these data for the TH seepage model is discussed in Section 6.2.1.1.2. Details of the generated random permeability fields based on the air permeability data are given in Sections 6.2.2.2.1 and 6.2.3.2.1. The DTN and values of mean and standard deviation are provided in Table 4.1-5. The number of log-air-permeability values $(n)$ available to calculate the mean and the standard deviation is indicated in the fourth column of the table. Only the standard deviation is used in this report as a basis for the stochastic generation of permeability fields. The mean permeability of these random fields is taken from the respective fracture permeability value of the DS/AFM-UZ-02-Mean property set.

All thermo-physical properties of water (density, viscosity, specific enthalpy, saturated vapor pressure) in TOUGH2 simulator (Pruess 1991 [DIRS 100413]) are described by steam table equations given by the International Formulation Committee (1967 [DIRS 156448]), as explained in program manuals and user's guides for the code (Pruess et al. 1999 [DIRS 160778]). Properties of air are those of an ideal gas and additivity of partial pressures of air and water vapor is implied. The viscosity of air-vapor mixtures is computed from a formulation given by Hirschfelder et al. (Pruess et al. 1999 [DIRS 160778]). Solubility of air in water is represented by Henry's law. Acceleration due to gravity is $9.80665 \mathrm{~m} / \mathrm{s}^{2}$ (Perry et al. 1984 [DIRS 125806], p. 1-22, Table 1-14).

\subsubsection{Model Boundary Conditions}

To account for the two main host rock units of the repository, two submodels are studied in this model report that reflect two different locations in the repository (see Section 6.2.1.2). The first one, the Tptpmn submodel, considers a drift located in the Topopah Spring Tuff middle 
nonlithophysal unit (Tptpmn unit), close to borehole USW SD-9. The second one is the Tptpll submodel, assuming a drift located in the Topopah Spring Tuff lower lithophysal unit (Tptpll unit), close to the center of the repository.

The top and bottom boundary conditions for the TH seepage model represent the conditions at these locations (see Section 6.2.1.3.1). Both the top and bottom boundaries are treated as Dirichlet-type conditions with specified constant temperature, gas pressure, and liquid saturation values. The ground surface of the mountain is taken as the top model boundary, representing an open atmosphere with atmospheric pressure and small water saturation. The water table as a flat, stable surface is used as the bottom boundary condition, with water saturation close to one. The top temperature boundary values represent long-term average conditions at the ground surface of Yucca Mountain, reflecting the altitude of the chosen location, while the bottom temperatures are approximately given by the geothermal gradient. It should be pointed out that the exact boundary condition values for temperature, gas pressure, and saturation are not important for $\mathrm{TH}$ seepage model results. This is because the temperature and gas pressure values define the initial temperature and pressure fields, respectively, which are soon significantly altered in the nearfield rock once the drifts are heated up. The thermal perturbation of the temperature and pressure fields is so strong in the near field that the initial distribution of these parameters hardly matters. With respect to water saturation in the model domain, the main factor affecting the initial water saturations is the surface infiltration imposed at the top boundary (see Section 4.1.1.4).

The specific boundary conditions values used in this report have been extracted from DTN: LB991131233129.004 [DIRS 162183] (file “pa99cal_ecm.out” in directory /AMR U0050 Data_1.6.00/LB991131233129.004-Charles), which is the product output from a previous version of the UZ Flow Models and Submodels (BSC 2001 [DIRS 158726]). Elements with names "Tpi64" and "Bti64" provide pressure, saturation, and temperature conditions at the top and the bottom of the Tptpmn submodel, respectively. Elements with names "Tpj34" and "Btj34" provide pressure, saturation, and temperature conditions at the top and bottom of the Tptpll submodel, respectively. Further information on developing these boundary conditions can be found in UZ Flow Models and Submodels (BSC 2001 [DIRS 158726], Sections 6.5 .2 and 6.7.2). The model boundary conditions used in this report are identical to the ones used in the THC modeling described in Drift-Scale Coupled Processes (DST and THC Seepage) Models (BSC 2004 [DIRS 169856]).

The UZ model grid and the boundary conditions assigned at the top and the bottom have been updated, details of which can be found in UZ Flow Models and Submodels (BSC 2004 [DIRS 169861]). The revised boundary conditions can be found in DTN: LB0303THERMSIM.001 [DIRS 165167]. As pointed out in Sections 6.3.2 and 6.3.3 of UZ Flow Models and Submodels (BSC 2004 [DIRS 169861]), some differences arise between previous and updated boundary values because additional measurements were used for the boundary value determination.

In the revised UZ model grid (DTN: LB03023DKMGRID.001 [DIRS 162354]; see Section 4.1.1.5), Column ' $h 28$ ' is closest to the location of Column ' $i 64$ ' in the earlier model grid (DTN: LB990501233129.004 [DIRS 111475]). Thus, the boundary conditions at the top and the bottom of the Tptpmn submodel in this report should be those of Column 'h28' as given in DTN: LB0303THERMSIM.001 [DIRS 165167]. In Table 4.1-6, a comparison is given of the 
top and bottom boundary conditions (in terms of pressure, temperature, and gas saturation) in Column 'h28' of the revised UZ numerical grid (DTN: LB03023DKMGRID.001 [DIRS 162354]) and those in Column 'i64' of the previous numerical grid (DTN: LB990501233129.004 [DIRS 111475]). The procedures for extracting these boundary conditions from the cited DTNs can be found in Appendix D. There are only minor differences in the boundary conditions between the revised values and the adopted values for the Tptpmn submodel. This minor difference in pressure and temperature boundary conditions at the top and bottom is unlikely to have any impact on the thermal seepage simulations presented in this report. Thus, it is justified to continue using boundary conditions for Column 'i64' from DTN: LB991131231129.004 [DIRS 162183]) for the Tptpmn submodel.

For the Tptpll submodel, the column closest to Column 'j34' of DTN: LB990501233129.004 [DIRS 111475] is Column ' $h 74$ ' in DTN: LB03023DKMGRID.001 [DIRS 162354]. Thus, the revised boundary conditions at the top and the bottom of the Tptpmn submodel should be those of Column 'h74' as given in DTN: LB0303THERMSIM.001 [DIRS 165167]. In Table 4.1-6, a comparison is also given of the top and bottom boundary conditions (in terms of pressure, temperature, and gas saturation) in Column ' $h 74$ ' of the updated UZ numerical grid (DTN: LB03023DKMGRID.001 [DIRS 162354]) and those in Column ' $\mathrm{j} 34$ ' of the older numerical grid (DTN: LB990501233129.004 [DIRS 111475]). The procedures for extracting these boundary conditions from the cited DTNs can also be found in Appendix D. There are only minor differences in the boundary conditions between the revised values and the adopted values for the Tptpll submodel. This minor difference in pressure and temperature boundary conditions at the top and bottom is unlikely to have any impact on the thermal seepage simulations presented in this report. Thus, it is justified to continue using boundary conditions for Column ‘j34’ from DTN: LB991131231129.004 [DIRS 162183] for the Tptpll submodel.

\subsubsection{Thermal Load and Ventilation Efficiency}

The thermal output of individual waste canisters placed into drifts is represented by an average thermal line load of $1.45 \mathrm{~kW} / \mathrm{m}$, according to the current design. A 50-year preclosure period is planned in which a significant fraction of the heat is removed from the repository by ventilation. The thermal line load of $1.45 \mathrm{~kW} / \mathrm{m}$ and the 50 -year preclosure period are defined in the repository design drawing entitled D\&E/PA/C IED Emplacement Drift Configuration and Environment (BSC 2004 [DIRS 168489], effective date 3/26/2004). Note that the value of 1.45 $\mathrm{kW} / \mathrm{m}$ refers to the initial thermal line load at emplacement time. This value decreases with time as a result of radioactive decay. The time-dependent thermal-line-load values are adopted from Repository Design, Repository/PA IED Subsurface Facilities (BSC 2003 [DIRS 161731]). More recent time-dependent thermal-line-load values are available in $D \& E / P A / C$ IED Typical Waste Package Components Assembly (BSC 2004 [DIRS 167369], effective date 01/30/2004). ${ }^{2}$ The time-dependent thermal-line-load values are virtually identical in the two sources, and hence no impact is expected on the TH simulations in this model report. The source references for the thermal line load and the thermal decay values are given in Table 4.1-1.

\footnotetext{
${ }^{2}$ This Information Exchange Drawing (IED) superseded the repository design drawing Repository/PA IED Subsurface Facilities Plan Sht. 5 of 5 (BSC 2002 [DIRS 159527], effective date 05/20/2002), which was in effect when the model simulations were conducted. See impact discussion in Section 6.2.1.3.3.
} 
As already mentioned in Section 1, the temperature conditions in the repository are expected to vary considerably, arising from heat output variation between individual waste packages, emplacement-time differences between repository sections, and three-dimensional edge effects. Therefore, in this report, four different sensitivity cases of thermal load are studied (see Sections 6.2.1.3.3 and 6.2.1.6). The first case, the so-called "base case" or "reference mode," uses the above given thermal line load of $1.45 \mathrm{~kW} / \mathrm{m}$ and a time-averaged ventilation efficiency value of 86.3 percent over the 50 years (see paragraph below for discussion on ventilation efficiency). The second temperature case is the high-temp mode, using a heat load identical to the reference case, but a smaller ventilation efficiency of 70 percent. This high-temp mode is identical to the high-temperature thermal operating mode (HTOM) selected in Total System Performance Assessment for the Site Recommendation (CRWMS M\&O 2000 [DIRS 153246], Section 1.7.1) and FY01 Supplemental Science and Performance Analyses, Volume 1: Scientific Bases and Analyses (SSPA) (BSC 2001 [DIRS 155950], Section 4.3.5.3.1). The other two thermal loads, as described in Section 6.2.1.3.3, are sensitivity cases that use thermal load values based on scientific judgment. Only the ventilation efficiency values used in the base case are considered direct input data to the model; the other values serve as the basis for selecting appropriate sensitivity cases of thermal load.

Ventilation efficiency denotes the fraction of heat removed from the repository as a result of ventilation during the 50-year preclosure period. The integrated ventilation efficiency provided by current Yucca Mountain Project (YMP) reports is 88 percent (DTN: MO0307MWDAC8MV.000 [DIRS 165395]; DTN: MO0307MWDAC8VD.000 [DIRS 167396]) when the emplacement drift is $600 \mathrm{~m}$ in length. When the emplacement drift is $800 \mathrm{~m}$ long, integrated ventilation efficiency is calculated to be 86 percent (DTN: MO0307MWDAC8MV.000 [DIRS 165395]; DTN: MO0307MWDAC8VD.000 [DIRS 167396]). For further details on how these ventilation efficiencies are calculated, refer to calculations in Ventilation Model and Analysis Report (BSC 2004 [DIRS 169862], Table 8-3). Uncertainties in calculated integrated ventilation efficiencies have also been reported (BSC 2004 [DIRS 169862], Table 8-3). For a $600 \mathrm{~m}$ long drift, the standard deviation of the calculated ventilation efficiency is 2.6 percent (BSC 2004 [DIRS 169862], Table 8-3). The standard deviation of the calculated ventilation efficiency for an 800-m-long drift is 2.7 percent (BSC 2004 [DIRS 169862], Table 8-3). Thus, the ventilation efficiency can be in the range 85.4 percent to 90.6 percent for a $600 \mathrm{~m}$ long drift. For $800 \mathrm{~m}$ long drifts, the range of ventilation efficiency is 83.3 percent to 88.7 percent.

The ventilation efficiency value adopted in this model report (unless otherwise stated) is 86.3 percent. The 86.3 percent value was reported in an earlier version of Ventilation Model (BSC 2002 [DIRS 160975], Table 6-6), which has subsequently been revised to address repository design changes and to replace calculations that utilized unqualified software. The ventilation efficiency of 86.3 percent, which was the best estimate available at the time that the majority of the analysis in this report was conducted, is qualified for use in this report by corroboration with the more recent, qualified data presented above (the data qualification plan is included in Appendix $\mathrm{H}$ ). This adopted ventilation efficiency value (=86.3 percent) is almost in the middle of the suggested range of ventilation efficiency values as defined by the range of standard deviations (see the paragraph immediately above), and actually is similar to the mean ventilation efficiency for an 800-m-long emplacement drift. Additionally, sensitivity analyses (see Section 6.2.4.2.1) have been performed with different ventilation efficiencies. The impact of the minor 
difference between adopted and best-estimate values of ventilation efficiencies on rock temperature in the drift vicinity is expected to be much smaller than the range of temperature conditions studied in the sensitivity analysis.

\subsubsection{Percolation Fluxes}

The base-case infiltration rates applied at the top of the TH seepage model are adopted from the mean infiltration scenario that includes present-day (0 to 600 years), monsoon (600 to 2,000 years), and glacial transition climates (more than 2,000 years), as described in Simulation of Net Infiltration for Modern and Potential Future Climates (USGS 2003 [DIRS 166518]). The selection of these time periods for climatic changes is provided in Multiscale Thermohydrologic Model (BSC 2004 [DIRS 169565]). The specific infiltration values-6, 16, and $25 \mathrm{~mm} / \mathrm{year}$ for the present-day, monsoon, and glacial transition periods, respectively-represent repository-wide averages. These values have been calculated as the arithmetic average of the 31 repository locations considered in a previous version of Multiscale Thermohydrologic Model (BSC 2001 [DIRS 158204], Section 6.3.1). Infiltration values at these 31 repository locations are provided in DTN: LL000114004242.090 ([DIRS 142884], file chimney_infiltration_fluxes). The calculation for deriving the repository-wide averages is given in Appendix B of this report. Note that the exact values of the base-case infiltration $(6,16$, and $25 \mathrm{~mm} / \mathrm{yr})$ are not important for the thermal seepage modeling study, as long as the long-term evolution of infiltration is appropriately represented for the three climate stages. This is because, per the discussion in Section 6.2.1.4, the base-case infiltration scenario is complemented by various additional scenarios with considerably higher percolation fluxes in order to cover the potential variability of flux over the repository area. These additional scenarios, defined by multiplying the base-case values with adequately chosen flux multiplication factors, are most relevant for the thermal seepage study, since the potential for ambient and thermal seepage increases with the amount of percolation flux arriving at the drifts.

More recent estimates of the average infiltration rates under different climatic conditions are available at present. For example, Table 6.1-2 in UZ Flow Models and Submodels (BSC 2004 [DIRS 169861]) provides the mean infiltration values at the top of the UZ model domain as 4.4, 11.8 and $17.0 \mathrm{~mm} / \mathrm{yr}$ under present-day, monsoon, and glacial climatic conditions. These numbers are obtained by averaging infiltration data in DTN: GS000308311221.005 [DIRS 147613]. Note also that average infiltration rates at the PTn-TSw interface have also been developed based on the average infiltration rates given in Table 6.1-2 of UZ Flow Models and Submodels (BSC 2004 [DIRS 169861]). These average rates are summarized in Table 6.6-11 of Abstraction of Drift Seepage (BSC 2004 [DIRS 169131]). For the sake of completeness, this table is reproduced here (see Table 4.1-7). From Table 4.1-7, over the entire UZ model domain, the average infiltration fluxes at the PTn-TSw interface under mean infiltration conditions are 4.8, 13.2, and $18.8 \mathrm{~mm} /$ year for the three climatic conditions. Over the repository footprint, the average infiltration fluxes at the same location (PTn-TSw interface) are 3.8, 11.7, and $17.9 \mathrm{~mm} / \mathrm{yr}$, respectively, for the three climatic conditions (see Table 4.1-7).

It is evident that the average percolation fluxes (6, 16, and $25 \mathrm{~mm} / \mathrm{yr}$ for the present-day, monsoon, and glacial climatic conditions, respectively) used in the thermal seepage simulations in this report are larger than the most recent estimates of 3.8, 11.7, and $17.9 \mathrm{~mm} /$ year, while the trends of infiltration changes between the different climates are similar. The difference between 
the average fluxes are not relevant in this study, however, because the simulation cases important for seepage are those cases with significantly higher percolation fluxes, representing fluxes at the high end of the probability spectrum. The cases relevant for seepage are those where the basecase fluxes have been multiplied by appropriately chosen flux multiplication factors (see Section 6.2.1.4). This justifies use of 6,16 , and $25 \mathrm{~mm} / \mathrm{yr}$ as the base-case infiltration fluxes for the three climate stages, because using the more recent estimates of infiltration would simply require adjusted flux multiplication factors to represent the same high-end range of the probability spectrum. Thus, the conclusions drawn from this report that feed into the seepage abstraction and TSPA are not affected by the choice of the base-case infiltration fluxes.

\subsubsection{Grid Design Data}

The data needed for grid design are the configuration of emplacement drifts (drift spacing and diameter) and the geologic stratigraphy for the Tptpmn and the Tptpll submodels. The current drift configuration, as given in the repository design drawing $D \& E / P A / C$ IED Emplacement Drift Configuration and Environment (BSC 2004 [DIRS 168489], effective date 3/26/2004), calls for a drift diameter of $5.5 \mathrm{~m}$ and a drift spacing of $81 \mathrm{~m}$. The grid design for in-drift component is discussed in Section 4.1.1.6.

The geologic data for the Tptpmn and Tptpll submodels were derived from the UZ model grid in DTN: LB99051233129.004 [DIRS 111475]. The UZ model grid was based on a previous version of the geologic framework model as described in Geologic Framework Model (GFM3.1) (CRWMS M\&O 2000 [DIRS 138860]), using geologic data of status 1999 (DTN: MO9901MWDGFM31.000 [DIRS 103769]). The stratigraphy in a one-dimensional column close to borehole USW SD-9 was chosen as representative for the vertical profile of geologic contacts into the Tptpmn submodel mesh. Geologic data for this location is best represented by Column “i64” in DTN: LB990501233129.004 [DIRS 111475]. The elevations of the contacts between various geological layers as implemented in the Tptpmn submodel are shown in Table 4.1-8. The stratigraphy of the Tptpll submodel was extracted at a location near the center of the repository (at approximately Nevada State Plane coordinates E170572, N233194). Geologic data from Column "j34" of the UZ model grid are used to map geologic contacts into the two-dimensional mesh (DTN: LB990501233129.004 [DIRS 111475]). The elevations of the contacts between various geological layers as implemented in the Tptpll submodel are shown in Table 4.1-9.

DTN: LB990501233129.004 [DIRS 111475] represents the UZ model grid that was current at the time that the thermal seepage modeling was performed. However, a new numerical grid for the UZ model is now available (DTN: LB03023DKMGRID.001 [DIRS 162354]), based on the current version of the geologic framework model (BSC 2004 [DIRS 170029], Section 6.1). The stratigraphy modifications in the current revision of the geologic framework model are small for the repository units. It is noted in Geologic Framework Model (BSC 2004 [DIRS 170029], Section 6.1) that the changes between the earlier and the new revision of the geologic framework model relating to the elevation in geologic layers are relatively small in magnitude, rarely as large as 25 feet, and are primarily near the edges of the geological framework model (GFM) boundary. Therefore, changes in thickness and contact elevations in the repository should be minor, much smaller than the extent of the host rock units. Since the relevant TH processes of boiling and condensation of water occur in close vicinity to the drifts, the results of this report 
should not affected by these changes. Below, the differences between the stratigraphy of the Tptpmn and Tptpll submodels are evaluated based on the two different versions of the UZ model grid.

Using the new UZ model grid (DTN: LB03023DKMGRID.001 [DIRS 162354]), the onedimensional column closest to borehole USW SD-9 is Column ' $h 28$ ', representative of the Tptpmn submodel. The elevations of the various geological layers in Column ' $h 28$ ' are shown (and compared with) those in Column 'i64' (from DTN: LB990501233129.004 [DIRS 111475]). A comparison of the adopted (Column 'i64' from DTN: LB990501233129.004 [DIRS 111475]) and revised (Column 'h28' from DTN: LB03023DKMGRID.001 [DIRS 162354]) stratigraphy is shown in Table 4.1-8. The thicknesses of the respective layers in these two columns (Column 'i64' and Column 'h28') are identical except for layers far away from the heat sources. For example, the thicknesses of layers 'tsw33', 'tsw34', 'tsw35', and 'tsw36' in Column 'i64' (the adopted thickness values in the TH seepage model) are 85.3, 35.3, 102.5, and $35.7 \mathrm{~m}$, respectively (see Table 4.1-8, third column). The revised thicknesses for these same layers, in the same order, are 85.6, 34.8, 102.5, and $35.5 \mathrm{~m}$. Thus, the differences between adopted and revised thickness for the geological units in the vicinity of the heat drifts are always less than one percent. Implementing geological data in the Tptpmn submodel from an older DTN (DTN: LB990501233129.004 [DIRS 111475]) in this report is justified as the difference is nominal with the revised stratigraphy data. In addition, since the difference in thickness of the repository units ('tsw33', 'tsw34', 'tsw35', and 'tsw36') is less than one percent, no additional sensitivity analyses are required. The procedures followed to calculate the elevations and thicknesses of the various units can be found in Appendix E.

For the Tptpll submodel, as has been noted earlier, geological data were adopted from Column 'j34' in DTN: LB990501233129.004 [DIRS 111475]. The elevations at the top of each geological layer in Column ' $\mathrm{j} 34$ ' are given in Table 4.1-9. Table 4.1-9 also gives the thickness of each geological layer in Column ' $j 34$ ' (see the third column in Table 4.1-6). These thickness values have been adopted for the Tptpll submodel. The column closest to the location of Column ' $\mathrm{j} 34$ ' in the new UZ numerical grid (DTN: LB03023DKMGRID.001 [DIRS 162354]) is Column 'h74.' The elevations and thicknesses of each geological layer in Column ' $h 74$ ' in LB03023DKMGRID.001 [DIRS 162354] are also shown in Table 4.1-9 (see the fourth and fifth columns). The procedures followed to obtain the numbers in Table 4.1-9 can again be found in Appendix E. Though not as close as those for the Tptpmn submodel, the top elevations and thicknesses of the geological layers in Column 'h74' (revised) are comparable with those of Column 'j34' (adopted), particularly for the geological layers in proximity to the sources of heat. For example, for the 'tsw33', 'tsw34', 'tsw35', and 'tsw36' layers, the (adopted) thicknesses in Column 'j34' are $80.1 \mathrm{~m}, 37.2 \mathrm{~m}, 101.4 \mathrm{~m}$, and $33.2 \mathrm{~m}$, respectively. The respective (revised) values in Column ' $h 74$ ' are $80.3,34.5,102.5$, and $32.7 \mathrm{~m}$. In the Tptpll submodel, the waste emplacement drift (and the source of heat) is located in the 'tsw35' geological layer. For this layer, the difference in adopted and revised thickness is only $1.1 \mathrm{~m}$ (or the difference is about one percent). The thickness of the 'tsw34' layer differs by about $2.7 \mathrm{~m}$ (or less than eight percent). However, the 'tsw34' layer is situated more than 50 meters away from the source of heat in the Tptpll submodel, and-as will be established later (see Section 6.2.3) - the impact of heating in the Tptpll submodel is not realizable that far away. Thus, the difference in thickness in the Tsw34 layer between the adopted and revised values is unlikely to have any impact on the thermal seepage simulations in the Tptpll submodel. The differences in thickness between 
adopted and revised values far away (both top and bottom) from the source of heat in the Tptpll submodel are similarly not expected to have any significant impact on the thermal seepage simulations. It is thus justified to use geological data from the older DTN (LB990501233129.004 [DIRS 111475]). No sensitivity analysis is considered necessary.

\subsubsection{In-Drift Geometry and Properties}

The focus of this report is on the thermal-hydrological processes that occur in the near-field rock as a response to the thermal load. This report also evaluates how these thermal-hydrological processes affect the magnitude of seepage during the period of elevated temperatures. Prediction of the in-drift thermal-hydrological conditions is NOT the purpose of this report. Thus, the indrift environment can be simulated in a simplified manner, only to the detail that is required to provide the proper boundary conditions for the near-field rock. This means that the in-drift geometry and the in-drift properties chosen for the TH seepage model are conceptual model choices. These conceptual model choices are explained below and in Table 4.1-10.

The open space inside the drift, i.e., the space between the invert and the drift wall, is represented by elements of high permeability $\left(1 \times 10^{-10} \mathrm{~m}^{2}\right)$, high porosity $(\sim 1.0)$, and small capillarity $(-5.0 \mathrm{~Pa})$. These parameters for the space between the drift wall and the invert are provided mostly for numerical simulation with the TOUGH2 simulator (Pruess 1991 [DIRS 100413]). The choice of these parameter values is consistent with the conceptual model of seepage into a large, open cavity. In other words, the drift (except the invert) is modeled similar to that of gasfilled cavity with a capillary barrier at the rock-drift interface, and no further justification is needed for the selection of these parameters. Note that water that seeps into the drift is collected without further consideration of the liquid flow processes that occur within the open cavity. Therefore, the in-drift elements have a zero permeability to water flow.

Drift elements are also given large heat conductivities $(10,000 \mathrm{~W} / \mathrm{m} / \mathrm{K})$ to simulate the effective heat transfer by radiation/convection/conduction within the drift. The grain heat capacities in the open cavity are set to $0.0 \mathrm{~J} / \mathrm{kg}$. Again, the choice of these parameters is consistent with the physical/conceptual model of seepage into an open cavity (see Sections 6.2.1.1.2 and 6.2.1.5). To test the large-heat-conductivity model choice, a sensitivity case was conducted with a smaller in-drift thermal conductivity of $10.568 \mathrm{~W} / \mathrm{m} / \mathrm{K}$. This value was based on an effective in-drift conductivity that was used in Drift Scale (DST and THC Seepage) Coupled Processes (BSC 2003 [DIRS 162050], Section 4.1-7). The impact of this change is negligible, as shown in Section 6.2.4.2.6.

The heat generated by the decaying waste is imposed as a boundary condition into one grid element that represents the waste package (see Figure 6.2.1.2-2). Flow and transport within the waste package are not simulated; only transport of heat between the waste package and the surrounding open cavity and the invert. The location and dimensions of the waste package are given in Table 4.1-10. While these dimensions were, in part, obtained from DTN: SN9908T0872799.004 [DIRS 108437], they have since been replaced by more recent information. Waste package density and heat capacity are also based on DTN: SN9908T0872799.004 [DIRS 108437]. Appendix G provides rationale and qualification effort to establish suitability of using data from DTN: SN9908T0872799.004 [DIRS 108437] for TH seepage model. Note that the waste package density given in Table 4.1-10 is the density of 
the outer shell. More recent information (BSC 2004 [DIRS 167758]) indicates that the density of the waste package internal cylinder is in the range $3,175-3,495 \mathrm{~kg} / \mathrm{m}^{3}$. The thermal conductivity used at the interface between the waste package and the drift elements is $10,000 \mathrm{~W} / \mathrm{m} / \mathrm{K}$, similar to the thermal conductivity value chosen for the gas-filled cavity. To test the property choices, a sensitivity case was conducted in Section 6.2.4.2.6 where the thermal properties of the waste package were set to those given in D\&E/ PA/C IED Typical Waste Package Components Assembly (BSC 2004 [DIRS 167758]) for the 21-PWR waste package (i.e., a density of 3495 $\mathrm{kg} / \mathrm{m}^{3}$, a heat capacity of $378 \mathrm{~J} / \mathrm{kg} / \mathrm{K}$, and a thermal conductivity of $1.5 \mathrm{~W} / \mathrm{m} / \mathrm{K}$ ). The impact of this change is negligible, as shown in Section 6.2.4.2.6. The drip shield was not explicitly modeled in the TH seepage model.

The invert at the bottom of the drift, to be made of crushed tuff rock material, is treated as a single continuum domain in the thermal seepage model. More complex conceptualizations like a dual-continuum approach are possible, as adopted for example in Multiscale Thermohydrologic Model (BSC 2004 [DIRS 169565], Section 6.2), but not necessary for the purpose of modeling thermal seepage (remember that thermal seepage deals with flow of water into the emplacement drifts but not flow within them). The discretization of the invert is consistent with the dimensions given in Table 4.1-10, within the limits imposed by the resolution of the model mesh (Figure 6.2.1.2-2). The thermal (heat capacity, thermal conductivity, and density) and selected hydrological (permeability and porosity) properties of the invert at the bottom of the drift (see Table 4.1-10) are obtained from DTN: SN9908T0872799.004 [DIRS 108437]. Appendix G justifies use of DTN: SN9908T0872799.004 [DIRS 108437] in this model report as the source for invert properties by demonstrating that the adopted values are within acceptance limits of invert properties from more recent sources. Similar to the open drift elements, the invert is given zero capillary suction, because the drying and wetting characteristics of the invert are not relevant for thermal seepage. In general, the chosen invert properties have limited impact on the overall TH behavior in the rock. In particular, the magnitude and evolution of thermal seepage is not affected by the choice of the invert properties.

\subsubsection{Input Data for DST TH Model}

The data presented in this subsection is considered corroborative because it is used for model validation purposes. In Section 7, the TH seepage model is validated in comparison with measured data from the DST through the DST TH model. The input information required for the DST TH model is explained below and listed in Table 4.1-11.

\subsubsection{Hydrological and Thermal Properties}

The DST TH model, intended for comparative model analysis with the measured data from the DST, utilizes two property sets. One property set used is the DS/AFM-UZ02-Mean property set as described in Section 4.1.1.1. The second property set is a sensitivity case that is partially based on site-specific characterization of the DST test block. This data set, referred to as DKM-TT99, is described in Thermal Tests Thermal-Hydrological Analyses/Model Report (BSC 2001 [DIRS 157330], Section 4.1, Table 5). Since the thermal and hydrologic properties in the DKM-TT99 property set (BSC 2001 [DIRS 157330], Section 4.1, Table 5) are specific to the site of the DST, their use in this report is justified. For comparison, the TH properties of the DKM-TT99 property set are summarized in Table 4.1-2 for the three geological units comprising 
the DST TH model, namely the Tptpul, the Tptpmn, and the Tptpll. Note that the open space of the Heated Drift is modeled similarly to the drift representation in the TH seepage model (see Section 4.1.1.1), using gridblock elements with high permeability, high porosity, small capillarity, and large heat conductivity.

\subsubsection{Model Boundary Conditions}

The top and bottom model boundary conditions are identical to those used in Thermal Tests Thermal-Hydrological Analyses/Model Report (BSC 2001 [DIRS 157330], Section 6.1.2). The boundary condition values are given in DTN: LB000300123142.001 ([DIRS 148120], file "Incon.heat" in directory /LBNL_DST_AMR_DKMTT99). Using these boundary conditions for the DST TH model is justified because the earlier DST modeling (BSC 2001 [DIRS 157330], Section 6.1.2) was carried out at the same location. Elements with names "Tt001" and "tt001" provide pressure, saturation, and temperature conditions at the top, while elements with names "Bb001" and "bb001" provide pressure, saturation, and temperature conditions at the bottom of the model domain (for both fracture and matrix continua). These boundary values were developed from simulations of a one-dimensional column extending from the land surface to the water table, mapped to the location of the top and bottom of the model domain.

\subsubsection{Heat Input}

In the DST, heat is provided by nine canister heaters, located on the floor of the Heated Drift. Additional heating is provided by 50 wing heaters (see Section 7.2.1). The total output power from both the canister and the wing heaters has been continuously collected. Average values of these total powers over certain time periods have been used in the DST TH model (see Section 7.3.4 for more details). Table 4.1-11 provides a list of DTNs for the total canister and wing heater powers at various times.

\subsubsection{Borehole and Sensor Location Data}

Passive monitoring of $\mathrm{TH}$ data (such as temperature, pressure, and humidity) from the DST is carried out with measurement sensors located in a number of boreholes (see Figure 7.2.1-2). Active monitoring of data (such as periodic air-injection tests and geophysical measurements) is carried out in boreholes specifically designed for such purposes. Results from the DST TH model are compared directly against these measured data from the DST. Though the boreholes and the sensors have not been explicitly modeled in the DST TH model, the three-dimensional numerical grid has been developed in such a way that simulated $\mathrm{TH}$ data can be easily interpolated to specific sensor locations. The DTN containing these design parameters of the DST is listed in Table 4.1-11.

\subsubsection{DST Measurements}

The data presented in this subsection are considered corroborative information (other input information), since they are used for model validation purposes. In Section 7, the TH seepage model is validated in comparison with measured data from the DST. The input information on measurement data used for validation is explained below and summarized in Table 4.1-12. 


\subsubsection{Temperature Measurements}

Temperature data, similar to heater power in Section 4.1.2.3, have been continuously collected from the DST. For model validation, these measured temperatures are directly compared against simulated temperatures from the DST TH model. The DTNs for the measured temperature data are listed in Table 4.1-12.

\subsubsection{Ground-Penetrating Radar Data}

Ground-penetrating radar (GPR) data are used to capture the redistribution of matrix pore water resulting from heating. Periodic GPR measurements have been carried out at the DST. At the beginning of heating for the DST, a baseline GPR measurement was carried out to obtain preheating water content in the matrix. Subsequent GPR measurements are then used to determine the spatial and temporal evolution of water redistribution in the matrix. The DST TH model (and hence the drift-scale TH seepage model) is validated by comparing the simulated water redistribution in the rock matrix with GPR measurements. DTNs are listed in Table 4.112.

\subsubsection{Air-Permeability Measurements}

While GPR (and other geophysical techniques such as neutron logging and electrical resistance tomography) captures redistribution of water in the rock matrix, changes in water saturation in the fractures are measured by air-permeability testing. Similar to GPR measurements, periodic air-permeability testing has been carried out at the DST. The air-permeability measurements at the DST also include pretest baseline tests to capture the ambient conditions in the fractures. Subsequent air-permeability measurements are used to determine fractional change in air permeability from the baseline air permeabilities. These measured air-permeability ratios are compared against simulated air-permeability ratios for validating the DST TH model. The DTN for the heating-phase air-permeability data is listed in Table 4.1-12.

\subsubsection{Water Sampling Data}

Liquid water was collected in several packed-off borehole intervals at different times during the DST. Occurrence of water seepage into boreholes should coincide with elevated liquid saturation in fractures close to the borehole interval. In this report, the location and timing of water collection in borehole intervals is compared to the simulated evolution of fracture saturation for validation of the DST TH model. The DTN for the water collection data is listed in Table 4.1-12.

\subsubsection{Input Data for DTN: LB0402THRMLPRP.001}

Wet and dry thermal conductivity, matrix porosity, and bulk density data for the nonrepository lithostratigraphic layers were obtained from DTN: SN0303T0503102.008 [DIRS 162401]. DTN: SN0208T0503102.007 [DIRS 160257]) provided these properties for the geological layers in the repository horizon, namely the upper lithophysal (Tptpul or tsw33), the middle nonlithophysal (Tptpmn or tsw34), the lower lithophysal (Tptpll or tsw35), and the lower nonlithophysal (Tptpln or tsw36) stratigraphic units of Topopah Spring welded tuff. Note that DTN: SN0208T0503102.007 [DIRS 160257] has been superceded by DTN: 
SN0404T0503102.011 [DIRS 169129] in order to rectify the omission of several files in the original data submittal. Since the superceding data source has the same thermal properties for the repository layers as in the superceded source, it is justified to use DTN: SN0208T0503102.007 [DIRS 160257] as the source of thermal properties for the repository layers.

The heat capacity values of the lithostratigraphic layers are taken from DTN: SN0402T0503102.010 [DIRS 170993]. The same heat capacity data are also available in DTN: SN0206T0503102.005 [DIRS 160258], which have been qualified in Data Qualification Report: Heat Capacity Values for Rock and Lithostratigraphic Layers of the Geologic Framework Model for Use on the Yucca Mountain Project (BSC 2004 [DIRS 171504]), and re-issued in the qualified DTN: SN0402T0503102.010 [DIRS 170993]. Table 4.1-13 lists these input DTNs and Appendix $\mathrm{F}$ describes how the thermal properties in DTN: LB0402THRMLPRP.001 are developed using these inputs. 
Table 4.1-1. Direct Input Data to the TH Seepage Model

\begin{tabular}{|c|c|c|c|}
\hline DTNs/Reference & Description & 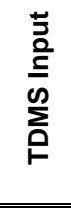 & 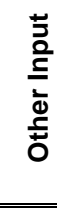 \\
\hline \multicolumn{4}{|c|}{ Hydrological and Thermal Rock Properties: } \\
\hline $\begin{array}{l}\text { LB0205REVUZPRP.001 } \\
\text { [DIRS 159525] }\end{array}$ & $\begin{array}{l}\text { Fracture parameters such as porosity, } \\
\text { aperture, frequency, and interface area }\end{array}$ & $x$ & \\
\hline $\begin{array}{l}\text { LB0208UZDSCPMI.002 } \\
\text { [DIRS 161243] }\end{array}$ & $\begin{array}{l}\text { Fracture and matrix calibrated parameters - } \\
\text { Mean Infiltration }\end{array}$ & $x$ & \\
\hline $\begin{array}{l}\text { LB0210THRMLPRP.001 } \\
\text { [DIRS 160799]; see also Section } \\
\text { 4.1.1.1 and Appendix C }\end{array}$ & Matrix thermal data and porosity & $x$ & \\
\hline $\begin{array}{l}\text { LB0302SCMREV02.002 } \\
\text { [DIRS 162273] }\end{array}$ & $\begin{array}{l}\text { Fracture capillary strength calibrated from the } \\
\text { seepage calibration model }\end{array}$ & $x$ & \\
\hline $\begin{array}{l}\text { LB0310AMRU0120.001 [DIRS } \\
\text { 166409] }\end{array}$ & $\begin{array}{l}\text { Statistics of fracture capillary strength defining } \\
\text { spatial variability of repository area }\end{array}$ & $x$ & \\
\hline $\begin{array}{l}\text { LB0302SCMREV02.002 } \\
\text { [DIRS 162273] }\end{array}$ & $\begin{array}{l}\text { Mean permeability and standard deviation for } \\
\text { air permeability measurements from niches }\end{array}$ & $x$ & \\
\hline $\begin{array}{l}\text { BSC } 2004 \text { [DIRS 166107], Section } \\
\text { 6.4.2.5; see Section } 6.2 .5\end{array}$ & $\begin{array}{l}\text { Bulking factor (only for TH simulations in } \\
\text { collapsed drifts) }\end{array}$ & & $x$ \\
\hline \multicolumn{4}{|l|}{ Model Boundary Conditions: } \\
\hline $\begin{array}{l}\text { LL000114004242.090 [DIRS } \\
\text { 142884]; see justification in } \\
\text { Section 4.1.1.4 }\end{array}$ & $\begin{array}{l}\text { Infiltration rates for present day, monsoon, and } \\
\text { glacial periods (the mean infiltration case is } \\
\text { used in this report) }\end{array}$ & $x$ & \\
\hline $\begin{array}{l}\text { LB991131233129.004 } \\
\text { [DIRS 162183]; see justification in } \\
\text { Section 4.1.1.2 }\end{array}$ & $\begin{array}{l}\text { Top and bottom boundary temperatures, } \\
\text { pressure, saturations } \\
\text { Column i64 used for Tptpmn submodel } \\
\text { Column j34 used for Tptpll submodel }\end{array}$ & $x$ & \\
\hline \multicolumn{4}{|c|}{ Thermal Load and Ventilation Efficiency: } \\
\hline $\begin{array}{l}\text { BSC } 2003 \text { [DIRS 161731]; see } \\
\text { also Section 4.1.1.3 }\end{array}$ & Thermal decay & & $x$ \\
\hline BSC 2004 [DIRS 168489] & Heat load $(1.45 \mathrm{~kW} / \mathrm{m})$ & & $x$ \\
\hline $\begin{array}{l}\text { BSC } 2002 \text { [160975], Table 6-6; } \\
\text { see also Section 4.1.1.3 }\end{array}$ & Ventilation efficiency & & $x$ \\
\hline \multicolumn{4}{|l|}{ Grid Design Data: } \\
\hline $\begin{array}{l}\text { LB990501233129.004 } \\
\text { [DIRS 111475]; see justification in } \\
\text { Section 4.1.1.5 }\end{array}$ & $\begin{array}{l}\text { Stratigraphy of UZ model grid } \\
\text { Borehole USW SD-9 (column i64) used for } \\
\text { stratigraphy of Tptpmn submodel } \\
\text { Center of the repository (column j34) used for } \\
\text { stratigraphy of Tptpll submodel }\end{array}$ & $x$ & \\
\hline $\begin{array}{l}\text { SN9908T0872799.004 [DIRS } \\
\text { 108437]; see Section 4.1.1.6 and } \\
\text { Appendix G }\end{array}$ & $\begin{array}{l}\text { Dimensions and properties of waste package } \\
\text { and invert }\end{array}$ & $x$ & \\
\hline BSC 2004 [DIRS 168489] & Drift geometry (diameter and spacing) & & $x$ \\
\hline
\end{tabular}




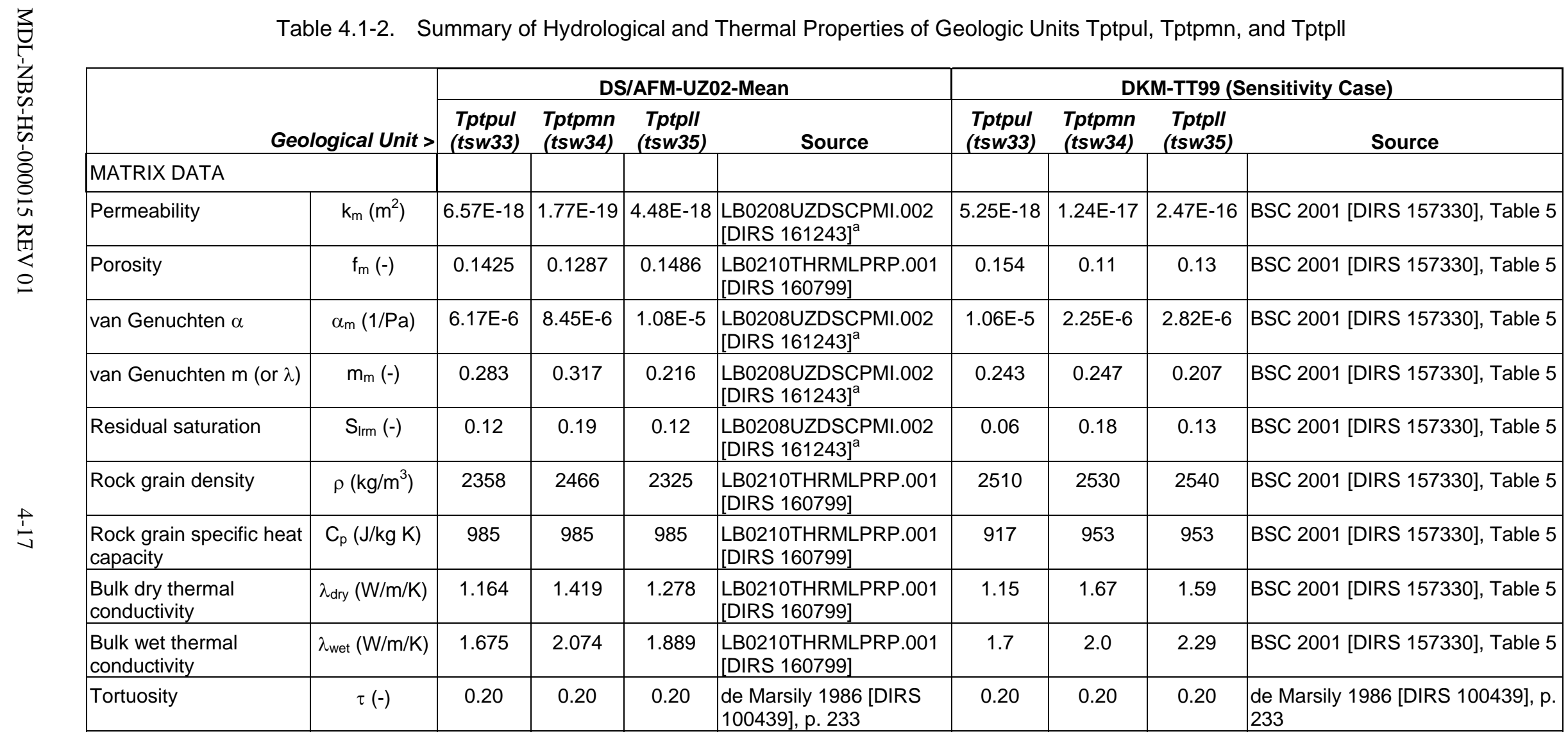


Table 4.1-2. Summary of Hydrological and Thermal Properties of Geologic Units Tptpul, Tptpmn, and Tptpll (Continued)

\begin{tabular}{|c|c|c|c|c|c|c|c|c|c|}
\hline & \multirow[b]{2}{*}{ Geol. Unit > } & \multicolumn{4}{|c|}{ DSIAFM-UZ02-Mean } & \multicolumn{4}{|c|}{ DKM-TT99 (Sensitivity Case) } \\
\hline & & $\begin{array}{c}\text { Tptpul } \\
\text { (tsw33) }\end{array}$ & $\begin{array}{l}\text { Tptpmn } \\
\text { (tsw34) }\end{array}$ & $\begin{array}{c}\text { Tptpll } \\
\text { (tsw35) }\end{array}$ & Source & $\begin{array}{c}\text { Tptpul } \\
\text { (tsw33) }\end{array}$ & $\begin{array}{l}\text { Tptpmn } \\
\text { (tsw34) }\end{array}$ & $\begin{array}{c}\text { Tptpll } \\
\text { (tsw35) }\end{array}$ & Source \\
\hline \multicolumn{10}{|l|}{ FRACTURE DATA ${ }^{b}$} \\
\hline Permeability & $k_{f}\left(m^{2}\right)$ & 7.8E-13 & 3.3E-13 & $9.1 \mathrm{E}-13$ & $\begin{array}{l}\text { LB0208UZDSCPMI.002 } \\
\text { [DIRS 161243] }^{\mathrm{C}}\end{array}$ & $\begin{array}{l}6.353 \mathrm{E}- \\
13 \\
\end{array}$ & 1.00E-13 & 1.87E-12 & BSC 2001 [DIRS 157330], Table 5 \\
\hline Porosity & $f_{f}(-)$ & $5.8 \mathrm{E}-3$ & 8.5E-3 & $9.6 \mathrm{E}-3$ & $\begin{array}{l}\text { LB0205REVUZPRP.001 } \\
\text { [DIRS 159525] }\end{array}$ & $0.171 \mathrm{E}-3$ & $0.263 E-3$ & $0.329 \mathrm{E}-3$ & BSC 2001 [DIRS 157330], Table 5 \\
\hline van Genuchten $\alpha$ & $\alpha_{f}(1 / P a)$ & $1.59 \mathrm{E}-3$ & $1.04 \mathrm{E}-4$ & $1.02 \mathrm{E}-4$ & $\begin{array}{l}\text { LB0208UZDSCPMI.002 } \\
\text { [DIRS 161243] }^{\mathrm{C}}\end{array}$ & $1.57 \mathrm{E}-4$ & $9.73 \mathrm{E}-5$ & $1.66 \mathrm{E}-5$ & BSC 2001 [DIRS 157330], Table 5 \\
\hline van Genuchten $m$ (or $\lambda$ ) & $m_{f}(-)$ & 0.633 & 0.633 & 0.633 & $\begin{array}{l}\text { LB0208UZDSCPMI.002 } \\
\text { [DIRS 161243] }^{\mathrm{C}}\end{array}$ & 0.492 & 0.492 & 0.492 & BSC 2001 [DIRS 157330], Table 5 \\
\hline Residual saturation & $S_{\text {Iff }}(-)$ & 0.01 & 0.01 & 0.01 & $\begin{array}{l}\text { LB0208UZDSCPMI.002 } \\
\text { [DIRS 161243] }^{\mathrm{C}}\end{array}$ & 0.01 & 0.01 & 0.01 & BSC 2001 [DIRS 157330], Table 5 \\
\hline Effective Tortuosity & $\tau(-)$ & $0.0041^{d}$ & $0.0060^{d}$ & $0.0067^{d}$ & $\begin{array}{l}\text { de Marsily } 1986 \text { [DIRS } \\
\text { 100439], p. } 233\end{array}$ & $0.2^{\mathrm{e}}$ & $0.2^{\mathrm{e}}$ & $0.2^{\mathrm{e}}$ & $\begin{array}{l}\text { de Marsily } 1986 \text { [DIRS 100439], p. } \\
233\end{array}$ \\
\hline AFM coefficient & $\gamma(-)$ & 0.60 & 0.57 & 0.57 & $\begin{array}{l}\text { LB0208UZDSCPMI.002 } \\
\text { [DIRS 161243] }^{\mathrm{C}}\end{array}$ & N/A & N/A & N/A & (AFM not applied) \\
\hline
\end{tabular}

a The tsw33, tsw34, and tsw35 units are referred to in the source document (DTN: LB0208UZDSCPMI.002 [DIRS 161243]) as tswM3, tswM4, and tswM5,

respectively.

${ }^{b}$ Fracture thermal properties are calculated from matrix thermal properties as discussed in Section 6.2.1.1.3.

c The tsw33, tsw34, and tsw35 units are referred to in the source document (DTN: LB0208UZDSCPMI.002 [DIRS 161243]) as tswF3, tswF4, and tswF5, respectively.

${ }^{d}$ Fracture tortuosity of 0.7 is multiplied by fracture porosity to arrive at effective tortuosity factor for the fracture continuum.

${ }^{\mathrm{e}}$ In the DKM-99 sensitivity case, effective tortuosity is set to 0.2 in order to be consistent with previous simulations. 
Table 4.1-3. Summary Statistics of Estimated Capillary-Strength Parameter for Lower Lithophysal Zone and Middle Nonlithophysal Zone from Seepage Calibration Model

\begin{tabular}{|c|c|c|c|c|c|c|c|}
\hline \multicolumn{8}{|c|}{ Lower Lithophysal Zone (TptpII) } \\
\hline \multirow{2}{*}{ Location } & \multirow{2}{*}{ Interval } & \multirow{2}{*}{$\begin{array}{l}\text { Number of } \\
\text { Inversions }^{a}\end{array}$} & \multicolumn{5}{|c|}{ Estimate $1 / \alpha[\mathrm{Pa}]$} \\
\hline & & & Mean & Std. Dev. ${ }^{b}$ & Std. Error ${ }^{c}$ & Min. & Max. \\
\hline SYBT-ECRB-LA\#1 & zone 2 & 17 & 534.3 & 56.8 & 13.8 & 447.7 & 674.1 \\
\hline SYBT-ECRB-LA\#2 & zone 2 & 21 & 557.1 & 56.4 & 12.3 & 457.1 & 676.1 \\
\hline SYBT-ECRB-LA\#2 & zone 3 & 19 & 534.8 & 57.8 & 13.3 & 443.1 & 645.7 \\
\hline SYBT-ECRB-LA\#3 & zone 1 & 23 & 452.0 & 54.7 & 11.4 & 382.8 & 616.6 \\
\hline Niche 1620 & $\mathrm{BH} \# 4$ & 30 & 671.2 & 223.2 & 40.8 & 356.0 & 1197.0 \\
\hline Niche 1620 & $\mathrm{BH} \# 5$ & 24 & 740.5 & 339.0 & 69.2 & 231.1 & 1840.8 \\
\hline \multicolumn{8}{|c|}{ Middle Nonlithophysal Zone (Tptpmn) } \\
\hline Niche 3107 & UM & 1 & 741 & - & - & - & - \\
\hline Niche 4788 & UL & 1 & 646 & - & - & - & - \\
\hline Niche 4788 & UM & 1 & 603 & - & - & - & - \\
\hline Niche 4788 & UR & 1 & 427 & - & - & - & - \\
\hline
\end{tabular}

DTN: LB0302SCMREV02.002 [DIRS 162273], also given in BSC 2004 [DIRS 171764], Table 6-8.

${ }^{a}$ Each inversion is based on a different realization of the heterogeneous permeability field.

${ }^{\mathrm{b}}$ Represents estimation uncertainty on account of small-scale heterogeneity (not available for estimates for the middle nonlithophysal zone).

${ }^{c}$ Standard error of mean.

Table 4.1-4. Intermediate-Scale Variability Statistics of Estimated Capillary-Strength Parameter over Repository Rock Block, Using Different Calculation Methods

\begin{tabular}{|c|c|c|c|c|}
\hline Method & $\begin{array}{c}\text { Number of } \\
\text { Samples }\end{array}$ & $\begin{array}{c}\text { Mean } \boldsymbol{\mu} \\
\mathbf{( P a )}\end{array}$ & $\begin{array}{c}\text { Std. Dev. } \boldsymbol{\sigma} \\
\mathbf{( P a )}\end{array}$ & $\begin{array}{c}\text { Std. Error } \\
\text { of Mean SE } \\
\mathbf{( P a )}\end{array}$ \\
\hline $\begin{array}{c}\boldsymbol{A} \text { All Samples, Both Units } \\
\text { B }\end{array}$ & $\mathbf{1 0}$ & $\mathbf{5 9 1}$ & $\mathbf{1 0 \mathbf { 9 } ^ { \mathbf { 1 } }}$ & $\mathbf{3 5}$ \\
\hline $\begin{array}{c}\text { All Locations, Both Units } \\
\text { C }\end{array}$ & 4 & 631 & 109 & 54 \\
\hline All Samples in Tptpmn & 4 & 604 & 131 & 66 \\
All Samples in Tptpll & 6 & 582 & 105 & 43 \\
\hline $\begin{array}{c}\text { D } \\
\text { All Locations in Tptpmn } \\
\text { All Locations in Tptpll }\end{array}$ & 2 & 650 & 129 & 91 \\
\hline
\end{tabular}

DTN: LB0310AMRU0120.001 [DIRS 166409], also given in BSC 2004 [DIRS 169131], Table 6.6-2. Inside the DTN, go to directory "capillary_strength_analysis" and locate the file "capillary_strength_summary_tables.doc" for the values reported in this table.

NOTE: Due to rounding, the standard deviation of Method $\mathrm{A}$ was set to $109 \mathrm{~Pa}$ in this analysis instead of $110 \mathrm{~Pa}$, as suggested by the Excel spreadsheet results referred to in Appendix II. This difference of less than $1 \%$ in the second moment is not relevant for the resulting parameter distributions. 
Table 4.1-5. Mean and Standard Deviation of Log-Air-Permeability Values of Disturbed Zones (PostExcavation) from Niches and Systematic Testing Boreholes SYBT-ECRB-LA\#2

\begin{tabular}{|l|l|l|l|c|}
\hline \multicolumn{1}{|c|}{ Location } & $\begin{array}{c}\text { Mean } \\
\text { Log(k) }\end{array}$ & $\begin{array}{c}\text { Std. } \\
\text { Dev. }\end{array}$ & \multicolumn{1}{c|}{$\boldsymbol{n}$} & Geologic Unit \\
\hline Niche 3107 & -12.14 & 0.80 & 78 & Tptpmn \\
\hline Niche 3650 & -11.66 & 0.72 & 84 & Tptpmn] \\
\hline Niche 4788 & -11.79 & 0.84 & 63 & Tptpmn \\
\hline $\begin{array}{l}\text { Borehole } \\
\text { SYBT-ECRB-LA\#2 }\end{array}$ & -10.73 & 0.21 & $6^{\text {a }}$ & Tptpll \\
\hline Niche 1620 & -10.95 & 1.31 & 61 & Tptpll \\
\hline
\end{tabular}

DTN: LB0302SCMREV02.002 [DIRS 162273], also given in BSC 2004 [DIRS 171764], Table 6-4.

${ }^{a}$ There are three injection zones in borehole SYBT-ECRB-LA\#2 that have each been tested twice.

Table 4.1-6. Top and Bottom Boundary Conditions for the Tptpmn and Tptpll Submodels

\begin{tabular}{|c|c|c|}
\hline Boundary & $\begin{array}{c}\text { Boundary Condition Adopted in This } \\
\text { Model Report }\end{array}$ & $\begin{array}{c}\text { Revised Boundary } \\
\text { Conditions }\end{array}$ \\
\hline Top, Tptpmn Submodel & $\begin{array}{l}T=17.68^{\circ} \mathrm{C} \\
S_{g}=0.99 \\
P=86339 \mathrm{~Pa}\end{array}$ & $\begin{array}{l}T=15.73^{\circ} \mathrm{C} \\
S_{g}=0.99 \\
P=84512 \mathrm{~Pa}\end{array}$ \\
\hline Bottom, Tptpmn Submodel & $\begin{array}{l}T=31.68^{\circ} \mathrm{C} \\
S_{L}=0.99999 \\
P=92000 \mathrm{~Pa}\end{array}$ & $\begin{array}{l}T=26.45^{\circ} \mathrm{C} \\
S_{L}=0.9999 \\
P=90842 \mathrm{~Pa}\end{array}$ \\
\hline Top, Tptpll Submodel & $\begin{array}{l}T=16.13^{\circ} \mathrm{C} \\
S_{g}=0.99 \\
P=84725 \mathrm{~Pa}\end{array}$ & $\begin{array}{l}\mathrm{T}=17.33^{\circ} \mathrm{C} \\
\mathrm{S}_{\mathrm{g}}=0.99 \\
\mathrm{P}=86304 \mathrm{~Pa}\end{array}$ \\
\hline Bottom, Tptpll Submodel & $\begin{array}{l}T=32.62^{\circ} \mathrm{C} \\
S_{L}=0.99999 \\
P=92000 \mathrm{~Pa}\end{array}$ & $\begin{array}{l}T=29.28^{\circ} \mathrm{C} \\
S_{L}=0.9999 \\
P=91998 \mathrm{~Pa}\end{array}$ \\
\hline
\end{tabular}

NOTES: Boundary conditions adopted in this report are given in DTN: LB991131233129.004 [DIRS 162183 ] (note that temperature and pressure for Tpj34 are given as $16.08^{\circ} \mathrm{C}$ and $84765 \mathrm{~Pa}$, respectively, in DTN: LB991131233129.004 [DIRS 162183 ]). Look for file "pa99cal_ecm.out" in directory /AMR U0050 Data_1.6.00/LB991131233129.004-Charles; see also Appendix D.

Revised boundary conditions are given in DTN: LB0303THERMSIM.001 [DIRS 165167]. Find the values in file "SAVE_2_20_03_as_final_calibrated," see also Appendix D. 
Table 4.1-7. Statistics of Percolation Flux Distributions at the PTn/TSw Interface

\begin{tabular}{|c|c|c|c|}
\hline \multicolumn{4}{|c|}{ Mean Climate Scenario: Flux in $\mathrm{mm} / y e a r$} \\
\hline Climate Period & Entire UZ & $\begin{array}{l}\text { Repository Area } \\
\text { (used in TSPA) }\end{array}$ & $\begin{array}{c}\text { Repository Area without } \\
\text { Fault Zones }\end{array}$ \\
\hline Present Day Average & 4.8 & 3.8 & 3.8 \\
\hline Present Day Maximum & 111.1 & 39.9 & 20.6 \\
\hline Monsoon Average & 13.2 & 11.7 & 11.5 \\
\hline Monsoon Maximum & 211.6 & 127.9 & 61.3 \\
\hline Glacial Transition Average & 18.8 & 17.9 & 17.8 \\
\hline Glacial Transition Maximum & 276.5 & 192.4 & 90.9 \\
\hline \multicolumn{4}{|c|}{ Lower-Bound Climate Scenario: Flux in mm/year } \\
\hline Climate Period & Entire UZ & $\begin{array}{l}\text { Repository Area } \\
\text { (used in TSPA) }\end{array}$ & $\begin{array}{c}\text { Repository Area without } \\
\text { Fault Zones }\end{array}$ \\
\hline Present Day Average & 1.1 & 0.4 & 0.4 \\
\hline Present Day Maximum & 83.5 & 3.2 & 3.2 \\
\hline Monsoon Average & 4.8 & 4.3 & 4.4 \\
\hline Monsoon Maximum & 103.3 & 22.8 & 16.3 \\
\hline Glacial Transition Average & 2.5 & 1.9 & 2.0 \\
\hline Glacial Transition Maximum & 77.5 & 11.6 & 10.5 \\
\hline \multicolumn{4}{|c|}{ Upper-Bound Climate Scenario: Flux in $\mathrm{mm} / y e a r$} \\
\hline Climate Period & Entire UZ & $\begin{array}{l}\text { Repository Area } \\
\text { (used in TSPA) }\end{array}$ & $\begin{array}{c}\text { Repository Area without } \\
\text { Fault Zones }\end{array}$ \\
\hline Present Day Average & 12.0 & 11.1 & 11.2 \\
\hline Present Day Maximum & 197.5 & 80.3 & 44.0 \\
\hline Monsoon Average & 21.7 & 20.3 & 20.1 \\
\hline Monsoon Maximum & 358.7 & 161.1 & 97.9 \\
\hline Glacial Transition Average & 35.6 & 35.1 & 35.3 \\
\hline Glacial Transition Maximum & 530.2 & 282.2 & 164.1 \\
\hline \multicolumn{4}{|c|}{ Alternative Flow Model for PTn Unit } \\
\hline \multicolumn{4}{|c|}{ Mean Climate Scenario: Flux in $\mathrm{mm} / y e a r$} \\
\hline Climate Period & Entire UZ & $\begin{array}{l}\text { Repository Area } \\
\text { (used in TSPA) }\end{array}$ & $\begin{array}{c}\text { Repository Area without } \\
\text { Fault Zones }\end{array}$ \\
\hline Present Day Average & 4.4 & 3.8 & 3.9 \\
\hline Present Day Maximum & 105.0 & 26.0 & 21.0 \\
\hline Monsoon Average & 12.6 & 11.8 & 11.7 \\
\hline Monsoon Maximum & 183.6 & 80.8 & 61.8 \\
\hline Glacial Transition Average & 18.2 & 17.9 & 18.0 \\
\hline Glacial Transition Maximum & 221.3 & 129.5 & 98.9 \\
\hline
\end{tabular}

DTN: LB0310AMRU0120.001 [DIRS 166409], also given in BSC 2004 [DIRS 169131], Table 6.6-11. To locate the data, go to directory "norm_flow_field_analysis," and then look into file "flow_field_summary_tables.doc." 
Table 4.1-8. Comparison of Adopted and Revised Values of Elevation and Thickness of Stratigraphic Layers for the Tptpmn Submodel

\begin{tabular}{|l|c|c|c|c|}
\hline $\begin{array}{c}\text { Model } \\
\text { Layer }\end{array}$ & $\begin{array}{c}\text { Adopted Elevation, } \\
\text { Column 'i64' in } \\
\text { LB990501233129.004 } \\
(\mathbf{m})\end{array}$ & $\begin{array}{c}\text { Adopted Thickness, } \\
\text { Column 'i64' in } \\
\text { LB990501233129.004 } \\
(\mathbf{m})\end{array}$ & $\begin{array}{c}\text { Revised Elevation, } \\
\text { Column 'h28' in } \\
\text { LB03023DKMGRID.001 } \\
(\mathbf{m})\end{array}$ & $\begin{array}{c}\text { Revised Thickness, } \\
\text { Column 'h28' in } \\
\text { LB03023DKMGRID.001 } \\
\text { (m) }\end{array}$ \\
\hline Top & 1302.5 & - & 1308.8 & - \\
\hline tcw12 & 1302.5 & 17.1 & 1308.8 & 21.3 \\
\hline tcw13 & 1285.4 & 5.8 & 1287.5 & 6.0 \\
\hline ptn21 & 1279.6 & 4.6 & 1281.5 & 4.4 \\
\hline ptn22 & 1275.0 & 5.9 & 1277.1 & 6.3 \\
\hline ptn23 & 1269.1 & 4.6 & 1270.8 & 3.0 \\
\hline ptn24 & 1264.5 & 9.0 & 1267.8 & 9.5 \\
\hline ptn25 & 1255.5 & 21.7 & 1258.3 & 21.0 \\
\hline ptn26 & 1233.8 & 12.8 & 1237.3 & 12.8 \\
\hline tsw31 & 1221.0 & 2.0 & 1224.5 & 0.1 \\
\hline tsw32 & 1219.0 & 53.3 & 1222.4 & 52.8 \\
\hline tsw33 & 1165.7 & 85.3 & 1169.6 & 85.6 \\
\hline tsw34 & 1080.4 & 35.3 & 1084.0 & 34.8 \\
\hline tsw35 & 1045.1 & 102.5 & 1049.2 & 102.5 \\
\hline tsw36 & 942.6 & 35.7 & 946.7 & 35.5 \\
\hline tsw37 & 906.9 & 17.8 & 911.2 & 26.2 \\
\hline tsw38 & 889.1 & 20.7 & 884.9 & 29.2 \\
\hline ch2z & 868.4 & 138.4 & 855.7 & 123.7 \\
\hline Bottom & 730.0 & - & 732.0 & - \\
\hline DT12: & & & & \\
\hline
\end{tabular}

DTNs: LB990501233129.004 [DIRS 111475], LB03023DKMGRID.001 [DIRS 162354]. See Appendix E for procedures to follow to obtain these numbers.

NOTE: In the actual numerical grid for the Tptpmn submodel, tcw12 was not modeled and the top of the grid was fixed at $1286.0 \mathrm{~m}$. Also, the stratigraphy was simplified under the ch2z layer. These simplifications, as they occur far away from the source of heat, are not expected to impact the TH results of the Tptpmn submodel in the vicinity of the emplacement drifts. 
Table 4.1-9. Comparison of Adopted and Revised Values of Elevation and Thickness of Stratigraphic Layers for the Tptpll Submodel

\begin{tabular}{|c|c|c|c|c|}
\hline $\begin{array}{l}\text { Model } \\
\text { Layer }\end{array}$ & \begin{tabular}{|c|} 
Adopted Elevation, \\
Column 'j34' in \\
LB990501233129.004 \\
(m)
\end{tabular} & $\begin{array}{c}\text { Adopted Thickness, } \\
\text { Column 'j34' in } \\
\text { LB990501233129.004 } \\
\text { (m) }\end{array}$ & \begin{tabular}{|} 
Revised Elevation, \\
Column 'h74' in \\
LB03023DKMGRID.001 \\
$(\mathrm{m})$
\end{tabular} & \begin{tabular}{|} 
Revised Thickness, \\
Column 'h74' in \\
LB03023DKMGRID.001 \\
$(\mathrm{m})$
\end{tabular} \\
\hline Top & 1446.6 & - & 1424.4 & - \\
\hline tcw11 & 1446.6 & 27.4 & 1424.4 & 3.6 \\
\hline tcw12 & 1419.2 & 77.1 & 1420.8 & 96.7 \\
\hline tcw13 & 1342.1 & 15.6 & 1324.1 & 5.3 \\
\hline ptn21 & 1326.5 & 3.4 & 1318.8 & 2.3 \\
\hline ptn22 & 1323.1 & 2.1 & 1316.5 & 5.1 \\
\hline ptn23 & 1321.0 & 2.8 & - & \\
\hline ptn24 & 1318.2 & 5.5 & 1311.4 & 4.3 \\
\hline ptn25 & 1312.7 & 9.1 & 1307.1 & 7.9 \\
\hline ptn26 & 1303.6 & 9.5 & 1299.2 & 13.6 \\
\hline tsw31 & 1294.1 & 14.4 & 1285.6 & 2.0 \\
\hline tsw32 & 1279.7 & 30.4 & 1283.6 & 39.1 \\
\hline tsw33 & 1249.3 & 80.1 & 1244.5 & 80.3 \\
\hline tsw34 & 1169.2 & 37.2 & 1164.2 & 34.5 \\
\hline tsw35 & 1132.0 & 101.4 & 1129.7 & 102.5 \\
\hline tsw36 & 1030.6 & 33.2 & 1026.2 & 32.7 \\
\hline tsw37 & 997.4 & 16.6 & 993.5 & 23.1 \\
\hline tsw38 & 980.8 & 13.8 & 970.4 & 9.2 \\
\hline tsw39 & 967.0 & 10.1 & 961.2 & 4.1 \\
\hline ch1v & 956.9 & 21.7 & 957.1 & 14.4 \\
\hline ch2v & 945.2 & 13.3 & 942.7 & 12.9 \\
\hline $\operatorname{ch} 3 v$ & 931.9 & 12.7 & 929.8 & 12.8 \\
\hline$\overline{\operatorname{ch} 4 z}$ & 919.2 & 12.8 & 917.0 & 10.3 \\
\hline $\operatorname{ch} 5 z$ & 906.4 & 14.0 & 906.7 & 20.3 \\
\hline ch6 & 892.4 & 13.9 & 886.4 & 7.8 \\
\hline pp4 & 878.5 & 12.6 & 878.6 & 13.3 \\
\hline pp3 & 865.9 & 32.7 & 865.3 & 50.3 \\
\hline pp2 & 833.2 & 15.0 & - & - \\
\hline pp1 & 818.2 & 61.5 & 815.0 & 64.1 \\
\hline bf3 & 756.7 & 33.7 & & - \\
\hline Bottom & 730.0 & - & 751.9 & - \\
\hline
\end{tabular}

DTNs: LB990501233129.004 [DIRS 111475], LB03023DKMGRID.001 [DIRS 162354]. See Appendix E for procedures to follow to obtain these numbers.

NOTE: The elevations in the second column above have been calculated by taking average of the elevations at nodes of respective elements in the vertical column 'j34.' Note also that in Column 'h74' of DTN: LB03023DKMGRID.001 [DIRS 162354], there is no ptn23 geologic layer. Also, geologic layers pp2 and bf3 are absent in this column. The water table is located at $751.9 \mathrm{~m}$ at this column. 
Table 4.1-10. In-Drift Geometry and Property Choices for TH Seepage Model

\begin{tabular}{|c|c|c|c|c|}
\hline \multirow{2}{*}{ Parameter } & \multicolumn{2}{|c|}{ Model Input } & \multicolumn{2}{|c|}{ Information Exchange Drawing (IED) ${ }^{1}$} \\
\hline & Source & Value & Current Value & Source \\
\hline \multicolumn{5}{|c|}{ Geometry } \\
\hline $\begin{array}{l}\text { Waste package outer } \\
\text { diameter }\end{array}$ & $\begin{array}{l}\text { BSC } 2003 \text { [DIRS 164053] } \\
\text { (44-BWR waste package) }\end{array}$ & $\begin{array}{l}1.67 \mathrm{~m} \\
\text { (rounded off } \\
\text { from } 1.674 \mathrm{~m} \text { ) }\end{array}$ & $\begin{array}{l}1.318-2.110 \mathrm{~m} \\
(1.674 \mathrm{~m} \text { for } 44- \\
\text { BWR waste } \\
\text { package })\end{array}$ & BSC 2003 [DIRS 164053] \\
\hline $\begin{array}{l}\text { Top of invert as } \\
\text { measured from bottom } \\
\text { of drift }\end{array}$ & BSC 2003 [DIRS 164052] & $\begin{array}{l}0.8 \mathrm{~m} \\
\text { (rounded off } \\
\text { from } 0.806 \mathrm{~m} \text { ) } \\
\end{array}$ & $0.806 \mathrm{~m}$ & BSC 2003 [DIRS 164052] \\
\hline $\begin{array}{l}\text { Location of waste } \\
\text { package center above } \\
\text { bottom of drift }\end{array}$ & $\begin{array}{l}\text { SN9908T0872799.004 } \\
\text { [DIRS 108437] (see } \\
\text { Appendix G) }\end{array}$ & $1.945 \mathrm{~m}$ & $1.750-2.150 \mathrm{~m}$ & $\begin{array}{l}\text { BSC } 2004 \text { [DIRS 168489] } \\
\text { (center line of waste } \\
\text { package height above } \\
\text { invert from Figure 1) and } \\
\text { BSC } 2004 \text { [DIRS 169776] } \\
\text { (invert thickness) }\end{array}$ \\
\hline $\begin{array}{l}\text { Location of waste } \\
\text { package center below } \\
\text { the drift springline }\end{array}$ & $\begin{array}{l}\text { SN9908T0872799.004 } \\
\text { [DIRS 108437] (see } \\
\text { Appendix G) }\end{array}$ & $0.805 \mathrm{~m}$ & $0.6-1.0 \mathrm{~m}$ & $\begin{array}{l}\text { BSC } 2004 \text { [DIRS 168489] } \\
\text { (drift diameter and center } \\
\text { line of waste package } \\
\text { height above invert from } \\
\text { Figure 1) and BSC } 2004 \\
\text { [DIRS 169776] (invert } \\
\text { thickness) }\end{array}$ \\
\hline $\begin{array}{l}\text { Air gap between waste } \\
\text { package surface and the } \\
\text { inside of drip shield (only } \\
\text { used for collapsed drift } \\
\text { scenarios in Section } \\
6.2 .5 \text { ) }\end{array}$ & $\begin{array}{l}\text { SN9908T0872799.004 } \\
\text { [DIRS 108437] (see } \\
\text { Appendix G) }\end{array}$ & $0.396 \mathrm{~m}$ & $0.367-1.132 \mathrm{~m}$ & $\begin{array}{l}\text { BSC } 2004 \text { [DIRS 168489], } \\
\text { Figure } 1\end{array}$ \\
\hline $\begin{array}{l}\text { Inside radius of drip } \\
\text { shield }\end{array}$ & $\begin{array}{l}\text { SN9908T0872799.004 } \\
\text { [DIRS 108437] (see } \\
\text { Appendix G) }\end{array}$ & $1.231 \mathrm{~m}$ & $1.285 \mathrm{~m}$ & BSC 2004 [DIRS 168283] \\
\hline \multicolumn{5}{|c|}{ Properties } \\
\hline $\begin{array}{l}\text { Open areas (gas-filled } \\
\text { cavity) }\end{array}$ & $\begin{array}{l}\text { Conceptual Model } \\
\text { Choice (Section 4.1.1.5 } \\
\text { and 6.2.1.5) }\end{array}$ & & Not in an IED & Not Applicable \\
\hline Permeability & & $1 \times 10^{-10} \mathrm{~m}^{2}$ & & \\
\hline Porosity & & 1.0 & & \\
\hline Capillary pressure & & -5.0 & & \\
\hline $\begin{array}{l}\text { Relative permeability } \\
\text { (Gas) }\end{array}$ & & $\begin{array}{l}\text { Linear from } \\
0 \text { to } 1 \text { for gas } \\
\text { saturation from } \\
0 \text { to } 1\end{array}$ & & \\
\hline $\begin{array}{l}\text { Relative permeability } \\
\text { (Liquid) }\end{array}$ & & 0 & & \\
\hline $\begin{array}{l}\text { Thermal conductivity } \\
\text { Heat capacity }\end{array}$ & & $\begin{array}{l}10,000 \mathrm{~W} / \mathrm{m} / \mathrm{K} \\
0 \mathrm{~J} / \mathrm{kg} / \mathrm{K}\end{array}$ & & \\
\hline $\begin{array}{l}\text { Waste package thermal } \\
\text { conductivity }\end{array}$ & $\begin{array}{l}\text { Conceptual Model } \\
\text { Choice (Section 4.1.1.5 } \\
\text { and 6.2.1.5) }\end{array}$ & $10,000 \quad \mathrm{~W} / \mathrm{m} / \mathrm{K}$ & $1.5 \mathrm{~W} / \mathrm{m} / \mathrm{K}$ & $\begin{array}{l}\text { BSC } 2004 \text { [DIRS 167758] } \\
\text { (homogeneous thermal } \\
\text { properties for waste } \\
\text { package internal cylinder) }\end{array}$ \\
\hline
\end{tabular}


Table 4.1-10. In-Drift Geometry and Property Choices for TH Seepage Model (Continued)

\begin{tabular}{|c|c|c|c|c|}
\hline \multirow{2}{*}{ Parameter } & \multicolumn{2}{|c|}{ Model Input } & \multicolumn{2}{|c|}{ Information Exchange Drawing (IED) ${ }^{1}$} \\
\hline & Source & Value & Current Value & Source \\
\hline \multicolumn{5}{|c|}{ Properties (Continued) } \\
\hline $\begin{array}{l}\text { Waste package shell } \\
\text { density (see Section } \\
\text { 4.1.1.6) }\end{array}$ & $\begin{array}{l}\text { SN9908T0872799.004 } \\
\text { [DIRS 108437] (see } \\
\text { Appendix G) }\end{array}$ & $8189.2 \mathrm{~kg} / \mathrm{m}^{3}$ & $8690 \mathrm{~kg} / \mathrm{m}^{3}$ & $\begin{array}{l}\text { DTN: } \\
\text { MO0003RIB00071.000 } \\
\text { [DIRS 148850] } \\
\text { Mass density of Alloy } 22 \\
\text { (N06022), which is the } \\
\text { outer barrier (shell) of the } \\
\text { following WPS: 21-PWR } \\
\text { AP, 44-BWR, } \\
5 \text { DHLW/DOE } \\
\text { SNF-SHORT, } 5 \\
\text { DHLW/DOE SNF-LONG. } \\
\text { The density of the waste } \\
\text { package internal cylinder is } \\
2,175-3,495 \mathrm{~kg} / \mathrm{m} 3 \text { (BSC } \\
2004 \text { [DIRS 167758])) }\end{array}$ \\
\hline $\begin{array}{l}\text { Waste package specific } \\
\text { heat }\end{array}$ & $\begin{array}{l}\text { SN9908T0872799.004 } \\
\text { [DIRS 108437] (see } \\
\text { Appendix G) }\end{array}$ & $488.86 \mathrm{~J} / \mathrm{kg} / \mathrm{K}$ & 378- $731 \mathrm{~J} / \mathrm{kg} / \mathrm{K}$ & $\begin{array}{l}\text { BSC } 2004 \text { [DIRS 167758], } \\
\text { Table } 20\end{array}$ \\
\hline $\begin{array}{l}\text { Waste package flow } \\
\text { properties }\end{array}$ & $\begin{array}{l}\text { Conceptual Model } \\
\text { Choice (Section 4.1.1.5 } \\
\text { and 6.2.1.5) }\end{array}$ & $\begin{array}{l}\text { No flow for gas or } \\
\text { liquid (zero } \\
\text { permeability) }\end{array}$ & Not in an IED & Not Applicable \\
\hline $\begin{array}{l}\text { Invert intrinsic } \\
\text { permeability }\end{array}$ & $\begin{array}{l}\text { SN9908T0872799.004 } \\
\text { [DIRS 108437] (see } \\
\text { Appendix G) }\end{array}$ & $6.152 \times 10^{-10} \mathrm{~m}^{2}$ & $6.0 \times 10^{-10} \mathrm{~m}^{2}$ & $\begin{array}{l}\text { BSC } 2003 \text { [DIRS 170881], } \\
\text { Section } 6.4 \text { and Attachment } \\
\text { XI; CRWMS M\&O 2001 } \\
\text { [152016], Attachment XV }\end{array}$ \\
\hline Invert porosity & $\begin{array}{l}\text { SN9908T0872799.004 } \\
\text { [DIRS 108437] (see } \\
\text { Appendix G) }\end{array}$ & 0.545 & 0.55 & $\begin{array}{l}\text { BSC } 2003 \text { [DIRS 170881], } \\
\text { Attachment XI; CRWMS } \\
\text { M\&O } 2001 \text { [DIRS 152016], } \\
\text { Attachment XIV }\end{array}$ \\
\hline Invert grain density & $\begin{array}{l}\text { SN9908T0872799.004 } \\
\text { [DIRS 108437] (see } \\
\text { Appendix G) }\end{array}$ & $2530 \mathrm{~kg} / \mathrm{m}^{3}$ & $2530 \mathrm{~kg} / \mathrm{m}^{3}$ & $\begin{array}{l}\text { BSC } 2003 \text { [DIRS 170881], } \\
\text { Attachment XI; CRWMS } \\
\text { M\&O } 2001 \text { [DIRS 152016], } \\
\text { Attachment XIV }\end{array}$ \\
\hline Invert specific heat & $\begin{array}{l}\text { SN9908T0872799.004 } \\
\text { [DIRS 108437] (see } \\
\text { Appendix G) }\end{array}$ & $948 \mathrm{~J} / \mathrm{kg} \mathrm{K}$ & $930 \mathrm{~J} / \mathrm{kg} / \mathrm{K}$ & $\begin{array}{l}\text { BSC } 2003 \text { [DIRS 170881], } \\
\text { Attachment XI }\end{array}$ \\
\hline $\begin{array}{l}\text { Invert thermal } \\
\text { conductivity (upper } \\
\text { invert) }\end{array}$ & $\begin{array}{l}\text { BSC } 2002 \text { [DIRS } \\
159906 \text { ], Table } 6-48 \\
\left(100^{\circ} \mathrm{C} \text { data, average }\right. \\
\text { between ballast } \\
\mathrm{K}=0.1 \text { and } 0.2 \mathrm{~W} / \mathrm{m}-\mathrm{K})\end{array}$ & $1.52 \mathrm{~W} / \mathrm{m} / \mathrm{K}$ & Not in an IED & Not Applicable \\
\hline $\begin{array}{l}\text { Invert thermal } \\
\text { conductivity (lower } \\
\text { invert, } 4-10 \text { crushed tuff) }\end{array}$ & $\begin{array}{l}\text { DTN: } \\
\text { GS000483351030.003 } \\
\text { [DIRS 152932] }\end{array}$ & $\begin{array}{l}0.15 \mathrm{~W} / \mathrm{m} / \mathrm{K} \\
\text { (value chosen } \\
\text { based on } 11 \\
\text { samples ranging } \\
\text { between } 0.14 \text { and } \\
0.17 \text { ) } \\
\end{array}$ & Not in an IED & Not Applicable \\
\hline Invert capillary pressure & $\begin{array}{l}\text { Conceptual Model } \\
\text { Choice (Section 4.1.1.5 } \\
\text { and 6.2.1.5) }\end{array}$ & - 5.0 Pa & Not in an IED & Not Applicable \\
\hline
\end{tabular}


Table 4.1-10. In-Drift Geometry and Property Choices for TH Seepage Model (Continued)

\begin{tabular}{|c|c|c|c|c|}
\hline \multirow{2}{*}{ Parameter } & \multicolumn{2}{|c|}{ Model Input } & \multicolumn{2}{|c|}{ Information Exchange Drawing (IED) ${ }^{1}$} \\
\hline & Source & Value & Current Value & Source \\
\hline \multicolumn{5}{|c|}{ Properties (Continued) } \\
\hline $\begin{array}{l}\text { Relative permeability } \\
\text { (gas) }\end{array}$ & $\begin{array}{l}\text { Conceptual Model } \\
\text { Choice (Section 4.1.1.5 } \\
\text { and 6.2.1.5) }\end{array}$ & $\begin{array}{l}\text { Linear from } \\
0 \text { to } 1 \text { for gas } \\
\text { saturation from } \\
0 \text { to } 1\end{array}$ & Not in an IED & Not Applicable \\
\hline $\begin{array}{l}\text { Relative permeability } \\
\text { (liquid) }\end{array}$ & $\begin{array}{l}\text { Conceptual Model } \\
\text { Choice (Section 4.1.1.5 } \\
\text { and 6.2.1.5) }\end{array}$ & 0 & Not in an IED & Not Applicable \\
\hline
\end{tabular}

NOTE: IEDs were not always used because many IEDs were not completed before the start of this study. Differences between values used and those in IEDs are not expected to significantly affect model results for locations in rock around the drift because these results are primarily dependent on the applied heat load and not on the specifics of in-drift engineered features. 
Table 4.1-11. Input Data for DST TH Model (Corroborative Information)

\begin{tabular}{|c|c|c|c|c|}
\hline DTNs/Reference & Description & $\begin{array}{l}\stackrel{T}{ \pm} \\
\stackrel{0}{0} \\
\sum_{0}^{\infty}\end{array}$ & 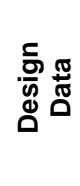 & 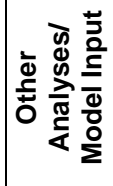 \\
\hline \multicolumn{5}{|c|}{ Hydrological and Thermal Rock Properties: } \\
\hline $\begin{array}{l}\text { LB0205REVUZPRP.001 } \\
\text { [DIRS 159525] }\end{array}$ & $\begin{array}{l}\text { Fracture parameters such as porosity, } \\
\text { aperture, frequency, and interface area for } \\
\text { simulations with DS/AFM-UZ02-Mean } \\
\text { property set. }\end{array}$ & $x$ & & \\
\hline $\begin{array}{l}\text { LB0208UZDSCPMI.002 } \\
\text { [DIRS 161243] }\end{array}$ & $\begin{array}{l}\text { Fracture and matrix calibrated parameters } \\
\text { for simulations with the DS/AFM-UZO2- } \\
\text { Mean property set. }\end{array}$ & $x$ & & \\
\hline $\begin{array}{l}\text { LB0210THRMLPRP.001 } \\
\text { [DIRS 160799] }\end{array}$ & $\begin{array}{l}\text { Matrix thermal data and porosity for } \\
\text { simulations with the DSIAFM-UZO2-Mean } \\
\text { property set. }\end{array}$ & $x$ & & \\
\hline $\begin{array}{l}\text { BSC } 2001 \text { [DIRS 157330], Section } \\
4.1, \text { Table } 5\end{array}$ & $\begin{array}{l}\text { Matrix and fracture thermal and } \\
\text { hydrological properties for simulations with } \\
\text { the DKM-TT99 property set (Sensitivity } \\
\text { Case) }\end{array}$ & & & $\mathrm{X}$ \\
\hline \multicolumn{5}{|l|}{ Model Boundary Conditions: } \\
\hline $\begin{array}{l}\text { LB000300123142.001 } \\
\text { [DIRS 148120] }\end{array}$ & $\begin{array}{l}\text { Top and bottom boundary temperature, } \\
\text { pressure, saturation } \\
\text { Elements Tt001 and tt001 for top } \\
\text { Elements Bb001 and bb001 for bottom }\end{array}$ & $x$ & & \\
\hline \multicolumn{5}{|l|}{ Heat Input: } \\
\hline $\begin{array}{l}\text { MO9807DSTSET01.000 } \\
\text { [DIRS 113644] }\end{array}$ & $\begin{array}{l}\text { Heater power: November 7,1997 - May } \\
1998\end{array}$ & $x$ & & \\
\hline $\begin{array}{l}\text { MO9810DSTSET02.000 } \\
\text { [DIRS 113662] }\end{array}$ & Heater Power: June 1998 - August 1998 & $x$ & & \\
\hline $\begin{array}{l}\text { MO9906DSTSET03.000 } \\
\text { [DIRS 113673] }\end{array}$ & $\begin{array}{l}\text { Heater power: September } 1998 \text { - May } \\
1999\end{array}$ & $x$ & & \\
\hline $\begin{array}{l}\text { MO0001SEPDSTPC. } 000 \\
\text { [DIRS 153836] }\end{array}$ & Heater power: June 1999 - October 1999 & $\mathrm{X}$ & & \\
\hline $\begin{array}{l}\text { MO0007SEPDSTPC.001 } \\
\text { [DIRS 153707] }\end{array}$ & Heater power: November 1999 - May 2000 & $x$ & & \\
\hline $\begin{array}{l}\text { MO0012SEPDSTPC. } 002 \\
\text { [DIRS 153708] }\end{array}$ & $\begin{array}{l}\text { Heater power: June } 2000 \text { - November } \\
2000\end{array}$ & $\mathrm{X}$ & & \\
\hline $\begin{array}{l}\text { MO0107SEPDSTPC.003 } \\
\text { [DIRS 158321] }\end{array}$ & Heater power: December 2000 - May 2001 & $x$ & & \\
\hline $\begin{array}{l}\text { MO0202SEPDSTTV.001 } \\
\text { [DIRS 158320] }\end{array}$ & $\begin{array}{l}\text { Heater power: June } 2001 \text { - January 14, } \\
2002\end{array}$ & $x$ & & \\
\hline \multicolumn{5}{|l|}{ DST Borehole and Sensor Locations: } \\
\hline $\begin{array}{l}\text { MO0002ABBLSLDS.000 } \\
\text { [DIRS 147304] }\end{array}$ & $\begin{array}{l}\text { Coordinates of borehole collar and bottom; } \\
\text { coordinates of sensor locations }\end{array}$ & $x$ & & \\
\hline
\end{tabular}


Table 4.1-12. Measured Data Used for Model Validation (Corroborative Information)

\begin{tabular}{|c|c|}
\hline DTNs & Description \\
\hline \multicolumn{2}{|l|}{ DST Measured Data: } \\
\hline \multicolumn{2}{|l|}{ Temperature Measurements: } \\
\hline $\begin{array}{l}\text { MO9807DSTSET01.000 } \\
\text { [DIRS 113644] }\end{array}$ & Temperature: November 7,1997-May 1998 \\
\hline $\begin{array}{l}\text { MO9810DSTSET02.000 } \\
\text { [DIRS 113662] }\end{array}$ & Temperature: June 1998-August 1998 \\
\hline $\begin{array}{l}\text { MO9906DSTSET03.000 } \\
\text { [DIRS 113673] }\end{array}$ & Temperature: September 1998-May 1999 \\
\hline $\begin{array}{l}\text { MO0001SEPDSTPC.000 } \\
\text { [DIRS 153836] }\end{array}$ & Temperature: June 1999-October 1999 \\
\hline $\begin{array}{l}\text { MO0007SEPDSTPC.001 } \\
\text { [DIRS 153707] }\end{array}$ & Temperature: November 1999-May 2000 \\
\hline $\begin{array}{l}\text { MO0012SEPDSTPC.002 } \\
\text { [DIRS 153708] }\end{array}$ & Temperature: June 2000-November 2000 \\
\hline $\begin{array}{l}\text { MO0107SEPDSTPC.003 } \\
\text { [DIRS 158321] }\end{array}$ & Temperature: December 2000-May 2001 \\
\hline $\begin{array}{l}\text { MO0202SEPDSTTV.001 } \\
\text { [DIRS 158320] }\end{array}$ & Temperature: June 2001-January 14, 2002 \\
\hline $\begin{array}{l}\text { MO0208SEPDSTTD.001 } \\
\text { [DIRS 161767] }\end{array}$ & Temperature: January 15, 2002-June 30, 2002 \\
\hline \multicolumn{2}{|l|}{ Ground-Penetrating-Radar Measurements: } \\
\hline $\begin{array}{l}\text { LB0210GPRDSTHP.001 } \\
\text { [DIRS 160895] }\end{array}$ & Ground-penetrating-radar measurement data during DST heating phase \\
\hline $\begin{array}{l}\text { LB0210GPRDSTCP.001 } \\
\text { [DIRS 160896] }\end{array}$ & Ground-penetrating-radar measurement data during DST cooling phase \\
\hline \multicolumn{2}{|l|}{ Air-Permeability Measurements } \\
\hline $\begin{array}{l}\text { LB0208AIRKDSTH.001 } \\
\text { [DIRS 160897] }\end{array}$ & Measured air-permeability data during DST heating phase \\
\hline \multicolumn{2}{|l|}{ Water Sampling Data } \\
\hline SN0208F3903102.002 [DIRS 161246] & Thermal Test Water Sampling Data during DST heating phase \\
\hline
\end{tabular}


Table 4.1-13. Input Data for LB0402THRMLPRP.001

\begin{tabular}{|c|c|c|c|c|}
\hline DTNs/Reference & Description & 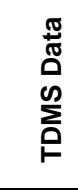 & 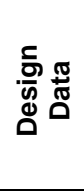 & 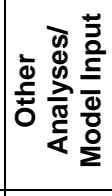 \\
\hline SN0303T0503102.008 [DIRS 162401] & $\begin{array}{l}\text { Porosity, bulk density, and dry and } \\
\text { wet thermal conductivities of the non- } \\
\text { repository units (see Section 4.1.4). }\end{array}$ & $x$ & & \\
\hline SN0208T0503102.007 [DIRS 160257] & $\begin{array}{l}\text { Porosity, bulk density, and dry and } \\
\text { wet thermal conductivities of the } \\
\text { repository units (see Section 4.1.4). }\end{array}$ & $x$ & & \\
\hline SN0402T0503102.010 [DIRS 170993] & Specific heat capacity & $\mathrm{x}$ & & \\
\hline
\end{tabular}

\subsection{CRITERIA}

The general requirements to be satisfied by TSPA are stated in 10 CFR 63.114 [DIRS 156605] (Requirements for Performance Assessment). Technical requirements to be satisfied by TSPA are identified in the Yucca Mountain Project Requirements Document (Canori and Leitner 2003 [DIRS 166275]). The acceptance criteria that will be used by the Nuclear Regulatory Commission (NRC) to determine whether the technical requirements have been met are identified in Yucca Mountain Review Plan, Final Report (YMRP) (NRC 2003 [DIRS 163274]). The pertinent requirements and acceptance criteria for this report are summarized in Table 4.2-1.

Table 4.2-1. Project Requirements and YMRP Acceptance Criteria Applicable to This Report

\begin{tabular}{|c|c|c|c|}
\hline $\begin{array}{l}\text { Requirement } \\
\text { Number }^{a}\end{array}$ & Requirement Title $^{\mathrm{a}}$ & $\begin{array}{l}10 \text { CFR } 63 \\
\text { Link }\end{array}$ & YMRP Acceptance Criteria \\
\hline PRD-002/T-015 & $\begin{array}{l}\text { Requirements for } \\
\text { Performance Assessment }\end{array}$ & $\begin{array}{l}10 \text { CFR } \\
63.114(\mathrm{a}-\mathrm{c}, \mathrm{e}) \\
\text { [DIRS } \\
156605]\end{array}$ & $\begin{array}{l}\text { Criteria } 1 \text { to } 5 \text { for Quantity and Chemistry of } \\
\text { Water Contacting Waste Packages and Waste } \\
\text { Forms }{ }^{b} \\
\text { Criteria } 1 \text { to } 4 \text { for Flow Paths in the Unsaturated } \\
\text { Zone }^{\mathrm{C}} \text {. }\end{array}$ \\
\hline
\end{tabular}

a From Canori and Leitner 2003 DIRS 166275], Section 3.

${ }^{b}$ From NRC 2003 [DIRS 163274], Section 2.2.1.3.3.3.

${ }^{c}$ From NRC 2003 [DIRS 163274], Section 2.2.1.3.6.3.

The pertinent acceptance criteria identified in Sections 2.2.1.3.3.3 and 2.2.1.3.6.3 of the YMRP (NRC 2003 [DIRS 163274])are included below. In cases where subsidiary criteria are listed in the YMRP for a given criterion, only the subsidiary criteria addressed by this scientific analysis are listed below. Where a subcriterion includes several components, only some of those components may be addressed. How these components are addressed is summarized in Section 8.4 of this report The acceptance criteria and subcriteria listed here and in Section 8.4 are consistent with those mentioned in Section 3.2.1 of Technical Work Plan for: Near-Field Environment and Transport: Near-Field Coupled Processes (TH Seepage and THM) Model Report Integration (BSC 2004 [DIRS 170236]), except for the following deviation. For "Quantity and Chemistry of Water Contacting Waste Packages and Waste Forms (Section 2.2.1.3.3)," Acceptance Criteria 5: Model Abstraction Output is Supported by Objective 
Comparisons is included here though not present in the technical work plan (BSC 2004 [DIRS 170236], Section 3.2.1).

\section{Acceptance Criteria from Section 2.2.1.3.3.3, Quantity and Chemistry of Water Contacting Waste Packages and Waste Forms}

\section{Acceptance Criterion 1: System Description and Model Integration Are Adequate.}

(1) Total system performance assessment adequately incorporates important design features, physical phenomena, and couplings, and uses consistent and appropriate assumptions throughout the quantity and chemistry of water contacting engineered barriers and waste forms abstraction process;

(2) The abstraction of the quantity and chemistry of water contacting engineered barriers and waste forms uses assumptions, technical bases, data, and models, that are appropriate and consistent with other related U.S. Department of Energy abstractions. For example, the assumptions used for the quantity and chemistry of water contacting engineered barriers and waste forms are consistent with the abstractions of "Degradation of Engineered Barriers" (Section 2.2.1.3.1); "Mechanical Disruption of Engineered Barriers (Section 2.2.1.3.2); "Radionuclide Release Rates and Solubility Limits" (Section 2.2.1.3.4); "Climate and Infiltration" (Section 2.2.1.3.5); and "Flow Paths in the Unsaturated Zone” (Section 2.2.1.3.6). The descriptions and technical bases provide transparent and traceable support for the abstraction of quantity and chemistry of water contacting engineered barriers and waste forms;

(3) Important design features, such as waste package design and material selection, backfill, drip shield, ground support, thermal loading strategy, and degradation processes, are adequate to determine the initial and boundary conditions for calculations of the quantity and chemistry of water contacting engineered barriers and waste forms;

(4) Spatial and temporal abstractions appropriately address physical couplings (thermalhydrologic-mechanical-chemical). For example, the U.S. Department of Energy evaluates the potential for focusing of water flow into drifts, caused by coupled thermal-hydrologic-mechanical-chemical processes;

(5) Sufficient technical bases and justification are provided for total system performance assessment assumptions and approximations for modeling coupled thermal-hydrologicmechanical-chemical effects on seepage and flow, the waste package chemical environment, and the chemical environment for radionuclide release. The effects of distribution of flow on the amount of water contacting the engineered barriers and waste forms are consistently addressed, in all relevant abstractions;

(6) The expected ranges of environmental conditions within the waste package emplacement drifts, inside of breached waste packages, and contacting the waste forms and their evolution with time are identified. These ranges may be developed to include: (i) the effects of the drip shield and backfill on the quantity and chemistry of water (e.g., the potential for condensate formation and dripping from the underside of the 
shield); (ii) conditions that promote corrosion of engineered barriers and degradation of waste forms; (iii) irregular wet and dry cycles; (iv) gamma-radiolysis; and (v) size and distribution of penetrations of engineered barriers;

(7) The model abstraction for quantity and chemistry of water contacting engineered barriers and waste forms is consistent with the detailed information on engineered barrier design and other engineered features. For example, consistency is demonstrated for: (i) dimensionality of the abstractions; (ii) various design features and site characteristics; and (iii) alternative conceptual approaches. Analyses are adequate to demonstrate that no deleterious effects are caused by design or site features that the U.S. Department of Energy does not take into account in this abstraction;

(8) Adequate technical bases are provided, including activities such as independent modeling, laboratory or field data, or sensitivity studies, for inclusion of any thermalhydrologic-mechanical-chemical couplings and features, events, and processes; and

(9) Performance-affecting processes that have been observed in thermal-hydrologic tests and experiments are included into the performance assessment. For example, the U.S. Department of Energy either demonstrates that liquid water will not reflux into the underground facility or incorporates refluxing water into the performance assessment calculation, and bounds the potential adverse effects of alteration of the hydraulic pathway that result from refluxing water.

\section{Acceptance Criterion 2: Data Are Sufficient for Model Justification.}

(1) Geological, hydrological, and geochemical values used in the license application are adequately justified. Adequate description of how the data were used, interpreted, and appropriately synthesized into the parameters is provided;

(2) Sufficient data were collected on the characteristics of the natural system and engineered materials to establish initial and boundary conditions for conceptual models of thermal-hydrologic-mechanical-chemical coupled processes, that affect seepage and flow and the engineered barrier chemical environment;

(3) Thermo-hydrologic tests were designed and conducted with the explicit objectives of observing thermal-hydrologic processes for the temperature ranges expected for repository conditions and making measurements for mathematical models. Data are sufficient to verify that thermal-hydrologic conceptual models address important thermal-hydrologic phenomena; and

(4) Sufficient information to formulate the conceptual approach(es) for analyzing water contact with the drip shield, engineered barriers, and waste forms is provided. 


\section{Acceptance Criterion 3: Data Uncertainty Is Characterized and Propagated Through the Model Abstraction.}

(1) Models use parameter values, assumed ranges, probability distributions, and bounding assumptions that are technically defensible, reasonably account for uncertainties and variabilities, and do not result in an under-representation of the risk estimate;

(2) Parameter values, assumed ranges, probability distributions, and bounding assumptions used in the total system performance assessment calculations of quantity and chemistry of water contacting engineered barriers and waste forms are technically defensible and reasonable, based on data from the Yucca Mountain region (e.g., results from large block and drift-scale heater and niche tests), and a combination of techniques that may include laboratory experiments, field measurements, natural analog research, and process-level modeling studies;

(3) Input values used in the total system performance assessment calculations of quantity and chemistry of water contacting engineered barriers (e.g., drip shield and waste package) are consistent with the initial and boundary conditions and the assumptions of the conceptual models and design concepts for the Yucca Mountain site. Correlations between input values are appropriately established in the U.S. Department of Energy total system performance assessment. Parameters used to define initial conditions, boundary conditions, and computational domain in sensitivity analyses involving coupled thermal-hydrologic-mechanical-chemical effects on seepage and flow, the waste package chemical environment, and the chemical environment for radionuclide release, are consistent with available data. Reasonable or conservative ranges of parameters or functional relations are established;

(4) Adequate representation of uncertainties in the characteristics of the natural system and engineered materials is provided in parameter development for conceptual models, process-level models, and alternative conceptual models. The U.S. Department of Energy may constrain these uncertainties using sensitivity analyses or conservative limits. For example, the U.S. Department of Energy demonstrates how parameters used to describe flow through the engineered barrier system bound the effects of backfill and excavation-induced changes; and

(6) Where sufficient data do not exist, the definition of parameter values and conceptual models is based on other appropriate sources, such as expert elicitation conducted in accordance with NUREG-1563 (Kotra et al. 1996).

Acceptance Criterion 4: Model Uncertainty Is Characterized and Propagated Through the Model Abstraction.

(1) Alternative modeling approaches of features, events, and processes are considered and are consistent with available data and current scientific understanding, and the results and limitations are appropriately considered in the abstraction;

(2) Alternative modeling approaches are considered and the selected modeling approach is consistent with available data and current scientific understanding. A description that 
includes a discussion of alternative modeling approaches not considered in the final analysis and the limitations and uncertainties of the chosen model is provided;

(3) Consideration of conceptual model uncertainty is consistent with available site characterization data, laboratory experiments, field measurements, natural analog information and process-level modeling studies; and the treatment of conceptual model uncertainty does not result in an under-representation of the risk estimate;

(4) Adequate consideration is given to effects of thermal-hydrologic-mechanical-chemical coupled processes in the assessment of alternative conceptual models. These effects may include: (i) thermal-hydrologic effects on gas, water, and mineral chemistry; (ii) effects of microbial processes on the engineered barrier chemical environment and the chemical environment for radionuclide release; (iii) changes in water chemistry that may result from the release of corrosion products from the engineered barriers and interactions between engineered materials and ground water; and (iv) changes in boundary conditions (e.g., drift shape and size) and hydrologic properties, relating to the response of the geomechanical system to thermal loading; and

(5) If the U.S. Department of Energy uses an equivalent continuum model for the total system performance assessment abstraction, the models produce conservative estimates of the effects of coupled thermal-hydrologic-mechanical-chemical processes on calculated compliance with the postclosure public health and environmental standards.

\section{Acceptance Criterion 5: Model Abstraction Output Is Supported by Objective Comparisons.}

(1) The models implemented in this total system performance assessment abstraction provide results consistent with output from detailed process-level models and/or empirical observations (laboratory and field testings and/or natural analogs);

(2) Abstracted models for coupled thermal-hydrologic-mechanical-chemical effects on seepage and flow and the engineered barrier chemical environment, as well as on the chemical environment for radionuclide release, are based on the same assumptions and approximations demonstrated to be appropriate for process-level models or closely analogous natural or experimental systems. For example, abstractions of processes, such as thermally induced changes in hydrological properties, or estimated diversion of percolation away from the drifts, are adequately justified by comparison to results of process-level modeling, that are consistent with direct observations and field studies; and

(3) Accepted and well-documented procedures are used to construct and test the numerical models that simulate coupled thermal-hydrologic-mechanical-chemical effects on seepage and flow, engineered barrier chemical environment, and the chemical environment for radionuclide release. Analytical and numerical models are appropriately supported. Abstracted model results are compared with different mathematical models, to judge robustness of results. 


\section{Acceptance Criteria from Section 2.2.1.3.6.3, Flow Paths in the Unsaturated Zone}

\section{Acceptance Criterion 1: System Description and Model Integration Are Adequate.}

(1) The total system performance assessment adequately incorporates, or bounds, important design features, physical phenomena, and couplings, and uses consistent and appropriate assumptions throughout the flow paths in the unsaturated zone abstraction process. Couplings include thermal-hydrologic-mechanical-chemical effects, as appropriate;

(2) The aspects of geology, hydrology, geochemistry, physical phenomena, and couplings that may affect flow paths in the unsaturated zone are adequately considered. Conditions and assumptions in the abstraction of flow paths in the unsaturated zone are readily identified and consistent with the body of data presented in the description;

(3) The abstraction of flow paths in the unsaturated zone uses assumptions, technical bases, data, and models that are appropriate and consistent with other related U.S. Department of Energy abstractions. For example, the assumptions used for flow paths in the unsaturated zone are consistent with the abstractions of quantity and chemistry of water contacting waste packages and waste forms, climate and infiltration, and flow paths in the saturated zone (Sections 2.2.1.3.3, 2.2.1.3.5, and 2.2.1.3.8 of the Yucca Mountain Review Plan, respectively). The descriptions and technical bases are transparent and traceable to site and design data;

(5) Sufficient data and technical bases to assess the degree to which features, events, and processes have been included in this abstraction are provided;

(6) Adequate spatial and temporal variability of model parameters and boundary conditions are employed in process-level models to estimate flow paths in the unsaturated zone, percolation flux, and seepage flux;

(7) Average parameter estimates used in process-level models are representative of the temporal and spatial discretizations considered in the model; and

(9) Guidance in NUREG-1297 and NUREG-1298 (Altman, et al., 1988a,b), or other acceptable approaches for peer review and data qualification, is followed.

\section{Acceptance Criterion 2: Data Are Sufficient for Model Justification.}

(1) Hydrological and thermal-hydrological-mechanical-chemical values used in the license application are adequately justified. Adequate descriptions of how the data were used, interpreted, and appropriately synthesized into the parameters are provided;

(2) The data on the geology, hydrology, and geochemistry of the unsaturated zone, are collected using acceptable techniques;

(3) Estimates of deep-percolation flux rates constitute an upper bound, or are based on a technically defensible unsaturated zone flow model that reasonably represents the 
physical system. The flow model is calibrated, using site-specific hydrologic, geologic, and geochemical data. Deep-percolation flux is estimated, using the appropriate spatial and temporal variability of model parameters, and boundary conditions that consider climate-induced change in soil depths and vegetation;

(4) Appropriate thermal-hydrologic tests are designed and conducted, so that critical thermal-hydrologic processes can be observed, and values for relevant parameters estimated;

(5) Sensitivity or uncertainty analyses are performed to assess data sufficiency, and verify the possible need for additional data;

(6) Accepted and well-documented procedures are used to construct and calibrate numerical models; and

(7) Reasonably complete process-level conceptual and mathematical models are used in the analyses. In particular: (i) mathematical models are provided that are consistent with conceptual models and site characteristics; and (ii) the robustness of results from different mathematical models is compared.

Acceptance Criterion 3: Data Uncertainty Is Characterized and Propagated Through the Model Abstraction.

(1) Models use parameter values, assumed ranges, probability distributions, and bounding assumptions that are technically defensible, reasonably account for uncertainties and variabilities, and

(2) The technical bases for the parameter values used in this abstraction are provided;

(3) Possible statistical correlations are established between parameters in this abstraction. An adequate technical basis or bounding argument is provided for neglected correlations;

(4) The initial conditions, boundary conditions, and computational domain used in sensitivity analyses and/or similar analyses are consistent with available data. Parameter values are consistent with the initial and boundary conditions and the assumptions of the conceptual models for the Yucca Mountain site;

(5) Coupled processes are adequately represented; and

(6) Uncertainties in the characteristics of the natural system and engineered materials are considered.

Acceptance Criterion 4: Model Uncertainty Is Characterized and Propagated Through the Model Abstraction. 
(1) Alternative modeling approaches of features, events, and processes, consistent with available data and current scientific understanding, are investigated. The results and limitations are appropriately considered in the abstraction;

(2) The bounds of uncertainty created by the process-level models are considered in this abstraction; and

(3) Consideration of conceptual model uncertainty is consistent with available site characterization data, laboratory experiments, field measurements, natural analog information and process-level modeling studies; and the treatment of conceptual model uncertainty does not result in an under-representation of the risk estimate.

\subsection{CODES, STANDARDS, AND REGULATIONS}

No codes, other than that referenced in Section 4.2, and no specific formally established standards and regulations have been identified as applying to this modeling activity. 


\section{ASSUMPTIONS}

This section contains a list of the basic assumptions of the TH models used in this report. Each statement of an assumption is followed by the rationale for why the assumption is considered valid or reasonable.

1. It is assumed that the TH processes modeled in Sections 6.2 and 7 can be adequately simulated without accounting for rock-property changes as a result of thermal-hydrological-mechanical (THM) and for thermal-hydrological-chemical (THC) effects.

Basis:

The general TH response of the rock mass to heating is not significantly affected by potential parameter changes as a result of thermal-mechanical stress and/or chemical precipitation/dissolution. This assessment is based on (1) the good agreement between measured and simulated TH behavior for the DST (Birkholzer and Tsang 2000 [DIRS 154608]; Mukhopadhyay and Tsang 2003 [DIRS 160790]) and (2) on simulation results described in two additional model reports that focus on the near-field THM and THC behavior. Drift-Scale THM Model (BSC 2004 [DIRS 169864]) specifically focuses on the future THM processes resulting from heating of the rock, using a fully coupled THM model. THC processes are investigated in Drift-Scale Coupled Processes (DST and THC Seepage) Models (BSC 2004 [DIRS 169856]). Both reports conclude that the THM or THC related property changes are moderate and do not change the overall TH conditions in the near-field rock. Thus the relevant conclusions of the thermal seepage report, as used in the seepage abstraction, are valid. This assumption is considered adequate and requires no further confirmation.

2. Tortuosity values of the fracture continuum for the fracture-fracture connections were obtained by multiplying the tortuosity of single fractures with the fracture porosity.

Basis:

The tortuosity parameter is used for calculating vapor-air diffusion processes. These processes are of minor importance for the modeling results, as their impact on the $\mathrm{TH}$ conditions in the rock is very small compared to conductive and convective processes. Thus, exact quantification or even calibration of this parameter is not needed; instead, appropriate tortuosity values are taken from the literature. From the range of values (0.1 for clay to 0.7 for sand) given in de Marsily (1986 [DIRS 100439], p. 233), a value of 0.7 is selected as the tortuosity of single fractures. This value corresponds to the highest tortuosity given by de Marsily (1986 [DIRS 100439], p. 233), with the rationale that paths are less tortuous within fractures than in the matrix. Fracture tortuosities of the fracture continuum are further modified for fracture-to-fracture connections by multiplication of the tortuosity by the fracture porosity of the bulk rock. For TOUGH2 simulations (Pruess 1991 [DIRS 100413]), this operation yields the appropriate value for the fracture-to-fracture interconnection area. This assumption is considered adequate and requires no further confirmation. 
3. The TH seepage model does not account for specific emplacement sequencing of waste forms with different decay heat characteristics. Rather, it is assumed that emplacement occurs all at once, followed by a preclosure period of 50 years, during which a large fraction of the decay heat is removed by ventilation (Section 6.2).

Basis:

Waste sequencing effects and generated heat differences between individual waste packages will give rise to heterogeneity in the drift-scale temperatures. The sensitivity studies (see Sections 6.2.2, 6.2.3, and 6.2.4.2) presented in this report give rise to both boiling and nonboiling $\mathrm{TH}$ conditions that more than adequately cover the range resulting from the temperature heterogeneity. This assumption is considered adequate and requires no further confirmation.

4. Since the volume of the fracture continuum is a small fraction of the matrix continuum, heat conduction occurs primarily through the matrix and, as a result, the model is not sensitive to the amount of heat conduction in fractures. Thermal conductivity of the fracture continuum is therefore assumed to be small compared to the thermal conductivity of the matrix continuum. This is done for both the TH seepage model and the DST TH model (Sections 6.2 and 7).

\section{Basis:}

Since the fractures are open channels, they do not have a grain thermal conductivity (as would be the case for the rock matrix) associated with them. The thermal conductivity of the fractures is therefore determined by the thermal conductivity of the fluid (either air or water) filling their open space. In the fractured tuff of Yucca Mountain, fractures are mostly air-filled. Air has negligible thermal conductivity compared to the rock matrix, and thus heat conduction through the fractures can be safely ignored. However, for numerical simulation of $\mathrm{TH}$ processes with the TOUGH2 simulator (Pruess 1991 [DIRS 100413]), a thermal conductivity value for the fracture continuum is needed.

In most simulation cases, the thermal conductivity of the fracture continuum is calculated by multiplying the matrix thermal conductivity with the fracture porosity and then by reducing the product further by 0.1 . The reduction by the factor 0.1 is to account for the limited spatial continuity and connectivity between fracture grid-blocks. The choice provides a reasonably small value for the thermal conductivity of the fracture continuum. For example, for the Tptpll (lower lithophysal) geological layer, this choice will yield $0.0018 \mathrm{~W} / \mathrm{m} / \mathrm{K} \quad(=1.89$ $\times 9.6 \times 10^{-3} \times 0.1$; see Table 4.1-2 for fracture porosity of Tptpll or tsw35) as the thermal conductivity of the fracture continuum. This fracture thermal conductivity is about three orders of magnitude smaller than the matrix thermal conductivity $(=1.891$ $\mathrm{W} / \mathrm{m} / \mathrm{K}$; see Table 4.1-2) of the Tptpll geological layer.

While most simulations were conducted with the above fracture continuum thermal conductivity, the TH simulations for the Tptpll submodel with heterogeneous permeability fields (LL-HET-01 and LL-HET-02; see Section 6.2.3) were performed with a slightly different method. For those simulations, fracture thermal conductivity 
was calculated by multiplying the thermal conductivity of air with the porosity of the fracture continuum. The adopted value of thermal conductivity of air is $0.03 \mathrm{~W} / \mathrm{m} / \mathrm{K}$ at 350K temperature (Perry et al. 1984 [DIRS 125806], p. 3-254, Table 3-314). For the Tptpll geological layer, this approach gives the fracture continuum thermal conductivity as $0.000288 \mathrm{~W} / \mathrm{m} / \mathrm{K}\left(=0.03 \times 9.6 \times 10^{-3}\right)$. This thermal conductivity value is about one-sixth the value of the Tptpll fracture thermal conductivity if the first approach was adopted. However, both values are small enough to have any significant impact on the $\mathrm{TH}$ results.

The thermal conductivity values for the fracture continuum selected in this model report are reasonable choices. In Section 6.2.4.3, sensitivity analyses with various fracture continuum thermal conductivity values are presented. It will be established in Section 6.2.4.3 that the choice of fracture thermal conductivity has almost no impact on thermal seepage results presented in this model report. This assumption is considered adequate and requires no further confirmation.

5. Measured data from flow visualization experiments of Su et al. (1999 [DIRS 107846]) are used as input for the alternative conceptual model in Section 6.3. These experiments were conducted with transparent replicas of natural granite fractures from the Stripa Mine in Sweden. It is assumed that the flow characteristics observed in these experiments can serve as reasonable estimates for episodic preferential flow in unsaturated fractures at Yucca Mountain.

Basis:

Differences between fractures from Yucca Mountain and the Stripa Mine-with respect to aperture distributions, surface roughness, and contact angle-will bring out differences in flow behavior and distribution. However, this approach is valid for a qualitative analysis intended to demonstrate the impact of an alternative flow conceptualization on thermal seepage. The main phenomenological aspects of episodic preferential flow observed by Su et al. (1999 [DIRS 107846], Sections 2 and 3) should hold true for fractures of similar geometric characteristics, since local aperture variation is the main driver inducing episodic finger flow (see details in Section 6.3.1.2). This assumption is considered adequate and requires no further confirmation.

6. In collapsed drifts that are filled with rubble rock material, capillary diversion depends upon the difference in capillary strength $(1 / \alpha)$ between the interior of the drift and the rock surrounding the drift. The rubble material is assumed to have a capillary strength of rubble material about $100 \mathrm{~Pa}$. This assumption is used in the thermal seepage predictions for collapsed drifts in Section 6.2.5. The chosen value is identical to the value used in the ambient seepage studies for collapsed drifts presented in Seepage Model for PA Including Drift Collapse (BSC 2004 [DIRS 167652], Section 5).

Basis:

The bulk porosity of the rubble material in the drift is much greater than the porosity of intact rock, because it includes large voids between chunks of fragmented rock. The chunks of fragmented rock are expected to have sizes on the order of centimeters 
to decimeters, as presented in Drift Degradation Analysis (BSC 2004 [DIRS 166107], Section 8.1). The voids are similar in size to the chunks of rubble and have almostzero capillary strength. The resulting capillary strength of the rubble-filled drift is therefore much weaker than that of the intact surrounding rock. Also note that an open space is expected to form between the solid rock at the ceiling of the drift and the collapsed rubble material (because of consolidation of the rubble material). This open space would even result in a zero capillarity at the drift ceiling, maintaining the full diversion potential for percolating water. The value of $100 \mathrm{~Pa}$ is therefore chosen as an upper limit to the expected effective capillary strength of the rubble-filled drift with an air gap forming at the ceiling. Using this upper limit for the capillary-strength parameter of the rubble-filled drift leads to more seepage compared to a zerocapillarity choice, because the capillary pressure difference between the fractured rock and the in-drift material becomes smaller. Thus this parameter choice gives rise to upper-bound seepage estimates. This assumption is considered adequate and requires no further confirmation.

7. In addition to the capillary-strength parameter discussed in Assumption 6, thermalhydrological simulations for collapsed drifts require knowledge about various other properties of the rubble material filling the drift. These include the properties of the fragmented rock blocks as well as the properties of the scattered voids between these blocks. The rock block properties are set identical to the well-characterized properties of the lower lithophysal rock matrix, where drift collapse is expected to occur (Table 4.1-2). The void properties must be estimated, since measurements are not available. As discussed in Assumption 6, the capillary-strength parameter of the voids is set to $100 \mathrm{~Pa}$. Other parameters defining the relative permeability and capillary pressure behavior of the voids-e.g., residual saturation or van Genuchten $m$-are chosen similar to those of the fracture continuum in the Tptpll (Table 4.1-2). The continuum permeability of the connected voids is set to $10^{-10} \mathrm{~m}^{2}$. The thermal conductivity is set to that of air; the heat capacity is set to zero. The interface area between the void continuum and the fragmented rock continuum, important for the fluid and heat exchange between the two media, is estimated from a simple geometry model, calculating the surface area of spherical rock blocks with a 0.1-m diameter. Two alternative assumptions were used to define the contact area for flow and heat transport between individual rock fragments. The maximum case assumes that the geometric interface area between grid elements is reduced by a factor of (1-0.231). The value 0.231 refers to the volume fraction of the voids in the rubble material, which is calculated in Section 6.2.5 based on the average bulking factors given in Drift Degradation Analysis (BSC 2004 [DIRS 166107], Section 6.4.2.5). The basis of calculating and the rationale of using this factor to adjust the interface area are further explained in Section 6.2.5. The alternative case assumes half as much as these maximum case values. These assumptions are used for the $\mathrm{TH}$ simulations in collapsed drifts in Section 6.2.5.

Basis:

The TH properties of the Tptpll matrix rock are appropriate for the fragmented rock blocks, because they have formed from chunks of Tptpll matrix rock that have fallen into the drift. From their expected sizes, the open voids between those blocks can be 
conceptualized as a high-permeability, low-capillarity medium, similar to a fractured continuum with extreme fracture apertures. As already discussed in Assumption 7, the $100 \mathrm{~Pa}$ capillarity value is a reasonably conservative choice for the void space. Since the voids act as large-aperture fractures, it makes sense to derive the other parameters defining the relative permeability and capillary pressure behavior for this mediume.g., residual saturation or van Genuchten $m$-from the respective fracture properties of the Tptpll unit (Table 4.1-2). The void continuum permeability of $10^{-10} \mathrm{~m}^{2}$ is an appropriate choice for a high-permeability medium, using a value that is about two orders of magnitude larger than the fracture continuum permeability of the Tptpll rock unit. Since this parameter is important for the in-drift TH processes, a sensitivity analysis was conducted with a one order of magnitude variation to higher and lower permeabilities. This analysis demonstrates that the general conclusions for seepage abstraction are not affected by this parameter variation. Since the voids are mostly airfilled, the thermal properties should be chosen similar to those of air (i.e., small thermal conductivity, negligible heat capacity). Calculation of the interface area between the void and the rock block continuum is based on the expected sizes of the fragmented rock, ranging from centimeters to decimeters (BSC 2004 [DIRS 166107], Section 8.1). Spherical blocks with a 0.1-m diameter provide meaningful average values. Since the contact area between rock fragments is hard to estimate (depending on the unknown degree of consolidation in the rubble material), two alternative approaches were chosen that represent a reasonably large range of the expected conditions. As explained in Section 6.2.5, the base case provides an upper bound for the contact area; it assumes that the geometric interface area between grid elements should be reduced by a factor of the volume fraction of the voids (see calculation of the volume fraction in Equation 6.2.5-2 and text thereafter). The alternative case provides a lower bound; it assumes smaller contact areas half as large as the base case values. These assumptions are considered adequate and require no further confirmation.

8. Capillary pressure in either the matrix pores or the fractures is assumed to be not directly dependent on temperature.

Basis:

In the TH simulations presented in this model report, capillary pressure in the rock matrix and fractures is a function of saturation (see Equations 6.2.1.1-10 and 6.2.1.111) and is assumed to be independent of temperature. Recent information from the literature (Grant 2003 [DIRS 171054]) indicates that matrix (not fracture) capillary pressure during imbibition (which is relevant for seepage) for nonwelded tuff can decrease by 20 to 25 percent if temperature is increased from $25^{\circ} \mathrm{C}$ to $80^{\circ} \mathrm{C}$. Though capillary pressure in the fracture (not matrix) has more direct impact on thermal seepage, to the best of the authors' knowledge, no information is available about temperature dependence of capillary pressure in fractures. Even if it is assumed that the fracture capillary pressure displays a trend similar to that of the matrix, using temperature-independent capillary pressure for the host rock is justified for the following reasons. First, matrix capillary pressure has insignificant impact on thermal seepage. Consequently, a decrease in matrix capillary pressure by 20 to 25 percent is not expected to alter the conclusions about thermal seepage. Second, as far as 
capillary pressure in the fractures is concerned, the seepage-relevant capillary-strength parameter is an (comparably small) effective (calibrated) capillary strength that not only captures the physical capillary behavior of fractures but also other physical processes (effects on seepage) such as small-scale fingering and lithophysal cavities (BSC 2004 [DIRS 171764]; BSC 2004 [DIRS 169131]). Such additional effects are independent of temperature. Thus the temperature effect on this effective parameter is probably smaller than the measured ones (Grant 2003 [DIRS 171054]). Finally, the measured 20 to 25 percent reduction in capillary pressure with increase in temperature (Grant 2003 [DIRS 171054) is well within the range of sensitivity analyses performed in this report (see Sections 6.2.4.2.2, where simulations are performed with fracture capillary strength parameter of $400 \mathrm{~Pa}$ against base case simulations with fracture capillary strength parameter of $589 \mathrm{~Pa}$ ). Thus, this assumption is considered adequate and requires no further justification. 


\section{MODEL DISCUSSION}

This section of the report describes the modeling framework and simulations to address the impact of heat on the potential seepage of water into waste emplacement drifts. Section 6.1 gives a brief introduction to the expected thermal-hydrological $(\mathrm{TH})$ processes in the fractured rock after waste emplacement. Section 6.2 presents the conceptual model, properties, numerical grid, and simulation results of the $\mathrm{TH}$ seepage model. The $\mathrm{TH}$ seepage model is the main prediction model in this report, used to investigate the coupled water, gas, and heat flow processes in the vicinity of representative emplacement drifts and to evaluate the potential rate of water seepage. The analyses performed with the TH seepage model comprise a variety of simulation cases in order to cover the potential variability of seepage-affecting factors and to evaluate related sensitivities. In short, these cases include:

- Two repository host rock units

- Four different thermal operating modes

- Various infiltration scenarios including the effect of climate changes and flow focusing

- Variation of drift-scale rock properties

- Homogeneous versus heterogeneous host rock properties

- Variation of drift-wall boundary conditions

- Active fracture model versus dual-permeability method

- Transient thermal representation versus steady-state ambient representation

A comprehensive list of all simulation cases performed with the TH seepage model is given in Section 6.2.1.6. Unless otherwise noted, the discussion of $\mathrm{TH}$ seepage model features and results is for intact open drifts. TH conditions in and around collapsed drifts are analyzed in Section 6.2.5.

An alternative conceptual model (ACM) is applied and presented in Section 6.3, designated to provide corroborative information for supporting the results and conclusions of the TH seepage model. This ACM explores the possibility of fast preferential water pathways draining down from the condensation zone above drifts. The potential of such preferential flow to overcome the vaporization barrier and reach emplacement drifts is evaluated using a semi-analytical solution scheme.

The model development, input data, and results for the TH seepage model and the ACM are documented in the scientific notebooks (SNs) listed in Table 6-1 below. Output from this report was submitted to the TDMS for all simulation cases considered relevant to downstream users (see Section 8.). 
Table 6-1. Scientific Notebooks Used in This Report

\begin{tabular}{|l|l|c|l|}
\hline LBNL Scientific Notebook ID & CRWMS M\&O Scientific Notebook ID & Relevant Pages & \multicolumn{1}{|c|}{ Citation } \\
\hline YMP-LBNL-JTB-1 & SN-LBNL-SCI-152-V1 & $151-233$ & $\begin{array}{l}\text { Wang 2003 } \\
\text { [DIRS 161123] }\end{array}$ \\
\hline YMP-LBNL-YWT-SM-3 & SN-LBNL-SCI-100-V3 & $1-314$ & $\begin{array}{l}\text { Wang 2003 } \\
\text { [DIRS 161123] }\end{array}$ \\
\hline YMP-LBNL-YWT-SM-4 & SN-LBNL-SCI-100-V4 & $1-109$ & $\begin{array}{l}\text { Wang 2004 [DIRS } \\
170510]\end{array}$ \\
\hline YMP-LBNL-YWT-ELM-1.4 & SN-LBNL-SCI-195-V1 & $96-97$ & $\begin{array}{l}\text { Wang 2003 } \\
\text { [DIRS 161123] }\end{array}$ \\
\hline
\end{tabular}

NOTE: $\quad$ LBNL = Lawrence Berkeley National Laboratory; CRWMS M\&O =Civilian Radioactive Waste Management System, Management and Operating Contractor.

Results of this model are part of the basis for the treatment of features, events, and processes (FEPs). The following Table 6-2 lists FEPs taken from the updated license application (LA) FEP List (DTN: MO0407SEPFEPLA.000 [DIRS 170760]). The selected FEPs are those taken from the updated LA FEP List that are associated with the subject matter of this report, as given in Technical Work Plan for: Near-Field Environment and Transport: Near-Field Coupled Processes (TH Seepage and THM) Model Report Integration (BSC 2004 [DIRS 170236], Section 2.1.6, Table 3). With regards to the selected FEPs in Table 6-2, there are some deviations from the technical work plan (TWP) (BSC 2004 [DIRS 170236], Section 2.1.6, Table 3). The following FEPs were not in the TWP but are present in Table 6-2 of this report: 1.1.02.02.0A, 1.2.03.02.0D, 2.2.01.01.0A, 2.2.10.03.0B, 2.2.10.12.0A (see Table 6-2 for names of these FEPs and where they are addressed). These changes were necessary to maintain consistency among reports after the RIT revision phase. The cross-reference for each FEP to the relevant section (or sections) of this report is also given in the table. The disposition of these FEPs feeds to TSPA-LA through Abstraction of Drift Seepage (BSC 2004 [DIRS 169131]).

Table 6-2. FEPs Addressed in This Report

\begin{tabular}{|c|c|c|}
\hline FEP No. & FEP Name & Section/Sections in this Report Where FEP is Addressed \\
\hline 1.1.02.02.0A & Preclosure ventilation & 4.1.1.3 and 6.2.1.1.3 \\
\hline 1.2.02.01.0A & Fractures & $4,4.1 .1,6.2 .1,6.2 .1 .5$, and 7.4 \\
\hline 1.2.03.02.0D & $\begin{array}{l}\text { Seismic induced drift collapse alters } \\
\text { in-drift thermal hydrology }\end{array}$ & 6.2 .5 \\
\hline 1.3.01.00.0A & Climate change & 4.1.1.4 and 6.2.1.4 \\
\hline 1.4.01.01.0A & $\begin{array}{l}\text { Climate modification increases } \\
\text { recharge }\end{array}$ & 6.2.1.4 \\
\hline 2.1.08.01.0A & Water influx at the repository & $\begin{array}{l}\text { 6.1.1 (and those listed therein such as 6.2.2.1.1, 6.2.2.2.3, } \\
\text { 6.2.4.2.1, and 6.2.4.2.2) and 6.2.1.4 }\end{array}$ \\
\hline 2.1.08.02.0A & Enhanced influx at the repository & 6.2.1 and 6.2.1.1.2 \\
\hline 2.2.01.01.0A & $\begin{array}{l}\text { Mechanical effects of } \\
\text { excavation/construction in the near } \\
\text { field }\end{array}$ & 4.1.1.1, 6.2.2, 6.2.3, 6.2.4, and 6.2.5 \\
\hline 2.2.03.01.0A & Stratigraphy & 4.1.1.5 and 6.2.1.2 \\
\hline 2.2.03.02.0A & $\begin{array}{l}\text { Rock properties of host rock and other } \\
\text { units }\end{array}$ & $4,6.2 .1,6.2 .1 .5$ and 7.4 \\
\hline
\end{tabular}


Table 6-2. FEPs Addressed in This Report (Continued)

\begin{tabular}{|c|c|c|}
\hline FEP No. & FEP Name & Section/Sections in this Report Where FEP is Addressed \\
\hline 2.2.07.02.0A & $\begin{array}{l}\text { Unsaturated groundwater flow in the } \\
\text { geosphere }\end{array}$ & 6.2.1.1 \\
\hline 2.2.07.04.0A & $\begin{array}{l}\text { Focusing of unsaturated flow (fingers, } \\
\text { weeps) }\end{array}$ & 6.2.1.1.3, 6.2.1.4, and 6.3 \\
\hline 2.2.07.08.0A & Fracture flow in the UZ & $6.2,6.3$, and 7.4 \\
\hline 2.2.07.09.0A & Matrix imbibition in the UZ & 6.2.1.1 and 7.4.3.2 \\
\hline 2.2.07.10.0A & $\begin{array}{l}\text { Condensation zone forms around } \\
\text { drifts }\end{array}$ & 6.2 and 7.4 . \\
\hline 2.2.07.11.0A & $\begin{array}{l}\text { Resaturation of geosphere dry-out } \\
\text { zone }\end{array}$ & $6.2,6.3$, and 7.4 \\
\hline 2.2.07.20.0A & Flow diversion around repository drifts & 6.2.1.1.2 \\
\hline 2.2.10.03.0B & $\begin{array}{l}\text { Natural geothermal effects on flow in } \\
\text { the UZ }\end{array}$ & 4.1.1.2 and 6.2.1.3 \\
\hline 2.2.10.10.0A & Two-phase buoyant flow/heat pipes & 6.2 and 7.4 \\
\hline 2.2.10.12.0A & Geosphere dryout due to waste heat & $6.1 .1,6.1 .2,6.2 .1,6.2 .2,6.2 .3,6.2 .4,6.2 .5$, and 6.3 \\
\hline
\end{tabular}

\subsection{COUPLED TH PROCESSES AND THERMAL SEEPAGE}

\subsubsection{Heat Transfer and Moisture Redistribution}

The reference mode and the high-temp mode discussed in this report give rise to above-boiling temperature conditions inside the drifts and in the fractured rock surrounding them. The ensuing TH processes have been examined theoretically and experimentally for the fractured welded tuffs at Yucca Mountain since the early 1980s (Pruess et al. 1984 [DIRS 144801]; Pruess et al. 1990 [DIRS 100819]; Buscheck and Nitao 1993 [DIRS 100617]; Pruess 1997 [DIRS 144794]; Kneafsey and Pruess 1998 [DIRS 145636]; Tsang and Birkholzer 1999 [DIRS 137577]; Birkholzer and Tsang 2000 [DIRS 154608]; Buscheck et al. 2002 [DIRS 160749]).

Key $\mathrm{TH}$ processes occurring around an intact, nondegraded drift are shown schematically in Figure 6.1-1. The figure indicates that heating of the rock causes pore water in the rock matrix to boil and vaporize. The vapor moves away from the boiling location through the permeable fracture network, driven primarily by pressure increase caused by boiling. Vapor will either flow into the open drifts, subject to in-drift convective flows along the drift axis, or will flow away from the drifts, further into the near-field rock. (Note that the fate of in-drift vapor flow is not subject of this report, because this process is not relevant for thermal seepage (see Section 6.2.1.2). Issues related to in-drift convective processes are analyzed in In-Drift Natural Convection and Condensation Model (BSC 2004 [DIRS 164327]). Vapor that remains in the near-field rock will condense in the rock fractures once it reaches cooler regions away from the drift. The condensate can then drain either toward the heat source from above or away from the drift into the zone below the heat source. Condensed water can also imbibe from fractures into the matrix, leading to increased liquid saturation in the rock matrix.

With continuous heating, a hot dryout zone may develop closest to the heat source, separated from the condensation zone by a nearly isothermal zone maintained at about the boiling temperature. This nearly isothermal zone is characterized by a continuous process of boiling, 
vapor transport, condensation, and migration of water back towards the heat source (either by capillary forces or gravity drainage), and is often referred to as a heat-pipe signature (Pruess et al. 1990 [DIRS 100819]). The longer the nearly isothermal temperature zone and the heatpipe signatures, the more intense are the two-phase circulation processes. Thus, analysis of the heat pipe signatures in temperature data can help to evaluate the intensity of heat-driven reflux processes (see Sections 6.2.2.1.1, 6.2.2.2.3, 6.2.4.2.1, and 6.2.4.2.2 for heat-pipe signatures encountered in the TH seepage model; see Sections 7.4.3.1.1 and 7.4.3.1.2 for analyses of heatpipe signatures in measured temperature data from the DST).

For the current repository design at Yucca Mountain, the dryout zone around drifts extends to a maximum distance of approximately 5 to 10 meters from the drift wall (see Section 6.2.2 and 6.2.3 of this report). This zone forms a barrier to water drainage since the above-boiling temperatures cause water to vaporize. The current repository design has parallel emplacement drifts that are separated by $81 \mathrm{~m}$ from center to center and a drift radius of $2.75 \mathrm{~m}$, adopted from D\&E / PA/C IED Emplacement Drift Configuration and Environment (BSC 2004 [DIRS 168489]). The drift spacing is large compared to the dryout zone, indicating that water above the repository can drain between drifts where the rock remains below boiling. This process of pillar drainage is important for performance, because it reduces the potential amount of water buildup above drifts.

There may be significant heterogeneity of the TH conditions within the repository. One factor causing heterogeneity is the spatial and temporal variability of the thermal load in different drift sections, stemming from heat output variation between individual waste packages and emplacement-time differences. Another factor is the variability of the formation properties and the local percolation fluxes. Thermal rock properties such as thermal conductivity directly affect the conductive transport of heat. Hydrological properties and local percolation fluxes, on the other hand, affect the significance of $\mathrm{TH}$ coupling as they determine the effectiveness of convective heat transport. While heat conduction is the major component of energy transport in Yucca Mountain tuff, the impact of TH coupling can be quite large. For example, a large percolation flux above a drift segment, combined with relatively high permeability, may cause strong heat-pipe effects that give rise to rock temperatures much lower and boiling periods much shorter than at average conditions (see Section 6.2.1.4).

TH processes occur at different physical scales. During the early part of the heating period, important $\mathrm{TH}$ processes are expected to occur near the emplacement drifts. These are the drift-scale processes addressed in this report. At this scale, variability in heat output from individual waste packages and different times of waste emplacement may give rise to variability in the extent of dryout, rewetting, and water flux along drifts and at different drift locations. At later times, heat-driven coupled processes are at the mountain scale. These include repository edge effects, large-scale enhanced water and gas flow, and potential alteration of perched-water bodies. For thermal seepage on the drift scale, the focus of this report, these mountain-scale effects are not relevant.

The TH conditions of the low-temp mode differ substantially from the reference mode and the high-temp mode. Most of the processes (boiling, vaporization, and condensation) illustrated in Figure 6.1-1 are negligible for the low-temp mode, since this mode gives rise to maximum rock temperatures that are always below boiling (see Section 6.2.2.1.3). TH conditions derived from 
the low-temp mode may occur in parts of the repository as a result of edge effects and of heat output variability. They could also be possible as a result of potential design changes using a smaller average thermal load.

As mentioned in Section 1, emplacement drifts in the Tptpll may collapse; see, as an example, Section 6.4.2.4 of Abstraction of Drift Seepage (BSC 2004 [169131). The thermal conditions in a collapsed drift are expected be different from those in an open drift, mainly because the thermal-hydrological processes in a drift filled with rubbly rock fragments are different from those in an open, gas-filled drift. The extent to which these differences can be important for thermal seepage is governed by the time at which the drift collapse occurs. Significant differences should only be expected when drift collapse occurs during the time period of strongly elevated temperatures.

\subsubsection{Thermal Seepage}

Seepage refers to the flow of liquid water into emplacement drifts. Underground openings in unsaturated rock have a tendency to divert water around them because of capillarity. This condition is well known as the capillary barrier, a condition which arises when coarse-grained soils are overlain by fine-grained soils (Ross 1990 [DIRS 141790]; Oldenburg and Pruess 1993 [DIRS 141594]). Here, the stronger negative capillary pressure developed in the fine-grained material prevents water from entering the larger pores of the underlying coarse-grained material (Birkholzer et al. 1999 [DIRS 105170]). If a drift is conceptualized as "very coarse grained" with essentially zero capillarity, seepage into the drift can only occur if the capillary pressure in the rock close to the drift walls becomes zero; i.e., the fractured rock becomes locally saturated. The rock can become locally saturated by disturbance to the flow field, which is caused by the presence of the drift opening (Philip et al. 1989 [DIRS 105743]) and more importantly by spatial heterogeneity that promotes channelized flow and local ponding (Birkholzer et al. 1999 [DIRS 105170]). The most important parameters that control seepage at ambient temperatures are the amount of percolation flux above the drifts, the local heterogeneity of the fracture flow field, and the capillary strength of the fractures close to the wall (Birkholzer et al. 1999 [DIRS 105170]; BSC 2004 [DIRS 167652], Section 6.3).

Thermal seepage refers to seepage during the time period that the flow around drifts is perturbed from heating. This effect is particularly important for above-boiling temperature conditions where a large, hot, dryout region develops in the vicinity of a drift. This hot dryout zone provides an additional barrier preventing seepage, since percolating water can be entirely vaporized prior to reaching the drift wall. Therefore, thermal seepage is unlikely as long as boiling conditions exist. However, condensed water does form a zone of elevated water saturation above the rock dryout zone. Water from this zone may be mobilized to flow rapidly down towards the drift, providing enhanced flux towards the source of heat. This effect may promote seepage. The combined effect of $\mathrm{TH}$ perturbation, vaporization barrier, and capillary barrier formation is investigated with the TH seepage model, as presented in Section 6.2. Other thermal phenomena such as THC and THM may also influence seepage; however, these phenomena are not addressed in this report, because these phenomena do not change the overall TH conditions in the near-field rock (see Section 5, Assumption 1). The ACM analysis in Section 6.3 complements the $\mathrm{TH}$ simulations of Section 6.2, applying a different conceptual model of downward water flow in the fractures. 


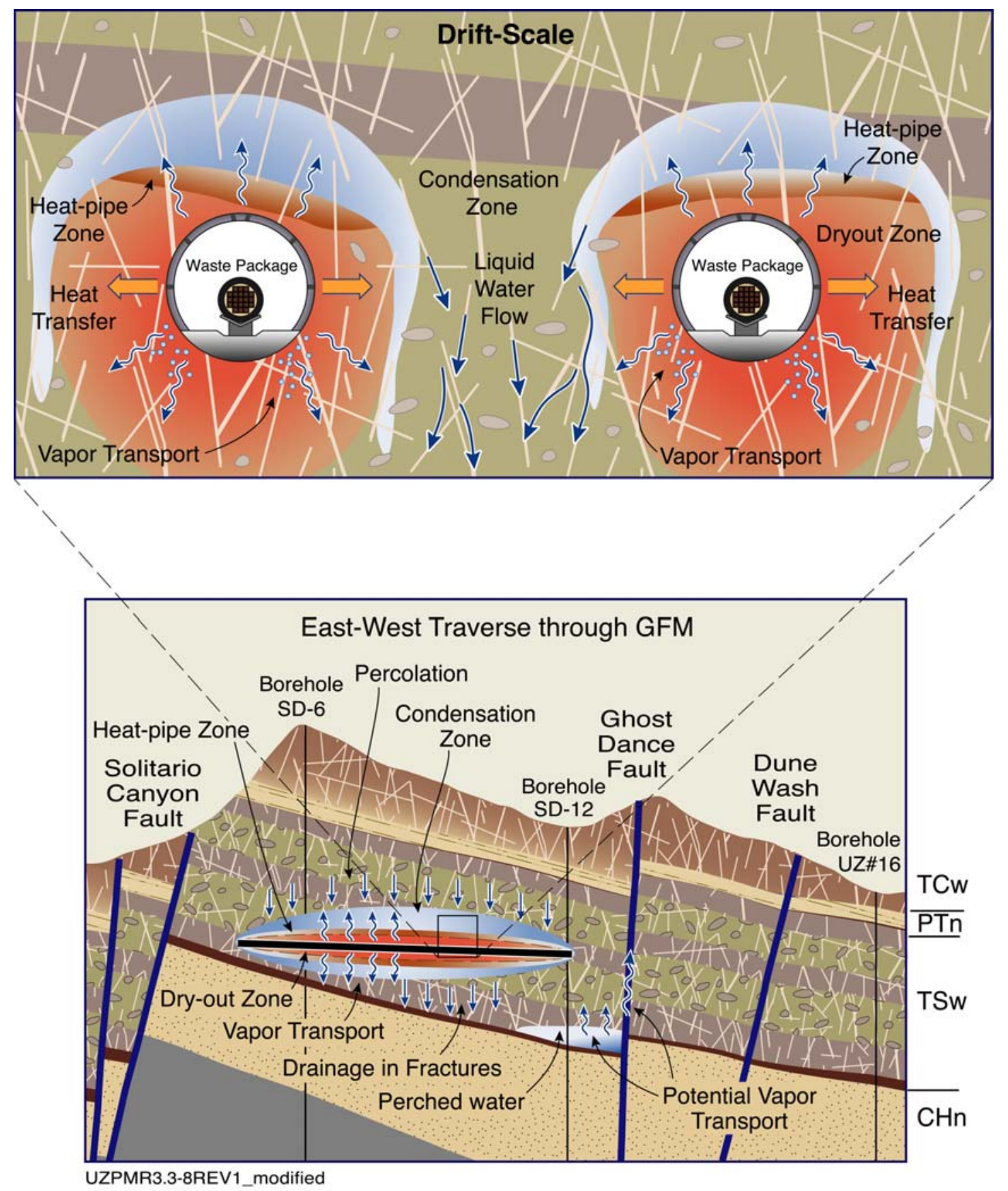

Source: CRWMS M\&O 2000 [DIRS 151940], Figure 3.3-8.

Figure 6.1-1. Schematic of TH Processes at the Drift Scale and the Mountain Scale 


\subsection{TH SEEPAGE MODEL}

\subsubsection{TH Model Description}

\subsubsection{Conceptual Model and Mathematical Formulation}

The general concept of simulating the coupled thermally driven flow and transport processes in the fractured rock at Yucca Mountain is described in Section 6.2.1.1.1 below. The conceptual model is similar to other process models that have been developed for studying various aspects of the unsaturated zone at Yucca Mountain. These other process models include, for example, the UZ flow models and submodels (BSC 2004 [DIRS 169861]), the multiscale thermohydrologic model (BSC 2004 [DIRS 169565]), and the drift-scale THM (BSC 2004 [DIRS 169864]) and THC models (BSC 2004 [DIRS 169856]). A specific conceptual model is needed to predict seepage into emplacement drifts under ambient and thermal conditions. This specific model approach is explained in Section 6.2.1.1.2. The mathematical formulation and governing equations are given in Section 6.2.1.1.3.

\subsection{General Conceptual Model Features}

\section{Continuum Representation}

Fractures are modeled as an effective continuum using averaged parameters for simulating the unsaturated flow and heat transport processes. A continuum representation of unsaturated fracture flow is appropriate when fracture density is high and a well-connected fracture network can form at the scale of interest. The appropriateness of this representation for the flow conditions in the UZ at Yucca Mountain has been discussed in detail in Conceptual and Numerical Models for UZ Flow and Transport (BSC 2004 [DIRS 170035], Sections 5 and 6.3.2). It is mainly supported by the dispersive nature of fracture water flow in the densely fractured, welded tuff repository units. Based on this assessment, continuum approaches are the main modeling method for the UZ at Yucca Mountain, applied in simulations for water flow, heat transfer, and contaminant transport (BSC 2004 [DIRS 170035], Section 6.3.2). Additional discussion on the validity of the continuum concept for seepage models is given in Section 6.2.1.1.2. Also note that an alternative conceptual model is presented in Section 6.3 that is not based on the continuum representation of unsaturated fracture flow.

\section{Dual-Permeability Method}

A key issue for simulating fluid and heat flow in the fractured-porous rock of Yucca Mountain is how to handle fracture and matrix flow and interactions under multiphase, multicomponent, nonisothermal conditions. For the work documented in this report, the dual-permeability method (DKM) is applied to evaluate fluid and heat flow and transport in the fracture rock. This methodology is based on the modeling framework of so-called dual-continuum models (BSC 2004 [DIRS 170035], Section 6.3.1.13). Such models are often applied to fractured porous rock, where one component (the fractures) typically has a large permeability, but small porosity, while the other component (the rock matrix) has a larger porosity, but small permeability. The dual-permeability method accounts for these differences by assuming two separate, but interacting continua that overlap each other in space, one describing flow and transport in the fractures, the other describing flow and transport in the matrix. Each continuum is simulated 
with a separate numerical grid, separate TH properties, and separate variables (pressure, saturation, and temperature). Thus at each location in space, there is a fracture gridblock and an overlapping matrix gridblock. The two gridblocks at each location are connected to model the interaction between the two continua. Global flow and transport occurs within the fracture continuum and the matrix continuum, while local interflow occurs between the two continua as a result of the local pressure and temperature difference. The interflow between fractures and matrix is handled using a quasi-steady transfer, estimating the exchange of fluid, gas, and heat between the two components by a linear gradient approximation. Details are documented in Doughty (1999 [DIRS 135997], Section 2).

\section{Active Fracture Model}

The DKM, as introduced above, typically considers flow to occur through all the connected fractures and to be uniformly distributed over the entire fracture area. In this case, the entire fracture-matrix interface area is available for coupling of flow between the matrix and fractures, implying relatively large fracture-matrix interactions. In natural systems, however, unsaturated fracture flow is not uniformly distributed because (a) flow channels may form within a fracture, and (b) only a subset of all fractures may be actively contributing to the flow processes. To account for this reduced coupling between the fracture and the matrix continua, the active fracture model (AFM) was developed to modify fracture-matrix interface areas for flow and transport between fracture and matrix systems (Liu et al. 1998 [DIRS 105729], p. 2636). The AFM proposes to use a fracture-matrix reduction factor proportional to a power function of liquid saturation, with the power function coefficient calibrated from measured data. (Note that the AFM does not affect the interface area assigned for the transport of heat between the fracture and the matrix continua.) In this report, the AFM was chosen as the primary conceptual model for predictive simulation of the $\mathrm{TH}$ processes. This choice was based mainly on consistency considerations, since the AFM has been implemented in other models for unsaturated flow and transport at Yucca Mountain (see, for example, the models presented in BSC 2004 [DIRS 170035]); BSC 2004 [DIRS 169861], Section 6.1; and BSC 2004 [DIRS 169857], Section 6.1). Both the AFM and a DKM with no reduction to the fracture-matrix interface area were applied in Section 7 to simulate the TH processes measured in the DST. The comparison of measured data and model results did not clearly discriminate between them because both conceptual models produced good agreement between measured and simulated TH behavior for the DST (see Section 7.4.4).

\subsection{Specific Conceptual Model for Thermal Seepage}

To address thermal seepage, the effectiveness of two barriers needs to be investigated. The first is the vaporization barrier that limits downward flow of water to emplacement drifts by vigorous boiling in the superheated rock (i.e., rock temperature above boiling point of water). The second is the capillary barrier that prevents water that has arrived in the immediate drift vicinity from actually seeping into the drifts. These are issues related to enhanced fluxes due to repository heat (FEP No. 2.1.08.02.0A; see Table 6-2).

Modeling of the vaporization barrier depends on an appropriate description of the thermally induced coupled flow processes, particularly on an accurate description of the potential reflux of condensate towards the heated drift. Since channelized flow in the fractures is most likely to 
penetrate the above-boiling rock zone to reach the drift crown, the conceptual model for thermal seepage calls for the inclusion of small-scale heterogeneity of the fracture continuum, using a stochastic continuum representation (see conceptual model for ambient seepage below). Note that the potential of small-scale flow events penetrating the vaporization zone is also addressed in the bounding-case analysis conducted with the alternative conceptual model THMEFF in Section 6.3.

Another important aspect of the capturing the vaporization barrier relates to conceptualization of the conductive heat transfer process at the fracture-matrix interface. The thermal conductivity in the matrix is determined by the thermal conductivity of the mineral grains. The fracture thermal conductivity, on the other hand, is determined by the fluid (either air or water) occupying its open space and is much smaller than the matrix thermal conductivity. As a result, the heat transfer in the fractured rock occurs mainly via heat conduction in the matrix. Most of the liquid flow, in contrast, occurs in the fractures. It follows that the effectiveness of the vaporization barrier is strongly affected by the rate of heat transfer from the matrix to the flowing water. Many TH models for fractured rock assume that (1) the heat transfer at the fracture-matrix interface is defined by the matrix thermal conductivity and (2) the entire interface area between the fractures and the matrix blocks contributes to the heat transfer, independent of the phases present. This conceptualization translates to rapid conductive heat transfer between the matrix and fracture, i.e., the resistance to conductive heat transfer in the fractures (due to the presence of the fluid and gas phases) is negligible. While this conceptualization has been successful in modeling the $\mathrm{TH}$ conditions measured in heater experiments, it may overpredict the energy transferred from the matrix rock to the flowing water, and would thus overpredict the effectiveness of the vaporization barrier. It was therefore decided to significantly reduce the thermal-conductivity at the fracture-matrix interface for the TH seepage model, making sure that the effectiveness of the vaporization barrier is not overestimated. In all $\mathrm{TH}$ simulations in this model report, thermal conductivity at the fracture-matrix interface was assigned the harmonic average of the thermal conductivities of the fracture and the matrix, respectively. Harmonic averaging ensured that the interface thermal conductivity was almost identical to the assigned fracture conductivity (being about three orders of magnitude smaller than that of the matrix conductivity). This choice provides a bounding case for thermal seepage; it uses a very small interface conductivity value that safely accounts for (1) the possible effect of heat transfer resistance at the fracture-matrix interface and (2) the impact of flow channeling, which can reduce the interface between the matrix and the flowing liquid. For comparison, a sensitivity case is conducted in Section 6.2.4.2.5, where the matrix conductivity is assigned at the interface.

For the capillary barrier, a modeling methodology was adopted from the analysis of ambient seepage, as described in Seepage Calibration Model and Seepage Testing Data (BSC 2004 [DIRS 171764], Section 6.3) and Seepage Model for PA Including Drift Collapse (BSC 2004 [DIRS 167652], Section 6.3). The ambient seepage modeling framework employs sophisticated process models - the seepage calibration model (SCM) and the seepage model for PA (SMPA) with feed of relevant parameters from calibration to liquid-release tests performed in the ESF (BSC 2004 [DIRS 171764], Section 6.3). It is reasonable to apply a consistent framework to the simulation of seepage during the thermally perturbed period. This framework incorporates several conceptual elements that are known to be important for ambient seepage. For example, unsaturated flow is modeled with a stochastic continuum concept that considers the small-scale variability of fracture permeability, in order to account for possible flow channeling. Other key 
elements of this model are a small capillary-strength parameter close to the drift wall, calibrated from seepage test results, and inclusion of the effects of discrete fractures in the immediate drift vicinity. Note that the specific conceptual model for thermal seepage is implemented in the TH seepage model only for simulation cases that focus on the potential for seepage and related sensitivities. These are the cases presented in Sections 6.2.2.2, 6.2.3.2, and 6.2.4 of this report.

The validity of the stochastic continuum concept for calculating drift seepage has been discussed in detail in Seepage Calibration Model and Seepage Testing Data (BSC (2004 [DIRS 171764], Section 5.1). It was demonstrated that the stochastic continuum method is capable of predicting seepage threshold and seepage rates for underground openings in the UZ at Yucca Mountain, provided that the predictive model is calibrated against seepage-relevant data (such as data from liquid-release tests), and provided that a conceptual framework is used for the predictive model consistent with the SCM. Furthermore, Finsterle (2000 [DIRS 151875]) compared seepage model results from a continuum model with results from a discrete fracture model. Predictions for low percolation fluxes made with the calibrated fracture continuum model were consistent with the synthetically generated data from the discrete feature model. In this report, the continuum approach is considered appropriate for seepage studies because it is applied within the framework defined in Seepage Calibration Model and Seepage Testing Data (BSC 2004 [DIRS 171764], Section 6.3).

Following the ambient seepage-modeling methodology, the seepage simulation cases utilize a stochastic continuum representation to account for the small-scale variability of fracture permeability in the drift vicinity. Fracture permeability is represented as a stochastic field, with spatial variability estimated from small-scale air-injection data measured above Niches 3107, 3605, and 4788 in the Tptpmn unit and in borehole SYBT-ECRB-LA\#2 above the ECRB Cross Drift in the Tptpll unit. The selected standard deviation of fracture permeability and the resolution of the numerical grid in drift vicinity for the $\mathrm{TH}$ seepage model are similar to that of the SCM (BSC 2004 [DIRS 171764]) and the SMPA (BSC 2004 [DIRS 167652]). Details of the generated random permeability fields are given in Sections 6.2.2.2.1 and 6.2.3.2.1. Note that, while the spatial variability is derived from the small-scale air permeability data, the mean permeability of these random fields is taken from the DS/AFM-UZ02-Mean property set (see Section 4.1.1.1). The latter is more representative of the average permeability over the repository, while the small-scale niche data may better represent the small excavation-disturbed region around the drift. For better capturing the overall $\mathrm{TH}$ behavior on the drift scale to the mountain scale, the permeability value from the DS/AFM-UZ02-Mean property set is used in this report. Also note that this permeability value is smaller than the permeability measured in the excavation-disturbed zone, which in turn will tend to overpredict thermal seepage (lower permeability results in less diversion capacity around drifts).

Another key element of seepage modeling is the choice of a small capillary-strength parameter for the fracture continuum in drift vicinity, derived from inverse modeling to niche liquid-release tests with the SCM (BSC 2004 [DIRS 171764], Section 6.6.4). This calibrated parameter incorporates potential effects from permeability changes due to excavation effects, small-scale wall roughness, high-frequency episodicity from small-scale flow processes, film flow, drop formation, discrete fractures that may terminate at the wall, artifacts of finite discretization, and, for the Tptpll unit, effects from lithophysal cavities. For thermal seepage analyses with the TH seepage model, the SCM fracture capillary-strength parameter is applied in the entire geological 
unit that hosts the waste emplacement drift (i.e., the Tptpmn unit and the Tptpll unit, respectively). A uniform value of this capillary-strength parameter is applied, with no correlation to the local fracture permeability. This is consistent with the seepage modeling framework of the SCM (also see Assumption 8 for further justification on the validity of this approach). The values of capillary strength that are used in the TH seepage model are given in Section 4.1.1.1. All other fracture and matrix rock properties in the host rock unit and in all other model units are taken from the DS/AFM-UZ02 property set, also introduced in Section 4.1.1.1.

Similar to the SCM and SMPA, the drift is modeled as an open cavity with zero capillary-strength parameter. (As pointed out in Section 4.1.1.6, a very small capillary-strength parameter of $-5.0 \mathrm{~Pa}$ is chosen in the open cavity for numerical reasons.) This assures that seepage into the drift can only occur if boundary elements are close to or at full saturation. The last vertical connection between the drift wall and the neighboring gridblock representing the fractured rock is set to $0.05 \mathrm{~m}$, independent of the actual grid size used. This implies a direct gravity-controlled vertical flow, without horizontal diversion within this $0.05 \mathrm{~m}$ distance, and accounts for short, discrete fractures that may end at the drift wall. The specific choice of $0.05 \mathrm{~m}$ was recommended in Seepage Calibration Model and Seepage Testing Data (BSC 2004 [DIRS 171764], Section 6.3.3.3); it was roughly based on estimates using fracture mapping data and supported by sensitivity studies. In the SCM, the fracture capillary-strength parameter was calibrated using this same $0.05 \mathrm{~m}$ boundary condition. Because of the $0.05 \mathrm{~m}$ vertical gravity flow at the drift wall, a capillary pressure that is higher (less negative) than a threshold value $P=-0.05 \rho \mathrm{g}$ in the formation next to the drift wall will induce seepage into the drift. At ambient temperature, this threshold pressure is about $-490 \mathrm{~Pa}$. Note that only the fracture continuum is assigned such specific seepage-boundary treatment to account for the effects of discrete fractures. Seepage from the rock matrix into the drift is unlikely because of the strong capillarity and low permeability of the matrix; thus, seepage from the matrix is not considered in the $\mathrm{TH}$ seepage model. Water that seeps into the drift is collected without further consideration of the flow processes that may occur within the open cavity, as modeling of in-drift water or vapor flow is beyond the scope of this report.

\subsection{Mathematical Formulation and Governing Equations}

The TH seepage model is applied to predict the drift-scale coupled processes of liquid, gas, and heat movement in the unsaturated fractured rock at Yucca Mountain. The computer code used for the simulations presented in this subsection is TOUGH2 V1.6 (LBNL 2003 [DIRS 161491]). TOUGH2 is an integral-finite-difference numerical code (Pruess 1991 [DIRS 100413]) for simulating coupled flow and transport of water, water vapor, air, and heat in heterogeneous porous and fractured media. TOUGH2 (Pruess 1991 [DIRS 100413]) accounts for the movement of gaseous and liquid phases (under pressure, viscous, and gravity forces according to Darcy's law, with interference between the phases represented by relative permeability functions); transport of latent and sensible heat; and phase transition between liquid and vapor. Mass- and energy-balance equations are written in integral form for an irregular flow domain in one, two, or three dimensions. Fluid flow is described with a multiphase extension of Darcy's law. Heat occurs by conduction and convection. The description of thermodynamic conditions is based on a local equilibrium model of the three phases (liquid, gas, and solid rock). The ideal 
gas law is assumed for the water-air mixture. Henry's law is assumed for the solubility of air in water. Vapor-pressure lowering effects are included.

The equations described in this section are included in the qualified (Q) code TOUGH2 (LBNL 2003 [DIRS 161491]) and hence are considered indirect input. The governing equations for flow of multiphase, multicomponent fluid mixtures solved with TOUGH2 V1.6 (LBNL 2003 [DIRS 161491]) are based on well-known thermodynamic principles. The assumed formulations are appropriate for its intended purpose of modeling the drift-scale $\mathrm{TH}$ processes that occur in the host rock in response to repository heating. The formulations are consistent with other models for unsaturated flow and transport at Yucca Mountain (see, for example, the models presented in BSC 2004 [DIRS 170035], Sections 5 and 6; BSC 2004 [DIRS 169861], Section 6.1; and BSC 2004 [DIRS 169857], Section 6.1). The mathematical formulation and the associated governing equations are presented in the documentation of the baseline software TOUGH2 V1.6 (LBNL 2003 [DIRS 161491]), as well as the TOUGH User's Guide (Pruess 1987 [DIRS 100684], Section 3) and the TOUGH2 User's Guide, Version 2.0 (Pruess et al. 1999 [DIRS 160778], Appendix A). A similar formulation is given in Lichtner and Walton (1994 [DIRS 152609], Section 2.1). A brief summary follows.

The basic mass- and energy-balance equations solved by TOUGH2 (Pruess 1991 [DIRS 100413]) can be written in the general form

$$
\frac{d}{d t} \int_{V_{n}} M^{\kappa} d V_{n}=\int_{\Gamma_{n}} \boldsymbol{F}^{\kappa} \boldsymbol{n} d \Gamma_{n}+\int_{V_{n}} q^{\kappa} d V_{n}
$$

The integration is over an arbitrary subdomain $V_{n}$ of the TH system under study, which is bounded by the closed surface $\Gamma_{n}$. The quantity $M$ appearing in the accumulation (left hand side) represents mass or energy per volume, with $\kappa=1,2$ labeling the mass components water and air, and $\kappa=3$ the "heat component." $F$ denotes mass or heat flux (see below), $q$ denotes sinks and sources, and $n$ is a normal vector on surface element $d \Gamma_{n}$, pointing inward into $V_{n}$.

The general form of the mass accumulation term is

$$
M^{\kappa}=\phi \sum_{\beta} S_{\beta} \rho_{\beta} X_{\beta}^{\kappa}
$$

The total mass of component $\kappa$ is obtained by summing over the phases $\beta$ (= liquid, gas), with $\phi$ the porosity, $S_{\beta}$ the saturation of phase $\beta$ (i.e., the fraction of pore volume occupied by phase $\beta$ ), $\rho_{\beta}$ the density of phase $\beta$, and $X_{\beta}^{\kappa}$ the mass fraction of component $\kappa$ in phase $\beta$. Similarly, the heat accumulation term in a multiphase system is

$$
\boldsymbol{M}^{3}=(1-\phi) \rho_{\boldsymbol{R}} \boldsymbol{C}_{\boldsymbol{R}} \boldsymbol{T}+\phi \sum_{\beta} \boldsymbol{S}_{\beta} \rho_{\beta} \boldsymbol{u}_{\beta}
$$

where $\rho_{R}$ and $\mathrm{C}_{R}$ are, respectively, rock-grain density and specific heat capacity of the rock, $\mathrm{T}$ is temperature, and $u_{\beta}$ is specific internal energy in phase $\beta$. Note that this formulation is based on accumulation of internal energy, rather than on accumulation of specific enthalpy (Nitao 2000 [DIRS 159883], Section 4). This simplification is valid for all TH systems where the energy 
associated with volumetric changes in the gas phase, caused by pressure changes, is small compared to the energy associated with temperature changes. For the fractured rock at Yucca Mountain, this condition is justified, and the distinction between enthalpy and internal energy of the gas phase can be neglected.

Advective mass flux is a sum over phases,

$$
\left.\boldsymbol{F}^{\kappa}\right|_{a d v}=\sum_{\beta} X_{\beta}^{\kappa} \boldsymbol{F}_{\beta},
$$

and individual phase fluxes are given by a multiphase version of Darcy's law (continuum representation),

$$
\mathbf{F}_{\beta}=\rho_{\beta} \mathbf{u}_{\beta}=-\boldsymbol{k} \frac{\boldsymbol{k}_{\boldsymbol{r} \beta} \rho_{\beta}}{\mu_{\beta}}\left(\nabla \boldsymbol{P}_{\beta}-\rho_{\beta} \mathbf{g}\right)
$$

Here, $\mathbf{u}_{\beta}$ is the Darcy velocity in phase $\beta, k$ is absolute permeability, $k_{r \beta}$ is the relative permeability to phase $\beta, \mu_{\beta}$ is viscosity, and

$$
P_{\beta}=P+P_{c \beta}
$$

is the fluid pressure in phase $\beta$, which is the sum of the pressure $P$ of a reference phase (gas pressure) and the capillary pressure $P_{c \beta}(\leq 0)$; and $g$ is the vector of gravitational acceleration. Vapor-pressure lowering is modeled by Kelvin's equation (Edlefsen and Anderson 1943 [DIRS 138932]),

$$
P_{v}\left(T, S_{l}\right)=f_{v p l}\left(T, S_{l}\right) P_{s a t}(T)
$$

where

$$
f_{v p l}=\exp \left[\frac{M_{w} P_{c l}\left(S_{l}\right)}{\rho_{l} R(T+273.15)}\right]
$$

is the vapor-pressure lowering factor, identical to the definition of relative humidity. $P_{\text {sat }}$ is the saturated vapor pressure of the bulk liquid phase, $P_{c l}$ is the difference between liquid and gas phase pressure, $M_{w}$ is the molecular weight of water, and $R$ is the universal gas constant. Vapor pressure lowering is a well-known physical process that allows for the presence of liquid water in small rock pores at temperatures above the nominal boiling point.

Molecular diffusion of vapor and air in the gas phase (binary diffusion) can also contribute to the mass flux in Equation 6.2.1.1-1. While implemented in and simulated with TOUGH2 (Pruess et al. 1999 [DIRS 160778], Appendices A and D), binary diffusion (being a slow transport process) has limited impact on the coupled transport processes studied in this model report. Therefore, the governing equations for binary diffusion are not provided in this section (though they have been simulated). 
Heat flux includes conductive and convective components

$$
\boldsymbol{F}^{3}=-\lambda \nabla T+\sum_{\beta} h_{\beta} F_{\beta}
$$

where $\lambda$ is the thermal conductivity of the rock-fluid mixture, and $h_{\beta}$ is the specific enthalpy in phase $\beta$.

The transport equations given above are complemented with constitutive relationships, which express all parameters as a function of a set of primary variables. In TOUGH2 (Pruess 1991 [DIRS 100413]), the thermophysical properties of water substance are accurately described by the steam table equations, as given by the International Formulation Committee (1967 [DIRS 156448]). Air is approximated as an ideal gas, and gas pressure is the sum of the partial pressures for air and vapor. The solubility of air in liquid water is calculated from Henry's law.

Capillary pressures and relative permeabilities depend on phase saturation. For liquid, the capillary suction and the relative permeability have the van Genuchten functional forms (van Genuchten 1980 [DIRS 100610]; Mualem 1976 [DIRS 100599]):

$$
\begin{gathered}
P_{c l}=-\frac{1}{\alpha}\left[\left(S_{l, e f f}\right)^{-1 / m}-1\right]^{1-m} \\
k_{r l}=\left(S_{l, e f f}\right)^{1 / 2}\left[1-\left(1-\left(S_{l, e f f}\right)^{1 / m}\right)^{m}\right]^{2} \\
S_{l, e f f}=\frac{\left(S_{l}-S_{l r}\right)}{\left(1-S_{l r}\right)}
\end{gathered}
$$

where $S_{l, \text { eff }}$ is liquid effective saturation, $S_{l}$ is liquid saturation, $S_{l r}$ is liquid residual saturation, and $m$ and $1 / \alpha$ are fitting parameters, the latter related to the capillary strength of the medium. In the AFM, $S_{l, \text { active }}$ denotes the effective saturation of all actively flowing fractures. This value is related to the effective saturation of all active and inactive fractures in a connected network, $S_{l, e f f}$, by a simple power function

$$
S_{l, a c t i v e}=\left(S_{l, e f f}\right)^{1-\gamma}
$$

with $\gamma$ a power function coefficient calibrated from a mountain-scale inversion procedure (BSC 2004 [DIRS 169857]). When the active fracture model is applied, relative permeability in the liquid-phase is calculated as:

$$
k_{r l}=\sqrt{S_{l, a c t i v e}}\left(S_{l, e f f}\right)^{\gamma}\left[1-\left(1-S_{l, a c t i v e}^{\frac{1}{m}}\right)^{m}\right]^{2}
$$

At very small saturation close to the residual saturation value, the van Genuchten capillary pressure function approaches infinity. This can lead to nonphysical, extremely high capillary pressure values, particularly in areas with strong heating and dryout of water close to or even below residual. Therefore, at saturation below a given small threshold value, a linear capillary 
pressure function is applied instead of the above power function. The slope of this linear function is determined by the slope of the van Genuchten equation at the threshold saturation value.

Relative permeability for gas flow is described by the modified Brooks and Corey (1966 [DIRS 119392]) formulation as follows:

$$
k_{r g}=\left(1-S_{l, e f f}\right)^{2}\left(1-\left(S_{l, e f f}\right)^{\frac{2+p}{p}}\right),
$$

where $\mathrm{p}=\mathrm{m} /(1-\mathrm{m})$. The selected formulations for the dependence of the capillary pressure and the relative permeability on liquid-phase saturation (6.2.1.1-10 through 6.2.1.1-12) are widely employed in the literature. The formulations are consistent with other models for unsaturated flow and transport at Yucca Mountain (see, for example, the models presented in BSC 2004 [DIRS 170035], Section 6.1; BSC 2004 [DIRS 169861], Section 6.1; and BSC 2004 [DIRS 169857], Section 6.1).

The thermal conductivity of the rock matrix is calculated using a square-root interpolation between dry and wet conductivities as a function of liquid saturation

$$
\lambda\left(S_{l}\right)=\lambda_{d r y}+\left(\lambda_{\text {wet }}-\lambda_{d r y}\right) \sqrt{S_{l}}
$$

This square-root relationship is commonly used in the literature (Pruess 1987 [DIRS 100684], p. 6). The resulting thermal conductivity represents the rock matrix plus fluid system. See Section 5 (Assumption 4) for a discussion of how thermal conductivities are calculated for the fracture continuum

In the TOUGH2 simulator (Pruess 1991 [DIRS 100413]), the continuum balance equations in Equation 6.2.1.1-1 are discretized in space using the integral finite difference approach, and time is discretized as fully implicit. The discretized balance equations are written in terms of residuals (difference in the primary variables between two successive iteration steps at all space locations) and iteration is continued until the residuals are reduced below a preset convergence tolerance. If convergence cannot be achieved within a certain number of (default or user supplied) iterations, the time step size is automatically reduced and a new iteration process is started. This ensures adequate time-stepping control without compromising accuracy.

\subsubsection{Model Dimensionality, Model Domain and Numerical Grid}

The $\mathrm{TH}$ behavior of the fractured rock is simulated in two-dimensional vertical domains perpendicular to the drift axis. A fully three-dimensional simulation of drift-scale coupled processes is difficult on account of computational limitations. The TH simulation requires a large vertical model domain because the thermally disturbed zone extends far into the overlying and underlying geological units. Also, with this report's focus on the near-drift conditions, it is important to represent the drift vicinity with refined discretization. As a result, a three-dimensional simulation model would be too time-consuming to allow for a large number of simulation runs, which is needed in this thermal seepage study to cover a wide range of 
parameters and conditions relevant for seepage. The consequences of using a two-dimensional representation of the drift-scale TH processes are discussed below:

1. A two-dimensional representation of the TH processes ignores the effect that the overall rock temperatures at the end of each emplacement drift and at the edges of the repository are different from those at center locations. To account for such effects, this report considers several sensitivity cases for the thermal load, covering a wide range of thermal conditions representative of drifts located at various locations in the repository.

2. In the two-dimensional representation, the thermal output of individual waste canisters placed into drifts is represented by an average linear thermal power per drift length. Using an average value ignores the thermal power differences between adjacent waste packages. To account for such effects, this report considers several sensitivity cases for the thermal load, covering a wide range of thermal conditions representative of local TH conditions close to individual waste packages. It should be noted that the differences between individual waste packages have rather limited impact on the near-field rock temperatures, because the mostly radiative heat exchange within the drift is rapid and will equilibrate most of the differences (BSC 2004 [DIRS 169565], Section 6.3.1).

3. A two-dimensional representation of the $\mathrm{TH}$ processes ignores the axial transport of vapor and air along the open drifts, a result of natural convection processes and gas pressure differences along the drifts. As demonstrated in (BSC 2004 [DIRS 164327]), such processes can effectively move water vapor from the heated emplacement sections of the drifts to the cooler rock surfaces at the drift ends outside of the emplacement sections (turn-out sections). Principles of thermodynamics suggest that the maximum amount of vapor that can be present in an air-vapor mixture decreases with declining temperature. Thus, the warm moist gas moving from hot waste packages into the comparably cool turnouts will be depleted of most of its vapor content by condensation on cooler rock surfaces. At the same time, relatively dry gas circulates back towards the emplacement sections of the drifts, thereby reducing the vapor mass and the relative humidities in these heated areas. Thus a two-dimensional representation-that does not account for axial vapor transport along drifts-is likely to overestimate the amount of vapor in the near-field rock mass in all heated drift sections, i.e., in those drift sections that are most relevant for the thermal seepage and the related abstraction model (see Section 6.2.4.1). Overestimating the amount of vapor in the near-field rock mass is synonymous with overpredicting the amount of condensation and potential reflux in the fractured rock. Thus a two-dimensional representation without accounting for in-drift vapor flux is an upper-bounding case for thermal seepage.

4. A two-dimensional representation neglects the three-dimensional behavior of small-scale flow channeling in the fractured rock, as caused by heterogeneity in the rock properties. However, with respect to the effectiveness of the capillary barrier for seepage into drifts, a two-dimensional representation is more critical in most cases of heterogeneous fracture permeability fields because the potential diversion of flow in the third dimension is neglected. Thus a two-dimensional representation of small-scale flow channeling is expected to provide an upper-bounding case for thermal seepage. 
It can be concluded from the itemized list that the two-dimensional representation used in this report is adequate for the intended application of predicting thermal seepage.

The boundaries chosen for the two-dimensional model domain are as follows: In the vertical direction, the ground surface of Yucca Mountain is taken as the top model boundary. The water table below the repository is used as the bottom boundary of the model area. Symmetry considerations are applied to reduce the model domain in the lateral direction, perpendicular to the drift axis, in order to increase the computational efficiency of the simulation runs. The current repository design of parallel drifts spaced at $81 \mathrm{~m}$ can be represented as a series of symmetrical, identical half-drift models with vertical no-flow boundaries between them. Accordingly, the numerical mesh is reduced to a half-drift model with a width of $40.5 \mathrm{~m}$, extending from the drift center to the midpoint between drifts. For a homogeneous, uniform-property medium, the vertical planes at the lateral boundaries are perfect symmetry axes for flow, and thus no-flow boundary conditions are fully justified. A heterogeneous system on the other hand, as studied in Sections 6.2.2.2, 6.2.3.2, and 6.2.4.2, can possibly produce lateral flow across the symmetry planes. However, since the spatial distribution of heterogeneous permeability values is essentially uncorrelated (see Sections 6.2.2.2.1 and 6.2.3.2.1), the impact of these imposed no-flow conditions is limited to a small region close to the boundaries. Thus the symmetry considerations are appropriate, and do not significantly affect the model results.

To account for the two main host rock units of the repository, two submodels with slightly different numerical gridding and different stratigraphy are studied. The first one, the Tptpmn submodel, considers a drift located in the Topopah Spring Tuff middle nonlithophysal unit (Tptpmn unit). The second one is the Tptpll submodel, assuming a drift located in the Topopah Spring Tuff lower lithophysal unit (Tptpll unit). Note that the current repository design includes two additional geologic units for emplacement, the Topopah Spring Tuff upper lithophysal unit (Tptpul) and the Topopah Spring Tuff lower nonlithophysal unit (Tptpln). Neither of these units is studied in this report. This is because the Tptpmn and the Tptpll are most important with respect to the fraction of the repository located in these units. Furthermore, only these two of the four repository units have been characterized in detail by underground testing (heater tests, liquid-release tests) in the Exploratory Studies Facility (ESF) and the Enhanced Characterization of Repository Block (ECRB) to provide sufficient basis for predictive modeling.

For the Tptpmn submodel, the stratigraphy at borehole USW SD-9 is chosen as representative for the vertical profile. Geologic data from this borehole, as implemented in UZ model grid UZ99_2_3-D.mesh (DTN: LB990501233129.004 [DIRS 111475], column “i64”), were used to map geologic contacts into the two-dimensional mesh. The mesh coordinate system was set with reference to the center of the drift. Figures 6.2.1.2-1 and 6.2.1.2-2 show the grid design at different scale. According to the dual-permeability method, the fractured rock is discretized with two identical overlapping numerical grids for the fracture and the matrix continuum, respectively, and only one of these is shown in the figures. The geology below the tsw38 model layer was simplified compared to the original USW SD-9 data to accommodate the coarser gridding in the model, i.e., all the model layers below tsw38 model layer are assigned the property of layer ch2 (see Table 4.1-8). These model layers are far off from the sources of heat and are not expected to impact the TH conditions near the emplacement drifts (which is the focus of this report). The above unit specification (tsw and ch2) uses the nomenclature of the unsaturated zone (UZ) model reports, which is different from the GFM nomenclature used in this 
report. The relationship between the UZ and the GFM nomenclature is given in several model reports (e.g., in BSC 2004 [DIRS 169855], Table 6-5).

Figures 6.2.1.2-1 and 6.2.1.2-2 show that the gridblock size is kept sufficiently small to provide enough resolution in the vicinity of the drift and at geologic contacts, but is coarser elsewhere in order to achieve computing efficiency. At the drift wall, gridblocks are about $20 \mathrm{~cm}$ in the radial direction, which is similar to the gridblock sizes used in ambient seepage models (see Section 6.2.2.2.1). The area within approximately $50 \mathrm{~m}$ above the drift is more finely gridded than areas beyond to better capture TH effects important for seepage into drifts. The inside of the drift is also finely discretized in anticipation of future modeling work pertaining to in-drift TH processes that are outside the scope of this report. The size and location of the waste package is designed according to the dimensions given in Section 4.1.1.6. The Tptpmn mesh has a total number of 2,511 gridblocks, including those representing matrix and fracture gridblocks.

The main difference between the Tptpll submodel grid and the Tptpmn submodel grid is that the drift - and its specific refined grid design in the drift vicinity - is located in the Topopah Spring Tuff lower lithophysal unit (Tptpll unit), where the majority of the emplacement drifts will be located. The stratigraphy of this model was taken at a location near the center of the repository (at approximately Nevada State Plane coordinates E170572, N233195). Geologic data from column “j34” of the UZ99_2_3-D mesh (DTN: LB990501233129.004 [DIRS 111475]) were used to map geologic contacts into the two-dimensional mesh. Figure 6.2.1.2-3 shows the entire vertical grid and a close-up view with focus on the Tptpll. The discretization within the drift and in close vicinity to the drift is identical to the one in the Tptpmn submodel (see Figure 6.2.1.2-2). Unlike the Tptpmn submodel, all geologic layers down to the water table below the modeled drift are incorporated into the numerical mesh. The Tptpll mesh consists of 3,181 gridblocks, including those representing fracture and matrix gridblocks. 


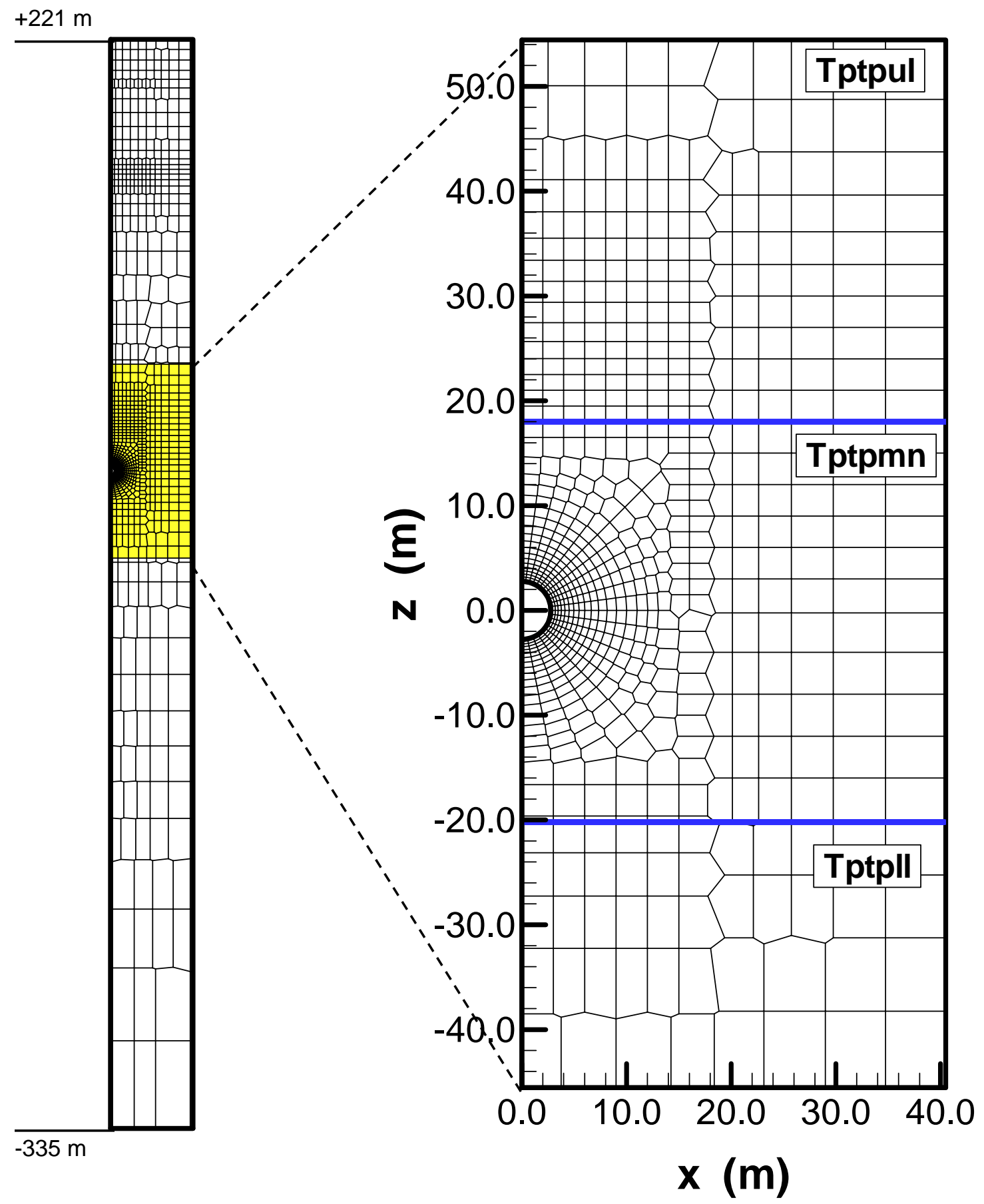

Input DTN (stratigraphy): LB990501233129.004 [DIRS 111475].

Output DTN: NA (see Section 8.5).

NOTE: The top of the entire mesh is at $+221 \mathrm{~m}$, the bottom is at $-335 \mathrm{~m}$. Blue lines show the interfaces between the host rock unit Tptpmn and the adjacent units Tptpul and Tptpll. The contact between the Tptpmn and the Tptpul was slightly raised compared to the USW SD-9 data to provide for better continuity at the interface.

Figure 6.2.1.2-1. Tptpmn Submodel Mesh with Close-Up View of Drift Vicinity 


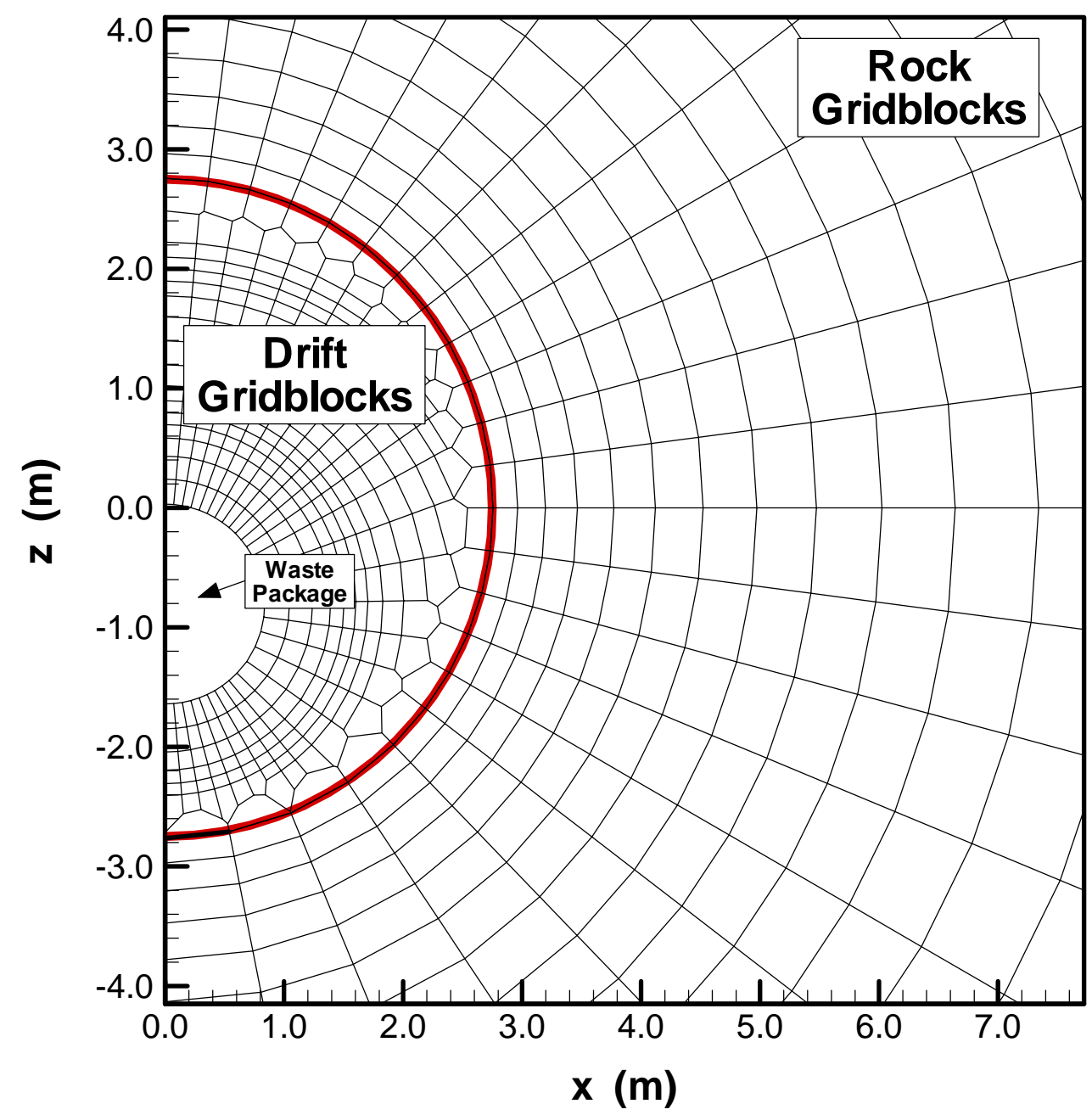

Output DTN: NA (see Section 8.5).

NOTE: The thick red line represents the outline of the drift wall.

Figure 6.2.1.2-2. Discretization Inside of the Drift and of the Immediate Drift Vicinity in the Tptpmn Submodel and the Tptpll Submodel 


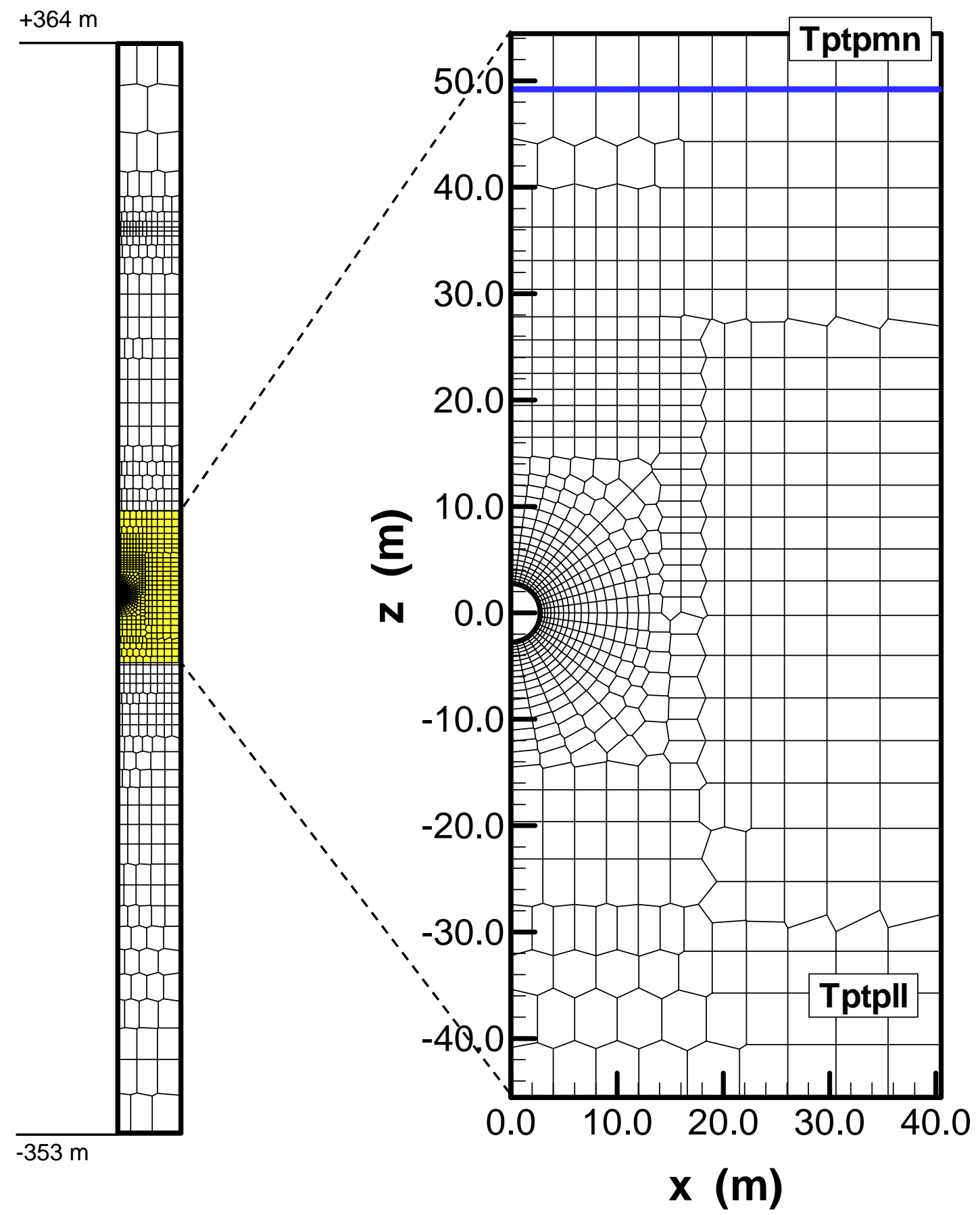

Input DTN (stratigraphy): LB990501233129.004 [DIRS 111475].

Output DTN: NA (see Section 8.5).

NOTE: The top of the entire mesh is at $+364 \mathrm{~m}$, the bottom is at $-353 \mathrm{~m}$. The blue line shows the interface between the host rock unit Tptpll and the adjacent unit Tptpmn. The top of the Tptpln below the Tptpll is at $-52.2 \mathrm{~m}$.

Figure 6.2.1.2-3. Tptpll Submodel Mesh with Close-Up View of Drift Vicinity 


\subsubsection{Model Boundary Conditions, Initial Conditions, and Thermal Load}

\subsection{Boundary Conditions}

The ground surface of the mountain is taken as the top model boundary, representing an open atmosphere. The water table as a flat, stable surface is used as the bottom boundary condition. Both the top and bottom boundaries are treated as Dirichlet-type conditions with specified constant temperature, gas pressure, and liquid saturation values (Table 6.2.1.3-1). In general, the top temperature boundary values represent long-term average conditions at the ground surface of Yucca Mountain, reflecting the altitude of the chosen location, while the bottom temperatures are approximately given by the geothermal gradient. Gas pressure values at the top boundary represent atmospheric pressure at the ground surface elevation. Gas pressure at the bottom is mainly driven by the pressure values at the top plus the hydrostatic component of the altitude difference. Saturation values at the top represent the small (residual) saturation close to the ground surface atmospheric boundary. The bottom saturation represents fully saturated conditions (water table), with the value of 0.99999 chosen for numerical reasons. It should be pointed out that the exact boundary condition values for temperature, gas pressure, and saturation are not important for TH seepage model results. The temperature and gas pressure values define the initial temperature and pressure fields, respectively, which are soon significantly altered once the drifts are heated up. The thermal perturbation of the temperature and pressure fields is so strong in the near field that the initial distribution of these parameters hardly matters. With respect to water saturation in the model domain, the main factor affecting the initial water saturations is the surface infiltration imposed at the top boundary. Surface infiltration defines the percolation flux in the unsaturated zone, which is important for the ambient saturation values in the fractured rock of the $\mathrm{UZ}$ and also affects the $\mathrm{TH}$ conditions during the thermal period. Surface infiltration, as discussed in Section 6.2.1.4, is applied using a source term in the first rock gridblocks at the top boundary.

The specific boundary values used for the Tptpmn submodel represent observation at the locations of the USW SD-9 borehole. The Tptpll submodel boundary uses values representative of the center of the repository. As discussed in Section 4.1.1.2, these values have been extracted from DTN: LB991131233129.004 [DIRS 162183], which is the product output from the UZ flow and transport model. For the Tptpll unit, the extracted values have been slightly adjusted to make them consistent with the drift-scale THC modeling effort (BSC 2004 [DIRS 169856], Table 6.5-2). There is a minor difference of about 0.3 percent in the boundary temperature and about 0.05 percent in the boundary pressure between the selected values for the Tptpll, as given in Table 6.2.1.3-1 of this report, and the values reported in the above-provided DTN. This discrepancy does not affect the model results. All lateral boundaries are no-flow boundaries for water, gas, and heat.

\subsection{Initial Conditions}

Initial conditions (such as temperature, pressure, and gas saturations) are derived by running the TH seepage model to steady state, simulating the repository conditions prior to waste emplacement. These runs are performed separately for each property set, using the prescribed hydrological boundary conditions and the present-day infiltration values. 


\subsection{Thermal Load}

The reference-mode heat load studied with the TH seepage model is $1.45 \mathrm{~kW} / \mathrm{m}$ (BSC 2004 [DIRS 168489]), which is measured along the axis of an emplacement drift. The value of 1.45 $\mathrm{kW} / \mathrm{m}$ refers to the initial thermal line load that decreases with time as a result of radioactive decay. The time-dependent thermal-line-load values are given in D\&E / PA/C IED Typical Waste Package Components Assembly (BSC (2004 [DIRS 167369]). Note that the actual values (see Section 4.1.1.3) used in this report are from an earlier document (BSC 2003 [DIRS 161731]). There are small differences between the provided values that are on the order of less than 1 percent for the time period from 0 to 1,000 years after emplacement. The impact of these differences on the predicted temperature conditions is much smaller than the impact of other sources of temperature variability (e.g., stemming from heat load variation between individual waste packages, emplacement time differences, and three-dimensional edge cooling effect). Thus, these differences are irrelevant for the results of this report. During the preclosure period, ventilation in the drifts will remove a significant amount of heat. For this analysis, it is estimated that, on average over the 50 years, 86.3 percent (BSC 2002 [DIRS 160975], Table 6-6) of the time-varying line load is effectively removed from the repository (see Section 4.1.1.3). Note that the adopted ventilation efficiency value (86.3\%) is slightly different from recent estimates of mean ventilation efficiency of 86 percent (BSC 2004 [169862], Table 8-3) for 800 meter long drifts; however, it is well within the range of 83.3 to 88.7 percent (BSC 2004 [DIRS 169862], Table 8-3). In other words, for the simulations in this model, only 13.7 percent of the given line load is used for the first 50 years after emplacement. After 50 years, the full line load is implemented.

Table 6.2.1.3-1. TH Seepage Model Boundary Conditions

\begin{tabular}{|c|c|c|}
\hline Boundary & Boundary Condition & Reference \\
\hline $\begin{array}{l}\text { Top Boundary for } \\
\text { Tptpmn Submodel } \\
\text { (ground surface) }\end{array}$ & $\begin{array}{l}\mathrm{T}=17.68^{\circ} \mathrm{C} \\
\mathrm{S}_{1}=0.01 \\
\mathrm{P}=86339 \mathrm{~Pa} \\
\text { Time-varying infiltration rate }\end{array}$ & $\begin{array}{l}\text { Section 4.1.1.2 } \\
\text { and Table 4.1-6 }\end{array}$ \\
\hline $\begin{array}{l}\text { Bottom Boundary for } \\
\text { Tptpmn Submodel } \\
\text { (water table) }\end{array}$ & $\begin{array}{l}\mathrm{T}=31.68^{\circ} \mathrm{C} \\
\mathrm{S}_{\mathrm{l}}=0.99999 \\
\mathrm{P}=92000 \mathrm{~Pa}\end{array}$ & $\begin{array}{l}\text { Section 4.1.1.2 } \\
\text { and Table 4.1-6 }\end{array}$ \\
\hline $\begin{array}{l}\text { Top Boundary for } \\
\text { Tptpll Submodel } \\
\text { (ground surface) }\end{array}$ & $\begin{array}{l}\mathrm{T}=16.13^{\circ} \mathrm{C} \\
\mathrm{S}_{1}=0.01 \\
\mathrm{P}=84725 \mathrm{~Pa} \\
\text { Time-varying infiltration rate }\end{array}$ & $\begin{array}{l}\text { Section 4.1.1.2 } \\
\text { and Table 4.1-6 }\end{array}$ \\
\hline $\begin{array}{l}\text { Bottom Boundary for } \\
\text { Tptpll Submodel } \\
\text { (water table) }\end{array}$ & $\begin{array}{l}\mathrm{T}=32.62^{\circ} \mathrm{C} \\
\mathrm{S}_{\mathrm{l}}=0.99999 \\
\mathrm{P}=92000 \mathrm{~Pa}\end{array}$ & $\begin{array}{l}\text { Section 4.1.1.2 } \\
\text { and Table 4.1-6 }\end{array}$ \\
\hline Sides & No flux for water, gas, heat & Not Applicable \\
\hline Drift Wall & Open boundary for water, gas and heat & Not Applicable \\
\hline
\end{tabular}


Table 6.2.1.3-1. TH Seepage Model Boundary Conditions (Continued)

\begin{tabular}{|c|c|c|}
\hline Boundary & Boundary Condition & Reference \\
\hline $\begin{array}{l}\text { Waste Package } \\
\text { Thermal Load }\end{array}$ & $\begin{array}{l}\text { Reference mode: } \\
\text { Initial heat load of } 1.45 \mathrm{~kW} / \mathrm{m} \text { decreasing with time (due to radioactive } \\
\text { decay), and reduced by } 86.3 \% \text { during the first } 50 \text { years (due to heat } \\
\text { removal by ventilation) } \\
\text { High-temp mode: } \\
\text { Initial heat load of } 1.45 \mathrm{~kW} / \mathrm{m} \text { decreasing with time (due to radioactive } \\
\text { decay), and reduced by } 70 \% \text { during the first } 50 \text { years (due to heat removal } \\
\text { by ventilation) } \\
\text { Low-temp mode: } \\
\text { Initial heat load of } 1.0 \mathrm{~kW} / \mathrm{m} \text { decreasing with time (due to radioactive } \\
\text { decay), and reduced by } 88.3 \% \text { during the first } 50 \text { years (due to heat } \\
\text { removal by ventilation) } \\
\text { Additional heat mode: } \\
\text { Initial heat load of } 1.2 \mathrm{~kW} / \mathrm{m} \text { decreasing with time (due to radioactive } \\
\text { decay), and reduced by } 86.3 \% \text { during the first } 50 \text { years (due to heat } \\
\text { removal by ventilation) }\end{array}$ & $\begin{array}{l}\text { Section 4.1.1.3 } \\
\text { and Table 4.1-1 }\end{array}$ \\
\hline
\end{tabular}

NOTE: $\quad \mathrm{T}=$ Temperature, $\mathrm{S}_{\mathrm{l}}=$ Liquid saturation, $\mathrm{P}=$ Pressure.

The reference mode is complemented by sensitivity cases using smaller and larger effective heat input. For above-boiling conditions, the high-temp mode is studied using $1.45 \mathrm{~kW} / \mathrm{m}$ line load with a heat removal efficiency of 70 percent for 50 years. This case is identical to the HTOM thermal load studied in the SSPA (BSC 2001 [DIRS 155950], Section 6.3.6.3.1]). Another case with fundamentally different $\mathrm{TH}$ response is the low-temp mode, in which the maximum rock temperature remains below boiling at any time. The line load in this case is $1.0 \mathrm{~kW} / \mathrm{m}$ and heat-removal efficiency is 88.3 percent for 50 years. For the heat decay in this case, time-varying values of the $1.45 \mathrm{~kW} / \mathrm{m}$ case are linearly scaled down by a factor of 1.0/1.45. In support of the proposed thermal seepage abstraction model, one additional thermal mode is studied in Section 6.2.4.2, specifically designed to represent near-drift thermal conditions with a relatively short boiling period and a maximum rock temperature just above boiling. This mode has a heat load of $1.2 \mathrm{~kW} / \mathrm{m}$, a heat-removal efficiency of 86.3 percent, and a 50 -year preclosure period. (The heat decay curve is linearly scaled down, as explained above.) Together, the four cases cover a wide range of the expected variability and uncertainty in $\mathrm{TH}$ response to the waste emplacement at Yucca Mountain.

Note that the dryout of the rock that occurs in the drift vicinity because of ventilation with relatively dry air is neglected during the 50-year preclosure period. Sensitivity studies in FY 01 Supplemental Science and Performance Analyses, Volume 1: Scientific Bases and Analyses (BSC 2001 [DIRS 155950], Section 5.3.2.4.4) indicate that inclusion of preclosure dryout gives rise to slightly higher temperatures during the heating period compared to a model that ignores the influence of preclosure dryout. Inclusion of preclosure dryout is not significant for thermal seepage. 


\subsubsection{Infiltration/Percolation}

This report adopts the mean infiltration scenario described in Simulation of Net Infiltration for Modern and Potential Future Climates (USGS 2003 [DIRS 166518]), which considers three long-term periods with different infiltration to account for future climate changes. The infiltration values used as input to the TH seepage model are $6 \mathrm{~mm} / \mathrm{yr}$ for the present-day period (up to 600 years from now), $16 \mathrm{~mm} / \mathrm{yr}$ for the monsoon period (600 to 2,000 years), and 25 $\mathrm{mm} / \mathrm{yr}$ for the glacial transition period (more than 2,000 years). These values have been extracted from the respective infiltration map; they represent the average downward percolation over the repository footprint (averaging was conducted using the values given in DTN: LL000114004242.090 [DIRS 142884], as described in Section 4.1.1.4; see also Table 4.1-7). Note that the exact values of the base-case infiltration $(6,16$, and $25 \mathrm{~mm} / \mathrm{yr})$ are not important for the thermal seepage modeling study. This is because, per the discussion below, the base-case infiltration scenario is complemented by various additional scenarios with considerably higher percolation fluxes. These additional scenarios are most relevant for the thermal seepage study, since the potential for ambient and thermal seepage increases with the amount of percolation flux arriving at the drifts.

In addition to climate changes, infiltration can deviate from values given in the mean infiltration scenario because of uncertainty in the climate/infiltration models and spatial variability in net infiltration. (Uncertainty related to climate and infiltration is covered in Simulation of Net Infiltration for Modern and Potential Future Climates (USGS 2003 [DIRS 166518]) by assuming two additional infiltration scenarios: the upper-bound scenario, with glacial transition infiltration of $47 \mathrm{~mm} / \mathrm{yr}$ as extracted at borehole USW SD-9, and the lower-bound scenario, with glacial transition infiltration of $3 \mathrm{~mm} / \mathrm{yr}$ as extracted at borehole USW SD-9). Since net infiltration is the ultimate source of percolation through the UZ, and since the potential for seepage increases with the magnitude of percolation flux, the range of infiltration in the $\mathrm{TH}$ seepage model should account for this uncertainty and spatial variability.

Note also that the TH seepage model is essentially a vertical column model that can not account for the potential differences between net infiltration at the ground surface and percolation flux in the different geological layers within the Yucca Mountain. These differences may stem from flow focusing as a result of spatially variable rock properties, from lateral flux diversion in the Paintbrush nonwelded unit, and from other effects. Flow focusing denotes the potential concentration of flow from the large scale, as simulated with the UZ flow model, to the drift scale, as simulated by the $\mathrm{TH}$ seepage model. Stochastic modeling analysis using a two-dimensional, finely gridded vertical cross section of the UZ has resulted in maximum flow-focusing factors between five and six (BSC 2004 [DIRS 167652], Section 6.8). The infiltration values imposed at the top of the TH seepage model must accommodate these additional effects in order to cover the resulting range of percolation fluxes within the repository units. This is achieved by multiplying the infiltration rates of the mean infiltration scenario with appropriate factors. In Sections 6.2.2 and 6.2.3 of this report, factors of five and ten have been selected that will give rise to maximum percolation values of $125 \mathrm{~mm} / \mathrm{yr}$ and $250 \mathrm{~mm} / \mathrm{yr}$, respectively, during the glacial transition time period after 2,000 years (Table 6.2.1.4-1). Additional factors of 20, 40, and-as an extreme case-100 are applied in Section 6.2.4.2.1. These give rise to maximum percolation fluxes of $500 \mathrm{~mm} / \mathrm{yr}, 1,000 \mathrm{~mm} / \mathrm{yr}$, and even 2,500 $\mathrm{mm} / \mathrm{yr}$, respectively. For convenience, the above factors of 5, 10, 20, 40, and 100 are referred to 
hereafter as flux multiplication factors. Applying these factors accounts for uncertainty, variability, and focusing of downward flow.

Together, the five cases more than adequately cover the possible range of percolation fluxes at any location and future time period at Yucca Mountain. See Section 6.6.5 in Abstraction of Drift Seepage (BSC 2004 [DIRS 169131]) for a discussion of the range of percolation fluxes to be considered in the TSPA-LA. According to this discussion, the maximum possible flux that can be expected at the repository horizon is about $1,400 \mathrm{~mm} / \mathrm{yr}$ during the glacial transition climate period (using the upper-bound climate scenario). However, while this maximum flux is theoretically possible (as a result of climate changes, spatial variability, and flow focusing), all fluxes above $1,000 \mathrm{~mm} / \mathrm{yr}$ are extremely unlikely (i.e., they have very small probabilities in the TSPA-LA calculation). Thus, the percolation flux scenario with a multiplication factor of 40 can be considered an upper bounding case for the conditions at Yucca Mountain. The percolation flux scenario with a multiplication factor of 100 is an extreme parameter case that is not realistic. It was only chosen to test the general concept of the vaporization barrier for extreme flow events, but is a zero-probability scenario for TSPA.

Table 6.2.1.4-1. Infiltration Boundary Condition for the TH Seepage Model

\begin{tabular}{|c|c|c|c|}
\hline Case & $\begin{array}{c}\text { Infiltration Rate } \\
\text { (mm/yr) }\end{array}$ & $\begin{array}{c}\text { Time Period } \\
\text { (years) }\end{array}$ & Reference \\
\hline Mean Infiltration Scenario & $\begin{array}{l}6 \\
16 \\
25 \\
\end{array}$ & $\begin{array}{l}0 \text { to } 600 \text { (present day) } \\
600 \text { to } 2000 \text { (monsoon) } \\
>2000 \text { (glacial transition) }\end{array}$ & Section 4.1.1.4 \\
\hline Flux multiplication factor 5 & $\begin{array}{l}30 \\
80 \\
125 \\
\end{array}$ & $\begin{array}{l}0 \text { to } 600 \\
600 \text { to } 2000 \\
>2000 \\
\end{array}$ & Not Applicable \\
\hline Flux multiplication factor 10 & $\begin{array}{l}60 \\
160 \\
250 \\
\end{array}$ & $\begin{array}{l}0 \text { to } 600 \\
600 \text { to } 2000 \\
>2000 \\
\end{array}$ & Not Applicable \\
\hline Flux multiplication factor 20 & $\begin{array}{l}120 \\
320 \\
500 \\
\end{array}$ & $\begin{array}{l}0 \text { to } 600 \\
600 \text { to } 2000 \\
>2000\end{array}$ & Not Applicable \\
\hline Flux multiplication factor 40 & $\begin{array}{l}240 \\
640 \\
1000 \\
\end{array}$ & $\begin{array}{l}0 \text { to } 600 \\
600 \text { to } 2000 \\
>2000 \\
\end{array}$ & Not Applicable \\
\hline Flux multiplication factor 100 & $\begin{array}{l}600 \\
1600 \\
2500\end{array}$ & $\begin{array}{l}0 \text { to } 600 \\
600 \text { to } 2000 \\
>2000\end{array}$ & Not Applicable \\
\hline
\end{tabular}

\subsubsection{Properties of Fractured Rock and In-Drift Properties}

The hydrological and thermal rock properties used for the TH seepage model and their sources are summarized in Section 4.1.1.1. While many relevant fracture and matrix hydrological properties are estimated in mountain-scale calibration runs, other hydrological and all thermal properties are taken from various sources (Table 4.1-2). The main property set used in this report is referred to as the DS/AFM-UZ02-Mean property set. This property set consists of fracture and matrix property values from various controlled sources including DTNs: LB0205REVUZPRP.001 [DIRS 159525], LB0208UZDSCPMI.002 [DIRS 161243], and 
LB0210THRMLPRP.001 [DIRS 160799]. As described in Section 6.2.1.1.2, modeling cases with specific focus on seepage calculation requires modifications of the fracture properties in close vicinity to the drift, since the small zone around the drift walls is very important for seepage. For example, spatial heterogeneity in fracture permeability and smaller fracture capillary-strength parameter may promote seepage (BSC 2004[DIRS 167652], Sections 6.6.1 and 6.6.2). Sensitivity of thermal seepage to the fracture capillary-strength parameter, fracture permeability, and rock matrix thermal conductivity (all near-field values) is analyzed in Section 6.2.4.2.2.

Prediction of the in-drift thermal-hydrological conditions is NOT the purpose of this report. Thus, the in-drift environment is simulated in a simplified manner, only to the detail that is required to provide the proper boundary conditions for the near-field rock. The open space inside the drift, i.e., the space between the invert and the drift wall, is represented by elements of high permeability $\left(1 \times 10^{-10} \mathrm{~m}^{2}\right)$, high porosity $(\sim 1.0)$, and small capillarity $(-5.0 \mathrm{~Pa})$. These parameters for the space between the drift wall and the invert are provided mostly for numerical simulation with the TOUGH2 simulator (Pruess 1991 [DIRS 100413]). The choice of these parameter values is consistent with the conceptual model of seepage into a large, open cavity. In other words, the drift (except the invert) is modeled similar to that of gas-filled cavity with a capillary barrier at the interface between the fractured rock and the drift. No further justification is needed for the selection of these parameters. These drift elements are also given large heat conductivities $(10,000 \mathrm{~W} / \mathrm{m} / \mathrm{K})$ to simulate the effective heat transfer by radiation/convection/conduction within the drift. Naturally, the grain heat capacities in the open cavity are set to $0.0 \mathrm{~J} / \mathrm{kg}$. Again, the choice of these parameters is consistent with the physical/conceptual model of seepage into an open cavity.

The heat generated by the decaying waste is imposed as a boundary condition into one grid element that represents the waste package (see Figure 6.2.1.2-2). Flow and transport within the waste package are not simulated; only transport of heat between the waste package and the surrounding open cavity and the invert. The values for waste package geometry and thermal properties (see Table 4.1-10) are consistent with the THC modeling of drift-scale processes (BSC 2004 [DIRS 169856], Section 4.1.7, Table 4.1-6), except for the conceptual model choices (see Section 4.1.1.6, Table 4.1-10). The drip shield is not explicitly modeled in the TH seepage model.

The invert at the bottom of the drift, to be made of crushed tuff rock material, is treated as a single continuum domain in the thermal seepage model. More complex conceptualizations like a dual-continuum approach are possible, as adopted for example in Multiscale Thermohydrologic Model (BSC 2004 [DIRS 169565], Section 6.2), but not necessary for the purpose of modeling thermal seepage. The discretization of the invert is consistent with the dimensions given in Table 4.1-10, within the limits imposed by the resolution of the model mesh (Figure 6.2.1.2-2). The thermal (heat capacity, thermal conductivity, and density) and selected hydrological (permeability and porosity) properties of the invert at the bottom of the drift (see Table 4.1-10) are consistent with Drift-Scale Coupled Processes (DST and THC Seepage) Models (BSC 2004 [DIRS 169856], Section 4.1.7), except as noted in Section 4.1.1.6. Similar to the open drift elements, the invert is given zero capillary suction, because the drying and wetting characteristics of the invert are not relevant for thermal seepage. In general, the chosen invert 
properties have limited impact on the overall $\mathrm{TH}$ behavior in the rock. In particular, the magnitude and evolution of thermal seepage is not affected by the choice of the invert properties.

\subsubsection{Overview of Simulation Cases Studied with the TH Seepage Model}

A large number of simulation cases performed with the TH seepage model are presented in the following sections (6.2.2, 6.2.3, and 6.2.4) of this report. To provide an overview and easy reference, a roadmap of all simulation cases is given in Figures 6.2.1.6-1 (for the Tptpmn submodel) and 6.2.1.6-2 (for the Tptpll submodel). The figures introduce the simulation cases, give a brief description, and provide the section reference where results are presented. In addition, a comprehensive list of all simulation cases is given in Table 6.2.1.6-1. The table also provides DTN numbers, when applicable, of output data developed from these simulations, in those cases deemed relevant for downstream users.

In the tables and figures, each simulation case is denoted by a specific name code as follows. The first two letters are either MN (for the Tptpmn submodel) or LL (for the Tptpll submodel), followed by HOM (for homogeneous representation of permeability) or HET (for heterogeneous representation of permeability), followed by a two-digit number. For example, a simulation name MN-HET-01 denotes the first simulation case with the Tptpmn submodel using a heterogeneous permeability field.

Results are presented for the Tptpmn submodel (Section 6.2.2) and the Tptpll submodel (Section 6.2.3). These sections are subdivided into two main parts, the first one explaining the main $\mathrm{TH}$ results in response to heating with related sensitivities (mainly for informative purposes) (Sections 6.2.2.1 and 6.2.3.1), the second focusing on the potential for thermal seepage with related sensitivities, for use in seepage abstraction and TSPA (Sections 6.2.2.2 and 6.2.3.2). An abstraction methodology for thermal seepage is suggested in Section 6.2.4.1, based on the simulation results. Additional simulation cases are presented in Section 6.2.4.2 to test the suggested abstraction model for a wider range of conditions, parameters, and conceptual model choices. Detailed explanation of all simulation cases is given in the respective subsections of this report. Note that all simulation cases listed in Table 6.2.1.6-1 assume intact open drifts. The few simulation cases analyzing $\mathrm{TH}$ conditions in collapsed drifts (see Section 6.2.5) are not categorized using a name code. 


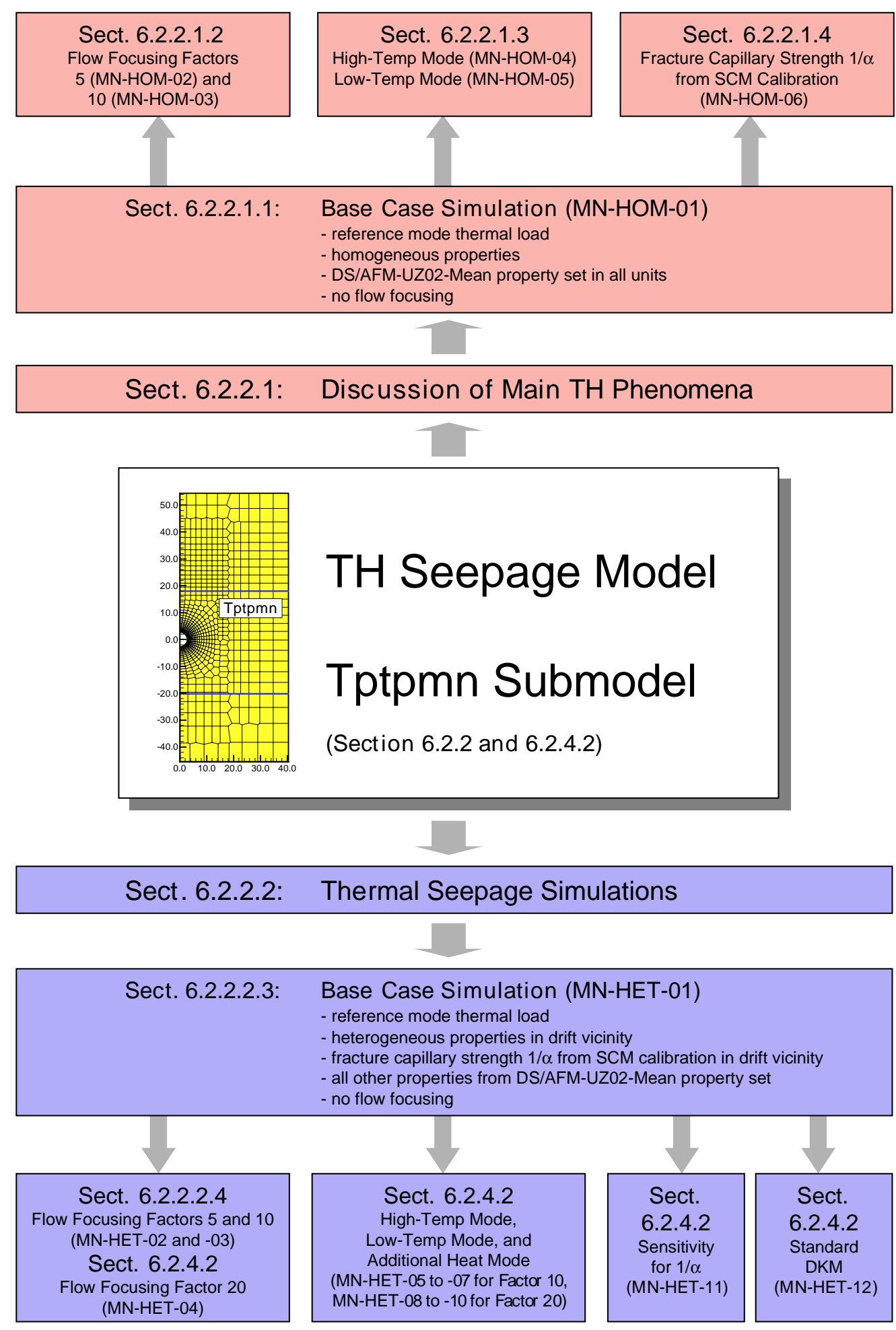

NOTE: Steady-state ambient simulation cases have been studied in addition to the above listed transient thermal simulation cases (see Section 6.2.2.2.2). These are not given in Figure 6.2.1.6-1.

Figure 6.2.1.6-1. Overview of Simulation Cases for the Tptpmn Submodel 


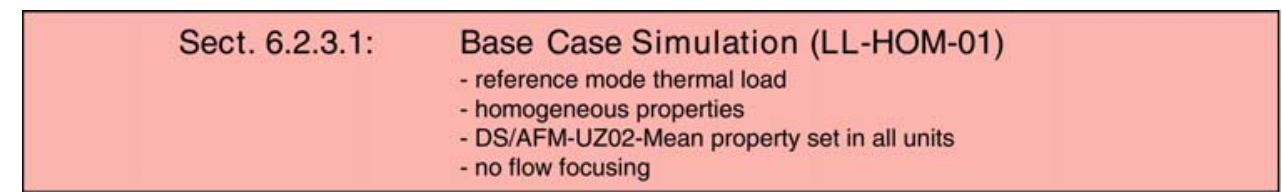

Sect. 6.2.3.1: Discussion of Main TH Phenomena

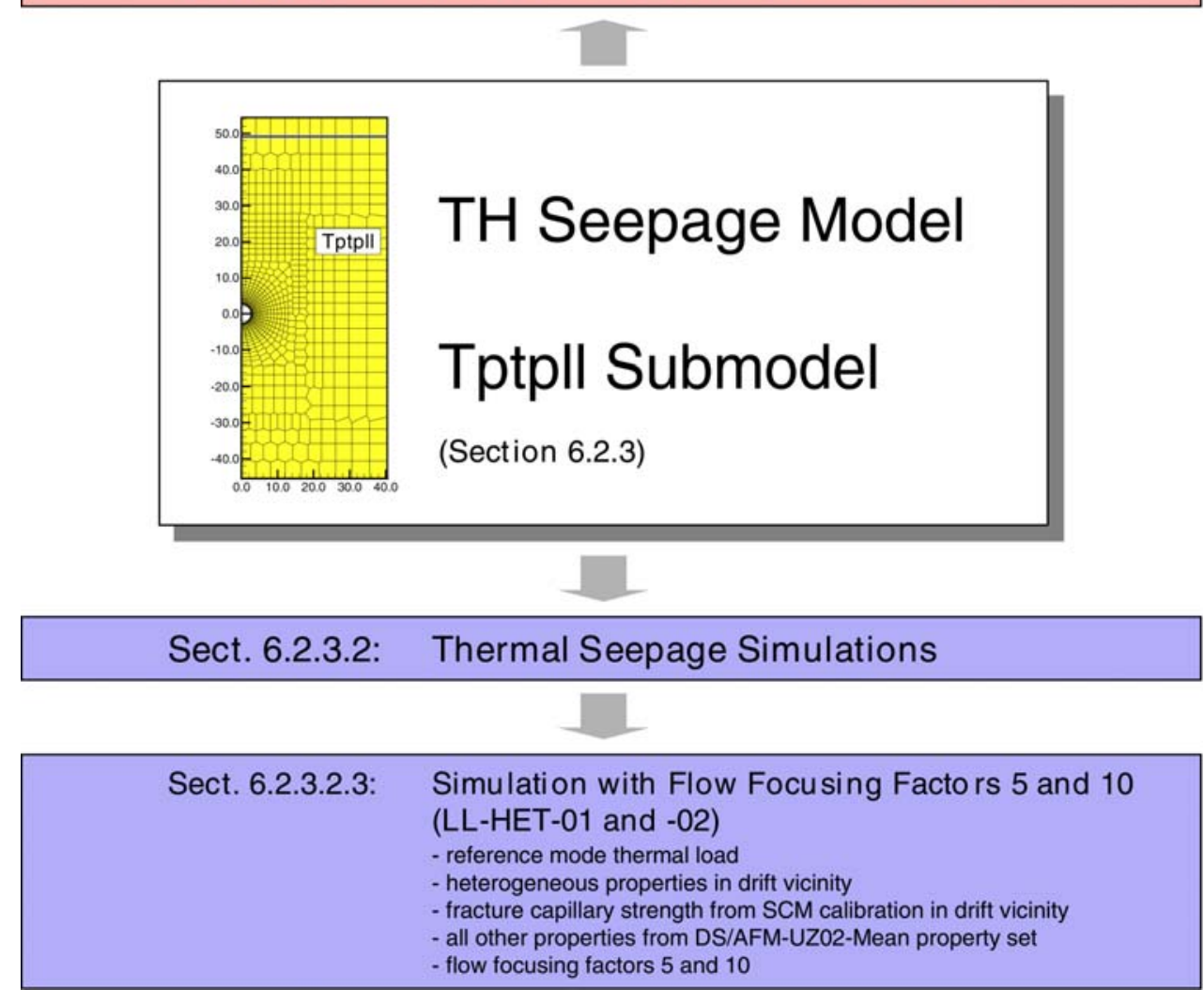

NOTE: Steady-state ambient simulation cases have been studied in addition to the above listed transient thermal simulation cases (see Section 6.2.3.2.2). These are not given in Figure 6.2.1.6-2.

Figure 6.2.1.6-2. Overview of Simulation Cases for the Tptpll Submodel 
Table 6.2.1.6-1. List of Simulation Cases for the Tptpmn Submodel and Tptpll Submodel

\begin{tabular}{|c|c|c|c|c|c|c|c|c|}
\hline $\begin{array}{c}\text { Simulation } \\
\text { Case }\end{array}$ & $\begin{array}{l}\text { Thermal } \\
\text { Load }\end{array}$ & $\begin{array}{c}\text { Flux } \\
\text { multiplication } \\
\text { factor }\end{array}$ & Property Set & $\begin{array}{l}\text { Permeability in } \\
\text { Drift Vicinity }\end{array}$ & $\begin{array}{c}\text { Capillary } \\
\text { Strength in Drift } \\
\text { Vicinity }\end{array}$ & $\begin{array}{c}\text { Other } \\
\text { Sensitivity }\end{array}$ & $\begin{array}{l}\text { Section of } \\
\text { this Report }\end{array}$ & Output DTN \\
\hline \multicolumn{9}{|c|}{ Tptpmn Submodel } \\
\hline MN-HOM-01 & $\begin{array}{l}\text { Reference } \\
\text { Mode }\end{array}$ & 1 & $\begin{array}{l}\text { DS/AFM- } \\
\text { UZO2-Mean }\end{array}$ & Homogeneous & $\begin{array}{l}\text { From DS-AFM- } \\
\text { UZ02-Mean }\end{array}$ & NA & 6.2.2.1.1 & NA (see Section 8.5) \\
\hline MN-HOM-02 & $\begin{array}{l}\text { Reference } \\
\text { Mode }\end{array}$ & 5 & $\begin{array}{l}\text { DS/AFM- } \\
\text { UZO2-Mean }\end{array}$ & Homogeneous & $\begin{array}{l}\text { From DS-AFM- } \\
\text { UZ02-Mean }\end{array}$ & NA & 6.2.2.1.2 & NA (see Section 8.5) \\
\hline MN-HOM-03 & $\begin{array}{l}\text { Reference } \\
\text { Mode }\end{array}$ & 10 & $\begin{array}{l}\text { DS/AFM- } \\
\text { UZO2-Mean }\end{array}$ & Homogeneous & $\begin{array}{l}\text { From DS-AFM- } \\
\text { UZ02-Mean }\end{array}$ & NA & 6.2.2.1.2 & NA (see Section 8.5) \\
\hline MN-HOM-04 & $\begin{array}{l}\text { High-Temp } \\
\text { Mode }\end{array}$ & 1 & $\begin{array}{l}\text { DS/AFM- } \\
\text { UZO2-Mean }\end{array}$ & Homogeneous & $\begin{array}{l}\text { From DS-AFM- } \\
\text { UZ02-Mean }\end{array}$ & NA & 6.2.2.1.3 & NA (see Section 8.5) \\
\hline MN-HOM-05 & $\begin{array}{l}\text { Low-Temp } \\
\text { Mode }\end{array}$ & 1 & $\begin{array}{l}\text { DS/AFM- } \\
\text { UZO2-Mean }\end{array}$ & Homogeneous & $\begin{array}{l}\text { From DS-AFM- } \\
\text { UZ02-Mean }\end{array}$ & NA & 6.2.2.1.3 & NA (see Section 8.5) \\
\hline MN-HOM-06 & $\begin{array}{l}\text { Reference } \\
\text { Mode }\end{array}$ & 1 & $\begin{array}{l}\text { DS/AFM- } \\
\text { UZO2-Mean }\end{array}$ & Homogeneous & $\begin{array}{l}\text { From SCM } \\
(1 / \alpha=589 \mathrm{~Pa})\end{array}$ & NA & 6.2.2.1.4 & NA (see Section 8.5) \\
\hline MN-HET-01 & $\begin{array}{l}\text { Reference } \\
\text { Mode }\end{array}$ & 1 & $\begin{array}{l}\text { DS/AFM- } \\
\text { UZO2-Mean }\end{array}$ & $\begin{array}{l}\text { Heterogeneous } \\
(3 \text { realizations })\end{array}$ & $\begin{array}{l}\text { From SCM } \\
(1 / \alpha=589 \mathrm{~Pa})\end{array}$ & NA & 6.2.2.2.3 & LB0303DSCPTHSM.001 \\
\hline MN-HET-02 & $\begin{array}{l}\text { Reference } \\
\text { Mode }\end{array}$ & 5 & $\begin{array}{l}\text { DS/AFM- } \\
\text { UZO2-Mean }\end{array}$ & $\begin{array}{l}\text { Heterogeneous } \\
\text { ( } 3 \text { realizations) }\end{array}$ & $\begin{array}{l}\text { From SCM } \\
(1 / \alpha=589 \mathrm{~Pa})\end{array}$ & NA & 6.2.2.2.4 & $\begin{array}{l}\text { LB0303DSCPTHSM.001 } \\
\text { LB0301DSCPTHSM.002 } \\
\end{array}$ \\
\hline MN-HET-03 & $\begin{array}{l}\text { Reference } \\
\text { Mode }\end{array}$ & 10 & $\begin{array}{l}\text { DS/AFM- } \\
\text { UZO2-Mean }\end{array}$ & $\begin{array}{l}\text { Heterogeneous } \\
\text { ( } 3 \text { realizations) }\end{array}$ & $\begin{array}{l}\text { From SCM } \\
(1 / \alpha=589 \mathrm{~Pa})\end{array}$ & NA & 6.2.2.2.4 & $\begin{array}{l}\text { LB0303DSCPTHSM.001 } \\
\text { LB0301DSCPTHSM.002 } \\
\end{array}$ \\
\hline MN-HET-04 & $\begin{array}{l}\text { Reference } \\
\text { Mode }\end{array}$ & 20 & $\begin{array}{l}\text { DS/AFM- } \\
\text { UZO2-Mean }\end{array}$ & $\begin{array}{l}\text { Heterogeneous } \\
\text { (1 realization) }\end{array}$ & $\begin{array}{l}\text { From SCM } \\
(1 / \alpha=589 \mathrm{~Pa})\end{array}$ & NA & 6.2.4.2.1 & $\begin{array}{l}\text { LB0303DSCPTHSM.001 } \\
\text { LB0301DSCPTHSM.002 }\end{array}$ \\
\hline MN-HET-05 & $\begin{array}{l}\text { High-Temp } \\
\text { Mode }\end{array}$ & 10 & $\begin{array}{l}\text { DS/AFM- } \\
\text { UZO2-Mean }\end{array}$ & $\begin{array}{l}\text { Heterogeneous } \\
\text { (1 realization) }\end{array}$ & $\begin{array}{l}\text { From SCM } \\
(1 / \alpha=589 \mathrm{~Pa})\end{array}$ & NA & 6.2.4.2.1 & $\begin{array}{l}\text { LB0303DSCPTHSM.001 } \\
\text { LB0301DSCPTHSM.002 } \\
\end{array}$ \\
\hline MN-HET-06 & $\begin{array}{l}\text { Additional } \\
\text { Heat Mode }\end{array}$ & 10 & $\begin{array}{l}\text { DS/AFM- } \\
\text { UZO2-Mean }\end{array}$ & $\begin{array}{l}\text { Heterogeneous } \\
(1 \text { realization })\end{array}$ & $\begin{array}{l}\text { From SCM } \\
(1 / \alpha=589 \mathrm{~Pa})\end{array}$ & NA & 6.2.4.2.1 & $\begin{array}{l}\text { LB0303DSCPTHSM.001 } \\
\text { LB0301DSCPTHSM.002 } \\
\end{array}$ \\
\hline MN-HET-07 & $\begin{array}{l}\text { High-Temp } \\
\text { Mode }\end{array}$ & 20 & $\begin{array}{l}\text { DS/AFM- } \\
\text { UZO2-Mean }\end{array}$ & $\begin{array}{l}\text { Heterogeneous } \\
(1 \text { realization })\end{array}$ & $\begin{array}{l}\text { From SCM } \\
(1 / \alpha=589 \mathrm{~Pa})\end{array}$ & NA & 6.2.4.2.1 & $\begin{array}{l}\text { LB0303DSCPTHSM.001 } \\
\text { LB0301DSCPTHSM.002 } \\
\end{array}$ \\
\hline MN-HET-08 & $\begin{array}{l}\text { Additional } \\
\text { Heat Mode }\end{array}$ & 20 & $\begin{array}{l}\text { DS/AFM- } \\
\text { UZO2-Mean }\end{array}$ & $\begin{array}{l}\text { Heterogeneous } \\
\text { (1 realization) }\end{array}$ & $\begin{array}{l}\text { From SCM } \\
(1 / \alpha=589 \mathrm{~Pa})\end{array}$ & NA & 6.2.4.2.1 & $\begin{array}{l}\text { LB0303DSCPTHSM.001 } \\
\text { LB0301DSCPTHSM.002 } \\
\end{array}$ \\
\hline MN-HET-09 & $\begin{array}{l}\text { Reference } \\
\text { Mode }\end{array}$ & 10 & $\begin{array}{l}\text { DS/AFM- } \\
\text { UZO2-Mean }\end{array}$ & $\begin{array}{l}\text { Heterogeneous } \\
\text { (1 realization) }\end{array}$ & $\begin{array}{l}\text { Sensitivity with } \\
1 / \alpha=400 \mathrm{~Pa}\end{array}$ & NA & 6.2.4.2.2 & $\begin{array}{l}\text { LB0303DSCPTHSM.001 } \\
\text { LB0301DSCPTHSM.002 }\end{array}$ \\
\hline
\end{tabular}




\begin{tabular}{|c|c|c|c|c|c|c|c|c|}
\hline $\begin{array}{l}\text { Simulation } \\
\text { Case }\end{array}$ & $\begin{array}{l}\text { Thermal } \\
\text { Load }\end{array}$ & $\begin{array}{c}\text { Flux } \\
\text { multiplication } \\
\text { factor }\end{array}$ & Property Set & $\begin{array}{l}\text { Permeability in } \\
\text { Drift Vicinity }\end{array}$ & $\begin{array}{l}\text { Capillary } \\
\text { Strength in Drift } \\
\text { Vicinity }\end{array}$ & $\begin{array}{c}\text { Other } \\
\text { Sensitivity }\end{array}$ & $\begin{array}{l}\text { Section of } \\
\text { this Report }\end{array}$ & Output DTN \\
\hline MN-HET-10 & $\begin{array}{l}\text { Reference } \\
\text { Mode }\end{array}$ & 1 & $\begin{array}{l}\text { DS/AFM- } \\
\text { UZO2-Mean }\end{array}$ & $\begin{array}{l}\text { Heterogeneous } \\
\text { ( } 1 \text { realization) }\end{array}$ & $\begin{array}{l}\text { From SCM } \\
(1 / \alpha=589 \mathrm{~Pa})\end{array}$ & DKM & 6.2.4.2.3 & $\begin{array}{l}\text { LB0303DSCPTHSM.001 } \\
\text { LB0301DSCPTHSM.002 }\end{array}$ \\
\hline MN-HET-11 & $\begin{array}{l}\text { Reference } \\
\text { Mode }\end{array}$ & 10 & $\begin{array}{l}\text { DS/AFM- } \\
\text { UZ02-Mean }\end{array}$ & $\begin{array}{l}\text { Heterogeneous } \\
\text { ( } 1 \text { realization) }\end{array}$ & $\begin{array}{l}\text { From SCM } \\
(1 / \alpha=589 \mathrm{~Pa})\end{array}$ & $\begin{array}{l}\text { Large } \\
\text { Thermal } \\
\text { Conduct. }\end{array}$ & 6.2.4.2.2 & $\begin{array}{l}\text { LB0309DSCPTHSM.001 } \\
\text { LB0309DSCPTHSM.002 }\end{array}$ \\
\hline MN-HET-12 & $\begin{array}{l}\text { Reference } \\
\text { Mode }\end{array}$ & 10 & $\begin{array}{l}\text { DS/AFM- } \\
\text { UZ02-Mean }\end{array}$ & $\begin{array}{l}\text { Heterogeneous } \\
\text { ( } 1 \text { realization) }\end{array}$ & $\begin{array}{l}\text { From SCM } \\
(1 / \alpha=589 \mathrm{~Pa})\end{array}$ & $\begin{array}{l}\text { Small } \\
\text { Thermal } \\
\text { Conduct. }\end{array}$ & 6.2.4.2.2 & $\begin{array}{l}\text { LB0309DSCPTHSM.001 } \\
\text { LB0309DSCPTHSM.002 }\end{array}$ \\
\hline MN-HET-13 & $\begin{array}{l}\text { Reference } \\
\text { Mode }\end{array}$ & 10 & $\begin{array}{l}\text { DS/AFM- } \\
\text { UZ02-Mean }\end{array}$ & $\begin{array}{l}\text { Heterogeneous } \\
\text { ( } 1 \text { realization) }\end{array}$ & $\begin{array}{l}\text { From SCM } \\
(1 / \alpha=589 \mathrm{~Pa})\end{array}$ & $\begin{array}{l}\text { Large } \\
\text { Fracture } \\
\text { Permeab. }\end{array}$ & 6.2.4.2.2 & $\begin{array}{l}\text { LB0309DSCPTHSM.001 } \\
\text { LB0309DSCPTHSM.002 }\end{array}$ \\
\hline MN-HET-14 & $\begin{array}{l}\text { Reference } \\
\text { Mode }\end{array}$ & 10 & $\begin{array}{l}\text { DS/AFM- } \\
\text { UZ02-Mean }\end{array}$ & $\begin{array}{l}\text { Heterogeneous } \\
\text { ( } 1 \text { realization) }\end{array}$ & $\begin{array}{l}\text { From SCM } \\
(1 / \alpha=589 \mathrm{~Pa})\end{array}$ & $\begin{array}{l}\text { Small } \\
\text { Fracture } \\
\text { Permeab. }\end{array}$ & 6.2.4.2.2 & $\begin{array}{l}\text { LB0309DSCPTHSM.001 } \\
\text { LB0309DSCPTHSM.002 }\end{array}$ \\
\hline MN-HET-15 & $\begin{array}{l}\text { Reference } \\
\text { Mode }\end{array}$ & 40 & $\begin{array}{l}\text { DS/AFM- } \\
\text { UZO2-Mean }\end{array}$ & $\begin{array}{l}\text { Heterogeneous } \\
\text { ( } 1 \text { realization) }\end{array}$ & $\begin{array}{l}\text { From SCM } \\
(1 / \alpha=589 \mathrm{~Pa})\end{array}$ & NA & 6.2.4.2.1 & $\begin{array}{l}\text { LB0309DSCPTHSM.001 } \\
\text { LB0309DSCPTHSM.002 }\end{array}$ \\
\hline MN-HET-16 & $\begin{array}{l}\text { Reference } \\
\text { Mode }\end{array}$ & 100 & $\begin{array}{l}\text { DS/AFM- } \\
\text { UZO2-Mean }\end{array}$ & $\begin{array}{l}\text { Heterogeneous } \\
\text { (1 realization) }\end{array}$ & $\begin{array}{l}\text { From SCM } \\
(1 / \alpha=589 \mathrm{~Pa})\end{array}$ & NA & 6.2.4.2.1 & $\begin{array}{l}\text { LB0309DSCPTHSM.001 } \\
\text { LB0309DSCPTHSM.002 }\end{array}$ \\
\hline MN-HET-17 & $\begin{array}{l}\text { Reference } \\
\text { Mode }\end{array}$ & 10 & $\begin{array}{l}\text { DS/AFM- } \\
\text { UZ02-Mean }\end{array}$ & $\begin{array}{l}\text { Heterogeneous } \\
\text { ( } 1 \text { realization) }\end{array}$ & $\begin{array}{l}\text { From SCM } \\
(1 / \alpha=589 \mathrm{~Pa})\end{array}$ & $\begin{array}{l}\text { Diff. Therm. } \\
\text { Cond. F-M } \\
\text { Interface } \\
\end{array}$ & 6.2.4.2.5 & NA (see Section 8.5) \\
\hline MN-HET-18 & $\begin{array}{l}\text { Reference } \\
\text { Mode }\end{array}$ & 10 & $\begin{array}{l}\text { DS/AFM- } \\
\text { UZ02-Mean }\end{array}$ & $\begin{array}{l}\text { Heterogeneous } \\
\text { ( } 1 \text { realization) }\end{array}$ & $\begin{array}{l}\text { From SCM } \\
(1 / \alpha=589 \mathrm{~Pa})\end{array}$ & $\begin{array}{l}\text { Diff. Therm. } \\
\text { Cond. Of } \\
\text { In-Drift } \\
\text { Elements }\end{array}$ & 6.2.4.2.6 & NA (see Section 8.5) \\
\hline MN-HET-19 & $\begin{array}{l}\text { Reference } \\
\text { Mode }\end{array}$ & 10 & $\begin{array}{l}\text { DS/AFM- } \\
\text { UZ02-Mean }\end{array}$ & $\begin{array}{l}\text { Heterogeneous } \\
\text { ( } 1 \text { realization) }\end{array}$ & $\begin{array}{l}\text { From SCM } \\
(1 / \alpha=589 \mathrm{~Pa})\end{array}$ & $\begin{array}{l}\text { Diff. Waste } \\
\text { Package } \\
\text { Therm. } \\
\text { Properties }\end{array}$ & 6.2.4.2.6 & NA (see Section 8.5) \\
\hline
\end{tabular}


Table 6.2.1.6-1. List of Simulation Cases for the Tptpmn Submodel and Tptpll Submodel (Continued)

\begin{tabular}{|c|c|c|c|c|c|c|c|c|}
\hline $\begin{array}{c}\text { Simulation } \\
\text { Case }\end{array}$ & $\begin{array}{c}\text { Thermal } \\
\text { Load }\end{array}$ & $\begin{array}{c}\text { Flux } \\
\text { multiplication } \\
\text { factor }\end{array}$ & Property Set & $\begin{array}{c}\text { Permeability in } \\
\text { Drift Vicinity }\end{array}$ & $\begin{array}{c}\text { Capillary } \\
\text { Strength in Drift } \\
\text { Vicinity } \\
\end{array}$ & $\begin{array}{c}\text { Other } \\
\text { Sensitivity }\end{array}$ & $\begin{array}{r}\text { Section of } \\
\text { this Report }\end{array}$ & Output DTN \\
\hline \multicolumn{9}{|c|}{ Tptpll Submodel } \\
\hline LL-HOM-01 & $\begin{array}{l}\text { Reference } \\
\text { Mode }\end{array}$ & 1 & $\begin{array}{l}\text { DS/AFM- } \\
\text { UZO2-Mean }\end{array}$ & Homogeneous & $\begin{array}{l}\text { From DS-AFM- } \\
\text { UZ02-Mean }\end{array}$ & NA & 6.2.3.1 & NA (see Section 8.5) \\
\hline LL-HET-01 & $\begin{array}{l}\text { Reference } \\
\text { Mode }\end{array}$ & 5 & $\begin{array}{l}\text { DS/AFM- } \\
\text { UZO2-Mean }\end{array}$ & $\begin{array}{l}\text { Heterogeneous } \\
\text { (1 realization) }\end{array}$ & $\begin{array}{l}\text { From SCM } \\
(1 / \alpha=589 \mathrm{~Pa})\end{array}$ & NA & 6.2.3.2.3 & $\begin{array}{l}\text { LB0303DSCPTHSM.001 } \\
\text { LB0301DSCPTHSM.002 }\end{array}$ \\
\hline LL-HET-02 & $\begin{array}{l}\text { Reference } \\
\text { Mode }\end{array}$ & 10 & $\begin{array}{l}\text { DS/AFM- } \\
\text { UZO2-Mean }\end{array}$ & $\begin{array}{l}\text { Heterogeneous } \\
(1 \text { realization })\end{array}$ & $\begin{array}{l}\text { From SCM } \\
(1 / \alpha=589 \mathrm{~Pa})\end{array}$ & NA & 6.2.3.2.3 & $\begin{array}{l}\text { LB0303DSCPTHSM.001 } \\
\text { LB0301DSCPTHSM.002 }\end{array}$ \\
\hline
\end{tabular}

NOTE: $\quad$ Steady-state ambient simulation cases have been studied in addition to the above listed transient thermal simulation cases (see Sections 6.2.2.2.2 and 6.2.3.2.2). These are not given in Table 6.2.1.6-1. 


\subsubsection{Simulation Results for the Tptpmn Submodel}

This subsection of the report presents modeling results for a representative drift located in the Tptpmn geological unit. Discussion of results focuses on the areas in the vicinity of the drift. TH effects in other geological horizons, though accounted for in the model, are not presented here because they are too far from the drift to be relevant to the primary purpose of evaluating thermal seepage. The analysis and discussion will be presented in two main sections, with emphasis on the TH processes and the barrier capabilities, respectively. Section 6.2.2.1 explains the major drift-scale flow phenomena in response to heating of the repository. For this purpose, the TH seepage model is applied without the specific seepage modeling methodology from the ambient seepage model as presented in Section 6.2.1.1.2. Sensitivity is studied with respect to thermal load, infiltration rate, and drift-scale fracture capillary-strength parameter. In the second step, presented in Section 6.2.2.2, the focus is on the seepage during the thermal period, evaluating the combined effectiveness of the vaporization and the capillary barrier. Here, the analysis concentrates on such flow scenarios and properties that tend to promote seepage; i.e., the conceptual model for thermal seepage is utilized using heterogeneous fracture permeability fields and small capillary-strength parameter in the drift vicinity, and large infiltration rates are applied.

\subsubsection{Drift-Scale Thermal-Hydrological Behavior and Sensitivities}

\subsection{Base-Case Simulation}

The primary simulation case with the Tptpmn submodel (base case) for discussion of $\mathrm{TH}$ processes on the drift scale is the following (referred to as Simulation Case MN-HOM-01 in Figure 6.2.1.6-1 and Table 6.2.1.6-1):

Thermal Load: $\quad$ Reference mode $(1.45 \mathrm{~kW} / \mathrm{m}, 86.3$ percent heat removal for 50 years)

Property Set: $\quad$ DS/AFM-UZ02-Mean

Drift-Scale Properties: Similar to DS/AFM-UZ02-Mean (Tptpmn unit), no heterogeneity

Infiltration: $\quad$ Mean infiltration scenario without flow focusing, stepwise change from $6 \mathrm{~mm} / \mathrm{yr}$ to $16 \mathrm{~mm} / \mathrm{yr}$ to $25 \mathrm{~mm} / \mathrm{yr}$, at 600 years and 2,000 years

Figure 6.2.2.1-1 shows the temperature history in the rock directly at the drift crown close to the drift centerline, for a simulation period of 4,000 years. Except for slight differences close to the boiling point of water, the temperatures in fractures and matrix are practically identical. In all temperature plots below, the temperatures presented are those of the fracture continuum. Postclosure temperature quickly climbs above the boiling point. The highest temperature of about $128^{\circ} \mathrm{C}$ is attained at 75 years, shortly after the 50 -year ventilation period has ended. The decay of heat output from the nuclear waste results in slowly decreasing rock temperature from this time on. Rock temperature returns to the boiling point at about 1,000 years after emplacement (boiling temperature at prevailing pressure of the drift horizon is about $96^{\circ} \mathrm{C}$ ). At the end of the displayed time period, rock temperature is still about $65^{\circ} \mathrm{C}$, indicating that the return to ambient temperature after heating takes significantly longer. However, the focus of this analysis is on the first several thousand years after emplacement, since the main TH perturbation 
of the rock occurs during and shortly after the time period in which temperature is above boiling. As seen in Figure 6.2.2.1-2, both the rock matrix and the fractures close to the drift have become completely dry shortly after the preclosure period is over. While the fracture saturation at the drift crown remains zero for about 1,000 years, corresponding to the duration of the boiling period, the rock matrix starts to rewet at about 250 years after emplacement. This early buildup of moisture in the matrix is a result of strong capillarity in the rock, which permits some fraction of liquid to be present in the rock pores even at above-boiling temperatures. Rewetting in the matrix is slower than in the fractures. After 4,000 years, the matrix saturation has almost fully recovered to pre-emplacement values.

The hydrological conditions in the fractures are important for seepage during the thermal period. For seepage to occur, water must accumulate in the fractures at the drift wall so that the capillary barrier related to the open cavity can break. The saturation history displayed in Figure 6.2.2.1-2 demonstrates that thermal effects cause fractures to be completely dry for a time period of about 1,000 years. In the base-case results, there is no evidence that condensate that has been accumulating above the repository during boiling conditions might move downwards subsequent to the boiling period to elevate fracture saturation at the drifts. The stepwise saturation increases shown in Figure 6.2.2.1-2 are mainly a result of the changes in overall net infiltration, from $6 \mathrm{~mm} / \mathrm{yr}$ at present-day climate to $16 \mathrm{~mm} / \mathrm{yr}$ and $25 \mathrm{~mm} / \mathrm{yr}$ at monsoon and glacial transition climate, respectively.

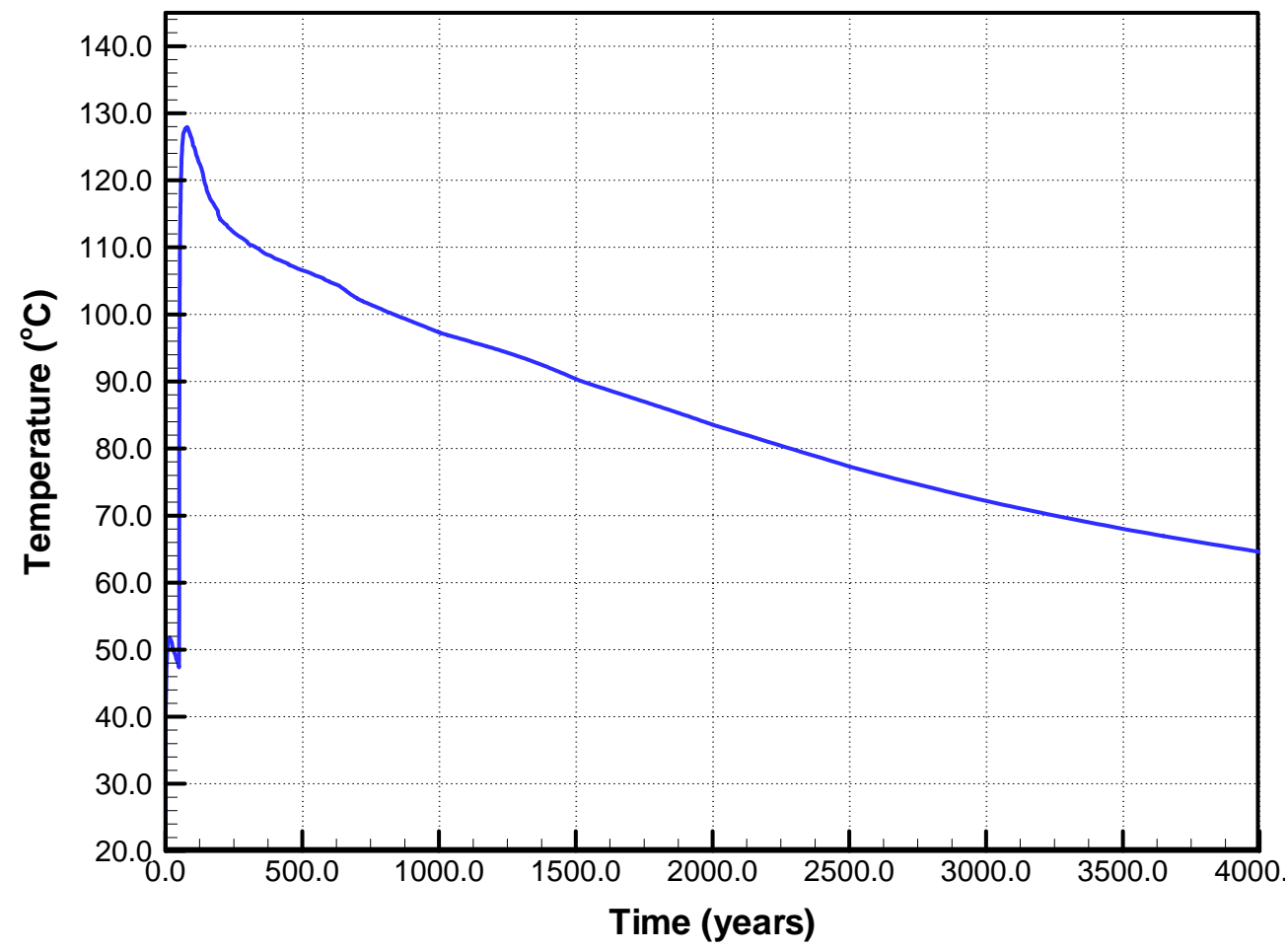

Output DTN: NA (See Section 8.5).

Figure 6.2.2.1-1. Rock Temperature at the Drift Crown for Tptpmn Submodel (Simulation Case MN-HOM-01) 
Contour plots of rock temperature and matrix saturation are given in Figures 6.2.2.1-3 and 6.2.2.1-4, for simulation times of 100 years, 500 years, 1,000 years, and 2,000 years. A steep thermal gradient is established in the radial direction at 100 years of heating, with a temperature of $128^{\circ} \mathrm{C}$ directly at the drift wall and a boiling zone of about $5 \mathrm{~m}$ extent above the drift crown. The maximum distance of the boiling zone is about $6 \mathrm{~m}$ at 500 years, indicating that the region of strong thermal perturbation is limited to the immediate drift vicinity. At later times (1,000 years and 2,000 years), the decay of heat output from the nuclear waste results in steadily declining rock temperatures. The majority of the rock volume between emplacement drifts remains below boiling temperature at all times, ensuring that infiltrating water can drain between drifts without being blocked by a continuously extending boiling zone. At 2,000 years, temperature has almost equilibrated across the repository horizon, with a temperature of $84^{\circ} \mathrm{C}$ at the drift wall and $77^{\circ} \mathrm{C}$ at the centerline between drifts. Matrix saturation shows intense drying at early heating stages, with the extent of the dryout zone peaking at about 500 years. Little saturation buildup is evident in the rock region outside of the dryout zone, indicating that the majority of the condensate is carried away in the fractures. Note that the wedges at the top and bottom left side of Figures 6.2.2.1-3 and 6.2.2.1-4 (and also in Figures 6.2.2.1-5 and 6.2.2.1-6 later on) are artifacts of the plotting software.

Thermally induced movement of water and gas flow occurs primarily in the fractures. As rock water in the matrix boils off, vapor is driven into the fractures and away from the boiling zone. Condensation causing water saturation to build up may lead to highly elevated water fluxes in the fractures. The fracture saturation contours and flux vectors in Figures 6.2.2.1-5 and 6.2.2.1-6 illustrate this behavior. Note that the size of the vectors correlates with the flux magnitude at the interfaces between gridblocks of the numerical mesh. Interface fluxes are a direct output of the integral-finite-difference simulator TOUGH2 V1.6 (LBNL 2003 [DIRS 161491]).

Figure 6.2.2.1-5 shows that flow of water in the fractures happens around the dryout zone at 100 years and 500 years after emplacement. Although saturation buildup is only a few percent in the condensation zone above the drift, it is enough to increase water fluxes considerably compared to the ambient downward flow (the magnitude of undisturbed downward flow corresponds to the small vertical flux vectors far away from the drift). Strong reflux of about 60 to $70 \mathrm{~mm} / \mathrm{yr}$ magnitude from the condensation zone back to the dryout region can be seen at 100 years, driven by the capillary gradient and by gravity. This water vaporizes, and a region of vapor-liquid counterflow develops (i.e., a heat pipe). A smaller, but still significant amount of condensate flows around the dryout zone and percolates downward, effectively removing water from the drift vicinity. At 500 years, similar flow processes occur, but the magnitude is smaller. The strongest flux perturbation occurs at early heating stages when the thermal load is intense. Note that there is no water flux inside the dryout region, because fracture saturation is zero. Saturation below the drift is smaller than above, indicating that the open drift creates a "shadow zone" of reduced moisture beneath it.

At 1,000 years (see Figure 6.2.2.1-6), the flow regime is in a transition state from a thermally perturbed system to an ambient system. The dryout zone has receded to a very small region around the drifts, and no saturation buildup is visible outside of this region. The flux vectors show a fairly uniform flow field, with all fluxes similar to the ambient downward percolation of $16 \mathrm{~mm} / \mathrm{yr}$. (Note that the ambient infiltration increases from $6 \mathrm{~mm} / \mathrm{yr}$ to $16 \mathrm{~mm} / \mathrm{yr}$ at 600 years because of an imposed climate change.) Finally, at 2,000 years (see Figure 6.2.2.1-6), the 
fracture saturations and flux vectors represent an ambient flow system, where the fractures close to the drift wall have rewetted and flow is diverted around the drift as a result of the capillary barrier capability of the drift opening. This is evident from the slightly elevated fracture saturation directly above the drift, and by the flux vectors showing water flow around the drift opening. Similar flow behavior was obtained in a number of studies on ambient seepage into drifts (Birkholzer et al. 1999 [DIRS 105170], p. 363; BSC 2004 [DIRS 167652], Figures 6-14 and 6-16).

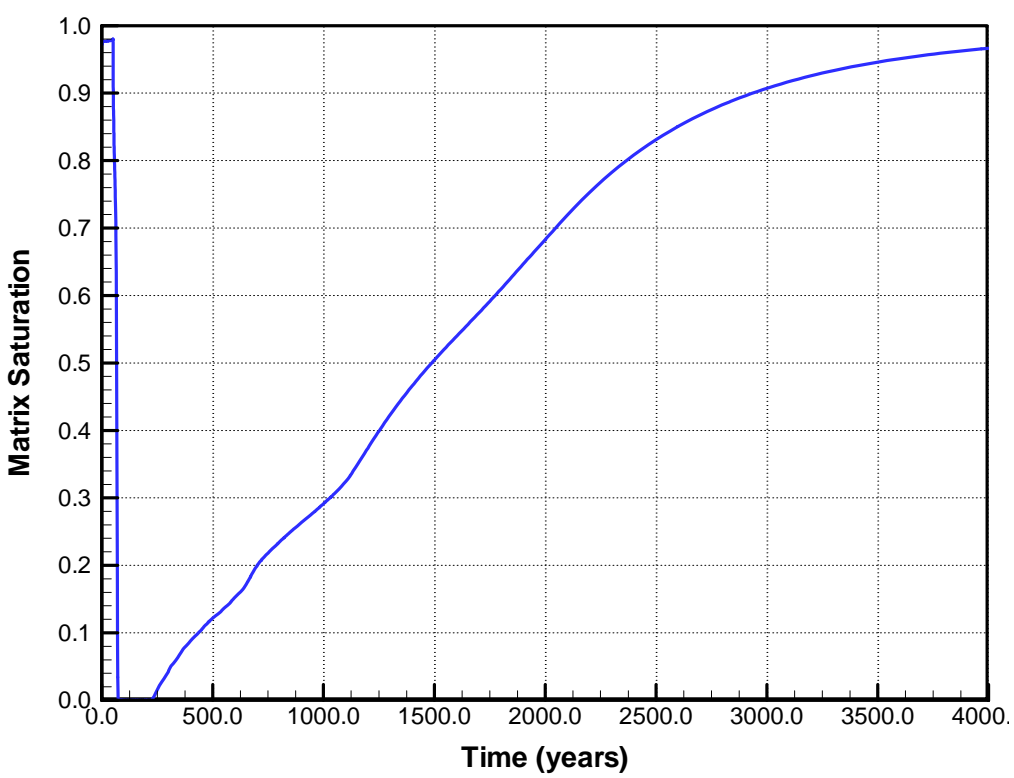

(a)

Time (years)

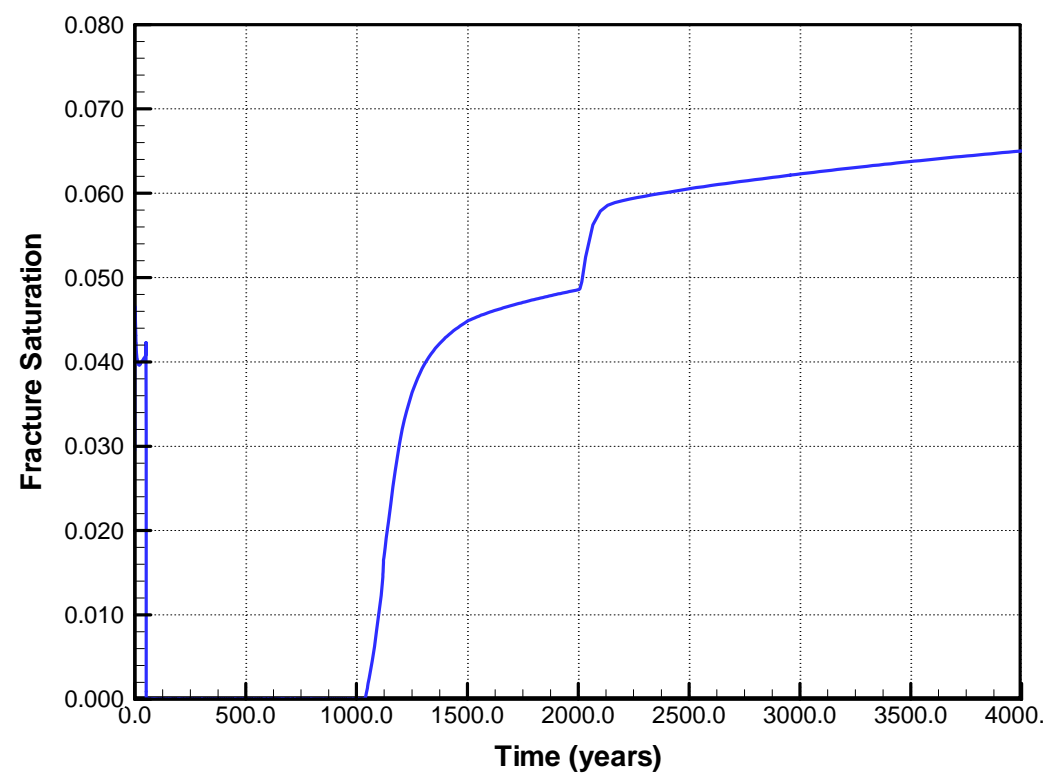

(b)

Time (years)

Output DTN: NA (See Section 8.5).

Figure 6.2.2.1-2. (a) Matrix Saturation and (b) Fracture Saturation at the Drift Crown for Tptpmn Submodel (Simulation Case MN-HOM-01) 


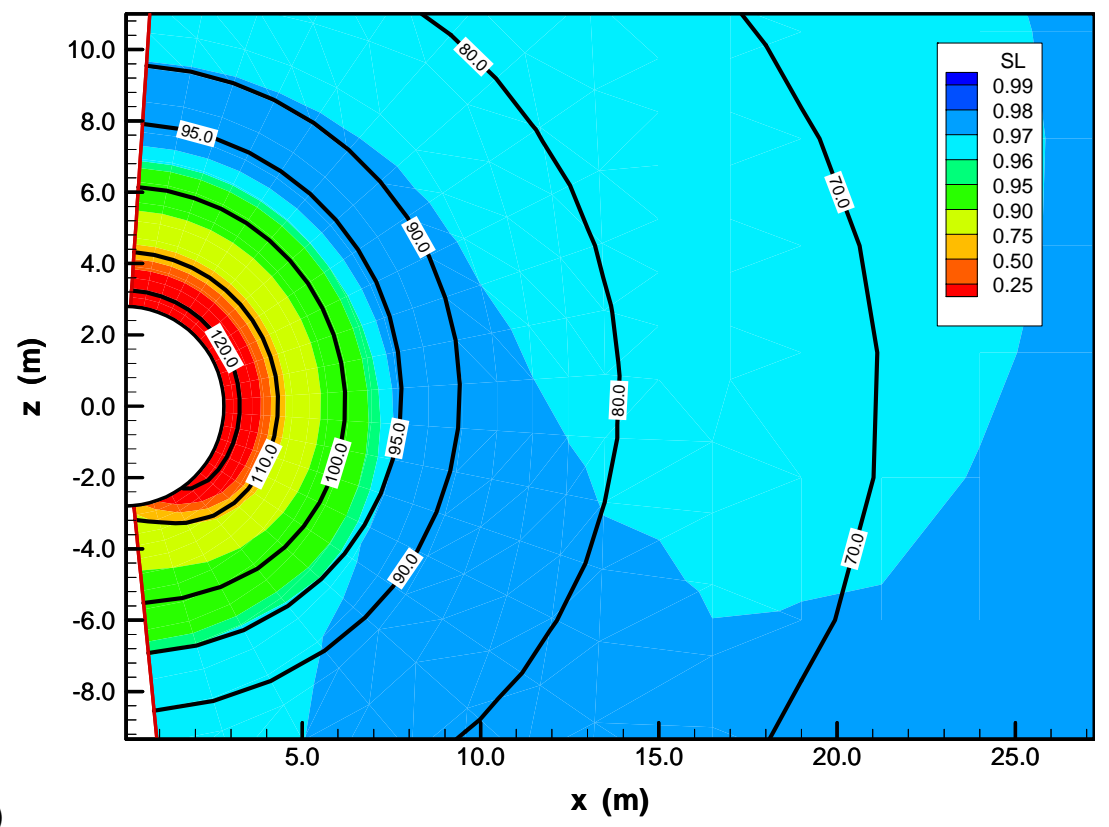

(a)

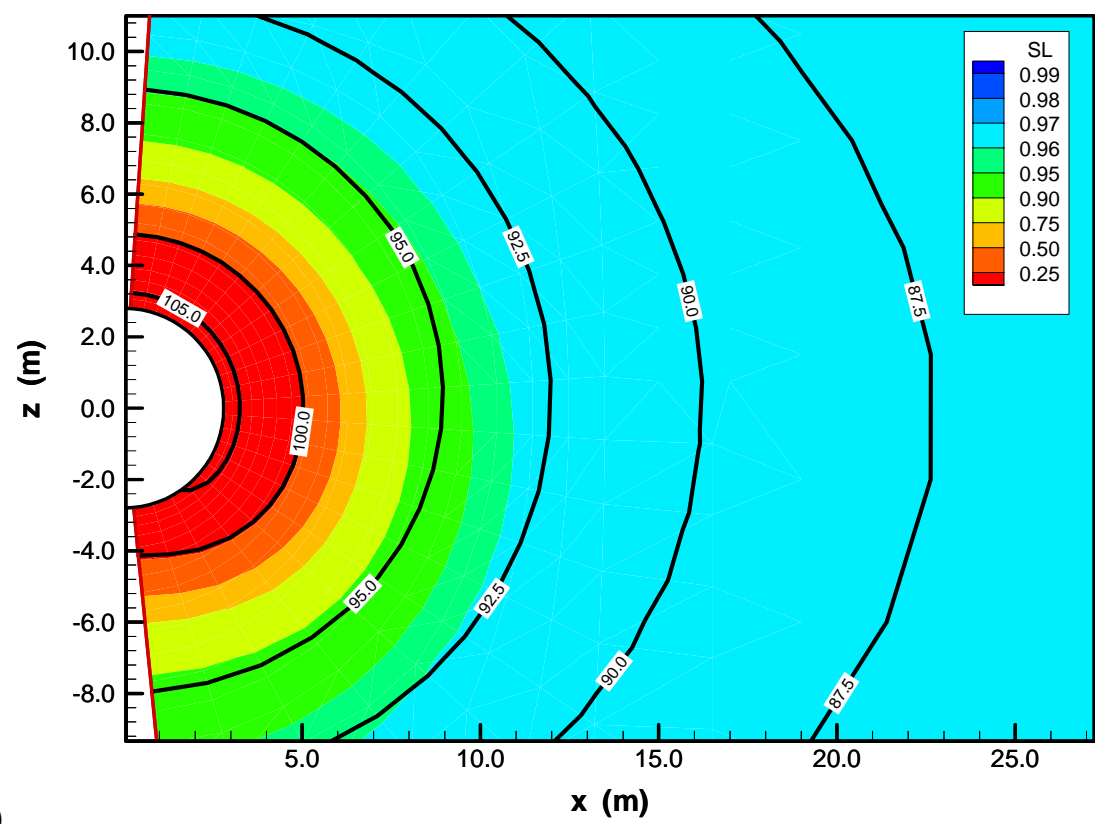

(b)

Output DTN: NA (See Section 8.5).

NOTE: SL denotes liquid saturation. Contoured areas show saturation, lines show temperature.

Figure 6.2.2.1-3. Matrix Saturation and Temperature for Tptpmn Submodel (Simulation Case MN-HOM-01) at (a) 100 Years and (b) 500 Years after Emplacement 


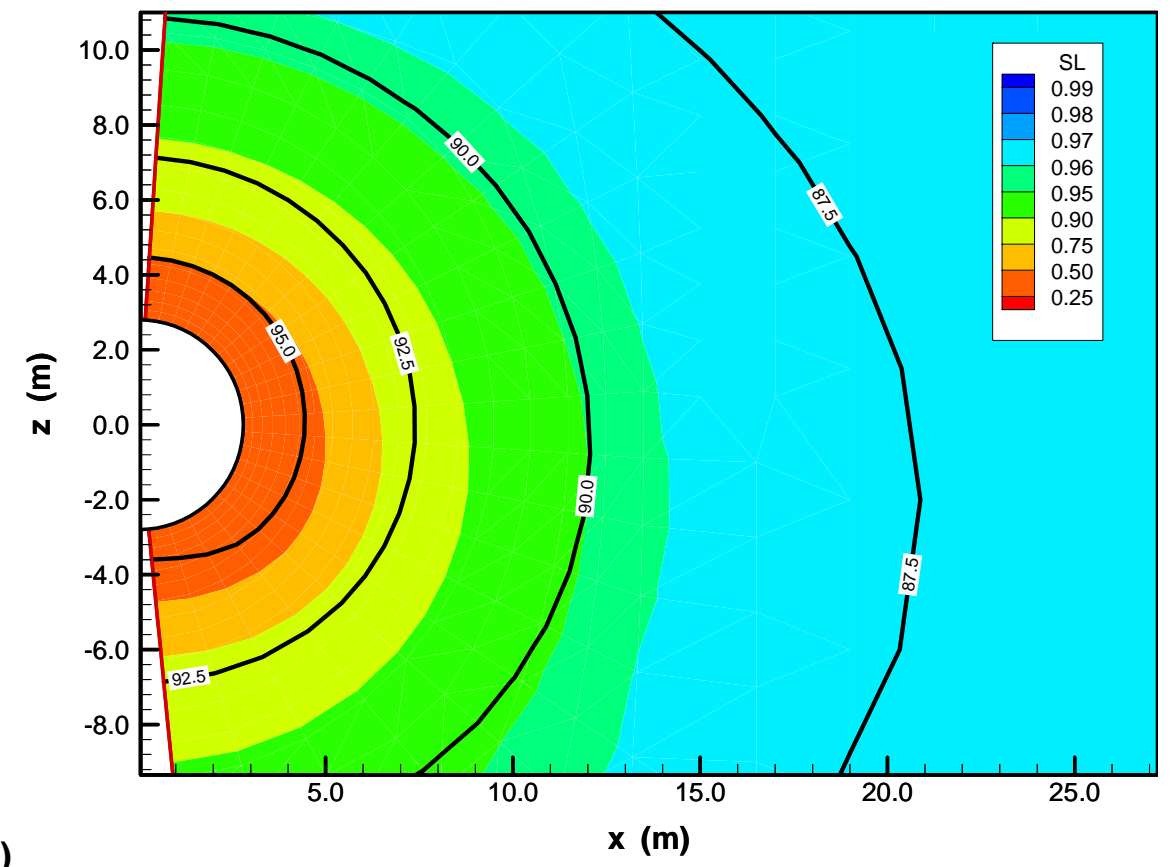

(a)

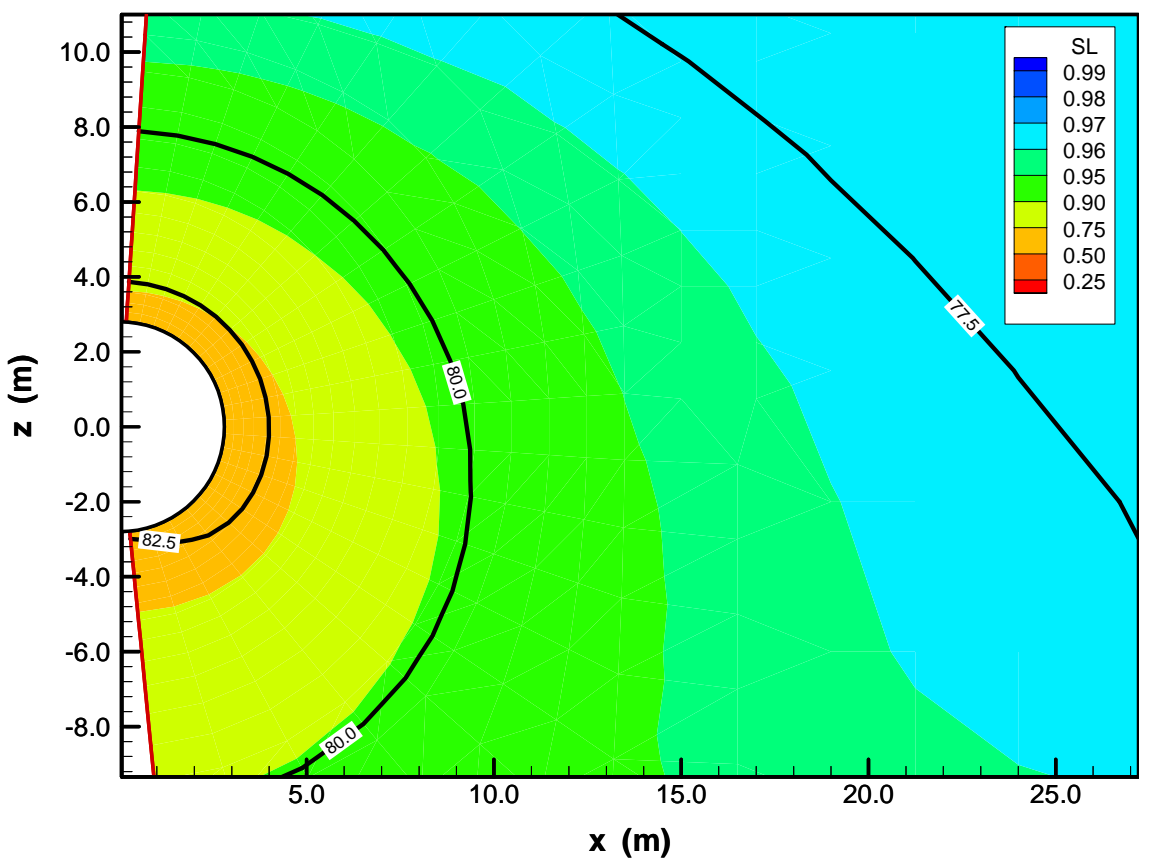

(b)

Output-DTN: NA (See Section 8.5).

NOTE: SL denotes liquid saturation. Contoured areas show saturation, lines show temperature.

Figure 6.2.2.1-4. Matrix Saturation and Temperature for Tptpmn Submodel (Simulation Case $\mathrm{MN}-\mathrm{HOM}-01$ ) at (a) 1,000 Years and (b) 2,000 Years after Emplacement 
Figure 6.2.2.1-7 allows for a more quantitative comparison of the fracture flow field above the drift. Saturation and downward flux are plotted along a vertical line above the drift crown, close to the drift centerline. The maximum downward flux of about $67 \mathrm{~mm} / \mathrm{yr}$ occurs at 100 years of heating just outside the dryout zone. This value is about 11 times larger than the ambient percolation of $6 \mathrm{~mm} / \mathrm{yr}$. At 500 years, downward flow is elevated by a factor of about 5 (compared to the ambient percolation of $6 \mathrm{~mm} / \mathrm{yr}$ ); at 1,000 years, downward flow is elevated by a factor of about 2 (compared to the ambient percolation of $16 \mathrm{~mm} /$ year). No flux elevation is evident at 2,000 years, when thermal effects on fracture flow have become marginal.

In summary, the following conclusions can be reached from the TH modeling analysis presented in this section:

- Fractures close to the drift are essentially dry as long as the temperature is above boiling (for about 1,000 years).

- The majority of vaporized and subsequently condensed matrix water is diverted around the dryout zone and drains down away from the drift.

- Maximum downward flow from the condensation zone back to the boiling zone occurs (at about 100 years) when heating is intense and the vaporization barrier is most effective.

- Downward percolation in the rock area between emplacement drifts is hardly affected by the thermal perturbation in the drift vicinity. 


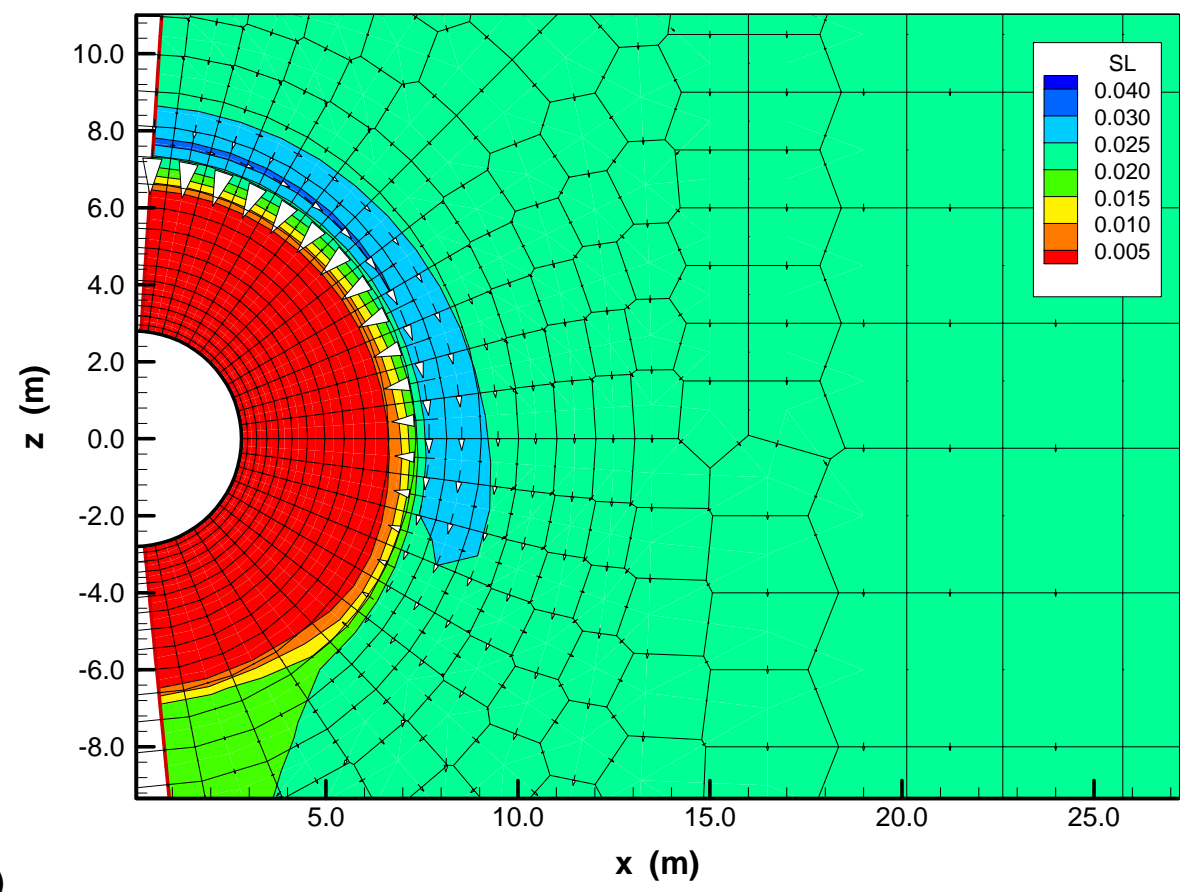

(a)

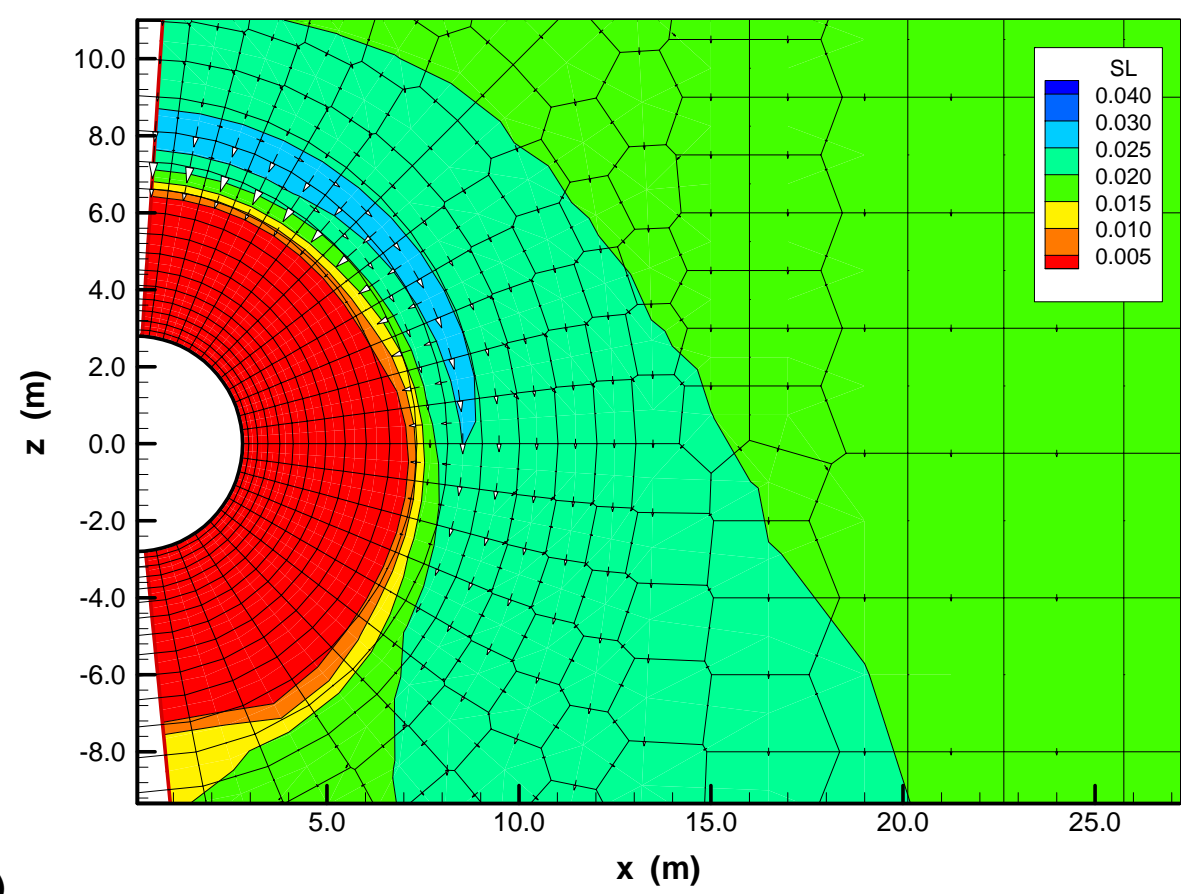

(b)

Output DTN: NA (See Section 8.5).

NOTE: SL denotes liquid saturation.

Figure 6.2.2.1-5. Fracture Saturation and Liquid Flux for Tptpmn Submodel (Simulation Case MN-HOM-01) at (a) 100 Years and (b) 500 Years after Waste Emplacement 


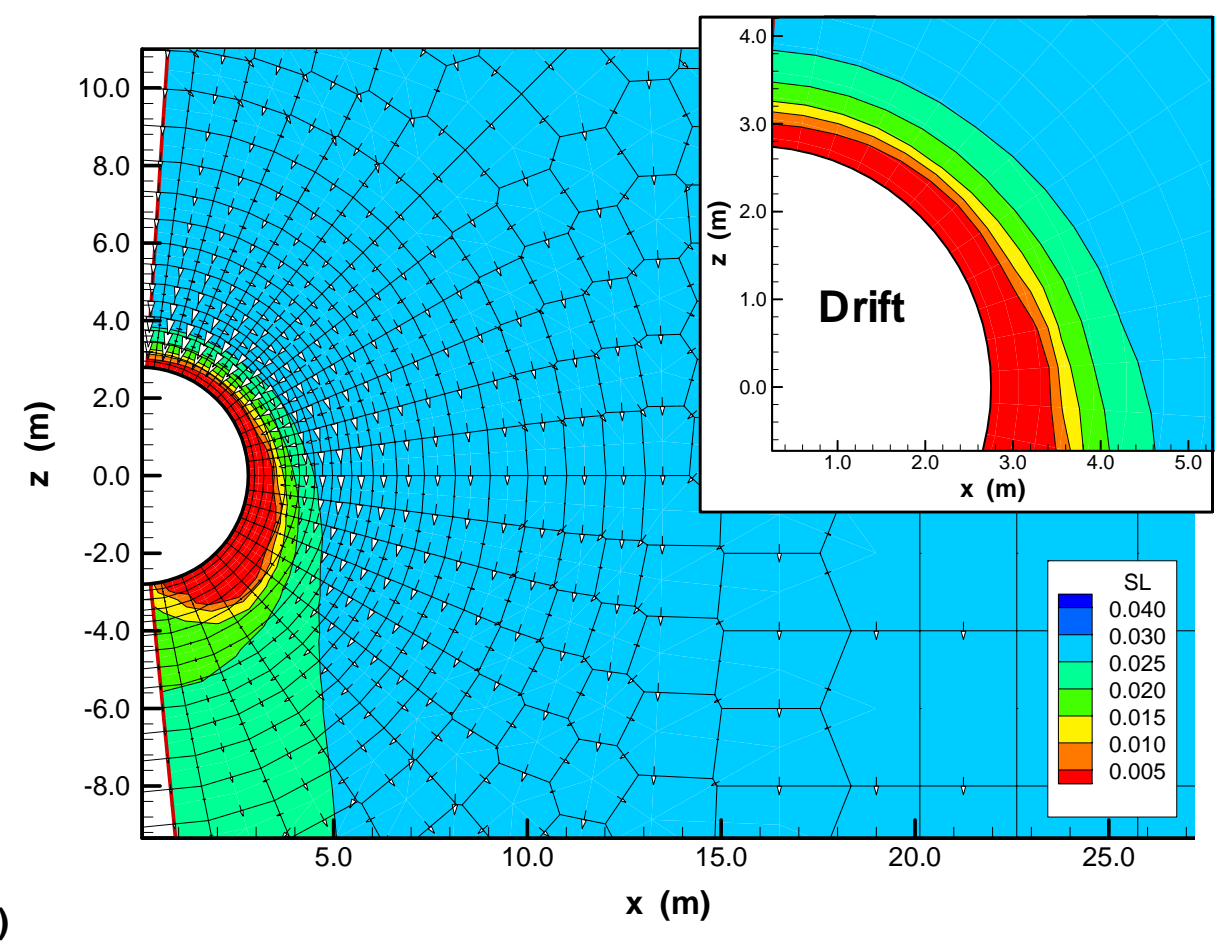

(a)

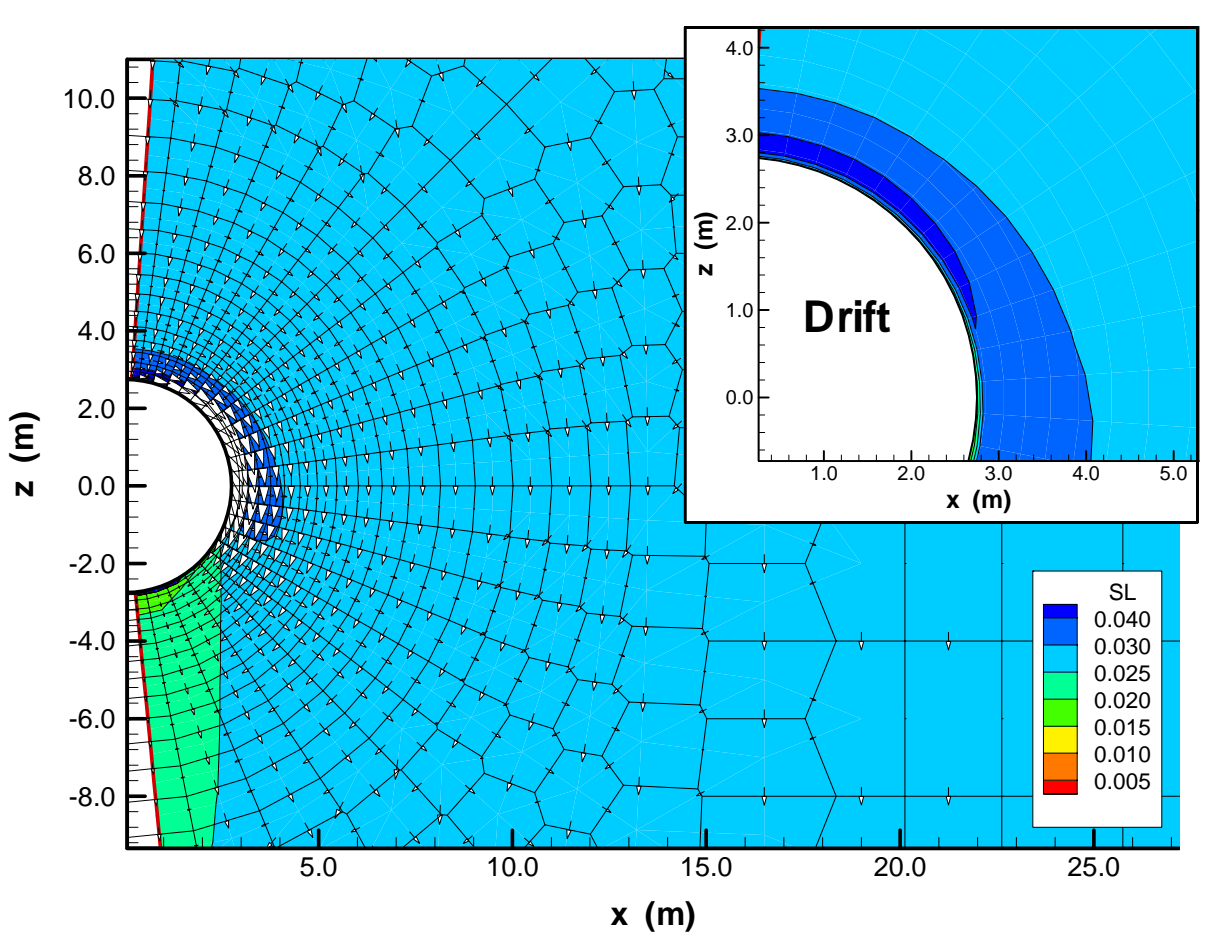

Output DTN: NA (See Section 8.5).

NOTE: SL denotes liquid saturation. The small frame shows a close-up view of the upper right drift vicinity.

Figure 6.2.2.1-6. Fracture Saturation and Liquid Flux for Tptpmn Submodel (Simulation Case MN-HOM-01) at (a) 1,000 Years and (b) 2,000 Years after Waste Emplacement 


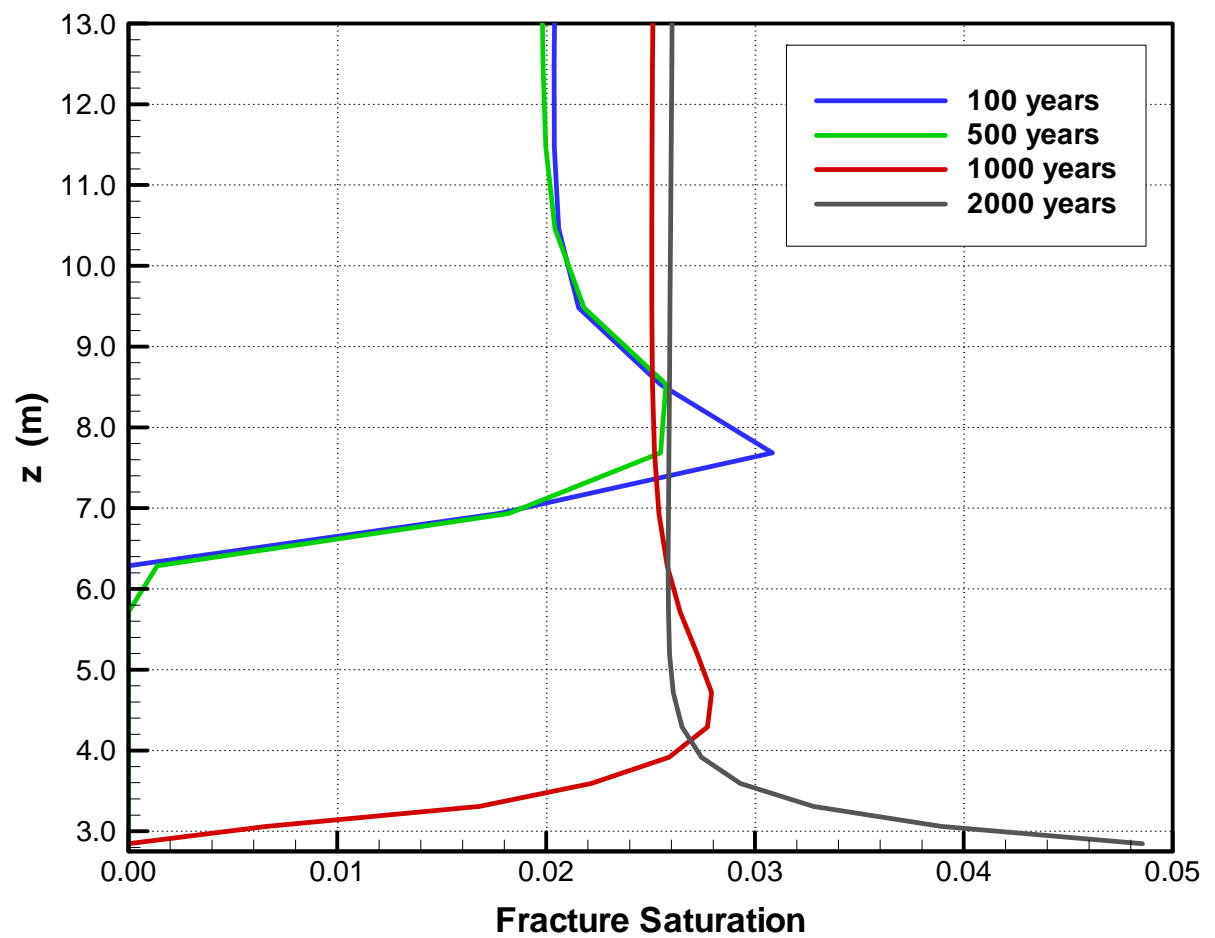

(a)

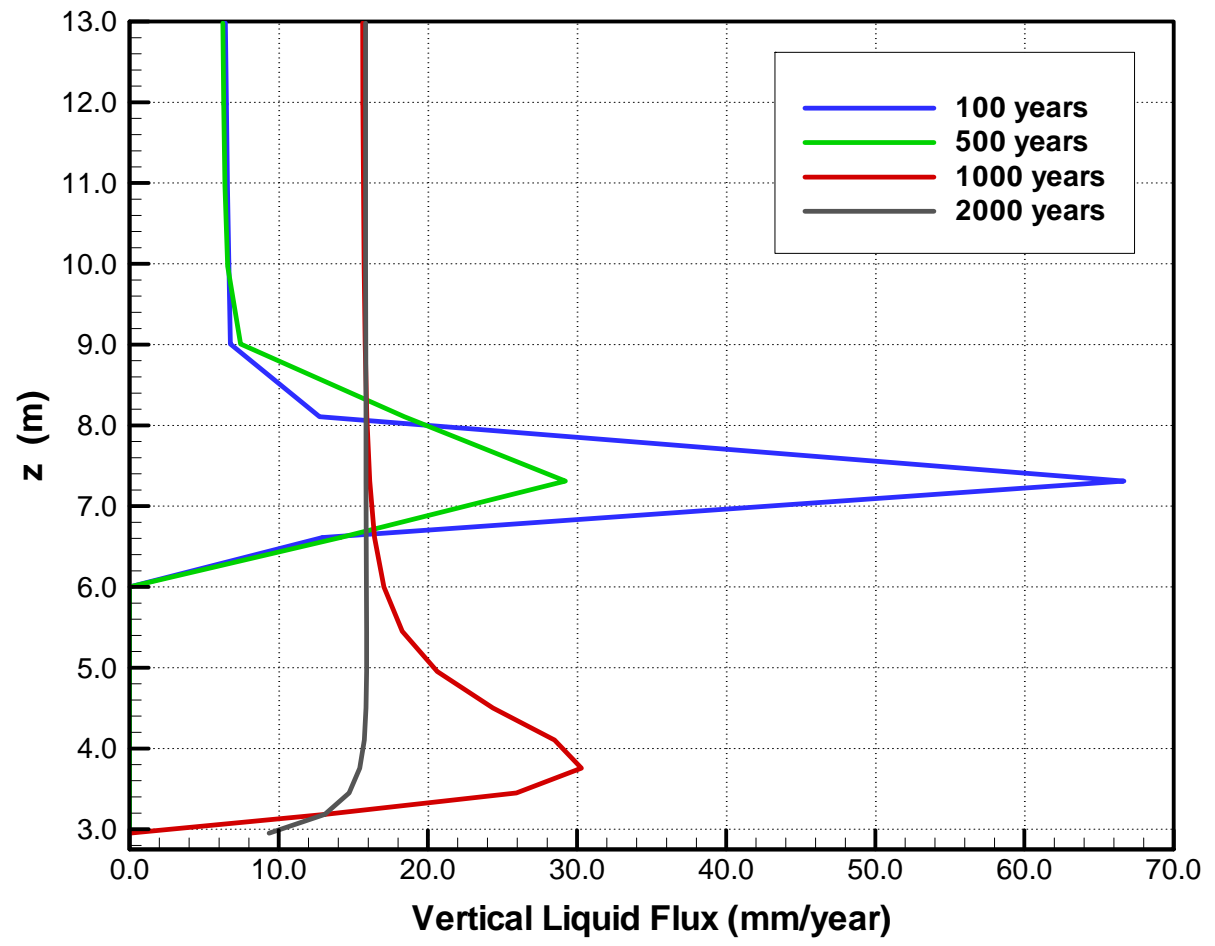

(b)

Output DTN: NA (See Section 8.5).

NOTE: The drift crown is located at $z=2.75 \mathrm{~m}$.

Figure 6.2.2.1-7. (a) Fracture Saturation and (b) Vertical Liquid Flux in a Vertical Cross Section above Drift Crown for Tptpmn Submodel (Simulation Case MN-HOM-01) 


\subsection{Sensitivity to Percolation Flux}

The simulation cases studied in this section are different from those analyzed in Section 6.2.2.1.1, in that flux multiplication factors of 5 and 10 are used to multiply the mean infiltration value. Thus, for the first factor, average downward flow is $30 \mathrm{~mm} / \mathrm{yr}$ for the first 600 years, $80 \mathrm{~mm} / \mathrm{yr}$ between 600 and 2,000 years, and $125 \mathrm{~mm} / \mathrm{yr}$ after 2,000 years (Simulation Case MN-HOM-02, see Table 6.2.1.6-1). For the second factor, average downward flow is 60 $\mathrm{mm} / \mathrm{yr}$ for the first 600 years, $160 \mathrm{~mm} / \mathrm{yr}$ between 600 and 2,000 years, and $250 \mathrm{~mm} / \mathrm{yr}$ after 2,000 years (Simulation Case MN-HOM-03, see Table 6.2.1.6-1).

Figure 6.2.2.1-8 shows the rock temperature history directly at the drift crown for the two flux multiplication cases compared to the base case. Simulation is performed for the first 2,000 years after emplacement (simulation till 4,000 years was not needed as the rock returned to almost ambient conditions within 2,000 years; see discussion regarding Figure 6.2.2.1-9). Increased infiltration gives rise to a reduction in temperature, and the duration of the above-boiling period is smaller than in the base case. Also, increased infiltration gives rise to distinct heat-pipe signatures (see Section 6.1.1) in the temperature data-i.e., temperature remains at the boiling-point of water for some time-indicating two-phase conditions with presence of both water and vapor. While the differences in peak temperature are only a few degrees centigrade, temperature at 2,000 years differs as much as $30^{\circ} \mathrm{C}$ between the factor-10-case and the base case.

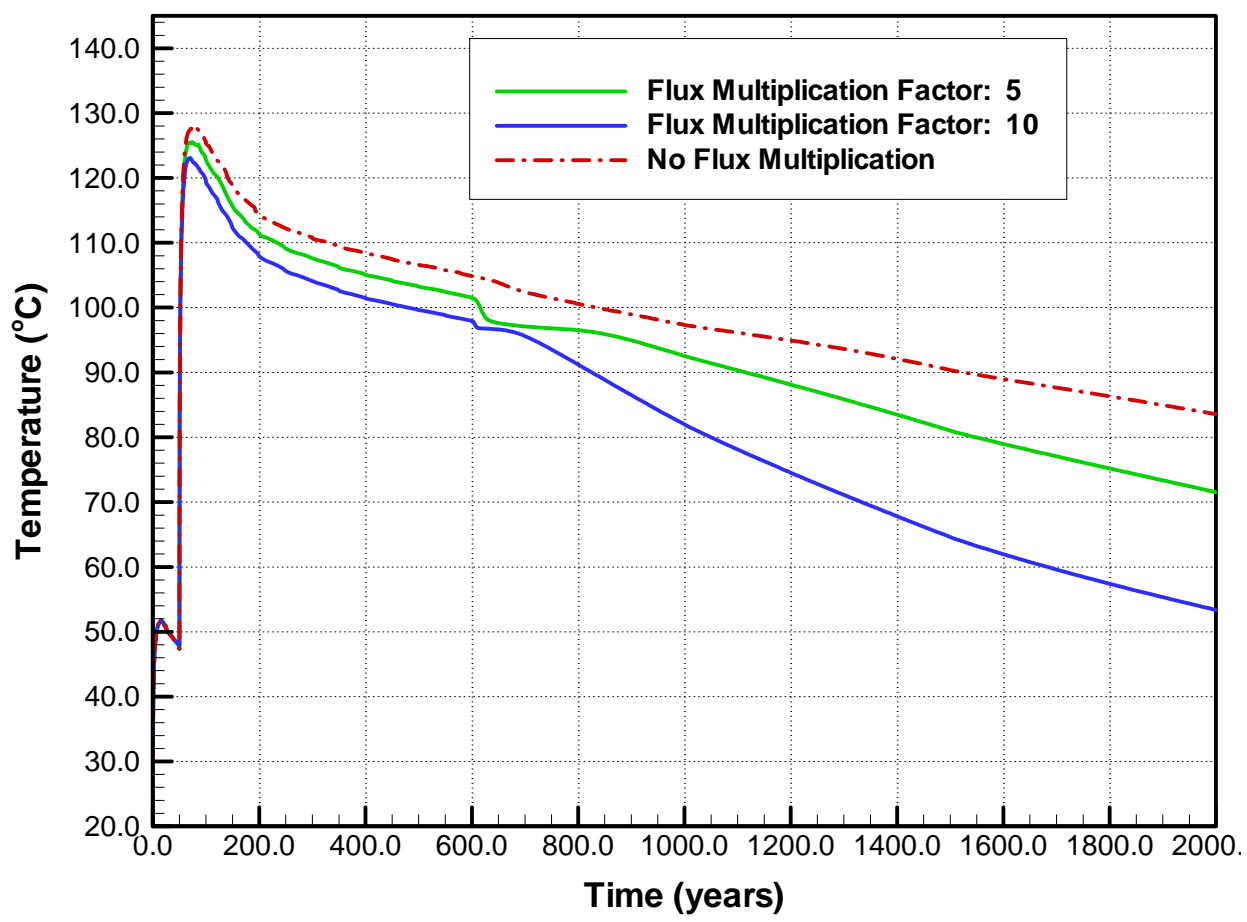

Output DTN: NA (See Section 8.5).

NOTE: The simulation cases are MN-HOM-02 and MN-HOM-03 compared to MN-HOM-01.

Figure 6.2.2.1-8. Rock Temperature at the Drift Crown for Tptpmn Submodel with Different Infiltration Scenarios 
The evolution of matrix and fracture saturation in the rock just above the drift crown is depicted in Figure 6.2.2.1-9. Both flux multiplication cases exhibit a time period in which matrix and fractures are completely dry, though this time period is shorter and the buildup of saturation after dryout is faster in the base case. At 2,000 years, the matrix saturations have almost returned to their initial values (recollect that, for the base case simulations with no flow multiplication, it takes almost 4,000 years for the matrix saturations to regain their initial saturations; see for example Figure 6.2.2.1-2(a)). Fracture saturation at 2,000 years is higher than the initial saturation before heating, corresponding to the increases in percolation from climate changes. Maximum saturation values are 10 percent for the factor- 5 case and 15 percent for the factor- 10 case, compared to about 5 percent for the mean infiltration case. All these values are significantly smaller than the threshold saturation for seepage, which is about 50 percent (see Section 6.2.2.2.2).

Figures 6.2.2.1-10 and 6.2.2.1-11 show vertical profiles of fracture saturation and downward flux above the drift crown for the two flux multiplication cases. (These figures should be compared to the base-case situation depicted in Figure 6.2.2.1-7.) In both cases, only the first two time steps at 100 and 500 years are affected by heating. The extent of the dryout rock zone is smaller than in the base case, between $2 \mathrm{~m}$ and $3 \mathrm{~m}$ at maximum. The maximum downward flux in the factor- 5 case is about $115 \mathrm{~mm} / \mathrm{yr}$ at 100 years of heating. This is slightly larger than the average percolation flux for the monsoon climate $(80 \mathrm{~mm} / \mathrm{yr})$, but smaller than the average percolation flux for the glacial transition climate $(125 \mathrm{~mm} / \mathrm{yr})$. Similar behavior is seen in the factor-10 case. Here, the maximum downward flux during the boiling period is about $155 \mathrm{~mm} / \mathrm{yr}$ at 100 years after emplacement, which is smaller than the percolation rates for both monsoon and glacial transition climate (i.e., $160 \mathrm{~mm} / \mathrm{yr}$ from 600 to 2,000 years, $250 \mathrm{~mm} / \mathrm{yr}$ after 2,000 years). Apparently, the impact of heating on downward flow above the drifts is smaller than the impact of the climate change. Even if there were no vaporization barrier, seepage would more likely occur at late time periods as a result of increased long-term infiltration than at early heating stages as a result of thermally enhanced downward flow.

The saturation and flux profiles at 1,000 and 2,000 years demonstrate that the flow field has returned to an ambient situation. Fractures have rewetted at the drift wall, and saturation has built up locally as a result of the capillary barrier of the drift opening. The vertical fluxes are equal to the average percolation of $80 \mathrm{~mm} / \mathrm{yr}$ except in the immediate vicinity of the drift, where flow is diverted sideways.

The following conclusions can be reached from the TH modeling analysis applying different infiltration scenarios:

- Elevated infiltration as a result of flow focusing leads to cooler temperatures and a shorter boiling period.

- No water reaches the drift in the fractures as long as temperature is above boiling (about 600 to 700 years after emplacement).

- The relative impact of heating on downward flow is less significant than in the base-case scenario. The maximum downward flux during the above-boiling period is in fact smaller than the long-term percolation flux assumed for the glacial transition climate. 


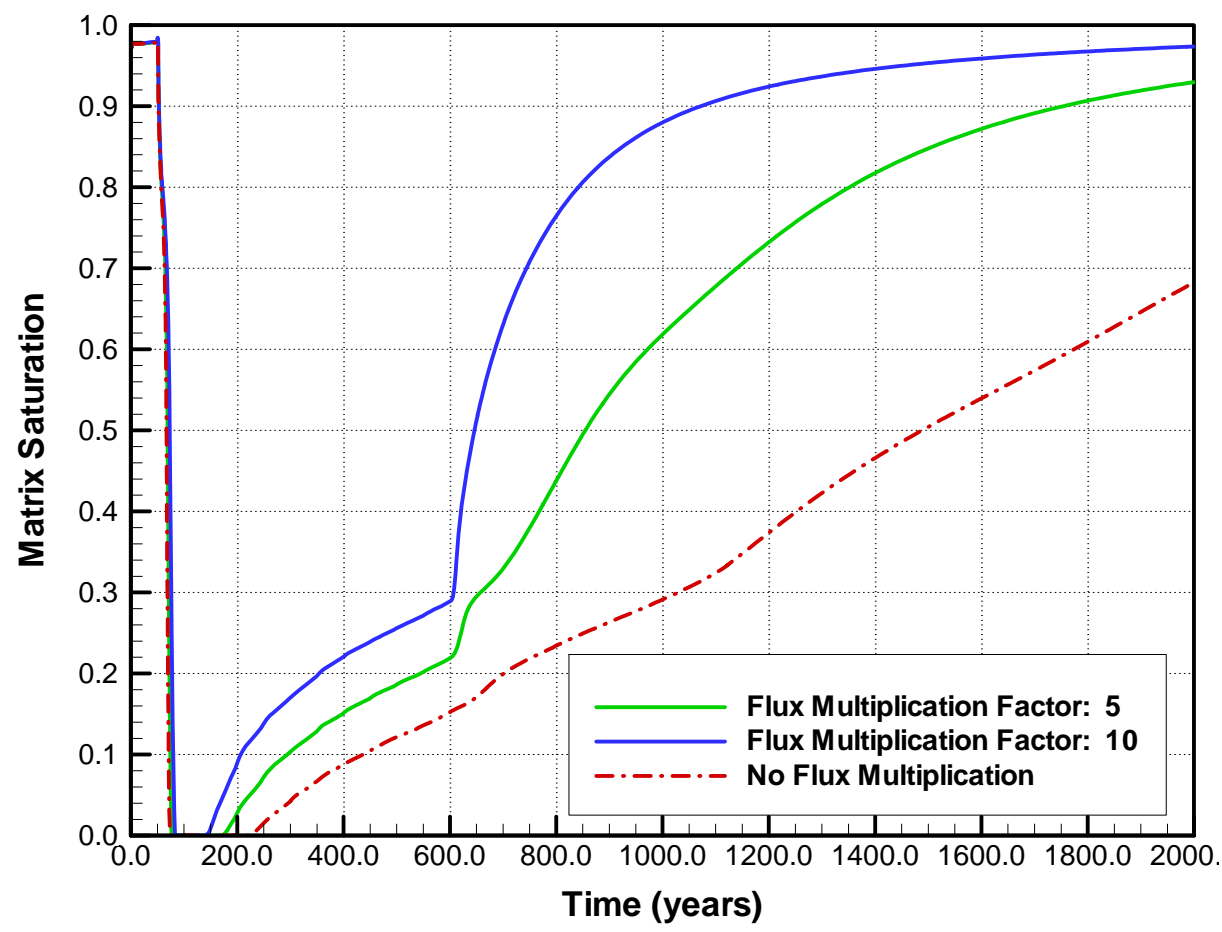

(a)

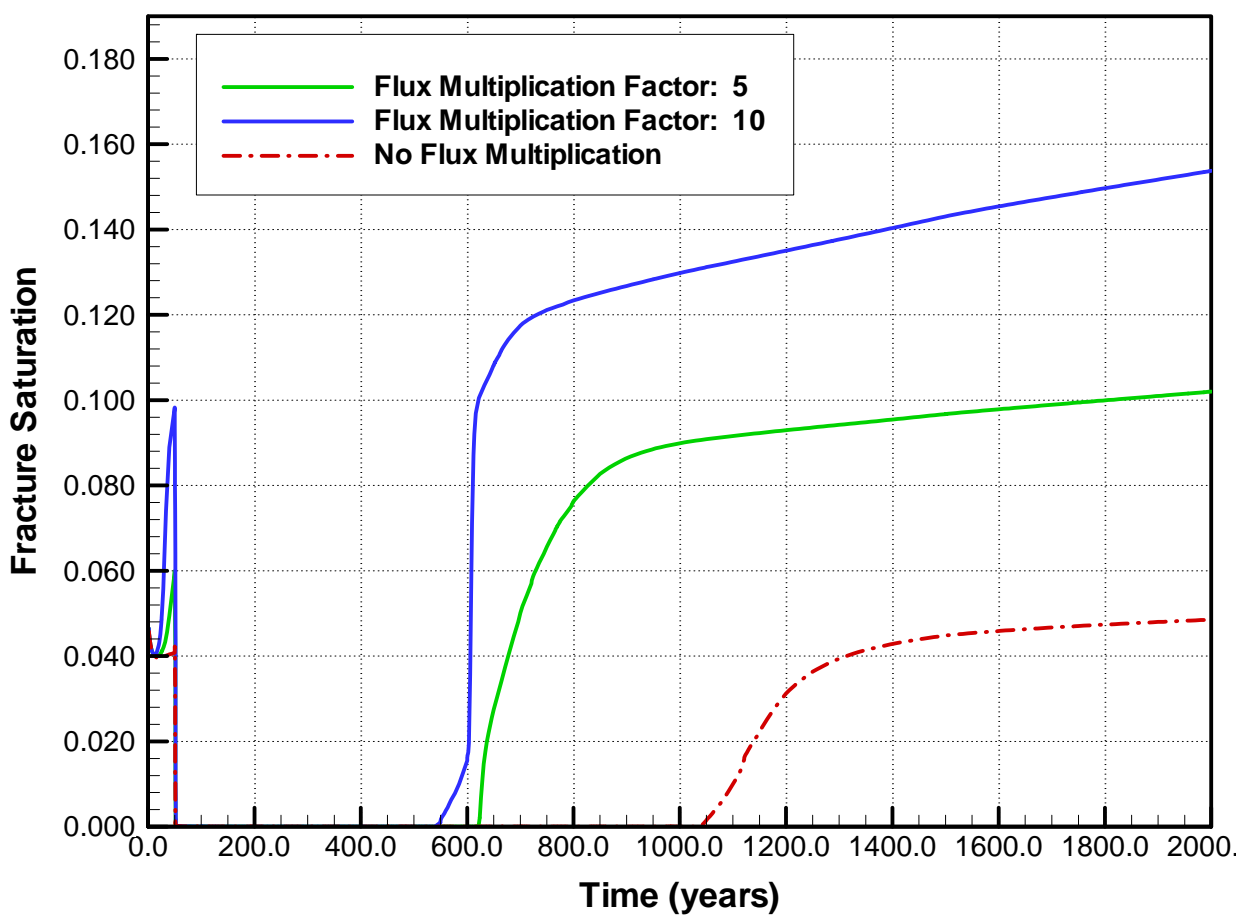

(b)

Output DTN: NA (See Section 8.5).

NOTE: The simulation cases are MN-HOM-02 and MN-HOM-03 compared to MN-HOM-01.

Figure 6.2.2.1-9. (a) Matrix Saturation and (b) Fracture Saturation at the Drift Crown for Tptpmn Submodel with Different Infiltration Scenarios 


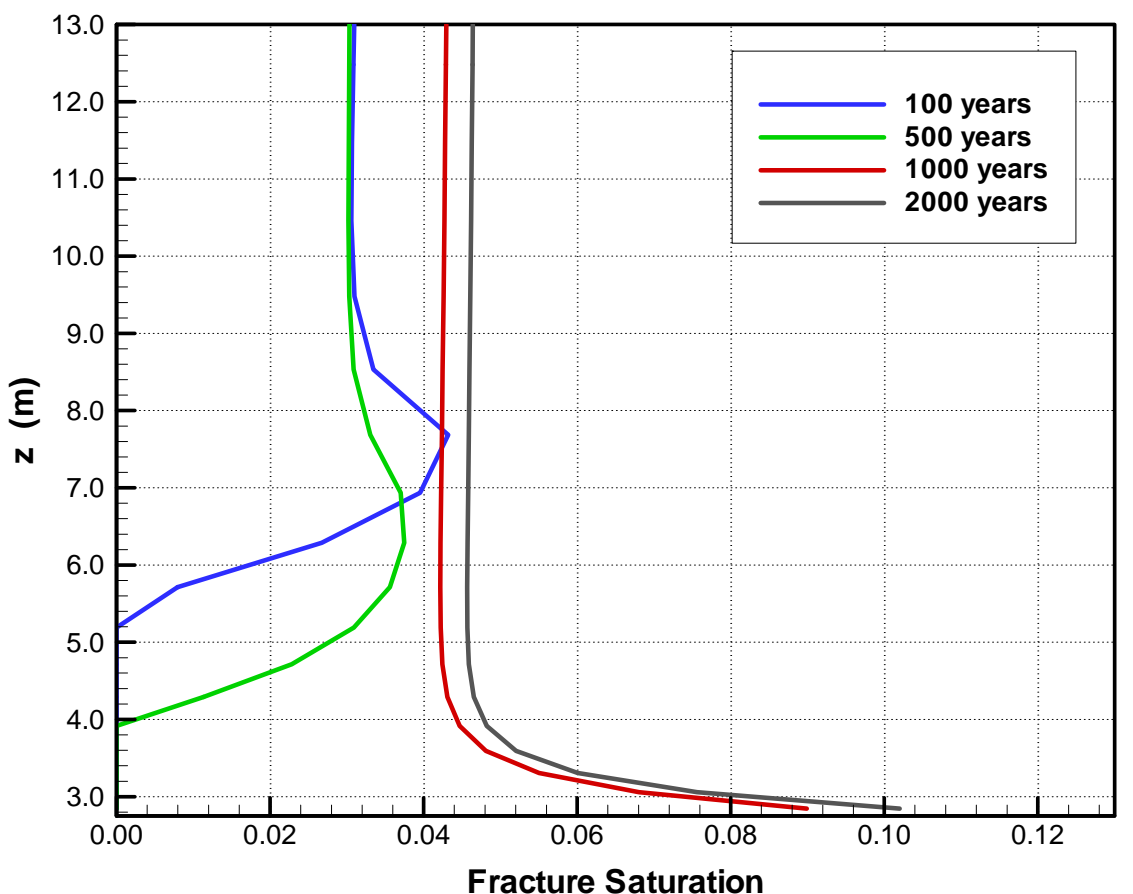

(a)

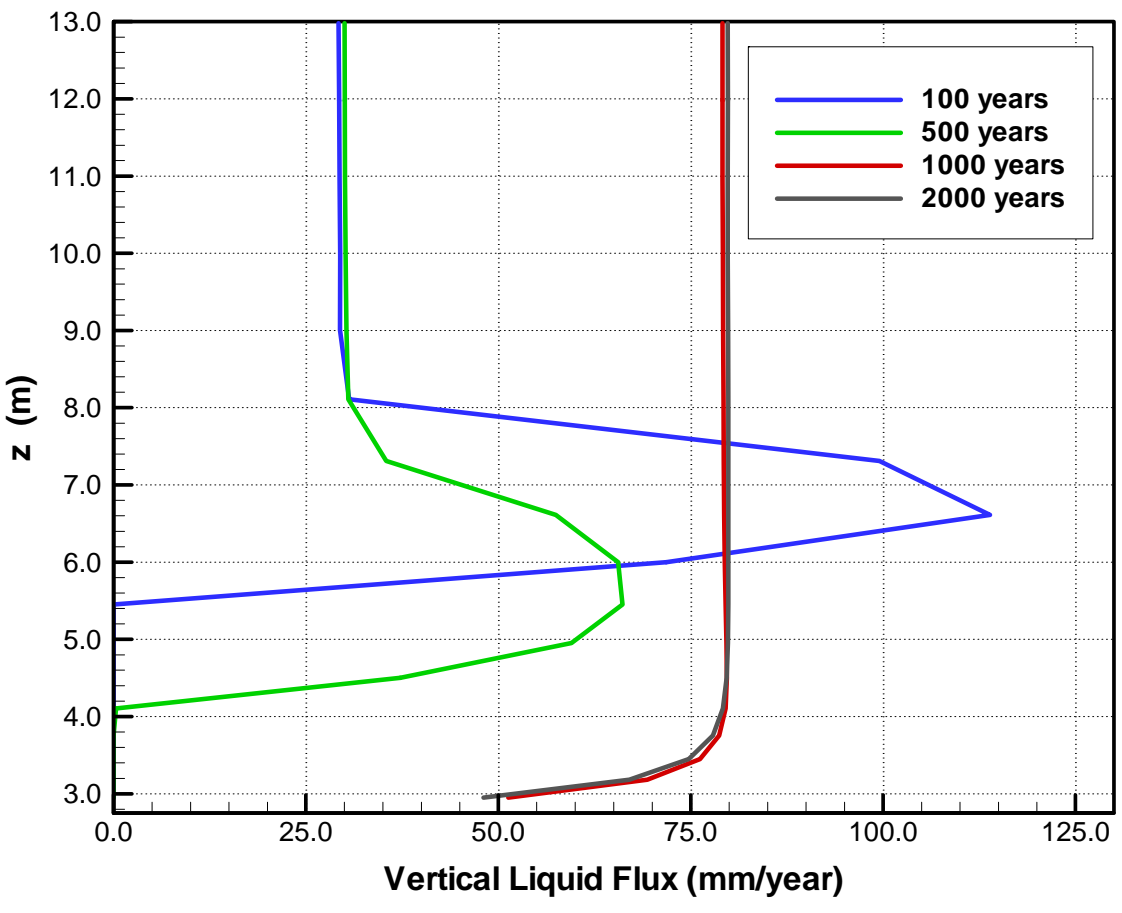

(b)

Output DTN: NA (See Section 8.5).

NOTE: The drift crown is located at $z=2.75 \mathrm{~m}$.

Figure 6.2.2.1-10. (a) Fracture Saturation and (b) Vertical Liquid Flux in a Vertical Cross Section above Drift Crown, for Tptpmn Submodel with a Flux Multiplication Factor of 5 (Simulation Case MN-HOM-02) 


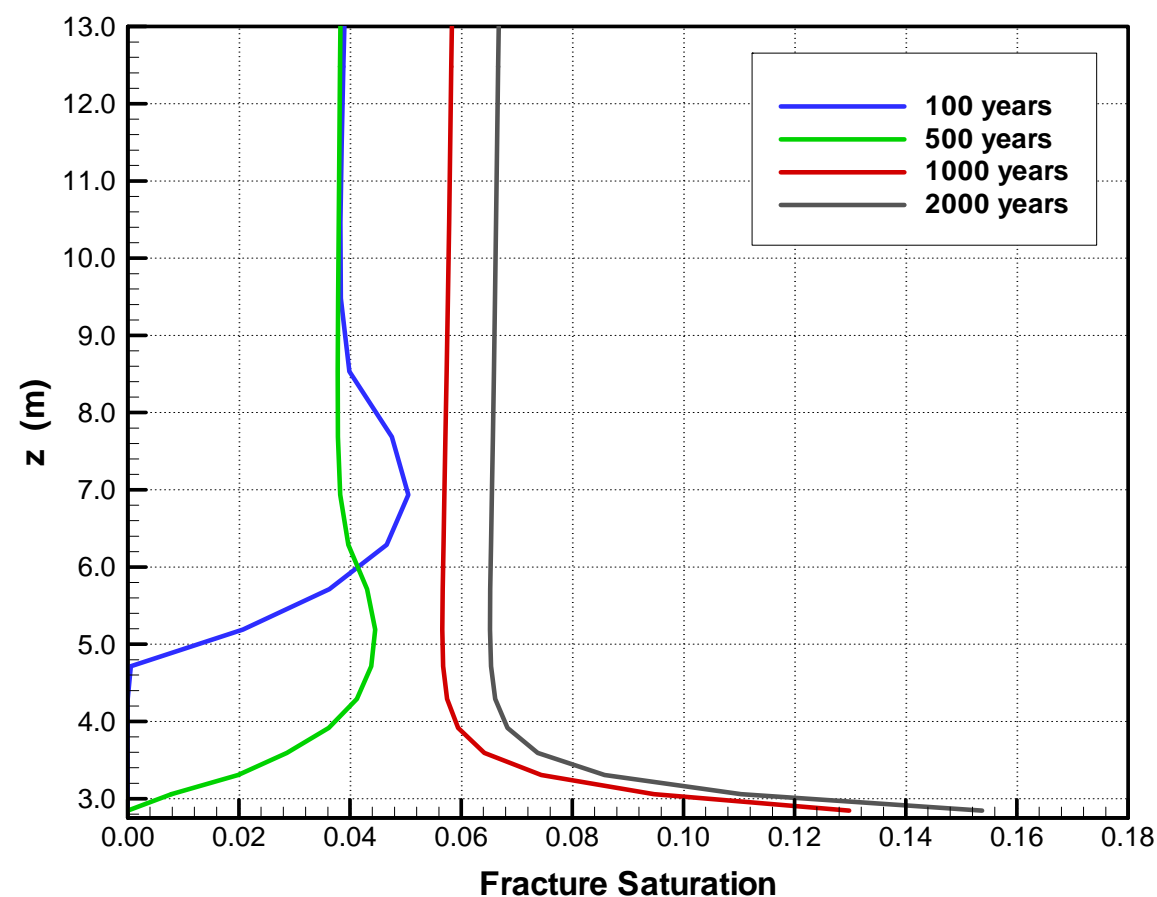

(a)

Fracture Saturation

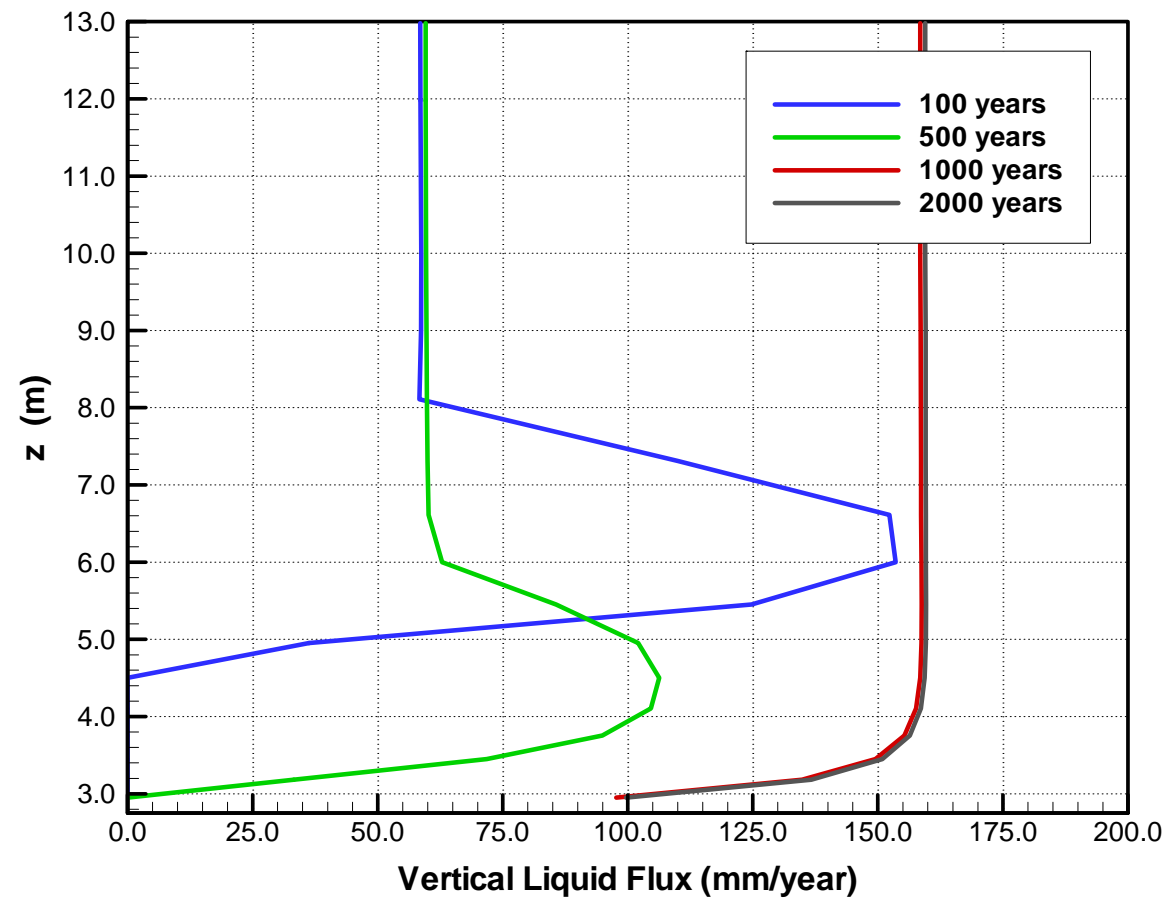

Output DTN: NA (See Section 8.5).

NOTE: The drift crown is located at $z=2.75 \mathrm{~m}$.

Figure 6.2.2.1-11. (a) Fracture Saturation and (b) Vertical Liquid Flux in a Vertical Cross Section above Drift Crown, for a Tptpmn Submodel with a Flux Multiplication Factor of 10 (Simulation Case MN-HOM-03) 


\subsection{Sensitivity to Thermal Load}

The simulation cases for analysis of different thermal loads are the high-temp mode $(1.45 \mathrm{~kW} / \mathrm{m}$, 70 percent heat removal for 50 years, Simulation Case MN-HOM-04; see Table 6.2.1.6-1) and the low-temp mode $(1.0 \mathrm{~kW} / \mathrm{m}, 88.3$ percent heat removal for 50 years, Simulation Case MN-HOM-05; see Table 6.2.1.6-1), as introduced in Section 6.2.1.3.3. The rock-property set and infiltration scenario are identical to the base-case simulation in Section 6.2.2.1.1. The evolution of rock temperature at the drift crown for the different thermal loads is shown in Figure 6.2.2.1-12. The high-temp mode has a peak temperature of $140^{\circ} \mathrm{C}$ at 75 years, about $12^{\circ} \mathrm{C}$ higher than for the reference mode. This demonstrates that a moderate change in heat-removal efficiency for the first 50 years, from 86.3 percent to 70 percent, gives rise to noticeable changes in rock temperature during the first several hundred years after emplacement. At later times, the difference in temperature between the high-temp mode and the reference mode almost vanishes. Rock temperature for the low-temp mode never reaches boiling conditions, with a peak temperature of $94^{\circ} \mathrm{C}$.

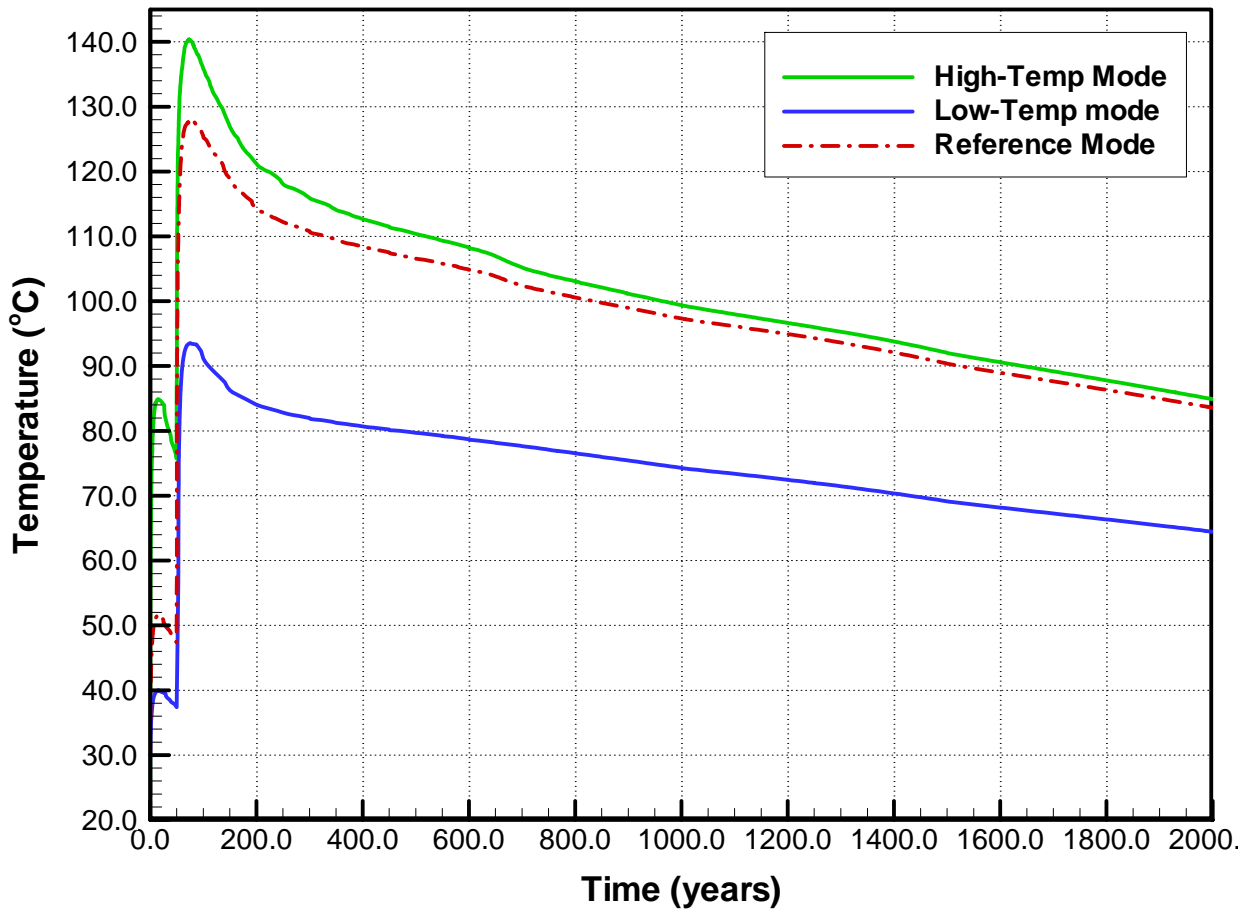

Output DTN: NA (See Section 8.5).

NOTE: The simulation cases are MN-HOM-04 and MN-HOM-05 compared to MN-HOM-01.

Figure 6.2.2.1-12. Rock Temperature at the Drift Crown for Tptpmn Submodel with Different Thermal Loads

The high-temp mode and the base-case mode exhibit qualitatively similar drying and rewetting trends in the rock close to the drift. Quantitatively, the TH signals are more pronounced in the high-temp mode; e.g., the period of complete dryout in the fractures and the matrix is about 100 to 200 years longer than in the reference mode (Figure 6.2.2.1-13.) The maximum extent of the fracture dryout zone above the drift is larger in the high-temp mode, approximately $6 \mathrm{~m}$ 
measured from the drift crown as opposed to about $4 \mathrm{~m}$ for the reference mode (Figure 6.2.2.1-14). The magnitude of vertical fluxes downward towards the drift is fairly similar for the two above-boiling temperature cases, indicating that the slightly higher thermal load does not necessarily lead to strong changes in the flow field. At 100 years of heating, the maximum downward flux simulated with the high-temp mode is $49 \mathrm{~mm} / \mathrm{yr}$, compared to $67 \mathrm{~mm} / \mathrm{yr}$ with the reference mode.

The effect of heating on the flow behavior is marginal for the low-temp mode. The evolution of saturation depicted in Figure 6.2.2.1-13 shows that evaporation of moisture at the wall leads to a minor saturation decrease in the rock matrix with corresponding dryout in the fractures. These signals last for a short time period of about 50 to 100 years after closure. After this minor perturbation, the rock saturation curves essentially represent the hydrological conditions of an ambient flow system. The jump in fracture saturation at 600 years corresponds to the infiltration change from $6 \mathrm{~mm} / \mathrm{yr}$ to $16 \mathrm{~mm} / \mathrm{yr}$. The profiles of fracture saturation and downward flux in Figure 6.2.2.1-15 demonstrate that the effect of evaporation at 100 years is restricted to a small area around the drift. The profiles for 500 years, 1,000 years, and 2,000 years basically represent unperturbed flow systems that are not affected by heating. There is no buildup of saturation or downward flow as a result of heating/condensation at any time.

The following conclusions can be reached from the $\mathrm{TH}$ modeling analysis presented in this section:

- The high-temp mode leads to higher peak temperature, a larger superheated rock zone, a larger dryout rock region, and a longer time period of above-boiling temperatures. The main characteristics of the $\mathrm{TH}$ processes, however, are fairly similar to the reference mode. Thus, evaluation of thermal seepage in Section 6.2.2.2 can focus on the base-case mode.

- Peak temperature in the low-temp-mode simulation never reaches boiling conditions, and, except for small localized effects of evaporation close to the drift wall, the hydrological processes in the rock remain mostly unaffected by heat. For the low-temp mode (and other thermal modes without boiling conditions), a detailed study on thermal seepage is not necessary, because upper bounds for seepage can be estimated from the ambient SMPA. (Viscosity changes as a result of heating the water from its ambient temperature would allow the flow to be more easily diverted around the drift.) 


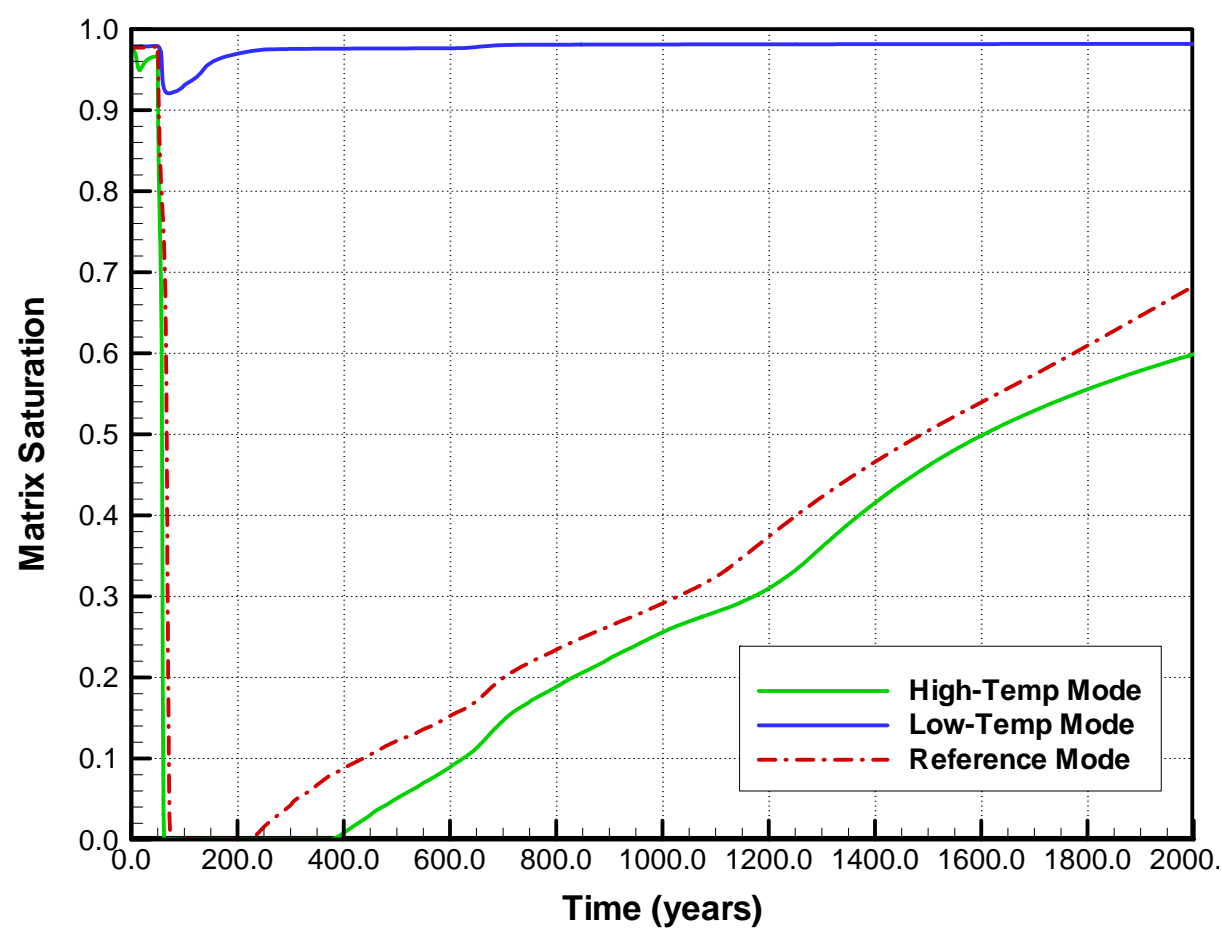

(a)

Time (years)

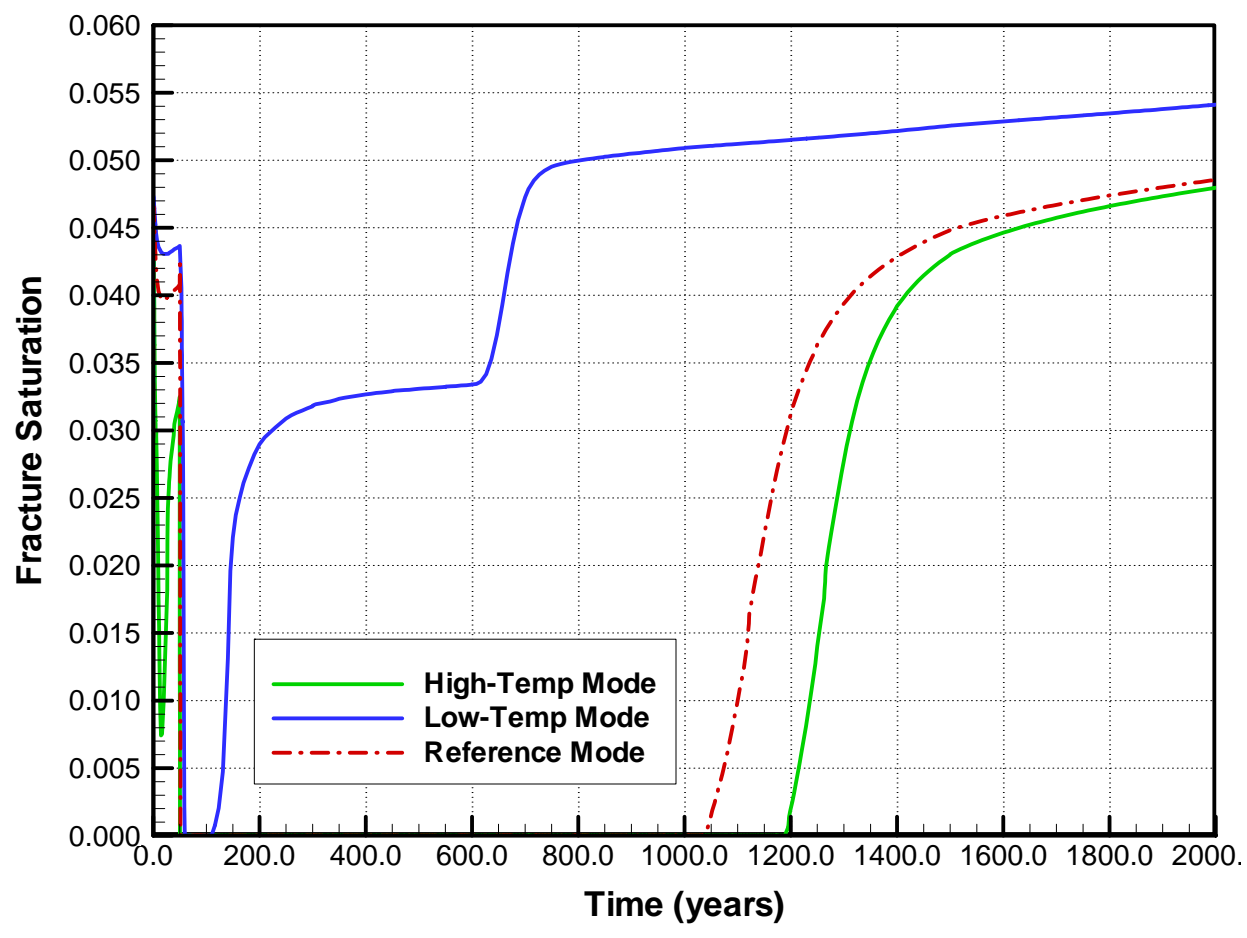

(b)

Output DTN: NA (See Section 8.5).

NOTE: The simulation cases are MN-HOM-04 and MN-HOM-05 compared to MN-HOM-01.

Figure 6.2.2.1-13. (a) Matrix Saturation and (b) Fracture Saturation at the Drift Crown for Tptpmn Submodel with Different Thermal Loads 


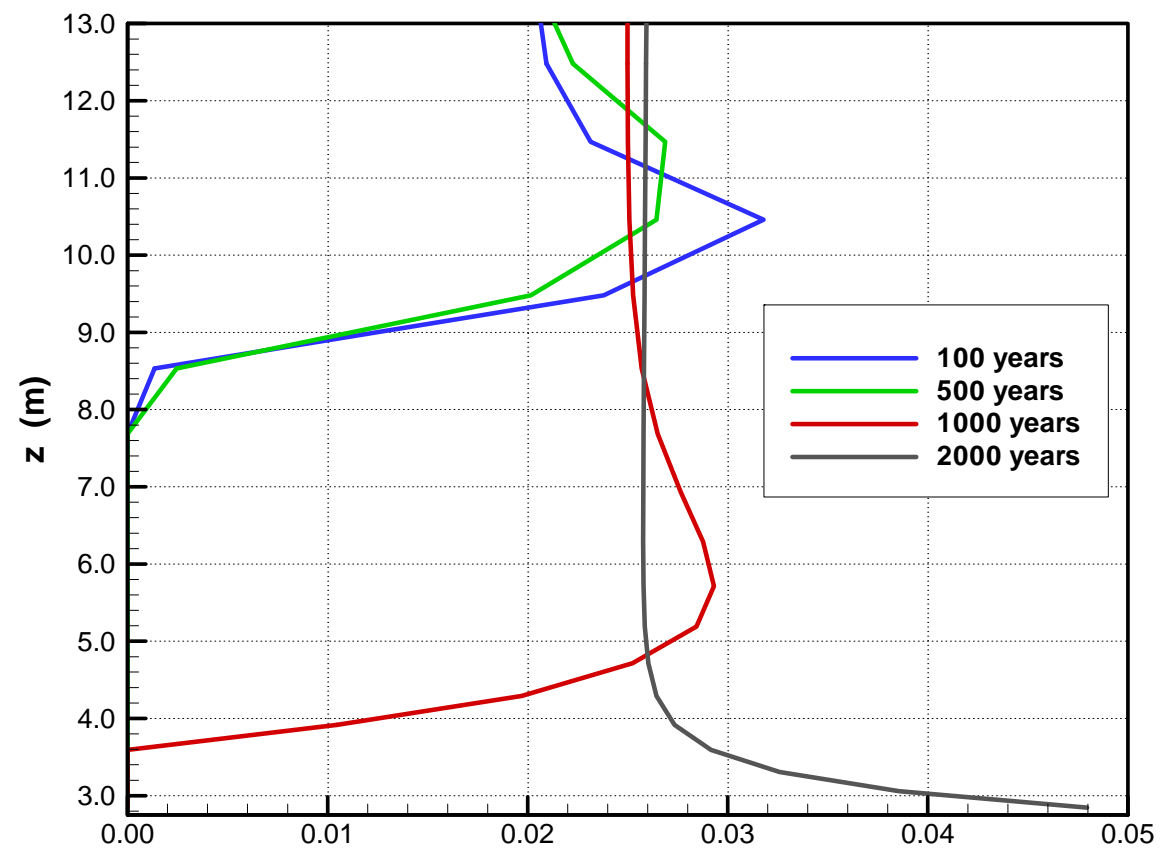

(a)

Fracture Saturation

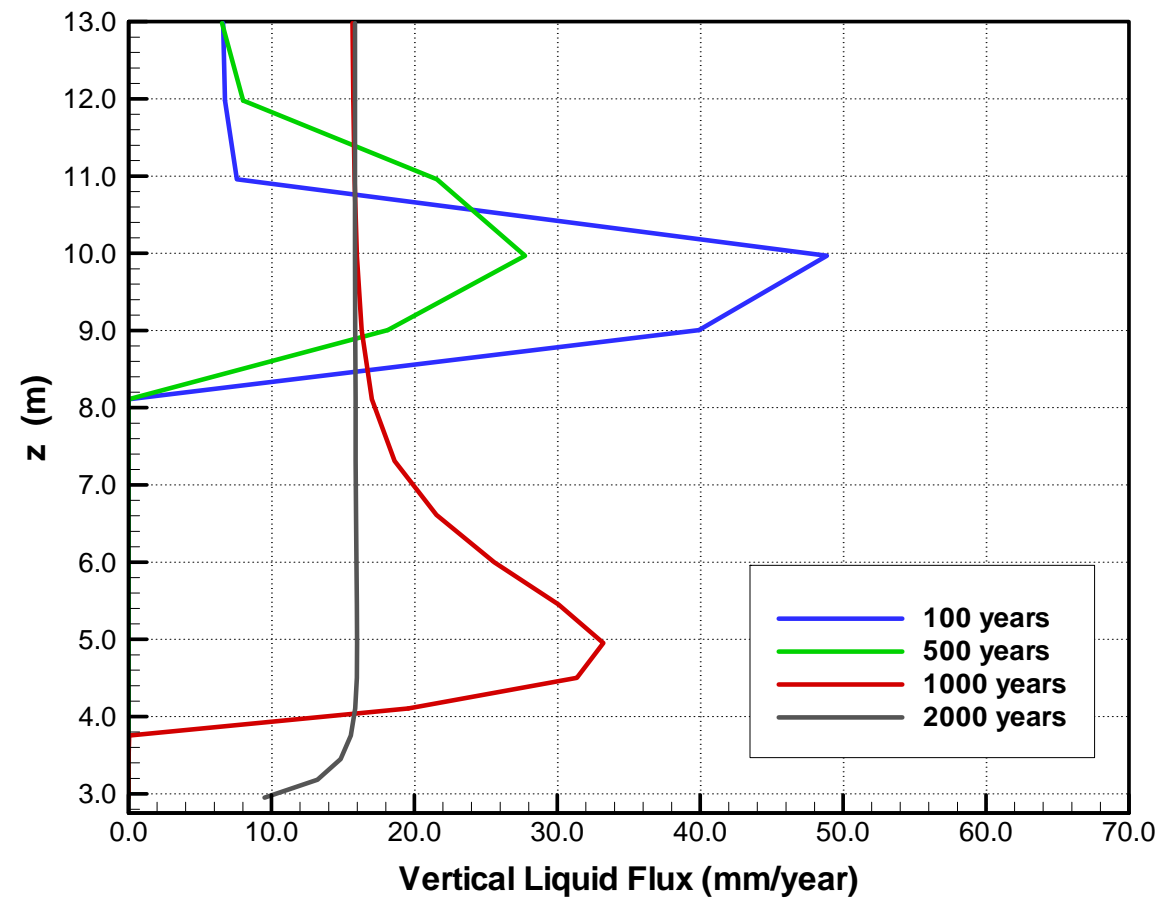

(b)

Output DTN: NA (See Section 8.5).

NOTE: The drift crown is located at $z=2.75 \mathrm{~m}$.

Figure 6.2.2.1-14. (a) Fracture Saturation and (b) Vertical Liquid Flux in a Vertical Cross Section above Drift Crown for Tptpmn Submodel with High-Temp Mode (Simulation Case MN-HOM-04) 


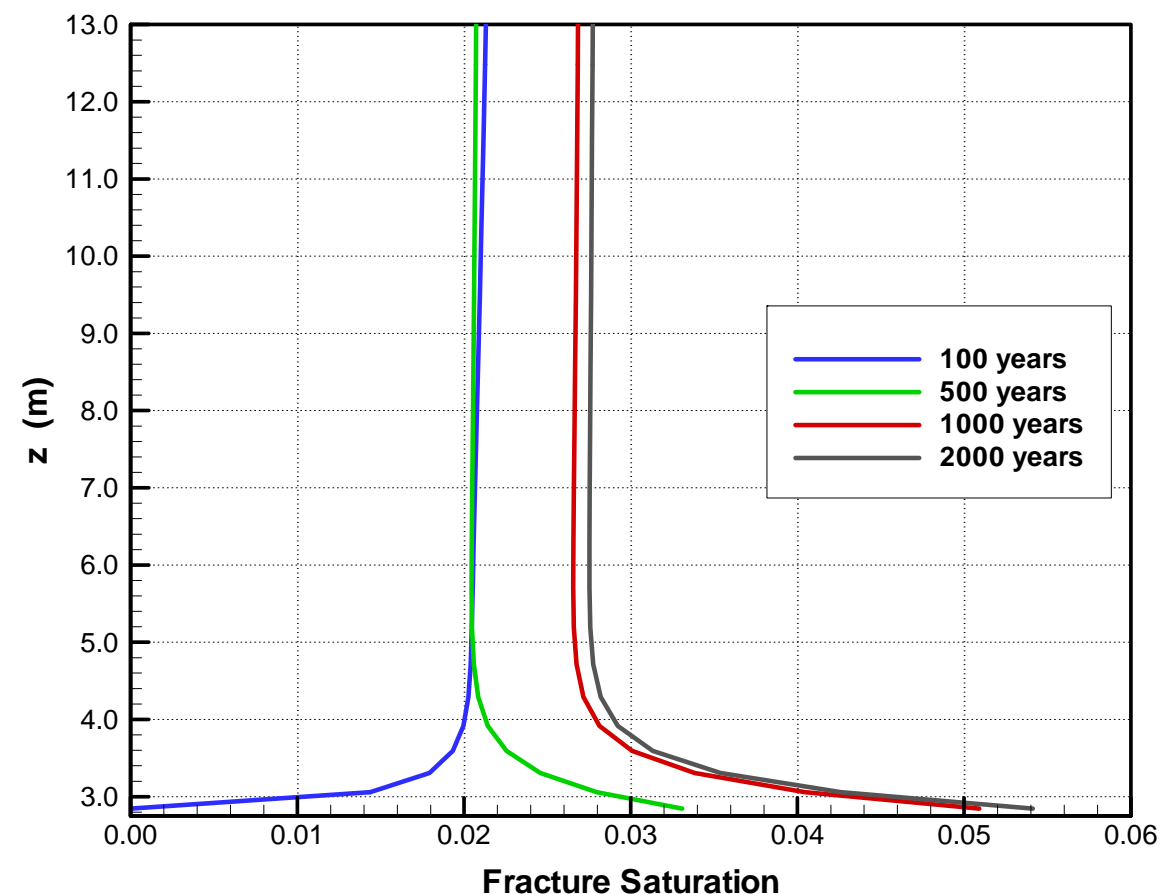

(a)

Fracture Saturation

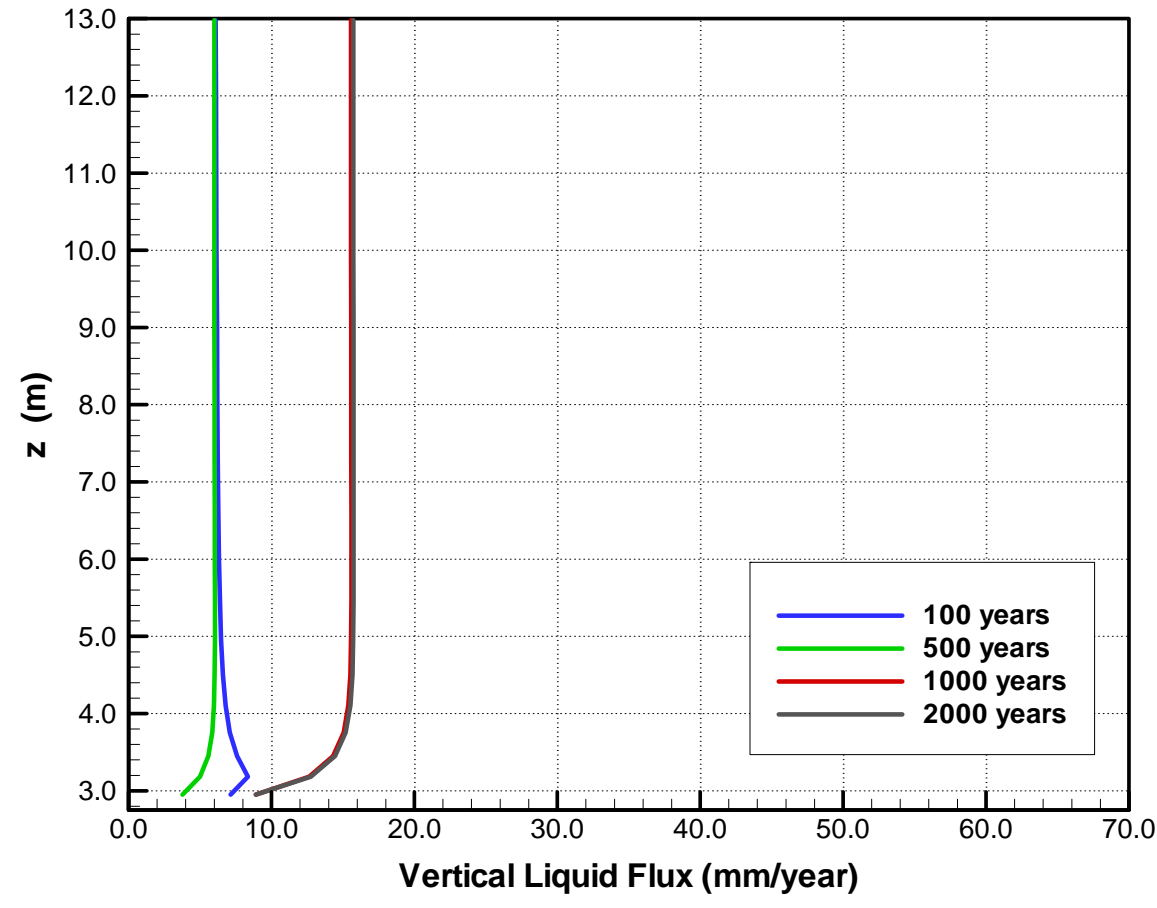

(b)

Output DTN: NA (See Section 8.5).

NOTE: The drift crown is located at $z=2.75 \mathrm{~m}$.

Figure 6.2.2.1-15. (a) Fracture Saturation and (b) Vertical Liquid Flux in a Vertical Cross Section above Drift Crown for Tptpmn Submodel with Low-Temp Mode (Simulation Case MN-HOM-05) 


\subsection{Sensitivity to Fracture Capillary-Strength Parameter}

The fracture capillary-strength parameter $1 / \alpha$ close to the drift wall is a key parameter for drift seepage. Appropriate values for $1 / \alpha$ have been calibrated in the SCM (BSC 2004 [DIRS 171764], Section 6.6.4; DTN: LB0302SCMREV02.002 [DIRS 162273]) to match experimental data from niche liquid-release tests. Typically, these calibrated values are comparably small, corresponding to a weak capillarity in the fractures (see Tables 4.1-3, 4.1-4, and discussion in Section 4.1.1.1). A value of $589 \mathrm{~Pa}$ was chosen in Section 4.1.1.1 as the base case value for most thermal seepage calculations to be conducted in Section 6.2.2.2 and 6.2.3.2, representative of the average calibrated values of capillary strength from various liquid release tests conducted in the ESF niches.

In contrast, the DS/AFM-UZ02-Mean property set has a much larger 1/ $\alpha$-value of 9,615 Pa for the Tptpmn. The latter value $(=9,615 \mathrm{~Pa})$ represents the calibrated fracture capillary strength for the entire Tptpmn stratigraphic layer and is reflective of the large-scale flow processes. The former value $(=589 \mathrm{~Pa})$ on the other hand represents the fracture capillary behavior in the vicinity of the emplacement drifts, which includes the small-scale seepage effects in the disturbed zone. Ideally, the SCM capillary-strength parameter should be used in a small region around the drift to better address thermal seepage, while the capillary-strength parameter from the DS/AFM-UZ02-Mean property set should be used outside of this region to better address the $\mathrm{TH}$ processes on the drift to mountain scale. Scoping simulations have shown, however, that such a numerical model implementation would create a capillary barrier at the interface between the two regions, which is clearly unphysical. Therefore, for the thermal seepage studies in Section 6.2.2.2, the small SCM fracture capillary-strength parameter is applied in the entire Tptpmn unit. To confirm that the main TH processes in the rock are not significantly affected by this parameter change, one simulation run is conducted using the SCM capillary-strength parameter (Simulation Case MN-HOM-06; see Table 6.2.1.6-1). Results from this run are compared with simulation results using the DS/AFM-UZ02-Mean capillary-strength parameter. All other rock properties, thermal load, and infiltration scenarios are similar to the base-case simulation presented in Section 6.2.2.1.1.

Expected effects from using the small SCM fracture capillary-strength parameter are as follows. At ambient conditions, the smaller capillarity in the fractures should give rise to a higher saturation in the rock matrix. For the long-term flow conditions, this effect may lead to elevated matrix saturations in the Tptpmn unit. During heating, gravity drainage of condensate in the fractures should be more pronounced because of the weak capillarity. Also, more condensate should be imbibed into the matrix because of the larger capillarity differences between the fractures and the rock matrix. Figure 6.2.2.1-16 shows contours of matrix saturation and temperature at 500 years of heating, while Figure 6.2.2.1-17 gives contours of fracture saturation and flux vectors. The length scale of the flux vectors is identical to Figures 6.2.2.1-5 and 6.2.2.1-6. Comparison with the respective figures of the base case indicates that rock temperature is essentially unaffected by the fracture capillarity change. Matrix saturation is higher outside of the thermally perturbed rock region. The matrix dryout zone is slightly more asymmetrical in the vertical direction, indicating stronger gravity drainage. This effect is also evident in the fracture saturations. The vertical extent of the region of elevated fracture saturation just outside of the dryout zone indicates that water drains further down after being diverted around the boiling region. The magnitude of flux above the drift appears to be similar 
to the base case. This is confirmed in Figure 6.2.2.1-18, where fracture saturation and downward flux is given for a vertical profile above the drift. The main difference from the base case occurs at 2,000 years, when the thermal perturbation has ended and the drift vicinity has rewetted. Here, the zone of elevated fracture saturation directly at the drift wall is much smaller, a result of the weaker capillary strength in the fractures.

The following conclusions can be reached from the $\mathrm{TH}$ modeling analysis presented in this section:

- Using the small value of fracture capillary-strength parameter as calibrated from the SCM (BSC 2004 [DIRS 171764]; DTN: LB0302SCMREV02.002 [DIRS 162273]) leads to modest changes in the TH behavior.

- The simulated case-using the SCM fracture capillary-strength parameter for the entire Tptpmn - is appropriate for studying thermal seepage. The predicted TH behavior is reasonably close to results obtained with the DS/AFM-UZ02-Mean property set. 


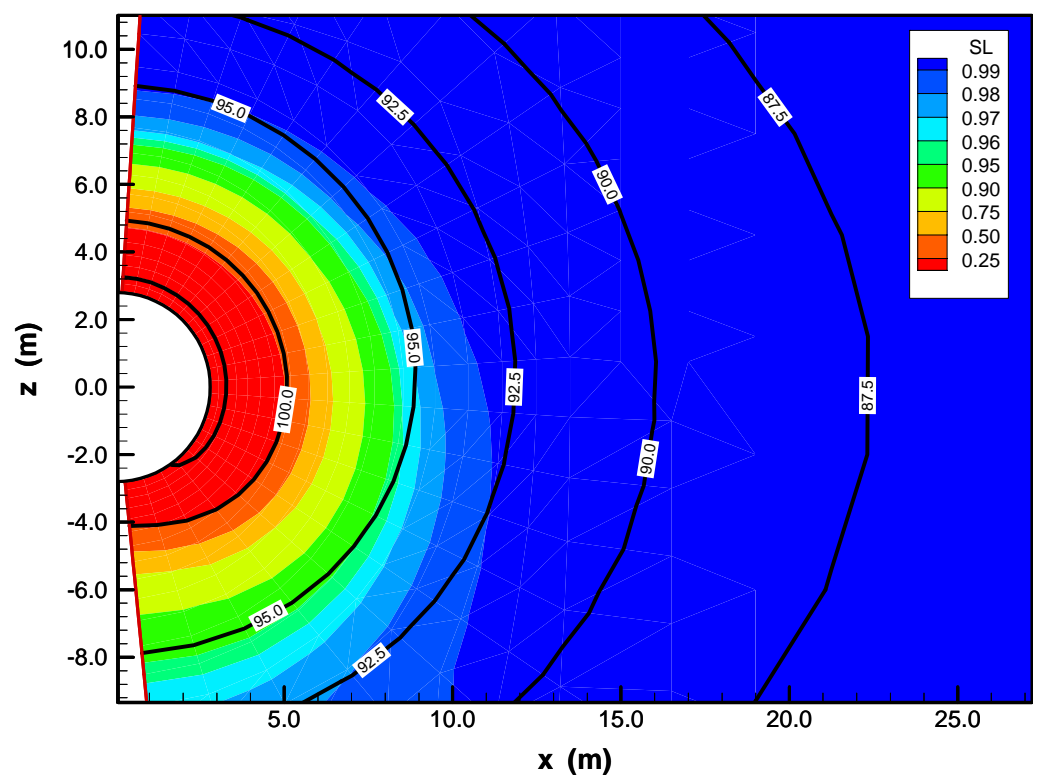

Output DTN: NA (See Section 8.5).

NOTE: SL denotes liquid saturation. Contour areas show saturation, lines show temperature.

Figure 6.2.2.1-16. Matrix Saturation and Temperature at 500 Years after Emplacement for Tptpmn Submodel with SCM Capillary-Strength Parameter (Simulation Case MN-HOM-06)

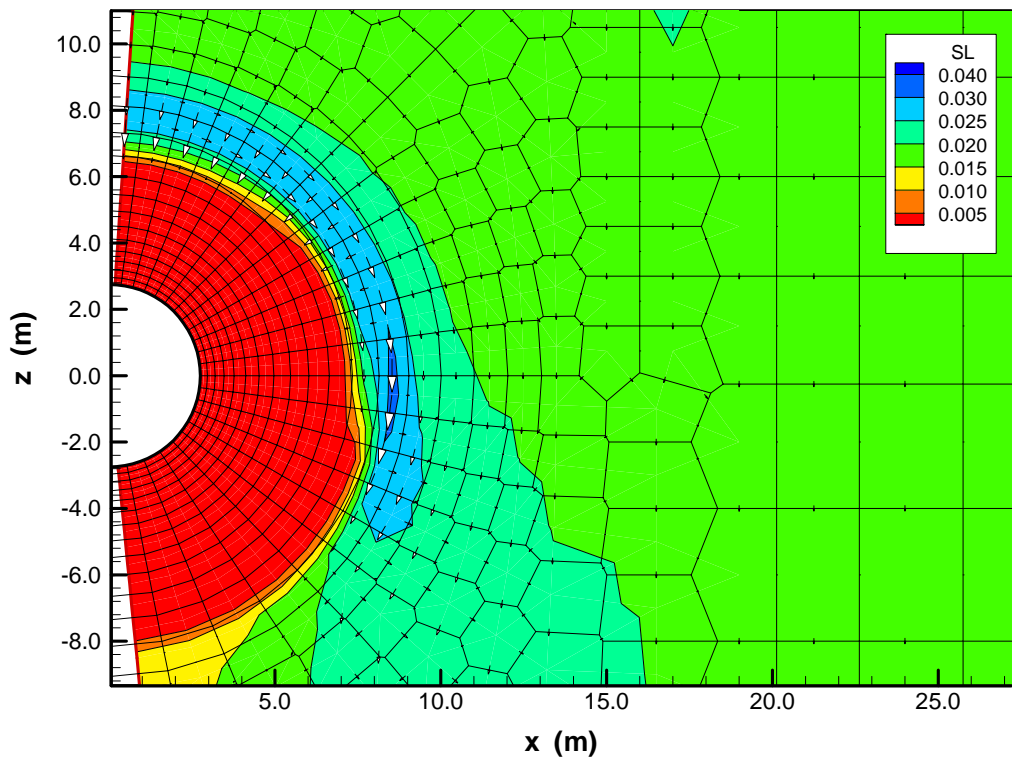

Output DTN: NA (See Section 8.5).

NOTE: SL denotes liquid saturation.

Figure 6.2.2.1-17. Fracture Saturation and Liquid Flux at 500 Years after Emplacement for Tptpmn Submodel with SCM Capillary-Strength Parameter (Simulation Case MN-HOM-06) 


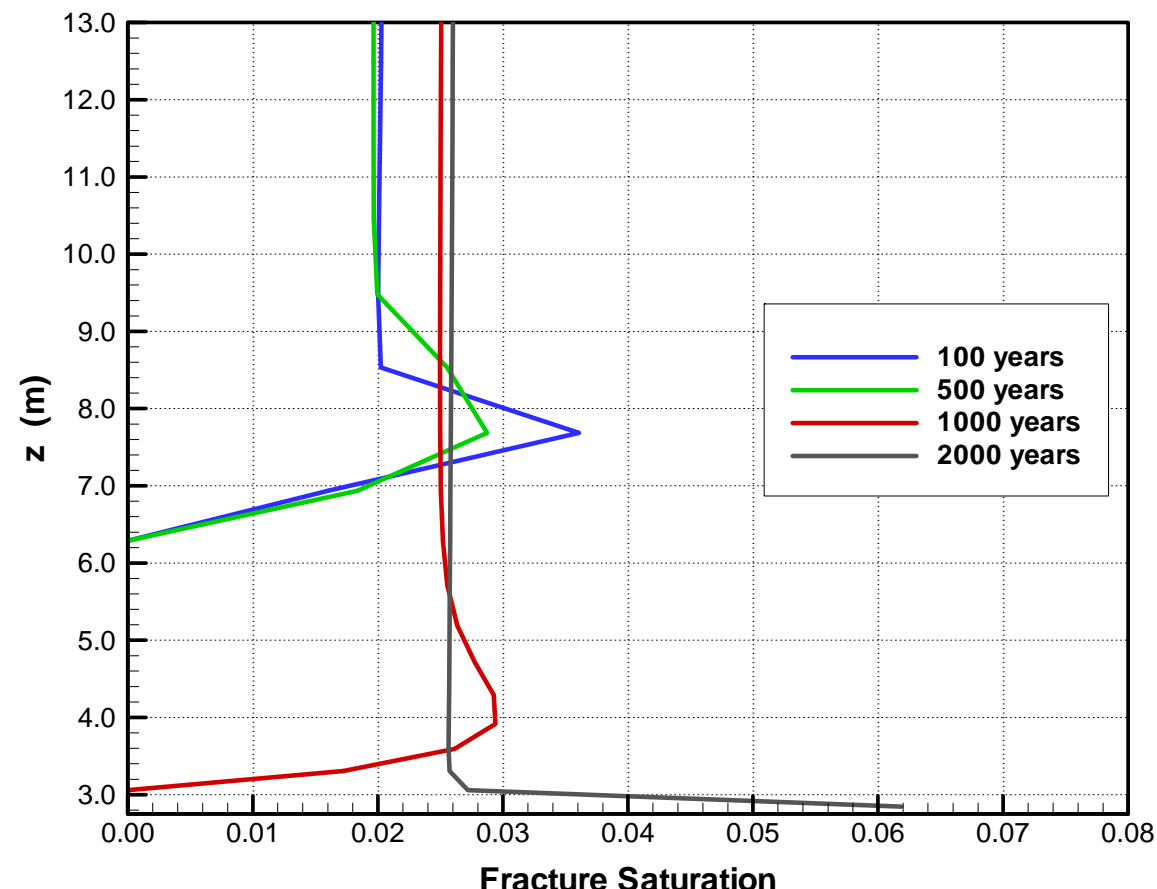

(a)

Fracture Saturation

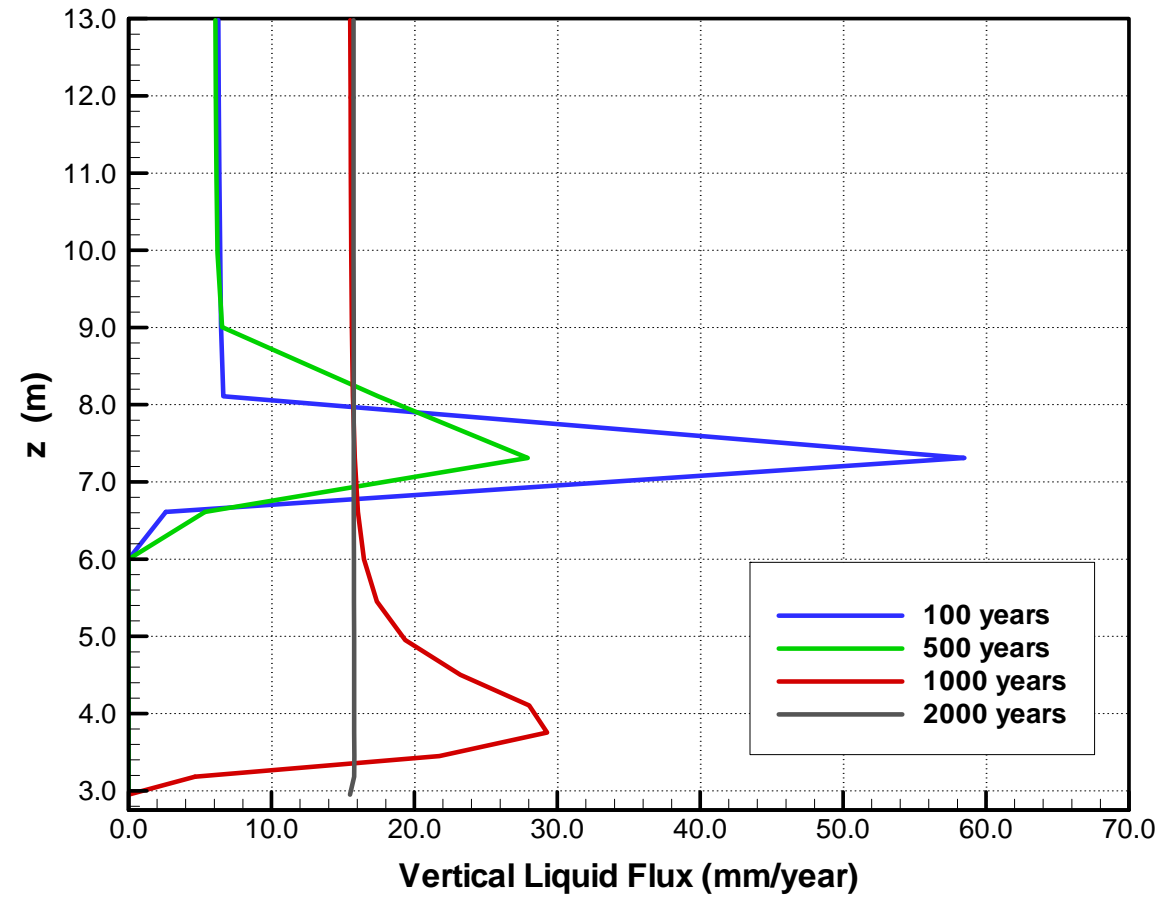

(b)

Output DTN: NA (See Section 8.5).

NOTE: The drift crown is located at $z=2.75 \mathrm{~m}$.

Figure 6.2.2.1-18. (a) Fracture Saturation and (b) Vertical Liquid Flux in a Vertical Cross Section above Drift Crown for Tptpmn Submodel with SCM Capillary-Strength Parameter (Simulation Case MN-HOM-06) 


\subsubsection{Thermal Seepage}

In this section, the potential for thermal seepage in the Tptpmn submodel is studied using the conceptual model presented in Section 6.2.1.1.2, incorporating heterogeneous fracture permeability and the SCM calibrated fracture capillary-strength parameter. The steps for estimating thermal seepage are as follows. First, three steady-state simulations without thermal load are performed, using the percolation flux values of the three climate periods-present-day, monsoon, and glacial transition climate-enhanced by a flux multiplication factor to determine long-term ambient seepage rates. These provide reference values for evaluating thermal seepage and the effectiveness of the vaporization barrier. In a second step, a transient TH simulation is conducted for the first 4,000 years after emplacement, assuming the reference-mode thermal load and the respective infiltration scenario with flow focusing are incorporated. The transient thermal seepage rates derived from these simulations are compared to the long-term ambient seepage rates for the respective climate period; i.e., the transient seepage during the first 600 years after emplacement is compared to the long-term ambient seepage rate calculated for the present-day infiltration value enhanced by the flux multiplication factor; the transient seepage between 600 and 2,000 years uses long-term ambient seepage for the monsoon climate; after 2,000 years, the transient seepage is compared to long-term ambient seepage for the glacial transition climate.

In Section 6.2.2.2.1 below, the random fields used for fracture permeability variation are explained in detail. Section 6.2.2.2.2 gives seepage results for long-term ambient simulations, using the mean infiltration as well as infiltration with flux multiplication factors of 5 and 10 . Differences in TH response arising from homogeneous and heterogeneous fracture properties are discussed for the mean infiltration scenario in Section 6.2.2.2.3. Finally, thermal seepage results for the different cases with enhanced infiltration are given in Section 6.2.2.2.4.

\subsection{Heterogeneous Fracture Permeability Fields}

Fracture permeability is varied within a radius of $20 \mathrm{~m}$ measured from the drift centerline. Twenty meters is sufficiently large for the purpose of seepage modeling, but small enough to not excessively increase the computational load of the TH simulations. Mean permeability is equal to the calibrated fracture permeability of the Tptpmn unit given in the DS/AFM-UZ02-Mean data set (i.e., $0.33 \times 10^{-12} \mathrm{~m}^{2}$ ). Similar to the ambient SMPA (BSC 2004 [DIRS 167652], Sections 6.3.2 and 6.3.3), standard deviation of permeability is based on air-permeability measurements for Niches 3107, 3650, and 4788 in the Tptpmn unit (see Section 4.1.1.1). For these three niches, the standard deviations in log10 space are $0.80,0.72$, and 0.84 , based on a total number of 78, 84, and 63 1-foot-measurement intervals, respectively (see Table 4.1-5). In a numerical study of seepage from a heterogeneous fracture continuum into a drift, Birkholzer et al. (1999 [DIRS 105170], pp. 375 to 376) found that the larger the permeability standard deviation, the more seepage is likely to occur. For the Tptpmn submodel, the largest of the measured standard deviations is used, i.e., a value of 0.84 . This selected standard deviation is slightly smaller than the value of 1.0 (in log10) used in the current revisions of SMPA modeling analysis (BSC 2004 [DIRS 167652], Section 6.3.3).

Using the specified mean and standard deviation, a log-normal fracture permeability field is generated. The choice of a log-normal permeability field is consistent with the ambient SMPA 
(BSC 2004 [DIRS 167652], Section 6.3.3). No spatial correlation is implemented, because the variograms developed from the air-permeability data show either short correlation length or a nugget effect close to the sill value (BSC 2004 [DIRS 171764], Section 6.6.2.1, Table 6-7). It was concluded (BSC 2004 [DIRS 171764], Section 6.6.2.1) that the permeability is essentially random, without a noticeable or significant correlation. Three different realizations of random permeability fields are studied in this report.

As an example, Figure 6.2.2.2-1 shows the permeability distribution of Realization 1 in the drift vicinity. Note that as a result of mapping random values to a nonuniform grid, the apparent correlation length of the resulting heterogeneity field increases with distance from the drift. (The complex grid design is required for the TH seepage model to provide sufficient resolution at key locations where steep gradients of the TH properties occur, while coarser grids are utilized elsewhere to achieve computational efficiency.) However, in a region within the first few meters from the drift wall, where an appropriate random field representation is most important for seepage, the variation of apparent correlation length is negligible.

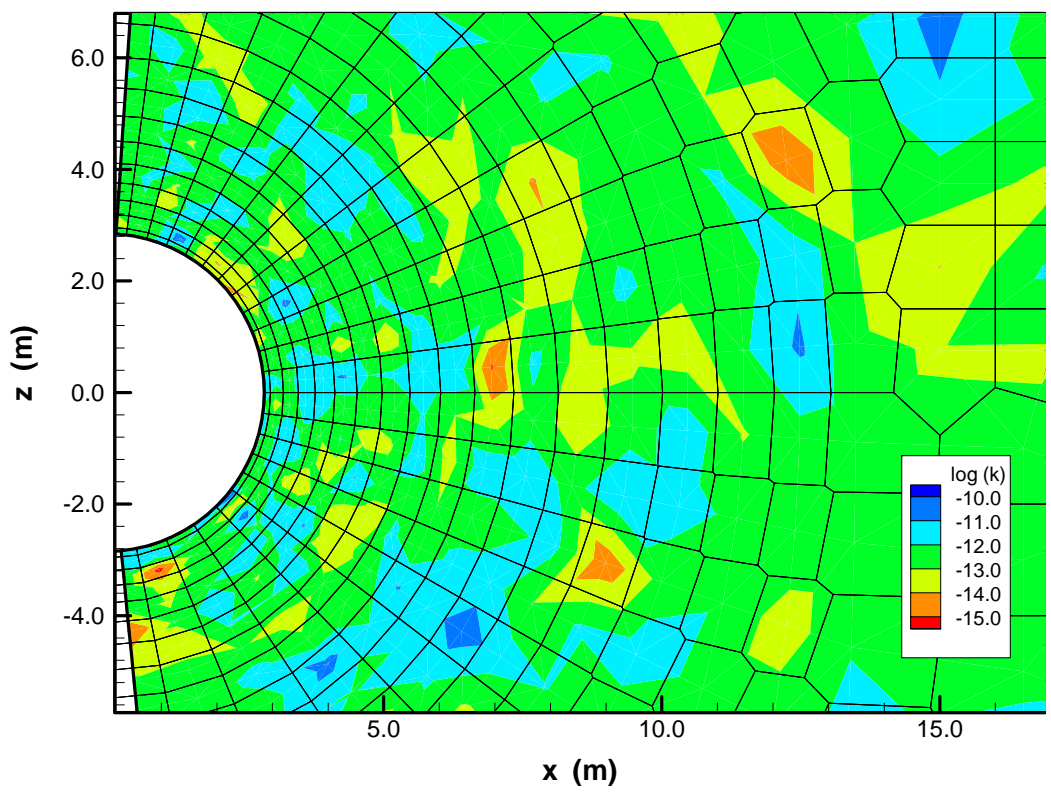

Output DTN: LB0303DSCPTHSM.001.

Figure 6.2.2.2-1. Fracture Permeability Distribution in $\log (\mathrm{k})$ for Heterogeneous Realization 1

Note that in contrast to the TH seepage model, the SMPA and the SCM have a regular grid with uniform element size and orientation. In the drift vicinity, the grid size designed for the $\mathrm{TH}$ seepage model is $0.2 \mathrm{~m}$ in radial direction, compared to $0.1 \mathrm{~m}$ for the SCM (BSC 2004 [DIRS 171764], Section 6.6.2.2) and the SMPA (BSC 2004 [DIRS 167652], Section 6.3.3). The issue of grid-resolution effects was analyzed in a previous version of the SMPA report (CRWMS M\&O 2000 [DIRS 153314], Section 6.7). It was concluded that, as long as the connection of the last gridblock in fractured rock and the drift wall is set at $0.05 \mathrm{~m}$ (see Section 6.2.1.1.2), the grid size dependence is rather small, similar to or less than the variability from different realizations of the heterogeneous permeability field. Also note that the model grid size used in the drift vicinity is comparable to the 1-foot-interval length of the air-injection tests conducted in the 
niches, assuring that the scale of measurement is consistent with the scale of heterogeneity described in the model.

\subsection{Long-Term Seepage for Ambient Conditions}

In this section, long-term seepage simulations are performed for a time period of 10,000 years, applying no thermal load. This time period is sufficient to achieve steady-state flow conditions. Results of these simulations provide a reference for evaluating the vaporization barrier. Constant percolation flux values are applied at the top boundary, having the percolation rates of the three different climate periods multiplied by the respective flux multiplication factors. Altogether, nine different constant percolation fluxes are considered in the steady-state simulation runs, using flux values of 6,16 , and $25 \mathrm{~mm} / \mathrm{yr}$ for the mean infiltration without flux multiplication, 30, 80 , and $125 \mathrm{~mm} / \mathrm{yr}$ for a flux multiplication factor of 5, and 60, 160, and $250 \mathrm{~mm} / \mathrm{yr}$ for a flux multiplication factor of 10 . The capillary-strength parameter in the Tptpmn unit is set to the SCM-calibrated value of $589 \mathrm{~Pa}$ (see Section 4.1.1.1). The simulation boundary conditions and rock properties for the steady-state simulation runs can be summarized as follows:

Thermal Load: $\quad$ No heat

Property Set: $\quad$ DS/AFM-UZ02-Mean

Drift-scale Properties: Fracture capillary-strength parameter $1 / \alpha=589 \mathrm{~Pa}$, heterogeneous fracture permeability field with $\mathrm{k}=0.33 \times 10^{-12} \mathrm{~m}^{2}$ and $\sigma=0.84$

Infiltration: $\quad$ No Flow Focusing: constant infiltration using $6 \mathrm{~mm} / \mathrm{yr}, 16 \mathrm{~mm} / \mathrm{yr}$ and $25 \mathrm{~mm} / \mathrm{yr}$

Flux multiplication factor 5: constant infiltration using $30 \mathrm{~mm} / \mathrm{yr}$, $80 \mathrm{~mm} / \mathrm{yr}$ and $125 \mathrm{~mm} / \mathrm{yr}$

Flux multiplication factor 10: constant infiltration using $60 \mathrm{~mm} / \mathrm{yr}$, $160 \mathrm{~mm} / \mathrm{yr}$ and $250 \mathrm{~mm} / \mathrm{yr}$

In simulation cases where seepage occurs, the so-called seepage percentage is calculated at the end of the 10,000-year time period, in a procedure similar to the one outlined in BSC (2004 [DIRS 167652]). The seepage percentage is defined as the ratio of the liquid flux that seeps into the drift to the total liquid flux percolating with constant infiltration rate through a cross-sectional area corresponding to the footprint of the drift. (Thus, for example, the observed seepage flux in a $250 \mathrm{~mm} / \mathrm{yr}$ simulation run would be related to a $250 \mathrm{~mm} / \mathrm{yr}$ percolation flux over the footprint of the drift.) Table 6.2.2.2-1 gives the simulated long-term seepage percentage values for the nine steady-state simulation runs, each of them with three different realizations of the random field. Table 6.2.2.2-1 also gives the maximum fracture saturation measured in the gridblocks immediately at the drift wall for each of the glacial transition infiltration rates: 25, 125 and $250 \mathrm{~mm} / \mathrm{yr}$. As explained in Section 6.2.1.1.2, seepage can occur when the capillary pressure in the gridblocks next to the wall is higher (less negative) than the threshold pressure $P$ $=-(0.05 \mathrm{~m}) \times \rho g$, which is $-490 \mathrm{~Pa}$ at ambient temperature. For the properties used in this simulation, such conditions exist when the fracture saturation at the wall exceeds about 0.5 . The threshold pressure for seepage increases slightly (becomes less negative) with elevated 
temperatures because of liquid density changes. Therefore, at higher temperatures, the threshold saturation for seepage may be slightly higher than 0.5. Note that the saturation values in Table 6.2.2.2-1 and the threshold saturation of 0.5 represent the average saturation of all active and nonactive fractures in the AFM. The higher saturation of active fractures can be calculated from the power function relationship given in Equation 6.2.1.1-11. The threshold-saturation value of 0.5 , for example, corresponds to an active fracture saturation of 0.74 .

Table 6.2.2.2-1 shows that the maximum saturations simulated at the drift wall are significantly higher than those in the homogeneous cases presented in Section 6.2.2.1. In several cases, saturation exceeds the seepage threshold saturation of 0.5 . Water seeps into the drift in all realizations of the $250 \mathrm{~mm} / \mathrm{yr}$ infiltration case, and in two out of three realizations of the $160 \mathrm{~mm} / \mathrm{yr}$, the $125 \mathrm{~mm} / \mathrm{yr}$, and the $80 \mathrm{~mm} / \mathrm{yr}$ infiltration cases. No seepage occurs for infiltration rates of $60,30,25,16$, and $6 \mathrm{~mm} / \mathrm{yr}$. Here, the fracture saturation close to the wall stays below the threshold saturation. The seepage threshold percolation flux is somewhere between $60 \mathrm{~mm} / \mathrm{yr}$ and $80 \mathrm{~mm} / \mathrm{yr}$. Seepage percentages vary from 8.32 to 19.54 percent for 250 $\mathrm{mm} / \mathrm{yr}$, from 0 to 15.73 percent for $160 \mathrm{~mm} / \mathrm{yr}$, from 0 to 12.79 percent for $125 \mathrm{~mm} / \mathrm{yr}$, and from 0 to 5.70 percent for $80 \mathrm{~mm} / \mathrm{yr}$.

The impact of using AFM for seepage evaluation was tested in scoping simulations. One simulation case (Realization 1) was conducted using a dual-permeability method (DKM) without employing the active fracture conceptualization (referred to hereafter as standard DKM, as used in the SMPA). The seepage rates are comparable to but smaller than the AFM results, indicating that the AFM is the more conservative conceptual model with respect to seepage. This is because the segregation into active and nonactive portions of the fracture network in the AFM is a flow channeling effect that can give rise to more seepage. Note that the AFM is not considered in the ambient seepage models (SCM and SMPA) because (1) flow channeling within fractures is already accounted for through explicit modeling of small-scale heterogeneity; (2) the correction of the fracture-matrix interface area (the main effect captured by the AFM) is not significant for ambient seepage; and (3) the potential impact of AFM effects on seepage is inherently reflected in the calibrated capillary-strength parameter. In the TH seepage model, the AFM is mainly applied because fracture-matrix interaction is important for the transient TH processes. Also, the model is intended to be consistent with other models for unsaturated flow and transport at Yucca Mountain (see Section 6.2.1.1.2).

Comparison of the seepage values in Table 6.2.2.2-1 with those calculated using the SMPA (BSC 2004 [DIRS 167652], Figures 6-4 through 6-13) is not straightforward, since the SMPA covers a wide range of rock properties and infiltration conditions that do not exactly match the cases studied here. Qualitatively, the seepage percentages given in Seepage Model for PA Including Drift Collapse (BSC 2004 [DIRS 167652]) appear to be higher, which can be attributed to various factors such as two-dimensional versus three-dimensional simulation, radially oriented grid versus regular rectangular grid, and consideration of matrix flow versus fracture-only model. Also, the differences between individual realizations are more significant for the TH seepage model compared to the SMPA, mainly because the two-dimensional simulations performed here result in seepage at a few locations only, while the three-dimensional runs of the SMPA show seepage at various places along the drift, allowing for a better averaging of individual seeps. However, the general trend of seepage increase with increased infiltration rate and the seepage-threshold percolation flux appear to be well represented. In the following 
subsections, seepage results from TH simulations with repository heat load will be presented for the three infiltration scenarios, and the transient seepage rates will be compared to the respective steady-state ambient seepage results given in Table 6.2.2.2-1.

Table 6.2.2.2-1. Seepage Percentage from Steady-State Simulation Runs Performed with the Tptpmn Submodel, Using Different Infiltration Scenarios and Different Realizations

\begin{tabular}{|c|c|c|c|c|}
\hline \multirow{3}{*}{ Realizations } & \multirow{2}{*}{\multicolumn{4}{|c|}{$\begin{array}{l}\text { Flux multiplication factor } 1 \\
16 \mathrm{~mm} / \mathrm{yr}\end{array}$}} \\
\hline & & & & \\
\hline & $\begin{array}{c}\text { Seepage } \\
(\%)\end{array}$ & $\begin{array}{c}\text { Seepage } \\
(\%)\end{array}$ & $\begin{array}{l}\text { Max. Fracture } \\
\text { Saturation }\end{array}$ & $\begin{array}{c}\text { Seepage } \\
(\%)\end{array}$ \\
\hline 1 & 0 & 0 & 0.338 & 0 \\
\hline 2 & 0 & 0 & 0.330 & 0 \\
\hline 3 & 0 & 0 & 0.194 & 0 \\
\hline \multirow[t]{3}{*}{1 , no AFM } & 0 & 0 & 0.550 & 0 \\
\hline & \multicolumn{4}{|c|}{$\begin{array}{l}\text { Flux multiplication factor } 5 \\
80 \mathrm{~mm} / \mathrm{yr}\end{array}$} \\
\hline & $\begin{array}{c}\text { Seepage } \\
(\%)\end{array}$ & $\begin{array}{c}\text { Seepage } \\
(\%)\end{array}$ & $\begin{array}{l}\text { Max Fracture } \\
\text { Saturation }\end{array}$ & $\begin{array}{c}\text { Seepage } \\
(\%)\end{array}$ \\
\hline 1 & 0 & 5.70 & 0.507 & 12.79 \\
\hline 2 & 0 & 1.48 & 0.544 & 4.55 \\
\hline 3 & 0 & 0 & 0.397 & 0 \\
\hline \multirow[t]{3}{*}{1, no AFM } & 0 & 0 & 0.744 & 7.45 \\
\hline & \multicolumn{4}{|c|}{$\begin{array}{l}\text { Flux multiplication factor } 10 \\
\qquad 160 \mathrm{~mm} / \mathrm{yr}\end{array}$} \\
\hline & $\begin{array}{l}\text { Seepage } \\
(\%)\end{array}$ & $\begin{array}{c}\text { Seepage } \\
(\%)\end{array}$ & $\begin{array}{l}\text { Max Fracture } \\
\text { Saturation }\end{array}$ & $\begin{array}{c}\text { Seepage } \\
(\%)\end{array}$ \\
\hline 1 & 0 & 15.73 & 0.549 & 19.54 \\
\hline 2 & 0 & 6.21 & 0.556 & 8.35 \\
\hline 3 & 0 & 0 & 0.504 & 8.32 \\
\hline 1, no AFM & 0 & 11.04 & 0.757 & 16.31 \\
\hline
\end{tabular}

Output DTN: LB0303DSCPTHSM.001 and LB0301DSCPTHSM.002.

NOTE: For 25,125 , and $250 \mathrm{~mm} / \mathrm{yr}$, the maximum fracture saturation in gridblocks at the drift wall is also given.

\subsection{TH Conditions for Mean Infiltration}

Table 6.2.2.2-1 indicates that there is no seepage at long-term ambient conditions using infiltration fluxes of 6,16 , and $25 \mathrm{~mm} / \mathrm{yr}$, respectively. The capillary barrier at the drift wall is capable of inhibiting water from entering the drift opening for these percolation fluxes. From the results derived in Section 6.2.2.1.1, it is not expected that heating of the rock will increase the probability of seepage compared to ambient conditions. Therefore, thermal seepage should not also be expected in the TH simulation where the reference-mode thermal load and the mean infiltration scenario (without flow focusing) are selected (Simulation Case MN-HET-01, see Table 6.2.1.6-1). Thus, presentation of results in this section is mainly intended to illustrate the changes in $\mathrm{TH}$ behavior stemming from the inclusion of fracture permeability variation in the drift vicinity. The conditions and properties used for Simulation Case MN-HET-01 are summarized as follows: 
Thermal Load: $\quad$ Reference mode ( $1.45 \mathrm{~kW} / \mathrm{m}, 86.3$ percent heat removal for 50 years)

Property Set: $\quad$ DS/AFM-UZ02-Mean

Drift-Scale Properties: Fracture capillary-strength parameter $1 / \alpha=589$ Pa, heterogeneous fracture permeability field with $\mathrm{k}=0.33 \times 10^{-12} \mathrm{~m}^{2}$ and $\sigma=0.84$

Infiltration:

Mean infiltration scenario without flow focusing, stepwise change from $6 \mathrm{~mm} / \mathrm{yr}$ to $16 \mathrm{~mm} / \mathrm{yr}$ to $25 \mathrm{~mm} / \mathrm{yr}$, at 600 years and 2,000 years

Figure 6.2.2.2-2 presents the temperature history and fracture saturation evolution at the drift wall for Realization 1 of the heterogeneous case (Simulation Case MN-HET-01) compared with the homogeneous simulation of Section 6.2.2.1.4 (Simulation Case MN-HOM-06; see Table 6.2.1.6-1). For the heterogeneous case, results are plotted for each rock element located directly at the drift wall and above the drift centerline (12 simulation elements). These locations are the most likely candidates for drift seepage. Rock temperature at the drift wall is not affected by the fracture-permeability heterogeneity; the heterogeneous and homogeneous temperatures are almost identical at all times. Minor deviations occur in the $96^{\circ} \mathrm{C}$ temperature range, where the differences in fracture permeability lead to differences in the temperature signal, stemming from more or less effective heat-pipe signatures (see Section 6.1.1).

Fracture saturation, in contrast, is clearly affected by permeability variation. Significant differences in fracture saturation values occur between the 12 gridblocks at the drift wall, with the smallest saturation at about 2 percent and the largest saturation at 24 percent. When the fractures in the drift vicinity start rewetting, local permeability contrasts promote channelized flow and create local saturation increase close to the drift walls. However, the simulated maximum saturation is still much smaller than the seepage threshold saturation of about 0.5 , so that no water seeps into the drift for this simulation case. Note that none of the gridblocks shows any water arrival during the first 1,000 years after emplacement. Apparently, the effectiveness of the vaporization barrier is not affected by the permeability variation. The first sign of rewetting is seen at 1,000 years for a few gridblocks of the heterogeneous case, which is about 100 years earlier than in the homogeneous simulation. Also note that saturation increases monotonically with time, with a jump at 2,000 years indicating the climate change from monsoon to glacial transition. There is no distinct saturation peak during rewetting, which would indicate fast downward flow of condensate towards the drift when the rock temperature is below boiling.

Figures 6.2.2.2-3 and 6.2.2.2-4 show contours of fracture saturation and vectors of water flux for the flow fields at 100 years, 500 years, 1,000 years, and 2,000 years after emplacement. (Matrix saturation is not significantly influenced by the heterogeneity in fracture permeability and is thus not presented here.) The relative length of the flux vectors is equal in Figures 6.2.2.1-5, 6.2.2.1-6 and 6.2.2.1-7, allowing for direct comparison. Heterogeneity of permeability gives rise to significant variation in fracture saturation and water flux. However, the effect of flow channeling is not strong enough to allow significant penetration of water into the dryout rock region around the drifts as long as temperature is above boiling. Mainly, water is diverted around the dryout zone and drains downward. The extent of the dryout region is similar to the homogeneous cases, measuring several meters from the drift wall at 100 years and 500 years. At 
1,000 years, after rock temperature decreases below the boiling point, saturation at the drift wall starts building up. Eventually, at 2,000 years, the effect of fracture permeability becomes evident at the drift wall as local saturation pools develop.

The following conclusions can be reached from the TH modeling analysis of thermal seepage presented in this section:

- For the mean infiltration case, the vaporization barrier is fully effective as long as rock temperature is above boiling, despite the fracture permeability variation. Channelized fast flow cannot penetrate into the superheated rock area during this "hot" period.

- At later times, heterogeneity in fracture permeability gives rise to local saturation buildup at the drift wall. However, this increase is slow, and saturation at 4,000 years after emplacement is still increasing to eventually reach the long-term steady-state conditions. There is no enhancement in rock saturation close to the drift wall as a result of the thermal perturbation. The capillary barrier at the drift wall is fully effective.

Various additional simulation cases are analyzed in the following sections of this report to test if these findings hold for higher infiltration rates, adjusted rock properties, and different thermal loads. 


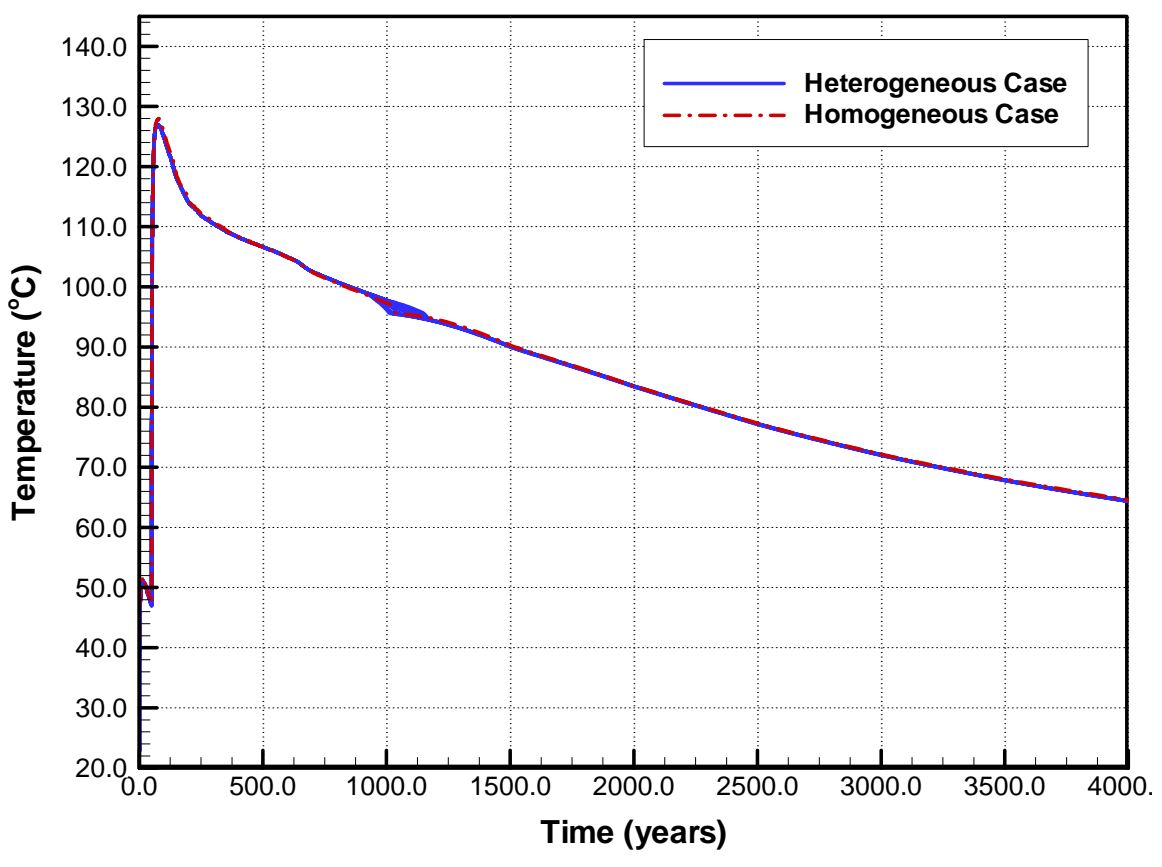

(a)

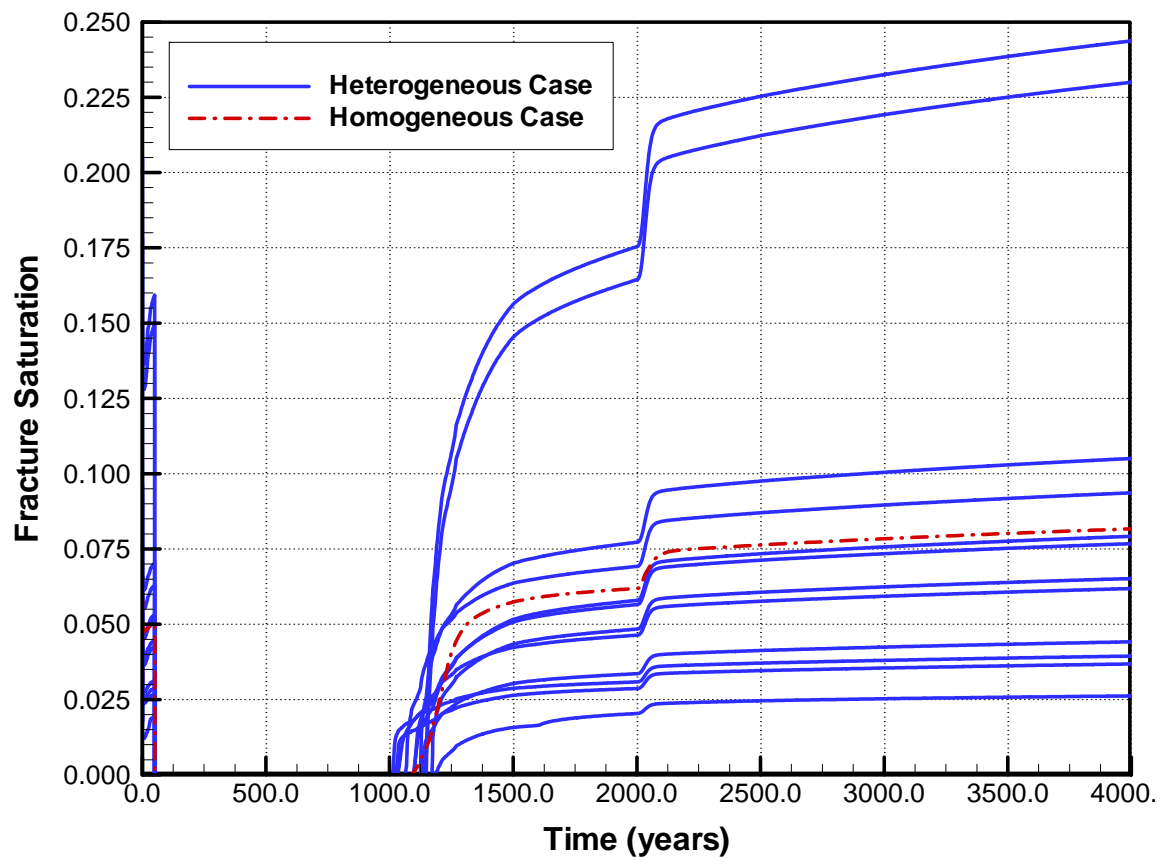

(b)

Output DTN: LB0303DSCPTHSM.001.

NOTE: Figure shows all rock discretization elements along the drift periphery from the crown to the springline.

Figure 6.2.2.2-2. (a) Fracture Temperature and (b) Fracture Saturation at the Drift Crown for Tptpmn Submodel with Heterogeneous Permeability Field (Simulation Case MN-HET-01, Realization 1), in Comparison with Homogeneous Simulation Run (Simulation Case $\mathrm{MN}-\mathrm{HOM}-06$ ) 


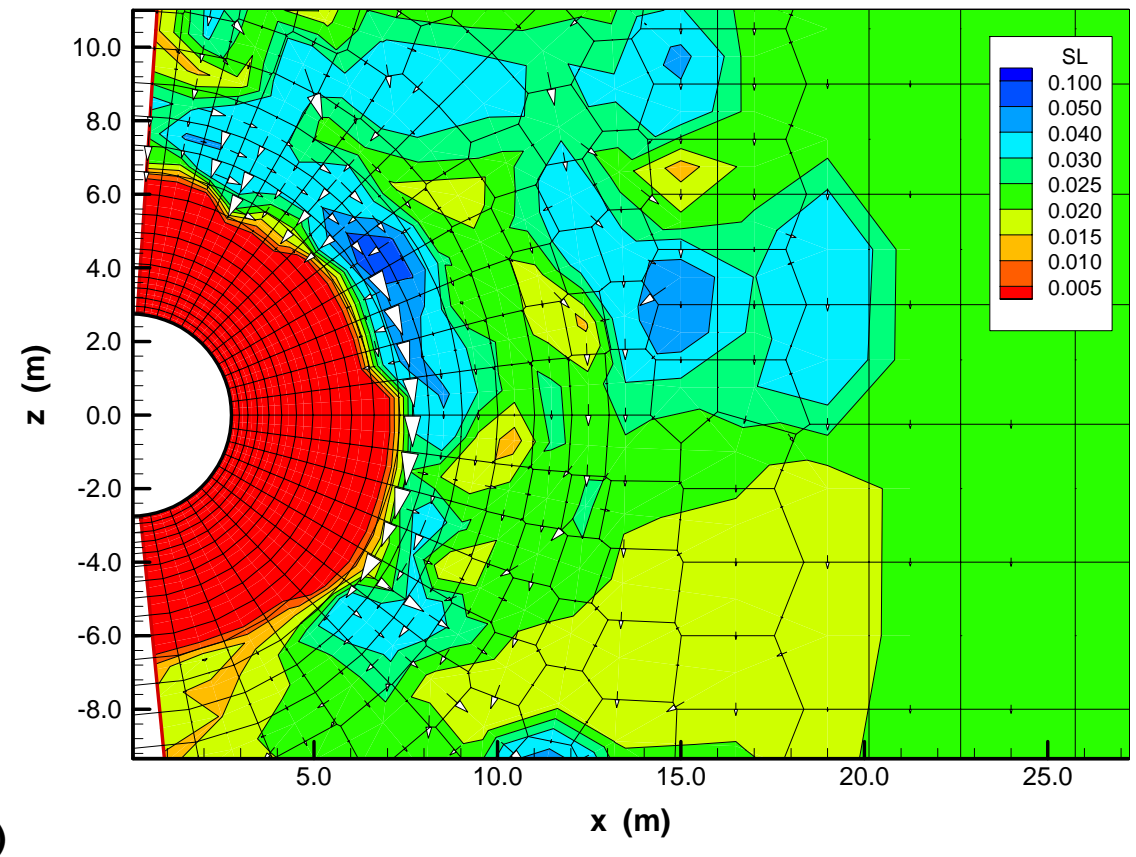

(a)

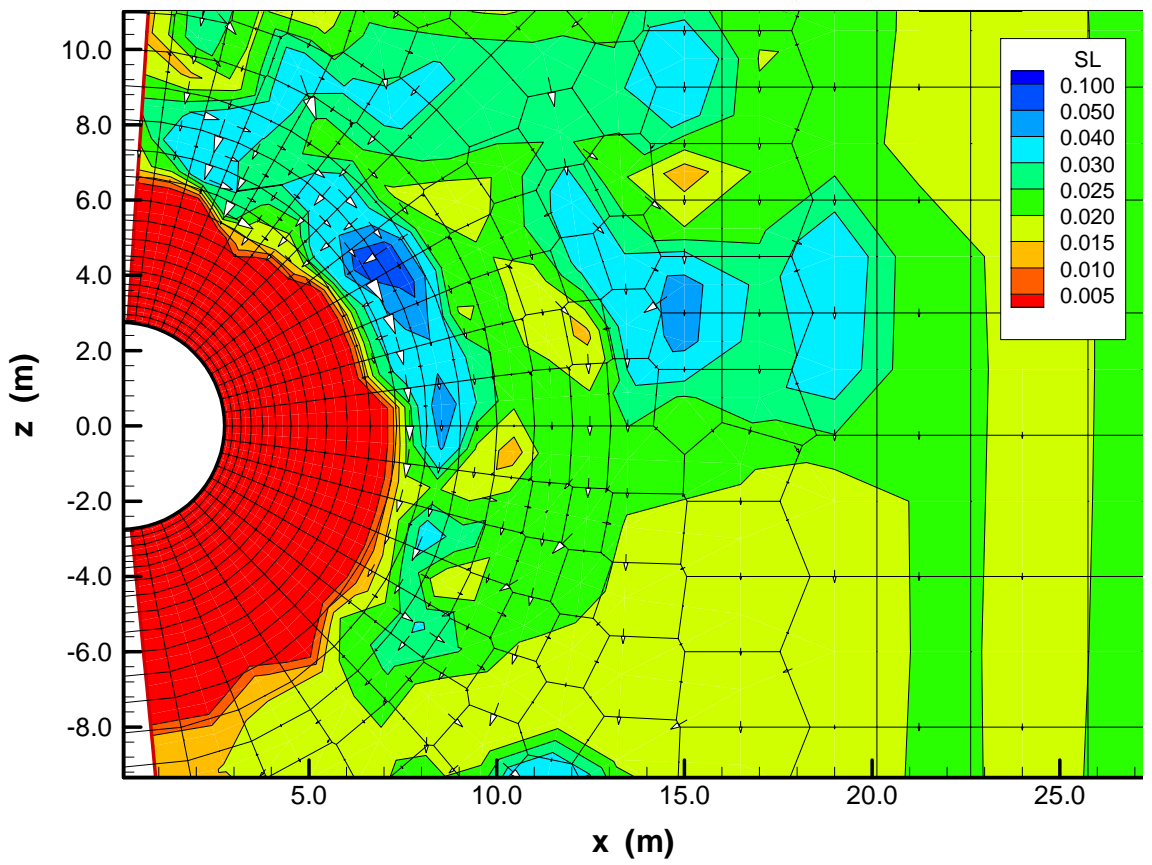

Output DTN: LB0303DSCPTHSM.001.

NOTE: SL denotes liquid saturation.

Figure 6.2.2.2-3. Fracture Saturation and Liquid Flux for Tptpmn Submodel with Heterogeneous Permeability Field (Simulation Case MN-HET-01, Realization 1) at (a) 100 Years and (b) 500 Years after Waste Emplacement 


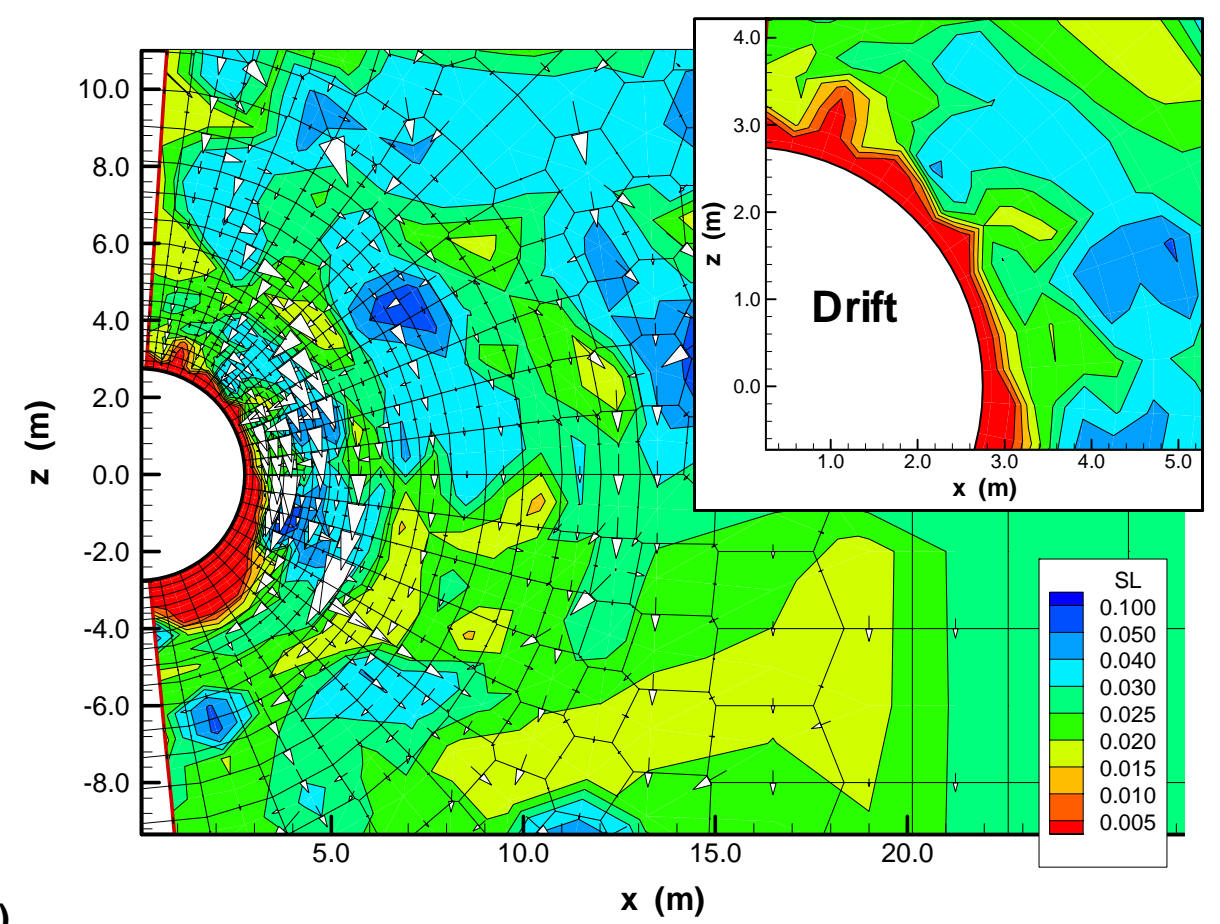

(a)

$x(m)$

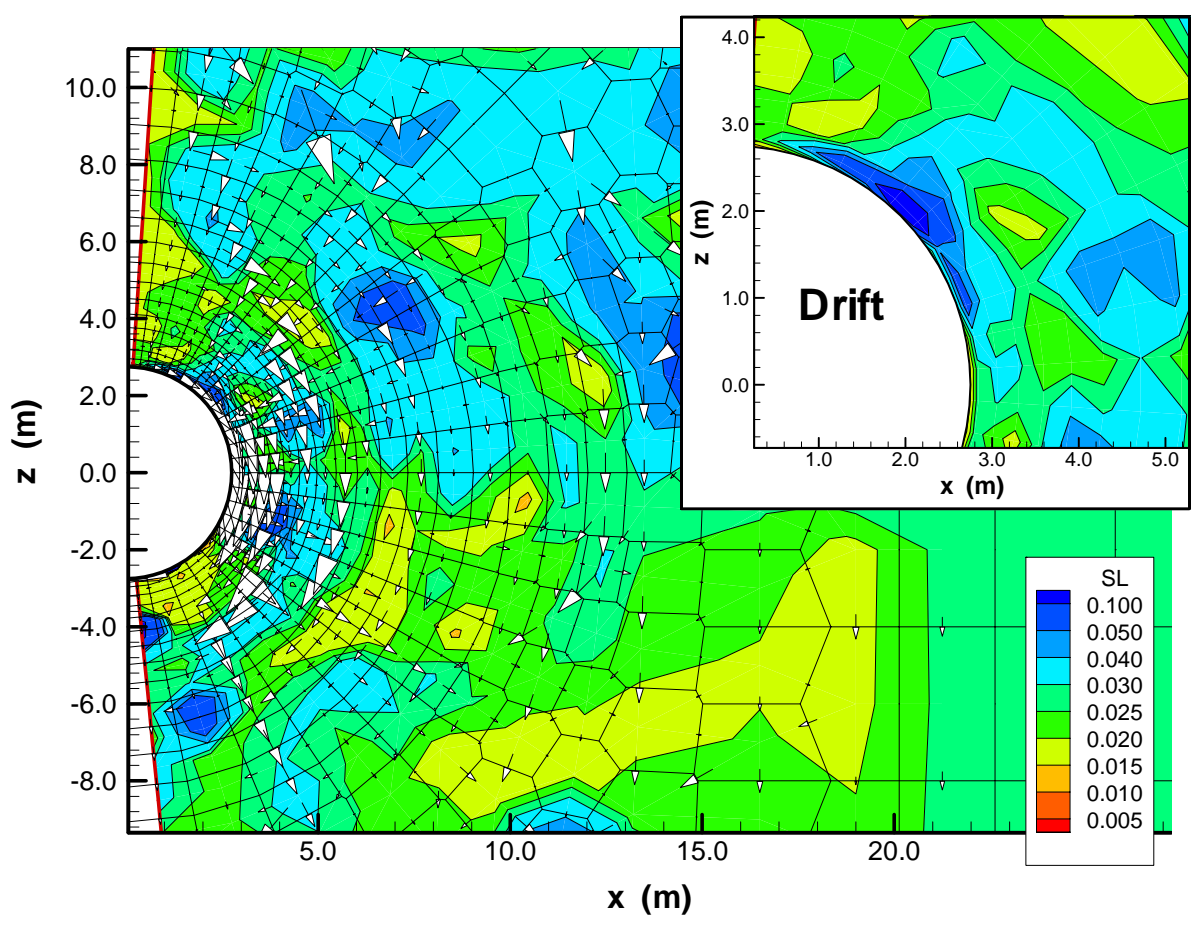

Output DTN: LB0303DSCPTHSM.001.

NOTE: SL denotes liquid saturation. The small frame gives a close-up view of the upper right drift vicinity.

Figure 6.2.2.2-4. Fracture Saturation and Liquid Flux for Tptpmn Submodel with Heterogeneous Permeability Field (Simulation Case MN-HET-01, Realization 1) at (a) 1,000 Years and (b) 2,000 Years after Waste Emplacement 


\subsection{Thermal Seepage for Infiltration Scenarios with Flow Focusing}

The TH simulation runs presented in this section assume flux multiplication factors of 5 and 10 , respectively. In the first case, the imposed infiltration flux into the model domain is $30 \mathrm{~mm} / \mathrm{yr}$ up to 600 years, $80 \mathrm{~mm} / \mathrm{yr}$ between 600 and 2,000 years, and $125 \mathrm{~mm} / \mathrm{yr}$ after 2,000 years (Simulation Case MN-HET-02; see Table 6.2.1.6-1). In the second case, these values are 60 $\mathrm{mm} / \mathrm{yr}, 160 \mathrm{~mm} / \mathrm{yr}$, and $250 \mathrm{~mm} / \mathrm{yr}$ for the respective time periods (Simulation Case MN-HET-03, see Table 6.2.1.6-1). Rock properties and thermal conditions are equal to those discussed in Section 6.2.2.2.3. The temperature conditions at the drift wall are illustrated in Figure 6.2.2.2-5, using Realization 1 of the random field. While the temperature history of all gridblocks along the wall is uniform except during the transition from boiling to nonboiling conditions, distinct differences occur between the two flux multiplication cases (compare to homogenous cases in Section 6.2.2.1.2). The higher infiltration rate in the factor-10 case gives rise to a significant decrease in temperature, as much as $18^{\circ} \mathrm{C}$ after 2,000 years and $12^{\circ} \mathrm{C}$ after 4,000 years after emplacement. The length of the boiling period is also slightly shorter for the higher infiltration case, lasting only about 500 years. In comparison, the boiling period was about 1,000 years for the mean infiltration scenario without flow focusing.

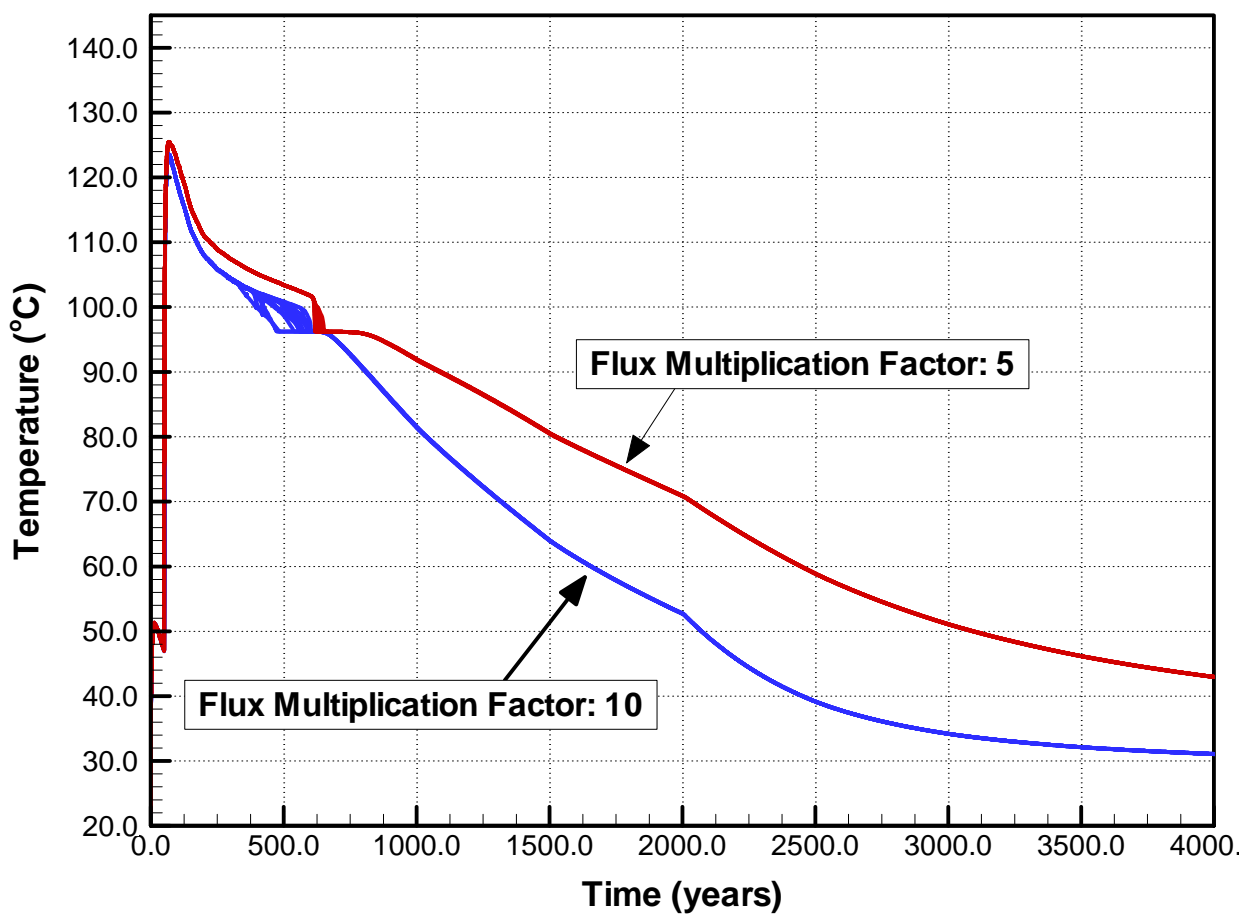

Output DTN: LB0303DSCPTHSM.001.

NOTE: $\quad$ Figure shows all rock discretization elements along the drift periphery from the crown to the springline. The simulation cases are MN-HET-02 and MN-HET-03, using Heterogeneous Realization 1.

Figure 6.2.2.2-5. Rock Temperature along Drift Periphery for Tptpmn Submodel with Different Infiltration Scenarios 
The following figures show the fracture saturation history at all gridblocks close to the drift. In cases where seepage into the drift occurs, the figures also present the evolution of thermal seepage percentage with time. As pointed out earlier, the seepage percentage is calculated as the ratio between the seepage flux and the percolation flux arriving at a cross-sectional area corresponding to the footprint of the drift (using the constant present-day percolation value for 0 to 600 years, the constant monsoon percolation value for 600 to 2,000 years, and the constant glacial transition value for 2,000 to 4,000 years). The thermal seepage rates are compared in these figures with the respective long-term ambient seepage results from steady-state simulations (see Table 6.2.2.2-1).

Figures 6.2.2.2-6 and 6.2.2.2-7 present results for Realization 1 and flux multiplication factors of 5 and 10, respectively. The saturation curves demonstrate that no water arrives at the drift during the boiling period. As rock temperature decreases and the first stepwise change in infiltration occurs at 600 years, the saturation values build up strongly, while strong variability in saturation becomes evident. For a flux multiplication factor of 5 (Figure 6.2.2.2-6a), the saturation buildup is generally slower and less pronounced compared to the case with factor 10 (Figure 6.2.2.2-7a). The change from monsoon to glacial transition climate at 2,000 years (from 80 to $125 \mathrm{~mm} / \mathrm{yr}$ ) is needed for the factor-5 case to eventually bring the saturation up to the threshold value for seepage. As a result, seepage starts to occur after about 2,500 years (Figure 6.2.2.2-6b). The seepage percentage increases with time up to 4.32 percent at 4,000 years, which is still significantly smaller than the long-term ambient value of 12.79 percent. Apparently, it will take a much longer time for the thermal seepage percentage to arrive at this long-term value. There are two reasons for this delay. First, the flow system at 4,000 years is still adjusting to the infiltration change at 2,000 years; a steady-state situation has not been reached yet. Second, the rock temperature at 4,000 years is still above ambient (about $43^{\circ} \mathrm{C}$ ), so that the fluid properties are different from the long-term situation. Viscosity, for example, is about 40 percent smaller than at ambient temperature. This increases the hydraulic conductivity by a significant factor, allowing more flow diversion around the drift and thus a better performance by the capillary barrier. Less important is the minor change in water density, which changes the seepage threshold value of capillary pressure.

For the infiltration scenario with flux multiplication factor 10 (Figure 6.2.2.2-7), saturation buildup is faster and seepage starts earlier, at about 1,400 years after emplacement while still in the monsoon climate period. With the stepwise increase of infiltration at 2,000 years, the seepage percentage increases strongly, and water starts to seep at a second location along the drift wall. At the end of the simulation period, the thermal seepage percentage is at 17.13 percent, only slightly smaller than the long-term ambient value of 19.54 percent for a 250 $\mathrm{mm} / \mathrm{yr}$ percolation flux. In contrast to the factor-5 case, the rock temperature at 4,000 years is only slightly elevated compared to the ambient state, so that viscosity differences are not significant.

Note that in both simulation cases of flux multiplication factors 5 and 10, the long-term ambient seepage from steady-state simulation runs performed with the present day infiltration rate-i.e., $30 \mathrm{~mm} / \mathrm{yr}$ and $60 \mathrm{~mm} / \mathrm{yr}$, respectively - is zero. In other words, even without heating of the repository, the capillary barrier at the drift wall is predicted to be fully effective during the first 600 years after waste emplacement. That no water arrives at the drift wall during these first 
600 years as a result of the vaporization barrier provides additional confidence, as two fully effective barriers operate simultaneously.

Figures 6.2.2.2-8 and 6.2.2.2-9 give saturation and seepage history for Realization 2 and flux multiplication factors of 5 and 10, respectively. The results are similar to Realization 1 . For the smaller infiltration rate, seepage starts at about 3,000 years, with a seepage percentage that is still much smaller than the long-term ambient value for $125 \mathrm{~mm} / \mathrm{yr}$ percolation. For the factor-10 case, water starts seeping at 1,500 years, and the amount of seepage is close to the long-term value at the end of the simulation period. Note that the scale of the seepage axis is different from Realization 1. In both infiltration cases, water does not arrive at the drift as long as the average rock temperature at the drift wall is above boiling.

In Realization 3, no seepage was obtained for the long-term ambient simulations with either 30, 80, or $125 \mathrm{~mm} / \mathrm{yr}$ infiltration. Thus, no thermal seepage is expected for the simulation run with flux multiplication factor 5. For the factor-5 case, Figure 6.2.2.2-10 shows that the fracture saturations at the drift wall stay below the threshold value during the entire simulation period; i.e., there is no thermal seepage for the infiltration scenario. For $250 \mathrm{~mm} / \mathrm{yr}$, the steady-state simulation resulted in long-term ambient seepage of 8.32 percent. However, thermal seepage is zero for the entire 4,000-year thermal period, because the maximum saturation stays below the threshold value (see Figure 6.2.2.2-11). Given the shape of the saturation curve, it may take a much longer time for seepage to occur. Table 6.2.2.2-1 may give a reason for this apparent difference between Realization 3 and the other realizations. In Realization 3, the seepage threshold saturation is barely exceeded for the $250 \mathrm{~mm} / \mathrm{yr}$ percolation, while the other realizations with that percolation rate show maximum values clearly above the threshold. Thus, the first two realizations are more likely to reach the threshold saturation within a reasonable time period.

The following conclusions can be reached from the TH modeling analysis of thermal seepage presented in this section:

- The vaporization barrier is effective as long as boiling conditions persist in the rock close to the drifts. Even for high infiltration fluxes, channelized fast flow cannot penetrate into the superheated rock during the "hot" time period.

- The period of above-boiling temperature coincides with the period of present-day mean infiltration, which is significantly smaller than infiltration during monsoon or glacial transition climate. This means that two fully effective barriers are operating simultaneously during the first several hundred years after waste emplacement, the vaporization barrier and the capillary barrier.

- Thermal seepage is always smaller than the long-term ambient seepage percentage calculated from steady-state simulation runs using the respective infiltration rate of the three climate periods.

- In general, thermal seepage may start to occur when the rock temperature is below boiling. Whether thermal seepage occurs (after the vaporization barrier has vanished) depends on the effectiveness of the capillary barrier, as evaluated by the long-term ambient seepage simulations for the steady state. The time when thermal seepage starts to occur depends on the time-dependent rewetting of the fractures at the drift wall. 


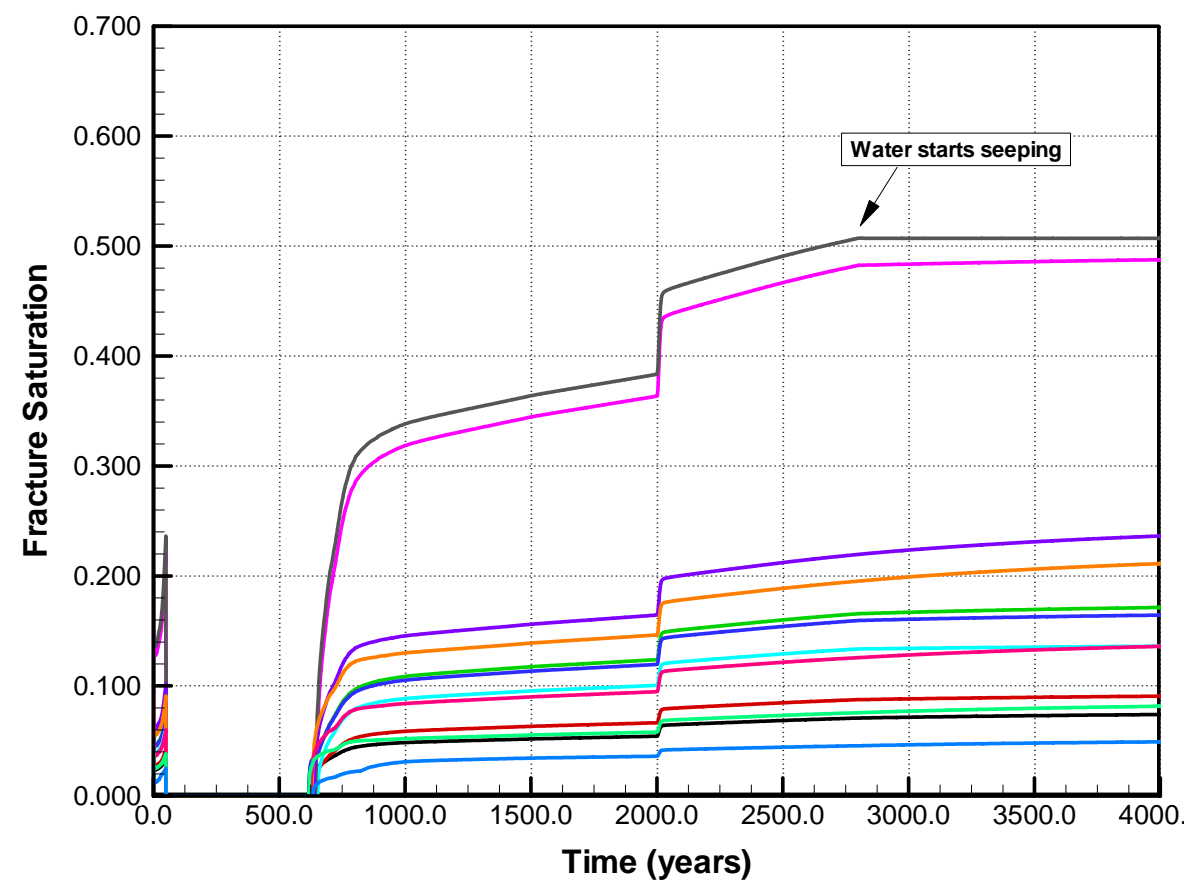

(a)

Time (years)

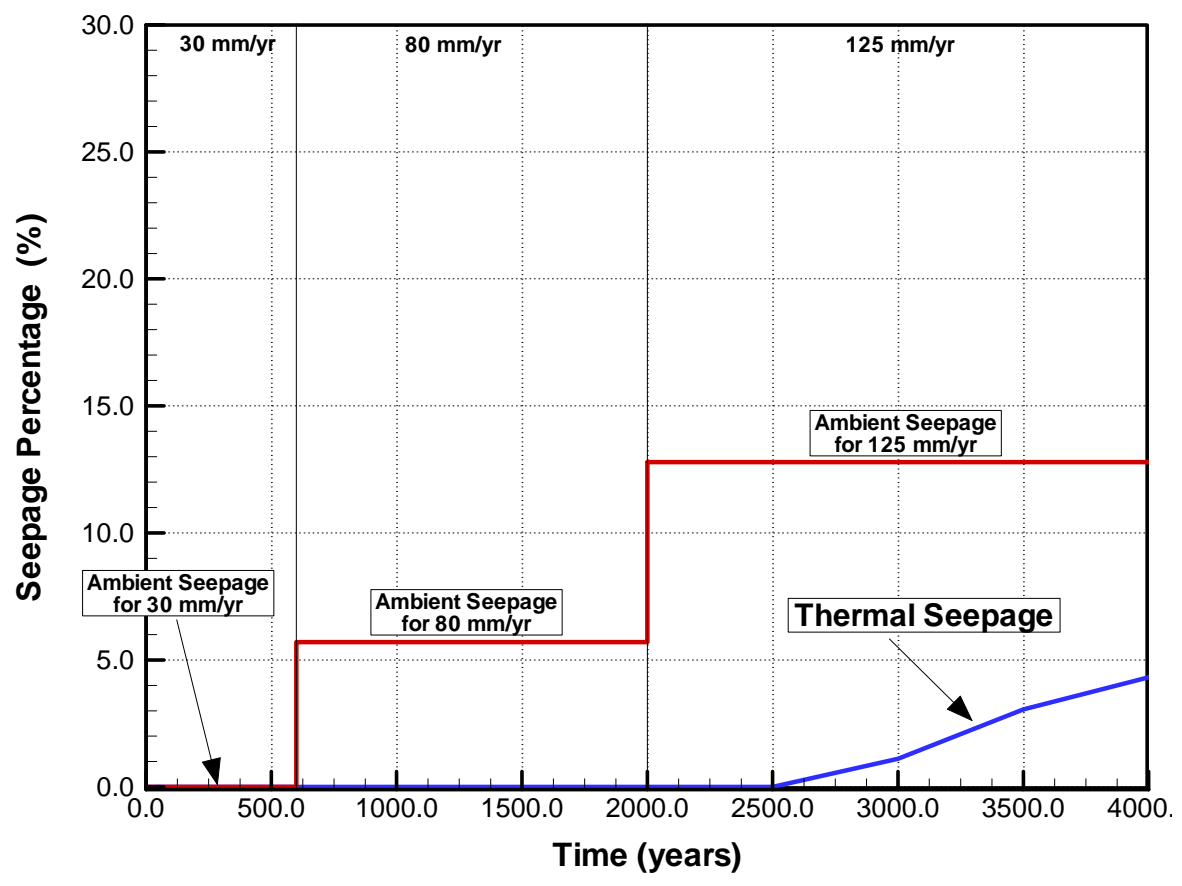

Output DTNs: (a) LB0303DSCPTHSM.001, (b) LB0301DSCPTHSM.002.

NOTE: (a) fracture saturation for all rock discretization elements along the drift periphery from the crown to the springline, and (b) seepage percentage for thermal run and long-term ambient runs.

Figure 6.2.2.2-6. TH Conditions for Tptpmn Submodel with Flux Multiplication Factor 5 (Simulation Case MN-HET-02, Realization 1) 


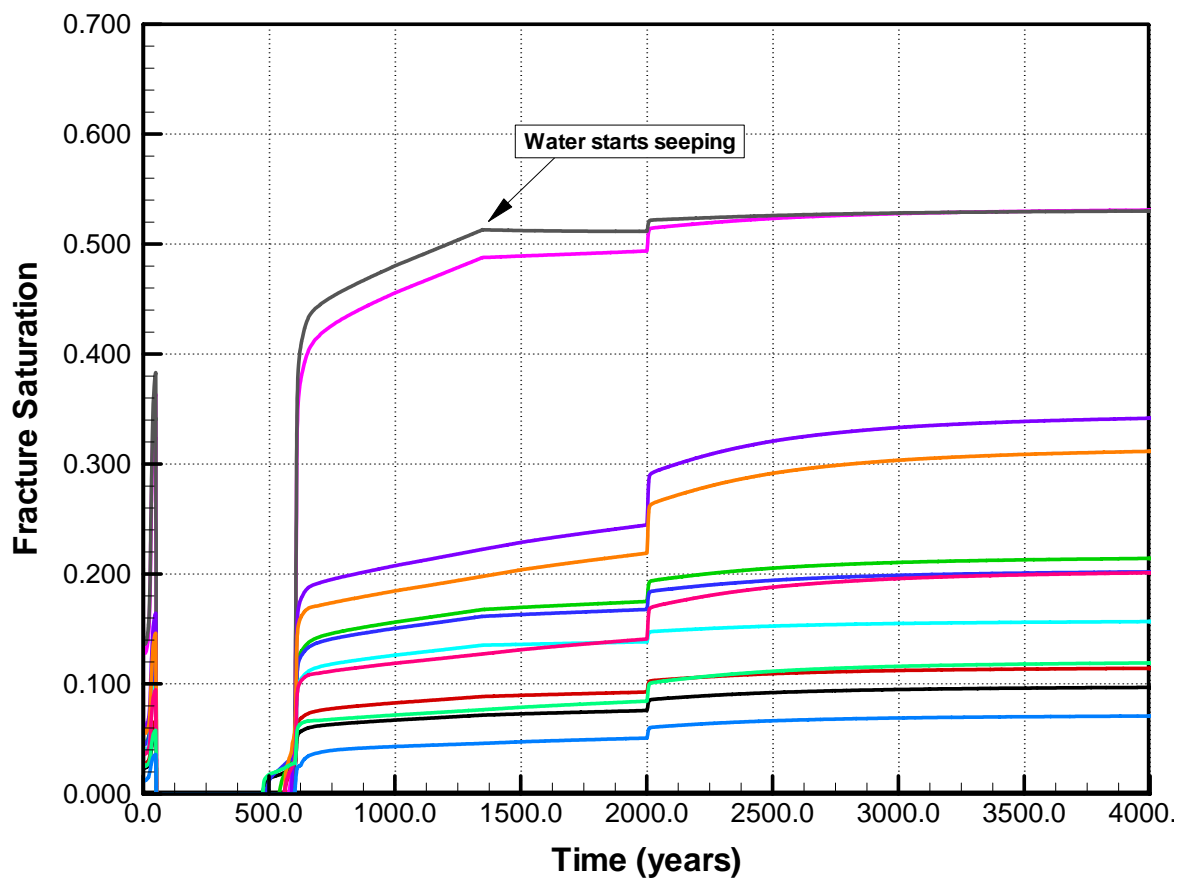

(a)

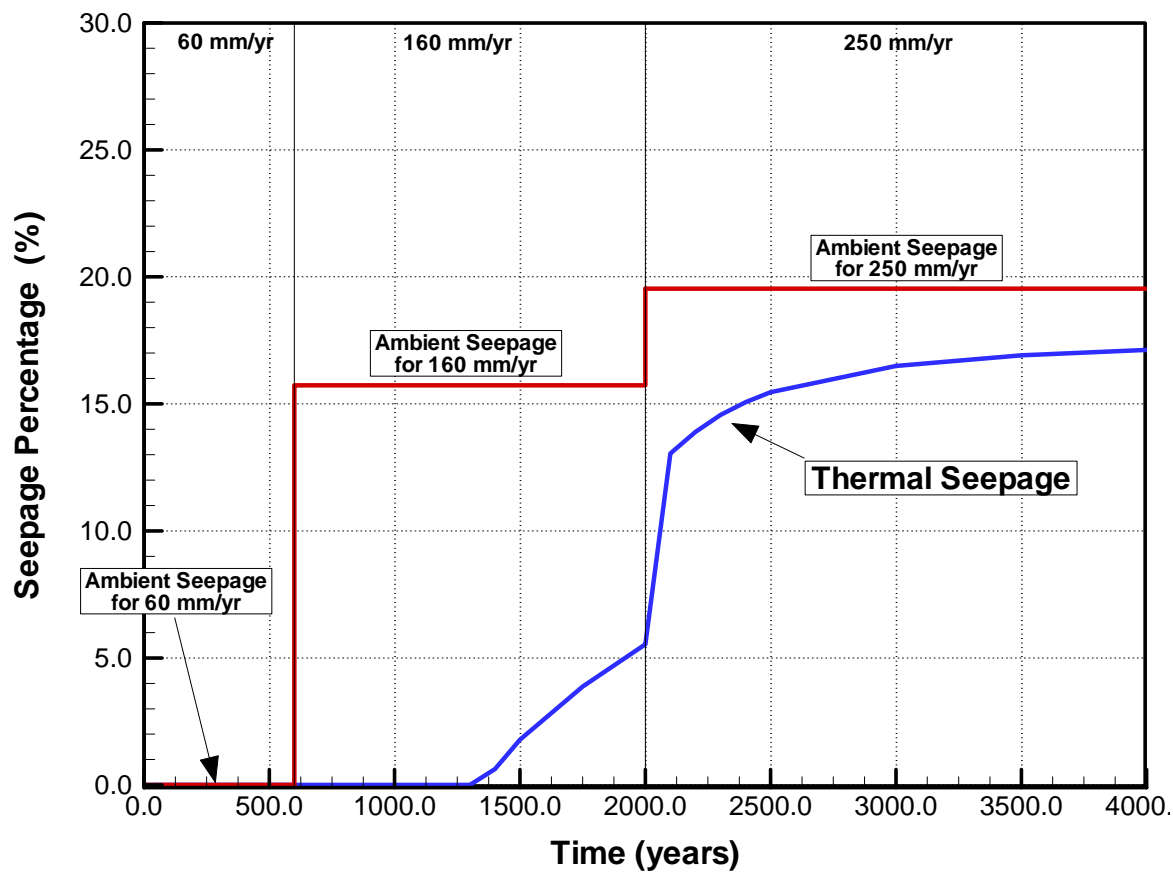

(b)

Output DTNs: (a) LB0303DSCPTHSM.001, (b) LB0301DSCPTHSM.002.

NOTE: (a) fracture saturation for all rock discretization elements along the drift periphery from the crown to the springline, and (b) seepage percentage for thermal run and long-term ambient runs.

Figure 6.2.2.2-7. TH Conditions for Tptpmn Submodel with Flux Multiplication Factor 10 (Simulation Case MN-HET-03, Realization 1) 


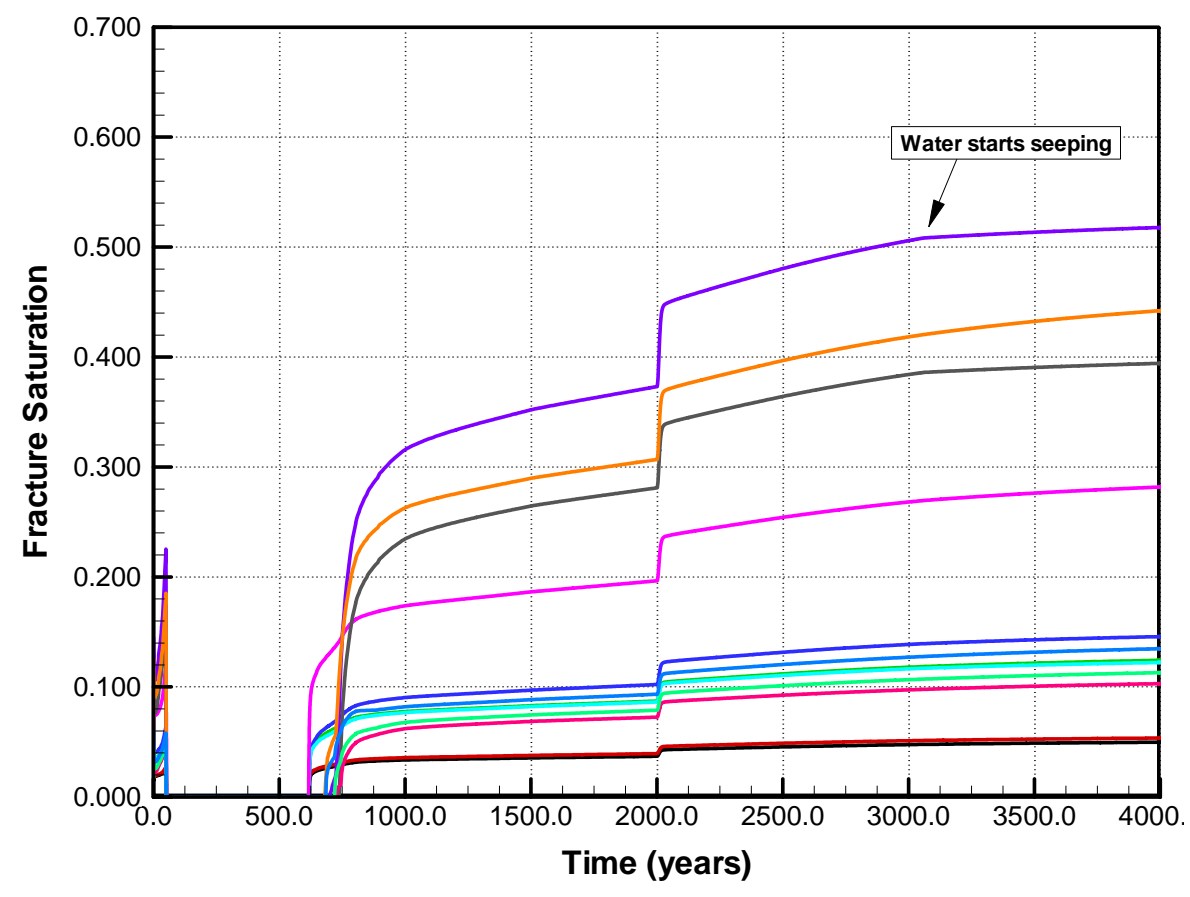

(a)

Time (years)

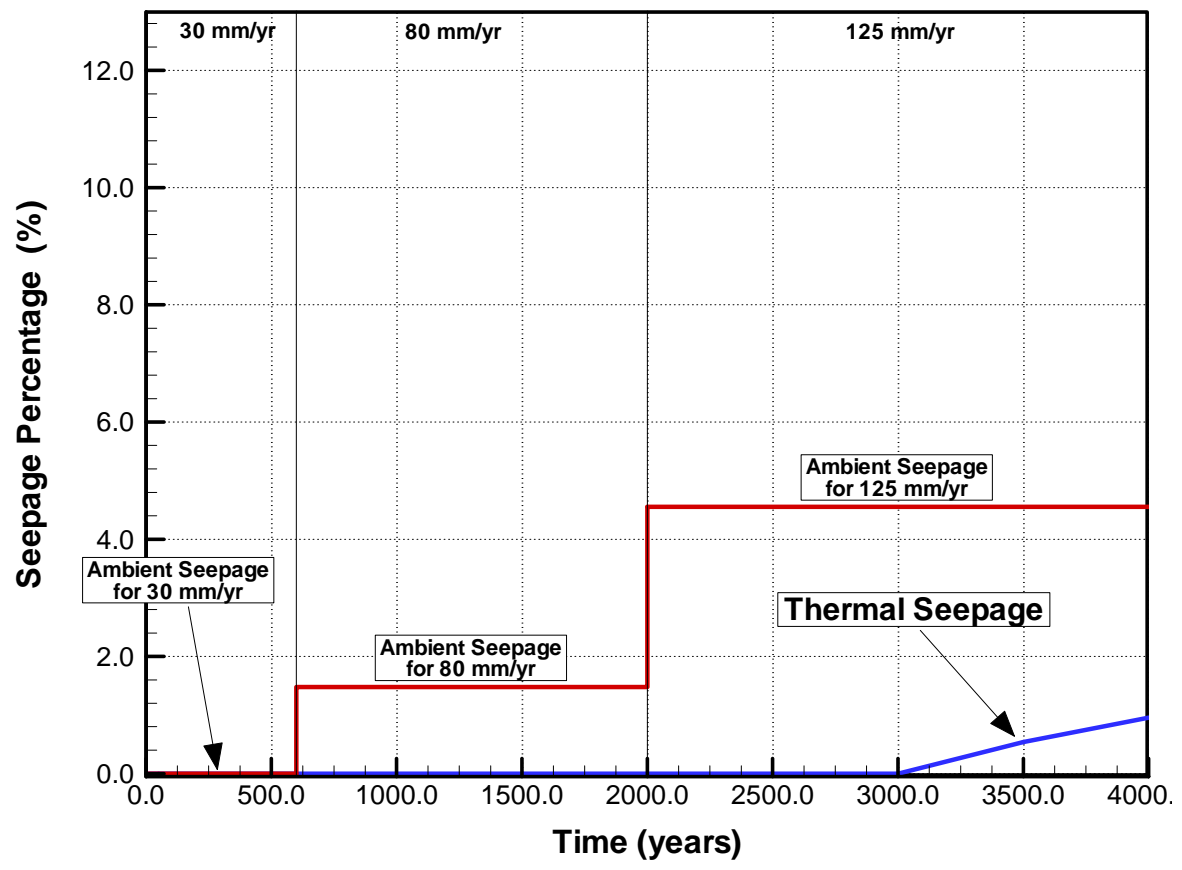

Output DTNs: (a) LB0303DSCPTHSM.001, (b) LB0301DSCPTHSM.002.

NOTE: (a) fracture saturation for all rock discretization elements along the drift periphery from the crown to the springline, and (b) seepage percentage for thermal run and long-term ambient runs.

Figure 6.2.2.2-8. TH Conditions for Tptpmn Submodel with Flux Multiplication Factor 5 (Simulation Case MN-HET-02, Realization 2) 


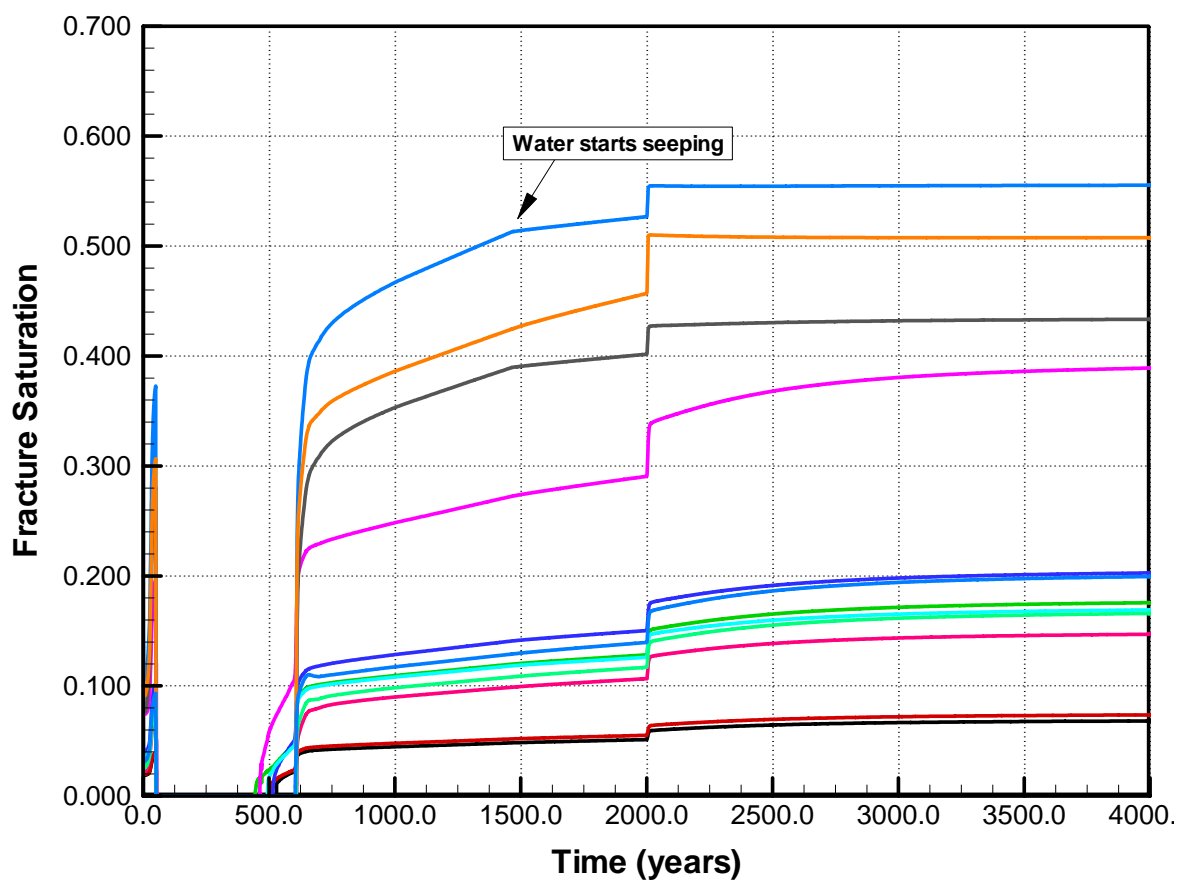

(a)

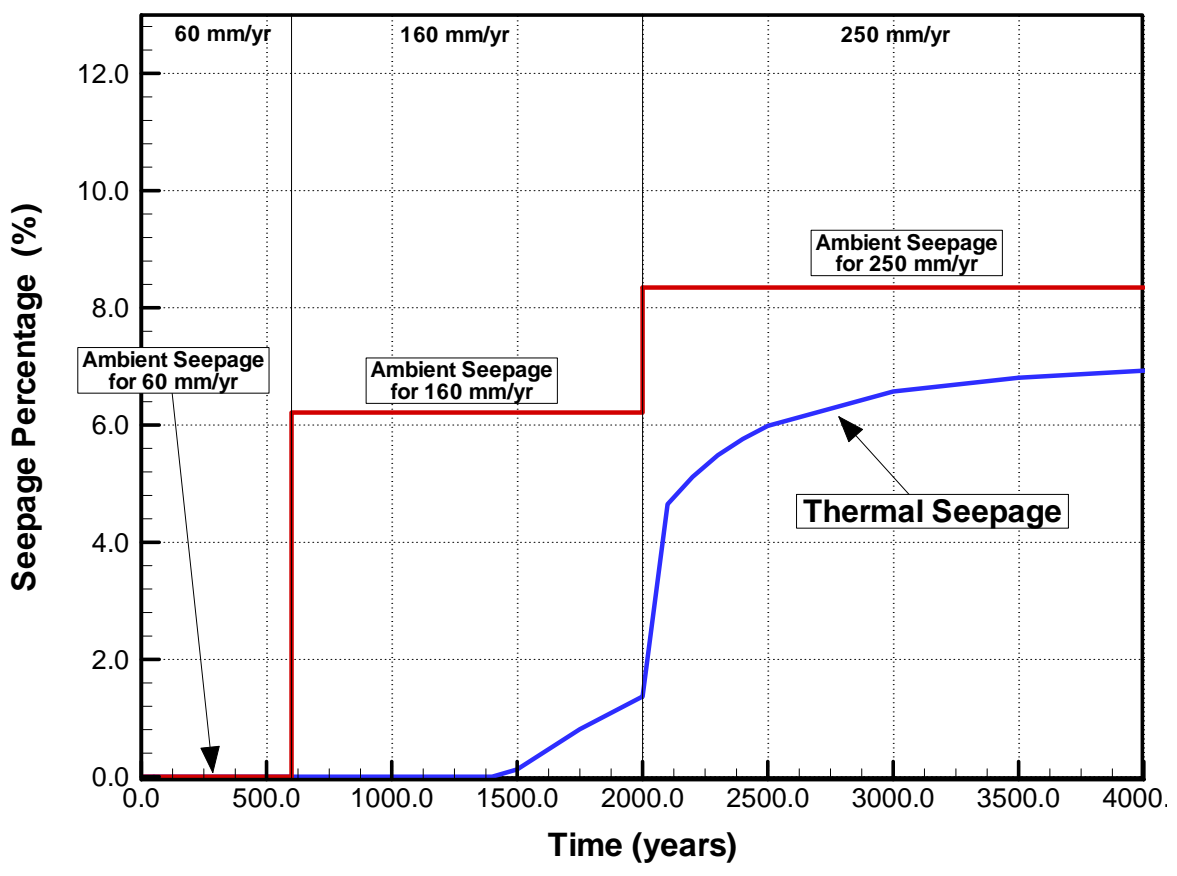

Output DTNs: (a) LB0303DSCPTHSM.001, (b) LB0301DSCPTHSM.002.

NOTE: (a) fracture saturation for all rock discretization elements along the drift periphery from the crown to the springline, and (b) seepage percentage for thermal run and long-term ambient runs.

Figure 6.2.2.2-9. TH Conditions for Tptpmn Submodel with Flux Multiplication Factor 10 (Simulation Case MN-HET-03, Realization 2) 


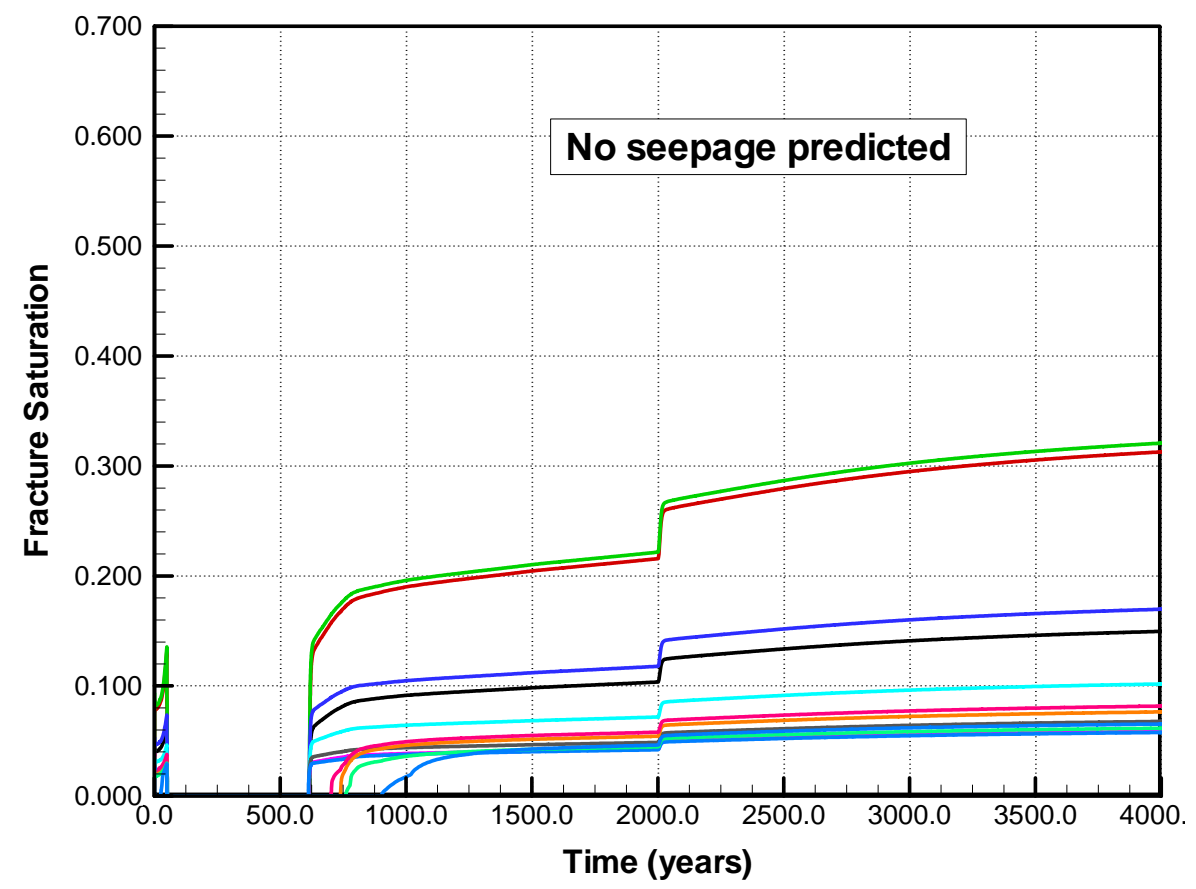

Output DTN: LB0303DSCPTHSM.001.

NOTE: $\quad$ Figure shows all rock discretization elements along the drift periphery from the crown to the springline.

Figure 6.2.2.2-10. Fracture Saturation for Tptpmn Submodel with Flux Multiplication Factor 5 (Simulation Case MN-HET-02, Realization 3) 


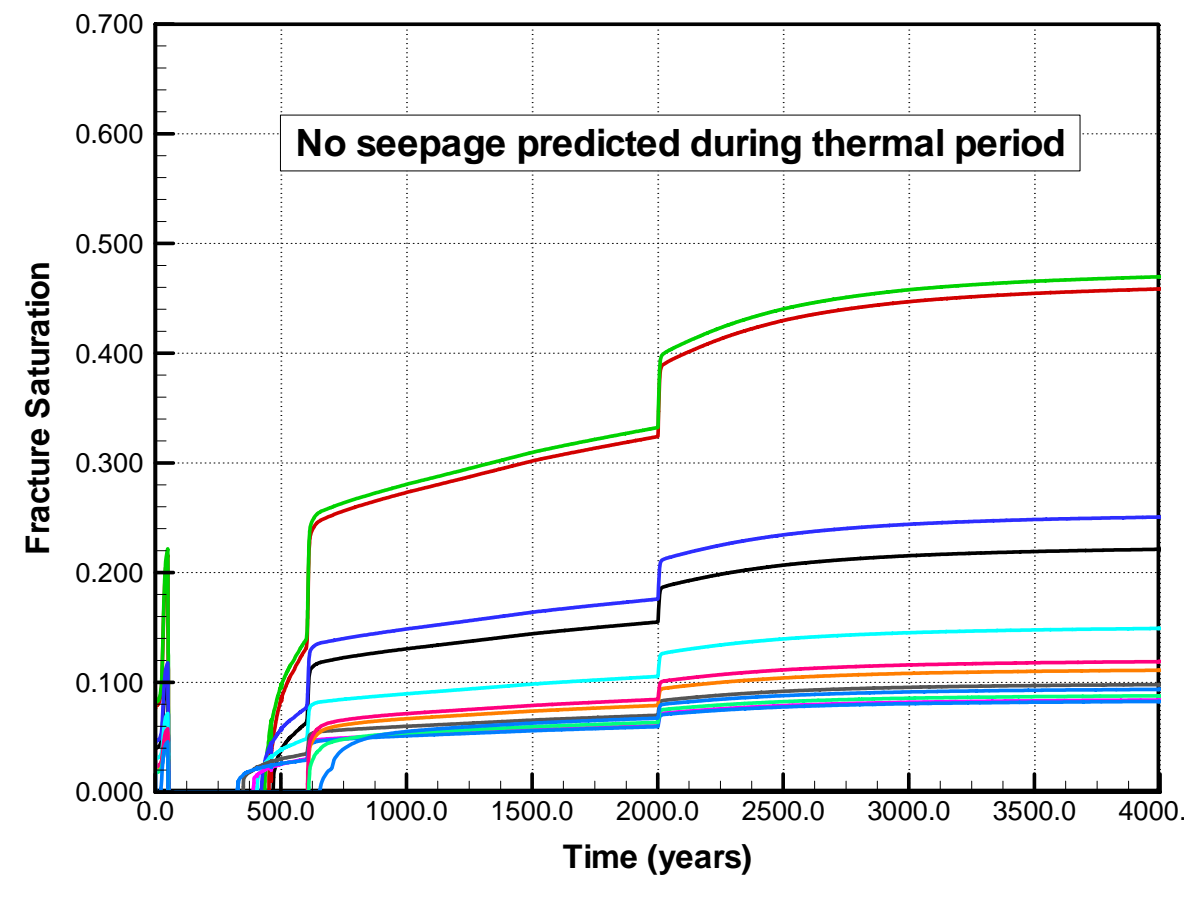

(a)

Time (years)

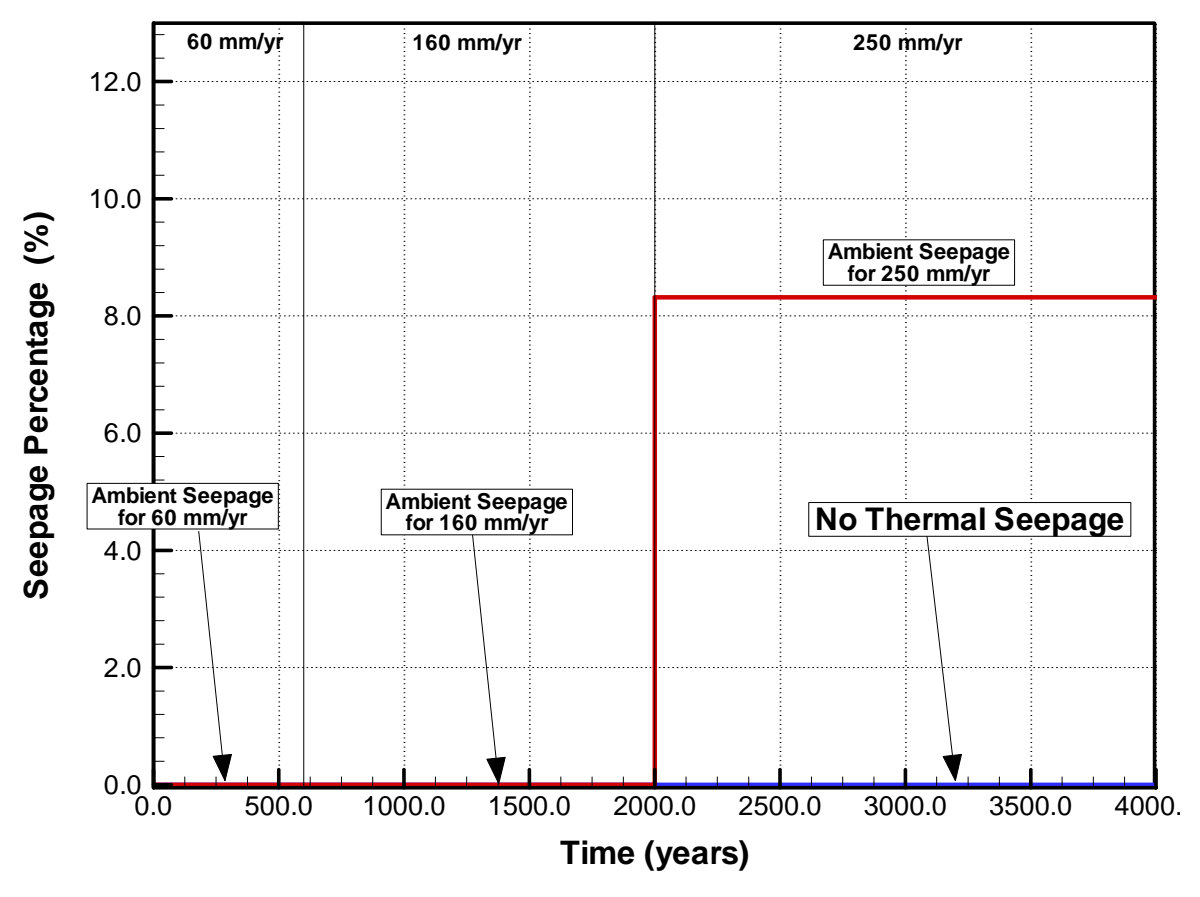

Output DTNs: (a) LB0303DSCPTHSM.001, (b) LB0301DSCPTHSM.002.

NOTE: (a) fracture saturation for all rock discretization elements along the drift periphery from the crown to the springline, and (b) seepage percentage for thermal run and long-term ambient runs.

Figure 6.2.2.2-11. TH Conditions for Simulation Run with Flux Multiplication Factor 10 (Simulation Case MN-HET-03, Realization 3) 


\subsubsection{Simulation Results for the Tptpll Submodel}

This subsection of the report presents modeling results for a representative drift located in the Tptpll geological unit. The TH properties of this host rock unit are different from the properties of the Tptpmn unit discussed in Section 6.2.2. While the fundamental processes are similar, there are quantitative differences in the TH response between the Tptpll and the Tptpmn units. In the analysis below, the main focus is on these differences and their impact on thermal seepage. Thus, presentation of results below will be shorter and include only a few of all the simulation cases studied in Section 6.2.2. Similar to the Tptpmn submodel, the analysis is separated into two main areas. In Section 6.2.3.1, the major drift-scale $\mathrm{TH}$ processes in response to heat are discussed for a base-case scenario. Section 6.2.3.2 concentrates on thermal seepage at elevated infiltration, applying the specific rock-property conditions of the thermal seepage conceptual model (see Section 6.2.1.1.2).

\subsubsection{Drift-Scale Thermal-Hydrological Behavior}

The base case for a discussion of the main TH processes in the Tptpll geological unit is referred to as Simulation Case LL-HOM-01 in Figure 6.2.1.6-2 and Table 6.2.1.6-2. Boundary conditions are identical to those given in Section 6.2.2.1.1, where the thermally induced flow processes in the Tptpmn are presented. The rock properties in the drift vicinity, however, are different, because the drift is located in the Tptpll (see Table 4.1-2). Rock-property set and boundary conditions are as follows:

Thermal Load: $\quad$ Reference mode $(1.45 \mathrm{~kW} / \mathrm{m}, 86.3$ percent heat removal for 50 years $)$

Property Set: $\quad$ DS/AFM-UZ02-Mean

Drift-Scale Properties: Similar to DS/AFM-UZ02-Mean (Tptpll-unit), no heterogeneity

Infiltration: $\quad$ Mean infiltration scenario without flow focusing, stepwise change from $6 \mathrm{~mm} / \mathrm{yr}$ to $16 \mathrm{~mm} / \mathrm{yr}$ to $25 \mathrm{~mm} / \mathrm{yr}$, at 600 years and 2,000 years

Calibrated properties from the DS/AFM-UZ02-Mean property set reveal several differences between the host rock units Tptpll and Tptpmn (see Table 4.1-2). Matrix permeability in the Tptpll is more than one order of magnitude higher than that in the very tight Tptpmn rock, while fracture permeability is higher by a factor of about three. The thermal conductivity of the Tptpll accounts for the presence of air-filled lithophysal cavities, and therefore thermal conductivity in the Tptpll is about 10 percent smaller than in the Tptpmn. Apart from its effect on thermal conductivity, the potential impact of lithophysal cavities on TH processes (e.g., heat capacity of the bulk rock, storage capacity for vapor) is not explicitly modeled in this report. Uncertainties related to the thermal conductivity of the lower lithophysal rock unit are discussed in Section 6.2.4.2.2.

As a result of the smaller thermal conductivity in the Tptpll unit, the transport of thermal energy away from the drift is not as effective as in the Tptpmn. Therefore, the rock temperature measured at the drift crown is significantly higher than in the Tptpmn (Figure 6.2.3.1-1). Differences are $15^{\circ} \mathrm{C}$ at the peak temperature and $13^{\circ} \mathrm{C}$ at 4,000 years of simulation. As shown in Figure 6.2.3.1-2, the higher temperature leads to a longer dryout period for the matrix (about 
400 years) and for fractures (about 1,200 years) at the drift crown. There are two interesting observations related to the matrix saturation curve, stemming from the higher matrix permeability in the Tptpll unit. First, the stepwise change in infiltration rate at 600 years gives rise to a noticeable increase in matrix saturation. Second, matrix saturation at the drift crown increases strongly at about 1,200 years, corresponding to a strong increase in fracture saturation, implying that a significant fraction of the water rewetting the fractures is imbibed into the matrix. In contrast, matrix saturation buildup in the Tptpmn is much slower and does not show any of the above signals, because the permeability of the rock is so small. The difference in fracture saturation between the two rock units is mainly a result of the different fracture permeability. Water is more easily conducted in the higher-permeability Tptpll unit, so that the same amount of water flux corresponds to a smaller fracture saturation.

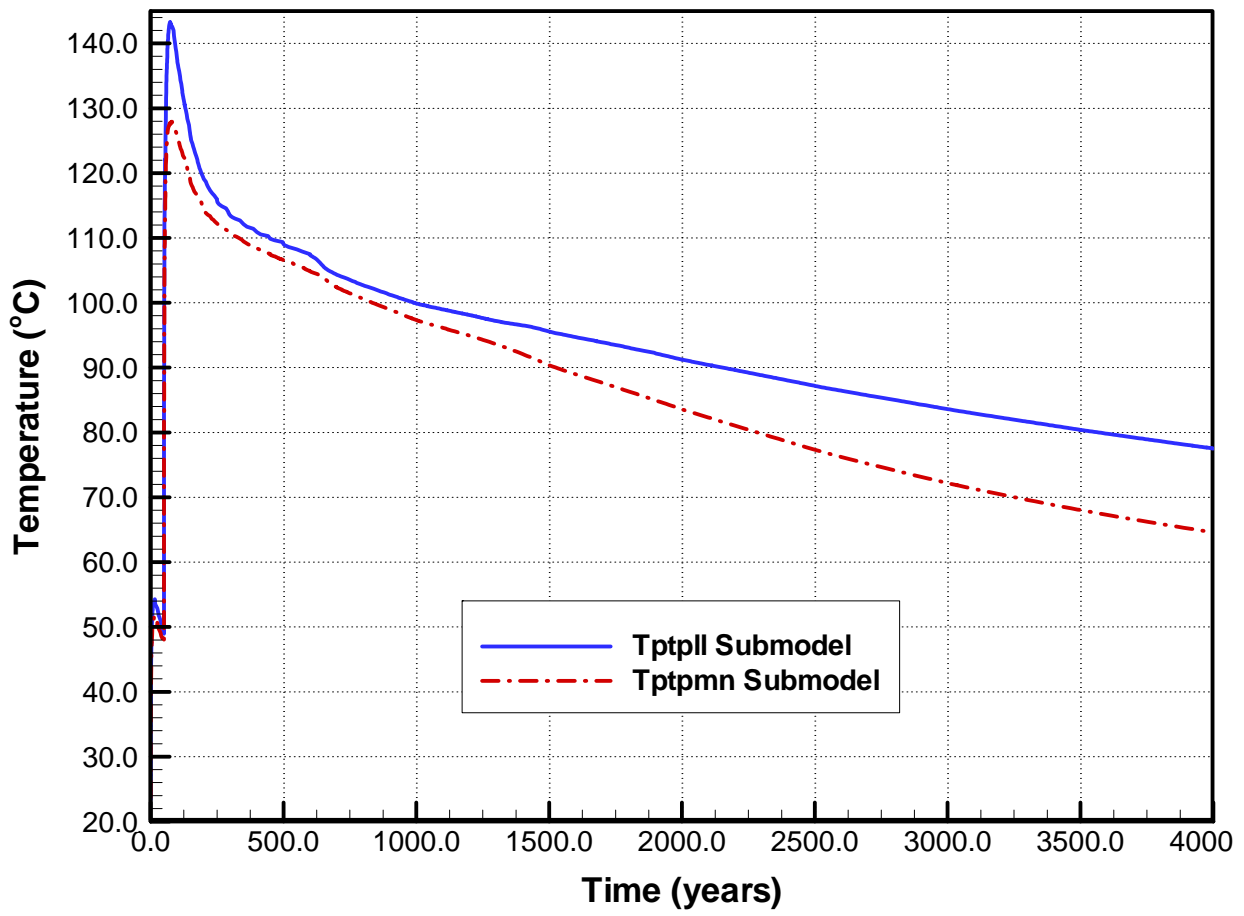

Output DTN: NA (See Section 8.5).

Figure 6.2.3.1-1. Rock Temperature at the Drift Crown for Tptpll Submodel (Simulation Case LL-HOM-01) Compared to Tptpmn Submodel (Simulation Case MN-HOM-01)

Figure 6.2.3.1-3 gives fracture saturation and downward liquid flux in a vertical cross section above the drift crown. The main characteristics of the fracture flow field are qualitatively similar to the base-case simulation of the Tptpmn unit shown in Figure 6.2.2.1-7, except that the vertical extent of the fracture dryout zone is larger in the Tptpll unit. The maximum downward flow from the condensation zone back to the heated area is $69 \mathrm{~mm} / \mathrm{yr}$ at 100 years of heating, compared to $67 \mathrm{~mm} / \mathrm{yr}$ in the Tptpmn case. 
The following conclusions can be reached from the TH modeling analysis using the Tptpll submodel:

- The Tptpll unit shows a higher peak temperature at the drift wall, a larger superheated zone, and a longer period of above-boiling temperature compared to the Tptpmn unit.

- The main characteristics of the fracture flow field in the drift vicinity, important for thermal seepage, are similar to the Tptpmn submodel (see Section 6.2.2.1.1). These findings are that (1) the fractures at the drift wall are dry as long as temperatures are above boiling, (2) most of the vaporized and subsequently condensed water drains down away from the drift, and (3) the maximum reflux of condensate towards the drift occurs at early heating stages, when the vaporization barrier is most effective. It can be concluded that results from the sensitivity study conducted with the Tptpmn submodel are also valid for the Tptpll submodel. 


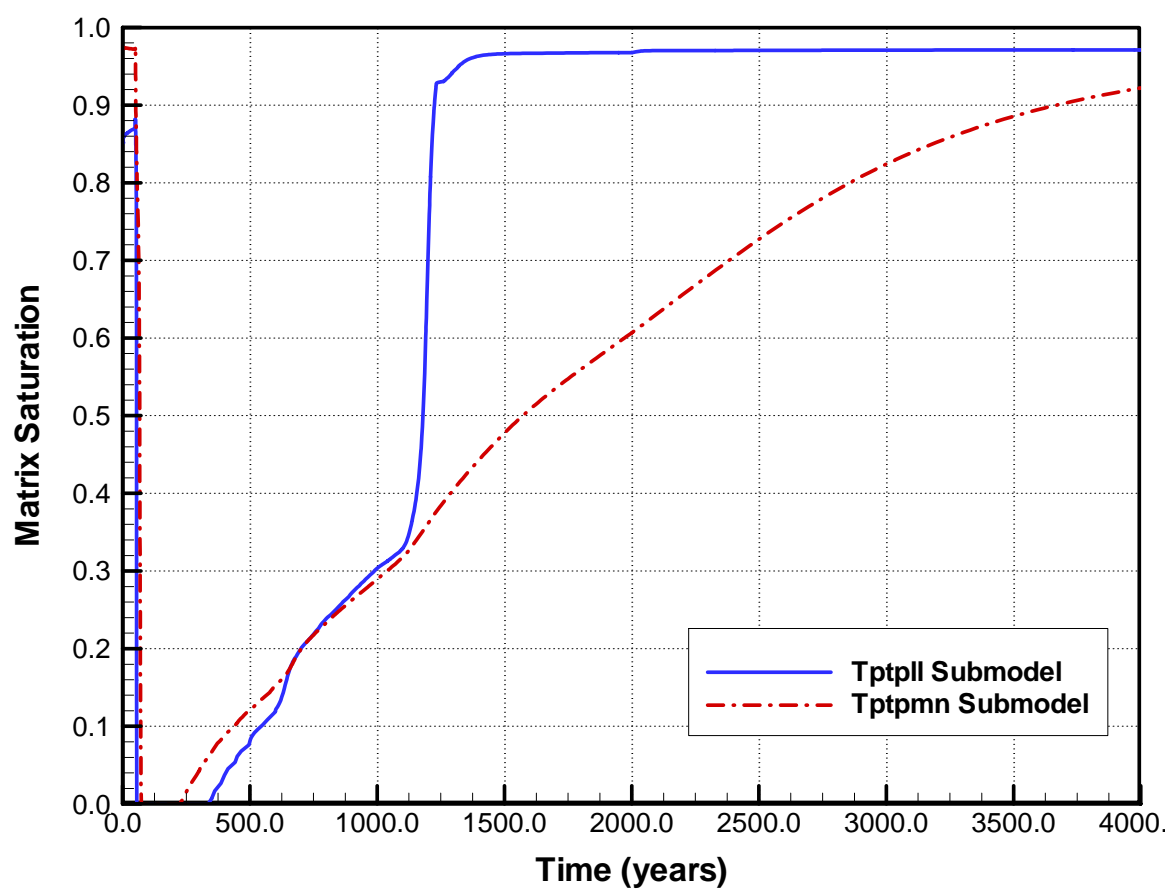

(a)

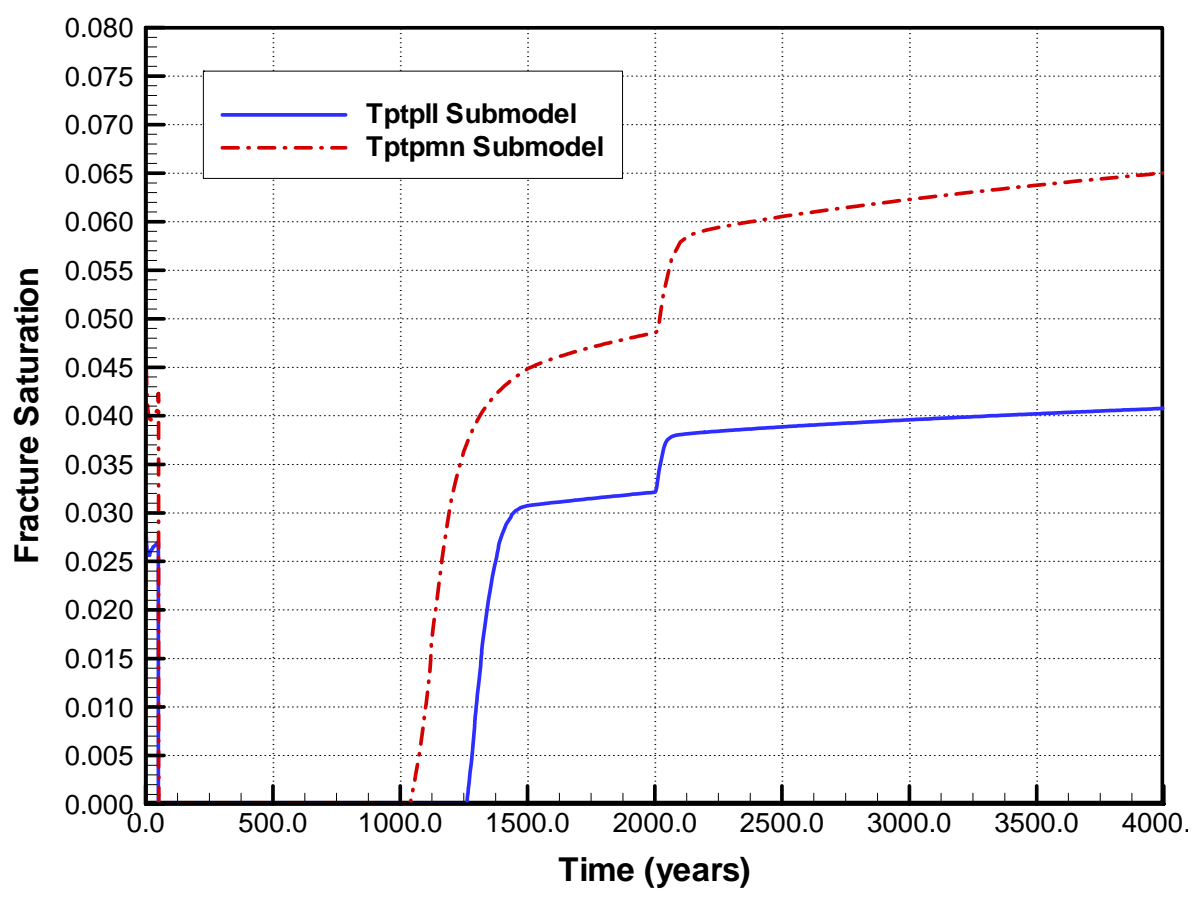

Output DTN: NA (See Section 8.5).

Figure 6.2.3.1-2. Matrix Saturation (a) and Fracture Saturation (b) at the Drift Crown for Tptpll Submodel (Simulation Case LL-HOM-01) Compared to Tptpmn Submodel (Simulation Case MN-HOM-01) 


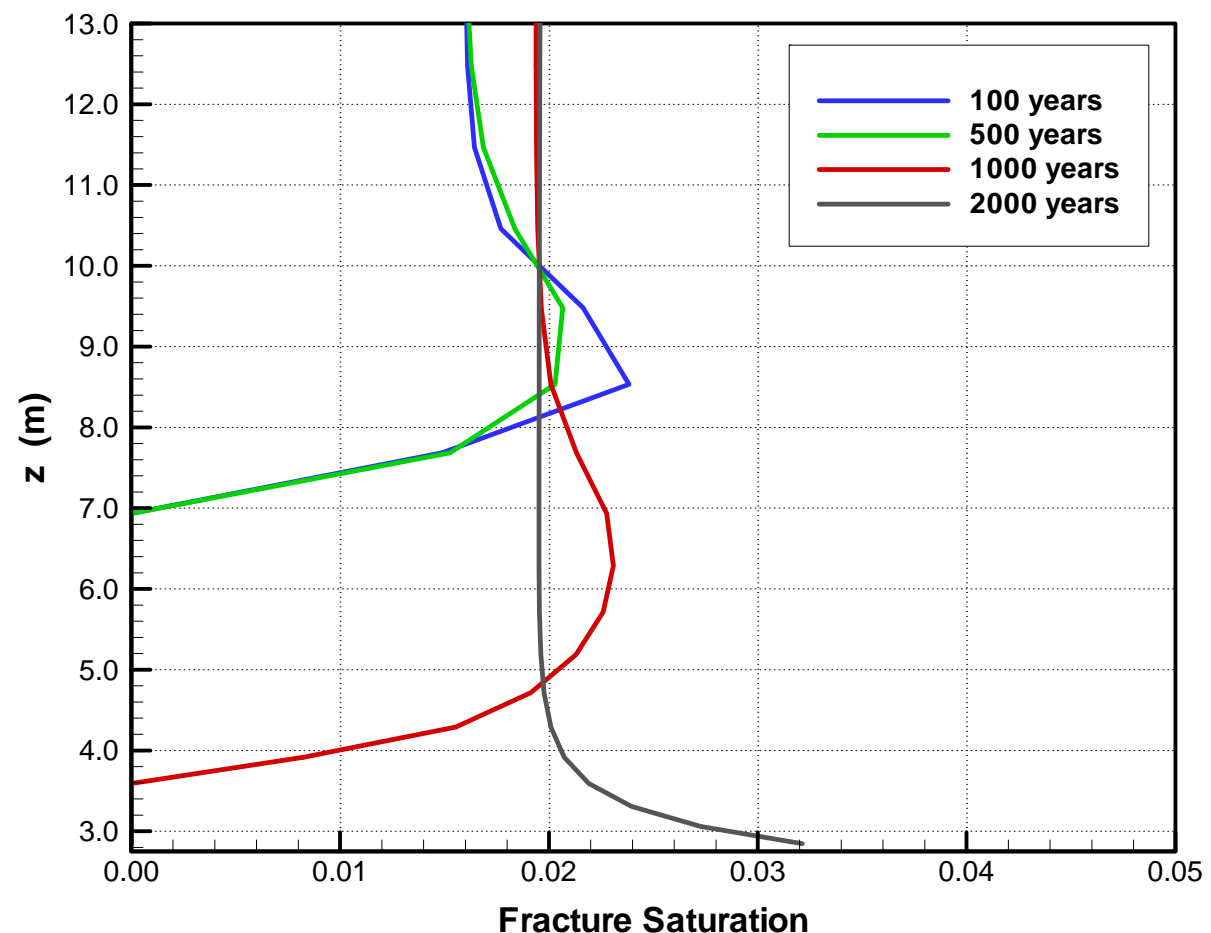

(a)

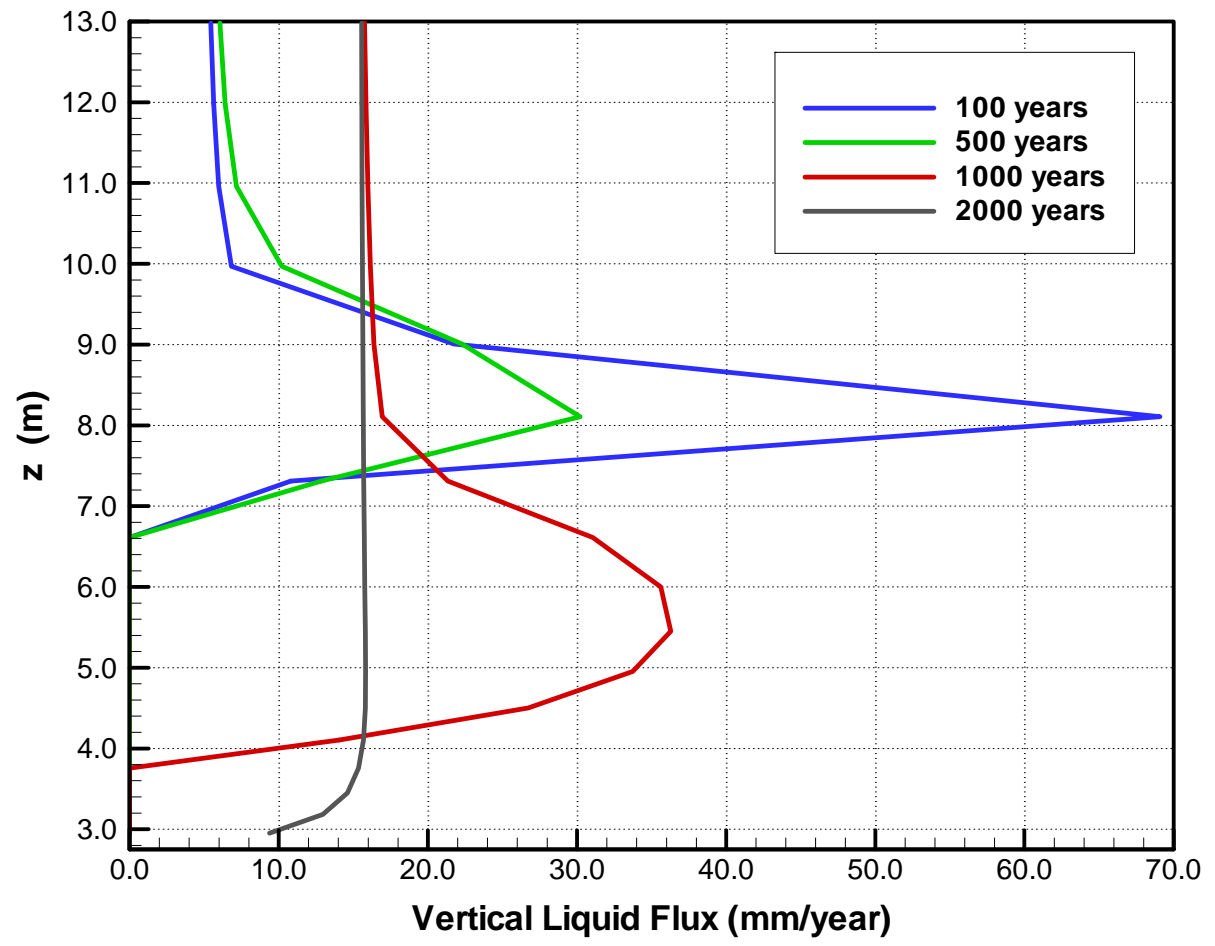

(b)

Output DTN: NA (See Section 8.5).

NOTE: The drift crown is located at $z=2.75 \mathrm{~m}$.

Figure 6.2.3.1-3. Fracture Saturation (a) and Vertical Liquid Flux (b) in a Vertical Cross Section above Drift Crown for Tptpll Submodel (Simulation Case LL-HOM-01) 


\subsubsection{Thermal Seepage}

In this subsection, the potential for thermal seepage in the Tptpll submodel is studied for simulation cases with a heterogeneous fracture permeabiltity field and the SCM calibrated fracture capillary-strength parameter. The focus is on such cases that have shown thermal seepage in the Tptpmn submodel, namely infiltration with flux multiplication factors of 5 and 10 . The methodology for estimating thermal seepage is similar to the methodology applied in Section 6.2.2.2, i.e., first performing steady-state runs with the long-term infiltration rates, then conducting transient $\mathrm{TH}$ simulations to compare thermal seepage with long-term ambient seepage. Section 6.2.3.2.1 below presents the heterogeneous fracture permeability field used in the Tptpll submodel. Section 6.2.3.2.2 gives seepage results for long-term ambient simulations. Thermal seepage results for flux multiplication factors of 5 and 10 are provided in Section 6.2.3.2.3.

\subsection{Heterogeneous Fracture Permeability}

Similar to Section 6.2.2.2.1, fracture permeability in the Tptpll is varied within a $20 \mathrm{~m}$ radius from the drift center. The probability distribution is log-normal and not spatially correlated. Mean permeability is equal to the calibrated fracture permeability of the DS/AFM-UZ02-Mean property set (i.e., $0.91 \times 10^{-12} \mathrm{~m}^{2}$ ). Geostatistical information on the variability of fracture permeability in the Tptpll is available from air-injection measurements in borehole SYBT-ECRB-LA\#2 in the ECRB and Niche 1620 (see Section 4.1.1.1). Measured data in borehole SYBT-ECRB-LA\#2 have a small standard deviation of 0.21 in log10 space, which is partly a result of the injection intervals being six times longer than those in Niches 3107, 3650, and 4788 (see Table 4.1-5).). From standard statistics, the standard deviation for a six times shorter measurement interval in the borehole can be estimated to be on the order of $0.21 \times 6^{1 / 2}=$ 0.51 , which is slightly smaller than the standard deviation obtained for $1 \mathrm{ft}$ intervals in the Tptpmn. For measured data in Niche 1620, the standard deviation in small-scale fracture permeability is 1.31 in log10 space (see Table 4.1-5). The arithmetic average of 0.51 and 1.31 is 0.91 in log10 space. Since this value is reasonably close to the standard deviation used in the Tptpmn submodel, a standard deviation of 0.84 is applied for the Tptpll submodel, identical to the one used for the Tptpmn simulations so that results can be more easily compared. Only one realization of the heterogeneous field is studied in this section, Realization 1. Realization 1 was the realization that showed the highest amount of seepage in the Tptpmn submodel. While the spatial structure and variability of the random fields are identical for both units, the mean fracture permeabilities $\left(0.91 \times 10^{-12} \mathrm{~m}^{2}\right.$; see Table $\left.4.1-2\right)$ of the Tptpll unit are about three times larger than the mean fracture permeabilities of the Tptpmn submodel $\left(0.33 \times 10^{-13} \mathrm{~m}^{2}\right)$.

\subsection{Long-Term Seepage for Ambient Conditions}

Long-term seepage simulations are performed for a period of 10,000 years, without heating of the rock. The constant percolation rates applied at the top boundary are 6, 16, $25 \mathrm{~mm} / \mathrm{yr}$ (mean infiltration scenario); 30, 80, $125 \mathrm{~mm} / \mathrm{yr}$ (flux multiplication factor 5); and 60, 160, $250 \mathrm{~mm} / \mathrm{yr}$ (flux multiplication factor 10). The fracture capillary-strength parameter used is $589 \mathrm{~Pa}$, which represents the average over the range of SCM-calibrated values for various liquid release tests (see Section 4.1.1.1). For comparison, a higher capillary-strength value of $871 \mathrm{~Pa}$ is also used in this section. This latter value was estimated for the Tptpll unit in a previous calibration effort 
(CRWMS M\&O 2001 [DIRS 153045], Section 6.3.3.3) with the SCM that did not include liquid release tests from Niche 1620. The conditions and properties used in the long-term seepage simulations can be summarized as follows:

Thermal Load: $\quad$ No heat

Property Set: $\quad$ DS/AFM-UZ02-Mean

Drift-scale Properties: Fracture capillary-strength parameter 1/ $\alpha=589 \mathrm{~Pa}$ and $871 \mathrm{~Pa}$, heterogeneous fracture permeability field with $\mathrm{k}=0.91 \times 10^{-12} \mathrm{~m}^{2}$ and $\sigma=0.84$

Infiltration:

No flow focusing: constant infiltration using $6 \mathrm{~mm} / \mathrm{yr}, 16 \mathrm{~mm} / \mathrm{yr}$ and $25 \mathrm{~mm} / \mathrm{yr}$

Flux multiplication factor 5: constant infiltration using $30 \mathrm{~mm} / \mathrm{yr}, 80$ $\mathrm{mm} / \mathrm{yr}$ and $125 \mathrm{~mm} / \mathrm{yr}$

Flux multiplication factor 10: constant infiltration using $60 \mathrm{~mm} / \mathrm{yr}, 160$ $\mathrm{mm} / \mathrm{yr}$ and $250 \mathrm{~mm} / \mathrm{yr}$

Table 6.2.3.2-1 gives the simulated long-term ambient seepage rates for the nine infiltration cases and the two cases of fracture capillarity. Also given is the maximum fracture saturation measured in the gridblocks immediately at the drift wall. No seepage is obtained for all infiltration rates between $6 \mathrm{~mm} / \mathrm{yr}$ and $125 \mathrm{~mm} / \mathrm{yr}$; moreover, the measured maximum fracture saturation at the drift wall is virtually identical for both capillary-strength values. At $160 \mathrm{~mm} / \mathrm{yr}$ and $250 \mathrm{~mm} / \mathrm{yr}$, however, seepage rates of 0.75 percent and 8.96 percent, respectively, are obtained using $1 / \alpha=589 \mathrm{~Pa}$, as the respective fracture saturation is slightly above the seepage threshold value of 0.5 . With $1 / \alpha=871 \mathrm{~Pa}$, seepage does not occur because the threshold saturation is considerably higher at approximately 76 percent. The thermal analysis presented in the following sections is conducted using the smaller fracture capillary-strength parameter value of $589 \mathrm{~Pa}$, i.e., the same value as applied in the Tptpmn submodel.

Comparison of Table 6.2.3.2-1 with Table 6.2.2.2-1 indicates that the long-term ambient seepage rates calculated for the Tptpll unit are generally smaller than for the Tptpmn unit, even though the same realization of random permeability field and the same fracture capillarity is applied. This difference is a result of the higher mean permeability of the Tptpll unit, where water can more easily be diverted around the drifts and thus the capillary barrier is more effective. This finding is consistent with results from the SMPA (BSC 2004 [DIRS 167652]Section 6.6.1), where the potential for seepage was highest for cases with small fracture permeability (and small fracture capillary-strength parameter). 
Table 6.2.3.2-1. Seepage Percentage from Steady-State Simulation Runs Performed with the Tptpll Submodel (Realization 1), Using Different Infiltration Scenarios and Two Different Fracture Capillary-Strength Parameter Values

\begin{tabular}{|c|c|c|c|c|}
\hline \multirow{3}{*}{$\begin{array}{l}\text { Fracture Capillary- } \\
\text { Strength Parameter }\end{array}$} & \multicolumn{4}{|c|}{ Flux multiplication Factor 1} \\
\hline & \multirow{2}{*}{$\begin{array}{c}6 \mathrm{~mm} / \mathrm{yr} \\
\text { Seepage } \\
(\%)\end{array}$} & $16 \mathrm{~mm} / \mathrm{yr}$ & \multicolumn{2}{|c|}{$25 \mathrm{~mm} / \mathrm{yr}$} \\
\hline & & $\begin{array}{c}\text { Seepage } \\
(\%)\end{array}$ & $\begin{array}{l}\text { Max Fracture } \\
\text { Saturation }\end{array}$ & $\begin{array}{c}\text { Seepage } \\
(\%)\end{array}$ \\
\hline $1 / \alpha=871 \mathrm{~Pa}$ & 0 & 0 & 0.223 & 0 \\
\hline \multirow[t]{3}{*}{$1 / \alpha=589 \mathrm{~Pa}$} & 0 & 0 & 0.223 & 0 \\
\hline & \multicolumn{4}{|c|}{$\begin{array}{l}\text { Flux multiplication Factor } 5 \\
\qquad 80 \mathrm{~mm} / \mathrm{yr}\end{array}$} \\
\hline & $\begin{array}{c}\text { Seepage } \\
(\%)\end{array}$ & $\begin{array}{c}\text { Seepage } \\
(\%)\end{array}$ & $\begin{array}{c}\text { Max Fracture } \\
\text { Saturation }\end{array}$ & $\begin{array}{c}\text { Seepage } \\
(\%)\end{array}$ \\
\hline $1 / \alpha=871 \mathrm{~Pa}$ & 0 & 0 & 0.454 & 0 \\
\hline \multirow[t]{3}{*}{$1 / \alpha=589 \mathrm{~Pa}$} & 0 & 0 & 0.454 & 0 \\
\hline & \multicolumn{4}{|c|}{$\begin{array}{l}\text { Flux multiplication Factor } 10 \\
160 \mathrm{~mm} / \mathrm{yr}\end{array}$} \\
\hline & $\begin{array}{c}\text { Seepage } \\
(\%)\end{array}$ & $\begin{array}{c}\text { Seepage } \\
(\%)\end{array}$ & $\begin{array}{c}\text { Max Fracture } \\
\text { Saturation }\end{array}$ & $\begin{array}{c}\text { Seepage } \\
(\%)\end{array}$ \\
\hline $1 / \alpha=871 \mathrm{~Pa}$ & 0 & 0 & 0.598 & 0 \\
\hline $1 / \alpha=589 \mathrm{~Pa}$ & 0 & 0.75 & 0.507 & 8.96 \\
\hline
\end{tabular}

Output DTN: LB0303DSCPTHSM.001 and LB0301DSCPTHSM.002.

NOTE: For 25,125 , and $250 \mathrm{~mm} / \mathrm{yr}$, the maximum fracture saturation in gridblocks at the drift wall is also given.

\subsection{Thermal Seepage for Infiltration Scenarios with Flow Focusing}

The transient thermal-seepage-simulation runs presented in this section assume flux multiplication factors of 5 and 10, respectively (Simulation Cases LL-HET-01 and LL-HET-02, see Table 6.2.1.6-1). The fracture capillary-strength parameter is equal to the one used in Tptpmn submodel seepage evaluation. Thermal conditions, rock properties, and infiltration conditions are as follows:

Thermal Load: $\quad$ Reference mode $(1.45 \mathrm{~kW} / \mathrm{m}, 86.3$ percent heat removal for 50 years $)$

Property Set: $\quad$ DS/AFM-UZ02-Mean

Drift-scale Properties: Fracture capillary-strength parameter $1 / \alpha=589 \mathrm{~Pa}$, heterogeneous fracture permeability field with $\mathrm{k}=0.91 \times 10^{-12} \mathrm{~m}^{2}$ and $\sigma=0.84$

Infiltration: $\quad$ Flux multiplication factor 5: stepwise change from $30 \mathrm{~mm} / \mathrm{yr}$ to 80 $\mathrm{mm} / \mathrm{yr}$ to $125 \mathrm{~mm} / \mathrm{yr}$, at 600 years and 2,000 years

Flux multiplication factor 10: stepwise change from $60 \mathrm{~mm} / \mathrm{yr}$ to $160 \mathrm{~mm} / \mathrm{yr}$ to $250 \mathrm{~mm} / \mathrm{yr}$, at 600 years and 2,000 years

Figure 6.2.3.2-1 shows the fracture saturation history at all gridblocks close to the drift for the flux multiplication factor of 5 . In general, the saturation buildup with time is similar to the 
respective simulation case of the Tptpmn submodel. No water arrives at the drift during the boiling period. As rock temperature decreases and the first stepwise change in infiltration occurs at 600 years, the saturation values build up strongly, while significant variability in saturation becomes evident. However, no saturation values reach the seepage threshold saturation of 0.5, and the seepage percentage is zero at all times. For the infiltration scenario with a flux multiplication factor of 10, saturation buildup is faster and more pronounced. Eventually, between 2,500 and 3,000 years after emplacement, fracture saturation in one gridblock at the wall reaches the threshold value, so that water starts seeping into the drift (Figure 6.2.3.2-2). The thermal seepage rate is small compared to the respective long-term ambient seepage rates. At the end of the simulation period, the thermal seepage percentage is at about 3.19 percent, compared to the long-term ambient value of the glacial transition period of 8.96 percent.

The following conclusions can be reached from the TH modeling analysis of thermal seepage in the Tptpll unit:

- The main conclusions derived from the Tptpmn submodel also hold for the Tptpll unit studied here. Thermal seepage occurs only at late times after emplacement (following a long period of fracture rewetting). The rate of thermal seepage is always smaller than the long-term ambient seepage percentage calculated from steady-state simulation runs using the respective infiltration rate of the three climate periods.

- Both ambient and thermal seepage rates are smaller in the Tptpll unit compared to the Tptpmn, as a result of the higher permeability of the fracture continuum. (The higher fracture capillary-strength parameter estimated from the SCM would give rise to even less seepage, but this estimate was not used in these thermal seepage simulations).

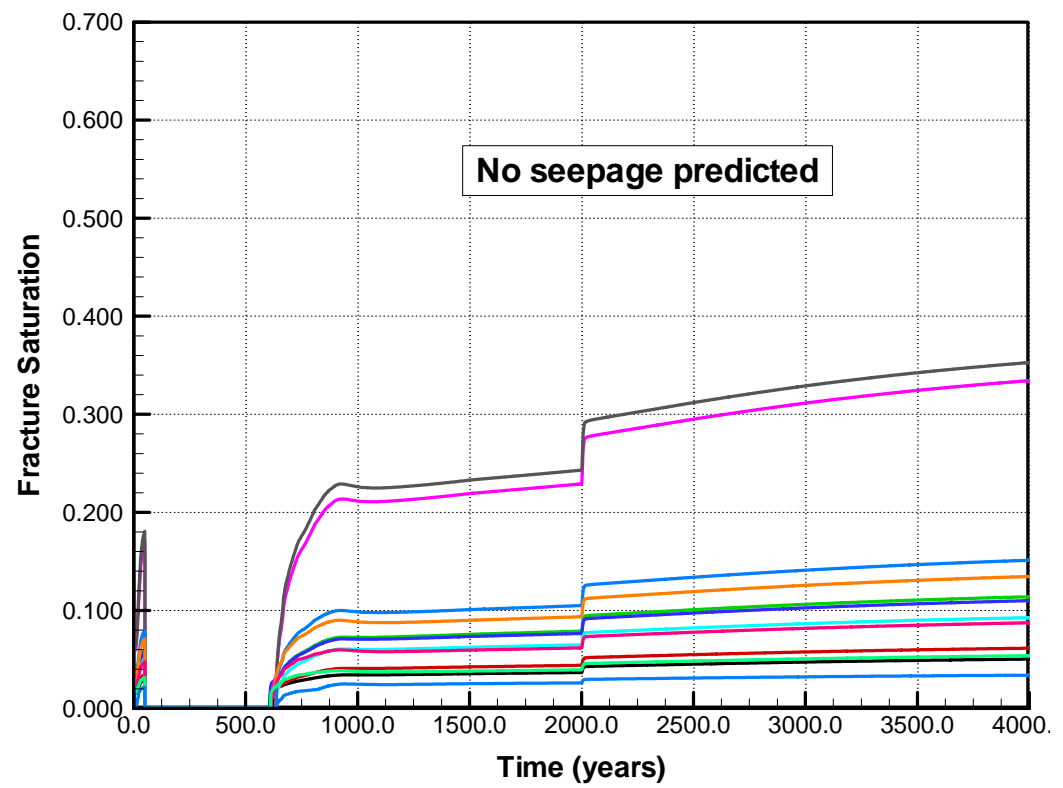

Output DTN: LB0303DSCPTHSM.001.

NOTE: Figure shows all rock discretization elements along the drift periphery from the crown to the springline.

Figure 6.2.3.2-1. Fracture Saturation for Tptpll Submodel with Flux Multiplication Factor 5 (Simulation Case LL-HET-01, Realization 1) 


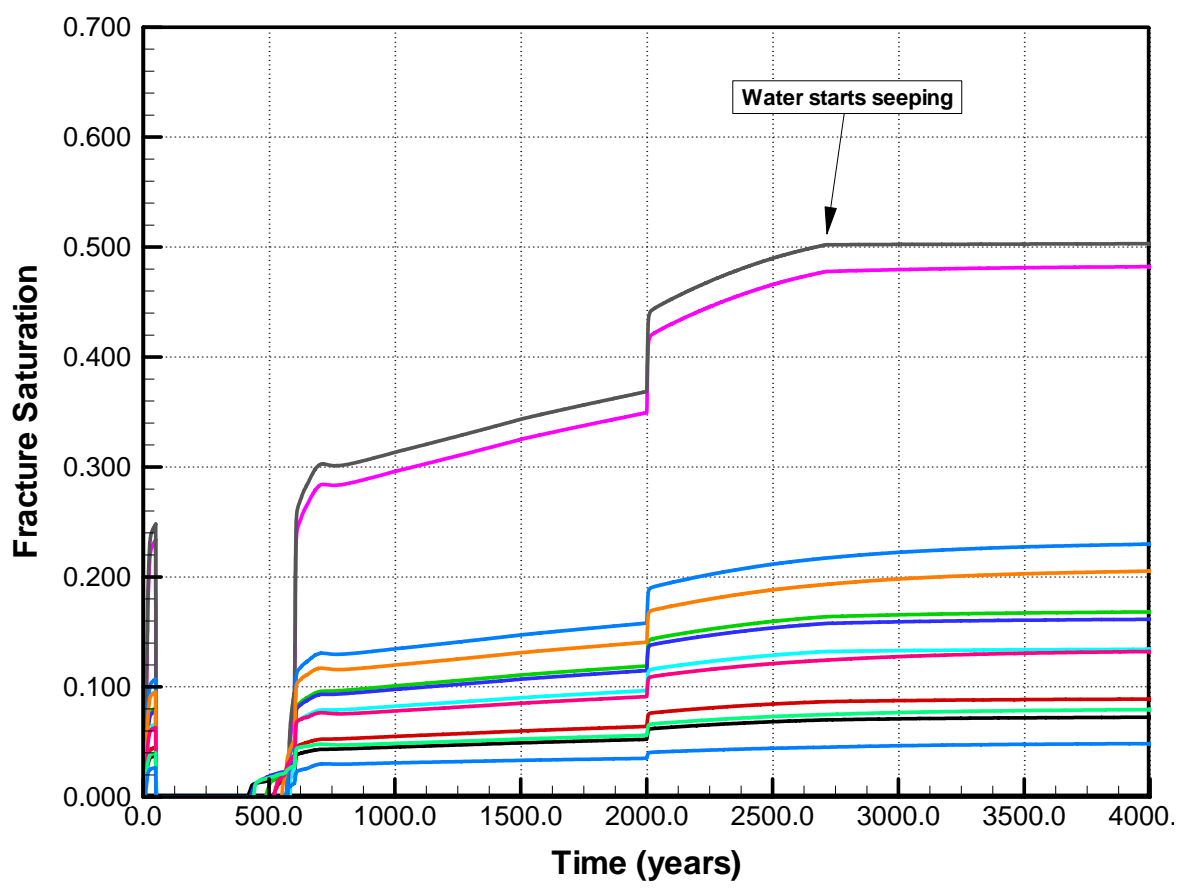

(a)

Time (years)

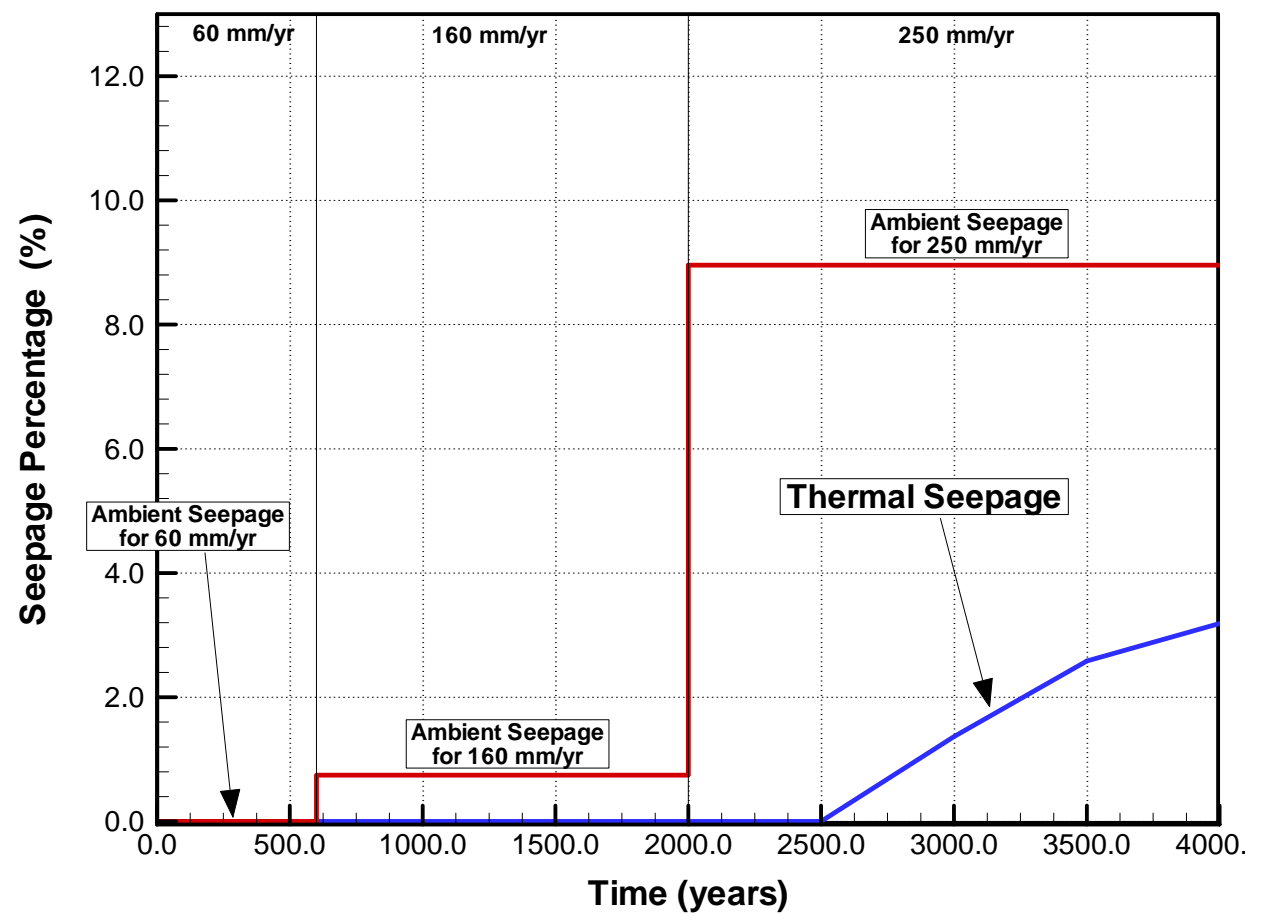

(b)

Output DTNs: (a) LB0303DSCPTHSM.001, (b) LB0301DSCPTHSM.002.

NOTE: (a) fracture saturation for all rock discretization elements along the drift periphery from the crown to the springline, and (b) seepage percentage for thermal run and long-term ambient runs.

Figure 6.2.3.2-2. $\quad$ TH Conditions for Tptpll Submodel with Flux Multiplication Factor 10 (Simulation Case LL-HET-02, Realization 1) 


\subsubsection{Discussion of TH Seepage Model Results}

The TH seepage model is intended to investigate the combined capability of two barriers that prevent downward infiltration from seeping into waste emplacement drifts during the time period of thermally perturbed flow conditions. The first barrier arises from vaporization of water in the heated rock zone. The second barrier is a result of capillary forces that tend to divert flow around the drifts. The modeling concept for thermal seepage is adopted from the ambient seepage model, i.e., the SMPA (BSC 2004 [DIRS 167652], Section 6.3). The conditions employed for this model are the inclusion of fracture permeability heterogeneity, the weak fracture capillarity as estimated from the SCM (BSC 2004 [DIRS 171764], Tables 6-8 and 8-1), the drift-wall boundary condition that accounts for discrete fractures terminating at the drift, and the enhanced percolation into the model domain as a result of flow variability and flow focusing. Output from the simulation model feeds into the seepage abstraction, where appropriate probability distributions of ambient and thermal seepage are developed for use in TSPA. The TH simulations also provide the basis for process models intended to evaluate THC and THM behavior in the drift vicinity.

Modeling results for the reference mode and the high-temp mode indicate that the vaporization barrier is fully effective as long as the local rock temperature at the drift wall is above boiling. Even for high percolation fluxes into the model domain, and for strong flow channeling as a result of fracture heterogeneity, water cannot penetrate far into the superheated rock during this time period. The thermal perturbation of the flow field-resulting in saturation buildup and increased downward flux in the condensation zone above drifts-is strongest during the first few hundred years after closure, corresponding to the time period when the vaporization barrier is most effective. This period also coincides with the present-day mean climate, with infiltration being smaller than during monsoon climate (after 600 years) or glacial transition climate (after 2,000 years). As a result of this smaller infiltration rate, the capillary barrier during this time period is predicted to be fully effective for the considered simulation cases (flux multiplication factors of 1,5 , and 10), so that seepage would not occur even in the absence of decay heat in the repository. Note that the majority of the condensate produced during the period of above-boiling conditions is diverted around the dryout rock region and drains down between drifts. At the time when the vaporization barrier has become ineffective (as temperature has returned to below-boiling conditions and fractures start rewetting at the drift, typically around 1,000 years after emplacement), downward fluxes from the condensation zone towards the drift are almost back to ambient. These slightly enhanced fluxes are smaller than the long-term ambient percolation during the glacial transition climate in the cases considered.

To provide reference cases for testing the capillary barrier during the thermal period, long-term ambient simulations were performed with the TH seepage model, in the absence of thermal load. Ambient seepage was simulated in steady-state runs, applying a constant infiltration boundary condition that is given by the respective infiltration rate of the present-day, monsoon, and glacial transition climates multiplied with the flux multiplication factors of 1,5 , and 10 . The calculated seepage percentages from these nine simulation runs are qualitatively similar to results from the SMPA. For most of the cases where long-term ambient seepage is predicted, seepage also occurs during the thermal simulation period of 4,000 years. However, the thermal seepage percentages are always smaller than the respective ambient reference values, indicating that no enhanced seepage occurs as a result of thermally induced condensate reflux. Typically, water 
starts to seep at several hundred to a few thousand years after rock temperature has returned below boiling, the delay caused by the slow saturation buildup in fractures. The higher the percolation rate (strong flow focusing), the earlier the initiation of thermal seepage, because rewetting in the fractures is faster. Of the two host rock units, the seepage rates for the Tptpll unit are smaller than for the Tptpmn, mainly because of more effective flow diversion around the drift as a result of the higher fracture permeability. Note that the rock temperatures never reach boiling conditions for the low-temp mode. In this case, thermal effects on flow are small, and the potential for thermal seepage can be estimated directly from the long-term ambient seepage results.

In summary, there were important observations with respect to thermal seepage that are common to all cases discussed in Section 6.2.2 and 6.2.3:

\section{Conclusion (1):}

Thermal seepage was never observed in simulation runs where the respective ambient seepage was zero.

\section{Conclusion (2):}

Thermal seepage never occurred during the period of above-boiling temperatures in the rock close to the emplacement drifts.

Conclusion (3):

In simulation cases where ambient seepage was obtained, thermal seepage was initiated a few hundred to a few thousand years after rock temperature has returned to and below boiling.

\section{Conclusion (4):}

Thermal-seepage rates were always smaller than the respective ambient reference values. The ambient seepage values provide an asymptotic upper limit for thermal seepage.

While these main conclusions hold for all simulation cases, considerable variability exists among simulation runs with respect to the thermal-seepage initiation time, the evolution of seepage with time, and the long-term rate of thermal seepage.

Uncertainty in the above results may stem from input to the simulation model—e.g., the selected rock properties, percolation fluxes, and thermal load conditions-as well as from the conceptual model for thermal seepage. The input uncertainty and variability has been analyzed in Sections 6.2.2 and 6.2.3 by using the different rock properties assigned for the two host rock units Tptpmn and Tptpll, by assigning different flux multiplication factors, and by simulating three cases of thermal loads. Additional sensitivity studies discussed in Sections 6.2.4.2.1 and 6.2.4.2.2 demonstrate that the above main conclusions regarding the effectiveness of the vaporization and capillary barrier remain unchanged. Uncertainty in the conceptual model used for the $\mathrm{TH}$ seepage model simulations is addressed in Sections 6.2.4.2.3 through 6.2.4.2.6, where specific model choices of the TH seepage model are discussed; in Section 6.3, where an alternative conceptual model for fracture flow processes is presented; and in Section 7, where the $\mathrm{TH}$ seepage model is validated against the DST data. 


\subsubsection{Recommendations for Thermal Seepage Abstraction}

A methodology for abstracting thermal seepage can be derived from analysis of Figures 6.2.2.2-6 through 6.2.2.2-9 for the Tptpmn unit and Figures 6.2.3.2-1 through 6.2.3.2-2 for the Tptpll unit. The rate of thermal seepage into the drift is plotted as a function of time against the respective long-term ambient seepage values calculated from steady-state simulation runs. The general trend is similar in all these figures, despite different rock properties and percolation conditions, demonstrating that seepage during the thermal period does not occur at above-boiling temperatures, and that the thermal seepage rate is always smaller than the respective long-term seepage value for the considered time period. It is reasonable to conclude that with regard to thermal seepage abstraction, this trend is consistent in all relevant parameter cases to be studied in the PA (see Section 6.2.4.2 for additional sensitivity studies); i.e., long-term ambient seepage rates define an upper limit to the potential magnitude of seepage during the thermal period. (Note that the alternative conceptual model presented in Section 6.3 supports the seepage results predicted by the TH seepage model.)

It is reasonable to account for the reduced thermal seepage in the PA calculations by using simplified time-dependent thermal-seepage rates that are based on the long-term ambient seepage estimates. A very simple abstraction model would be, for example, that thermal seepage during each climate period is equal to the long-term ambient seepage calculated using the infiltration rate of this climate period. The abstraction is based on the model finding that ambient seepage provides an asymptotic upper limit for thermal seepage (i.e., there is no enhanced seepage as a result of thermal perturbation). Figure 6.2.4.1-1 gives an example of such a simple abstraction procedure. Here, the abstracted thermal seepage percentage would be zero for the first 600 years after emplacement, 15.73 percent between 600 and 2,000 years, and 19.54 percent after 2,000 years. Obviously, more complex abstraction models-giving rise to less seepageare also possible. More complex abstraction models could include, for example, additional information on the duration of the boiling period close to the drift wall in order to define the no-seepage period. The preferred abstraction model would set thermal seepage to zero for the period of above-boiling temperatures in the drift vicinity. For the remaining period, thermal seepage would be equal to the respective ambient seepage. (This more complex abstraction model would require prediction of temperature evolution close to the drift wall at various locations throughout the repository, including variation of key parameters for thermal seepage. This type of information is provided in Multiscale Thermohydrologic Model (BSC 2004 [DIRS 169565]), which simulates the local drift-scale TH conditions for a large number of emplacement drift locations.) This alternative abstraction model is based on model findings that thermal seepage never occurs at above-boiling temperatures and that the ambient seepage values provide an asymptotic upper limit for thermal seepage. Both abstraction methods suggested above cover the expected uncertainty in thermal seepage model results by choosing adequate upper-bound estimates for the evolution of thermal seepage. The abstraction procedure for thermal seepage using the results presented in this report is documented in Abstraction of Drift Seepage (BSC 2004 [DIRS 169131], Sections 6.5.2 and 6.5.3).

The long-term ambient seepage rates - to be used for thermal seepage abstraction — should be provided by the SMPA. The ambient SMPA model, computationally much less demanding compared to the TH seepage model, can be applied to a wide range of parameters and flux boundary conditions. Also, the SMPA results are quantitatively more reliable, due to the 
three-dimensional model representation and the large number of realizations considered. Seepage results from the SMPA are presented in Seepage Model for PA Including Drift Collapse (BSC 2004 [DIRS 167652], Section 6.6.1).

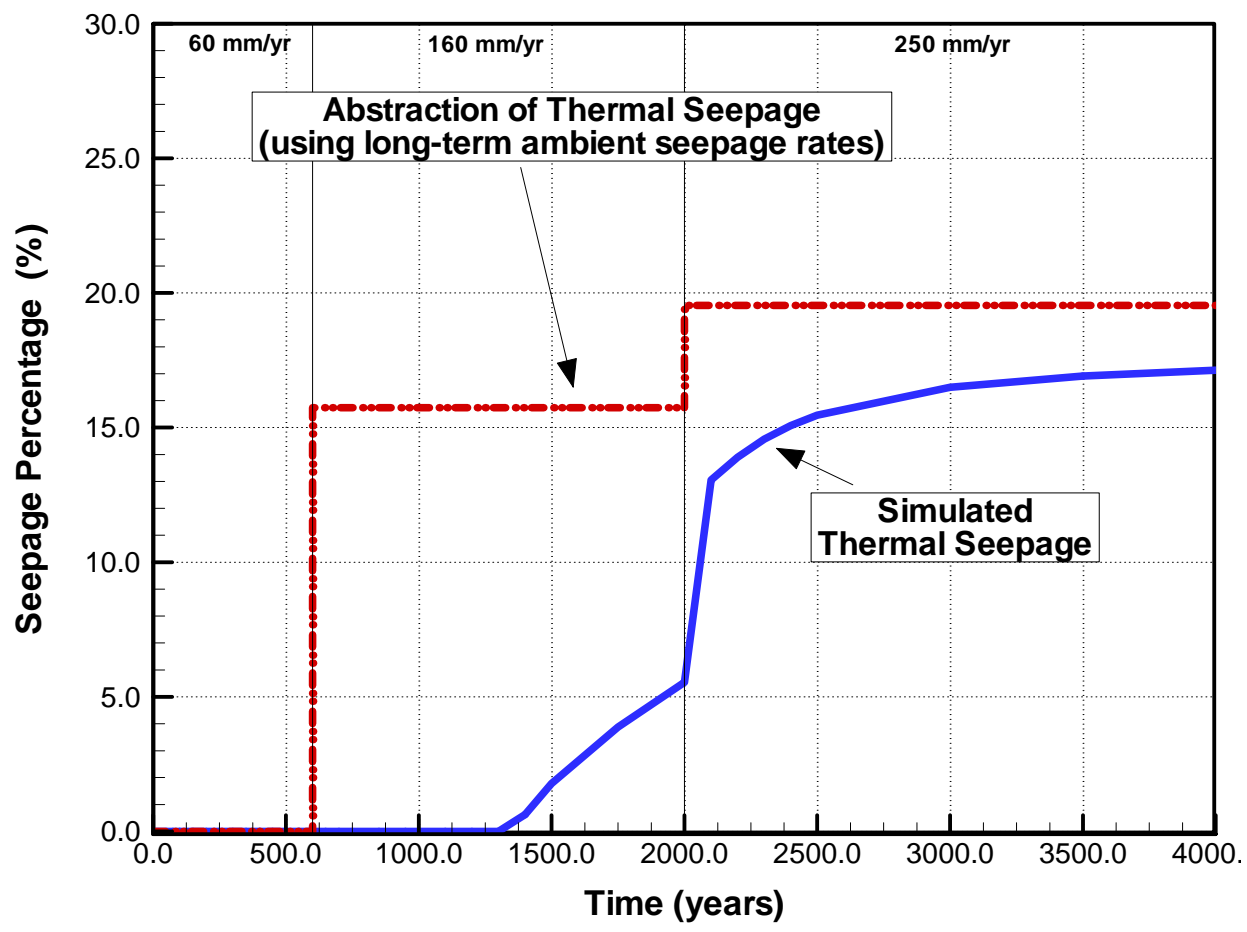

Output DTN: LB0301DSCPTHSM.002.

NOTE: The red dashed-dotted curve shows a possible abstraction model for thermal seepage. The other curve shows simulated thermal seepage, as presented in Figure 6.2.2.2-7.

Figure 6.2.4.1-1. Possible Abstraction Model for Thermal Seepage Percentage as a Function of Time after Waste Emplacement

\subsubsection{Sensitivity Studies for Thermal Seepage Abstraction}

This section provides thermal-seepage-modeling results for additional simulation cases, to demonstrate that the observed trends in thermal seepage and the proposed abstraction methodology hold true for a wider range of hydrological and thermal boundary conditions (Section 6.2.4.2.1), rock properties (Section 6.2.4.2.2), and conceptual model variations (Sections 6.2.4.2.3 through 6.2.4.2.5). Except for the simulation case in Section 6.2.4.2.4, all additional runs are performed using Realization 1 of the Tptpmn submodel; similar sensitivity results are expected from the Tptpll submodel.

\subsection{Sensitivity to Percolation Fluxes and Heat Load}

The most important model boundary conditions for thermal seepage are the percolation fluxes imposed at the top boundary and the thermal load of the waste packages. The average percolation flux at Yucca Mountain is less than $10 \mathrm{~mm} / \mathrm{yr}$ at current climate conditions, a flux value that would typically not give rise to seepage because it is below the seepage threshold 
value (see Sections 6.2.3.2.2 and 6.2.3.2.3). However, the maximum percolation fluxes may be much higher at certain emplacement locations (as a result of spatial variability over the repository horizon and future climate changes), which is reflected in the fact that Abstraction of Drift Seepage (BSC 2004 [DIRS 169131], Section 6.6.5) considers percolation fluxes up to $1,000 \mathrm{~mm} / \mathrm{yr}$ during the glacial transition climate period (see Section 6.2.1.4). Since the potential for seepage increases with percolation flux, the high end of the distribution may be most relevant for TSPA, although the probability of such high fluxes is small. As a result, seepage abstraction and its supporting process models need to make sure that such high-end parameter ranges are adequately addressed. This means that not just the reasonable mean cases need to be addressed, but also some rather "extreme" choices at the low end of the probability spectrum.

To investigate these high-end limits of percolation fluxes to be used in TSPA, the TH seepage model is applied to two additional cases using a flux multiplication factor of 20, 40, and 100 (Simulation Cases MN-HET-04, MN-HET-15, and MN-HET-16; see Table 6.2.1.6-1). When the flux multiplication factor is 20, the infiltration rate is $120 \mathrm{~mm} / \mathrm{yr}$ for the first 600 years after emplacement, $320 \mathrm{~mm} / \mathrm{yr}$ between 600 and 2,000 years, and $500 \mathrm{~mm} / \mathrm{yr}$ thereafter (see Table 6.2.4.1-2). For the extreme factor- 100 case, the infiltration rate is $600 \mathrm{~mm} / \mathrm{yr}$ for the first 600 years after emplacement, 1,600 mm/yr between 600 and 2,000 years, and 2,500 mm/yr thereafter. Thermal seepage is also simulated for two additional thermal-load cases, to address the expected variability of above-boiling temperature conditions in the repository. One additional case is the high-temp mode already introduced in Section 6.2.2.1.3, which represents the high end of expected repository temperature conditions. The other case is somewhat generic; it features an initial heat load of $1.2 \mathrm{~kW} / \mathrm{m}$, a ventilation efficiency of 86.3 percent, and a 50-year preclosure period. This case is specifically designed to represent near-drift thermal conditions with a relatively short boiling period and a maximum temperature that is just above boiling.

Figures 6.2.4.2-1 and 6.2.4.2-2 show the evolution of temperature at the drift wall for a selection of these additional cases. The first figure gives results for the three flux multiplication factors (5, 10, and 20) and the reference thermal mode; the second figure plots the three above-boiling temperature cases for a flux multiplication factor of 10 . The large percolation flux in the factor-20 case effectively suppresses temperature in the rock (Figure 6.2.4.2-1). The above-boiling period-much shorter compared to the other cases-is followed by a long heat-pipe period in which temperature remains at the boiling point. After 600 years, rock temperature at the wall drops rapidly because of the infiltration increase from $120 \mathrm{~mm} / \mathrm{yr}$ to 320 $\mathrm{mm} / \mathrm{yr}$. Figure 6.2.4.2-2 shows that the additional heat-mode case gives rock temperature values at the drift wall that are considerably smaller than in the other heat modes. The maximum temperature is about $108^{\circ} \mathrm{C}$, and the time period of above-boiling temperature is only a few hundred years long.

Selected results for the additional simulation runs, showing thermal seepage over time, are presented in Figure 6.2.4.2-3 for a flux multiplication factor of 10 and in Figure 6.2.4.2-4 for a flux multiplication factor of 20. Similar to Sections 6.2.2.2.4 and 6.2.3.2.3, thermal seepage is plotted in comparison to the long-term ambient seepage calculated for the three climate periods. Figure 6.2.4.2-3 demonstrates that the reference mode and the high-temp mode give almost identical results with respect to thermal seepage. This is because the temperature difference between the two thermal load cases has almost vanished at the time when thermal seepage first 
occurs (see Figure 6.2.4.2-2). In the additional heat-mode case, thermal seepage starts at about 1,050 years, several hundred years earlier than in the other cases, as a result of less effective vaporization of water. Overall, the difference in seepage percentage is relatively small between all thermal-load cases, indicating the importance of the capillary barrier in limiting seepage.

In the factor-20 case, the imposed percolation fluxes of all three climate periods are so large that long-term ambient seepage is predicted to occur even for the present-day climate period. From the steady-state simulation runs, the ambient seepage percentages are estimated to be 12.21 percent at $120 \mathrm{~mm} / \mathrm{yr}$ percolation (present-day climate), 21.05 percent at $320 \mathrm{~mm} / \mathrm{yr}$ percolation (monsoon climate), and 23.09 percent at $500 \mathrm{~mm} / \mathrm{yr}$ percolation (glacial transition climate). Accordingly, the thermal seepage curve starts out at 12.21 percent, the present-day ambient seepage value. (Note that the initial rock dry out resulting from ventilation effects during the 50-year preclosure period are not considered in this study.) As a result of the rising rock temperatures, the seepage percentage drops to zero shortly after the 50-year ventilation period, and no seepage is predicted until about 600 years after emplacement. At 600 years, thermal seepage increases rapidly, mainly because percolation increases from $120 \mathrm{~mm} / \mathrm{yr}$ to $320 \mathrm{~mm} / \mathrm{yr}$ (while the rock temperatures have significantly decreased and thermal effects have diminished). For the remaining time period, the thermal seepage percentage is relatively close to, but consistently smaller than, the long-term ambient seepage estimates.

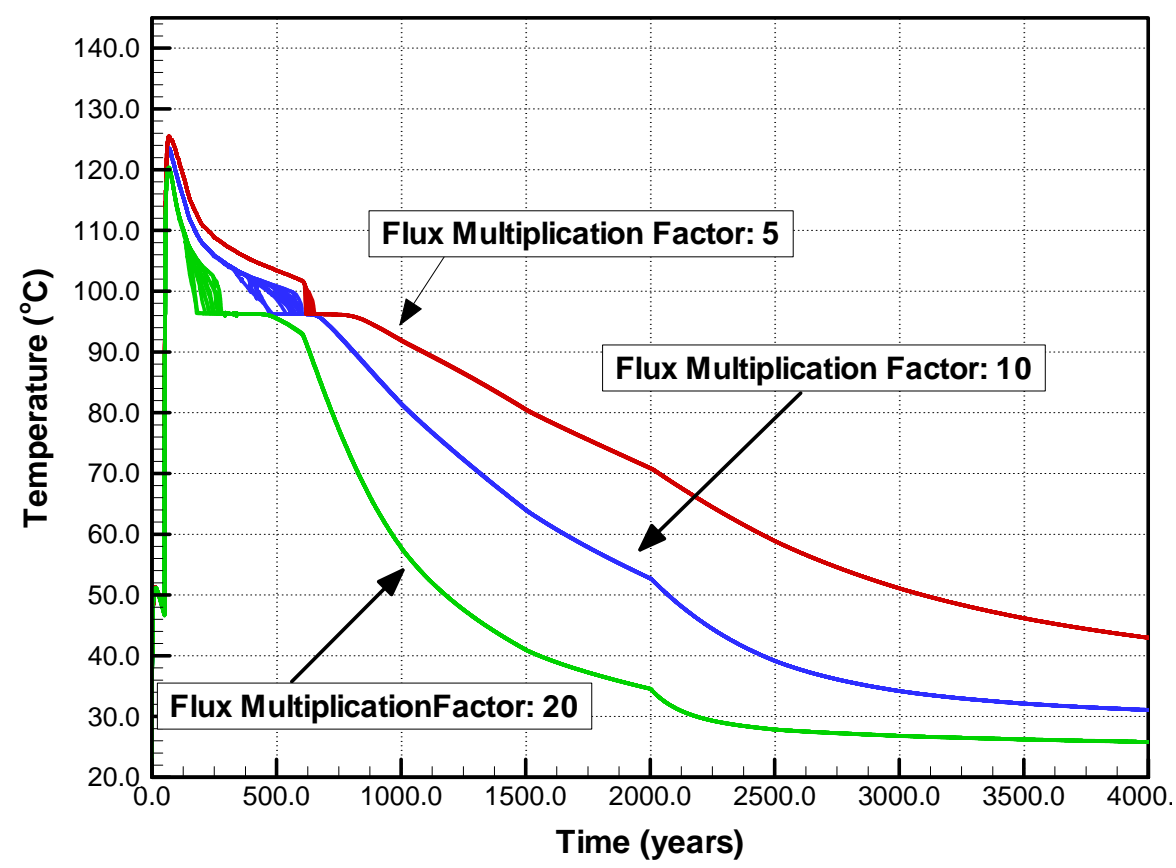

Output-DTN: LB0303DSCPTHSM.001.

NOTE: $\quad$ Figure shows all rock discretization elements along the drift periphery from the crown to the springline. The simulation cases are MN-HET-02, MN-HET-03, and MN-HET-04.

Figure 6.2.4.2-1. Rock Temperature for Tptpmn Submodel with Different Flux Multiplication Factors and Reference Mode Thermal Load 


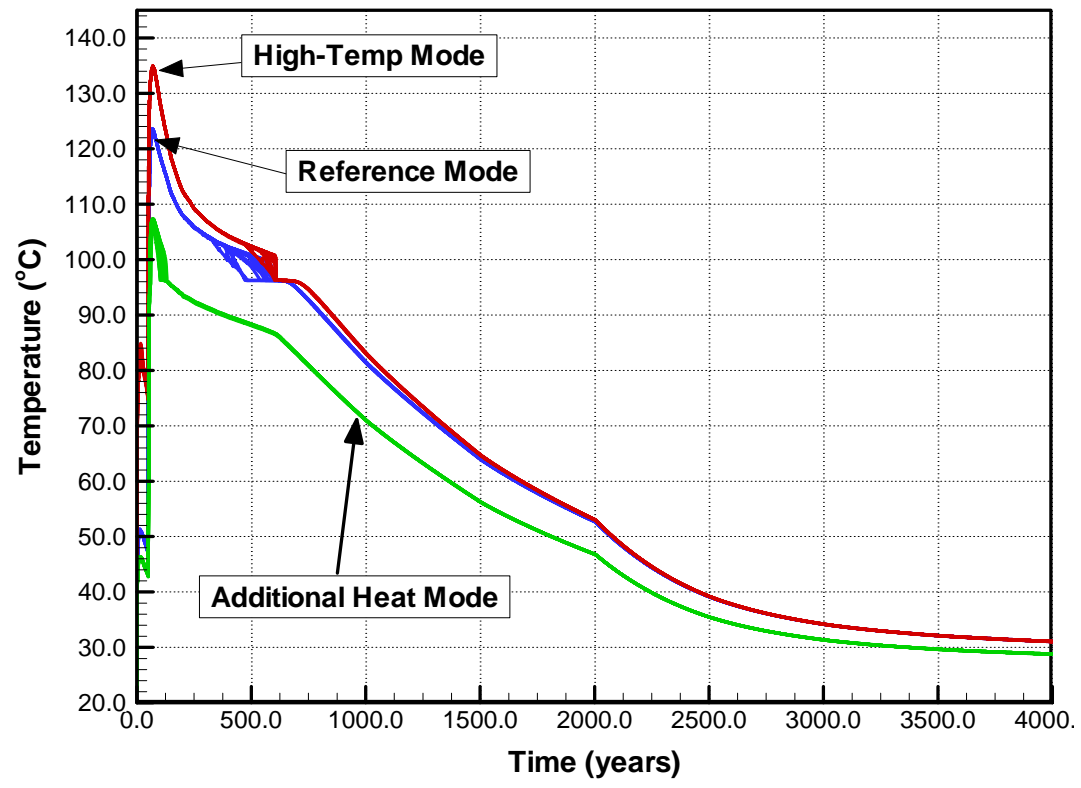

Output DTN: LB0303DSCPTHSM.001.

NOTE: $\quad$ Figure shows all rock discretization elements along the drift periphery from the crown to the springline. The simulation cases are MN-HET-03, MN-HET-05 and MN-HET-06.

Figure 6.2.4.2-2. Rock Temperature for Tptpmn Submodel with Different Heat Loads and Flux Multiplication Factor 10.

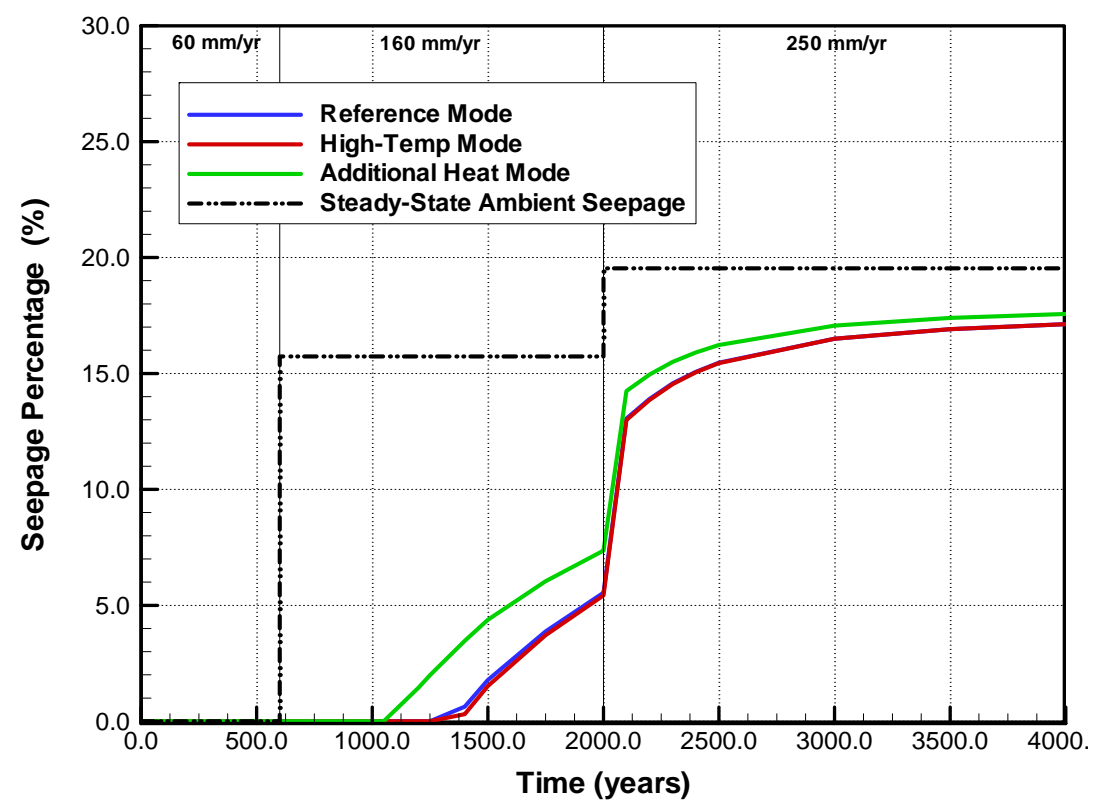

Output DTN: LB0301DSCPTHSM.002.

NOTE: The simulation cases are MN-HET-03, MN-HET-05 and MN-HET-06.

Figure 6.2.4.2-3. Seepage Percentage for Tptpmn Submodel with Different Heat Loads and Flux Multiplication Factor 10 Showing Results from Thermal Run and from Long-Term Ambient Runs 


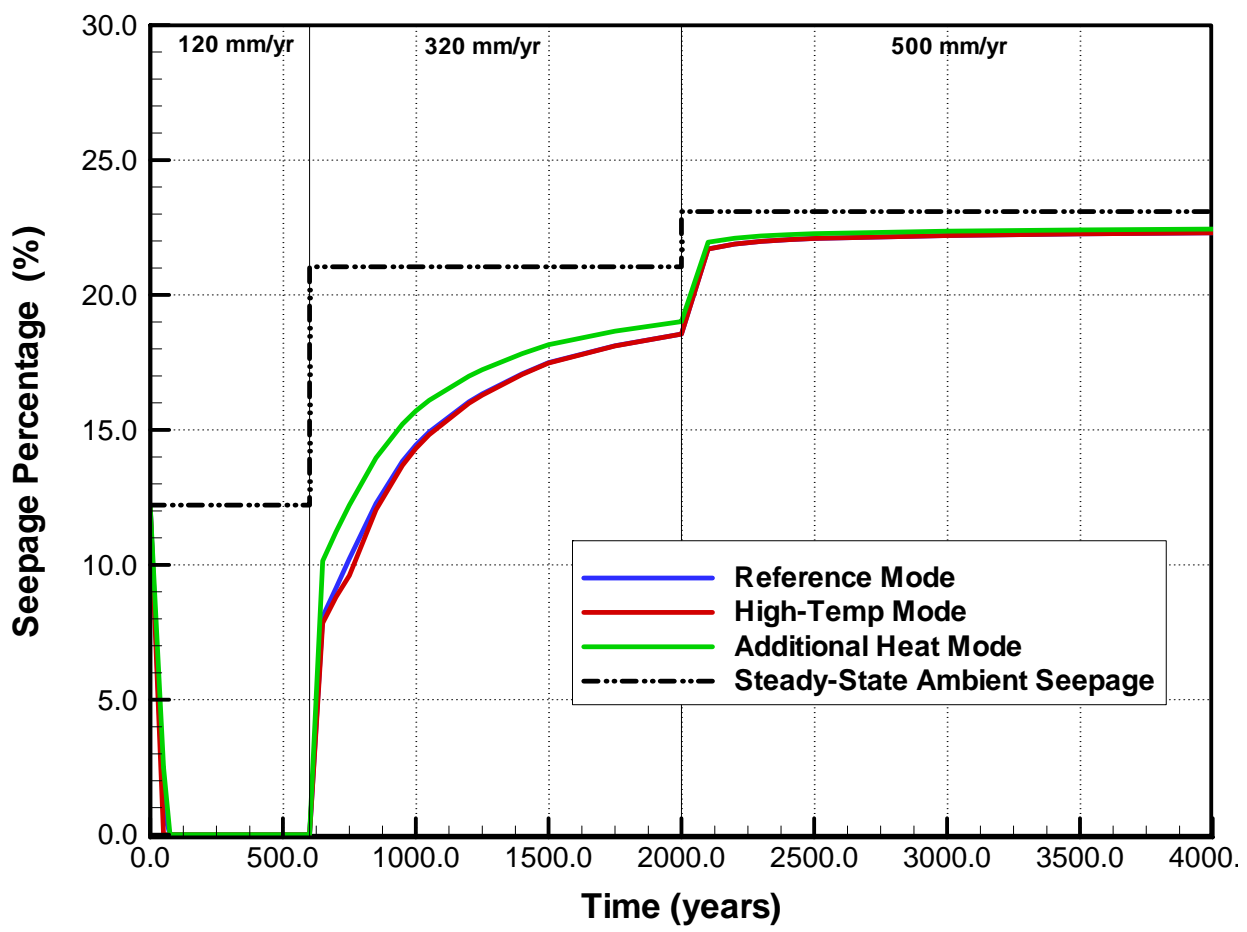

Output DTN: LB0301DSCPTHSM.002.

NOTE: The simulation cases are MN-HET-04, MN-HET-07 and MN-HET-08.

Figure 6.2.4.2-4. Seepage Percentage for Tptpmn Submodel with Different Heat Loads and Flux Multiplication Factor 20, Showing Results from Thermal Run and from Long-Term Ambient Runs

Figures 6.2.4.2-5 and 6.2.4.2-6 provide simulation results (evolution of rock temperature and thermal seepage) for the extreme simulation case with the flux multiplication factor of 100 . (Note that the factor-40 case is not discussed in this report, but is included in the output DTNs: LB0309DSCPTHSM.001 and LB0309DSCPTHSM.002.) Increasing the percolation flux to such extreme values has strong impact on the temperature evolution in the rock (Figure 6.2.4.2-5). In fact, the resulting drift wall temperatures never exceed the boiling temperature of water at prevailing pressure because the elevated percolation arriving at the drifts effectively suppresses further temperature buildup. Thus, a fully effective vaporization barrier can not evolve in this case and, as shown in Figure 6.2.4.2-6, thermal seepage occurs throughout the entire simulation period of 4,000 years. The seepage rates are close to the long-term ambient rates except for a short time period at early heating stages, when the rock temperature is at the boiling temperature of water. This simulation case demonstrates the considerable impact of extremely elevated percolation fluxes on the near-drift $\mathrm{TH}$ conditions and the increased potential for thermal seepage. This also establishes that the conclusions drawn in Section 6.2.4 are valid for a wide range of thermal conditions and percolation fluxes. This provides confidence that a reliable abstraction methodology for thermal seepage can be based on those conclusions. 


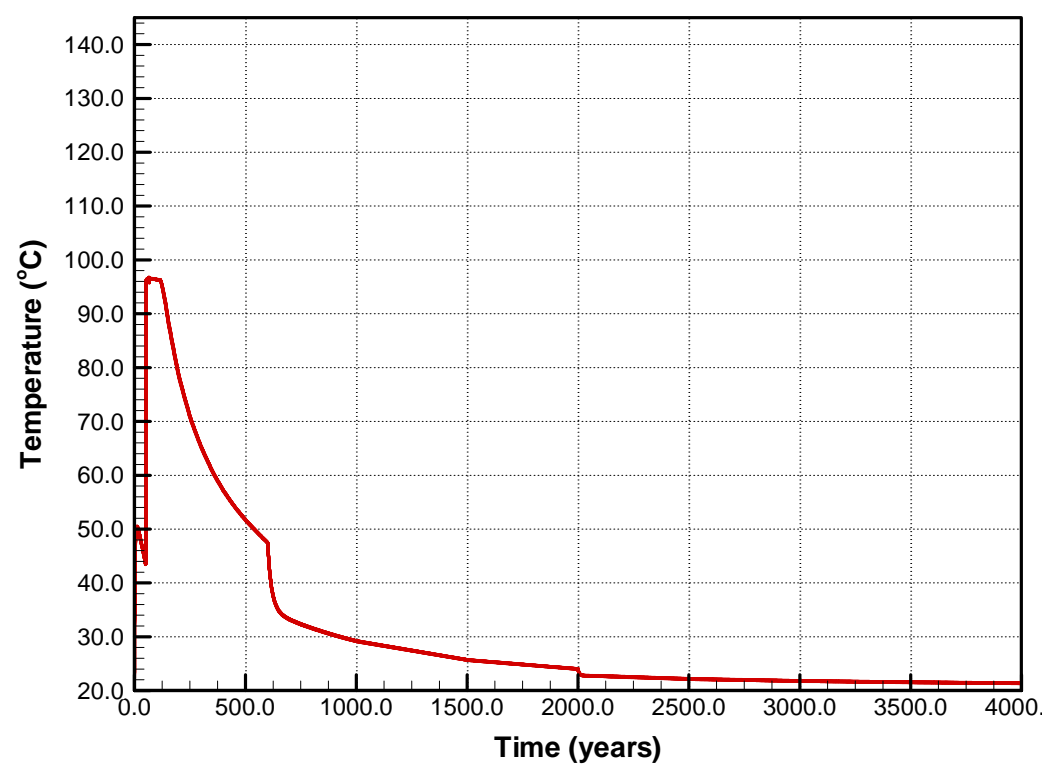

Output DTN: LB0309DSCPTHSM.001.

NOTE: $\quad$ Figure shows all rock discretization elements along the drift periphery from the crown to the springline. The simulation case is MN-HET-016.

Figure 6.2.4.2-5. Rock Temperature for Tptpmn Submodel with Flux Multiplication Factor of 100 and Reference Mode Thermal Load

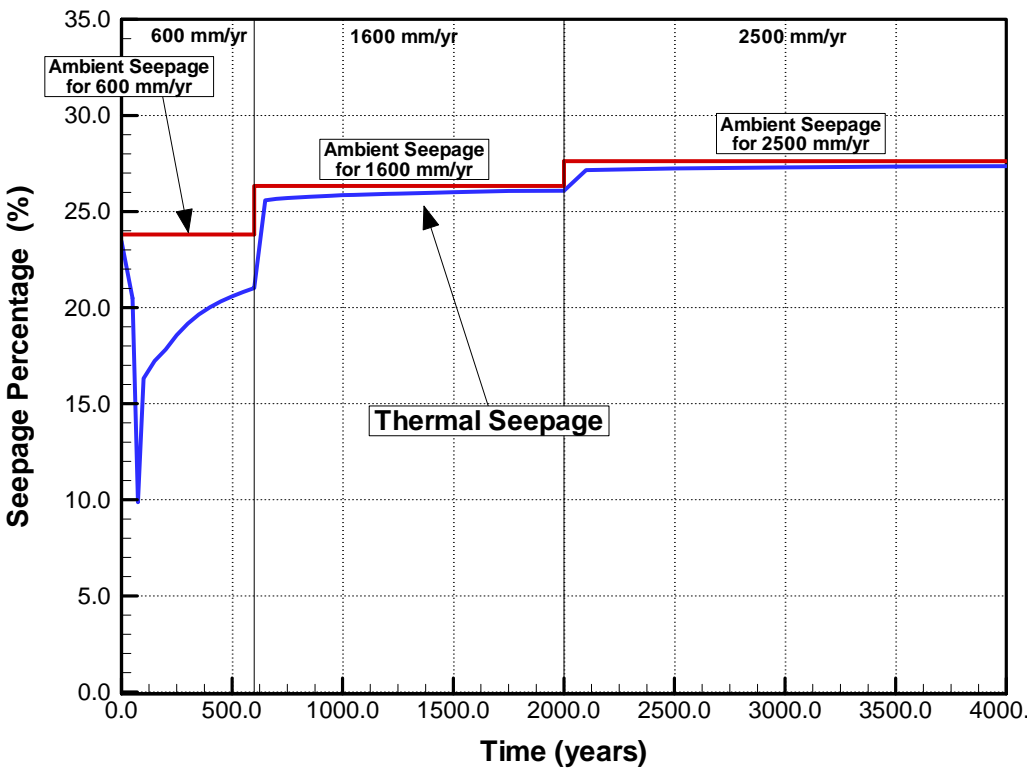

Output DTN: LB0309DSCPTHSM.002.

NOTE: The simulation case is MN-HET-16.

Figure 6.2.4.2-6. Seepage Percentage for Tptpmn Submodel with Flux Multiplication Factor 100 and Reference Mode Thermal Load Showing Results from Thermal Run and from LongTerm Ambient Runs. 


\subsection{Sensitivity to Rock Properties Relevant For Thermal Seepage}

Some sensitivity to rock properties has already been studied in Section 6.2.2 and 6.2.3 by using the different parameter values assigned for the two host rock units Tptpmn and Tptpll. In addition, carefully selected simulation cases with variation of specific properties known to be important for seepage are conducted below. As was already pointed out in Section 6.2.1.1.2, the near-drift fracture capillary-strength parameter and fracture permeability are the most important rock properties defining the magnitude of ambient seepage. The rock properties that have the strongest impact on the TH conditions in the fractured tuff are the bulk thermal conductivity (important for conductive heat transport) and the fracture permeability (important for moisture redistribution). Thus, the below sections focus on sensitivity to fracture capillary strength, fracture permeability, and bulk thermal conductivity.

To analyze the potential impact of variation in fracture capillarity (BSC 2004 [DIRS 169131]; DTN: LB0310AMRU0120.001 [DIRS 166409]), thermal seepage results are presented from a simulation run performed with a smaller fracture capillary-strength parameter of $1 / \alpha=400 \mathrm{~Pa}$. (All other cases were conducted using a value of $589 \mathrm{~Pa}$ ). The simulation is performed with the Tptpmn submodel using the reference-mode heat load and a flux multiplication factor of 10 (Simulation Case MN-HET-09; see Table 6.2.1.6-1). Thermal seepage results are given in Figure 6.2.4.2-7. (Note that the rock temperatures are virtually unchanged from the reference case.) As known from ambient seepage studies, a smaller capillary-strength parameter increases the potential for seepage. Accordingly, both the transient thermal seepage and the long-term ambient seepage values are higher than in the reference case with $1 / \alpha=589 \mathrm{~Pa}$ (compare to Figure 6.2.2.2-7b). However, the general trend of the thermal seepage rate being smaller than the respective long-term seepage estimate holds true, and the proposed thermal-seepage abstraction model is still valid. 


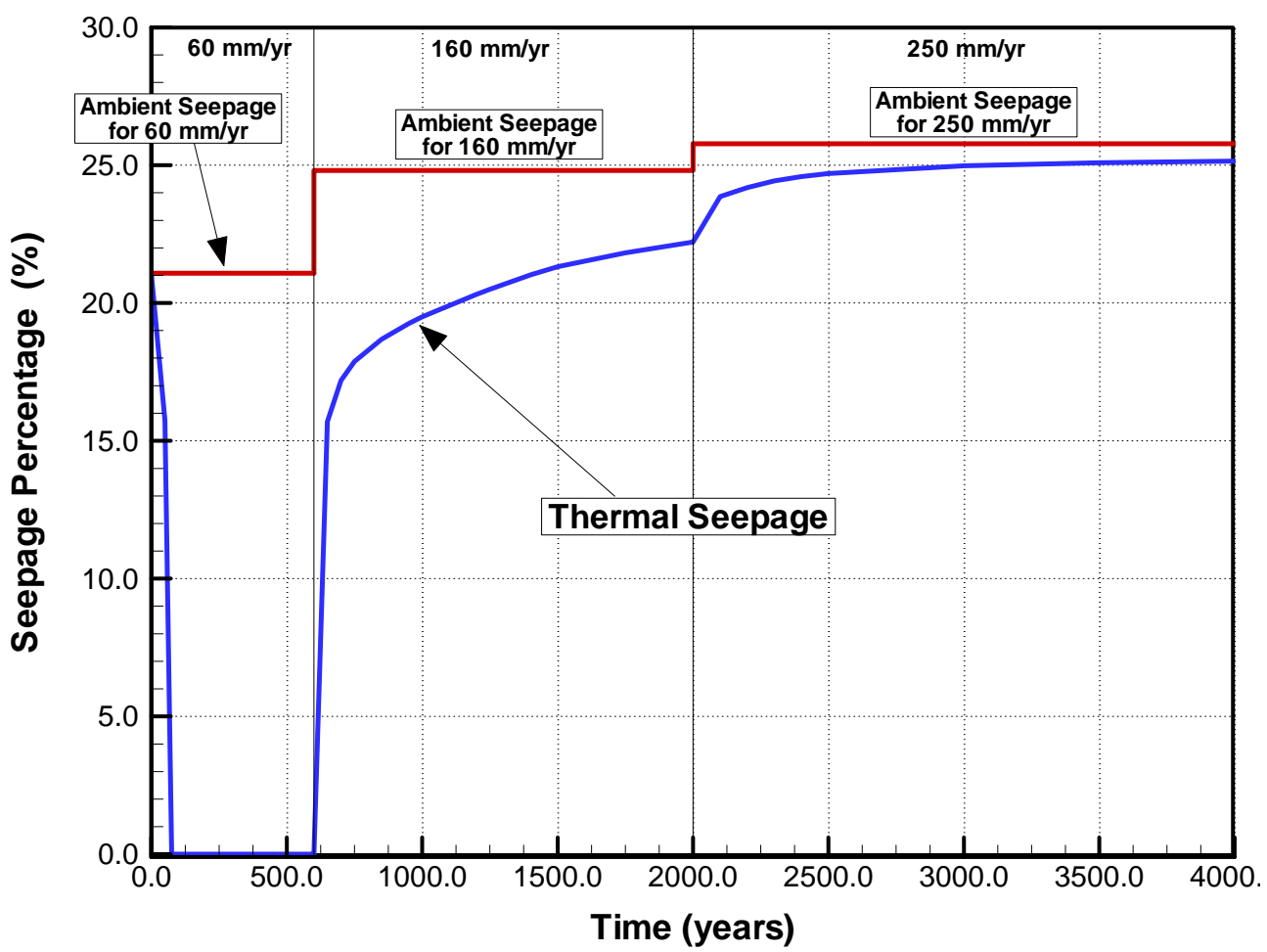

Output DTN: LB0301DSCPTHSM.002.

NOTE: The simulation case is MN-HET-09.

Figure 6.2.4.2-7. Seepage Percentage for Tptpmn Submodel with a Fracture Capillary-Strength Parameter of $1 / \alpha=400 \mathrm{~Pa}$, Showing Results from Thermal Run and from Long-Term Ambient Runs

Variation in fracture permeability is an important parameter for ambient seepage, and also affects the intensity of TH coupling. Figure 6.2.4.2-8 shows the temperature evolution at the drift wall for sensitivity cases with roughly a one-order-of-magnitude variation of fracture permeability above and below the reference case 10 (Simulation Cases MN-HET-13 and MN-HET-14). The simulation is performed with the Tptpmn submodel using the reference-mode heat load and a flux multiplication factor of 10 . For most of the depicted time period, the temperatures are almost identical for these cases. The main differences occur during the time period when the rock returns to boiling temperature, with stronger heat pipe signals (see Section 6.1.1 for discussion on heat pipes) evident for the high-permeability case. As a result, the boiling period for this case is shorter compared to the other cases. The peak temperature difference between the sensitivity cases is less then $2^{\circ} \mathrm{C}$. Strong differences occur with respect to the seepage results. While there is no seepage at any time for the high-permeability case, both thermal and ambient seepage rates are significantly increased for the low-permeability case (Figure 6.2.4.2-9 compared to Figure 6.2.2.2-7b). The ambient seepage rates are higher because flow diversion around the drift is less effective for small fracture permeabilities. As a result of these differences in the flow diversion capacity of the fracture rock, the evolution of thermal seepage is also affected. In the low-permeability case, thermal seepage starts earlier and is higher than in the reference case. However, despite these differences, the main conclusions, i.e., thermal seepage 
does not occur during the period of above-boiling rock temperatures and thermal seepage rates are always smaller than the respective ambient reference values hold for both permeability variation cases.

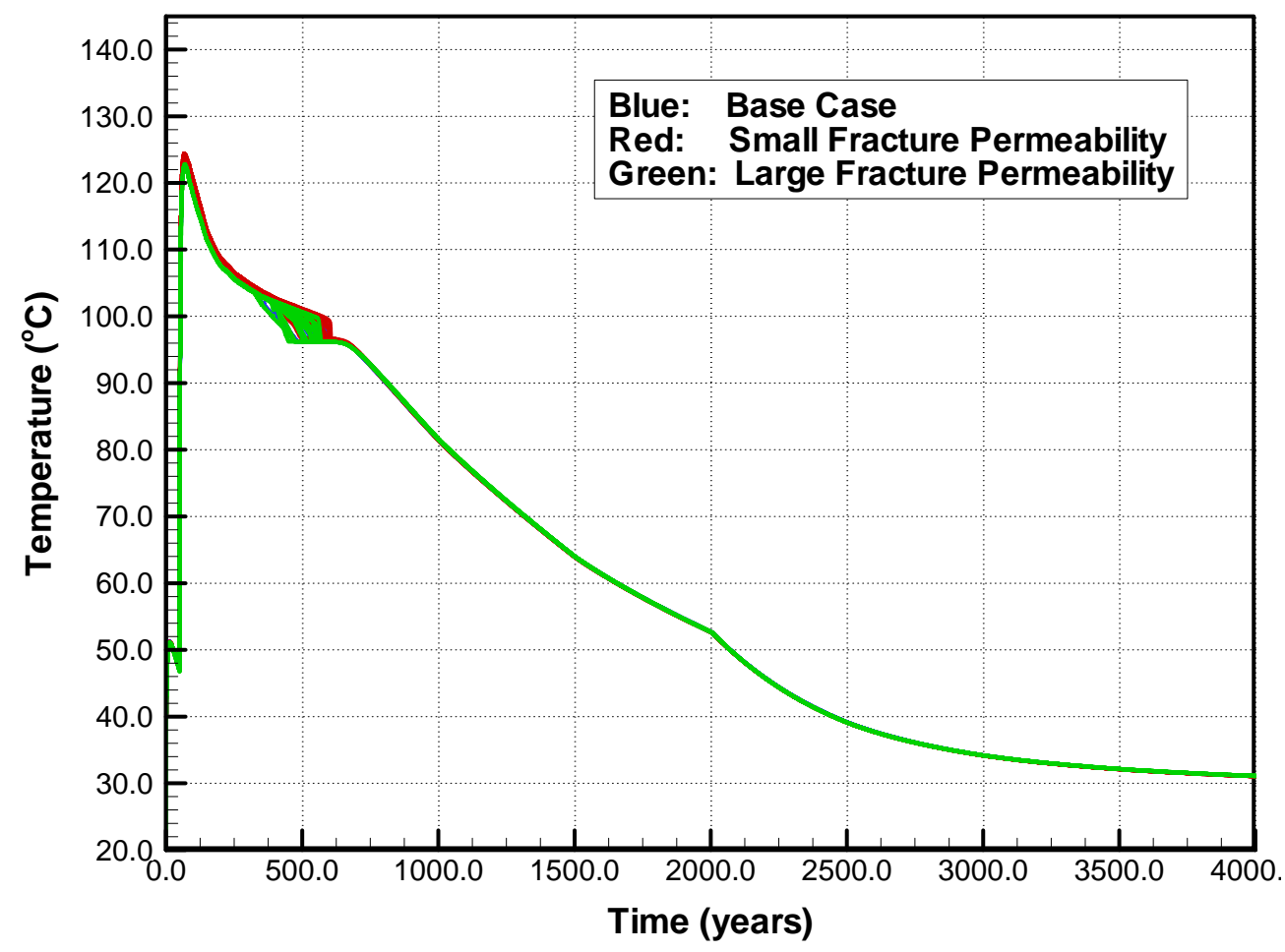

Output DTNs: LB0309DSCPTHSM.001 compared with LB0303DSCPTHSM.001.

NOTE: $\quad$ Figure shows all rock discretization elements along the drift periphery from the crown to the springline. The sensitivity cases have mean fracture permeability values roughly one order of magnitude above and below the base case value (simulation cases MN-HET-13 and MN-HET-14 compared with MN-HET-03). For each simulation case, the temperature histories in all gridblocks along the drift perimeter are depicted in the same color.

Figure 6.2.4.2-8. $\quad$ Rock Temperature Evolution at the Drift Wall for Tptpmn Submodel Showing Different Fracture Permeability Simulations for Reference Thermal Mode Using Percolation Flux Scenario with Multiplication Factor 10 


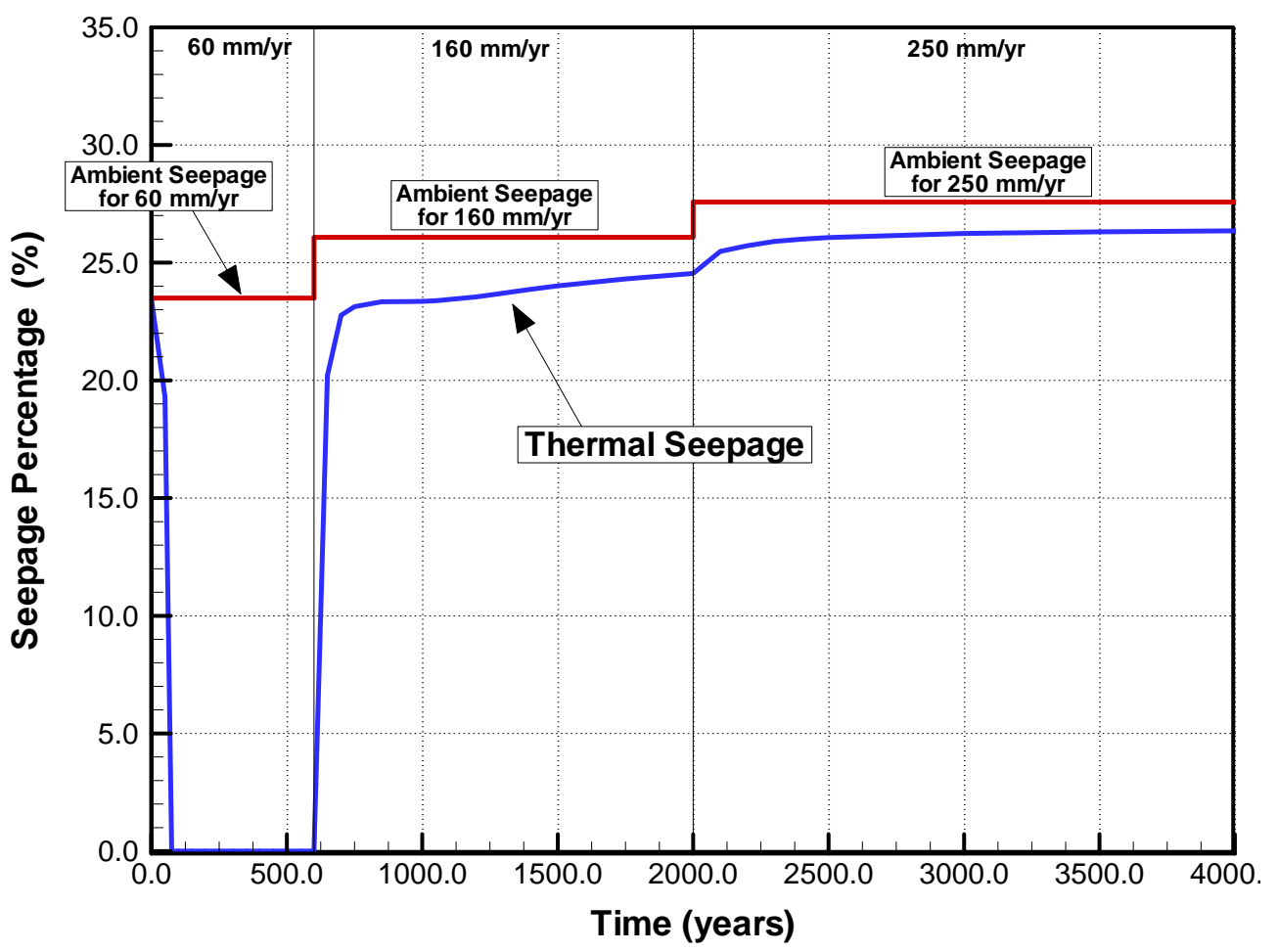

Output DTN: LB0309DSCPTHSM.001.

NOTE: The mean fracture permeability in this simulation is decreased by roughly one order of magnitude compared to the base case. The simulation case is MN-HET-14.

Figure 6.2.4.2-9. $\quad$ Seepage Percentage for Tptpmn Submodel for Reference Thermal Mode Using Percolation Flux Scenario with Multiplication Factor 10

The rock property considered to have the strongest impact on the near-field TH conditions is the bulk thermal conductivity. Estimates for variation of thermal properties within the host rock units is provided in Table 7-10 of Thermal Conductivity of the Potential Repository Horizon (BSC 2004 [DIRS 169854]), based on a geostatistical evaluation of the influence of porosity variation across the entire site. (Most thermal properties of the bulk rock are a function of the porosity and the mineralogy. Thus, in lithophysal rock, uncertainty associated with lithophysal porosity introduces uncertainty in thermal properties of the bulk rock.) The resulting standard deviation describing the variability of dry and wet bulk thermal conductivity was reported to be of the order of $0.25 \mathrm{~W} / \mathrm{m} / \mathrm{K}$ in the Tptpmn and the Tptpll units.

Figures 6.2.4.2-10 and 6.2.4.2-11 show the evolution of rock temperature along the drift perimeter and the evolution of thermal seepage for sensitivity cases with thermal conductivity of the host rock $0.25 \mathrm{~W} / \mathrm{m} / \mathrm{K}$ above and below the base case value. The simulations were performed for the Tptpmn submodel, applying the reference thermal mode and a flux multiplication factor of 10. Figure 6.2.4.2-10 shows that the rock temperatures at the drift wall vary as much as $17^{\circ} \mathrm{C}$ at peak temperature between the sensitivity cases, and the duration of the boiling period is about 200 years shorter for the high-conductivity case as compared to the lowconductivity case. However, differences in the evolution of thermal seepage are marginal (Figure 6.2.4.2-11). This is because (a) the adjusted parameter thermal conductivity does not 
affect the ambient seepage rate (which defines the upper asymptotic limit for thermal seepage at later stages) and (b) the temperature difference between the sensitivity cases has already vanished at the time when thermal seepage begins to occur.

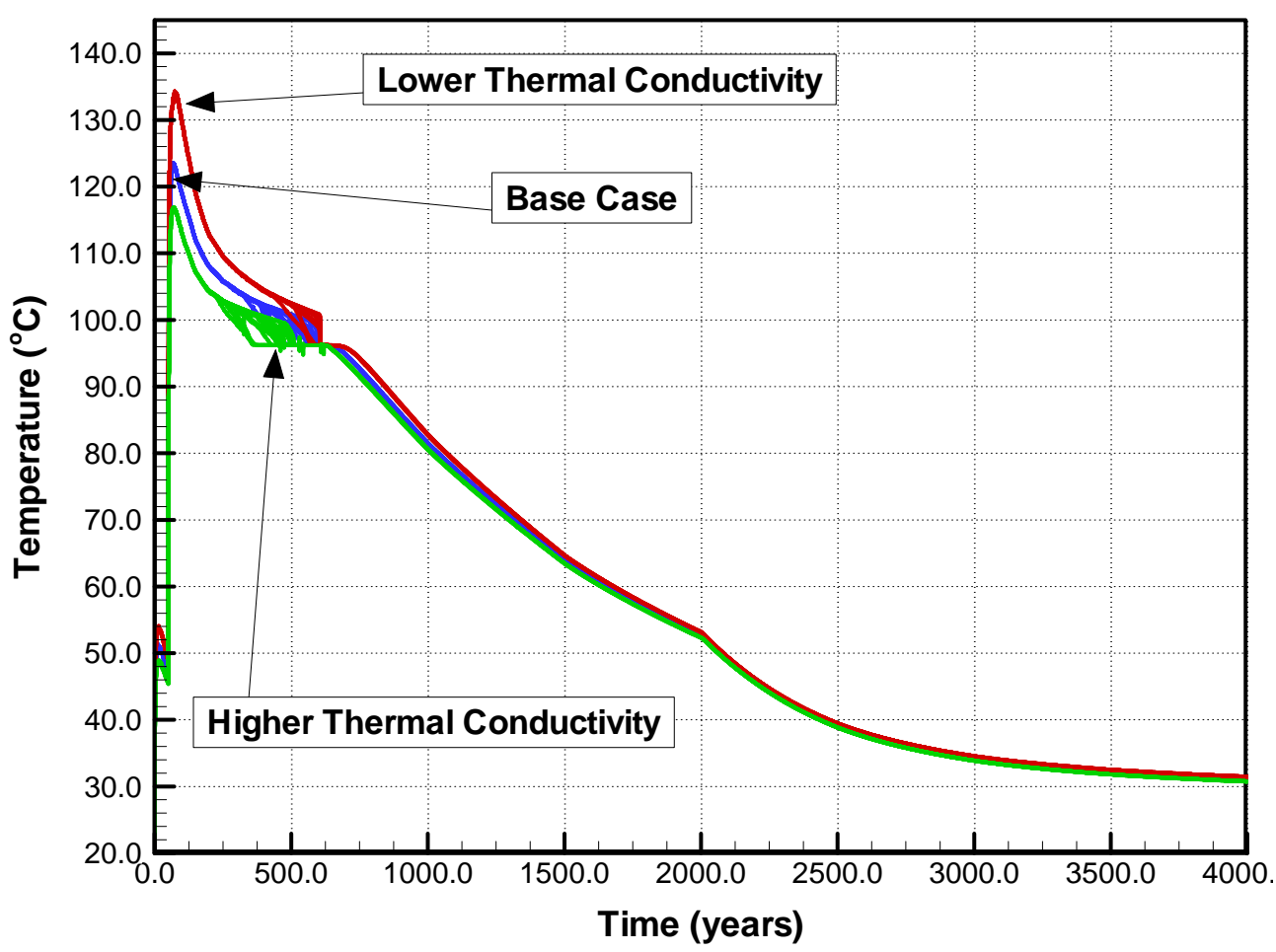

Output DTNs: LB0309DSCPTHSM.001 compared with LB0303DSCPTHSM.001.

NOTE: $\quad$ Figure shows all rock discretization elements along the drift periphery from the crown to the springline. The sensitivity cases have thermal conductivity values of $0.25 \mathrm{~W} / \mathrm{m} / \mathrm{K}$ above and below the base case value (simulation cases MN-HET-11 and MN-HET-12 compared with MN-HET-03). For each simulation case, the temperature histories in all gridblocks along the drift perimeter are depicted in the same color.

Figure 6.2.4.2-10. Rock Temperature Evolution at the Drift Wall for Tptpmn Submodel Showing Different Thermal Conductivity Simulations for Reference Thermal Mode Using Percolation Flux Scenario with Multiplication Factor 10 


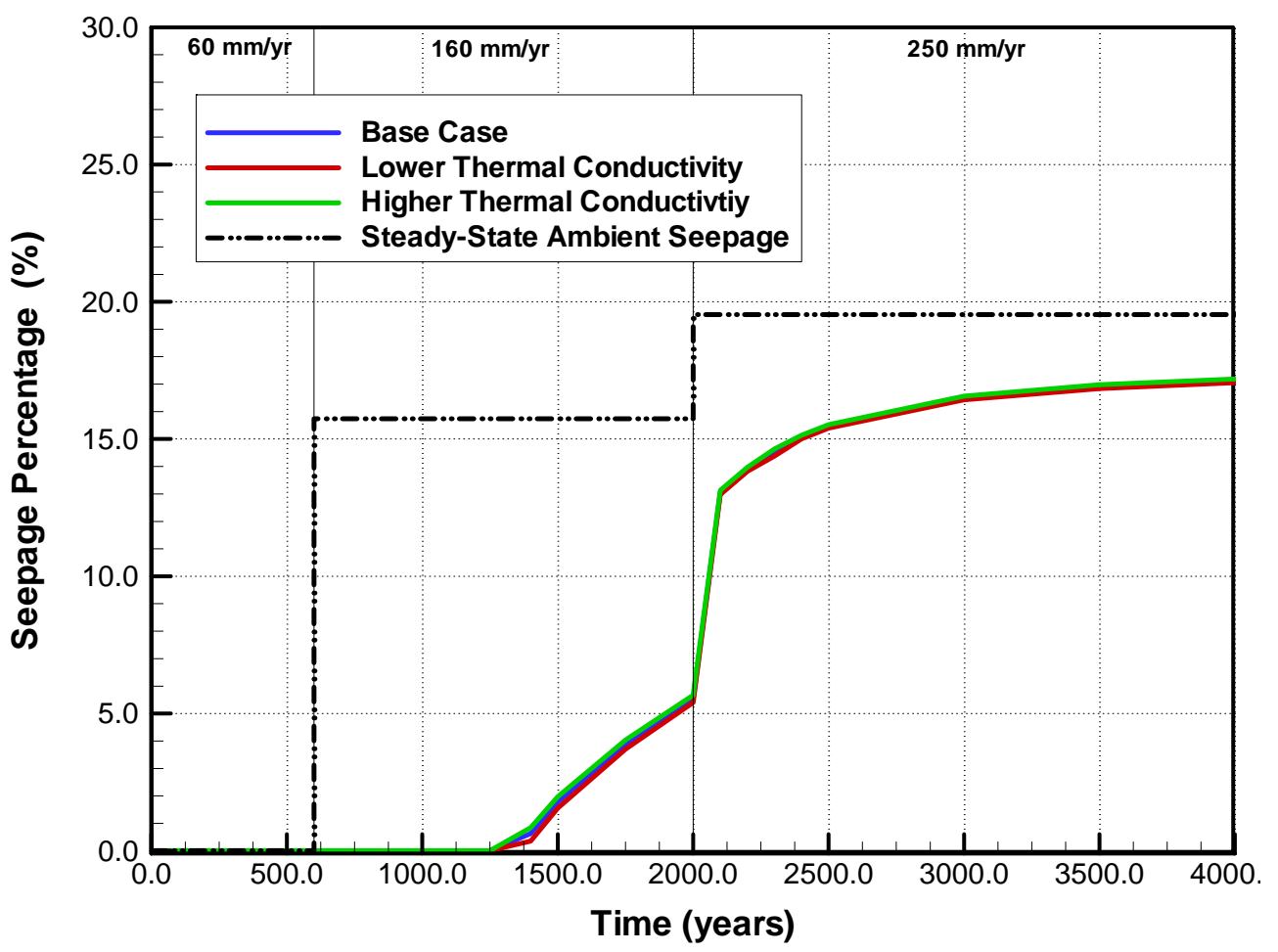

Output DTNs: LB0309DSCPTHSM.001 compared with LB0303DSCPTHSM.001.

NOTE: The sensitivity cases have thermal conductivity values of $0.25 \mathrm{~W} / \mathrm{m} / \mathrm{K}$ above and below the base case value (simulation cases MN-HET-11 and MN-HET-12 compared with MN-HET-03).

Figure 6.2.4.2-11. Seepage Percentage for Tptpmn Submodel Showing Different Thermal Conductivity Simulations for Reference Thermal Mode Using Percolation Flux Scenario with Multiplication Factor 10.

\subsection{Fracture-Matrix Interaction Using DKM Instead of AFM}

In another simulation run, a different conceptual model for fracture flow and fracture-matrix interaction is tested, using the standard dual-permeability method (DKM) for flow in the fractured rock instead of the AFM (Simulation Case MN-HET-10, see Table 6.2.1.6-1). It was already shown in Section 6.2.2.2.2 that the long-term ambient seepage rates estimated from the standard DKM are comparable to but smaller than the AFM results. As demonstrated in Figure 6.2.4.2-12, this trend is also true for thermal seepage. In this figure, thermal seepage is simulated with a standard DKM model, while using the reference-mode heat input and the factor-10 infiltration scenario. Thermal seepage is smaller and starts a few hundred years later than a similar simulation performed with the AFM (compare with Figure 6.2.2.2-7b for the AFM results). 


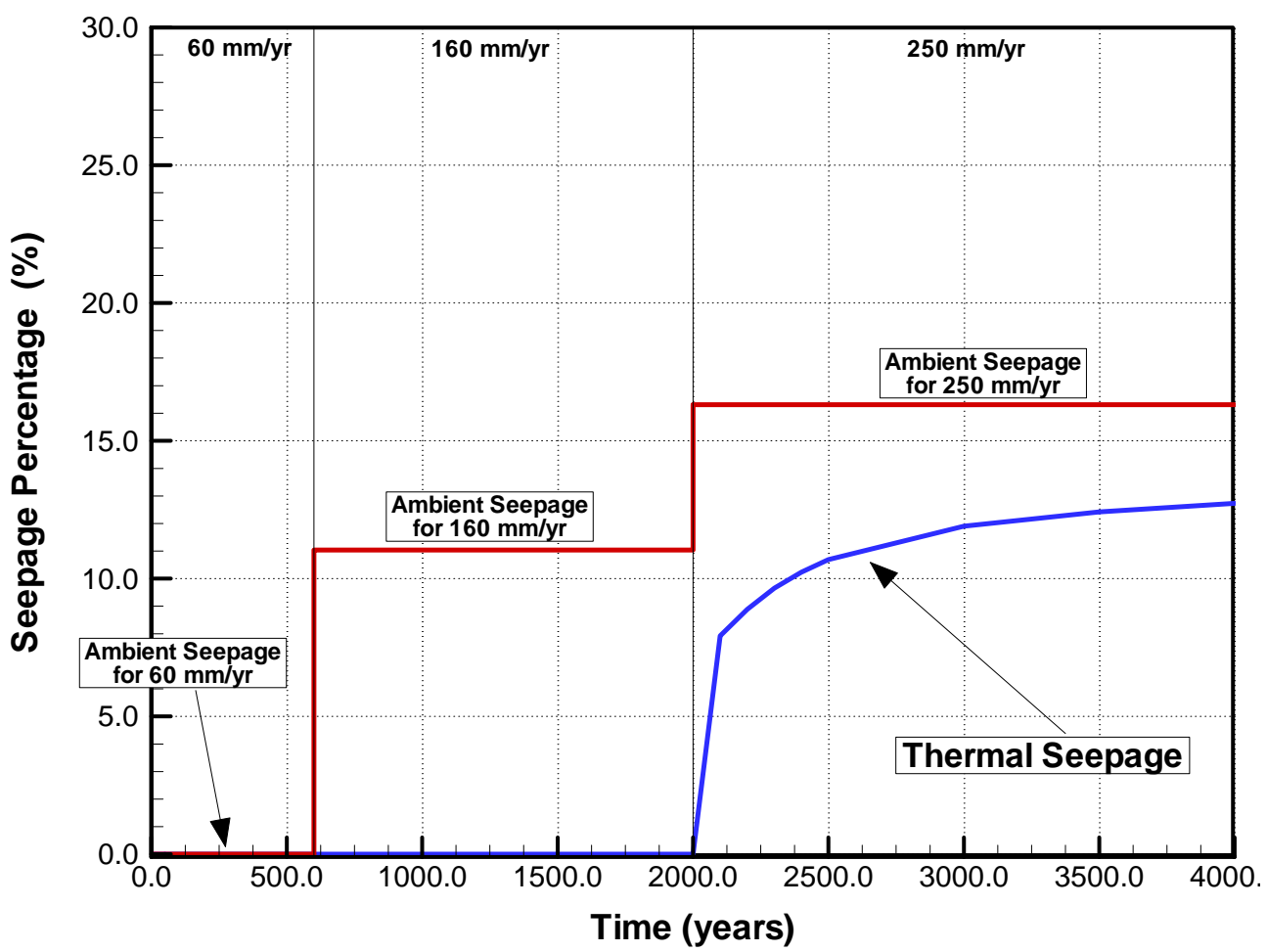

Output DTN: LB0301DSCPTHSM.002.

NOTE: The simulation case is MN-HET-10.

Figure 6.2.4.2-12. Seepage Percentage Tptpmn Submodel Using a Standard Dual-Permeability Method, Showing Results from Thermal Run and from Long-Term Ambient Runs

\subsection{Sensitivity to Fracture Continuum Thermal Conductivity}

It has been stated in Section 5 (Assumption 4) that the fracture continuum thermal conductivity for most of the thermal seepage simulations are assumed to be the product of thermal conductivity of the matrix continuum and the fracture continuum porosity, which is further reduced by the factor of 0.1 . For example, this resulted in fracture thermal conductivity of $0.0018 \mathrm{~W} / \mathrm{m} / \mathrm{K}$ (see Assumption 4). However, the heterogenous simulation runs for the Tptpll submodel (LL-HET-01 and LL-HET-02) have been performed with a different conceptual model for calculating fracture thermal conductivity. For these cases, fracture thermal conductivity is calculated as the product of thermal conductivity of air and the porosity of the fracture continuum. This resulted in, as an example, a fracture thermal conductivity of $0.000288 \mathrm{~W} / \mathrm{m} / \mathrm{K}$ for the tsw35 model layer. A sensitivity analysis (LL-HET-03; see Table 6.2.1.6-1) is carried out to demonstrate that this difference in fracture thermal conductivity does not impact the $\mathrm{TH}$ simulations at all. All aspects of the LL-HET-03 sensitivity simulation are identical to the LLHET-01 run except for the changed fracture thermal conductivity (for example, the fracture thermal conductivity for tsw35 is $0.000288 \mathrm{~W} / \mathrm{m} / \mathrm{K}$ in LL-HET-01 and $0.0018 \mathrm{~W} / \mathrm{m} / \mathrm{K}$ in LLHET-03). The flow multiplication factor applied for the sensitivity simulation is 5 . Figure 6.2.4.2-13 shows a comparison of temperature at the drift crown with the two approaches adopted for calculating the fracture thermal conductivity. Figure 6.2.4.2-14 compares the fracture saturation for the two approaches. From Figures 6.2.4.2-13 and 6.2.4.2-14, it can be concluded 
that the two approaches adopted for calculating fracture continuum thermal conductivity yield identical results and the TH results in this model report are not sensitive to fracture continuum thermal conductivity. This is expected as the fracture continuum thermal conductivity is significantly smaller than that of the rock matrix. In both cases, no seepage is obtained at all times.

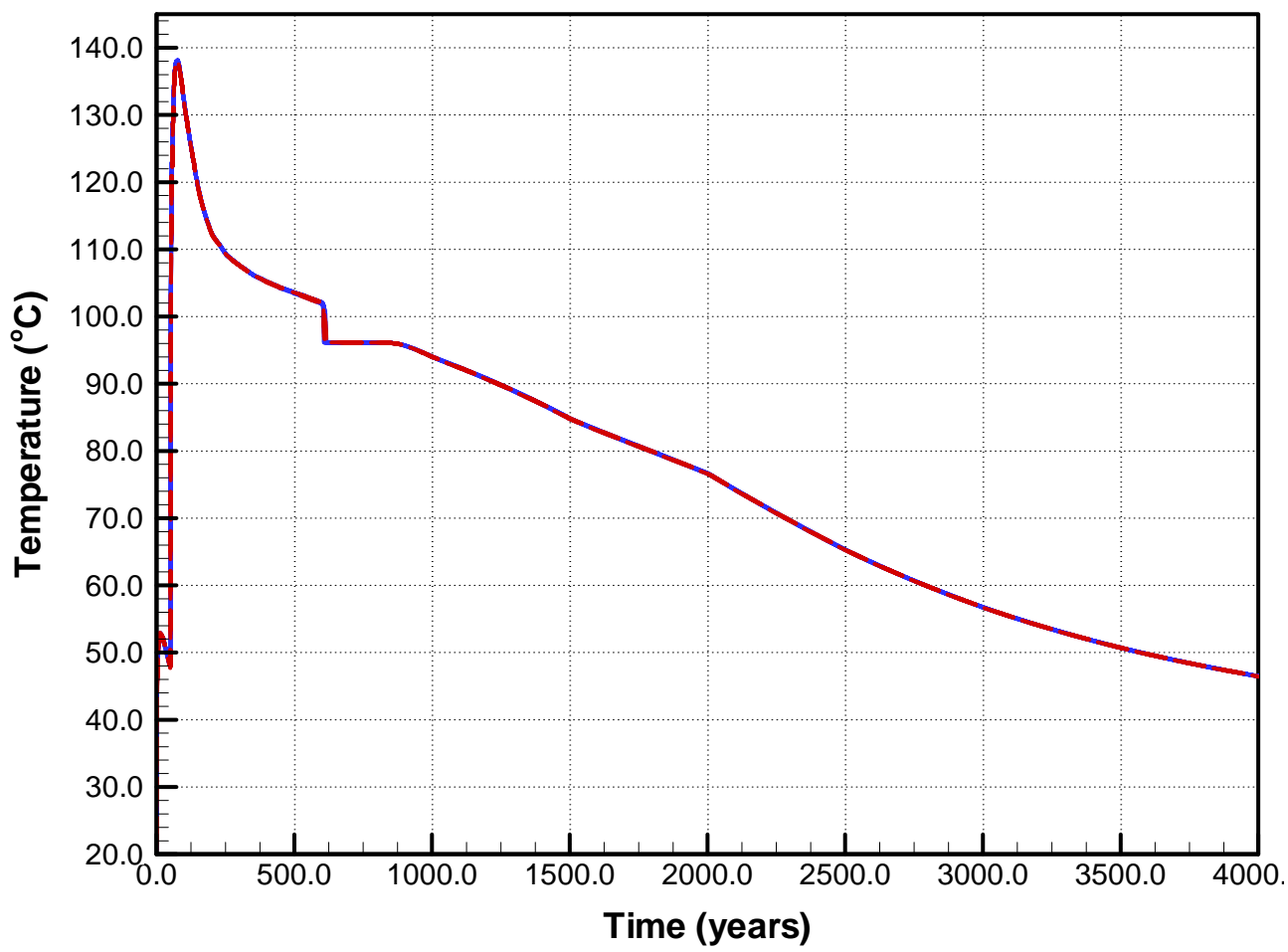

Output DTN: NA (see Section 8.5).

NOTE: Figure shows all rock discretization elements along the drift periphery from the crown to the springline. Blue lines are for the scenario where fracture thermal conductivity is calculated by multiplying the matrix thermal conductivity with the fracture porosity and then by reducing the product by 0.1 (LL-HET-03). Red dashed lines are for the scenario where fracture thermal conductivity is calculated by multiplying fracture porosity with 0.03 (LL-HET-01). The simulations were carried out for the Tptpll submodel with a flow multiplication factor of 5 .

Figure 6.2.4.2-13. Temperature at Drift Crown from Two Different Approaches Adopted for Calculating the Fracture Continuum Thermal Conductivities 


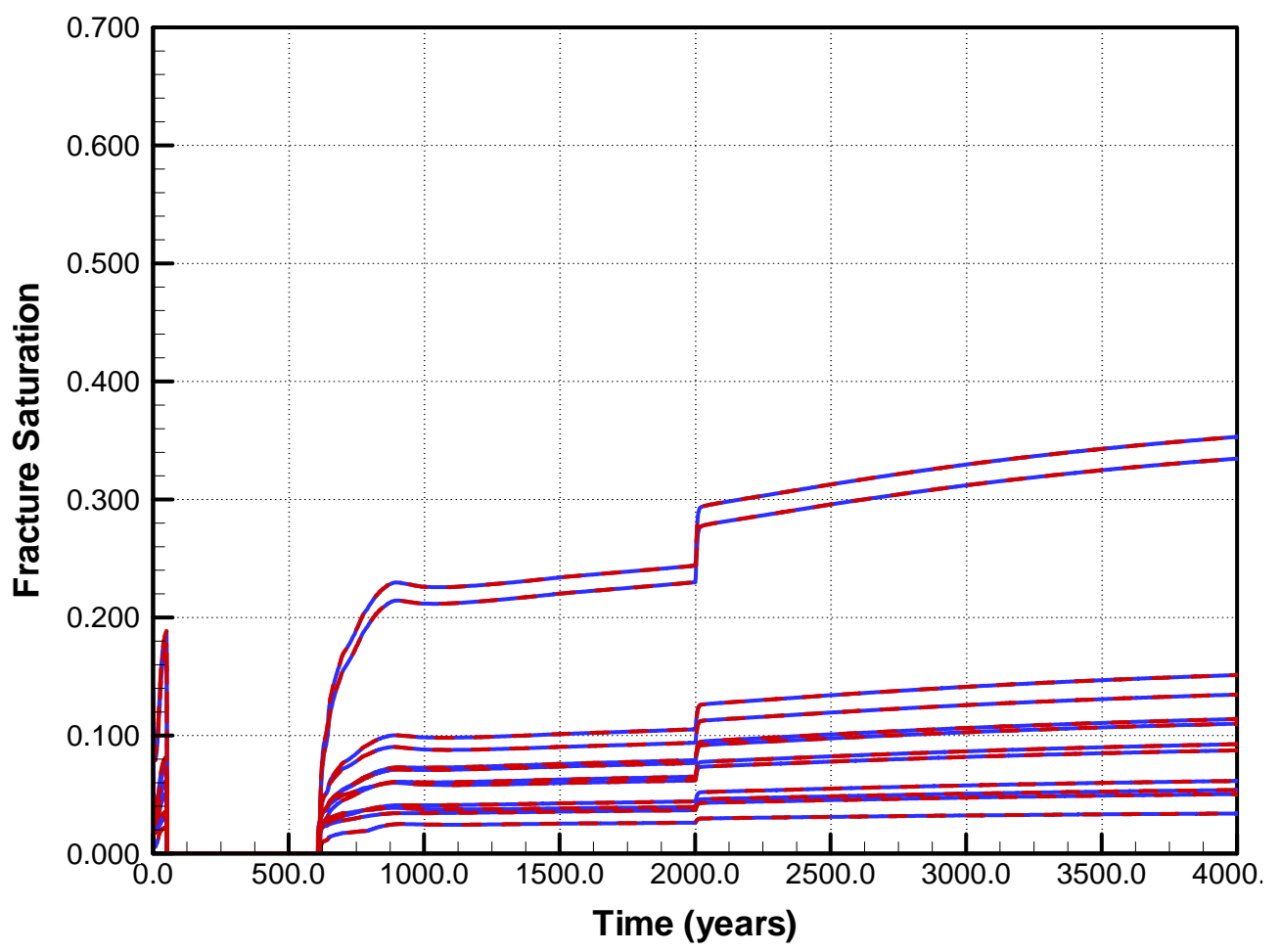

Output DTN: NA (see Section 8.5).

NOTE: $\quad$ Figure shows all rock discretization elements along the drift periphery from the crown to the springline. Blue lines are for the scenario where fracture thermal conductivity is calculated by multiplying the matrix thermal conductivity with the fracture porosity and then by reducing the product by 0.1 (LL-HET-01). Red dashed lines are for the scenario where fracture thermal conductivity is calculated by multiplying fracture porosity with 0.03 (LL-HET-03). The simulations were carried out for the Tptpll submodel (LL-HET-01) with a flow multiplication factor of 5 .

Figure 6.2.4.2-14. Fracture Saturation at Drift Crown from Two Different Approaches Adopted for Calculating the Fracture Continuum Thermal Conductivities

\subsection{Sensitivity to Fracture-Matrix Interface Thermal Conductivity}

As pointed out in Section 6.2.1.1.2, all TH simulations in this report used a thermal conductivity at the fracture-matrix interface that was calculated from the harmonic average of the thermal conductivities of the fracture and the matrix continua, respectively. Harmonic averaging ensured that the interface thermal conductivity was closer to the (much smaller) fracture conductivity value. This conceptual model choice provides a bounding case for thermal seepage, as the reduced heat transfer from the matrix to the fractures reduces the effectiveness of the vaporization barrier to water flow in the fractures. An alternative conceptualization is to assign the matrix thermal conductivity to the fracture-matrix interface. This conceptualization translates to rapid conductive heat transfer between the matrix and fracture continua.

To illustrate the difference between these two conceptualizations, a sensitivity analysis is carried out with the Tptpmn submodel with a flow multiplication factor of 10 (simulation case MNHET-17 compared to MN-HET-03; see Table 6.2.1.6-1). Figures 6.2.4.2-15 through 6.2.4.2-17 show the results of this sensitivity analysis. Figure 6.2.4.2-15 depicts the fracture continuum 
temperatures at the drift crown for the two cases. Figure 6.2.4.2-16 shows the fracture saturation at the same location and Figure 6.2.4.2-17 shows the predicted seepage percentage into the emplacement drift for the two cases. Simulated fracture temperatures, fracture saturations, and seepage percentage for the two conceptualizations are similar except for the following subtle differences. The heat-pipe signature is much longer when harmonic weighting is used to define the interface thermal conductivity. In addition, resaturation for this case (see Figure 6.2.4.2-16) begins earlier. As far as the predicted seepage percentage is concerned (see Figure 6.2.4.2-17), the two conceptualizations produce almost identical results, with the harmonic weighted model predicting a slightly earlier start of seepage. Thus, using a harmonic weighted interface thermal conductivity is conservative with respect to the prediction of thermal seepage.

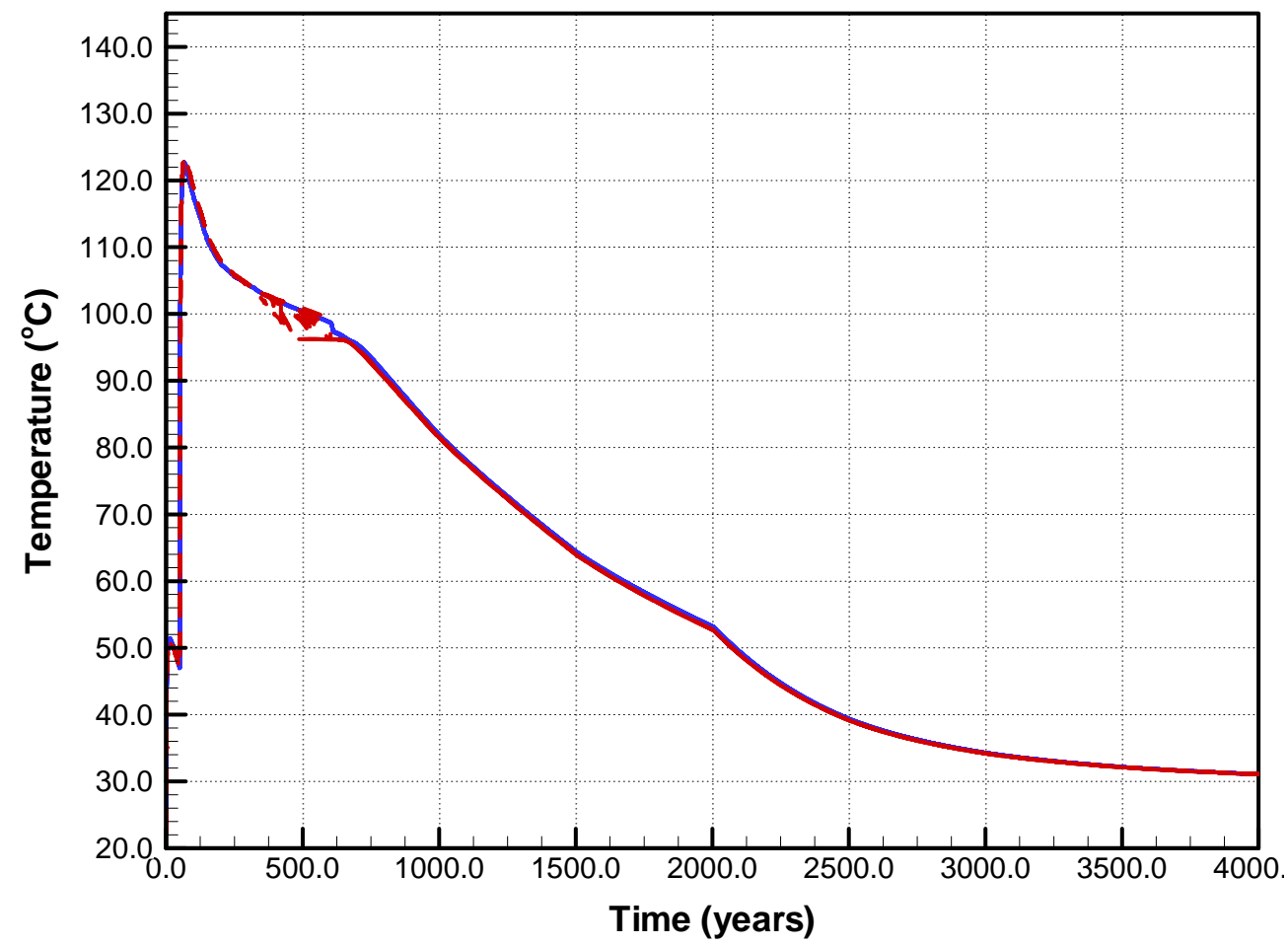

Output DTN: NA (see Section 8.5).

NOTE: $\quad$ Figure shows all rock discretization elements along the drift periphery from the crown to the springline. Blue lines represent the scenario where the interface thermal conductivity is equal to the matrix thermal conductivity (MN-HET-17). Red dashed lines represent the base case scenario where the interface thermal conductivity is a harmonic average of the fracture and matrix thermal conductivities (MN-HET-03). Simulations are performed for the Tptpmn submodel with a flow multiplication factor of 10 .

Figure 6.2.4.2-15. Temperatures in the Fractures at the Drift Crown for Two Alternative Conceptualizations of Fracture-Matrix Interface Thermal Conductivity 


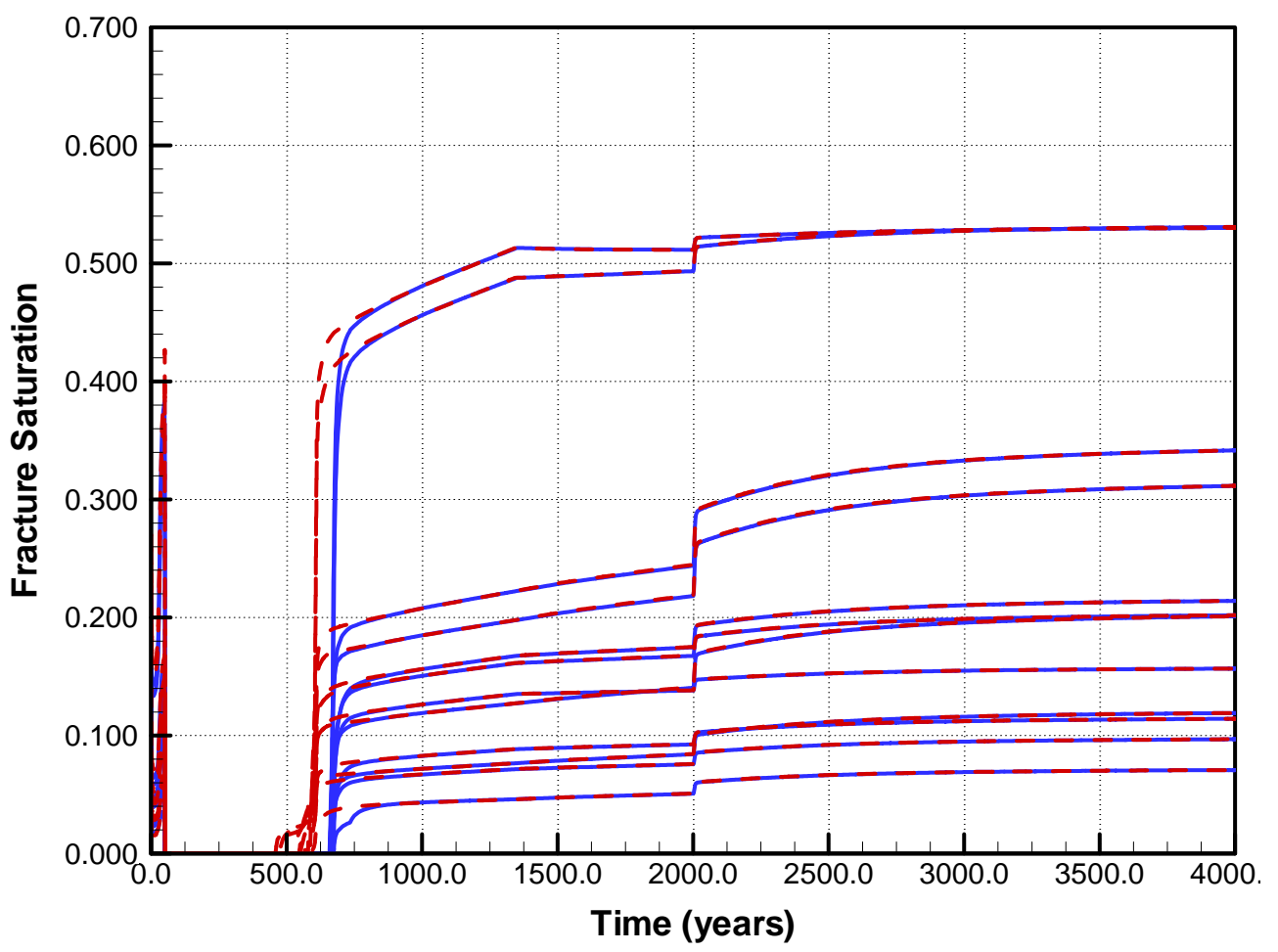

Output DTN: NA (see Section 8.5).

NOTE: $\quad$ Figure shows all rock discretization elements along the drift periphery from the crown to the springline. Blue lines represent the scenario where the interface thermal conductivity is equal to the matrix thermal conductivity (MN-HET-17). Red dashed lines represent the base case scenario where the interface thermal conductivity is a harmonic average of the fracture and matrix thermal conductivities (MN-HET-03). Simulations are performed for the Tptpmn submodel with a flow multiplication factor of 10 .

Figure 6.2.4.2-16. Fracture Saturation at the Drift Crown for Two Alternative Conceptualizations of Fracture-Matrix Interface Thermal Conductivity 


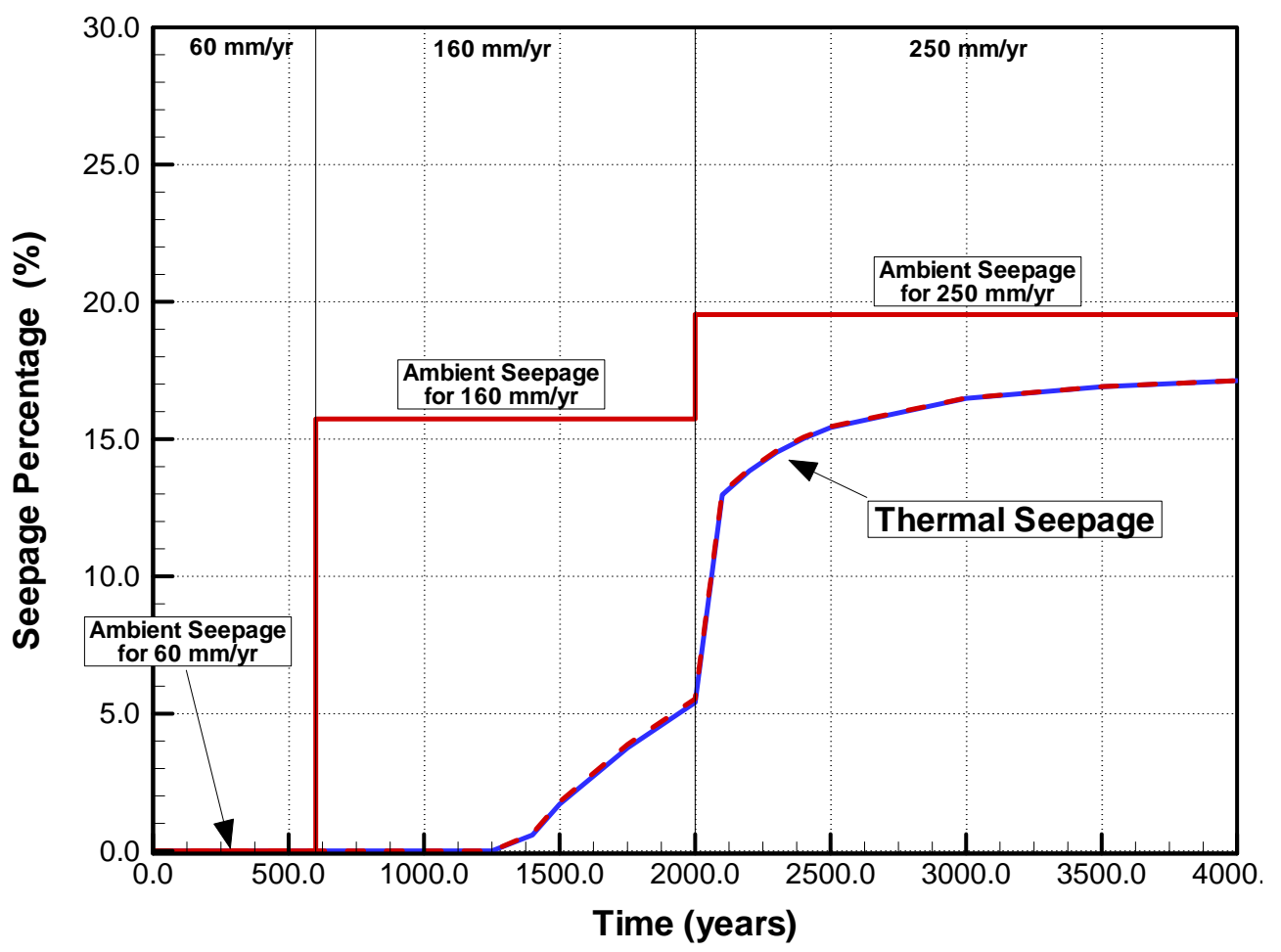

Output DTN: NA (see Section 8.5).

NOTE: Blue line represents the scenario where the interface thermal conductivity is equal to the matrix thermal conductivity (MN-HET-17). Redline represents the base case scenario where the interface thermal conductivity is a harmonic average of the fracture and matrix thermal conductivities (MN-HET-03). Simulations are performed for the Tptpmn submodel with a flow multiplication factor of 10.

Figure 6.2.4.2-17 Predicted Seepage Percentage for Two Alternative Conceptualizations of FractureMatrix Interface Thermal Conductivity

\subsection{Sensitivity to In-Drift Conceptual Model}

As pointed out in Sections 4.1.1.6 and 6.2.1.5, the in-drift flow and transport processes are simulated in a simplified manner. The conceptual model choices for the in-drift treatment are tested below.

The first test is regarding the model choice of a large thermal conductivity assigned to the gasfilled open cavity. Simulation case MN-HET-18 (see Table 6.2.1.6-1) uses a thermal conductivity value of $10.568 \mathrm{~W} / \mathrm{m} / \mathrm{K}$ (see discussion in Section 4.1.1.6) for the open drift instead of the base case value of $10,000 \mathrm{~W} / \mathrm{m} / \mathrm{K}$ (see Section 4.1.1.6). The simulation is carried out with the Tptpmn submodel with a flow multiplication factor of 10. Figures 6.2.4.2-18 through 6.2.4.2-20 show the results of this sensitivity analysis in comparison with the base case scenario MN-HET-03. Figure 6.2.4.2-18 depicts the fracture continuum temperatures at the drift crown for the two cases. Figure 6.2.4.2-19 shows the fracture saturation at the same location and Figure 6.2.4.2-20 shows the predicted seepage percentage into the emplacement drift for the two cases. All simulated fracture temperatures, fracture saturations, and seepage percentages for the two conductivity values are virtually identical. 


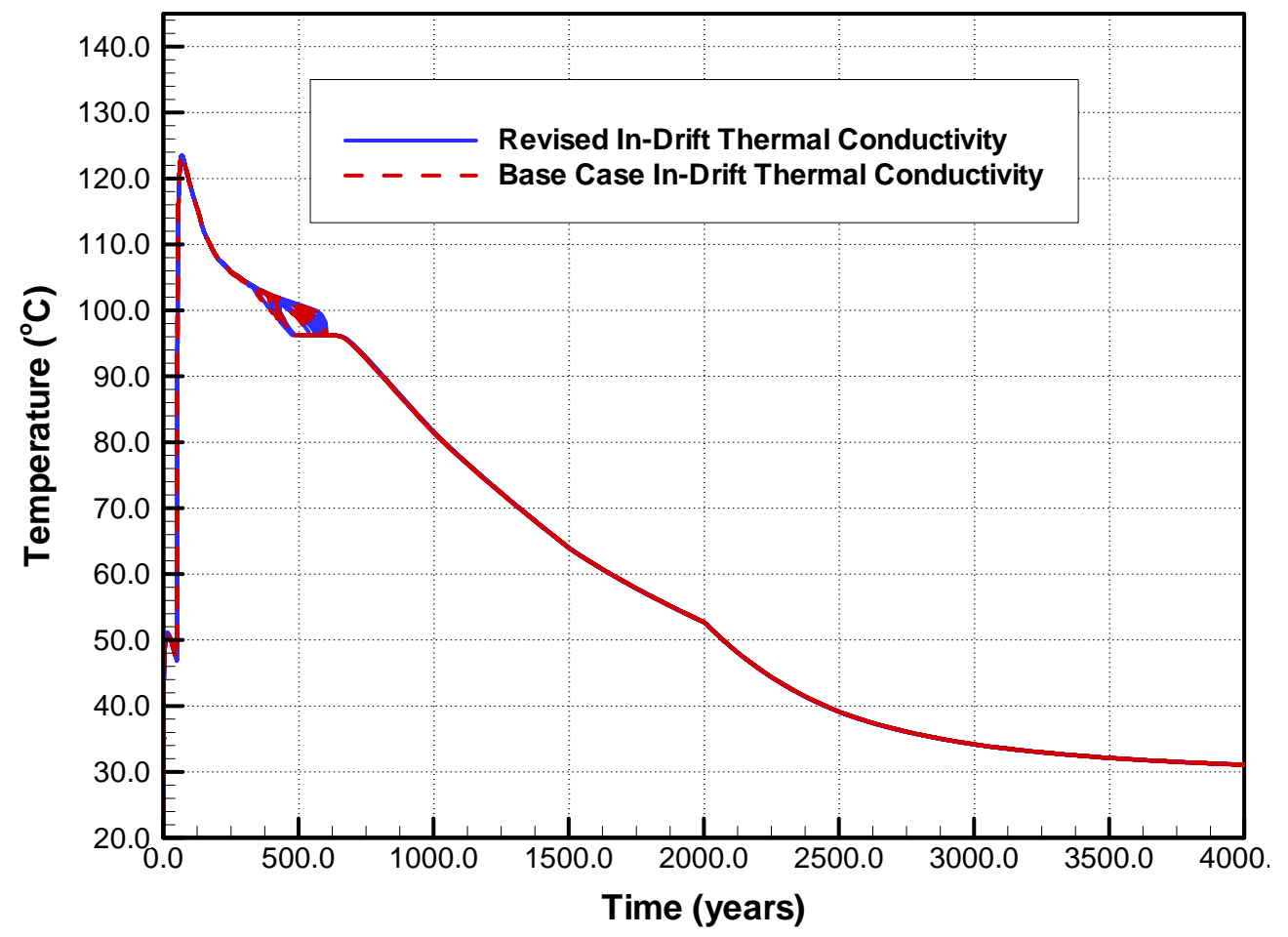

Output DTN: NA (see Section 8.5).

NOTE: $\quad$ Figure shows all rock discretization elements along the drift periphery from the crown to the springline. Blue lines represent the scenario with the revised in-drift thermal conductivity (MN-HET-18). Red dashed lines represent the base case scenario (MN-HET-03). Simulations are performed for the Tptpmn submodel with a flow multiplication factor of 10.

Figure 6.2.4.2-18. Temperatures in the Fractures at the Drift Wall for Two Alternative Thermal Conductivity Values Assigned to In-Drift Open-Cavity Elements 


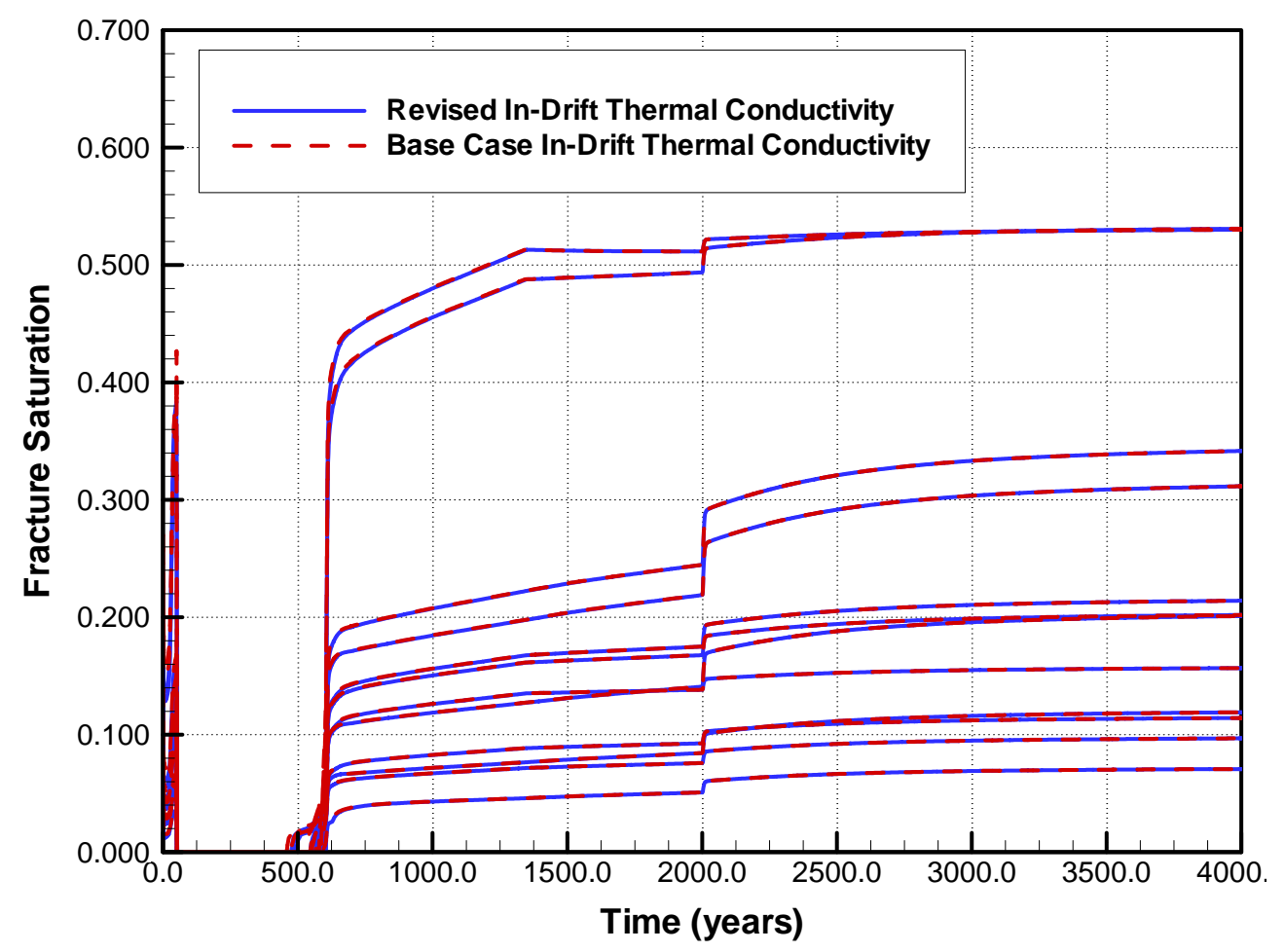

Output DTN: NA (see Section 8.5).

NOTE: $\quad$ Figure shows all rock discretization elements along the drift periphery from the crown to the springline. Blue lines represent the scenario with the revised in-drift thermal conductivity (MN-HET-18). Red dashed lines represent the base case scenario (MN-HET-03). Simulations are performed for the Tptpmn submodel with a flow multiplication factor of 10.

Figure 6.2.4.2-19. Fracture Saturations at the Drift Wall for Two Alternative Thermal Conductivity Values Assigned to In-Drift Open-Cavity Elements 


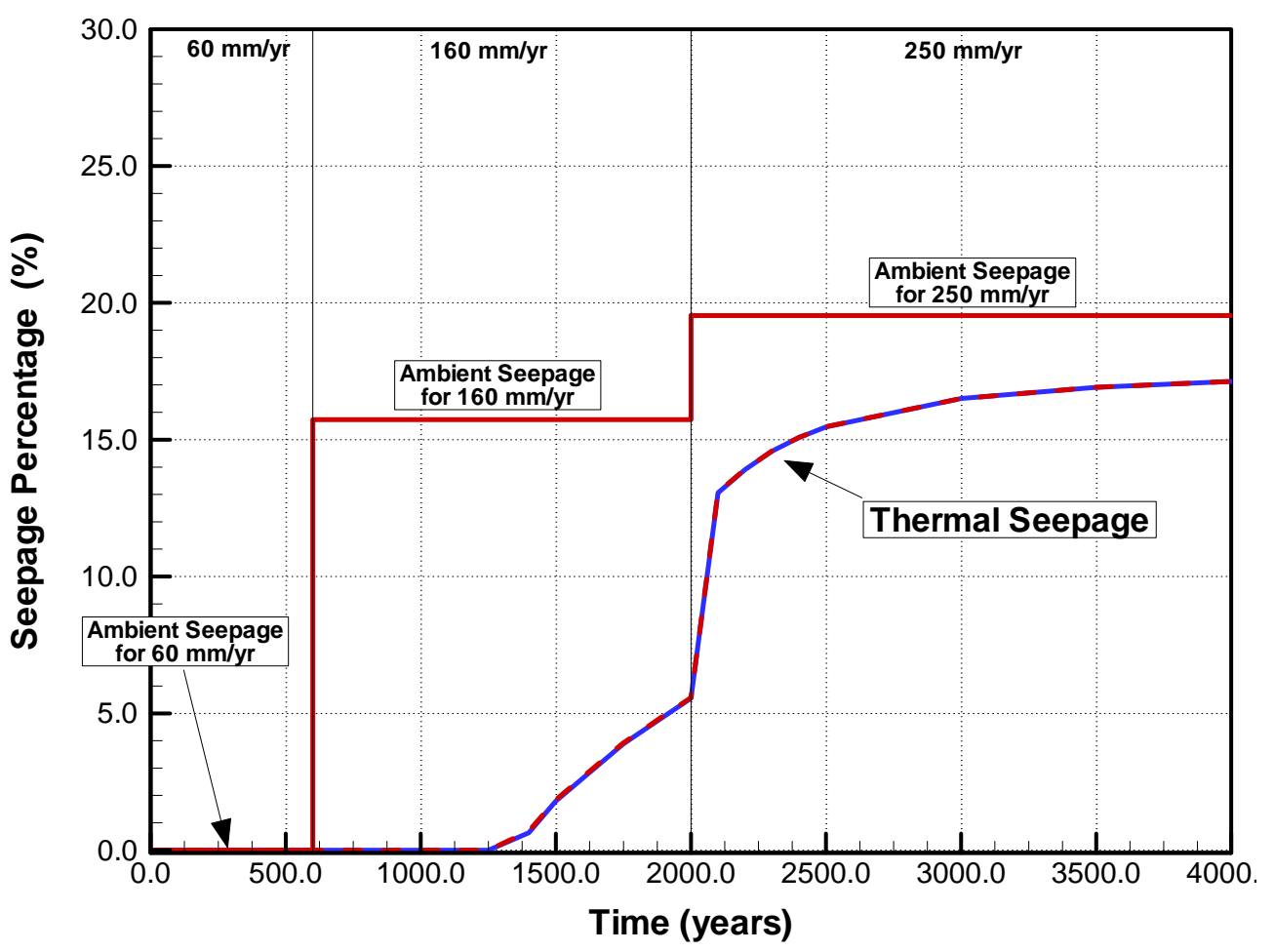

Output DTN: NA (see Section 8.5).

NOTE: Blue lines represent the scenario with the revised in-drift thermal conductivity (MN-HET-18). Red dashed lines represent the base case scenario (MN-HET-03). Simulations are performed for the Tptpmn submodel with a flow multiplication factor of 10.

Figure 6.2.4.2-20. Predicted Thermal Seepage Percentage for Two Alternative Thermal Conductivity Values Assigned to In-Drift Open-Cavity Elements

The second test is regarding the model choices for the waste package thermal properties. Simulation case MN-HET-19 (see Table 6.2.1.6-1) uses the thermal properties of the 21-PWR waste package given in D\&E / PA/C IED Typical Waste Package Components Assembly (BSC 2004 [DIRS 167758]) (i.e., a density of 3,495 kg/m $\mathrm{m}^{3}$, a heat capacity of $378 \mathrm{~J} / \mathrm{kg} / \mathrm{K}$, and a thermal conductivity of $1.5 \mathrm{~W} / \mathrm{m} / \mathrm{K}$ ), instead of the values listed in Table $4.1-10$. The simulation is carried out with the Tptpmn submodel with a flow multiplication factor of 10. Figures 6.2.4.221 through 6.2.4.2-23 show the results of this sensitivity analysis in comparison with the base case scenario MN-HET-03. Figure 6.2.4.2-21 depicts the fracture continuum temperatures at the drift crown for the two cases. Figure 6.2.4.2-22 shows the fracture saturation at the same location and Figure 6.2.4.2-23 shows the predicted seepage percentage into the emplacement drift for the two cases. All simulated fracture temperatures, fracture saturations, and seepage percentages for the two conductivity values are virtually identical. 


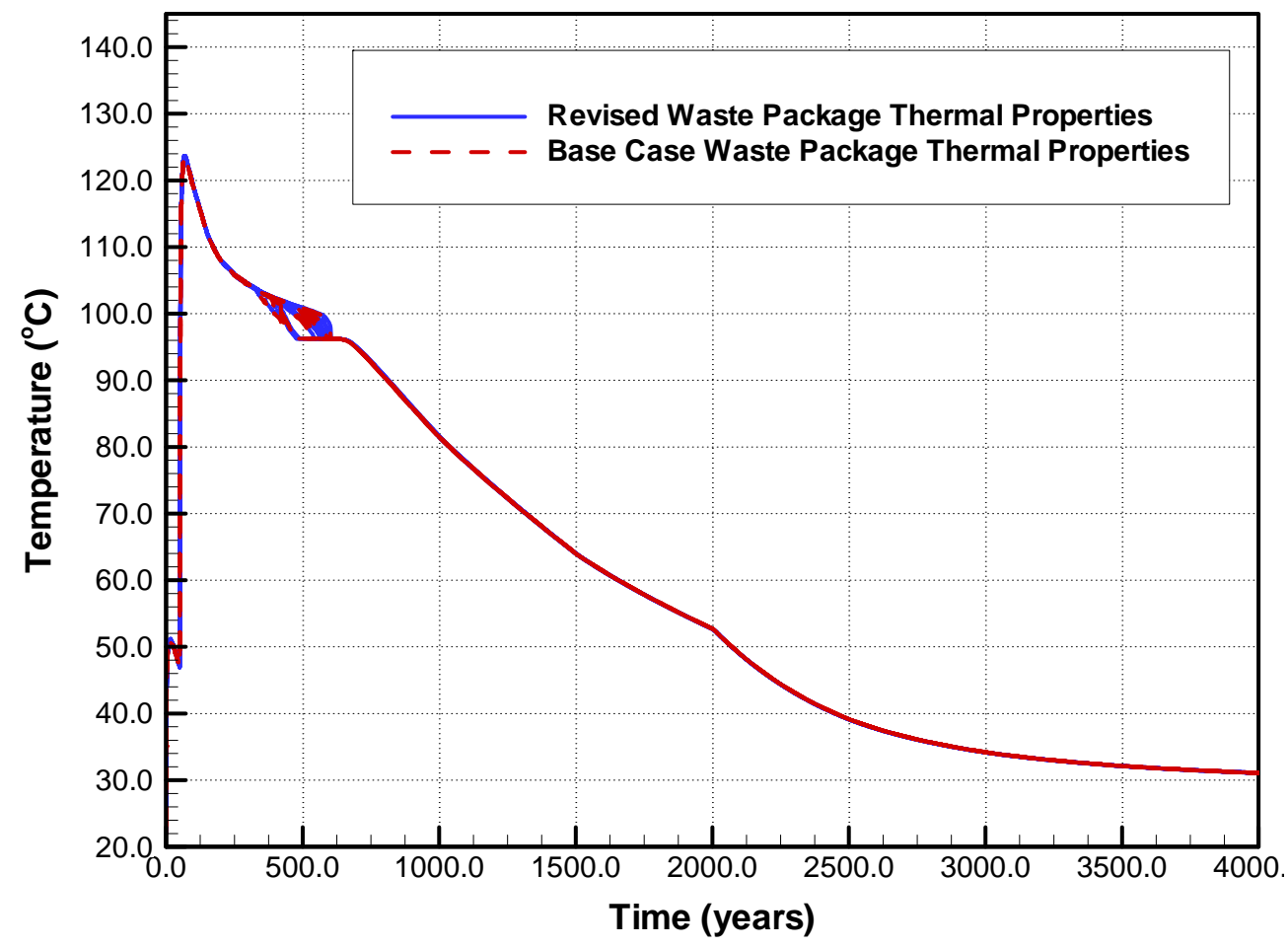

Output DTN: NA (see Section 8.5).

NOTE: $\quad$ Figure shows all rock discretization elements along the drift periphery from the crown to the springline. Blue lines represent the scenario with the revised waste package thermal properties (MN-HET-19). Red dashed lines represent the base case scenario (MN-HET-03). Simulations are performed for the Tptpmn submodel with a flow multiplication factor of 10.

Figure 6.2.4.2-21. Temperatures in the Fractures at the Drift Wall for Two Alternative Thermal Property Sets Assigned to Waste Package Elements. 


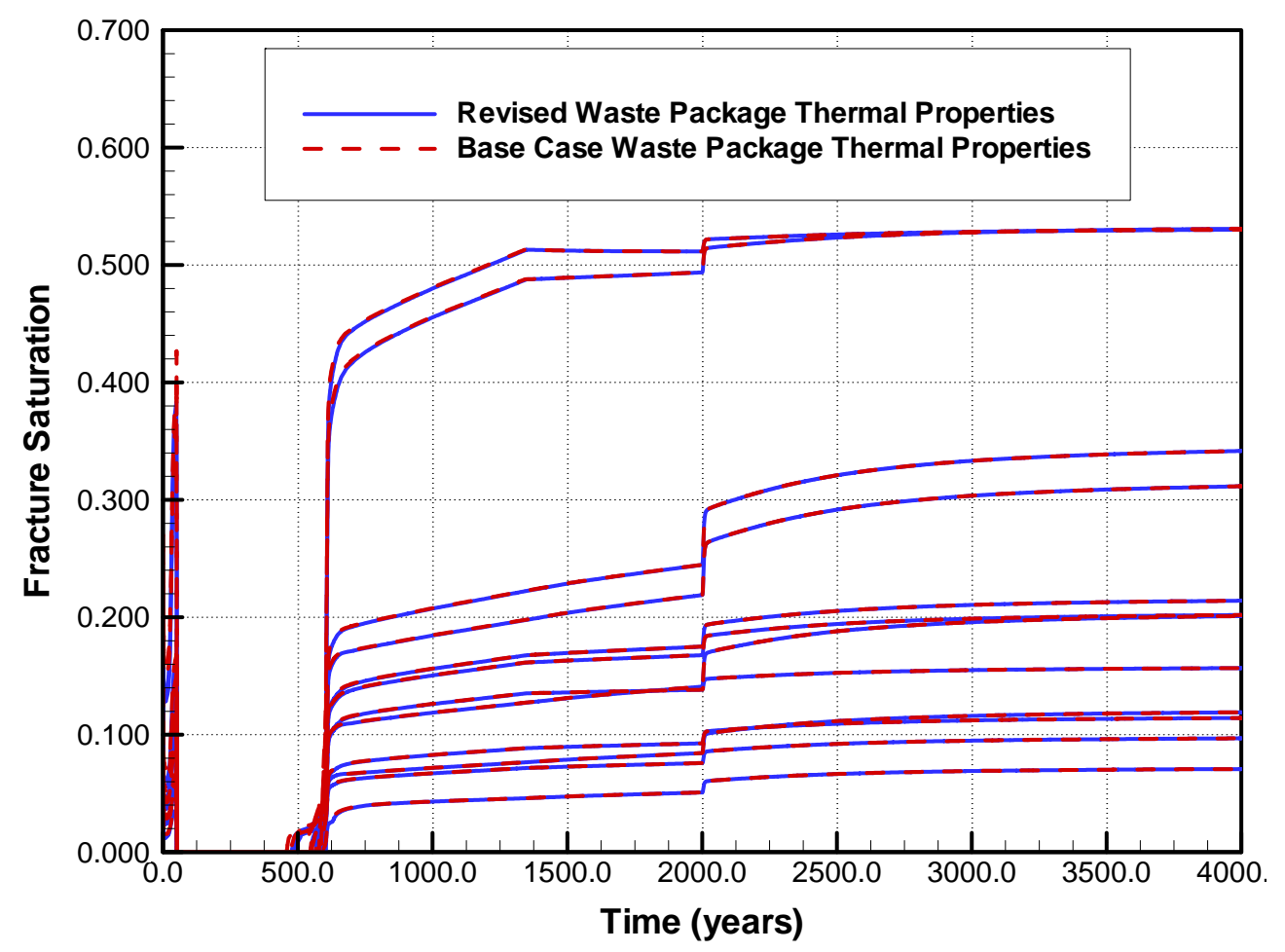

Output DTN: NA (see Section 8.5).

NOTE: $\quad$ Figure shows all rock discretization elements along the drift periphery from the crown to the springline. Blue lines represent the scenario with the revised waste package thermal properties (MN-HET-19). Red dashed lines represent the base case scenario (MN-HET-03). Simulations are performed for the Tptpmn submodel with a flow multiplication factor of 10 .

Figure 6.2.4.2-22. Fracture Saturations at the Drift Wall for Two Alternative Thermal Property Sets Assigned to Waste Package Elements 


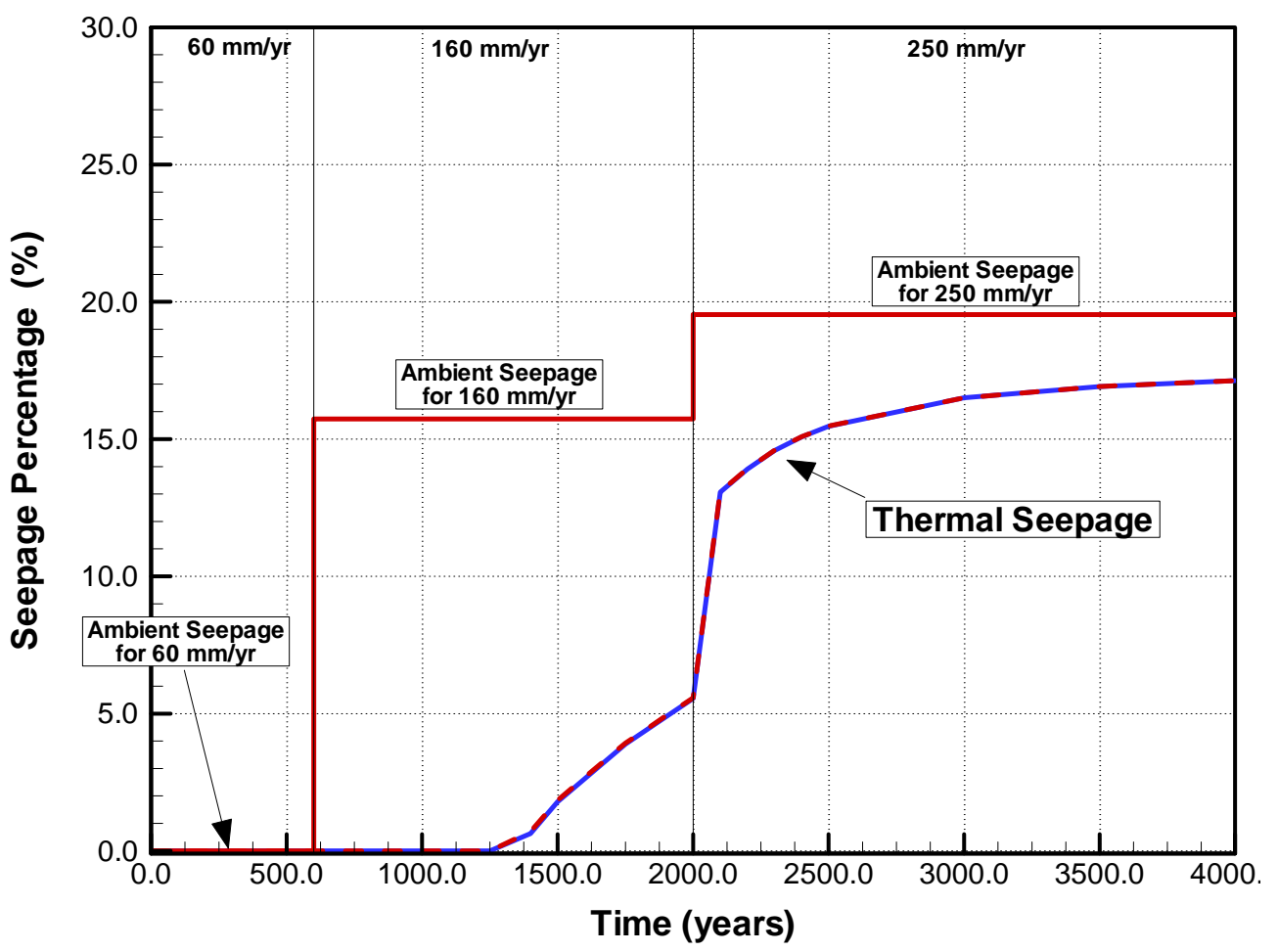

Output DTN: NA (see Section 8.5).

NOTE: Blue lines represent the scenario with the revised waste package thermal properties (MN-HET-19). Red dashed lines represent the base case scenario (MN-HET-03). Simulations are performed for the Tptpmn submodel with a flow multiplication factor of 10 .

Figure 6.2.4.2-23. Predicted Thermal Seepage Percentage for Two Alternative Thermal Property Sets Assigned to Waste Package Elements

\subsubsection{TH Conditions in Collapsed Drifts}

Emplacement drifts in the relatively deformable lithophysal rock may completely collapse (BSC 2004 [DIRS 169131], Section 6.4.2.4). In the event of collapse, either sudden or gradual, the rock mass above an underground opening disintegrates into a number of fragments that fall down and begin to fill the open space. Because there are large voids between the rock fragments, the bulk porosity of the fragmented rubble is much larger than the intact rock. As a result, the open space of the original excavation plus the collapsed portion of rock above completely fill with rubble at a certain stage. When this occurs, the broken rock provides backpressure, which prevents further collapse of the rock mass (BSC 2004 [DIRS 166107], Section 6.4.2.5). Therefore, the final situation after drift collapse can be categorized as follows. The original opening has increased in size, but is filled with fragmented rubble and large voids. The solid wall rock surrounding the rubble-filled opening is intact, but may have increased permeability and reduced capillary strength because of the dynamic motion and the stress redistribution (see Section 6.4.4.1.2 of BSC 2004 [169131]). For convenience, the rubble-filled opening is called a "collapsed drift", although technically there is no drift after collapse. 
In Abstraction of Drift Seepage (BSC 2004 [DIRS 169131], Section 6.4.2.4), a worst-case drift profile for seepage was selected representative of the drift collapse scenarios depicted in Drift Degradation Analysis (BSC 2004 [DIRS 166107], Appendix R). The chosen profile after collapse has a circular shape with a diameter of $11 \mathrm{~m}$. Although unlikely, a complete drift collapse may lead to significantly different seepage behavior, at both ambient and thermal conditions. Ambient seepage studies conducted in Seepage Model for PA Including Drift Collapse (BSC 2004 [DIRS 167652], Section 6.6.3) have demonstrated that, even though the collapsed drifts are filled with rubble material, capillary barrier effects can still give rise to flow diversion at the interface between the solid rock and the rubble-filled drift opening. This is because of the large scattered voids between the fragmented rock particles (particle sizes on the order of centimeters and decimeters; see BSC 2004 [DIRS 166107], Section 8.1), suggesting that the capillary strength parameter in the rubble filled drift is very small, most likely close to the zero capillary strength of an air-filled opening. (In the simulation runs, a capillary strength parameter of $100 \mathrm{~Pa}$ was used for the fragmented rock material within the collapsed drift. This value was considered a conservative choice for seepage calculations, because the capillary strength of the rubble material is most likely smaller.) Also, a small gap can be expected between the solid rock at the ceiling and the collapsed rubble material as a result of consolidation. Therefore, even under this scenario, capillary-driven flow diversion remains an important mechanism reducing seepage in collapsed drifts.

The following section evaluates the TH conditions in collapsed drifts and discusses the impact of drift collapse on thermal seepage. The thermal conditions in a collapsed drift will be different from those in an open drift, as schematically indicated in Figure 6.2.5-1. In an open, gas-filled drift, thermal radiation is strong enough to effectively transport heat to the drift walls, creating a $\mathrm{TH}$ environment in the rock above the drifts that combines capillary and vaporization barrier effects. Above a collapsed drift, a capillary barrier is still expected to form at the interface between the solid rock and the rubble material. Vaporization, on the other hand, may not be effective in the solid rock above the drift, as the rock temperatures at this location may never reach boiling. This is because (1) the drift size above the heat-producing waste canisters has increased after the collapse and (2) thermal conduction within the rubble material is less effective than thermal radiation within an open drift, giving rise to a much stronger in-drift temperature gradient. A vaporization barrier is not expected to develop at the crown of the collapsed drift, whereas significant vaporization will occur in the rubble material within the drift. This will give rise to in-drift $\mathrm{TH}$ processes that may or may not be beneficial for the integrity of waste canisters. Such processes may be particularly important when the drift collapse occurs early after waste emplacement. In this extreme case, the falling rock blocks are still at ambient saturation, holding significant amounts of water that will boil off, condense, and possibly flow back towards the waste packages. Although, from the definition given in Section 6.1.2, these indrift processes are not considered seepage, they may nevertheless lead to the presence of liquid water close to the waste packages and must therefore be investigated in the context of thermal seepage. 

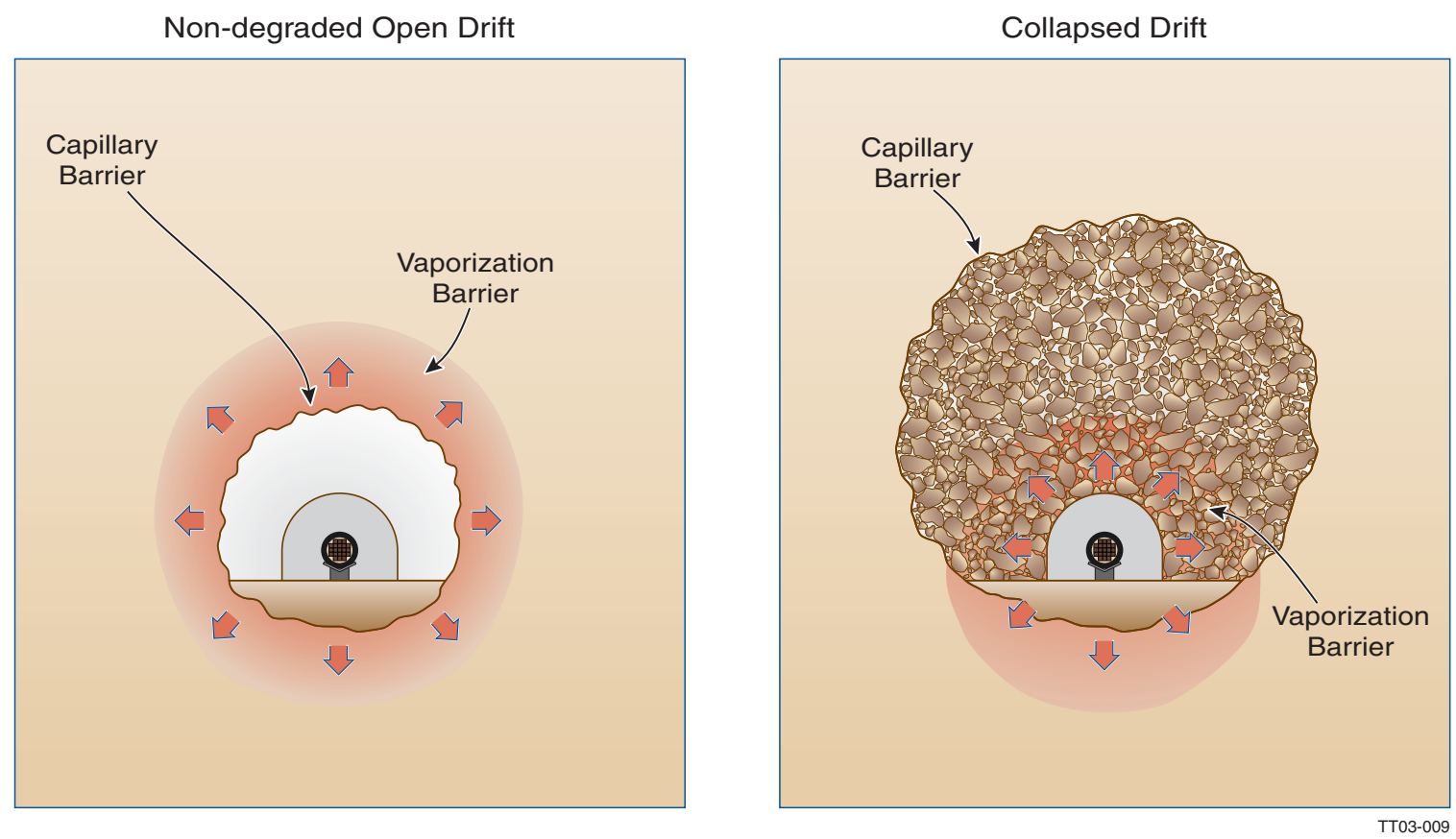

Figure 6.2.5-1. Schematic of TH Differences between an Open Non-Collapsed Drift and a RubbleFilled Collapsed Drift

Additional $\mathrm{TH}$ simulations were conducted with the $\mathrm{TH}$ seepage model to analyze the $\mathrm{TH}$ conditions within and around collapsed drifts and to determine the impact on seepage abstraction. In these simulations, the drift collapse occurs immediately after emplacement of the radioactive waste. It is shown in Multiscale Thermohydrologic Model (BSC 2004 [DIRS 169565]) that this assumption gives rise to the strongest differences in TH conditions between intact and collapsed scenarios, because the thermal output of the radioactive waste is still large.

To account for drift collapse in the lower lithophysal rock, the Tptpll submodel introduced in Section 6.2.1.2 was adjusted in the following manner (see Figure 6.2.5-2). All grid elements of the original Tptpll submodel grid with their center nodes located in the collapsed drift (with the assumed 11-m diameter) are converted into rubble material elements, with the exception of the waste package elements, the invert elements, and the air-filled space between the waste package and the drip shield. (Note that the drip shield is expected to remain intact after drift collapse, as demonstrated in BSC 2004 [DIRS 166107], Section 6) The rubble material consists of fragmented rock particles with sizes on the order of centimeters to decimeters with large voids between them. The volume fraction of the voids can be estimated from the selected bulking factors in Section 6.4.2.5 of Drift Degradation Analysis (BSC 2004 [DIRS 166107]). The bulking factor $B$ defines the volume increase of the rubble material after caving (volume $V_{B}$ ), compared to the initial intact volume $V$ of the collapsed rock (after Eq. 6-8 of BSC 2004 [DIRS 166107]), as follows:

$$
V_{B}=(1+B) V
$$

The void volume must be equal to the difference between $V_{B}$ and $V$. Using Equation 6.2.5-1, the volume fraction $f_{V}$ of the voids, relative to the total volume $V_{B}$ of the rubble material, is given as: 


$$
f_{V}=\frac{V_{B}-V}{V_{B}}=\frac{B V}{(1+B) V}=\frac{B}{(1+B)}
$$

From Equation 6.2.5-2, the volume fraction of the void space in the rubble rock material becomes 0.231 for an average bulking factor of 0.3 (average value based on the range of values given in Section 6.4.2.5 of BSC 2004 [DIRS 166107]). Consequently, the volume fraction of the fragmented rock blocks is 0.769 of the total volume of the rubble material.
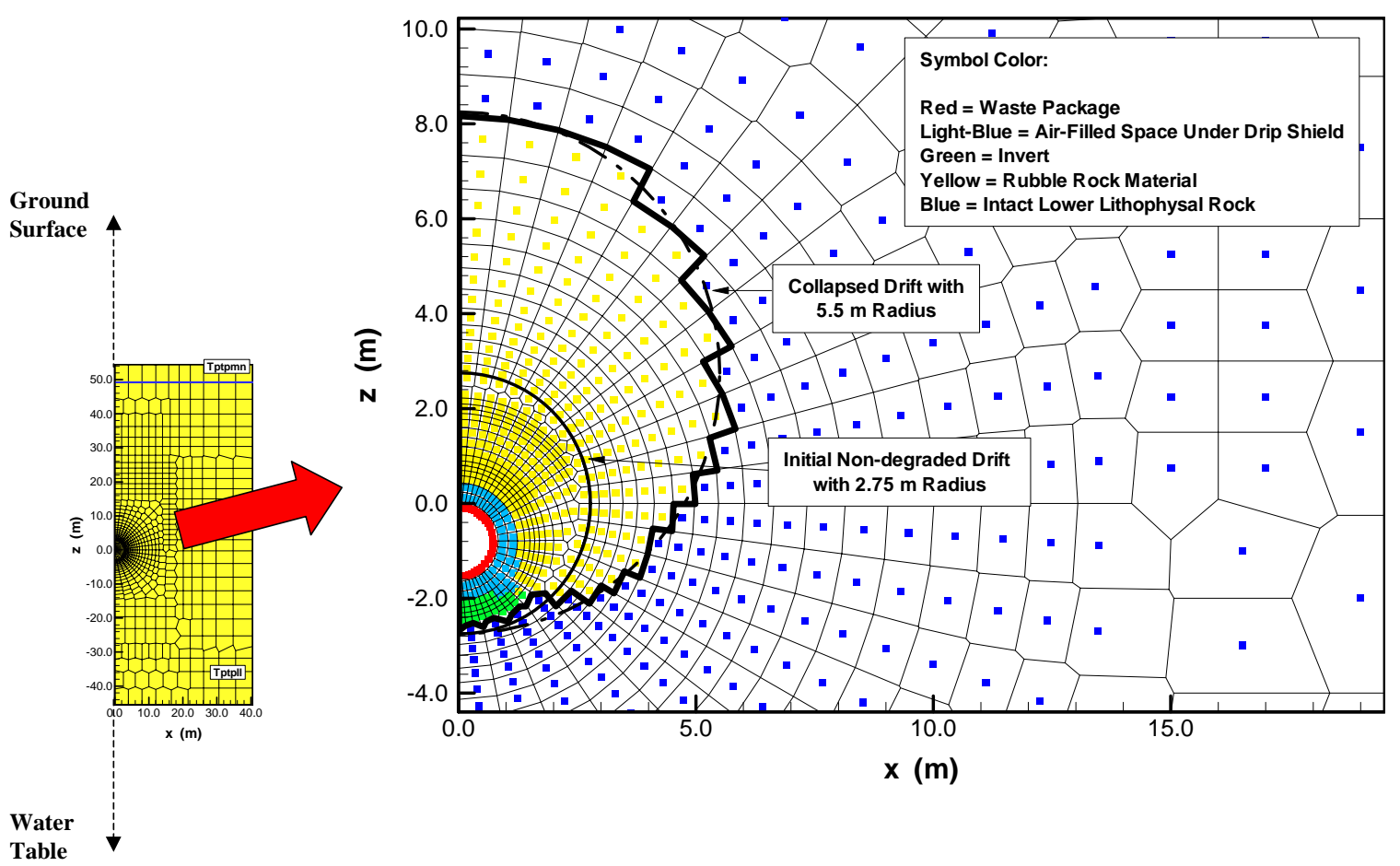

Output DTN: LB0310DSCPTHSM.002.

NOTE: The heavy line shows the model representation of the collapsed drift. The entire model domain extends from the ground surface at the top down to the water table at the bottom. (In the vertical direction, $\mathrm{z}=0 \mathrm{~m}$ refers to the springline of the non-collapsed drift.)

Figure 6.2.5-2. Close-Up View of the Collapsed Drift Discretization and Properties Assignment

Since a collapsed drift is almost completely filled with rubble rock, the main mechanisms of heat transfer within the rubble and between the rubble and the intact rock are conduction and convection; radiative heat transfer is expected to be negligible. Even if a small gap would form at the ceiling of the drift as a result of consolidation of the rubble material (which is not considered in the model), the open space would be too small to allow for significant radiative heat transfer.

It can be expected that the thermal-hydrological properties of the fragmented rock blocks are similar to the matrix properties of the intact rock, e.g., having the same small permeability and large capillarity values that are typically associated with the lithophysal tuff. Also the thermal conductivity and the heat capacity should be similar to that of the lithophysal rock matrix. The 
open voids, on the other hand, are expected to form a high-permeability, low-capillarity medium, comparable to a well-connected fracture network with very large apertures. To account for the significant property differences between rock blocks and voids, the rubble material is conceptualized as a dual-permeability medium, with one continuum representing the fragmented rock fraction and the other continuum representing the scattered connected voids.

In light of the above discussion, the properties of the fragmented rock were set identical to the matrix properties of the Tptpll rock unit, as given in Table 4.1-2. While these properties are based on measurements and a related calibration effort, the properties of the void space are unknown and must be estimated. Similar to the ambient seepage studies for collapsed drifts, the capillarity of the void space is set to $100 \mathrm{~Pa}$, which is considerably smaller than the capillarity in the surrounding fractures. Other relevant properties chosen for the void space are a continuum permeability of $10^{-10} \mathrm{~m}^{2}$ (about two orders of magnitude larger than the fracture continuum permeability of the Tptpll rock unit) and a thermal conductivity similar to that of air (see Assumptions 6 and 7 in Section 5). The interface area between the void continuum and the fragmented rock continuum, important for the fluid and heat exchange between the two media, is estimated from a simple geometry model, calculating the surface area of spherical rock blocks with a 0.1-m diameter. Depending on the degree of settling after collapse, individual rock blocks in the rubble material may only have a limited contact area with other rock blocks. This limited contact area would reduce direct flow of gas, liquid, and heat between the fragmented rock pieces. Two alternative cases were analyzed since the resulting contact area is hard to quantify. The base case assumes that the geometric interface area between grid elements of the fractured rock continuum should be reduced by a factor of (1-0.231), i.e., only the volume fraction of the voids is used to reduce the interface area (see calculation of the volume fraction in Equation 6.2.5-2 and text thereafter). This is the maximum possible interface for a medium with a given porosity (void volume fraction); therefore this case is also referred to as full contact area case. The alternative case assumes smaller contact areas half as large as these base case values. The void grid elements, on the other hand, have full geometric interfaces assigned, consistent with the definition of the void properties as equivalent continuum parameters. Note that the same contact area assumptions are used to connect the continua for the in-drift rubble material with the continua of the intact fractured rock at the interface. This means that the possibility of a gap forming between the crown rock and the consolidated rubble-potentially beneficial for reducing seepage-is not considered. Note also that the void space within the collapsed drift is connected to the fracture continuum outside, whereas the fragmented rock blocks inside the collapsed drift are connected to the matrix continuum outside.

The thermal-hydrological properties of the intact Tptpll rock surrounding the collapsed drift, as well as the properties of all other geologic units, remain unchanged from the TH seepage model, as provided in Section 4. Note, however, that the specific seepage modeling methodology from the TH seepage model-including fracture heterogeneity in the drift vicinity and using the SCM calibrated capillarity values-is not implemented in the collapsed drift runs. Since the differences in capillary barrier behavior of collapsed drifts have already been addressed in the ambient seepage study presented in Seepage Model for PA Including Drift Collapse (BSC 2004 [DIRS 167652], Section 6.6.3), the focus of the TH analysis is mainly on the changes in the TH conditions and the potential for in-drift flux perturbations, which can be evaluated with a less complex numerical model. Besides, since the basic grid design of the numerical mesh was not changed in the collapsed drift simulations, the gridblock size at the crown of the collapsed drift 
would be too coarse for accurately simulating the capillary barrier behavior. The condition that the grid resolution should be consistent with the SCM would not be met at this key location for ambient seepage. Also, in contrast to the thermal seepage analyses for non-collapsed drifts, the collapsed drift TH simulations are conducted using homogeneous rock properties in the drift vicinity.

Collapsed drift simulations were conducted for selected cases, using the reference mode thermal load and applying multiplication factors of 1 and 10 for the local percolation flux arriving at the drift. The initial conditions at the onset of heating are identical to those of the Tptpll submodel for intact drifts. Note that the fragmented rock pieces within the collapsed drift have saturation values representing the ambient water content of the lithophysal rocks (about 85\% water saturation). This means that a significant volume of stagnant water is present in the rock blocks close to the waste package at the onset of heating. Water saturation in the void space is set to a very small value at initial state, consistent with the small capillarity assigned to this medium.

The discussion of simulation results starts with the average percolation flux scenario (i.e., using a flux multiplication factor of 1). Figure 6.2.5-3 shows the temperature evolution at three selected locations within and close to the collapsed drift, for the cases with full and with reduced contact area between fragmented rock blocks. The first location is immediately at the waste package, the second is in the center of the collapsed drift (equivalent to the crown of the originally intact drift), and the third is at the crown of the collapsed drift. The temperature variation between the three locations is significant. The waste package may become as hot as $260^{\circ} \mathrm{C}$ for the reduced contact case, whereas the rock in the center of the collapsed drift has maximum temperatures of about $148^{\circ} \mathrm{C}$ (reduced contact area) and $135^{\circ} \mathrm{C}$ (base case). The latter value is a few degrees centigrade cooler than the maximum crown temperature of the intact drift of the Tptpll submodel (Figure 6.2.3.1-1). In contrast, the crown of the collapsed drift approaches, but never exceeds, the boiling temperature of water at prevailing pressures. This means that a vaporization barrier is not expected to form in the intact rock above the collapsed drifts; it will rather form within the rubble-filled drifts in vicinity of the waste packages. Compared to the full-contact-area case, the simulation with the 50\%-contact area results in higher temperatures close to the heat source (at the waste package and also the center location), but slightly cooler temperatures at the drift crown. This is mainly a result of the less effective heat conduction between the fragmented rock pieces, resulting in hotter conditions at the waste package and cooler conditions further away. Thus the contact area between rock blocks in the rubble material is an important uncertainty factor determining the $\mathrm{TH}$ environment close to the waste package, in particular the waste package temperature. 


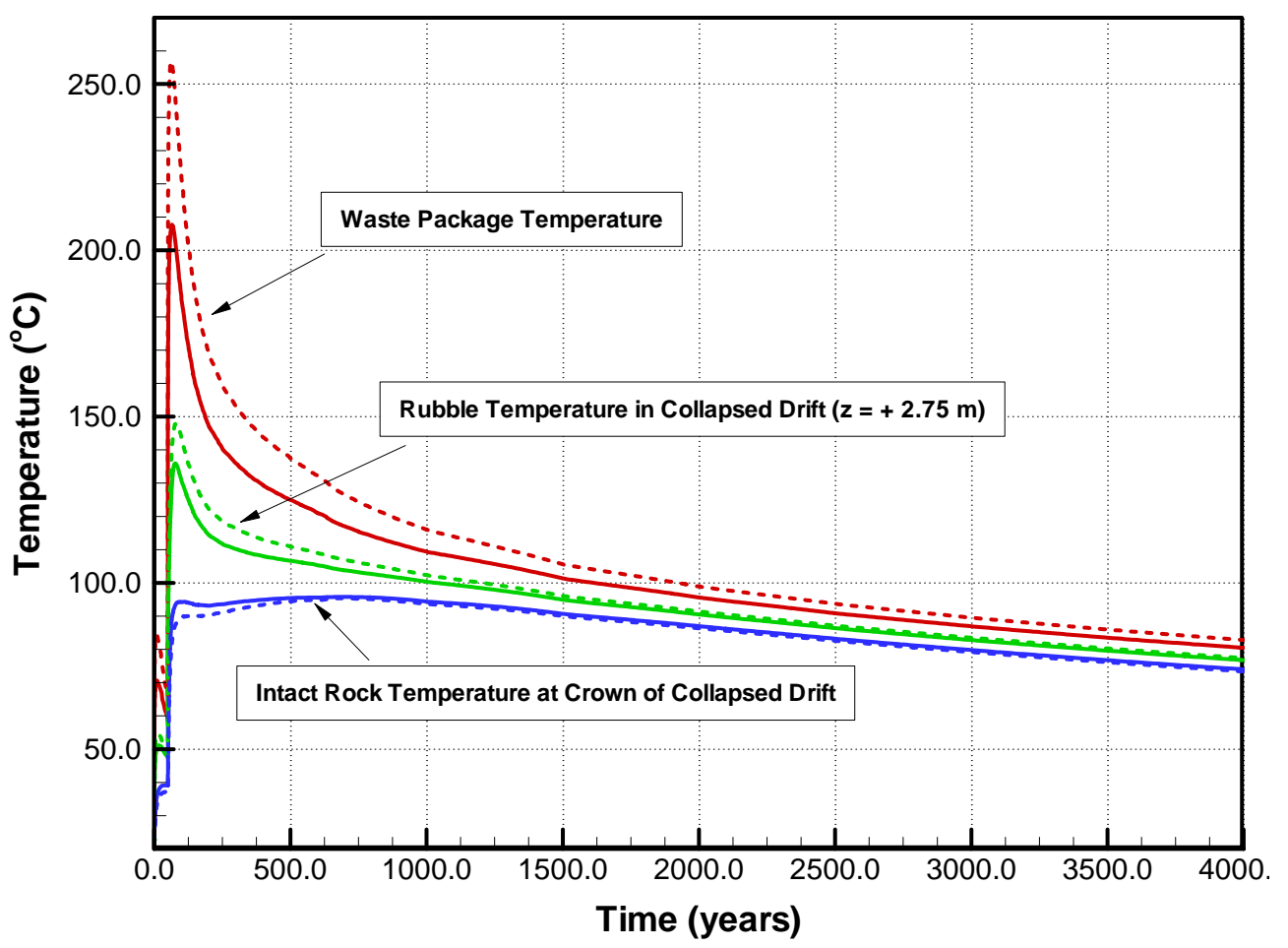

Output DTNs: LB0310DSCPTHSM.001 and LB0310DSCPTHSM.002.

NOTE: Solid lines represent base case; dashed lines represent 50\%-contact area case.

Figure 6.2.5-3. Rock Temperature Evolution for Base Case and 50\%-Contact Area Case at Three Representative Locations within and Close to Collapsed Drift

In both contact-area cases, the boiling of rock water close to the waste packages and the potential condensation may lead to flux perturbations that are potentially important for performance assessment. These flux perturbations are visualized in a sequence of contour plots given in Figures 6.2.5-4 through 6.2.5-11, showing water saturation, temperature, and liquid flux vectors at 100,1,000, 2,000, and 10,000 years after emplacement, using the full contact area case as an example. Temperatures are only shown for the matrix (fragmented rock blocks) continuum; these are almost identical to the fracture (void space) temperatures. Liquid fluxes are only shown for the fracture (void space) continuum. The matrix fluxes are much smaller; they can be neglected in the seepage abstraction. For comparison, refer to the contour plots for intact drifts depicted in Figures 6.2.2.1-3 through 6.2.2.1-6. (Note that the plots in Figures 6.2.2.1-3 through 6.2.2.1-6 show the TH conditions for an intact drift in the Tptpmn unit, with somewhat different behavior from the Tptpll, because no comparable figures are shown for intact drift in the Tptpll in this report. However, the Tptpmn contour plots can be used to demonstrate the fundamentally different $\mathrm{TH}$ behavior in collapsed and in nondegraded drifts.)

The temperature and saturation contours in Figure 6.2.5-4 indicate that almost the entire collapsed drift is heated to and above the boiling point of water at 100 years after emplacement. As a result, most of the ambient water content in the fragmented rock blocks has vaporized. Most of the vapor is driven away by the pressure gradient and condenses in the cooler rock surrounding the collapsed drift. Above the drift, the boiling-point isotherm follows roughly the 
interface between the intact rock and the rubble material. Thus, the water shedding that can be seen at the drift crown (Figure 6.2.5-5) is a result of both condensate and percolation water being diverted sideways, mainly by capillary forces at the rock-rubble interface. The voids within the collapsed drift are essentially dry.

At 1,000 years after waste emplacement, the temperatures in the rubble material have decreased, but are still above boiling in most of the drift except for the crown (Figure 6.2.5-6). In the upper half of the drift, the matrix saturations have slightly increased compared to the situation at 100 years, indicating rewetting of the fragmented rock blocks. This is mainly a result of condensation in the small below-boiling zone at the drift crown. A small degree of rewetting may also stem from direct flow between the water-bearing rock matrix outside of the drift and the fragmented rock blocks of the rubble material. This flux is limited by (1) the small permeability of the rock matrix, and (2) the limited contact area between the matrix and the rubble. Condensation also leads to moderate rewetting in the void space immediately at the drift crown (Figure 6.2.5-7). However, downward drainage of water is prevented by the strong vaporization processes below this condensation zone. In contrast to intact open drifts, the vaporization barrier is not effective in the intact rock above the drift, but in the rubble material closer to the waste package. Note that there is no liquid flow from the intact fractured rock directly into the void space, as capillary forces effectively drive water sideways and around the collapsed drift. At 1,000 years, most of the water shedding around the drift is percolation flux. Compared to the conditions at 100 years, the amount of percolation has substantially increased with the change from present-day to monsoon climate, while the amount of condensation has decreased in the area above the drift crown.

At 2,000 years (Figures 6.2.5-8 and 6.2.5-9), with the heat output of the waste further reduced by decay, only the lower half of the rubble material is still above boiling and remains dry. In contrast, both the fragmented rock blocks and voids show increased saturations in the upper part of the drift. As discussed earlier, this is mainly caused by in-drift condensation, since the amount of water influx from the surrounding rock into the drift is limited by the small matrix permeability and contact area. As a result, two almost independent water flow systems have developed. In the intact fractured rock, water percolating down towards the collapsed drift is diverted sideways by capillary forces, as evident by the saturation increase at the crown and the sideways oriented flux vectors. Within the collapsed drift, small amounts of water boil and condense, with possible reflux occurring from these coupled processes. The magnitude of this in-drift reflux is discussed later in this section.

Figures 6.2.5-10 and 6.2.5-11 show the TH conditions after 10,000 years. The temperatures in the drift are below boiling at around $55^{\circ} \mathrm{C}$, and most of the fragmented rock blocks have rewetted to saturation values similar to the surrounding rock, with the exception of the area closest to the waste package. The voids are dry in the lower half of the collapsed drift, but show saturation values slightly above residual saturation in the upper half. The situation at 10,000 years is not yet at steady-state, but already gives some indication of the final steady-state conditions, which are as follows. The capillary barrier at the rock-rubble interface limits flow of percolation water from the fractures into the collapsed drift. Flow within the collapsed drift is essentially zero, as the boiling, condensation, and reflux processes have ceased due to the close-to-ambient temperature conditions. The voids are in equilibrium with the rubble rock blocks, which means that they are essentially dry (at residual saturation) because of their very small capillary strength. 
The fragmented rock blocks are expected to have saturation values similar to the surrounding rock matrix, because direct flux of water may be possible between the surrounding matrix rock and the fragmented rock pieces. These matrix fluxes are very small and can be neglected for the performance of the repository.

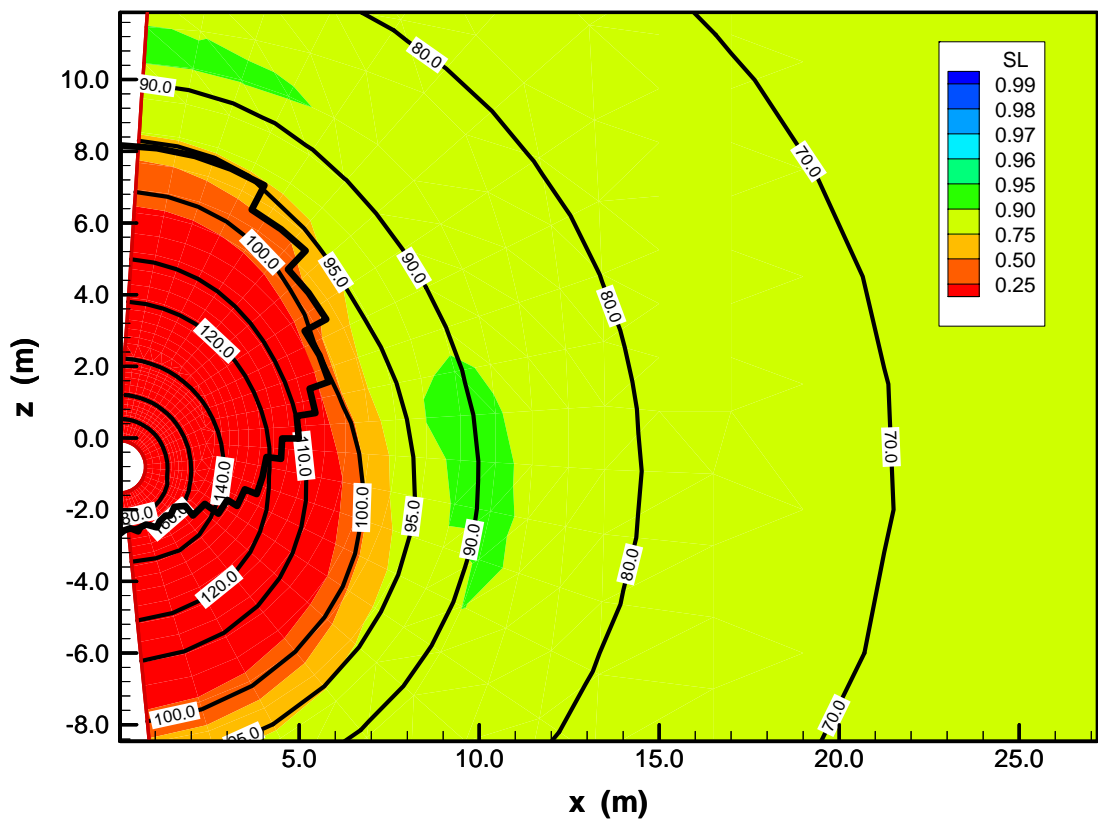

Output DTNs: LB0310DSCPTHSM.001 and LB0310DSCPTHSM.002.

NOTE: SL denotes liquid saturation. Contoured areas show saturation, lines show temperature.

Figure 6.2.5-4. Saturation and Temperature at 100 Years after Emplacement, for Fragmented Rock Blocks (within Collapsed Drift) and Matrix Rock (Outside of Collapsed Drift)

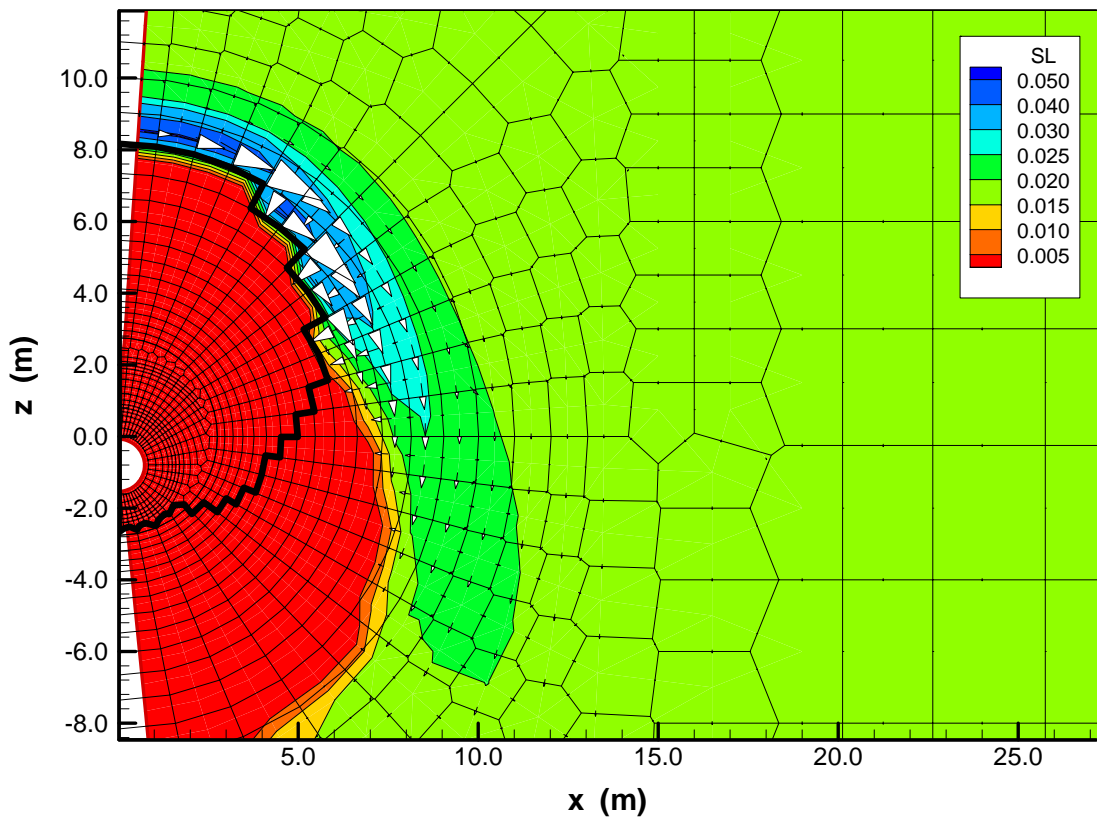


Output DTNs: LB0310DSCPTHSM.001 and LB0310DSCPTHSM.002.

NOTE: SL denotes liquid saturation.

Figure 6.2.5-5. Saturation and Liquid Fluxes at 100 Years after Emplacement, for Void Space (within Collapsed Drift) and Fractures (Outside of Collapsed Drift)

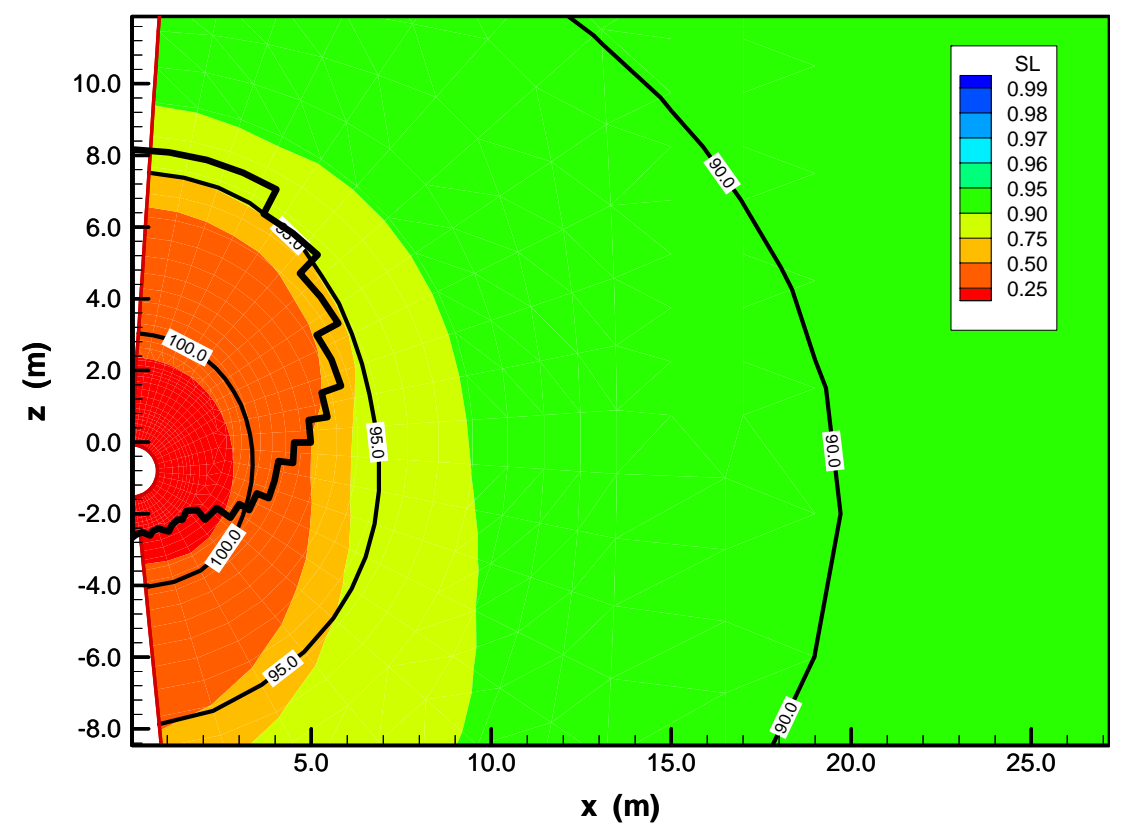

Output DTNs: LB0310DSCPTHSM.001 and LB0310DSCPTHSM.002

NOTE: $\quad$ SL denotes liquid saturation. Contoured areas show saturation, lines show temperature.

Figure 6.2.5-6. Saturation and Temperature at 1,000 Years after Emplacement, for Fragmented Rock Blocks (within Collapsed Drift) and Matrix Rock (Outside of Collapsed Drift)

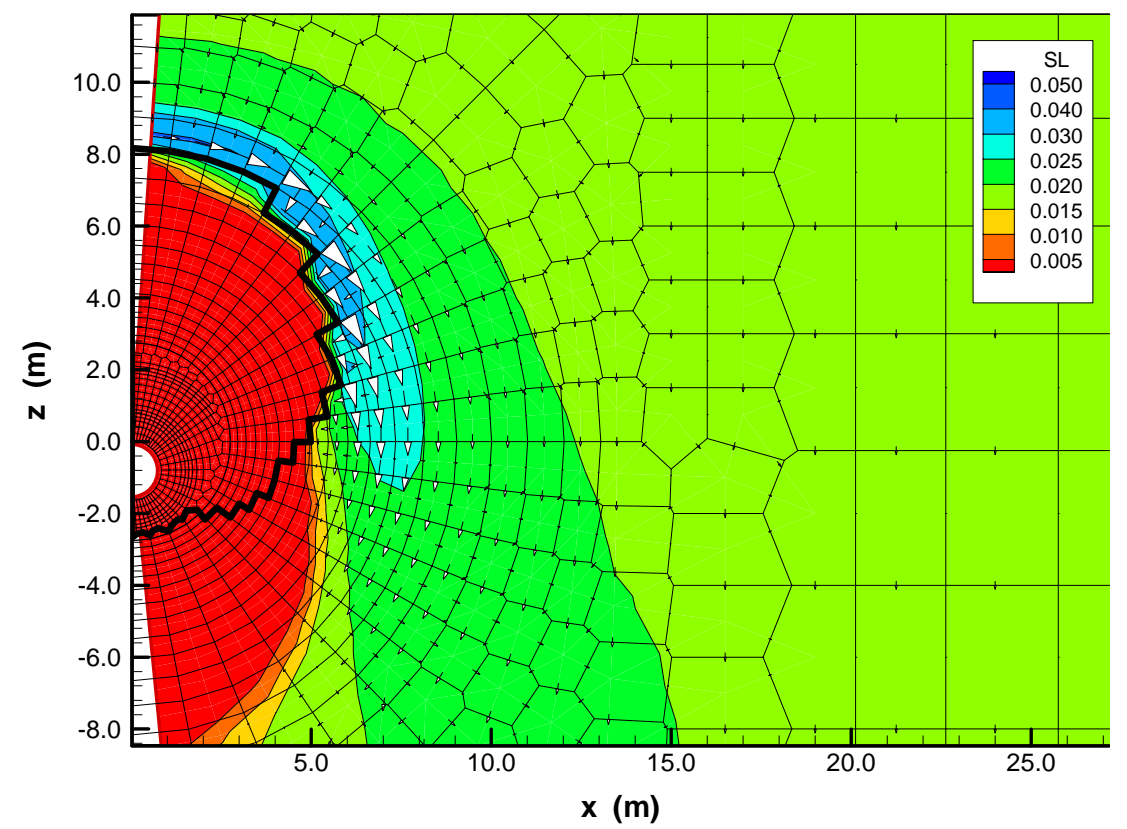


Output DTNs: LB0310DSCPTHSM.001 and LB0310DSCPTHSM.002.

NOTE: SL denotes liquid saturation.

Figure 6.2.5-7. Saturation and Liquid Fluxes at 1,000 Years after Emplacement, for Void Space (within Collapsed Drift) and Fractures (Outside of Collapsed Drift)

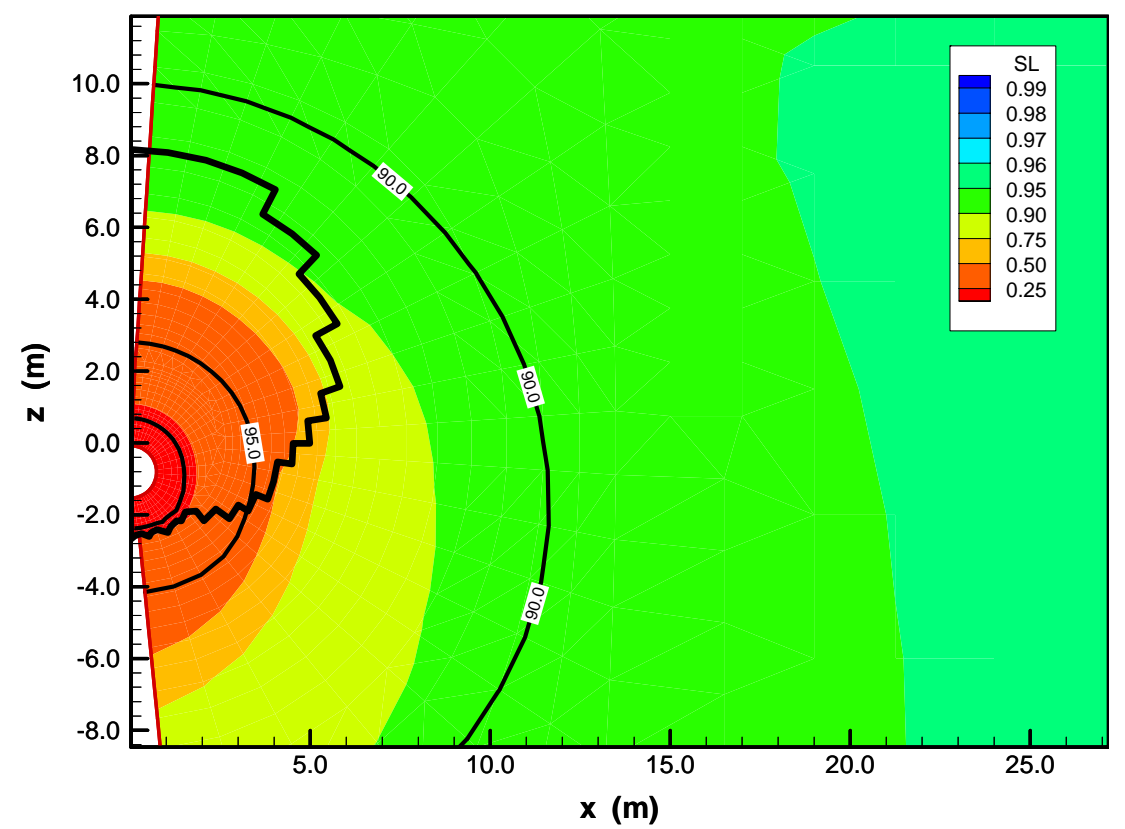

Output DTNs: LB0310DSCPTHSM.001 and LB0310DSCPTHSM.002.

NOTE: SL denotes liquid saturation. Contoured areas show saturation, lines show temperature.

Figure 6.2.5-8. Saturation and Temperature at 2,000 Years after Emplacement, for Fragmented Rock Blocks (within Collapsed Drift) and Matrix Rock (Outside of Collapsed Drift)

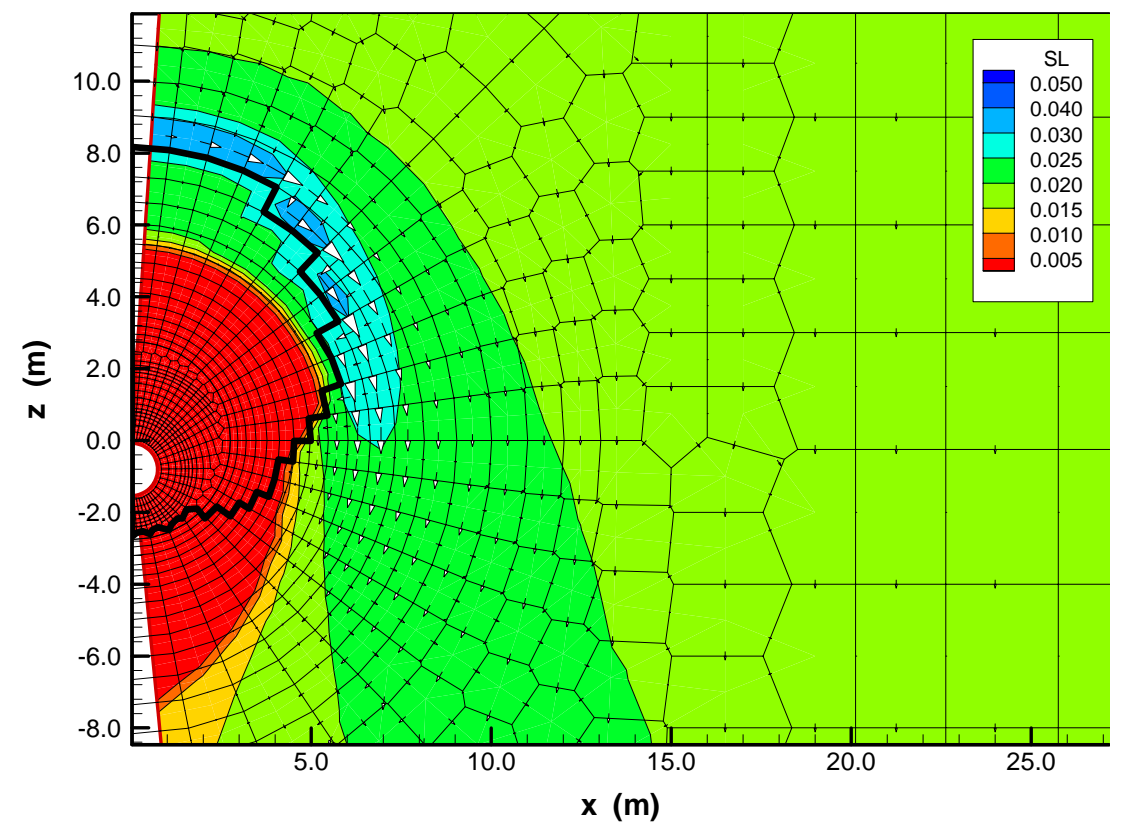


Output DTNs: LB0310DSCPTHSM.001 and LB0310DSCPTHSM.002.

NOTE: SL denotes liquid saturation.

Figure 6.2.5-9. Saturation and Liquid Fluxes at 2,000 Years after Emplacement, for Void Space (within Collapsed Drift) and Fractures (Outside of Collapsed Drift)

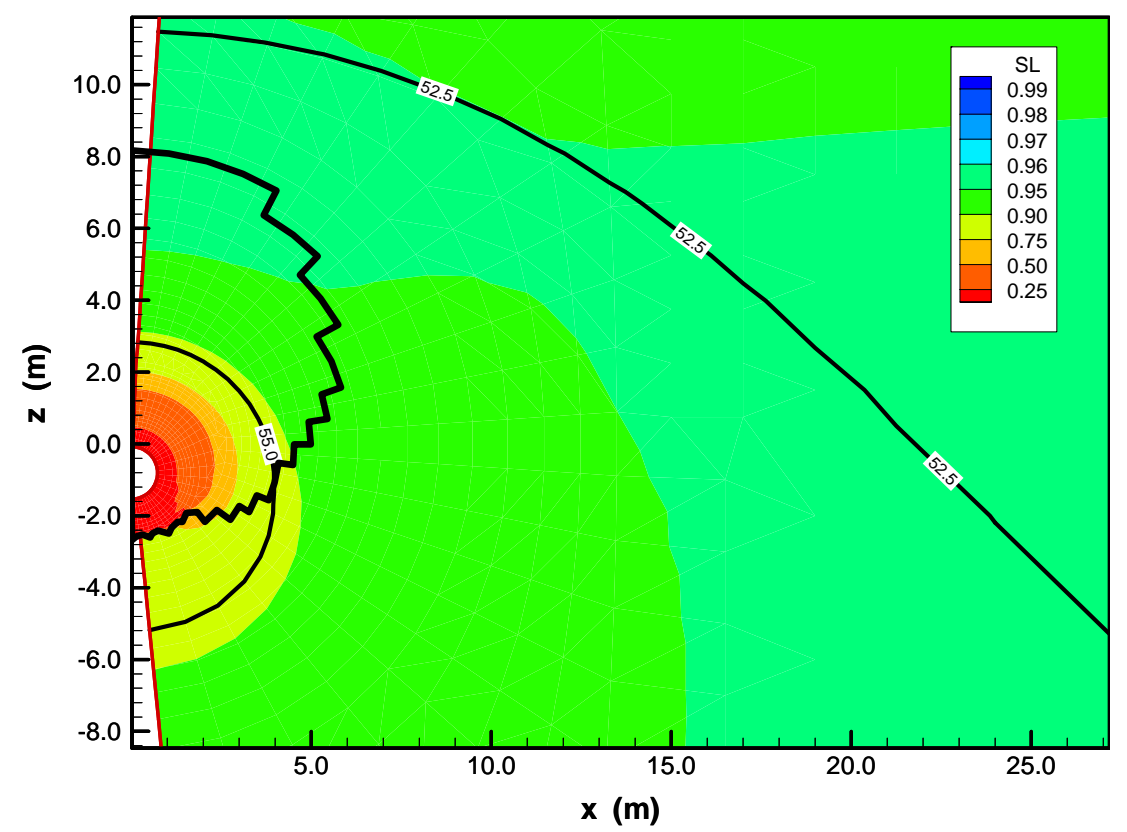

Output DTNs: LB0310DSCPTHSM.001 and LB0310DSCPTHSM.002.

NOTE: SL denotes liquid saturation. Contoured areas show saturation, lines show temperature.

Figure 6.2.5-10. Saturation and Temperature at 10,000 Years after Emplacement, for Fragmented Rock Blocks (within Collapsed Drift) and Matrix Rock (Outside of Collapsed Drift)

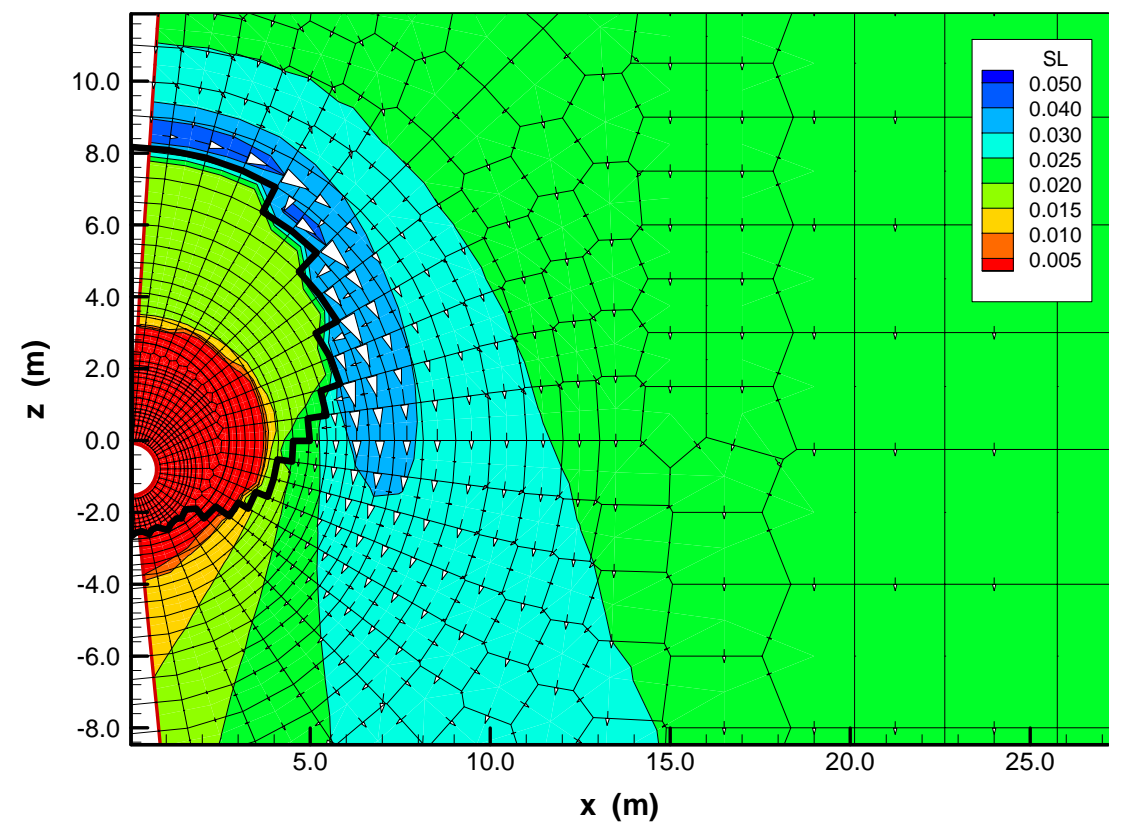


Output DTNS: LB0310DSCPTHSM.001 and LB0310DSCPTHSM.002.

NOTE: SL denotes liquid saturation. Contoured areas show saturation, lines show temperature.

Figure 6.2.5-11. Saturation and Liquid Fluxes at 10,000 Years after Emplacement, for Void Space (within Collapsed Drift) and Fractures (Outside of Collapsed Drift)

The above discussion has indicated the possibility of in-drift flux perturbations in the rubble material, mainly because ambient water-present in the collapsed rock blocks at the onset of heating-boils off, condenses, and may flow back towards the waste package. Figure 6.2.5-12 analyzes the magnitude of this reflux, showing the downward fluxes at different times along a vertical line that runs through the center of the collapsed drift. The vertical coordinate $\mathrm{z}=0 \mathrm{~m}$ refers to the springline of the intact drift; the crown of the collapsed drift is at approximately $\mathrm{z}=8.25 \mathrm{~m}$. The vertical location of the drip shield is at about $\mathrm{z}=0.43 \mathrm{~m}$ (in the model grid), with the top of the waste package in close proximity below it.

The figure shows in-drift fluxes of a few millimeters per year in the upper half of the collapsed drift. The maximum vertical flux occurs at 1,500 years after emplacement, when boiling is still effective in the waste package vicinity. At later stages, when the flow system approaches steadystate conditions, the flux values return to zero. No downward flow occurs in the lower half of the collapsed drift at any time. Thus, it can be concluded that water will not contact the waste package or the drip shield as a result of in-drift flux perturbation in the rubble material. (This is supported by the evolution of relative humidity in the rubble rock immediately above the drip shield, shown in Figure 6.2.5-14.) Notice that water flux at the interface between the intact rock and the crown of the collapsed drift is always zero, a result of the capillary barrier (Figure 6.433). Fluxes in the rock outside of the drift reflect the percolation flux conditions at the respective times; i.e., 6, 16, and $25 \mathrm{~mm} / \mathrm{yr}$ for the present-day, the monsoon, and the glacial transition climates (i.e., using a flux multiplication factor of 1). The flux peaks that can be seen close to the crown during the early heating phase (100 and 500 years) stem from the additional effect of condensation in this zone. 


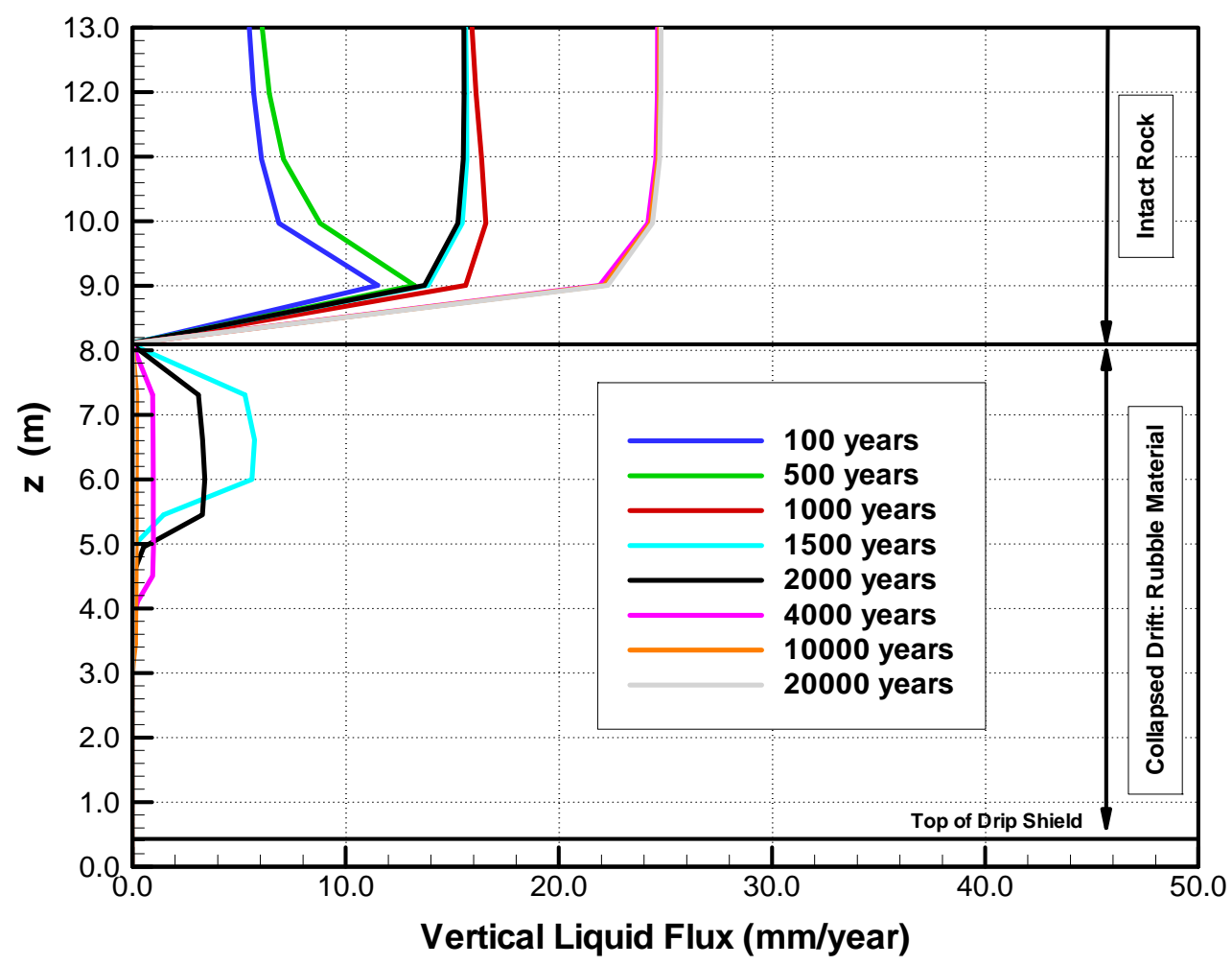

Output DTNS: LB0310DSCPTHSM.001 and LB0310DSCPTHSM.002.

NOTE: The vertical coordinate $z=0 \mathrm{~m}$ refers to the springline of the intact drift.

Figure 6.2.5-12. Downward Flux in the Fractures/Voids along a Vertical Line through the Center of the Collapsed Drift for Base Case Simulation

Essentially similar results were obtained for the simulation case with the reduced contact area between rock pieces in the collapsed drift. As shown in Figure 6.2.5-13, the vertical fluxes in the lower half of the collapsed drift are zero at all times. Also, the relative humidity above the drip shield is smaller than 70 percent for the first 2,000 years after emplacement and remains below 90 percent for the rest of the 10,000-year compliance period (Figure 6.2.5-14). The main difference from the base case is that a maximum flux of about $25 \mathrm{~mm} / \mathrm{yr}$ occurs after 100 years near the crown of the collapsed drift in Figure 6.2.5-13, comparable in magnitude to the percolation flux. This is a result of condensation; the boiling zone in the collapsed drift is less extended in this simulation case and allows in-drift condensation close to the crown. Thus, the $\mathrm{TH}$ conditions close to the crown of the collapsed drift are sensitive to the rubble area contact factor. However, this early-time difference is not relevant for the integrity of the waste canister, because (1) the distance between the crown and the waste package comprises several meters of above-boiling rubble material and (2) the considered time coincides with the period of most effective vaporization in the lower part of the drift. 


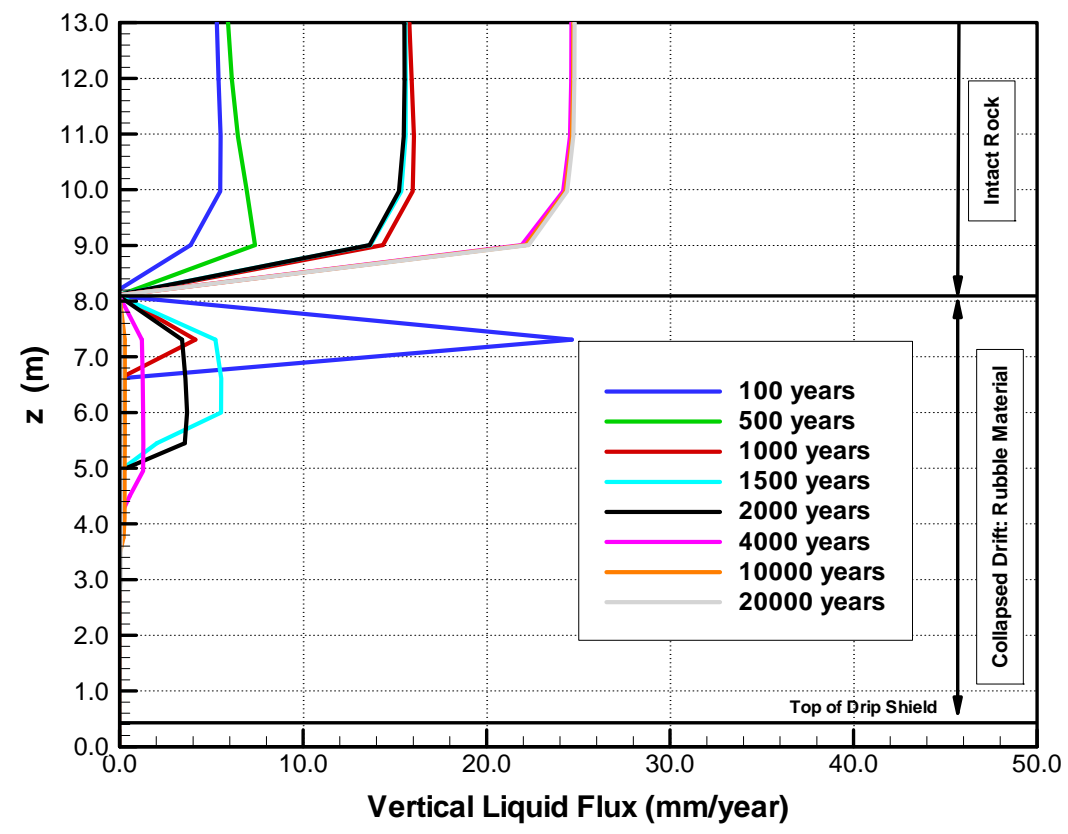

Output DTNs: LB0310DSCPTHSM.001 and LB0310DSCPTHSM.002.

NOTE: The vertical coordinate $z=0 \mathrm{~m}$ refers to the springline of the intact drift.

Figure 6.2.5-13. Downward Flux in the Fractures/Voids along a Vertical Line through the Center of the Collapsed Drift for Simulation with Limited Contact Area (50\% Contact Area)

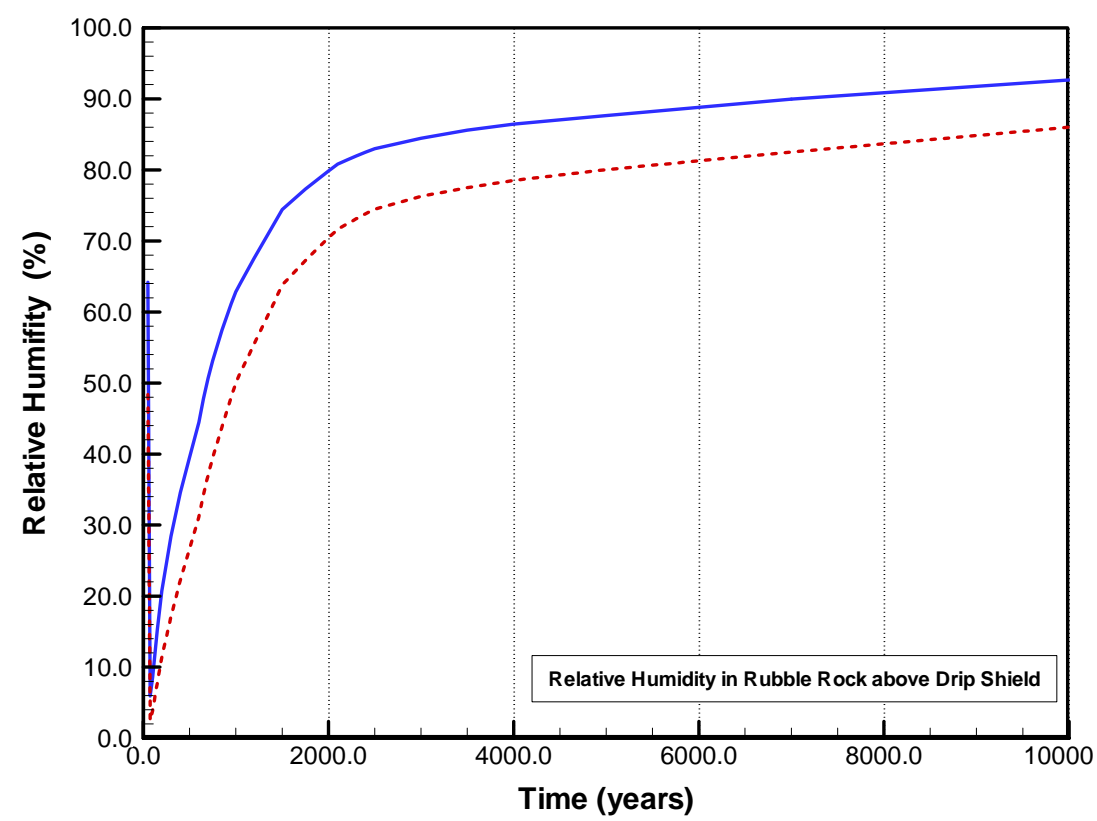

Output DTNS: LB0310DSCPTHSM.001 and LB0310DSCPTHSM.002.

NOTE: $\quad$ Solid line represents base case; dashed line represents 50\%-contact area case.

Figure 6.2.5-14. Evolution of Relative Humidity in the Rubble Material Immediately Above the Drip Shield, for Base Case and 50\%-Contact Area Case 
As mentioned above, collapsed-drift simulation runs were also conducted for enhanced percolation fluxes, using a multiplication factor of 10 . Example results are given in Figures 6.2.5-15 and 6.2.5-16 for the case with a full contact area between the fragmented rock blocks. With respect to in-drift fluxes and seepage abstraction, results from the 50\%-contact area case are quite similar. (The results for the $50 \%$-contact area case are not depicted in this report, but are included in the output DTNs that are specified later in this paragraph.) In general, the effect of increasing the local percolation flux is comparable to the intact cases discussed in Sections 6.2.2, 6.2.3, and 6.2.4, with elevated percolation leading to cooler temperatures and a shorter boiling period (Figure 6.2.5-15). However, the in-drift flux conditions are hardly affected by these differences, as shown in Figure 6.2.5-16. (Note the different horizontal scale as compared to Figures 6.2.5-12 and 6.2.5-13.) The maximum downward fluxes within the collapsed drift are rather small (up to about $20 \mathrm{~mm} / \mathrm{yr}$ ) and concentrated in the upper half of the rubble material, away from the waste package. The maximum flux in the lower half of the collapsed drift has an almost negligible magnitude of $0.3 \mathrm{~mm} / \mathrm{yr}$, occurring close to the center of the collapsed drift. Just above the drip shield, the downward fluxes are always zero. Outside of the collapsed drift, the vertical fluxes reflect the percolation flux boundary conditions imposed at the top of the model area, with fluxes of 60,160 , and $250 \mathrm{~mm} / \mathrm{yr}$ during the three climate stages. It is because these increased fluxes cannot enter the collapsed drift-as a result of capillary forces - that the in-drift conditions are hardly affected by the change in percolation. This gives confidence that the observed results hold for all relevant percolation flux scenarios. Note that additional sensitivity cases are provided in output DTNs: LB0310DSCPTHSM.001 and LB0310DSCPTHSM.002, varying the void permeability of the in-drift rubble material by one order of magnitude up and down. Results from these simulations show in-drift flux behavior similar to the cases previously discussed. 


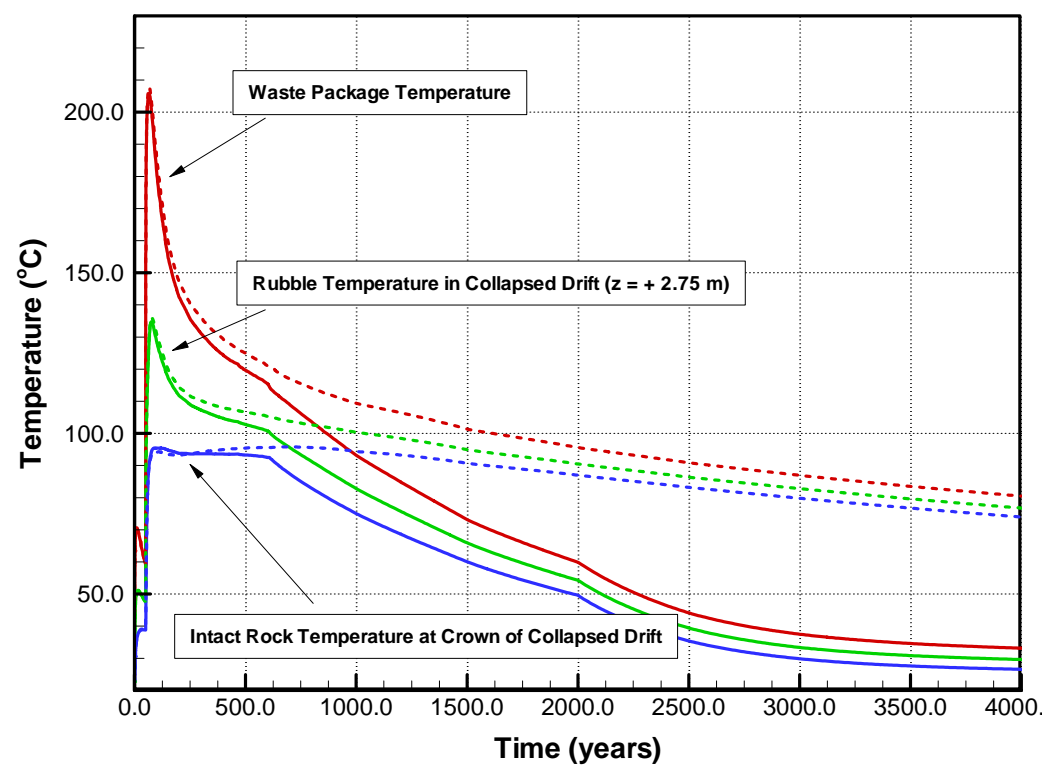

Output DTNs: LB0310DSCPTHSM.001 and LB0310DSCPTHSM.002.

NOTE: Solid lines represent percolation flux scenario with multiplication factor of 10; dashed lines represent base case.

Figure 6.2.5-15. Rock Temperature Evolution for Percolation Flux Scenario with Multiplication Factor of 10 Compared to Base Case at Three Representative Locations within and Close to Collapsed Drift

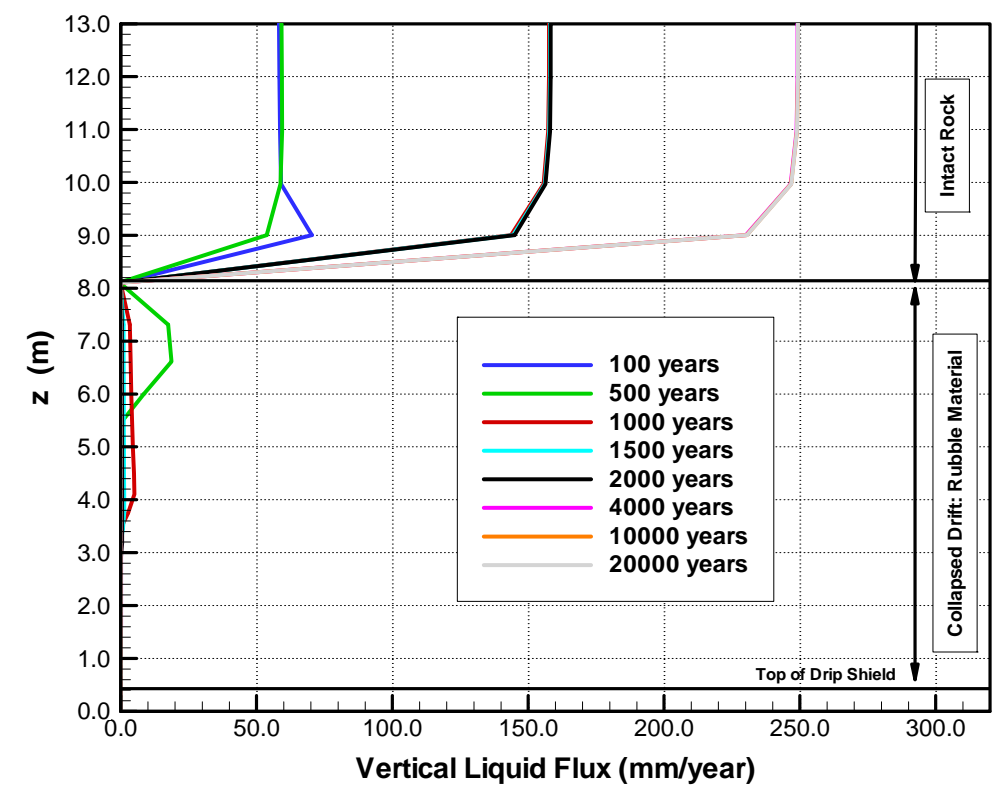

Output DTNS: LB0310DSCPTHSM.001 and LB0310DSCPTHSM.002.

NOTE: The vertical coordinate $z=0 \mathrm{~m}$ refers to the springline of the intact drift.

Figure 6.2.5-16. Downward Flux in the Fractures/Voids Along a Vertical Line through the Center of the Collapsed Drift, for Percolation Flux Scenario with a Multiplication Factor of 10 
Results from the collapsed drift simulations can be summarized as follows:

- In contrast to open drifts, where a combined capillary and vaporization barrier at the drift crown prevents water seepage during the period of above-boiling temperatures, vaporization is not effective at the crown of collapsed drifts.

- With ambient rock water boiling off in the rubble material, in-drift flux perturbation gives rise to moderate reflux of condensate in the upper half of collapsed drifts. However, water drainage down to the waste packages is not possible, a result of the vaporization barrier forming in the vicinity of the waste package.

- The vaporization and reflux processes cease after a few thousand years and the TH conditions slowly approach steady-state (ambient) behavior. During this transition phase, the fluxes in the lower half of the collapsed drift remain zero at all times. Later, when steady-state conditions have been reached, the entire collapsed drift is characterized by zero fluxes, as the void spaces are essentially dry (at residual saturation).

- The above in-drift flow processes are largely unaffected by changes in the percolation flux because the capillary barrier at the drift crown limits water flux from the intact rock into the rubble material.

Based on these results, an abstraction methodology for thermal seepage in collapsed drifts is developed in Abstraction of Drift Seepage (BSC 2004 [DIRS 169131], Section 6.5.3).

\subsection{ALTERNATIVE CONCEPTUAL MODEL}

The alternative conceptual model (ACM) analyzed in this subsection is used as corroborative information to support the results and conclusions of the TH seepage model. The TH seepage model is the drift-scale process model used for evaluating thermal seepage as input to seepage abstraction and TSPA. The ACM results support validation of this main process model (see Section 7), but are not carried forward to seepage abstraction or TSPA-LA.

The ACM considers the possibility that unsaturated fracture flow may occur in fast-flowing preferential pathways (thin fingers) that drain downward intermittently. Water buildup in the condensation zone above waste emplacement drifts can provide a potential source of such downward finger flow, carrying water at flow rates much larger than the average infiltration. Such conditions may promote the potential of seepage during the thermal period at Yucca Mountain, because finger flow may penetrate far into the superheated rock zone (i.e., rock temperature above boiling point of water) around waste emplacement drifts. It is not clear whether process models using a continuum representation, such as the TH seepage model, are able to capture such small-scale processes, even though small-scale heterogeneity in fracture permeability has been incorporated. Further study of episodic processes was suggested in Near-Field/Altered Zone Coupled Effects Expert Elicitation Project (CRWMS M\&O 1998 [DIRS 100351], Appendix D, p. YY-15). The alternative conceptual model, referred to hereafter as the TH model for episodic finger flow (THMEFF), is applied to investigate the potential impact of episodic finger flow on thermal seepage. 
The THMEFF analyzes the fate of episodic preferential-flow events that originate somewhere in the condensation zone above the repository and percolate downward towards the emplacement drifts. Figure 6.3-1 shows an illustration of episodic fingers flowing through fractures and penetrating into the superheated rock in the vicinity of waste emplacement drifts. As flow arrives at the superheated rock region around drifts, water begins to boil off. Depending on magnitude and duration of each flow event, and temperature and pressure conditions in the fractured rock, the water may completely vaporize above the drift crown, or it may penetrate far into the superheated region and eventually reach the drift. In this report, a semi-analytical solution is used to simulate the complex flow processes of episodic finger flow under thermal conditions (Birkholzer 2002 [DIRS 160748]). With this solution, the maximum penetration distance into the superheated rock is determined for specific episodic flow events and thermal conditions, and the amount of water arriving at the drift crown is calculated. Water arrival at the drift crown does not necessarily mean that this water will seep into the drift, since the open cavity acts as a capillary barrier, diverting downward flow around the tunnel. This additional barrier is not considered in the episodic finger-flow model. The following Section 6.3.1 describes the conceptual model and the modeling procedure. Modeling results are given in Section 6.3.2 for a drift located in the Tptpmn unit, and in Section 6.3.3 for a drift located in the Tptpll unit. 


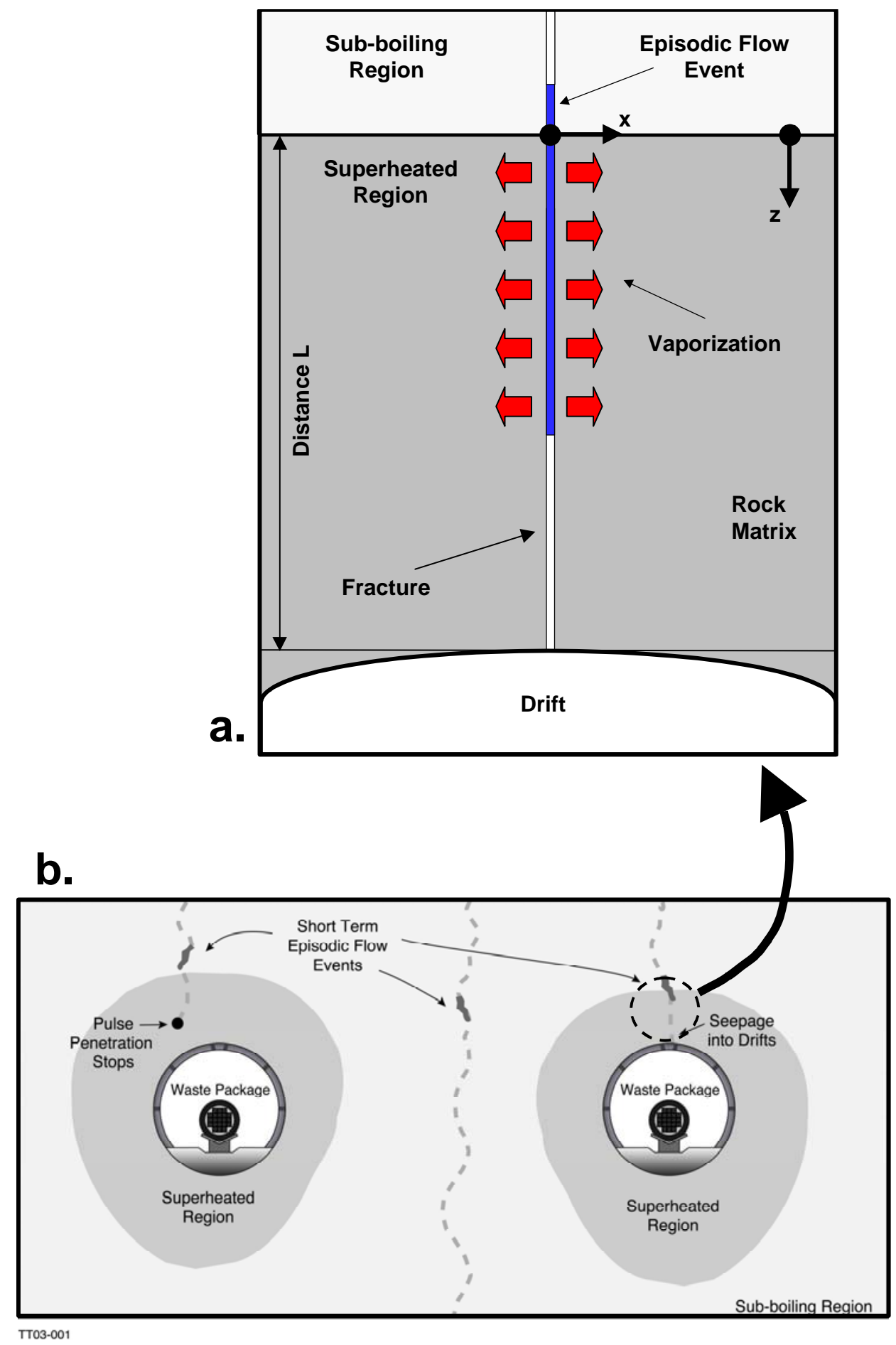

NOTE: The drip shield above waste packages is not shown here for simplicity.

Figure 6.3-1. (a) Schematic Illustration of Conceptual Model for Finger Flow in a Vertical Fracture above a Drift with Heat Conduction from the Adjacent Rock, and (b) Episodic Finger Flow in Unsaturated Fractured Rock in the Vicinity of Waste Emplacement Drifts 
This report does not explicitly describe model validation activities for the alternative conceptual model. This is consistent with the technical work plan (BSC 2004 [DIRS 170236]), where no validation activity is planned for the THMEFF. According to current procedures, model validation is not necessary for alternative conceptual models since they are only used for corroboration of main process models. It should be pointed out, however, that verification and validation activities have been carried out for the THMEFF, as described in a journal publication (Birkholzer 2002 [DIRS 160748], pp. 42 to 44) as well as in a scientific notebook (Wang 2003 [DIRS 161123], pp. 99 to 142). The validation methods that are described in these references are consistent with the model validation planned in a previous version of the technical work plan (BSC 2004 [DIRS 167969]).

\subsubsection{Modeling Procedure and Conceptual Model}

\subsubsection{Modeling Procedure}

The first step in applying the THMEFF is to derive estimates for the potential characteristics of episodic finger flow at Yucca Mountain. Experimental data from a comprehensive laboratory study by Su et al. (1999 [DIRS 107846]) are used for that purpose, and a simplified finger-flow model for downward drainage is developed (Section 6.3.1.2). The second step is to simulate the fate of such episodic finger-flow events when the flow penetrates into the superheated rock region above waste emplacement drifts, using the semi-analytical solution of Birkholzer (2002 [DIRS 160748]). The conceptual model and the semi-analytical solution are presented in Section 6.3.1.3. The solution is implemented at several discrete times after waste emplacement, to cover the range of rock temperature conditions and extent of the superheated zone around drifts. Analysis is performed separately for the Tptpmn and Tptpll units, since the TH properties of these units and their thermal behavior are different. The third and final step is to evaluate the results, namely the relative percentage of water arriving at the drift crown at different times after emplacement, in relation to the perturbed flow situation above the drifts at these times, namely the elevated downward flux from the condensation zone towards the drift.

\subsubsection{Characteristics of Episodic Preferential Flow and Conceptual Flow Model}

Note that episodic preferential flow behavior has not been observed in the ambient natural environment at Yucca Mountain. Furthermore, there are no experimental studies using test samples from the fractured rock at Yucca Mountain (or replicas mimicking Yucca Mountain fractures) that demonstrate the potential for such flow conditions. However, several small-scale flow visualization experiments, most of them using fracture analogues composed of assemblies of textured glass plates, and several related modeling studies exhibited fast flow forming in narrow fingers and/or episodic flow patterns developing even for constant inlet conditions (e.g., Glass 1993 [DIRS 160751]; Nicholl et al. 1993 [DIRS 160759]; Nicholl et al. 1994 [DIRS 141580]; Persoff and Pruess 1995 [DIRS 160758]; Pruess 1998 [DIRS 107843]; Kneafsey and Pruess 1998 [DIRS 145636]; Su et al. 1999 [DIRS 107846]). Two studies, by Persoff and Pruess (1995 [DIRS 160758]) and Su et al. 1999 [DIRS 107846]), conducted flow visualization experiments on transparent replicas of natural granite fractures from the Stripa Mine in Sweden. Transparent fracture replicas are epoxy casts made from a silicone mold of the fracture surfaces, representing the realistic geometry of the small-scale aperture distribution. 
It is assumed in the analysis that the flow characteristics observed in the above experiments can serve as reasonable estimates for episodic preferential flow in unsaturated fractures at Yucca Mountain. From the experimental studies cited above, the fracture replica analysis of Su et al. (1999 [DIRS 107846]) is probably the best suited for this matter, because the realistic geometry of natural fractures is accounted for, and detailed quantitative measurements are provided. Differences between fractures from the Yucca Mountain and the Stripa Mine-with respect to aperture distributions, surface roughness, and contact angle-will bring out differences in flow behavior and distribution. However, this approach is valid for a qualitative analysis intended to demonstrate the impact of an alternative flow conceptualization on thermal seepage. The main phenomenological aspects of episodic preferential flow observed by $\mathrm{Su}$ et al. (1999 [DIRS 107846], Sections 2 and 3) should hold true for fractures of similar geometric characteristics, since local aperture variation is the main driver inducing episodic finger flow.

Phenomena of small-scale flow patterns observed by Su et al. (1999 [DIRS 107846], Sections 2 and 3) can be briefly summarized as follows. In spite of the uniform and constant boundary conditions applied in the experiments, the infiltrating water moved in preferential flow paths, consisting of broader, water-filled regions (capillary pools) that were connected by long, thin, fast-moving water rivulets. In almost all experiments, flow proceeded in an intermittent manner, consistent in geometry and frequency. The episodic pattern was caused by capillary differences between regions of smaller apertures within the fracture plane located above regions of larger apertures. In such a geometric setup, water may accumulate in the smaller-aperture regions because the interface between the smaller and the larger apertures acts as a capillary barrier to the infiltration of water. As a result, saturated capillary pools form that continue to fill slowly until the hydraulic head exceeds the capillary force difference between the small and the large apertures. Once this occurs, the almost static flow system becomes a dynamic one: the capillary barrier breaks, and a large portion of the accumulated water drains rapidly, creating fast preferential flow events of short duration that proceed downward. The sequence of water accumulation and subsequent drainage can occur again and again, generating episodic infiltration patterns.

Su et al. (1999 [DIRS 107846], p. 1032, Table 4) report a small range of water volumes accumulating in and draining from capillary pools for the entire suite of experiments, fairly unaffected by the order-of-magnitude variation in flow rate imposed at the inlet boundary. Also, the width of the rivulets was observed to be independent of the applied flow rate, while the temporal frequency of flow events correlated well with the flow rate imposed at the inlet boundary. These observations are consistent with the concept of capillary-induced episodic flow patterns, in which the accumulation and flow distribution of water depends on local aperture variation, while the time required between subsequent flow events-required for water accumulation-depends on the rate of overall downward percolation in the fractured rock. Adopting this concept for the thermal conditions at Yucca Mountain, it is assumed that the thermally perturbed percolation fluxes in the condensation zone-as predicted by the $\mathrm{TH}$ seepage model-drain downward in episodic finger-flow patterns. The characteristics of individual fingers (i.e., finger geometry, water volume per flow event and flow rate) are assumed to be independent of the actual percolation flux magnitude. Their frequency, however, is directly correlated to the percolation flux; i.e., strongly elevated downward fluxes at early stages of heating should result in finger flow that occurs more often in time and space. 
Basic characteristics defining episodic finger flow, namely water volume of individual flow events $V$, fracture aperture $b$, and finger width $w$, are directly extracted from the experimental results given by Su et al. (1999 [DIRS 107846], Sections 2 and 3). Using representative values for these parameters, additional parameters are derived from a simplified conceptual model for the downward flow of the periodically released water. According to this conceptual model, the episodic flow events drain downward in one-dimensional vertical rivulets of constant width, within fractures of uniform aperture and infinite extent. Also, flow is gravity-dominated, laminar, and fully developed, while water losses caused by wetting of the fracture behind the advancing front or matrix diffusion are neglected. Possible negligible effects of film flow or water flow along the footwall of a subvertical fracture are not considered. Using a parallel-plate representation of the fracture plane, the downward flow velocity of the finger, $v_{P}$, is given as:

$$
v_{P}=\frac{b^{2}}{12} \frac{\rho g}{\mu}
$$

where $\rho$ is density of water, $g$ is gravitational acceleration, and $\mu$ is the dynamic viscosity of water. With given finger width $w$, the mass flow rate $m_{P}$ of the finger flow can be calculated as follows:

$$
m_{P}=\rho b w v_{P}
$$

while the duration of the finger flow, $t_{P}$, is given from mass continuity:

$$
t_{P}=\frac{\rho V}{m_{P}}
$$

The flow duration denotes the time period needed for the finger to flow past a given location. This flow period is followed by a longer time period without downward flow of the finger, because a sufficient amount of water has to accumulate at the capillary pool before drainage resumes. According to the above, $v_{P}, m_{P}$, and $t_{P}$ are constant at isothermal conditions; thus, after initiation, flow would propagate downward towards the boiling zone with constant velocity. However, this is no longer the case when the finger penetrates into the superheated rock environment and part of the water vaporizes.

The experimental data of Su et al. (1999 [DIRS 107846], Sections 2 and 3) suggest the following representative values for fracture aperture $b$, water volume $V$, and finger width $w$. Assuming log-normal distribution, the geometric mean aperture of the fracture replica investigated in Su et al. (1999 [DIRS 107846], p. 1024) is $0.141 \mathrm{~mm}$, while the standard deviation is 0.559 in natural $\log$ space. $^{3}$ Comparison of these statistical parameters with conditions at Yucca

3 The small-scale aperture measurements of the fracture replica are reported in Su et al. (1999 [DIRS 107846], p. 1024) to yield a mean aperture of $0.16 \mathrm{~mm}$ and a standard deviation of $0.11 \mathrm{~mm}$ without confining gas pressure, and a mean aperture of $0.17 \mathrm{~mm}$ and a standard deviation of $0.09 \mathrm{~mm}$ with confining gas pressure. The averages of these values are a mean of $0.165 \mathrm{~mm}$ and a standard deviation of $0.10 \mathrm{~mm}$. The respective mean and standard deviation of log-normally distributed data can be derived from the following transformation (e.g., Ang and Tang 1975 [DIRS 160321], pp. 104-105). 
Mountain is difficult, since comparable small-scale measurements are not available for the fractures in the Tptpmn and the Tptpll. However, first-order estimates of hydraulic aperture can be derived from fracture frequency and fracture permeability data. Following Analysis of Hydrologic Properties Data (BSC (2004 [DIRS 170038], Section 6.1.2, Equation 6-7) and using the values of fracture permeability and frequency given in Table 7 of the same reference, the geometric mean of fracture hydraulic aperture can be readily calculated. From this calculation, the hydraulic aperture in the Tptpmn unit is approximately $1 \mathrm{~mm}$ (using a fracture permeability of $3.3 \times 10^{-13} \mathrm{~m}^{2}$ and a frequency of $\left.4.321 / \mathrm{m}\right)$. The hydraulic aperture in the Tptpll is about 1.5 mm (using a fracture permeability of $9.1 \times 10^{-13} \mathrm{~m}^{2}$ and a frequency of $3.16 / \mathrm{m}$ ). These mean values are similar to the mean aperture reported by Su et al. (1999 [DIRS 107846], p. 1024). With respect to aperture variation, it is noted that the variability coefficient of the Stripa sample, defined as the ratio of standard deviation to mean aperture, correlates well with other measurements in natural fractures of various rock types (e.g., Hakami and Barton 1990 [DIRS 160754]; Hakami 1995 [DIRS 160760]). Data on water volumes are derived using the 17 (out of 21) flow visualization experiments of Su et al. (1999 [DIRS 107846], Table 4) that exhibit episodic behavior, giving a geometric mean of $0.161 \mathrm{~mL}$ and a standard deviation of 0.438 (in natural $\log )^{4}$. In the analysis below, the geometric mean values of fracture aperture and water volume are applied as base cases. In addition, uncertainty is addressed in a sensitivity analysis in which these base-case values are varied by adding/subtracting the respective standard deviation (in log space). For finger geometry, Su et al. (1999 [DIRS 107846], p. 1032) report a fairly consistent finger width of about $1 \mathrm{~mm}$, often forming behind advancing water drops that are slightly larger, on the order of $4.5 \mathrm{~mm}$. Since these two values are not sufficient to derive statistical properties, two equally probable cases with $w=1 \mathrm{~mm}$ and $w=4.5 \mathrm{~mm}$ are considered.

With given values for fracture aperture $b$, water volume per flow event $V$ and finger width $w$, the downward velocity $v_{P}$, mass flow rate $m_{P}$, and duration $t_{P}$ of episodic finger flow can be calculated using Equations 6.3.1.2-1, 6.3.1.2-2, and 6.3.1.2-3, respectively. Table 6.3.1.2-1 lists

$$
\begin{aligned}
& \alpha=\ln (\mu)-\frac{\sigma^{2}}{2}, \\
& \beta^{2}=\ln \left(1+\frac{\sigma^{2}}{\mu^{2}}\right)
\end{aligned}
$$

where $\mu$ and $\sigma$ are mean and standard deviation of aperture, and $\alpha$ and $\beta$ are mean and standard deviation of natural log of aperture. With $\mu=0.165 \mathrm{~mm}$ and $\sigma=0.10 \mathrm{~mm}, \alpha$ becomes -1.958 and $\beta$ is 0.559 . The geometric mean is $0.141 \mathrm{~mm}$.

${ }^{4}$ The mean and standard deviation are directly calculated from the natural logarithm of the values given by Su et al. (1999 [DIRS 107846], Table 4). Note that about half of the experiments were conducted using a simplified parallel-plate geometry with a small-to-large-to-small aperture sequence. These experiments typically resulted in slightly larger volumes compared to the natural fracture replica. The larger values are included to account for uncertainties involved in estimating these volumes. Note that the experiments have been conducted at room temperature (about $20^{\circ} \mathrm{C}$ ). For finger flow in the superheated rock (i.e., rock temperature above boiling point of water), the density change as a result of the increased temperature needs to be accounted for. The measured water volumes of Su et al. (1999 [DIRS 107846], Table 4) have therefore been adjusted by a factor of 1.036 , the ratio of water density at $20^{\circ} \mathrm{C}\left(996 \mathrm{~kg} / \mathrm{m}^{3}\right)$ and water density at $96^{\circ} \mathrm{C}\left(961 \mathrm{~kg} / \mathrm{m}^{3}\right)$, the nominal boiling point of water at prevailing pressure. Other thermodynamic properties of water required for the semi-analytical solution applied in the alternative conceptual model are dynamic viscosity $\mu$ and specific enthalpy of vaporization $\mathrm{h}$. The boiling-point properties for these parameters are $2.912 \times 10^{-4} \mathrm{~kg} / \mathrm{m}$-s and $2.27 \times 10^{6} \mathrm{~J} / \mathrm{kg}$. Thermodynamic properties of water are given in numerous textbooks (for example in Perry et al. 1984 [DIRS 125806], e.g., Figure 3-43 for dynamic viscosity, Table 3-28 for density, Table 3-301 for specific enthalpy). 
the input properties and the calculated flow characteristics of all simulation cases studied in the below analysis. Case 1, for example, uses the geometric mean values of fracture aperture and water volume with a finger width of $1 \mathrm{~mm}$, which gives a downward flow velocity of $0.054 \mathrm{~m} / \mathrm{s}$, a mass flow rate of $7.3 \times 10^{-6} \mathrm{~kg} / \mathrm{s}$, and a flow event duration of 21.2 seconds. Using the same aperture and water volume, but a wider $(4.5 \mathrm{~mm})$ finger, the downward flow velocity is still $0.054 \mathrm{~m} / \mathrm{s}$, but mass flow rate is larger at $3.3 \times 10^{-5} \mathrm{~kg} / \mathrm{s}$, while the flow duration is smaller at 4.7 seconds (Case 2 ). In the sensitivity cases, either fracture aperture is varied (Cases 1a and 2a for larger aperture, Cases $1 \mathrm{~b}$ and $2 \mathrm{~b}$ for smaller aperture) or the water volume is adjusted (Cases 1c and 2c for larger water volume, Cases $1 \mathrm{~d}$ and $2 \mathrm{~d}$ for smaller water volume). Changes in aperture invoke changes in flow velocity, mass flow rate, and duration of flow event, while changes in water volume affect only the flow duration. Typically, a larger aperture is associated with a fast, intense, and short flow event. Larger water volumes are related to longer flow duration. Note that the thermodynamic properties of water needed to derive $v_{P}, m_{P}, t_{P}$ in Table 6.3.1.2-1 are the values at the boiling point of water (as water in the superheated rock is at boiling temperature).

Table 6.3.1.2-1. Suite of Episodic Flow Events Analyzed with the TH Model for Episodic Finger Flow

\begin{tabular}{|c|c|c|c|c|c|c|}
\hline Simulation Cases & $\begin{array}{c}\text { Fracture } \\
\text { Aperture } \\
b \\
(\mathrm{~mm}) \\
\end{array}$ & $\begin{array}{c}\text { Water } \\
\text { Volume } \\
V \\
(\mathrm{~mL})\end{array}$ & $\begin{array}{c}\text { Finger } \\
\text { Width } \\
w \\
(\mathrm{~mm}) \\
\end{array}$ & $\begin{array}{c}\text { Flow } \\
\text { Velocity } \\
v_{P} \\
(\mathrm{~m} / \mathrm{s}) \\
\end{array}$ & $\begin{array}{c}\text { Mass Flow } \\
\text { Rate } \\
m_{P} \\
(\mathrm{~kg} / \mathrm{s}) \\
\end{array}$ & $\begin{array}{c}\text { Flow } \\
\text { Duration } \\
t_{P} \\
(s)\end{array}$ \\
\hline $\begin{array}{l}\text { Case } 1 \\
\text { (uses geometric mean of } b \\
\text { and } V, w=1 \mathrm{~mm} \text { ) }\end{array}$ & 0.141 & 0.161 & 1.0 & 0.054 & $7.3 \times 10^{-6}$ & 21.2 \\
\hline \multicolumn{7}{|l|}{ Sensitivity Cases to Case 1} \\
\hline Case 1a (large aperture ${ }^{a}$ ) & 0.247 & 0.161 & 1.0 & 0.164 & $3.9 \times 10^{-5}$ & 4.0 \\
\hline Case $1 b$ (small aperture ${ }^{a}$ ) & 0.081 & 0.161 & 1.0 & 0.018 & $1.4 \times 10^{-6}$ & 113.4 \\
\hline Case 1c (large volume ${ }^{a}$ ) & 0.141 & 0.249 & 1.0 & 0.054 & $7.3 \times 10^{-6}$ & 32.9 \\
\hline Case 1d (small volume ${ }^{a}$ ) & 0.141 & 0.104 & 1.0 & 0.054 & $7.3 \times 10^{-6}$ & 13.7 \\
\hline $\begin{array}{l}\text { Case } 2 \\
\text { (uses geometric mean of } b \\
\text { and } V, w=4.5 \mathrm{~mm} \text { ) }\end{array}$ & 0.141 & 0.161 & 4.5 & 0.054 & $3.3 \times 10^{-5}$ & 4.7 \\
\hline \multicolumn{7}{|l|}{ Sensitivity Cases to Case 2} \\
\hline Case 2a (large aperture ${ }^{a}$ ) & 0.247 & 0.161 & 4.5 & 0.164 & $1.8 \times 10^{-4}$ & 0.9 \\
\hline Case $2 b$ (small aperture ${ }^{a}$ ) & 0.081 & 0.161 & 4.5 & 0.018 & $6.1 \times 10^{-6}$ & 25.2 \\
\hline Case 2c (large volume ${ }^{a}$ ) & 0.141 & 0.249 & 4.5 & 0.054 & $3.3 \times 10^{-5}$ & 7.3 \\
\hline \multirow[t]{2}{*}{ Case 2d (small volume ${ }^{a}$ ) } & 0.141 & 0.104 & 4.5 & 0.054 & $3.3 \times 10^{-5}$ & 3.0 \\
\hline & \multicolumn{3}{|c|}{$\begin{array}{l}\text { Extracted from Su et al. } 1999 \text { [DIRS } \\
\text { 107846] }\end{array}$} & \multicolumn{3}{|c|}{$\begin{array}{l}\text { Calculated from Equations } 6 \cdot 3 \cdot 1 \cdot 2-1 \text { to } \\
6.3 \cdot 1.2-3 \text { with } b, V \text {, and } w \text { as input }\end{array}$} \\
\hline
\end{tabular}

${ }^{a}$ Parameter change calculated from: $p=\exp (\mu \pm \sigma$ ), where $p$ is adjusted parameter, $\mu$ is mean value (in natural log), and $\sigma$ is standard deviation (in natural log). 


\subsubsection{Water Penetration into Superheated Rock}

The semi-analytical solution of Birkholzer (2002 [DIRS 160748]) is used to determine the maximum penetration distance of episodic fingers subject to vigorous vaporization from the hot rock. In case the flow from these events penetrates through the entire superheated zone above drifts, the solution also gives the total amount of water arriving at the drift crown. A brief review of the mathematical formulation and solution procedure is given below. Note that the solution of Birkholzer (2002 [DIRS 160748], Sections 1.2 and 1.3) is an extension of the analytical solution presented by Phillips (1996 [DIRS 152005], Section 3) that was used in the SSPA (BSC 2001 [DIRS 155950], Section 4.3.5.5). However, Phillips (1996 [DIRS 152005], Section 3) derived an approximate asymptotic solution for long-term behavior of continuous finger flow, while the semi-analytical solution of Birkholzer (2002 [DIRS 160748], Section 1.3) provides an exact simulation method for early and late time periods of flow events that can be episodic or continuous.

The basic conceptual model for the semi-analytical solution of finger penetration into superheated rock is schematically depicted in Figure 6.3-1, showing a superheated region of length $L$ above the crown of a waste emplacement drift. Here, the ambient rock water has long been boiled off, and fractures and rock are essentially dry. The rock temperature in the superheated zone is above the boiling temperature at prevailing pressure. Initially, before finger flow occurs, the temperature field is uniform in the lateral $x$-direction and a function of location in the vertical $z$-direction. Episodic flow events of given mass flow rate $m_{P}$, duration $t_{P}$, and finger width $w$ enter the superheated region at $z=0$ and $t=0$. The infiltrating water is already heated up to almost boiling temperature $T_{P}$ upon arrival at the superheated region, and begins boiling as it passes the boiling-point isotherm. As was presented in the previous section, the downward flow of the finger is gravity-driven and strictly one-dimensional. Upon contact with the water, the rock surface cools to boiling temperature, and a steep temperature gradient is established in the surrounding matrix when the liquid front in the fractures reaches the considered position. With time, the thermal perturbation penetrates further into the rock, the thermal gradient decreases, and heat flow from the matrix to the fracture is reduced. As conduction in the matrix is slow compared to the vertical movement of the liquid pulse, the conductive heat flow within the matrix and from the matrix to the fracture is considered as strictly lateral, perpendicular to the fracture plane. Note that the accumulation time between two consecutive episodic flow events is usually longer than the flow duration $t_{p}$, so that for all practical purposes the rock temperature, perturbed from contact with one flow event, has equilibrated to its initial state before the next flow event arrives.

The downward flow rate at a location $z$ in the superheated region can be derived from a balance between the energy required for vaporization of water and the energy supplied by heat conduction from the rock. This energy balance is given in Birkholzer (2002 [DIRS 160748], p. 5, Eq. 9) as follows

$$
\frac{\partial m(z, t)}{\partial z}=-\frac{2 w \lambda_{d r y}}{h} \frac{T_{R I}-T_{P}}{\sqrt{\pi \kappa\left(t-t_{0}(z)\right)}}
$$

using an analytical solution of Carslaw and Jaeger (1959 [DIRS 100968], pp. 58 to 62) to solve for the lateral temperature distribution in the rock matrix. Here, $m(z, t)$ is mass flow rate at 
location $z$ and time $t, \lambda_{\text {dry }}$ is dry thermal conductivity of the rock matrix, $h$ is specific enthalpy of vaporization, $T_{R I}$ is the initial rock temperature, and $\kappa$ is rock thermal diffusivity. The period $t_{0}(z)$ denotes the time interval after initial entry of the water finger into the superheated zone until the arrival of the tip of the liquid finger at location $z$. Equation 6.3.1.3-1 is valid as long as the thermal perturbation in the rock is nearly uniform across the width of the liquid finger. Since thermal perturbation grows with $(\kappa t)^{1 / 2}$, the maximum time period $t_{m}$ associated with uniform thermal perturbation is of order

$$
t_{m}=\frac{w^{2}}{\kappa}
$$

For $t>t_{m}$, the nearly one-dimensional heat flow perpendicular to the fracture-rock interface transforms to a more circular spreading of heat.

A simple Lagrangian solution scheme was presented in Birkholzer (2002 [DIRS 160748], pp. 10 to 12) that solves Equation 6.1.3.1-1 for episodic flow events of given flow rate and duration. A time-marching procedure tracks the movement of finite water masses traveling downwards while part of the water boils off. The semi-analytical solution scheme was shown to be accurate, robust, and extremely fast. For details on the numerical methods and for verification/validation of the solution (in comparison with TOUGH2 modeling results and an analytical solution), refer to Birkholzer (2002 [DIRS 160748], pp. 10 to 12, 42 to 44).

\subsubsection{ACM Application for the Tptpmn Unit}

\subsubsection{Results for Cases 1 and 2 (Mean Cases)}

To gain a basic understanding of the flow mechanisms of episodic preferential flow events in hot fractures around drifts, the analysis starts with the particular flow events referred to as Cases 1 and 2 in Table 6.3.1.2-1. The thermal properties of the rock matrix, required as input for the semi-analytical solution of Birkholzer (2002 [DIRS 160748], Section 2.3), are based on the Tptpmn values given in Section 4, Table 4.1-2. Note that the dry thermal-conductivity value is used for the semi-analytical solution (as heat conduction is calculated in the superheated dry rock). The thermal conditions of the rock mass above the drift are extracted from the simulation results of the TH seepage model, using the base-case simulation presented in Section 6.2.2.1.1. For illustration of results, a one time snapshot at 550 years after emplacement is chosen. According to the $\mathrm{TH}$ seepage model results, the vertical extent of the superheated rock at this time is $3.537 \mathrm{~m}$, with a maximum rock temperature at the drift wall of $105.8^{\circ} \mathrm{C}$. Assuming that the temperature profile in the superheated zone is linear (which is a reasonable approximation as demonstrated by the TH seepage model results), the rock temperature $T_{R I}$ at each vertical location $z$ in the superheated zone is defined. This rock temperature profile represents the initial rock temperature prior to liquid penetration into the superheated zone. An episodic flow event entering this zone encounters a temperature field of $96^{\circ} \mathrm{C}$ at a location of $3.537 \mathrm{~m}$ above the drift crown that increases linearly to $105.8^{\circ} \mathrm{C}$ at the drift wall.

Figure 6.3.2.1-1 shows results of the semi-analytical solution of Birkholzer (2002 [DIRS 160748]), giving the penetration of the tip of the draining finger versus time, with $\mathrm{z}=0$ the top of the superheated domain and $t=0$ the time when the tip of the finger first enters the 
boiling zone. (The arrow gives the penetration curve for water flowing with the undisturbed velocity $v_{P}=0.054 \mathrm{~m} / \mathrm{s}$.) After about $2 \mathrm{~m}$, the penetration of the finger slows down noticeably compared to $v_{P}$. The further the finger infiltrates, the stronger this effect, caused by water being effectively boiled off. Initially, the two cases of finger width (Cases 1 and 2) exhibit identical penetration curves. The larger flow rate for the case of finger width $4.5 \mathrm{~mm}$ is compensated by the larger interface area available for heat conduction, so that the relative impact of water vaporization is the same. The major difference between the two cases is related to the location where the flow events come to a final stop when the water volume has completely boiled off. The flow event with $w=4.5 \mathrm{~mm}$, shorter in duration compared to $w=1 \mathrm{~mm}$, ends at a maximum penetration of $2.91 \mathrm{~m}$ after a total time of $59 \mathrm{~s}$. For $w=1 \mathrm{~mm}$, water penetrates further and eventually arrives at the drift wall. These differences occur even though the initial water volumes are identical. Thus, the effectiveness of the vaporization barrier varies with the assumed finger width. Note that the time period of finger flow in these cases is longer than the time period $t_{m}$ defined in Equation 6.3.1.3-2 where uniform thermal perturbation across the width of the finger can be safely assumed. Applying the semi-analytical solution for times larger than $t_{m}$ neglects the more circular spreading of heat in the rock, which underestimates the amount of thermal energy available for boiling of water. This in turn tends to underestimate effectiveness of the vaporization barrier.

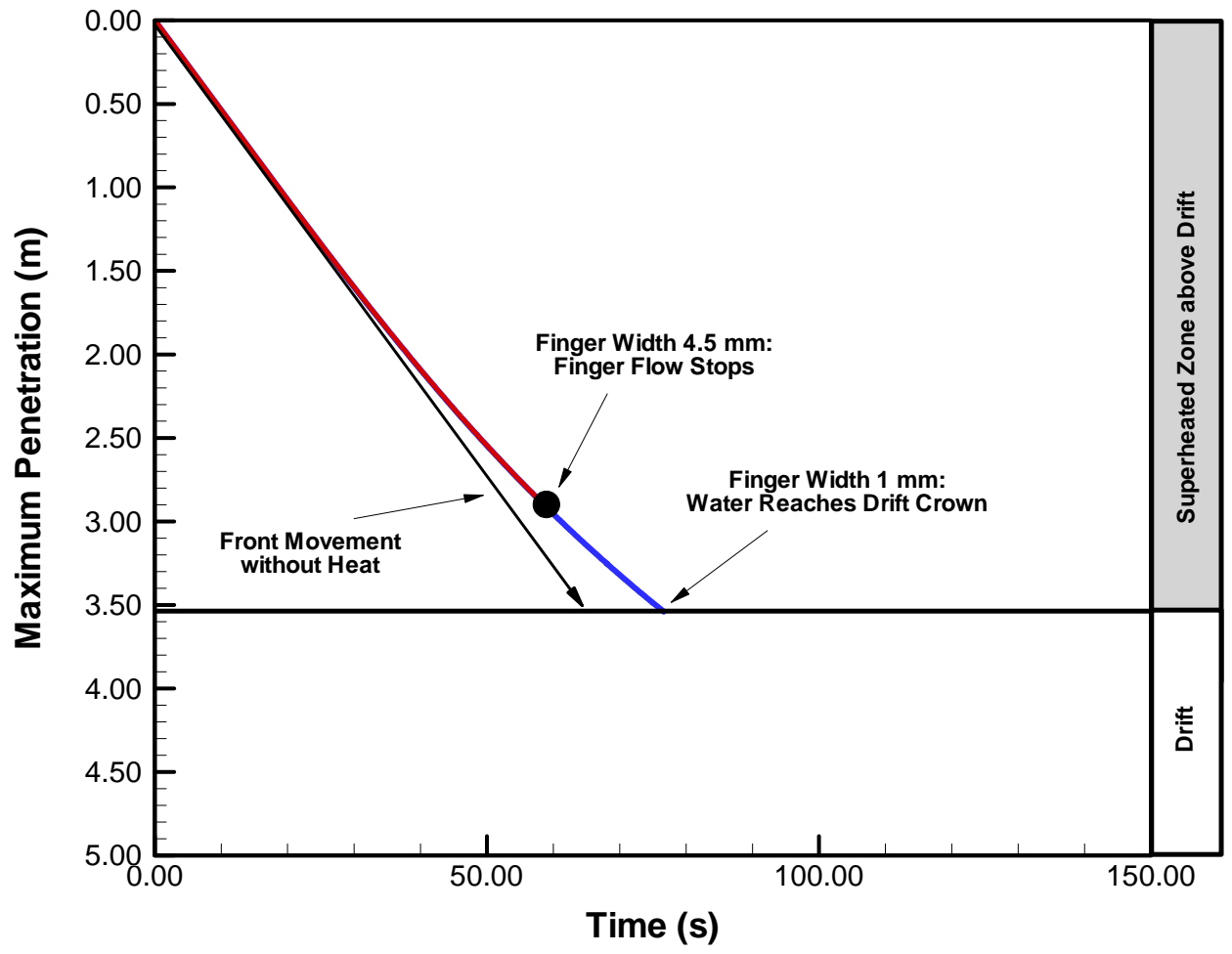

Output DTN: NA (See Section 8.5).

NOTE: At this time, the extent of the superheated region above the drift is $3.54 \mathrm{~m}$; the maximum rock temperature at the drift crown is $105.8^{\circ} \mathrm{C}$.

Figure 6.3.2.1-1. Maximum Penetration of Tip of Finger versus Time at 550 Years of Heating for Case 1 and Case 2 (Tptpmn Unit) 
After investigating whether episodic preferential flow can overcome the vaporization barrier to arrive at the drift crown, the focus is now on the amount of water reaching the drift. Obviously, the water mass flowing past a given location in the superheated rock decreases, caused by vaporization as the liquid pulse moves down the fracture. The further the infiltrating finger penetrates into the superheated region, the less water is available. In other words, the larger the superheated zone above a waste emplacement drift, the less water can reach the drift crown. This is demonstrated in Figure 6.3.2.1-2, where the total amount of water breakthrough is plotted as a function of vertical infiltration distance, given relative to the initial water volume entering the superheated rock. The effect of boiling is significant in both cases of finger width; however, as a result of the larger interface area, more heat is conducted to the $4.5 \mathrm{~mm}$ finger. Thus, the rate of water vaporization is stronger and the initial water volume boils off earlier. For the $1 \mathrm{~mm}$ finger, about 16.5 percent of the initial water volume arrives at the drift crown, whereas the major fraction of the initial water volume vaporizes in the superheated rock.

The above results indicate that the relative rate of water arriving at the drift crown is small at 550 years. However, this relative rate needs to be evaluated in conjunction with the flow perturbation in the condensation zone above the repository. Water accumulation from condensation of water in this zone increases the downward flux towards the superheated zone. Thus, following the conceptual model outlined in Section 6.3.1.2, episodic flow events could more frequently — in time and space-originate from the condensation zone, thereby increasing the absolute amount of water arriving at the drift. (Based on the discussion in Section 6.3.1.2, the characteristics of individual fingers are not affected by the change in average downward flux.) According to results from the TH seepage model, the maximum flux in the fracture continuum above the drift at 550 years is about $28 \mathrm{~mm} / \mathrm{yr}$, which is about 4.6 times higher than the ambient percolation of $6 \mathrm{~mm} / \mathrm{yr}$ (see Figure 6.2.2.1-7). It is assumed that the entire elevated vertical flux in the condensation zone drains down in an episodic finger-type manner. Then the potential water arrival at the drift crown-including the combined effect of flux elevation and vaporization barrier — can be estimated by multiplying the thermally elevated percolation flux of $28 \mathrm{~mm} / \mathrm{yr}$ with the relative rate of mass arrival at the drift from the semi-analytical solution. In Case 1, with 16.5 percent of the initial water arriving at the drift, the resulting flux at the drift crown would be $4.6 \mathrm{~mm} / \mathrm{yr}$. In Case 2, no water would arrive at the drift. Thus in both cases, the thermally enhanced downward fluxes in the condensation zone can be effectively reduced by vaporization to fluxes that are (1) much smaller than the maximum disturbed downward fluxes in the condensation zone above the drifts and (2) are also smaller than the ambient non-disturbed percolation fluxes (the latter small enough to not allow for seepage because of the capillary barrier at the drift wall). While exclusion of water from penetrating down to the drifts may not be absolute at the considered time, the vigorous boiling in the superheated rock still acts as a significant barrier that reduces the thermally induced maximum fluxes by a significant fraction. 


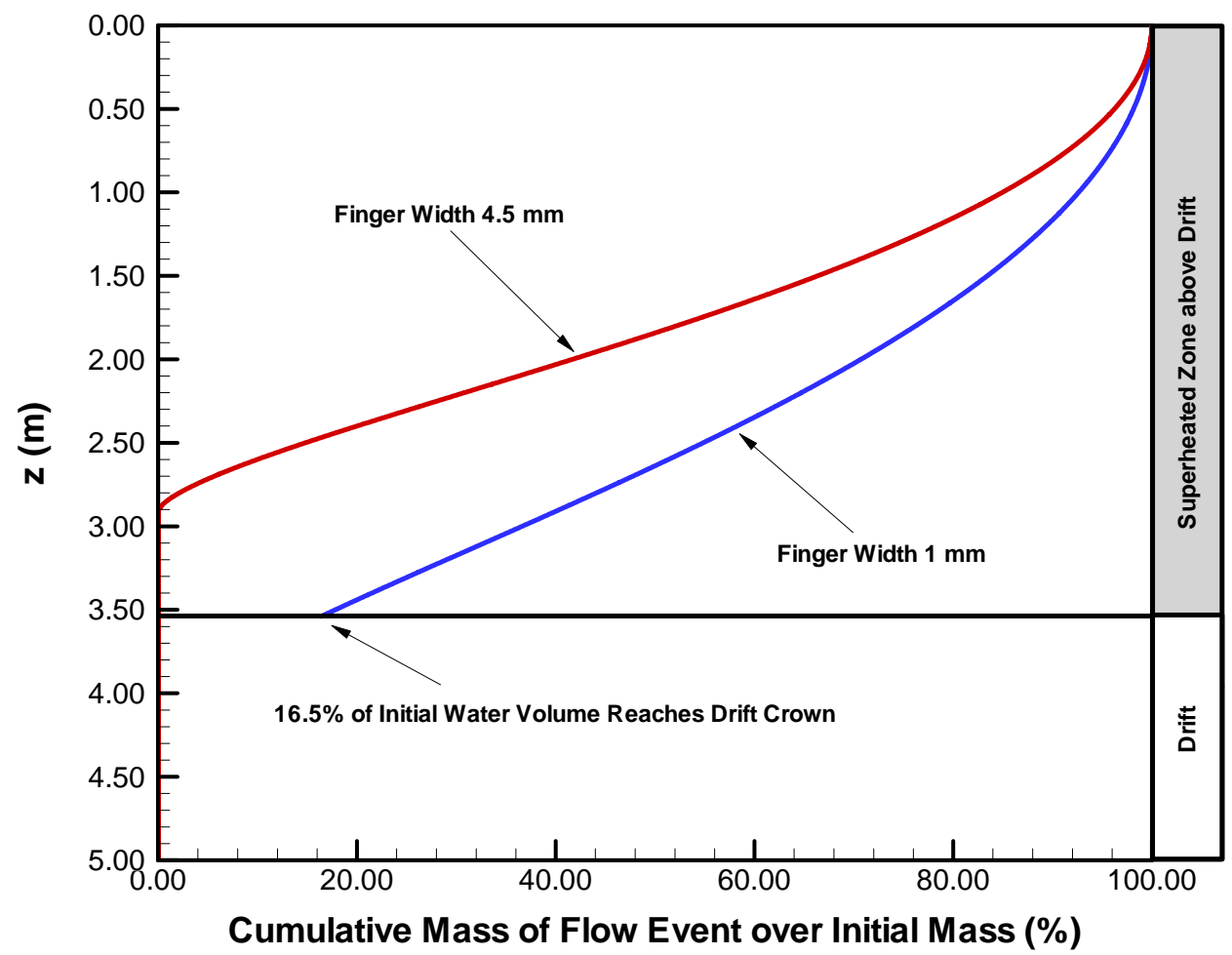

Output DTN: NA (See Section 8.5).

NOTE: At this time, the extent of the superheated region above the drift is $3.54 \mathrm{~m}$; the maximum rock temperature at the drift crown is $105.8^{\circ} \mathrm{C}$.

Figure 6.3.2.1-2. Total Water Mass Breakthrough at Location z at 550 Years of Heating for Case 1 and Case 2 (Tptpmn Unit)

The above analysis conducted for the conditions at 550 years can be performed for a series of time steps that adequately cover the time period during which rock temperature is above boiling. Altogether, eleven time steps are chosen for this purpose. As before, the thermal conditions at these times are extracted from results of the $\mathrm{TH}$ seepage model. In Figure 6.3.2.1-3, the square-shaped symbols show the extracted rock temperature close to the drift wall at discrete times, whereas the circular symbols give the related extent of the superheated zone (superheated refers to temperatures above $96^{\circ} \mathrm{C}$ ). The first time step considered is 75 years, where the maximum temperature occurs. The last time step is 950 years, shortly before the rock above the drift returns to nonboiling conditions. 


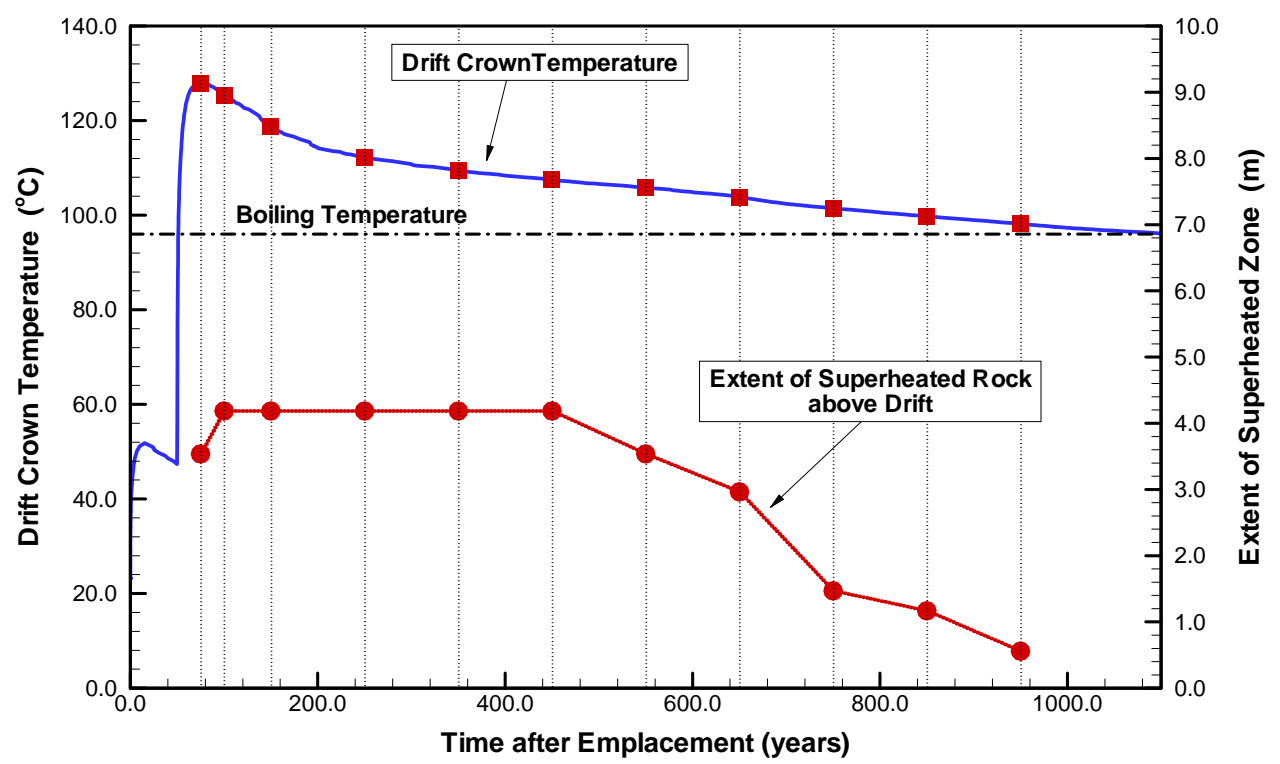

Output DTN: NA (See Section 8.5).

NOTE: $\quad$ Figure uses results from the TH seepage model for the Tptpmn unit (Section 6.2.2.1.1, Simulation Case MN-HOM-01). Symbols indicate the discrete time steps chosen for the analysis.

Figure 6.3.2.1-3. Predicted Wall Temperature History in and Extent of Superheated Rock above Waste Emplacement Drifts for Tptpmn Unit

Figure 6.3.2.1-4 provides results of the semi-analytical solution considering these eleven discrete time steps and using the flow event referred to as Case 1 (i.e., finger width is $1 \mathrm{~mm}$ ). The red diamond symbols give the maximum penetration distance into the superheated rock, while the blue circular symbols show the relative amount of water arrival at the drift. The maximum penetration distance should be compared to the curve formed by open circles showing the extent of the superheated region above the drift crown. According to this figure, no water would reach the drift for the first 450 years after emplacement, caused by intense heat and a sufficiently large hot region. At later times, the possible maximum penetration (in the absence of the drift opening) becomes larger than the boiling zone; i.e., water would arrive at the drift crown. The relative amount of water reaching the drift increases significantly between 450 years and 750 years after emplacement, as a result of the decreasing rock temperature and the smaller superheated rock zone. Eventually, at 950 years, the effect of vaporization becomes marginal, so that the water mass arriving at the drift is almost equal to the initial mass of the episodic flow event. At all later times, though not simulated with the THMEFF, vaporization no longer occurs, with the effect that the relative amount of water arrival at the drift would be equal to one; i.e., the water mass arriving at the drift crown is equal to the initial water mass.

In Figure 6.3.2.1-5, the relative rates of water arrival at the drift crown at given times are related to the flux perturbation in the condensation zone at these times. The red dashed line connecting circular symbols shows the so-called flux elevation factor, which is defined as the maximum downward flux in the condensation zone divided by the undisturbed ambient percolation. Flux elevation factors have been calculated for fourteen time steps. These are the eleven time steps where results from the THMEFF are available plus three additional time steps at 1,050, 1,200, and 1,500 years, representing nonboiling conditions. As the circular symbols indicate, the most 
significant flux elevation occurs at 75 years of heating, where the maximum downward flux is $73.2 \mathrm{~mm} / \mathrm{yr}$, more than 12 times that of the ambient flux of $6 \mathrm{~mm} / \mathrm{yr}$. With time progressing, this effect declines rapidly and is essentially negligible at 1,500 years after waste emplacement. (The drop at 650 years is caused by increasing infiltration as a result of the climate changes at 600 years. The climate change has two effects on the curve: 1 . Temperature drops as a result of increased percolation, giving rise to less intense boiling, condensation, and thus less downward flux. 2. Flux elevation factors are calculated relative to the current percolation flux, which increases for the 650-year time step compared to all previous time steps.) The blue solid line gives the water flux arriving at the drift crown when the combined effect of flux perturbation and vaporization barrier is considered. Note that this flux ratio is given relative to the undisturbed ambient percolation at the respective time and is obtained by multiplying the flux-elevation factor with the relative mass-arrival rate calculated from the THMEFF, as given in Figure 6.3.2.1-4. For the additional time steps at 1,050,1,200, and 1,500 years, the relative mass-arrival rate used in this multiplication is set to one, corresponding to the fact that vaporization is not effective at these late times. If the displayed values of the resulting blue-line curve are larger than one, the amount of water potentially arriving at the drift wall exceeds the ambient percolation flux.

Figure 6.3.2.1-5 shows that vaporization considerably reduces the impact of flux perturbation in the condensation zone. For the first 450 years of heating, vaporization is so effective that the amount of water arriving at the drift crown is zero, although there is a significant flux elevation in the condensation zone. Between 450 and 650 years, some amount of water penetrates down to the drift crown, but vaporization is still strong enough to reduce the elevated fluxes to values smaller than the ambient percolation (i.e., the resulting flux ratio is smaller than one). These are important results, demonstrating that the time period of strongly elevated vertical flux in the condensation zone coincides with the time period of very effective vaporization. Thus, even if the downward flux from the condensation zone towards the drift would flow entirely in episodic finger-type patterns - an extreme flow conceptualization that has never been observed at Yucca Mountain - the vaporization barrier would be fully effective for several hundred years. Only at later times, when vaporization effects diminish, is the flux arriving at the drift slightly higher than the natural ambient percolation. However, it is important to remember that these results are based on various simplifications that tend to promote the potential amount of water reaching drifts, most of them related to the idealized conceptual model of finger flow and heat transport. Also, the capillary barrier capability of the drift opening, which has not been considered in this analysis, ensures that no seepage would result from this small increase in fluxes close to the drift crown. 


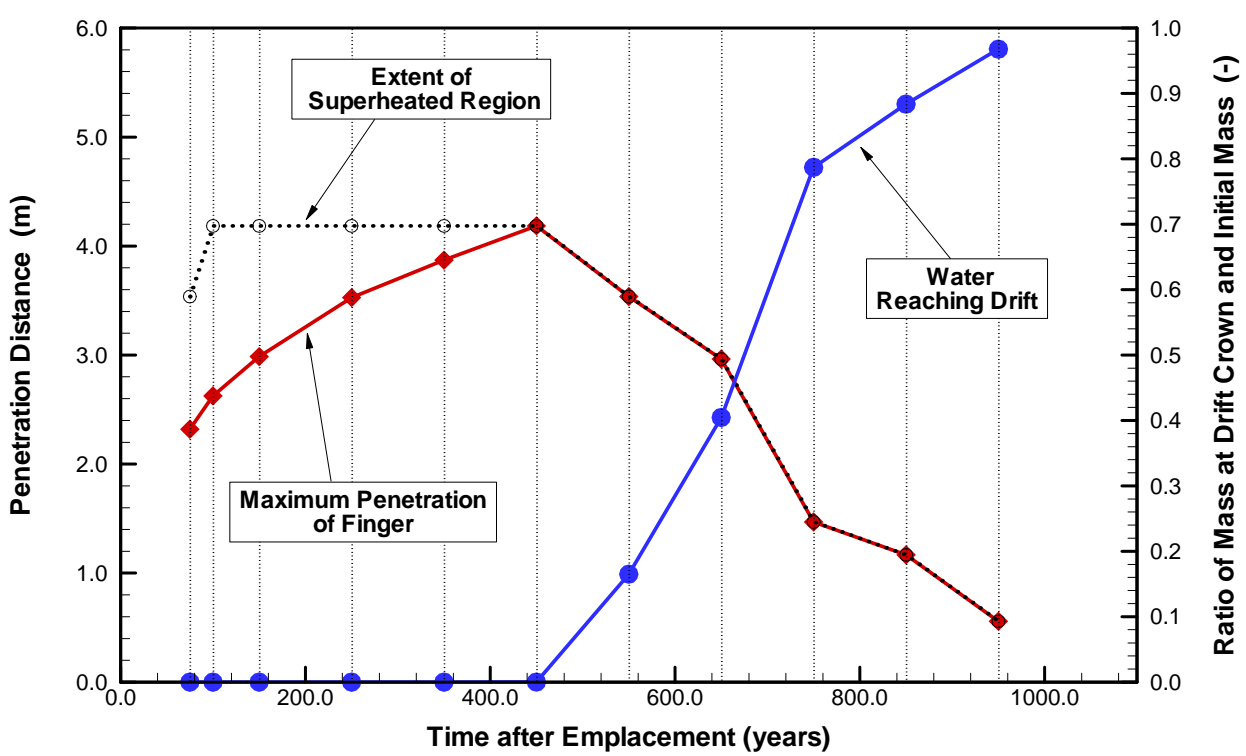

Output DTN: NA (See Section 8.5).

NOTE: $\quad$ Symbols indicate the discrete time steps chosen for the analysis. Finger width is $1 \mathrm{~mm}$.

Figure 6.3.2.1-4. Maximum Penetration and Percentage of Water Mass Arriving at Drift Crown for Case 1 (Tptpmn Unit)

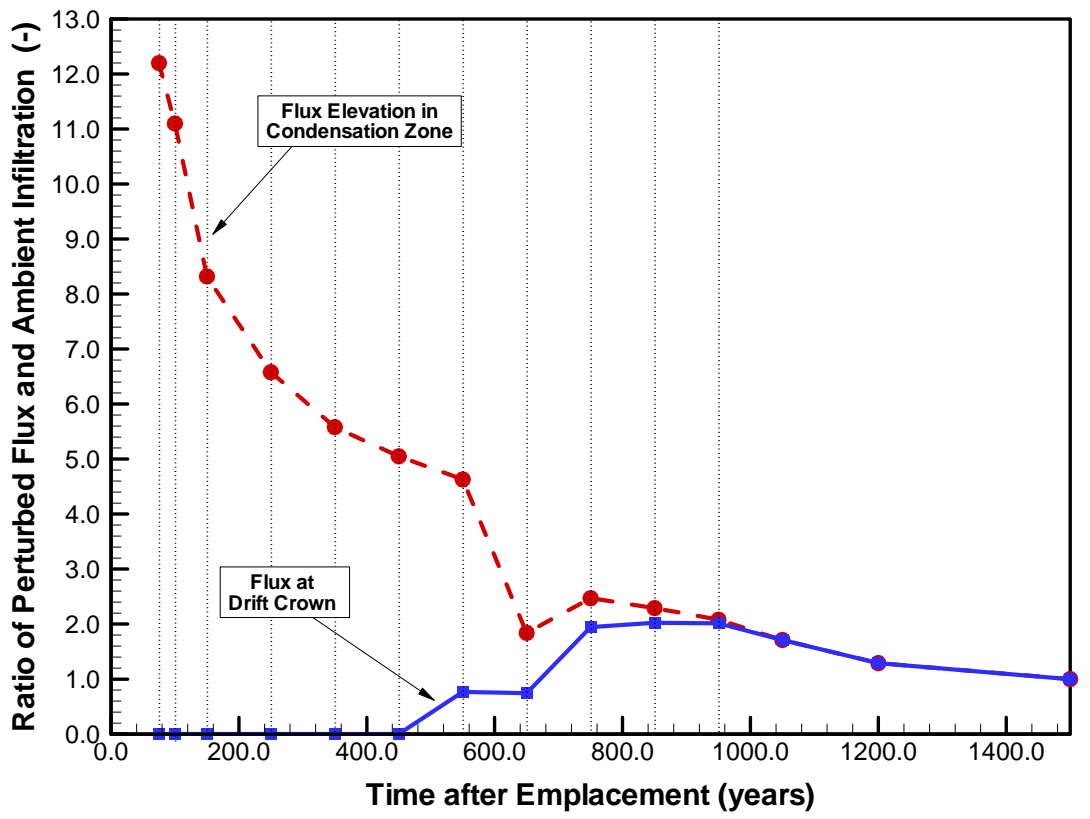

Output DTN: NA (See Section 8.5).

NOTE: The red line shows flux ratio in the condensation zone, simulated with the TH seepage model. The blue line shows the flux ratio of water at the drift crown, including the effect of vaporization. Symbols indicate the discrete time steps chosen for the analysis. Finger width is $1 \mathrm{~mm}$.

Figure 6.3.2.1-5. Ratio of Thermally Perturbed Vertical Flux and Ambient Percolation for Case 1 (Tptpmn Unit), at Fourteen Different Time Steps after Waste Emplacement 
A similar integrated analysis is conducted for Case 2, with a finger width of $4.5 \mathrm{~mm}$. Results are presented in Figures 6.3.2.1-6 and 6.3.2.1-7. Because vaporization is relatively more effective, the maximum penetration distances calculated for this case are smaller than in Case 1. Water starts to arrive at the drift crown at 650 years after heating, 200 years later than in the $1 \mathrm{~mm}$ finger case, and the relative rate of water arrival is significantly smaller. Clearly, the wider the downward draining finger, the less significant the potential of water arrival at the drift.

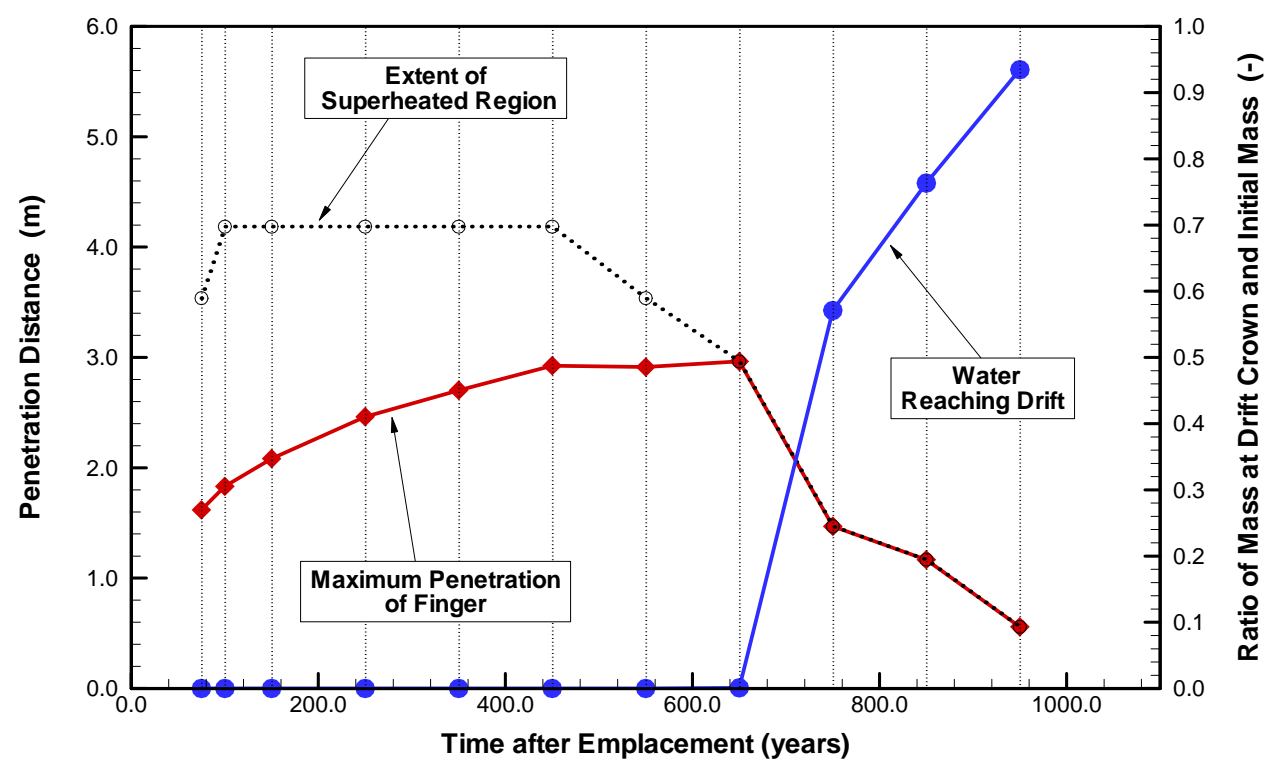

Output DTN: NA (See Section 8.5).

NOTE: $\quad$ Symbols indicate the discrete time steps chosen for the analysis. Finger width is $4.5 \mathrm{~mm}$.

Figure 6.3.2.1-6. Maximum Penetration and Percentage of Water Mass Arriving at Drift Crown for Case 2 (Tptpmn Unit) 


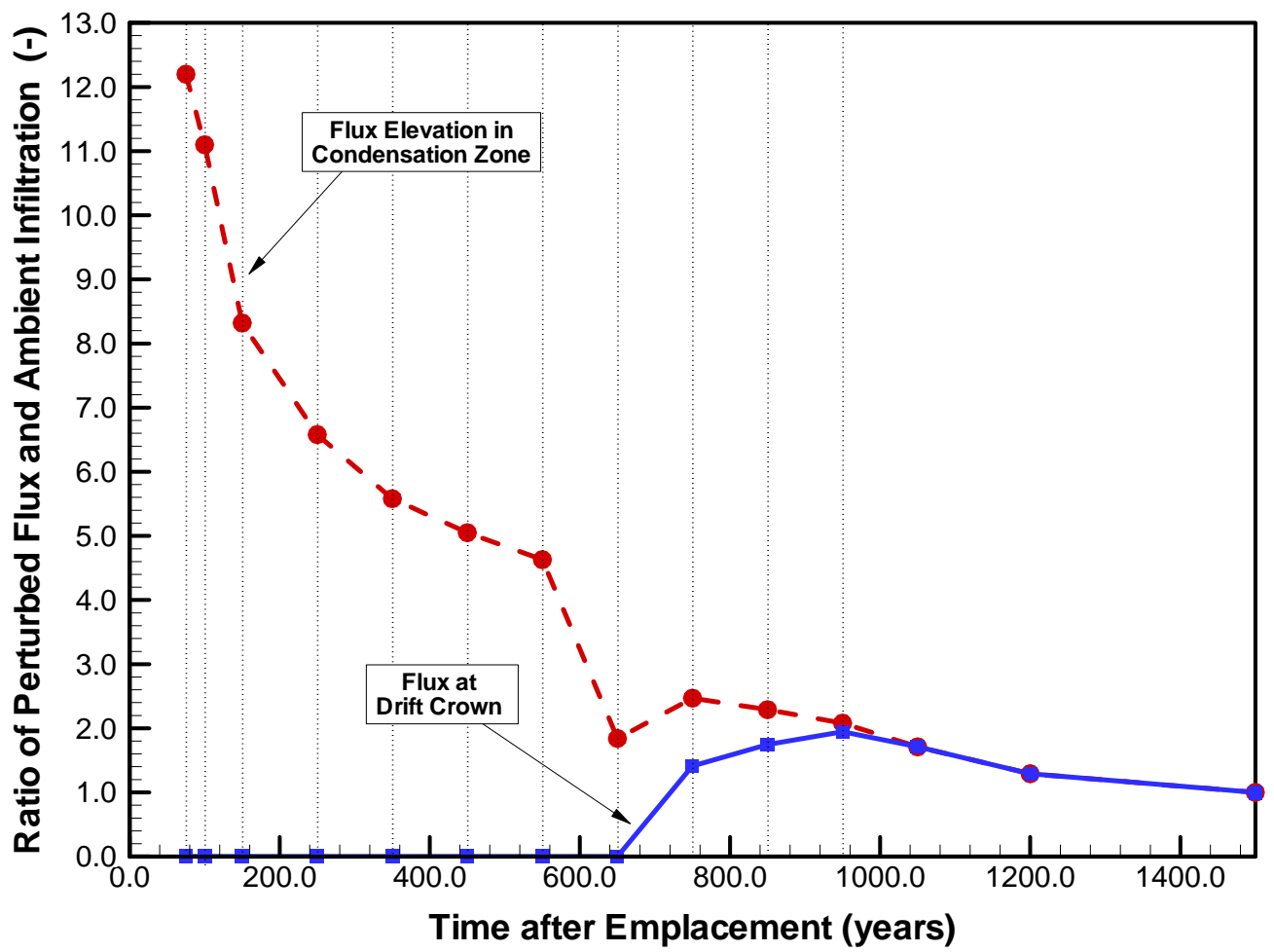

Output DTN: NA (See Section 8.5).

NOTE: The red line shows flux ratio in the condensation zone, simulated with the TH seepage model. The blue line shows the flux ratio of water at the drift crown, including the effect of vaporization. Symbols indicate the discrete time steps chosen for the analysis. Finger width is $4.5 \mathrm{~mm}$.

Figure 6.3.2.1-7. Ratio of Thermally Perturbed Vertical Flux and Ambient Percolation for Case 2 (Tptpmn Unit)

\subsubsection{Sensitivity Cases}

Several sensitivity cases are studied to analyze the uncertainty of water arrival at the drift caused by the potential variability in the flow characteristics of episodic finger flow. Of all input parameters required for the semi-analytical solution, those properties related to the small-scale finger-flow characteristics, as extracted from analyses by Su et al. (1999 [DIRS 107846], Sections 2 and 3), are the most uncertain and variable. In contrast, thermal properties of the rock and the future thermal conditions at Yucca Mountain are well constrained by laboratory data, in situ measurements, and associated modeling work. Thus in the sensitivity study, fracture aperture and initial water volume per flow event are varied, causing changes in the finger flow properties $v_{P}, m_{P}$, and $t_{P}$ as given in Table 6.3.1.2-1. The thermal properties of the rock and the temperature conditions remain unchanged. Results of the sensitivity analysis are given in Figure 6.3.2.2-1 for Cases 1a through 1d, featuring a finger width of $1 \mathrm{~mm}$ (see Table 6.3.1.2-1). Figure 6.3.2.2-2 presents Cases 2a through 2d, with a finger width of $4.5 \mathrm{~mm}$. The black and green lines in each figure mark the potential water flux at the drift crown-under thermal conditions, considering flux elevation and vaporization effects-relative to the ambient infiltration for cases 
of large and small aperture (water volume), respectively. For reference, the blue dotted lines show the respective mean case results.

Fracture aperture is clearly the more sensitive parameter compared to water volume. For both parameters, a change to larger values gives rise to an increased potential for water arrival at the drift. Sensitivity is smaller for the case with a finger width of $4.5 \mathrm{~mm}$ compared to the $1 \mathrm{~mm}$ case. Of all sensitivity cases, Case 1a is the most critical (large fracture aperture and small finger width). In this case, the episodic flow event is comparably fast and intense, while the effect of vaporization is small, because of the small interface area available for heat conduction and the reduced contact time between water and hot rock. Even then, however, vaporization in the superheated zone is strong enough to significantly reduce the effect of elevated vertical fluxes draining down from the condensation zone, particularly at early times when the thermal perturbation is largest. The maximum flux elevation ratio at the drift crown is about three at 550 years after emplacement; i.e., the amount of water potentially arriving at the drift would be $18 \mathrm{~mm} / \mathrm{yr}$, compared to $6 \mathrm{~mm} / \mathrm{yr}$ at ambient. This is a small increase that is not expected to result in seepage, once the capillary barrier is accounted for. For all sensitivity cases, the effect of variation in finger-flow characteristics is noticeable. All cases, however, exhibit a vaporization barrier that is fully effective for several hundred years, covering the time period of strong thermal perturbation. 

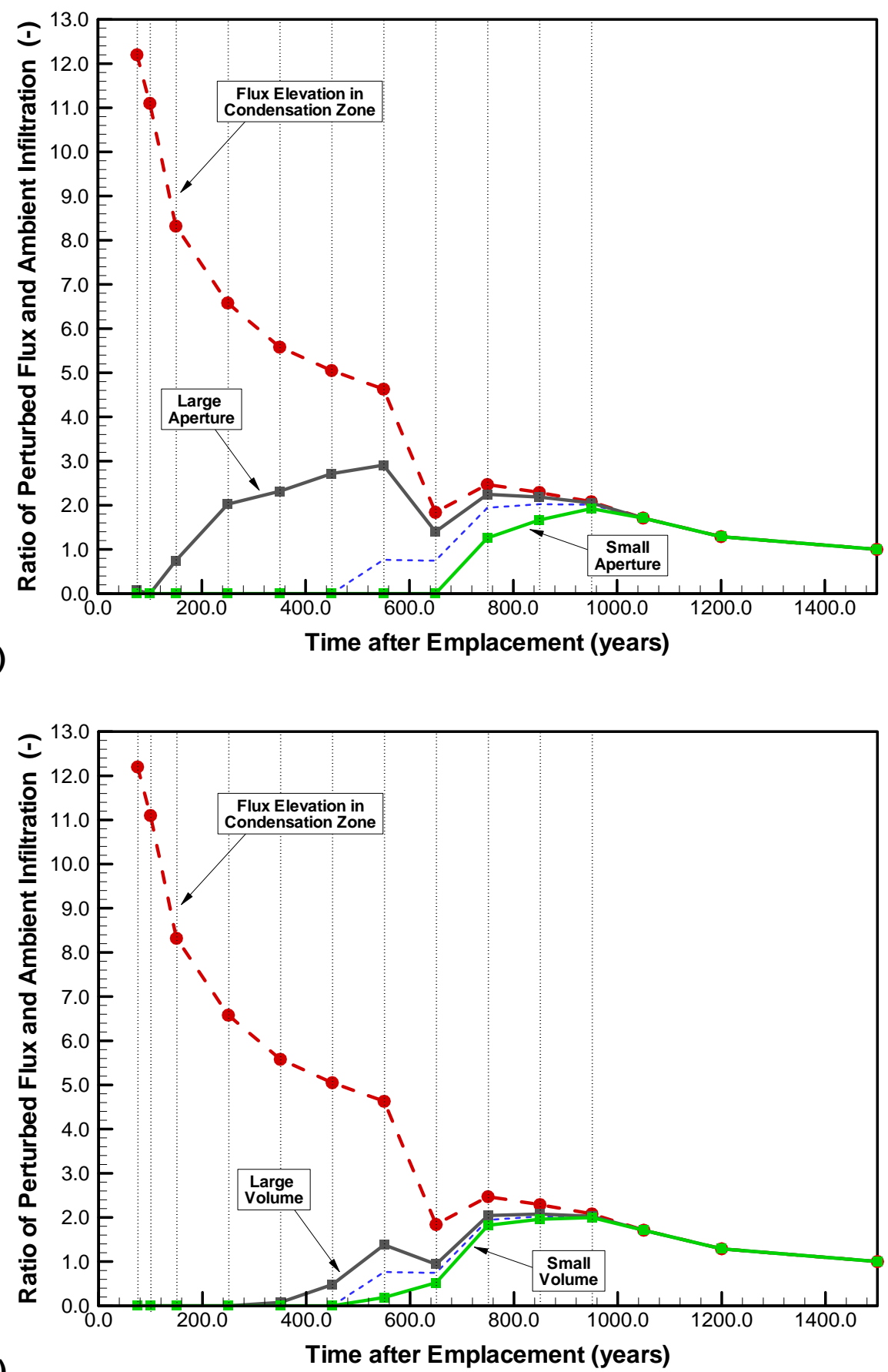

(b)

Output DTN: NA (See Section 8.5).

NOTE: $\quad$ Finger width is $1 \mathrm{~mm}$. The red line shows the flux ratio in the condensation zone, simulated with the TH seepage model. The other lines show the flux ratio of water at the drift crown, including the effect of vaporization. The dashed blue line is the mean case presented in Figure 6.3.2.1-5. Symbols indicate the discrete time steps chosen for the analysis.

Figure 6.3.2.2-1. Ratio of Thermally Perturbed Vertical Flux and Ambient Percolation, Showing Sensitivity of Model Results to (a) Fracture Aperture (Cases 1, 1a, 1b) and (b) Initial Water Volume (Cases 1, 1c, 1d) 

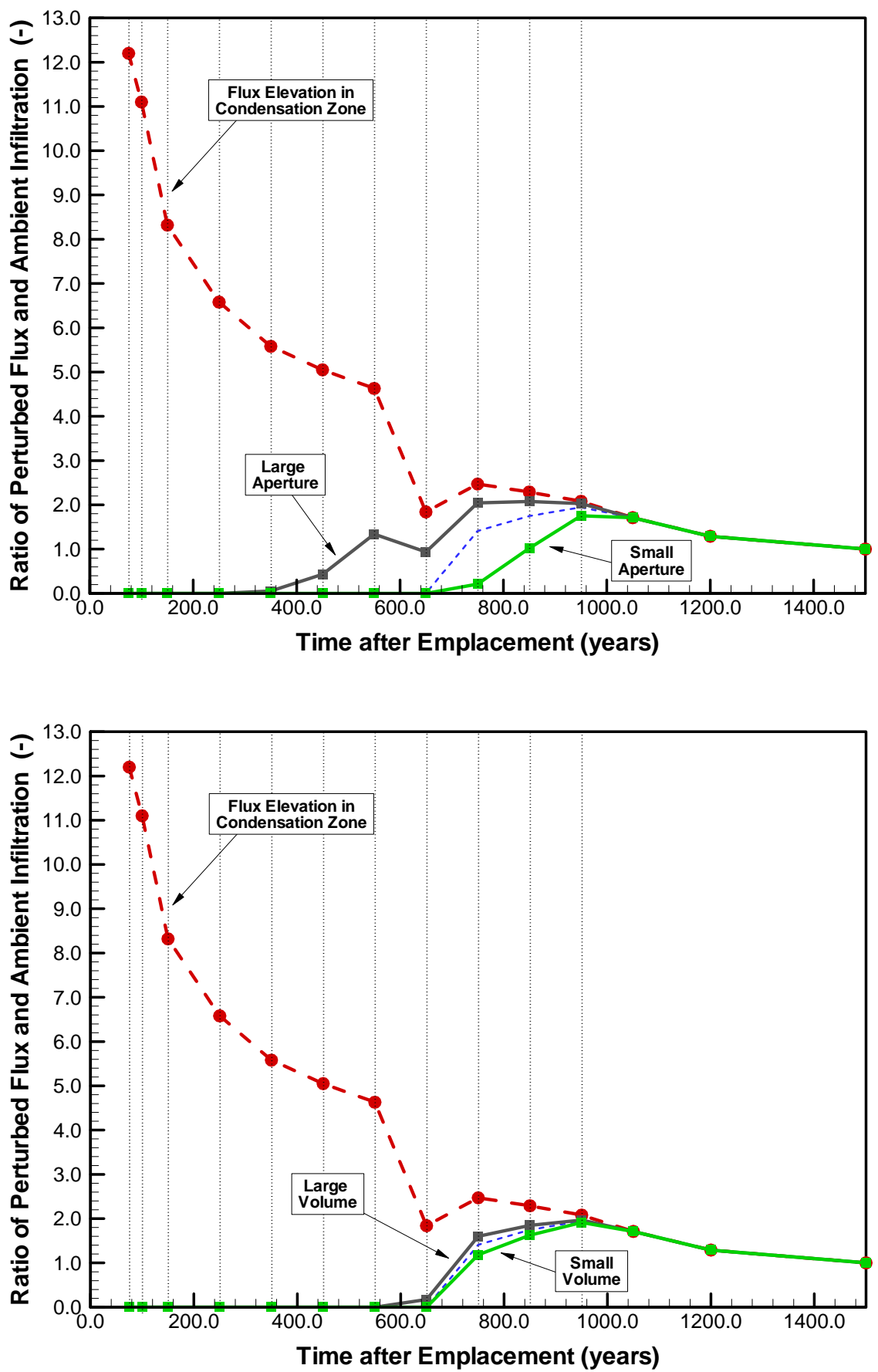

(b)

Output DTN: NA (See Section 8.5).

NOTE: $\quad$ Finger width is $4.5 \mathrm{~mm}$. The red line shows the flux ratio in the condensation zone, simulated with the $\mathrm{TH}$ seepage model. The other lines show the flux ratio of water at the drift crown, including the effect of vaporization. The dashed blue line is the mean case presented in Figure 6.3.2.1-7. Symbols indicate the discrete time steps chosen for the analysis.

Figure 6.3.2.2-2. Ratio of Thermally Perturbed Vertical Flux and Ambient Percolation, Showing Sensitivity of Model Results to (a) Fracture Aperture (Case 2, 2a, 2b) and (b) Initial Water Volume (Case 2, 2c, 2d) 


\subsubsection{Application for the Tptpll Unit}

In this subsection, the THMEFF is applied to the Tptpll unit at Yucca Mountain. Figure 6.3.3-1 shows the evolution of rock temperature at the drift and the extent of the superheated zone as predicted from the TH seepage model, using the base-case simulation results of Section 6.2.3.1. Similar to the previous results for the Tptpmn unit, symbols indicate model predictions that have been extracted at several discrete time steps. The first time step is 75 years for the peak temperature; the last time step depicted in Figure 6.3.3-1 is at 1,050 years, when rock temperature is about to return to nonboiling conditions. Compared to the Tptpmn unit, the rock temperature is higher and the superheated zone is larger in the Tptpll, so that the impact of vaporization on finger flow should be more significant. On the other hand, the heat conductivity of the Tptpll rock is about 10 percent smaller, which reduces the amount of heat transferred from the rock to the draining finger. ${ }^{5}$ The suite of episodic flow events applied to the Tptpll conditions is equal to the previous section, as listed in Table 6.3.1.2-1. The discussion of results concentrates on the more conservative Case 1 with $1 \mathrm{~mm}$ finger width. Sensitivities to fracture aperture and water volume are similar to the previous section and shall not be presented here.

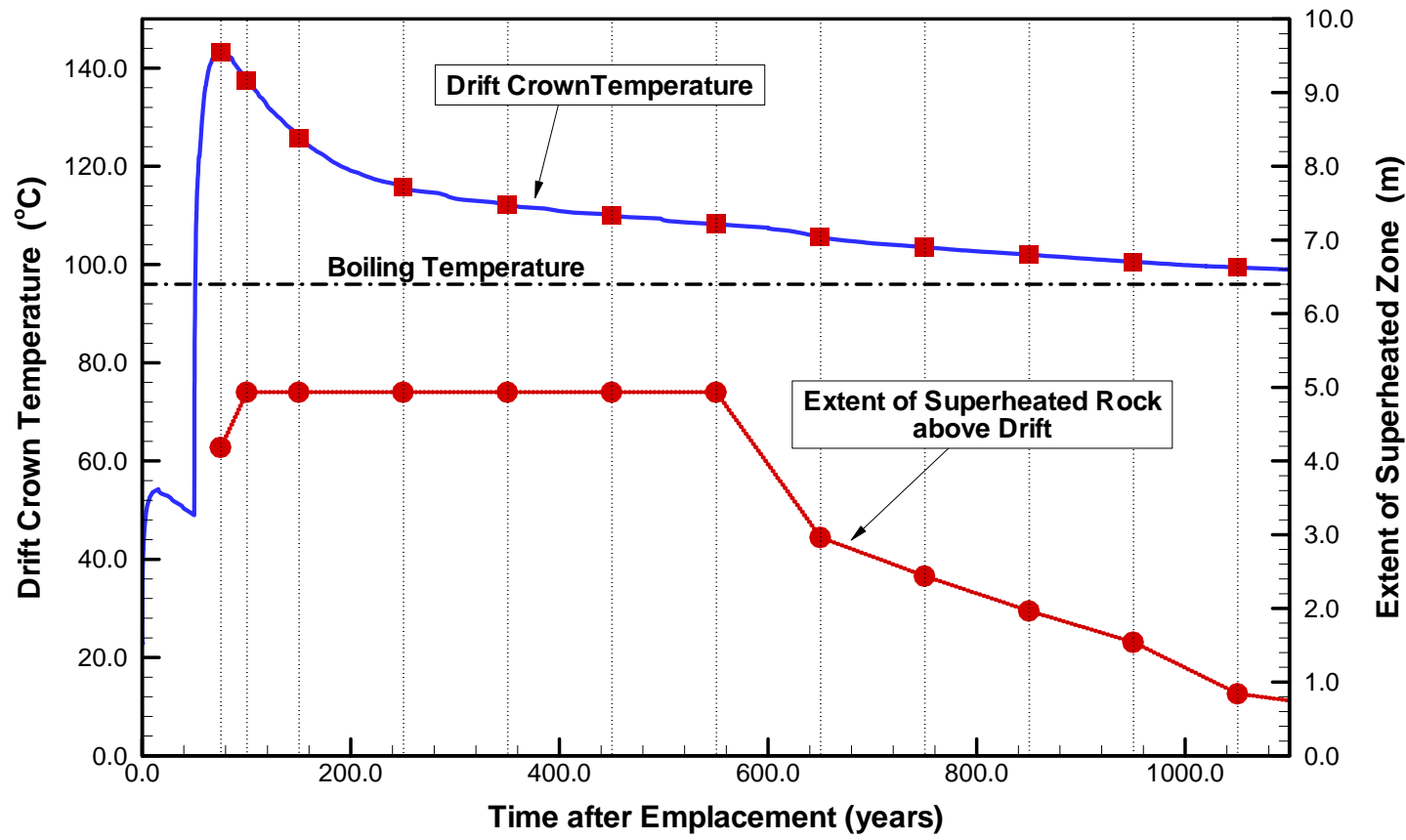

Output-DTN: NA (See Section 8.5).

NOTE: $\quad$ Figure uses results from the TH seepage model for the Tptpll unit (Section 6.2.3.1, Simulation Case LL-HOM-01). Symbols indicate the discrete time steps chosen for the analysis.

Figure 6.3.3-1. Predicted Wall Temperature History in and Extent of Superheated Rock above Waste Emplacement Drifts for Tptpll Unit

Figure 6.3.3-2 gives the maximum penetration distance of the flow event and the percentage of water arriving at the drift for the thirteen selected time steps. In the Tptpll, the vaporization

5 The thermal properties of the rock matrix, required as input for the semi-analytical solution, are based on the Tptpll values given in Section 4, Table 4.1-2. Note that the dry thermal-conductivity value is used for the semi-analytical solution (as heat conduction is calculated in the superheated dry rock). 
barrier is fully effective for the first 600 years after emplacement, because the superheated rock zone is large enough to avoid full penetration. Compared with Figure 6.3.2.1-4 for the Tptpmn, water arrival at the drift crown starts later, and the amount of water is smaller, for the Tptpll conditions. This is also reflected in Figure 6.3.3-3 (results are shown till 1,500 years in this figure), where the combined effect of flux perturbation and vaporization is considered. Though this perturbation is more significant than in the Tptpmn (with a maximum downward percolation of about $97 \mathrm{~mm} / \mathrm{yr}$ at 75 years, giving a flux-elevation factor of 16.1), the resulting potential for water arrival at the drift crown is very small, and seepage is not to be expected.

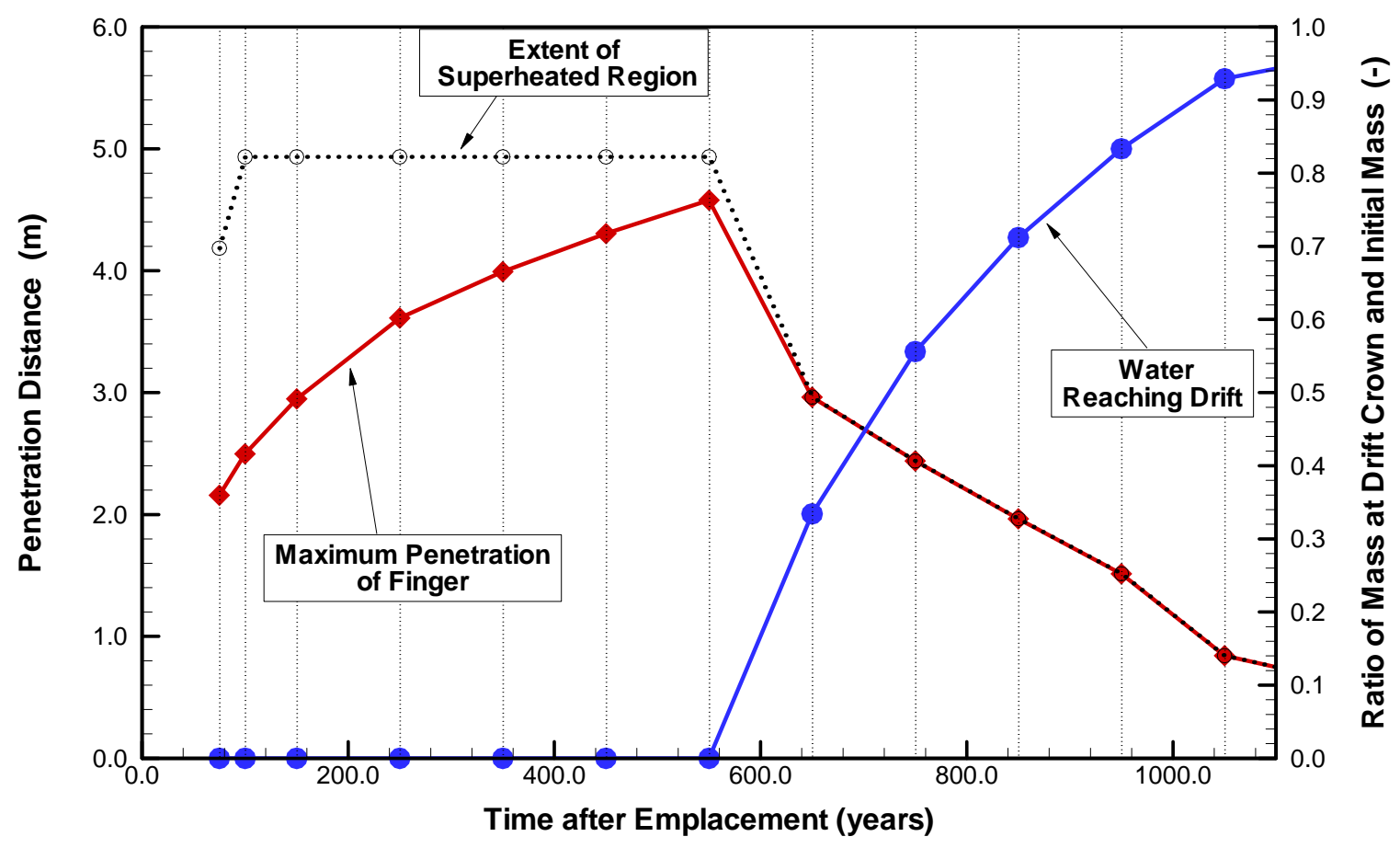

Output DTN: NA (See Section 8.5).

NOTE: $\quad$ Finger width is $1 \mathrm{~mm}$. Symbols indicate the discrete time steps chosen for the analysis.

Figure 6.3.3-2. Maximum Penetration and Percentage of Water Mass Arriving at Drift Crown for Case 1 (Tptpll Unit) 


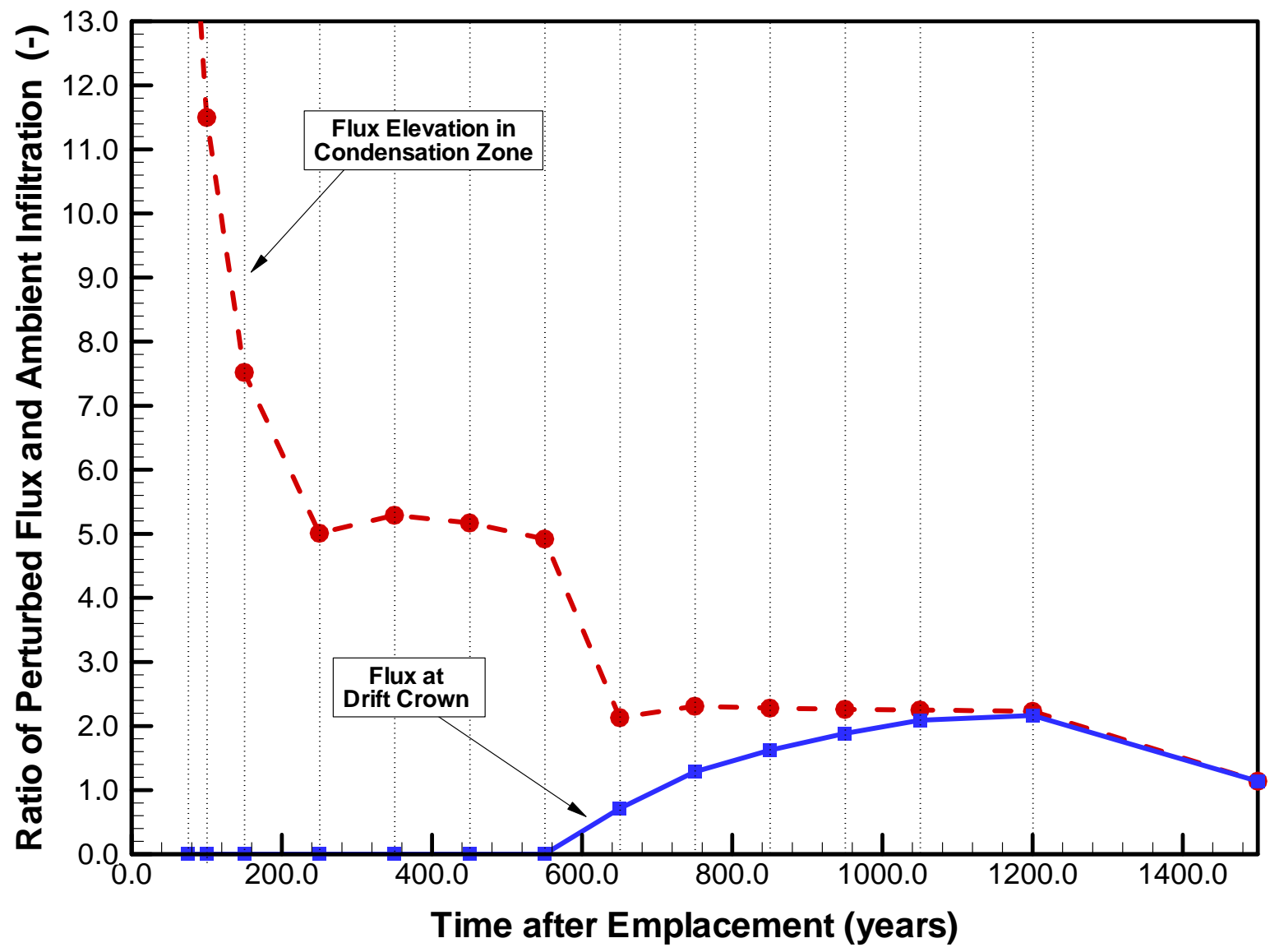

Output DTN: NA (See Section 8.5).

NOTE: The red line shows the flux ratio in the condensation zone, simulated with the TH seepage model. The blue line shows the flux ratio of water at the drift crown, including the effect of vaporization. Finger width is $1 \mathrm{~mm}$. Symbols indicate the discrete time steps chosen for the analysis.

Figure 6.3.3-3. Ratio of Thermally Perturbed Vertical Flux and Ambient Percolation for Case 1 (Tptpll Unit)

\subsubsection{Discussion of THMEFF Results}

The alternative conceptual model applied in this section is used as corroborative information to support the results and conclusions of the TH seepage model. The THMEFF uses a conceptualization of unsaturated fracture flow that is conservative with respect to the potential for thermal seepage (see Section 6.3.1.2). The assumed finger-flow events are fast and intense compared to the average flow conditions generally considered in process models like the $\mathrm{TH}$ seepage model, and vaporization effects are limited as a result of the small cross-sectional area between the draining water and the hot rock. These conditions, along with a simplified one-dimensional finger-flow model representing continuous vertical fractures, create an adverse environment for the vaporization barrier above heated waste emplacement drifts. The most favorable conditions for episodic finger flow to occur are the early stages of heating, when moisture redistribution processes are most active. Water builds up in the condensation zone above drifts, providing a potential source for downward drainage of fingers. 
In spite of this conservatism, the THMEFF results are fairly consistent with the process model results obtained with the TH seepage model. Most importantly, the THMEFF demonstrates that finger flow is not able to penetrate through the superheated rock during the first several hundred years of heating, when rock temperature is high and boiling conditions exist in a sufficiently large region above the drifts. These are the conditions in which the largest thermal perturbation occurs, or, in other words, when the potential for episodic finger flow is highest. Only later, when the boiling zone is small and the impact of vaporization is limited, can finger flow arrive at the drift crown. The fact that water can reach the drift during the period of above-boiling temperatures makes the alternative conceptual model distinct from the TH seepage model. However, the strong thermal perturbation observed at early heating stages has already diminished during this time period, and the net result of water arrival at the drift-considering the combined impact of water buildup in the condensation zone and vaporization in the superheated zone-is similar to ambient percolation. Seepage of water into the drift is not expected from this water arrival, because the flow should be effectively diverted around the drift by the capillary barrier capability of the open cavity. These findings are consistent over a wide range of finger flow characteristics studied in a sensitivity analysis, covering the potential uncertainty in finger flow patterns. Thus the THMEFF model results clearly support the main findings of the $\mathrm{TH}$ seepage model, adding confidence into the model and reducing the comceptual model uncertainty. Of the two host rock units, the Tptpll unit allows less water to arrive at the drift wall, as a result of the higher rock temperature and the larger superheated rock zone above the drift. This again is consistent with the TH seepage model.

\subsubsection{Discussion of Other Alternative Numerical Approaches}

The main simulation method applied in this report-the $\mathrm{TH}$ seepage model-features a heterogeneous continuum approach for the fractures, a dual-permeability method with active fracture formulation for fracture matrix interaction, and a specific modeling framework for estimating seepage (see Section 6.1). Another numerical approach often applied in fractured rock hydrology is the discrete-fracture network method (DFNM), which is based on a detailed representation of each individual (connected) fracture in the model domain. The development of a defensible DFNM requires collecting a very large amount of geometric and hydrological data. While part of the required geometric information can be obtained from fracture mappings, the description of the network remains incomplete and potentially biased towards fractures of a certain orientation and a certain size. Moreover, unsaturated hydrological parameters on the scale of individual fractures are required, along with conceptual models and simplifying assumptions regarding unsaturated flow within fractures and across fracture intersections. The databases required to develop a defensible DFNM are currently not available and are generally difficult or even impossible to obtain for site-specific simulations. As a result, the cumulative effect of all the input uncertainties is likely to outweigh the apparent advantage of a detailed representation of the fracture network.

The appropriateness of using a continuum model for predicting the main TH processes has been demonstrated in comparison with measured data from heater tests (see Section 7). The appropriateness of using a continuum model for the prediction of average seepage quantities was demonstrated by Finsterle (2000 [DIRS 151875]). In this study, seepage predictions with a calibrated fracture continuum model were compared to those of a DFNM, yielding consistent results even when applied outside the range of calibration. Given these results, the parsimony of 
the continuum model is considered a key advantage over the complexity of the DFNM, which is difficult to support or justify despite its visual appeal. Also note that the THMEFF is in fact a special (extreme) case of a discrete fracture model, considering one vertical fracture of infinite extent located above the drift crown (see Section 6.3.1.2). This geometric setup of the THMEFF, together with the simplified conceptual model of downward drainage of episodic fingers, creates flow conditions that overpredict seepage estimates compared to those occurring in a natural fracture network.

For the reasons outlined above, the full development of a DFNM as a potential alternative to the base-case continuum model was considered unnecessary. 


\section{INTENTIONALLY LEFT BLANK}




\section{VALIDATION}

\subsection{VALIDATION ACTIVITIES}

The purpose of this report is to document simulations of the $\mathrm{TH}$ behavior in Yucca Mountain fractured rock close to emplacement drifts. This includes determining (1) the fluid flow in the vicinity of the drifts for a range of thermal conditions, and (2) the amount of thermal seepage into the emplacement drifts. Therefore, the TH seepage model in this report is a model supporting seepage into emplacement drifts relevant to TSPA component model "Seepage into Emplacement Drifts.” AP-2.27Q, Planning for Science Activities (Attachment 3, Table 1), requires Level I validation for models supporting seepage into emplacement drifts (models with less importance on annual dose). However, thermal seepage influences the moisture conditions close to waste packages and drip shields at elevated temperatures. Thus, the TH seepage model also supports the TSPA component model "Waste Package/Drip Shield Moisture and Chemistry," which requires Level II validation. Therefore, the more stringent Level II validation is considered adequate for the drift-scale TH seepage process model (models with moderate effect on annual dose). The general validation criteria for Level II validation are listed in Attachment 3 of AP-2.27Q, and are further explained in Section 2.2.1.2 of Technical Work Plan for: Near-Field Environment and Transport: Near-Field Coupled Processes (TH Seepage and THM) Model Report Integration (BSC 2004 [DIRS 170236]). The choice of Level II validation criteria in this report is different from the model validation plan in the previous technical work plan (TWP) (BSC 2004 [DIRS 167969]), where a Level I validation was considered sufficient.

\subsubsection{Confidence Building During Model Development to Establish Scientific Basis and Accuracy for Intended Use}

For Level II validation, Section 2.2.1.2 of the current TWP (BSC 2004 [DIRS 170236]) specifies the following steps for Confidence Building During Model Development: The development of the model should be documented in accordance with the requirements of Section 5.3.2(b) of AP-SIII.10Q, Models. Additional steps are listed in AP-2.27Q, Attachment 3. The development of the TH seepage model has been conducted according to all these criteria, as follows:

1. Selection of input parameters and/or input data, and a discussion of how the selection process builds confidence in the model. [AP-SIII.10 Q 5.3.2(b) (1) and AP-2.27Q Attachment 3 Level I (a)]

The inputs to the TH seepage model have all been obtained from controlled sources (see Section 4.1.1, Table 4.1-1), including discussion about selection of input and design parameters. Model assumptions have been described in Section 5. Detailed discussion about model concepts can be found in Section 6.2.1. In short, the input data to the model have been developed from the best available sources for this modeling effort, based on site-specific test information (and often subsequent calibration) acquired mostly in underground niches and alcoves. Most of these tests were designed explicitly for the purpose of developing hydrogeologic model parameters at the scale relevant for seepage and thermal seepage. The model parameters developed from the input data have been applied in a model framework consistent with the scale of the underground tests and the 
uncertainty pertaining to some test data. Thus, this requirement can be considered satisfied.

2. Description of calibration activities, and/or initial boundary condition runs, and/or run convergences, simulation conditions set up to span the range of intended use and avoid inconsistent outputs, and a discussion of how the activity or activities build confidence in the model. Inclusion of a discussion of impacts of any non-convergence runs. [(AP-SIII.10Q 5.3.2(b)(2) and AP-2.27Q Attachment 3 Level I (e)].

Detailed discussion of initial and boundary conditions for the TH seepage model can be found in Sections 4.1.1.2 and 6.2.1. Sections 6.2.2 through 6.2.4 provide detailed discussion of various model results (i.e., those of convergence runs), including discussion of the range of conditions studied and how this range is appropriate considering the intended use of the model. Discussion about nonconvergence runs is not relevant for this report. In short, most of the upper and lower model boundary conditions as well as the initial conditions have been developed from available input sources reflecting the ambient (nonheated) conditions at Yucca Mountain. These are the boundary conditions that remain essentially unchanged over the heating period because the model boundary is far away from the waste emplacement drifts. Other boundary conditions such as the heat source imposed in the drifts or the percolation flux through the mountain, both important for thermal seepage, have been varied in wide ranges that cover the expected variability and uncertainty related to them. Thus, this requirement can also be considered satisfied.

3. Discussion of the impacts of uncertainties to the model results including how the model results represent the range of possible outcomes consistent with important uncertainties. [(AP-SIII.10 Q 5.3.2(b)(3) and AP-2.27Q Attachment 3 Level 1 (d) and (f)]

Discussion of model uncertainties and sensitivity analyses are provided in Section 6.2.4.2. A summary discussion on uncertainties and their impact is given in Section 8.3. In short, uncertainty of model input parameters was adequately addressed with the $\mathrm{TH}$ seepage model by conducting sensitivity analyses with respect to the uncertain hydrogeologic properties or the uncertain model boundary conditions. It was shown that the main feeds of this report to TSPA-i.e., the qualitative findings on thermal seepage that form the basis for seepage abstraction-hold true for the range of conditions analyzed. Uncertainty with respect to the conceptual model is adequately accounted for by selecting an abstraction method for thermal seepage (see Section 6.2.4.1 and BSC 2004 [DIRS 169131], Sections 6.5.2 and 6.5.3) that safely covers all uncertainties (in choosing a conservative upper bound for thermal seepage). Thus, this requirement can also be considered satisfied.

4. Formulation of defensible assumptions and simplifications. [AP-2.27Q Attachment 3 Level I (b)].

Discussion of assumptions and simplifications is provided in Section 5 and Section 6.2.1 (TH seepage model), and in Section 6.3.1 (THMEFF). These assumptions and simplifications are adequate and defensible. Thus, this requirement can also be considered satisfied. 
5. Consistency with physical principles, such as conservation of mass, energy, and momentum. [AP-2.27Q Attachment 3 Level I (c)]

Consistency with physical principles is demonstrated by the conceptual and mathematical formulation in Section 6.2.1.1 and the selection of the thoroughly tested and widely used TOUGH2 Code (LBNL 2003 [DIRS 161491]) in Section 3. Thus, this requirement can also be considered satisfied.

\subsubsection{Confidence Building After Model Development to Support the Scientific Basis of the Model}

For confidence building after model development, the TWP (BSC 2004 [DIRS 170236], Section 2.2.1.2, "Confidence Building After Model Development") imposes the following requirements for model validation:

1. AP-SIII.10Q, Section 5.3.2(c), Method 1: Corroboration of model results with data acquired from the Drift Scale Test (DST).

Comparison of model results with experimental data is the main method of validation for the TH seepage model. The remainder of Section 7 explains the respective validation and modeling activities in great detail, and discusses explicitly how the criteria for this validation method, as defined in Section 2.2.1.4 of the TWP (BSC 2004 [DIRS 170236]), have been met.

2. AP-SIII.10Q, Section 5.3.2(d), Technical review through publication in a refereed professional journal to demonstrate additional confidence in the model, if publication is used in conjunction with the above validation step.

The validation criterion is that technical review is conducted through at least one publication in a professional journal (BSC 2004 [DIRS 170236], Section 2.2.1.4). The publication needs to describe the modeling activity for the models in the DST TH Seepage report. Since the following articles on the subject have already been published, this validation criterion has been met:

- "Modeling the Thermal-Hydrologic Processes in a Large-Scale Underground Heater Test in Partially Saturated Fractured Tuff.” Water Resources Research (Birkholzer and Tsang 2000 [DIRS 154608]).

This publication describes the modeling approach and model results for the DST TH model, and discusses comparison with measured data from the early heating phase of the DST.

- "Uncertainties in Coupled Thermal-Hydrological Processes Associated with the Drift Scale Test at Yucca Mountain, Nevada." Journal of Contaminant Hydrology (Mukhopadhyay and Tsang 2003 [DIRS 160790]). 
This publication describes the modeling approach and model results for the DST TH model, and discusses the issue of heat losses through the bulkhead and how these are accounted for in the model (Section 7.3.4).

- "Understanding the Anomalous Temperature Data from the Large Block Test at Yucca Mountain, Nevada.” Water Resources Research (Mukhopadhyay and Tsang 2002 [DIRS 160788]).

This publication provides additional confidence in the TH seepage model because it describes application of a similar $\mathrm{TH}$ model to the temperature response measured in the Large Block Test at Yucca Mountain.

- "Predictions and Observations of the Thermal-Hydrological Conditions in the Single Heater Test.” Journal of Contaminant Hydrology (Tsang and Birkholzer 1999 [DIRS 137577]).

This publication provides additional confidence in the TH seepage model because it describes application of a similar TH model to the thermal-hydrological response measured in the Single Heater Test at Yucca Mountain.

3. AP-SIII.10Q, Section 5.3.2(c), Method 2: Corroboration of results with alternative conceptual models

This method was suggested as an optional requirement in the TWP (BSC 2004 [DIRS 170236]). The validation criterion is that alternative conceptual or mathematical models shall qualitatively support the results of the main model. As pointed out in Section 6.3, this criterion has been met by applying the alternative conceptual model THMEFF and demonstrating that it corroborates the findings of the TH seepage model.

\subsubsection{Corroboration of Model Results with Experimental Data}

Corroboration of model results with experimental data is the preferred method of validation in this report because measured data allow for a direct validation with respect to the relevant processes. In situ heater tests conducted in the unsaturated fracture tuff at Yucca Mountain provide a wealth of valuable data for model validation. Three heater tests have been conducted at Yucca Mountain, all of which are located in one of the repository units, the middle nonlithophysal unit (Tptpmn). Of these three tests, the Drift Scale Test (DST) is the best suited for validation against measured data, in particular because its geometric setup and scale is similar to the proposed design of waste emplacement drifts. Thus measured data from this test are used for validation of the TH seepage model. The other two tests - the Single Heater Test (SHT) and the Large Block Test (LBT) - are of smaller scale and of a geometry different from that of waste emplacement drifts. Comparative analysis of the Single Heater Test and the Large Block Test shall not be presented in this report. However, the coupled TH processes observed in these two tests have been successfully simulated with conceptual approaches similar to the one used here. Documentation of the modeling of the Single Heater Test can be found in Thermal Tests Thermal-Hydrological Analyses/Model Report (BSC 2001 [DIRS 157330]) or in the peer-reviewed journal article of Tsang and Birkholzer (1999 [DIRS 137577]). Modeling of the 
Large Block Test is found in the Large Block Test Final Report (Lin et al. 2001 [DIRS 159069]) and in the peer-reviewed journal article of Mukhopadhyay and Tsang (2002 [DIRS 160788]).

The numerical model used to demonstrate the good agreement of model results with data from the DST is the Drift Scale Test (DST) TH model. The DST TH model uses the same conceptual model as the TH seepage model, and both models are at the same scale (drift scale). Therefore, if the DST TH model is validated by comparison with data, the predictive TH seepage model can also be considered validated with respect to $\mathrm{TH}$ behavior of the fractured rock in the vicinity of emplacement drifts. Results from the DST TH model are directly compared to measured data from the DST. The thermal load applied to the DST is designed to induce TH coupled processes such as vaporization, vapor transport, drying, and condensation in the duration of the DST for four years of heating. In the repository, these same processes will also occur, but over a time period of hundreds of years after emplacement. By the agreement of model predictions with measurements, confidence is gained that similar models deploying these same processes and incorporating the repository conditions/time scales can help to address questions important to repository performance. The good agreement between the DST TH model and the measured data is described in the journal article of Birkholzer and Tsang (2000 [DIRS 154608]).

The thermal load in the DST resulted in vigorous boiling and subsequent condensation of water, with rock temperature exceeding $200^{\circ} \mathrm{C}$. With such intense $\mathrm{TH}$ processes occurring, the DST data provide the base for an excellent model validation with respect to the near-field $\mathrm{TH}$ conditions in the rock mass, as described by temperature and saturation changes. With respect to the vaporization barrier, however, the DST data are not sufficient for validation. To this date, no seepage of liquid water has been observed in the Heated Drift of the DST. The vaporization barrier generated by the heater output appears to be totally effective in the DST, because of the intense thermal load. However, heat load designed for the repository is less intense and will be applied over much longer time frames, thus giving rise to maximum temperatures lower than in the DST. This, together with concern over vapor losses through the bulkhead of the Heated Drift (see Section 7.3.4), implies that the DST results should not be used as direct evidence for "no seepage." The DST results therefore provide demonstration of the potential performance of the repository under a "hot" thermal operating mode, but offer no seepage data (observed seepage rates and seepage fractions) that can be used for thermal-seepage validation purposes. Therefore, validation of the seepage part of the TH seepage model is an indirect one. First, the better the overall TH behavior can be predicted by the DST TH model, the more confidence is gained for the seepage results obtained with the TH seepage model. In other words, a successful validation of the DST TH model with respect to coupled processes (i.e., saturation distribution, temperature signals) adds confidence to the seepage part of the TH seepage model. Second, the conceptual model for thermal seepage calculation is similar to the conceptual model applied in the ambient seepage studies (see Section 6.2.1.1.2), i.e., the seepage model for PA (SMPA). Applying a similar conceptual model and key properties (permeability variability and fracture capillary-strength parameter) that are identical to the SMPA increases confidence in the seepage part of the TH seepage model, since the modeling framework for the capillary barrier treatment can already be considered validated from the validation activities performed for ambient seepage studies (BSC 2004 [DIRS 171764], Section 7; BSC 2004 [DIRS 167652], Section 7). Third, to gain additional confidence, an alternative conceptual model was introduced in Section 6.3, demonstrating that an alternative conceptualization of unsaturated fracture flow confirms the assessment of the vaporization barrier from the TH seepage model. 
Since there is no thermal test in the lower lithophysal unit at Yucca Mountain, validation of the TH seepage model does not include direct comparison with measured data from the Tptpll. By the agreement of the model predictions with data from the Tptpmn, confidence is gained that the TH processes in response to heating are well captured by the model. This means that application to the Tptpll unit is appropriate because essentially the same TH processes need to be described. Uncertainties regarding the lower lithophysal unit are mostly captured and propagated to the seepage abstraction through the uncertainties in the rock properties and through the choice of an adequate upper-bound abstraction method for thermal seepage (Section 6.2.4.1).

The following sections describe in detail the validation activities performed with the DST TH model. Section 7.2 introduces the DST setup and measurement activities. Section 7.3 briefly describes the DST conceptual model and different phases of model development and refinement. Comparison of model data and measured data is presented in Section 7.4. A summary and discussion of the validation activities using the DST data is given in Section 7.5.

\subsection{THE DRIFT SCALE TEST}

\subsubsection{Design and Geometry}

The Drift Scale Test (DST) is probably the largest in situ heater test ever performed in a fractured rock environment. The test area is located in one of the side alcoves of the Exploratory Studies Facility (ESF) in the Tptpmn unit. Figure 7.2.1-1 gives a plan view of the test block, and Figure 7.2.1-2 shows a three-dimensional perspective of the DST with heaters and many of the approximately 150 instrumented boreholes for measuring thermal, hydrological, mechanical, and chemical processes. The DST centers around the Heated Drift, having a $47.5 \mathrm{~m}$ long heated (hot) section separated from the unheated (cold) section by a thermally insulated bulkhead. Heating is provided by nine canister heaters within the Heated Drift, as well as 50 rod heaters, referred to as "wing heaters," placed into horizontal boreholes emanating from the Heated Drift. Each wing heater is composed of two equal-length segments $(4.44 \mathrm{~m})$ separated by a $0.66 \mathrm{~m}$ gap. The distance between the Heated Drift wall and the tip of the first heater segments is $1.66 \mathrm{~m}$. The dimensions of the Heated Drift and canister heaters are similar to the current design of waste emplacement drifts. The heaters of the DST were activated on December 3, 1997. The heating phase continued for approximately four years, until January 14, 2002. Currently, the DST is in the midst of a planned four-year period of monitoring the natural cooling process of the rock block. 


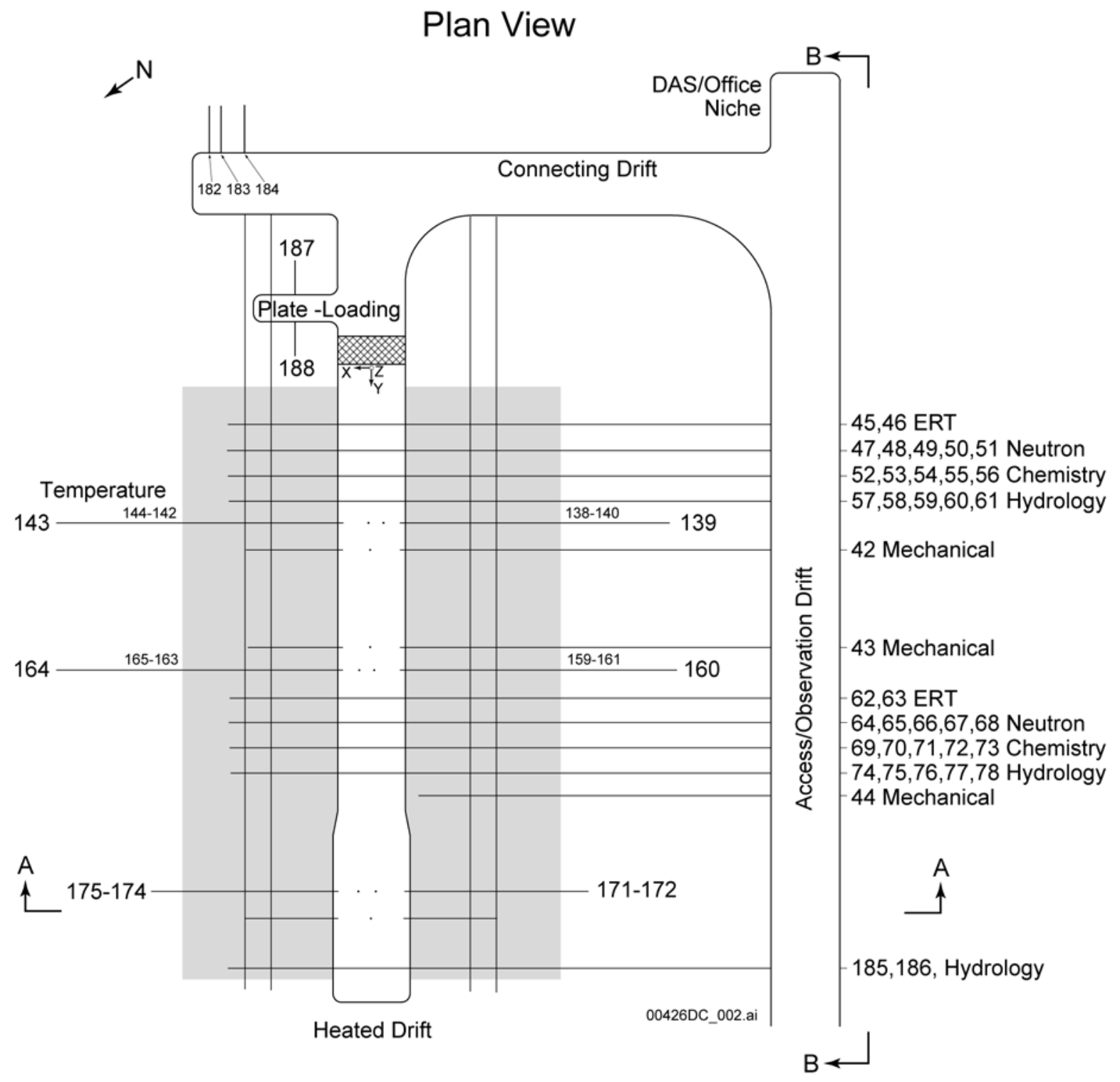

Source: Birkholzer and Tsang 1997 [DIRS 100597], Figure 3.1-1.

Figure 7.2.1-1. Plan View of DST Area 


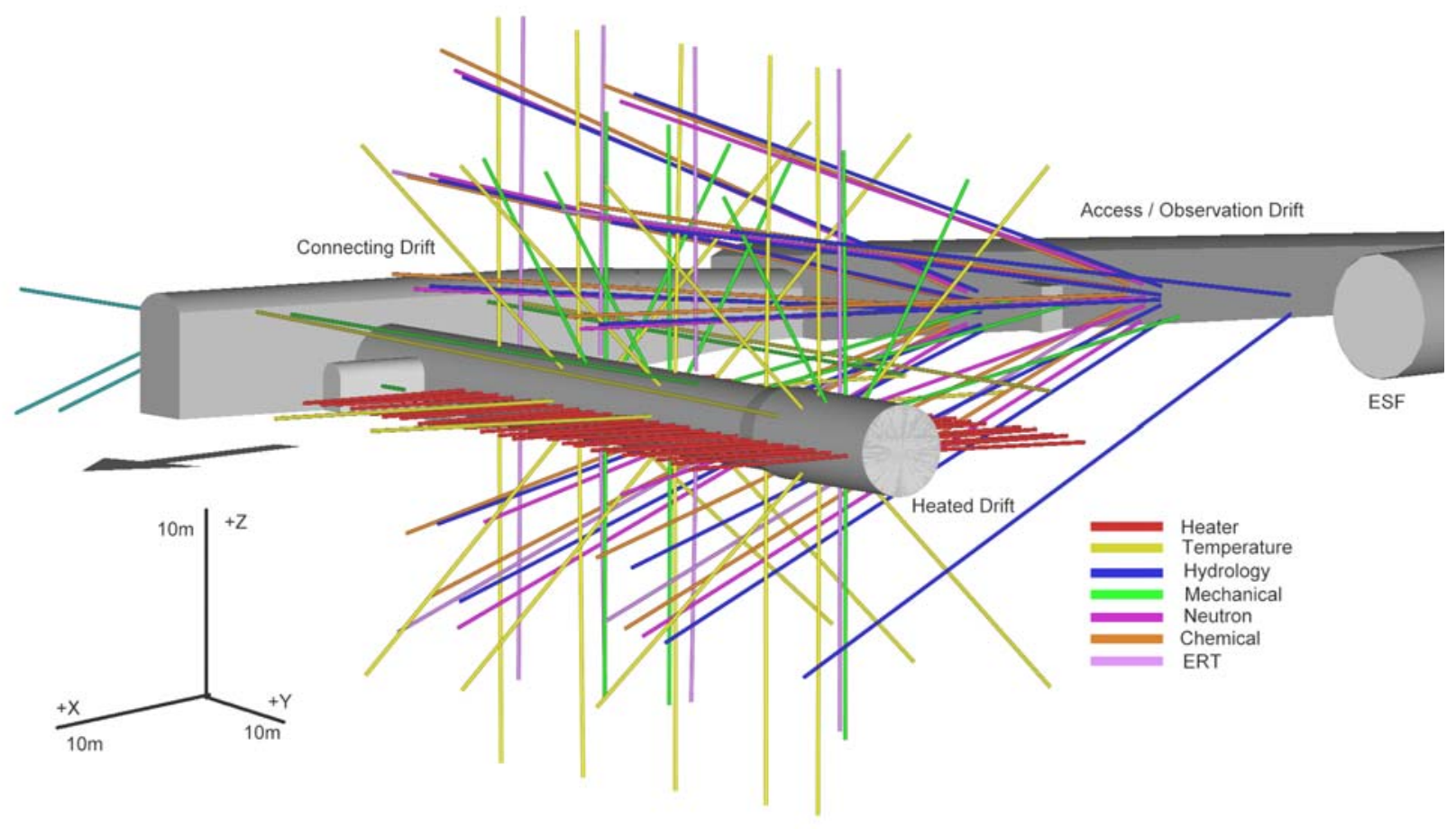

Source: BSC 2004 [DIRS 169900], Figure 6.3-2.

Figure 7.2.1-2. Three-Dimensional Perspective of the As-Built Borehole Configuration of the DST

\subsubsection{Measurements to Probe the Coupled Processes}

Measurements in the DST include laboratory and field characterization of the thermal test block prior to the activation of heaters; passive monitoring and active testing during the heating and subsequent cooling phase; and planned postcooling laboratory and field characterization activities similar to those conducted prior to activation of heaters. Pretest laboratory characterization included measurements of thermal properties, hydrological properties, mechanical properties, mineral-petrology studies, and pore-water chemical and isotopic analysis from rock cores. Preheat field characterization of the thermal test block involved rock-mass classification, fracture mapping, video logging of the boreholes, geophysical measurements, and air-permeability testing.

Measurements during the heating and cooling phases of the DST are divided into two categories: the continuous passive monitoring data and the active testing data, which are taken periodically. The DST test block has been instrumented with thousands of sensors to monitor the thermal, mechanical, hydrological, and chemical processes on at least an hourly basis. In Figure 7.2.1-2, the instrumented boreholes are color-coded according to their functions. For the purposes of this report, the focus is on boreholes designed to measure thermal (yellow) and hydrological behavior (blue), as extracted in Figures 7.2.2-1 and 7.2.2-2, respectively. Radial arrays of $20 \mathrm{~m}$ long boreholes emanating from the Heated Drift monitor the temperature evolution, as do longitudinal 
boreholes parallel to and extending over the entire length of the Heated Drift. Temperature sensors are installed at approximately $30 \mathrm{~cm}$ intervals. Most boreholes labeled as "hydrological" originate from the Observation Drift. These are clusters of $40 \mathrm{~m}$ long boreholes forming vertical fans that bracket the Heated Drift and the wing heaters. Humidity, temperature, and pressure sensors were installed in twelve of the hydrology holes to provide passive monitoring data. These boreholes are also used for periodic active testing of air-permeability changes to track the time evolution and spatial distribution of drying and condensation zones in the test block. Since gas flow occurs predominantly in the fractures, interference air-permeability measurements in selected hydrological boreholes target the spatial variation and time evolution of liquid-saturation changes in the fractures. The hydrology boreholes are also used for collection of water (if present) and gas sampling for chemical and isotopic analysis. Finally, neutron logging, electrical resistivity tomography, and crosshole radar tomography are carried out at appropriate time intervals throughout the heater test to probe the changes in the rock moisture in the matrix pores. Crosshole radar tomography and neutron logging are performed in the boreholes shown in Figure 7.2.2-3.

The DST design and geometry are described in the following reports: Drift Scale Test Design and Forecast Results (CRWMS M\&O 1997 [DIRS 146917]) and Drift Scale Test As-Built Report (CRWMS M\&O 1998 [DIRS 111115]). The results of preheat characterization of the test block are contained in the report Ambient Characterization of the Drift Scale Test Block (CRWMS M\&O 1997 [DIRS 101539]). Results of the DST have been presented and discussed in seven thermal tests progress reports, \#1 through \# 7 (CRWMS M\&O 1998 [DIRS 159512]; CRWMS M\&O 1999 [DIRS 154585]; CRWMS M\&O 1999 [DIRS 159513]; CRWMS M\&O 1999 [DIRS 160806]; CRWMS M\&O 2000 [DIRS 160807]; Williams 2001 [DIRS 156323]; Williams 2001 [DIRS 160809]), roughly covering the heating phase of the test. A comprehensive documentation of DST measurements for the four-year heating period is given in Thermal Testing Measurements Report (BSC 2004 [DIRS 169900]). This report elaborates on the testing methods, gives representative results, and discusses measurement uncertainties. The comparison of simulated and measured DST results below mainly uses data described in this report; some additional temperature data are used to include results for the first several months of natural cooling (see Table 4.1-12). 


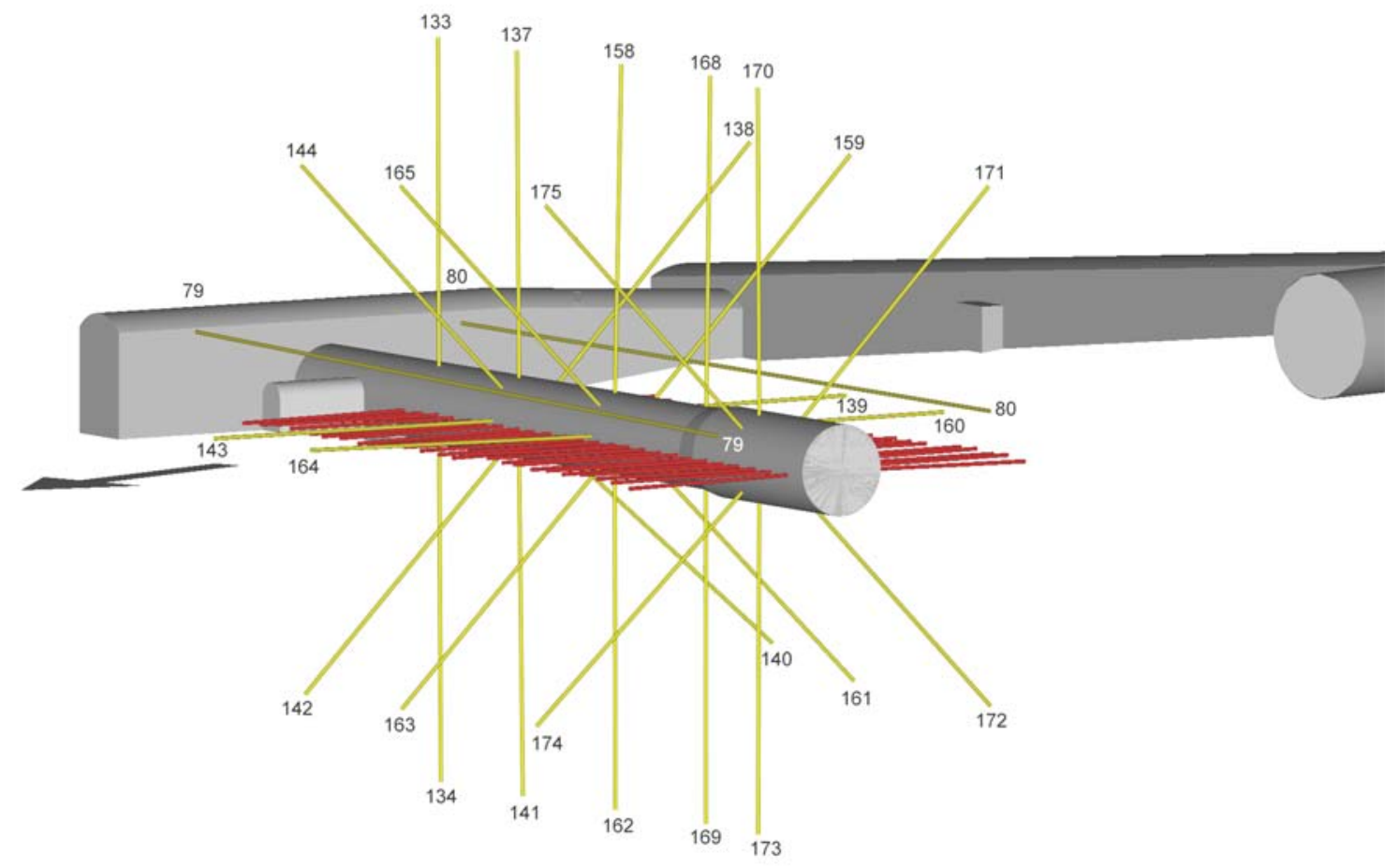

Source: BSC 2004 [DIRS 169900], Figure 6.3-3.

Figure 7.2.2-1. Three-Dimensional Perspective of Wing Heaters and Temperature Boreholes in the DST

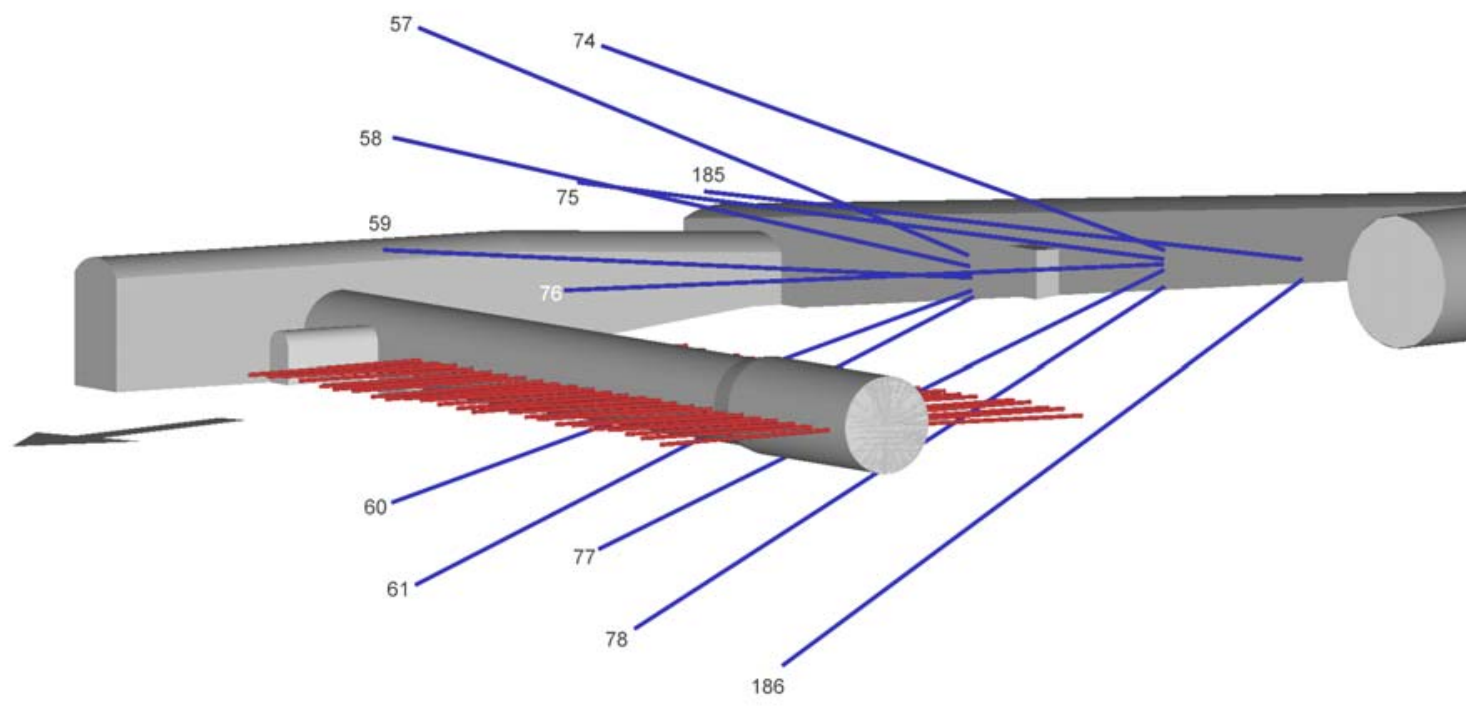

Source: BSC 2004 [DIRS 169900], Figure 6.3-4.

Figure 7.2.2-2. Three-Dimensional Perspective of Wing Heaters and Hydrology Boreholes in the DST 


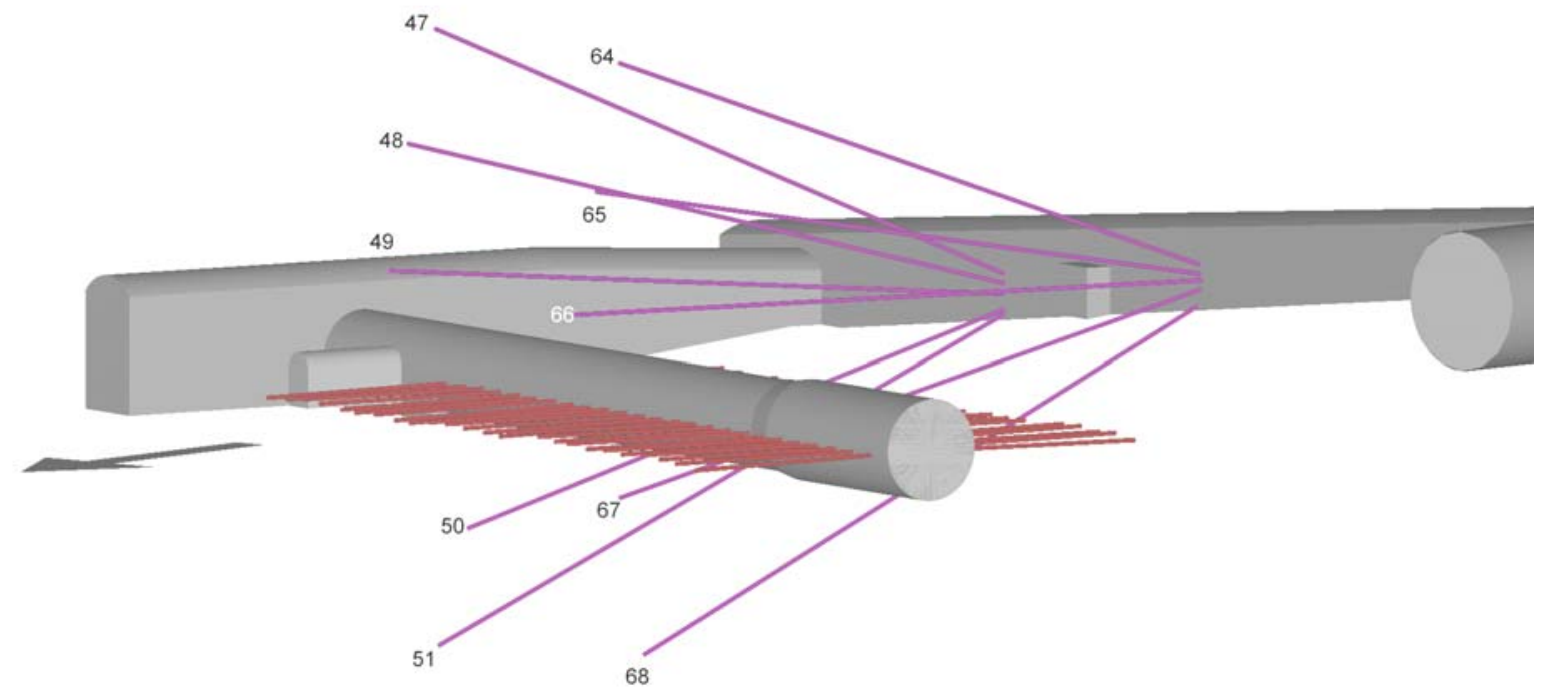

Source: BSC 2004 [DIRS 169900], Figure 6.3-6.

Figure 7.2.2-3. Three-Dimensional Perspective of Wing Heaters and Boreholes for Geophysical Measurements (GPR and Neutron Logging) in the DST

\subsection{DST TH MODEL}

\subsubsection{Stages of Model Development}

In 1997, prior to initiation of the test, a predictive DST TH model was developed accounting for realistic representation of the complex test geometry in three dimensions and using properties based on site-specific pretest characterization (e.g., laboratory measurements of matrix saturation and thermal conductivity, in situ air-injection tests for fracture permeability). The predictive model was used to guide the design of the DST and to predict the outcome of the planned 8-year test period. Different conceptual models, e.g., for fracture-matrix interaction and heat flow within the drift, were analyzed in a sensitivity study. Results of this predictive model were presented in Pretest Analysis of the Thermal-Hydrological Conditions of the ESF Drift Scale Test (Birkholzer and Tsang 1997 [DIRS 100597]).

Once the heaters had been activated and the first measurements of temperature, gas pressure, and water saturation became available, early test results from the first six months of heating were used to discriminate between alternative modeling concepts applied in pretest simulations. It became apparent, for example, that the dual-permeability method describes fracture-matrix interaction much better than the effective-continuum model. Temperature data also showed that heat radiation within the Heated Drift is effective, indicating that a uniform temperature distribution at the drift wall can be assumed. In addition to model conceptualization, several model modifications were made to account for test conditions that were different from the assumed conditions of the pretest simulations. These modifications were: (1) adjusting the input heater power to account for the actual heat load of the DST, (2) changing the boundary conditions at the bulkhead to allow for gas exchange between the hot and the cool side of the Heated Drift, (3) adding the concrete invert in the Heated Drift, and (4) including the effects of 
ventilation and minor temperature buildup close to the drift walls prior to heater activation. Other than adjusting the conceptual model and better representing the actual test conditions, the predictive model was not changed. In particular, the assumed site-specific rock properties were not adjusted. The rationale for refining the model and comparison of measured and simulated data is given Drift Scale Test Progress Report Lawrence Berkeley National Laboratory, Version 0.0 (Tsang et al. 1998 [DIRS 144941], Section 2).

At six months of heating, the refined DST TH model was frozen. The frozen model was used to predict the remaining heating and the cooling phase of the DST. With the test ongoing and more and more data becoming available, a continued comparative analysis of predictive simulations and measured data was performed. Based on the generally good agreement between measured and simulated data, only one more model modification became necessary. At 30 months of heating (September 2000), gridblocks representing wing heaters were given a permeability value three orders of magnitude higher than that of the surrounding rock mass, to account for the fact that wing heaters are installed in boreholes that are open conduits for gas flow. All simulation results presented in this report are based on the conceptual model that includes this last modification.

The subsequent re-evaluation of the accuracy of the numerical model is documented in a series of seven informal progress reports intended to communicate the progress of the YMP thermal test program at different test stages (CRWMS M\&O 1998 [DIRS 159512]; 1999 [DIRS 154585]; [DIRS 159513]; [DIRS 160806]; 2000 [DIRS 160807]; Williams 2001 [DIRS 156323]; [DIRS 160809]). These reports provide a comprehensive source of information regarding measurements and modeling results, not only for TH behavior, but also for thermally induced mechanical and chemical changes. One specific report, progress report \#7 (Williams 2001 [DIRS 160809], Sections 3.2 and 3.3), contains a detailed discussion about the important issue of heat and mass losses through the DST bulkhead. A scientific evaluation of this phenomenon is also provided in the peer-reviewed journal article of Mukhopadhyay and Tsang (2003 [DIRS 160790]). A brief summary is given in Section 7.3.4.

There is only one previous report summarizing results from the DST TH model: Thermal Tests Thermal-Hydrological Analyses/Model Report (BSC 2001 [DIRS 157330]). One purpose of this report was to compare model predictions and data using different TH property sets. Comparison was performed for the DST, using data from the first 18 months of the heating, as well as for the SHT and the LBT to analyze in situ tests of varying duration and scale. The first tested property set for the DST was the one based on site-specific characterization as introduced above, referred to as the DKM-TT99 property set; the second utilized results from a mountain-scale calibration effort conducted with ambient hydrological data. While the first properties describe the local test conditions only, the latter properties represent average conditions for the various stratigraphic layers of Yucca Mountain, used for the mountain-scale prediction runs in TSPA. It was concluded that the site-specific property set captured the DST TH behavior slightly better than the mountain-scale property set. However, both property sets were considered to have produced results within acceptable limits of the measured data. This was an important conclusion for performance assessment, because it ensured that the hydrological properties calibrated from the ambient inverse model can also be applied for PA simulations that incorporate the thermal perturbation caused by repository heating. Since the completion of Thermal Tests Thermal-Hydrological Analyses/Model Report (BSC 2001 [DIRS 157330]), a new calibrated 
property set was developed as described in Section 4, referred to as the DS/AFM-UZ02-Mean property set. As this new property set is applied in Section 6.2 to predict the future repository conditions, the analysis is re-evaluated as a basis for validation of the $\mathrm{TH}$ seepage model. Sections 7.4.3 and 7.4.4 of this report present results of this re-evaluation, using measured DST data from 4 years of heating and about 6 months of cooling, while applying the DST TH model with property sets DKM-TT99 and DS/AFM-UZ02-Mean, respectively.

\subsubsection{Conceptual Model and Mathematical Formulation}

The modeling framework of the DST TH model is similar to that of the TH seepage model (Section 6.2.1.1.1). The mathematical description of the coupled transport of water, water vapor, air, and heat, as described in Section 6.2.1.1.1, is identical. The resulting mass-and energy-balance equations are solved with the integral finite-difference simulator TOUGH2V1.3MEOS4 V1.0 (LBNL 1999 [DIRS 147569]) for simulation presented in Section 7.4.3 and TOUGH2 V1.6 (LBNL 2003 [DIRS 161491]) for simulation presented in Section 7.4. Two DST simulation cases are studied to analyze sensitivity to the conceptual model for fracture-matrix interaction; one uses a standard dual-permeability method (DKM), the other applies the DKM with the active fracture concept (AFM).

\subsubsection{Model Domain and Numerical Grid}

The numerical grid for the DST TH model was designed to represent the test geometry and dimensions, including the drifts, alcoves, the decline of the observation drift, and the location of boreholes, as realistically as possible. Note that the nominal design dimensions were used for construction of the grid. The differences between nominal and as-built dimensions are small, and do not affect the modeling results. This required development of a three-dimensional model. Significant rock volumes in all directions beyond the immediate DST block are included in the modeled domain to guarantee a proper definition of boundary conditions (that is, to insure that boundaries remain in their ambient, preheat conditions for the duration of the DST).

Figure 7.3.3-1 shows the model domain and discretization of a typical x-z cross section in the three-dimensional model for the DST. The origin of the three-dimensional coordinate system is located on the hot side of the bulkhead, in the center of the drift. The positive x-axis points horizontally, approximately towards the north (transverse to the Heated Drift away from the Observation Drift); the positive y-axis points horizontally along the Heated Drift, approximately towards the west; and the positive z-direction points vertically upward from the origin. Thus, the Heated Drift originates at $y=0$ and terminates at $y=47.5 \mathrm{~m}$. Note that the vertical extent of the model region includes the stratigraphic units both above and below that of the middle nonlithophysal unit (Tptpmn) of the test block. (The stratigraphy is extracted from the nearby borehole USW SD-9.) They are respectively the upper (Tptpul) and lower (Tptpll) lithophysal units of the Topopah Spring welded tuff. The grid was designed such that the assumed interfaces between layers are represented by gridblock interfaces (i.e., interfaces are maintained at $\mathrm{z}=+14.0 \mathrm{~m}$ and $\mathrm{z}=-26.68 \mathrm{~m}$ ). The discretization in the DST model domain is extremely refined near the sources of heat and is less so away from them. The discretized numerical grid has been developed through trial and experimentation, and is considered adequate for its intended use (as also evidenced by absence of convergence issues with the three-dimensional DST TH model). 
Figure 7.3.3-2 shows the same cross section in a detailed view of the rock areas adjacent to the Heated Drift and the wing heaters. The figure also depicts the configuration of boreholes 158 through 165, which form a cluster oriented radially outward from the Heated Drift. This vertical plane intersects the long axis of the drift at $\mathrm{y} \sim 23 \mathrm{~m}$. Temperature sensors are grouted in each of these boreholes at approximately $0.3 \mathrm{~m}$ spacing. Figure $7.3 .3-3$ presents a detailed view of another cross section depicting the location of five hydrology boreholes 57 through 61, which are collared on the north wall of the Observation Drift. The solid symbols indicate the location of temperature sensors (DTN: MO0002ABBLSLDS.000 [DIRS 147304]).

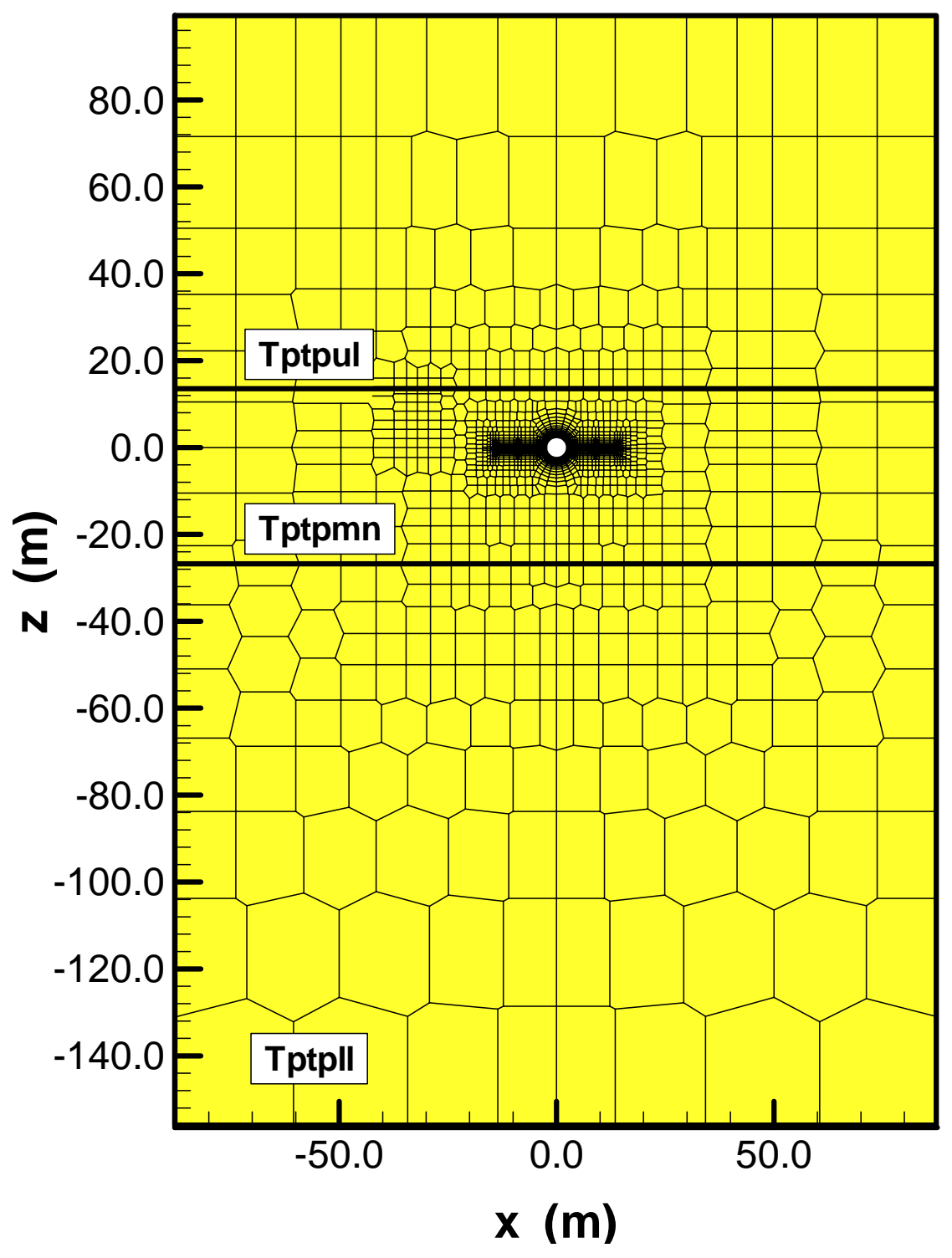

Output DTN: NA (See Section 8.5).

Figure 7.3.3-1. Vertical Cross Section of DST Numerical Grid 


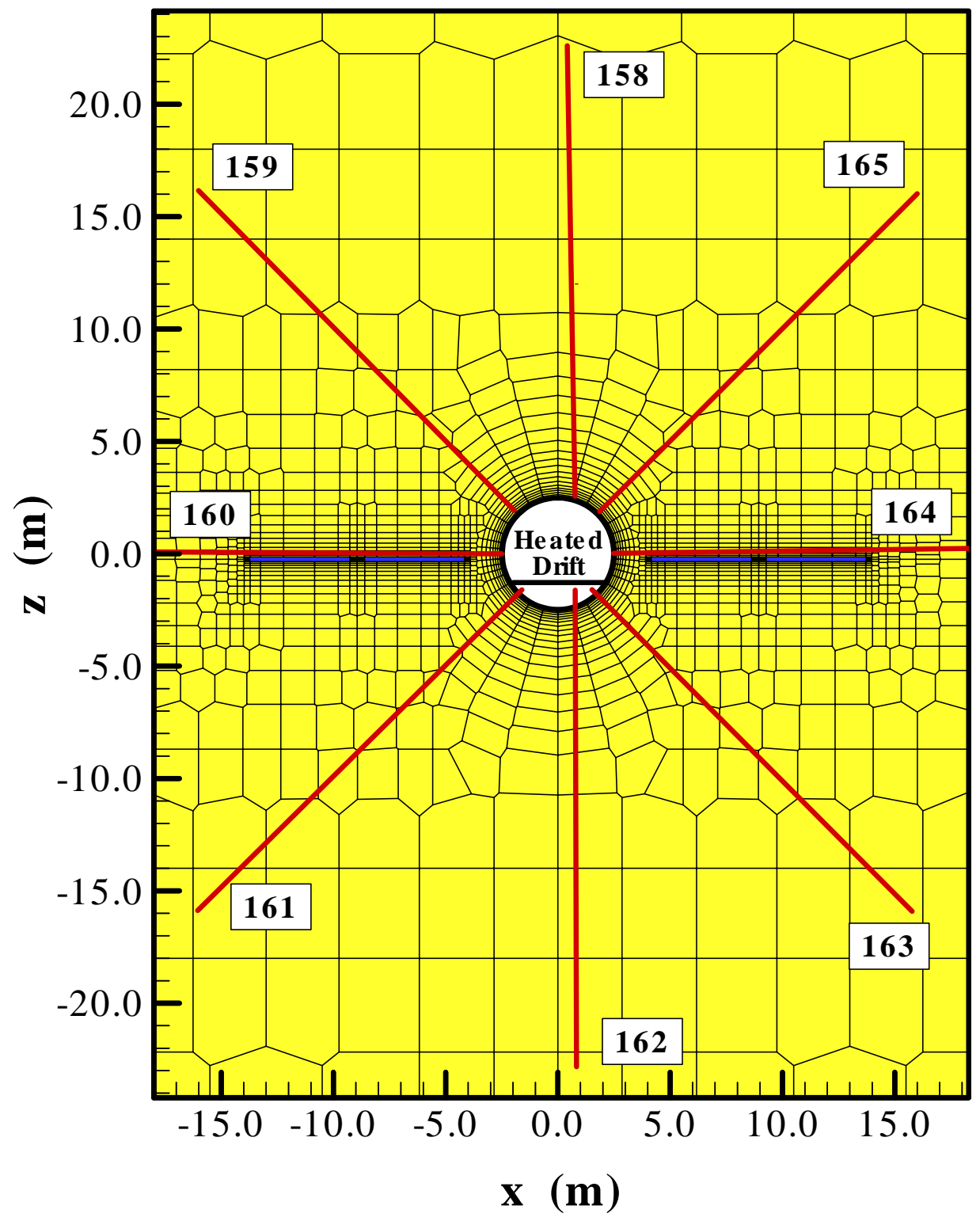

Input DTN (borehole location): MO0002ABBLSLDS.000 [DIRS 147304]. Output DTN: NA (See Section 8.5).

NOTE: Numerous temperature sensors are installed in each borehole with a sensor spacing of about $30 \mathrm{~cm}$.

Figure 7.3.3-2. Detailed View of Vertical Cross Section of DST Numerical Grid through Plane Containing Temperature Boreholes 158 to 165 


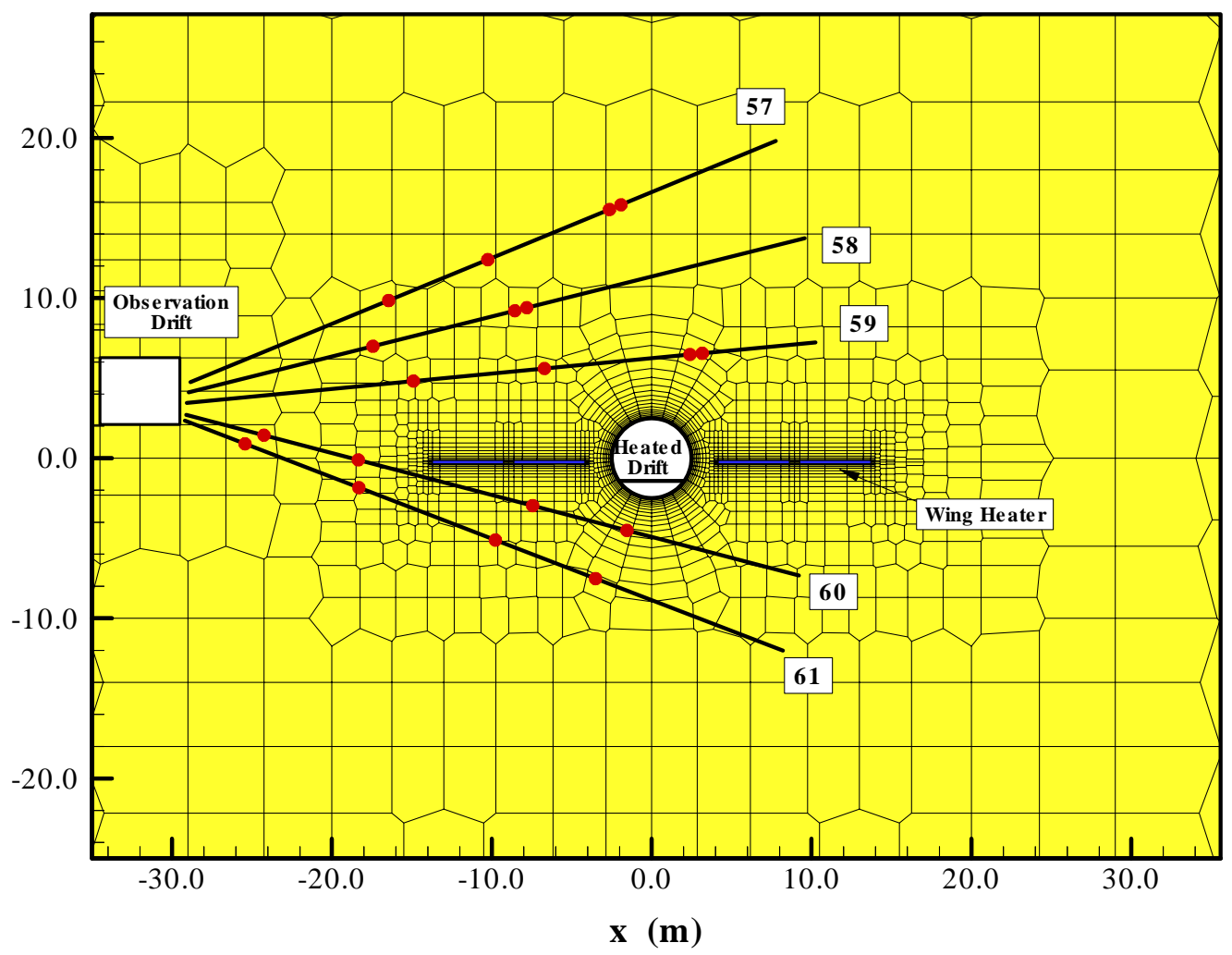

Input DTN (borehole and sensor location): MO0002ABBLSLDS.000 [DIRS 147304].

Output-DTN: NA (See Section 8.5).

NOTE: Circular symbols indicate location of temperature sensors.

Figure 7.3.3-3. Detailed View of Vertical Cross Section of DST Numerical Grid through Plane Containing Hydrology Boreholes 57 to 61

\subsubsection{Model Boundary and Initial Conditions}

\section{Boundary Conditions}

The top and bottom boundaries of the DST domain $(\mathrm{z}=+99.39 \mathrm{~m}$ and $-156.76 \mathrm{~m}$, respectively) are given constant boundary conditions of pressure, saturation, and temperature (see Section 4.1.2.2). The side boundaries of the domain are located outside of the test influence area and are implemented as no-flow boundaries, i.e., these side boundaries are far away enough not to have an impact on the TH conditions in the DST model domain even if an open boundary was used. The Observation Drift, the Connecting Drift, and the cool section of the Heated Drift are given constant pressure, temperature, and saturation boundary conditions. The nonheated section of the Heated Drift and the walls of the Connecting Drift and Observation Drift near the Heated Drift are insulated, but allow for moisture to escape from the test block in the form of both liquid water and vapor. The Heated Drift is open to advection and conduction of heat and mass as well as vapor diffusion. 


\section{Thermal Bulkhead}

Early pressure measurements from the hot and cool sides of the Heated Drift indicated that the insulated bulkhead was acting as an open boundary for gas flow, allowing vapor to escape from the Heated Drift. As a result, the predictive numerical model for the DST was changed in 1998, utilizing a bulkhead boundary condition that conforms to the actual test conditions. A high-permeability connection for gas flow was introduced between the gridblocks, representing the hot side and the cool side of the Heating Drift, so that the simulated bulkhead acts as an open boundary. Model results using this boundary condition show significant amounts of vapor escaping from the Heated Drift. On the other hand, the bulkhead is given small thermal conductivity, preventing heat transfer at the bulkhead by conduction.

The issue of heat and mass loss through the bulkhead has been discussed and evaluated in several thermal workshops. In short, there was concern that the amount of vapor escaping through the bulkhead is not appropriately monitored, and that the thermal response of a closed system might be different from the thermal response of an open system, where the volume of condensed water remaining in the rock is smaller. A detailed evaluation of this issue is presented in the informal thermal test progress report \#7 (Williams 2001 [DIRS 160809], Sections 3.2 and 3.3) and in Mukhopadhyay and Tsang (2003 [DIRS 160790], Sections 2 and 3). This issue was further elaborated in Williams (2002 [DIRS 171270]) and it was concluded that the objectives of the DST-acquiring a more in-depth understanding of the coupled TH processes and validating the conceptual models in comparison with data - are being met. The revised model with the open-bulkhead boundary condition was considered appropriate for representing heat losses through the bulkhead, based on a reasonably small difference between measured and simulated temperature. It was concluded that the uncertainty in the fate of thermally mobilized water and uncertainty in understanding the moisture redistribution in the DST is acceptable. However, it was also understood that the measurements in the DST should not be directly used to evaluate the potential of seepage into drifts during the thermal period, because the potential of seepage in the DST might be reduced as a result of the vapor losses.

\section{Thermal Load}

The total heating power applied to the DST TH model reflects average values of the actual heating power. Average values were calculated for each time period that had a different heater output as designed by the Thermal Test Team. This means that the few planned power reductions or increases during the test period are accounted for explicitly, while short-term heater output variations - e.g., as a result of short-term power outages - are averaged out. The periods of identical average heater power output, as applied to the model, are given in Table 7.3.4-1 separately for the floor heaters and the wing heaters. The heaters were turned off on January 14, 2002, after about 49.5 months of heating.

In the DST model, the heat generated from in-drift heaters is applied directly to the drift wall, which is assigned a large thermal conductivity that would equilibrate its temperature. Because the main objective of this report is the quantification of TH processes in the rock mass outside the drift, it is not necessary to capture the rapid radiative heat transfer within the drift in detail. Also, to limit the complexity of the three-dimensional numerical grid, the wing heaters are represented as smeared-out, spatially uniform heat sources. This is appropriate as the rock 
between two adjacent wing heaters reaches a uniform temperature rapidly compared to that outside the wing heaters. Only the rock temperatures within one heater spacing of the wing heaters will be misrepresented in the simulation because of this simplified representation, and few temperature sensors are located there.

Table 7.3.4-1. Total Average Heater Power at Various Times of Heating in the DST

\begin{tabular}{|l|c|c|}
\hline \multicolumn{1}{|c|}{ Time } & Floor Heaters $\mathbf{( k W )}$ & Wing Heaters (kW) \\
\hline $12 / 03 / 1997-05 / 31 / 1999$ & 52.1 & 132.1 \\
\hline $06 / 01 / 1999-03 / 02 / 2000$ & 50.0 & 125.1 \\
\hline $03 / 02 / 2000-05 / 02 / 2000$ & 47.9 & 120.4 \\
\hline $05 / 02 / 2000-08 / 15 / 2000$ & 45.8 & 114.6 \\
\hline $08 / 15 / 2000-03 / 31 / 2001$ & 43.3 & 106.4 \\
\hline $04 / 01 / 2001-05 / 02 / 2001$ & 43.4 & 106.7 \\
\hline $05 / 02 / 2001-08 / 22 / 2001$ & 41.4 & 101.6 \\
\hline $08 / 22 / 2001-09 / 30 / 2001$ & 39.4 & 96.3 \\
\hline $10 / 01 / 2001-01 / 14 / 2002$ & 39.4 & 96.8 \\
\hline
\end{tabular}

Input DTNs: MO9807DSTSET01.000 [DIRS 113644]; MO9810DSTSET02.000 [DIRS 113662]; MO9906DSTSET03.000 [DIRS 113673]; MO0001SEPDSTPC.000 [DIRS 153836]; MO0007SEPDSTPC.001 [DIRS 153707]; MO0012SEPDSTPC.002 [DIRS 153708]; MO0107SEPDSTPC.003 [DIRS 158321]; MO0202SEPDSTTV.001 [DIRS 158320]

\section{Initial Conditions}

The initial values of pressure, temperature, and saturation in the DST model are developed from initialization runs with the three-dimensional grid, using the selected top and bottom boundary conditions. The initialization runs are performed for ten thousand years before turning on the heat, ensuring that an equilibrium condition is achieved. In addition, the impact of elevated temperatures in the drifts (from installation activities in the summer months prior to starting the test), and of rock mass drying within a few meters of drift walls from ventilation of the drifts are accounted for in the numerical model.

\subsubsection{Model Parameters and Rock Properties}

Following a strategy similar to that in the previous Thermal Tests Thermal-Hydrological Analyses/Model Report (BSC 2001 [DIRS 157330], Sections 6.2.2 and 6.3.2), the DST TH model employs two different rock-property sets for validation (see Section 4). The first rock-property set utilizes site-specific properties and is identical to the property set used in Thermal Tests Thermal-Hydrological Analyses/Model Report (BSC 2001 [DIRS 157330], see Section 4.1, Table 5) (DKM-TT99). The intent of model simulations using this data set is to demonstrate the accuracy of the model, using the best available data for the local conditions in the test block. The second property set is identical to the calibrated property set used in the predictive TH seepage model simulations. This property set, derived from mountain-scale calibration runs for ambient conditions (i.e., DS/AFM-UZ02-Mean), is expected to better represent average properties of the various stratigraphic layers. The intent of model simulations using this data set is to demonstrate that the TH behavior in the DST can be represented with reasonable accuracy using a property set applied in the TH seepage model simulations. Comparison of the model results from the two property sets can help to evaluate the uncertainty 
introduced by parameter variability. For example, a reasonable agreement between the simulation results of the two sets would reveal a small uncertainty of model output stemming from parameter variation. Both property sets assume homogeneous rock properties within each geologic layer, so that heterogeneity within the DST test block is not accounted for, and neither data set has been specifically calibrated to the measured DST data to improve the agreement between model and data. This should be considered when assessing the accuracy of the model results.

The active fracture model (AFM) is applied when using the DS/AFM-UZ02-MEAN property set, to be consistent with the $\mathrm{TH}$ seepage model. In contrast, simulations performed with the DKM-TT99 property set are performed with a standard dual-permeability method (DKM) to be consistent with the previous DST TH model simulations as presented in Thermal Tests Thermal-Hydrological Analyses/Model Report (BSC 2001 [DIRS 157330], Section 6.2 .2 and 6.3.2).

\subsection{DST VALIDATION RESULTS}

\subsubsection{DST Data Used for Validation and Validation Criteria}

This section introduces the data available from measurements conducted in the DST, gives some information on the data uncertainty introduced by measurement errors or data analysis and reprocessing, provides the rationale for selection of data for model validation, and reiterates on the validation criteria defined in Section 2.2.1.4 of the TWP (BSC 2004 [DIRS 170236]).

The validation criteria for model corroboration with data have been developed based on the model's intended use. The purpose of the TH seepage model is to provide findings on the evolution of thermal seepage to form the basis for thermal seepage abstraction. These findings are (1) that water is prevented from entering drifts as long as the fractured rock near the drift wall is at above-boiling temperature and (2) that the amount of thermal seepage is bounded by the respective long-term ambient seepage rate. Based on these findings, two alternative abstraction methodologies for thermal seepage are developed in Abstraction of Drift Seepage (BSC 2004 [DIRS 169131], Sections 6.5.2 and 6.5.3) for further use in the total system performance assessment (TSPA). The selected abstraction methods use upper-bound estimates of thermal seepage to account for various sources of model uncertainty. The first one of the abstraction methods sets thermal seepage equal to ambient seepage, which means that uncertainty is accounted for by not using the potential benefit of a vaporization barrier in the TSPA-LA. Quantitative model results are not needed for this upper-bound method. The second method suggests to set thermal seepage to zero during the period of above-boiling temperatures at the drift wall, which requires prediction of the duration of the boiling period. This quantitative information is provided to TSPA by another model, the multiscale thermohydrologic model (BSC 2004 [DIRS 169565]). In the second method, uncertainty is accounted for by choosing a threshold temperature for the duration of the boiling period that is a few degrees higher than the nominal boiling period (BSC 2004 [169131], Section 6.5.2.2). This ensures that the boiling isotherm is at some distance from the drift (and there is a small completely dry zone around the wall) when the zero seepage is switched back to ambient seepage in the abstraction. Also, the abstraction model does not incorporate the delayed seepage initiation caused by the slow saturation buildup in the near-field rock. In other words, while the predictive results show that 
seepage can only occur after a few hundred to thousand years of resaturation because of the capillary barrier at the wall, the seepage abstraction allows for seepage as soon as the fractured rock close to the drifts starts to have non-zero saturation values. Thus both abstraction methods account for a wide uncertainty margin in the TH Seepage Results.

Following the above discussion, for the TH seepage model and its validation, it is most important that the $\mathrm{TH}$ processes of moisture redistribution are qualitatively captured so that the basis for the thermal seepage abstraction is valid. Thus for the purpose of providing thermal seepage estimates for seepage abstraction, the model needs to predict reasonably well the disturbance of the fracture and matrix flows induced by heating of the fractured rock, because potential for thermal seepage is mostly affected by the flux perturbation. Considering the selected upperbound abstraction method with its wide uncertainty margin, the criterion for model validation defined in Section 2.2.1.4 of the TWP (BSC 2004 [DIRS 170236]) is that the simulated locations of dryout and condensation should qualitatively be corroborated by these deduced from temperature, geophysical and air permeability measurements.

The specific data from the DST used for validation of the drift-scale TH model are those data related to TH measurements as follows:

- Temperatures measured at approximately 1750 sensor locations.

- Changes in matrix saturation estimated from geophysical measurements conducted at periodic intervals (approximately once in three months) through the duration of the DST.

- Changes in fracture saturation estimated from air-permeability measurements conducted at periodic intervals (approximately once in three months) through the duration of the DST.

About 1,750 temperature sensors installed in 26 boreholes are available for comparison of temperature data. Qualitative comparison can be performed using temperature profiles at a particular time along temperature boreholes or plotting the temperature history of selected sensors. A quantitative evaluation can be performed using statistical measures such as the mean difference between modeled and measured results. (Definition of these statistical measures is given in Section 7.4.2.) While the temperature rise in the test block is dominated by heat conduction, evidence of $\mathrm{TH}$ coupling is manifested in heat-pipe signatures in the temperature data, indicating two-phase conditions with presence of both water and vapor. The location of heat-pipe signatures provides an estimate for the location of the boiling front and indicates the magnitude of heat-induced two-phase circulation processes of water and air. A validation criterion is that the location and duration characteristics of these two-phase heat-pipe signatures in the predictions should also be observed in the measurements (BSC 2004 [DIRS 170236], Section 2.2.1.4). As for temperature statistics, a mean difference of less than $10^{\circ} \mathrm{C}$ is considered acceptable (BSC 2004 [DIRS 170236], Section 2.2.1.4). A mean difference of $10^{\circ} \mathrm{C}$ is about 4 percent of the maximum rock temperature at the end of heating. As pointed out above, the TH seepage model does not provide quantitative estimates of temperature to TSPA. Thus, the temperature predictions have to be accurate enough to allow for a reasonable prediction of the heat-induced flux perturbations, but do not require a close quantitative match at all times and 
locations. The $10^{\circ} \mathrm{C}$ temperature criterion ensures that the temperature predictions form a reasonably good basis for the prediction of $\mathrm{TH}$ processes.

The measurement uncertainty related to different types of experimental data is described in Thermal Testing Measurements Report (BSC 2004 [DIRS 169900]), which points out that the measurement error of temperature devices (either thermocouples or resistance temperature devices) is on the order of $1^{\circ} \mathrm{C}$, small compared to the uncertainty related to the simulated temperature.

The main phenomenon of TH coupling is the redistribution of moisture via condensed vapor in the rock mass. As mentioned earlier, zones of increased or decreased water saturation in fractures and matrix (compared to preheat baseline data) are monitored in the DST by periodic geophysical methods and air-permeability measurements. The geophysical measurements provide data related to changes in water saturation of the rock matrix. These data can be used to validate the drift-scale TH seepage process models in the following manner. Simulated matrix liquid saturation contours at different phases of heating are generated in the appropriate planes of geophysical measurements. Measured zones of drying and wetting are compared to the simulated contours of liquid saturation at specific times of measurement.

Periodic air injection tests provide information on the wetting and drying in the fractures. Wetting of fractures means increased resistance to air flow during air-injection tests, leading to a decrease in air permeability from its preheat value in certain boreholes. As heating progresses and the drying front expands, certain borehole sections that were previously zones of increased liquid saturation would become zones of decreased liquid saturation, corresponding to a return of air permeability back toward their preheat levels. These measured permeability data can be used to validate the process model in the following manner. The simulated fracture liquid saturations can be used to estimate the related (simulated) changes in air permeability. These changes in air permeability, as simulated by the numerical model, can then be compared to those observed in the measurements.

All the above methods for estimating moisture redistribution processes are useful for evaluating qualitative changes, but do not give direct and reliable measured values of the absolute liquid saturation. Geophysical measurements such as electrical resistivity tomography (ERT) and ground-penetrating radar (GPR) involve tomographic measurements of electrical resistivity and electromagnetic velocity performed in horizontal or vertical planes between boreholes, with ERT larger in measurement scale than the GPR. In both methods, the measured values must be converted into volumetric water-content changes by means of inverse algorithms, introducing further uncertainty into the processed values. Neutron-logging data are considered more reliable because they stem from point measurements; however, the rock volume covered by the measurement is much smaller than that covered by ERT or GPR (i.e., a radius of 10 to $15 \mathrm{~cm}$ from the borehole). It was concluded in Thermal Tests Thermal-Hydrological Analyses/Model Report (BSC 2001 [DIRS 157330], Section 7) that results from the three geophysical measurement techniques are comparable and reasonable. Therefore, in this report, the GPR data are used for qualitative comparison of matrix saturation changes with the model results. While air-injection tests provide reliable estimates of fracture permeability, converting the measured changes of air permeability into fracture saturation changes involves selection of an appropriate gas relative-permeability model and increases model uncertainty. 
It is evident from the discussion above that measurements for monitoring moisture redistribution in the DST are by nature indirect and qualitative. Accordingly, employment of statistical measures is not appropriate for saturation results. Hence, the criterion for model validation defined in Section 2.2.1.4 of the TWP (BSC 2004 [DIRS 170236]) is that locations of dryout and condensation indicated by the simulated time evolution of the liquid-saturation changes in the matrix and fractures should in general be corroborated by these deduced from geophysical and air permeability measurements.

The many geochemical measurements of the DST (e.g., water and gas chemistry, mineralogic and petrographic analyses) are also valuable for validation of the DST TH model. The simulation model for analyzing THC processes in the DST is fundamentally dependent on a thorough understanding of the water and gas flow processes. Thus, a good agreement between measured chemical data and results from the DST THC model provides additional confidence in the DST TH model, because both models share similar concepts and rock properties. Validation of the DST THC model is described in Drift-Scale Coupled Processes (DST and THC Seepage) Models (BSC 2004 [DIRS 169856], Section 7).

\subsubsection{Statistical Measures for Temperature Evaluation}

Statistical methods have been introduced and applied in Thermal Tests Thermal-Hydrological Analyses/Model Report (BSC 2001 [DIRS 157330], Section 6.2.1.2) to derive "single-number" quantitative measures for the goodness of fit between simulated and measured temperature data. They are based on standard statistical tools modified to better adapt to interpretation of measured and simulated behavior in the DST. A brief review of methodology and equations is given below.

The two statistical measures applied in this report are the mean difference and the root mean square difference. Note that only the first statistical measure is mentioned in the model validation plan as defined in Section 2.2.1 of the TWP (BSC 2004 [DIRS 170236]); the second measure is introduced in this report as an additional evaluation tool. Both statistical measures are a function of simulated $\left(\mathrm{T}_{\mathrm{sim}, \mathrm{i}}\right)$ and measured $\left(\mathrm{T}_{\text {meas, }, \mathrm{i}}\right)$ temperatures. Simulated temperatures are spatially and temporally interpolated, as needed, to ensure proper correlation to the measured variables. Measured variables are directly taken from sensor readings. The statistical evaluation is conducted for specific times during the DST heating and cooling phase. Usually, all sensors are included in the evaluation; however, investigators can also decide to evaluate subsets of data, e.g., all sensors with temperatures above boiling (greater than $96^{\circ} \mathrm{C}$ ), and all thermal sensors below boiling (less than $96^{\circ} \mathrm{C}$ ).

For a given number of sensors $\mathrm{N}$, the mean difference (MD) at a specified time is given as:

$$
M D=\frac{\sum_{i=1}^{N} w_{i}\left(T_{\text {sim }, i}-T_{\text {mea }, i}\right)}{\sum_{i=1}^{N} w_{i}}
$$

In Equation 7.4-1, $w_{i}$ is a weighting factor introduced to give equal importance to all temperature subranges in the total range of temperatures observed (see Equation 7.4-3 below). This ensures 
that the entire zone affected by heat-induced flux perturbations (which is roughly representative of the volume covered by the instrumented boreholes) is adequately represented. A positive mean difference indicates an overestimate of the measured variable; that is, the simulation predicts more heat in the test block than measured. The opposite applies for a negative mean difference.

The root mean square difference (RMSD) for a specific time is described as:

$$
R M S D=\left[\frac{\sum_{i=1}^{N} w_{i}\left(T_{\text {sim }, i}-T_{\text {mea }, i}\right)^{2}}{\sum_{i=1}^{N} w_{i}}\right]^{1 / 2}
$$

The smaller the root mean square difference, the better the agreement between simulated and measured data. Thus, the root mean square difference reveals the accuracy of the simulation.

Weighting factors $\left(w_{i}\right)$ in Equations 7.4-1 and 7.4-2 are based on a frequency analysis of the temperature measurements, acknowledging that the sensors are not uniformly distributed throughout the test block. The total range of temperature measurements is divided into 20 equally sized temperature subranges, and the number of measurements falling into each subrange was calculated. Then $w_{i}$ is defined as the inverse of the number of data in each subrange $i$ (exception: if this number is zero, $w_{i}$ is zero). Basically, this weighing scheme gives equal weighting to (i.e., uses a mean temperature for) each temperature subrange. (Note that a suite of qualified codes is used for data interpolation, extraction, and calculation of the statistical measures. These are codes mk_3dinter*.f (LBNL 2000 [DIRS 147550]), mk_temp3d_all.f (LBNL 2000 [DIRS 147551]), and mk_evaluate_*.f (LBNL 2000 [DIRS 147552]) (see Table 3-1)).

\subsubsection{Comparative Analysis of Measurements and Results from Simulations with Site-Specific Property Set}

In this section, TH data collected from the DST are compared with simulation results from the three-dimensional DST TH model using the site-specific property set DKM-TT99 (see Section 4.1.2.1). As discussed earlier, simulation runs using the DST-TT99 property set are performed with a standard dual-permeability method (DKM). Measured and simulated TH data to be compared are temperature, water redistribution in the matrix, and water redistribution in the fracture. Because of the vast amount of measured data available in the DST, both in space and time, the presentation of validation results can only include selected examples of each data type. Note that the presented examples have been chosen to be representative of the overall $\mathrm{TH}$ behavior in the DST.

\subsubsection{Temperature}

The comparison between measured and simulated temperatures is illustrated by showing temperature profiles and temperature history plots for a few selected boreholes. Additionally, statistical measures of the "goodness of fit" are provided as a way to quantitatively compare 
simulation and measurements. To start, it should be noted that the simulated temperatures of the fractures are indistinguishable from those of the matrix, implying that, for all practical purposes, the matrix and fractures are in thermal equilibrium. The subsequent discussion of temperature distributions in the DST rock mass does not distinguish between matrix and fracture temperatures.

\subsection{Temperature Profile}

Figures 7.4.3.1-1a through 7.4.3.1-1d show a comparison of measured and simulated temperature profiles in boreholes 158 through 160 at 12, 24, 36, and 48 months of heating, respectively. In these figures, temperatures (both measured and simulated) are shown as a function of distance from the borehole collar. The boreholes chosen are arranged in a cluster oriented radially outward from the Heated Drift at a distance of $\mathrm{y} \sim 23 \mathrm{~m}$ to the bulkhead (see Figure 7.2.1-1) and are representative of other temperature borehole clusters. Borehole 158 is oriented vertically up from the Heated Drift wall, borehole 159 makes an angle of $45^{\circ}$ with the vertical, and borehole 160 is horizontal and runs slightly above the wing heaters (see Figures 7.2.2-1 and 7.3.3-2).

At 12 months of heating (Figure 7.4.3.1-1a), the drift wall is close to $160^{\circ} \mathrm{C}$. In boreholes 158 and 159, both measured and simulated temperatures decline continually with the increase in distance from the drift wall. A good match exists between the measured and simulated temperatures in these two boreholes. The temperature profile in borehole 160 is different from that in the other two boreholes, because of its proximity with the wing heaters. A gap of about $1.66 \mathrm{~m}$ between the wall of the Heated Drift and the start of the inner wing heater accounts for the drop in measured and simulated temperatures near the collar of the borehole. Beyond this gap, temperatures increase with distance because of additional heat emanating from the inner wing heaters. The effect of the gap of $0.66 \mathrm{~m}$ between the inner and outer wing heaters is again reflected in the drop in temperatures. Temperatures then rise along the length of the outer wing heaters, before finally declining monotonically with distance beyond the end of the outer wing heaters. In the rock mass further away from the wing heaters, the measured and simulated temperatures in borehole 160 are in good agreement. Along the length of the wing heaters, however, the measured temperatures are higher than the simulated ones. This may be attributed to the fact that the wing heaters in the DST TH model are represented as smeared-out, spatially uniform planar heat sources (see Section 7.3.4), while in reality wing heaters are line sources with a spacing of about $1.8 \mathrm{~m}$ in the y-direction. Thus, measurements close to the wing heater boreholes are expected to be higher than the simulated temperatures that represent a spatial averaging over a few gridblocks. The fact that the simulated temperatures are slightly higher than the measured temperatures at the wall of the Heated Drift is a result of the modeling approximation in which heat was applied directly at the drift wall. This trend is expected to persist through the heating phase.

Measured and simulated temperature profiles in these boreholes at 24 months of heating can be seen in Figure 7.4.3.1-1b. The general pattern of the temperature profile in this figure is similar to that of Figure 7.4.3.1-1a, with higher temperatures at 24 months than at 12 months. While there is generally good agreement between measured and simulated temperatures, the simulated temperatures are slightly higher than the measured ones in boreholes 158 and 159, indicating that the model is retaining more heat than the DST test block. This is a likely scenario in an open field test like the DST, where it is difficult to account for all the heat losses in the numerical 
model. However, it is later demonstrated that these unaccounted losses have not altered understanding of the TH processes in any significant manner. (This has also been discussed in detail in Mukhopadhyay and Tsang 2003 [DIRS 160790], Sections 2 and 3) The smaller simulated temperatures in borehole 160, on the other hand, result from the smeared-out implementation of the heat sources in the numerical grid, as was explained in the above paragraph. The temperature profiles in Figures 7.4.3.1-1c, for 36 months of heating, and 7.4.3.1-1d, for 48 months of heating, can be similarly explained. Notice that by the end of heating, the difference between measured and simulated temperatures in borehole 160 along the wing heaters has decreased. This confirms that the smeared-out implementation is acceptable, because the averaging of supplied heat evens out over a large-enough time scale. As mentioned above, there are differences between the measured and the simulated temperatures at the wall of the Heated Drift. Most of these differences are an artifact of the modeling approximation in the DST TH model in which the in-drift processes are not considered and the canister heat output is applied directly to the drift walls. Had these processes and boundary conditions been more precisely described rather than the simplifications used for the model analysis, then the agreement between simulated and measured wall temperatures would have improved. In the predictive TH seepage model, these simplifications are not used. Also note that the intended use of the TH seepage model is not to provide future temperature results for use in the TSPA, but to demonstrate that the general (qualitative) findings on thermal seepage hold true for a wide range of TH conditions (see discussion in Section 7.4.1). These qualitative findings are used in Section 6.2.4.1 to develop abstraction methods for thermal seepage. Quantitative temperature results are not needed for the first one of the suggested abstraction methods (i.e., thermal seepage equals to ambient seepage). The second method, which conceptualizes setting thermal seepage to zero during the period of above-boiling temperatures at the drift wall, requires prediction of the duration of the boiling period. This information is provided to TSPA by the multiscale thermohydrologic model (BSC 2004 [DIRS 169565]), which simulates the in-drift and near-drift $\mathrm{TH}$ processes in great detail. Thus, for the $\mathrm{TH}$ seepage model and its validation, it is most important that the $\mathrm{TH}$ processes of moisture redistribution are qualitatively captured so that the basis for the qualitative thermal seepage abstraction is valid.

The above analysis of four time snapshots during heating indicates that the model captures the main elements of heat transfer in the DST rock block. Since temperature rise in the rock from heating is predominantly governed by heat conduction, which is a linear process, the coupling between TH processes, which is nonlinear in nature, is evidenced in subtle signals in the temperature data. Typically, effects of $\mathrm{TH}$ coupling appear as a zone of flat region in temperature profiles (or temperature evolution plots) at the nominal boiling point of water (heat-pipe signature), indicating two-phase boiling conditions with presence of both liquid water and vapor. (In such conditions, most of the energy supply is used as latent heat of phase change, so that temperature does not change until all water has boiled away.) The general agreement of location, extent, and duration of such temperature signals is an important part of the model validation process, because it indicates that the thermally induced flow processes of vapor and water are accurately represented.

Heat-pipe signals can be seen in both the measured and the simulated data from all time snapshots depicted in Figures 7.4.3.1-1a through 7.4.3.1-1d. At 12 months of heating, boreholes 158 and 159 exhibit small signatures at about 2 to $4 \mathrm{~m}$ from the Heated Drift wall, indicating that the boiling front is at that distance from the drift. In borehole 160, a minute heat-pipe signature 
exists at around 12 to $13 \mathrm{~m}$, just beyond the end of the wing heaters. As heating progresses, these signals become longer, as more and more water reaches the nominal boiling point, and they move away from the heat source with the location of the boiling front. At 48 months, boiling takes place at about 6 to $10 \mathrm{~m}$ from the drift in boreholes 158 and 159, and at around 14 to $15 \mathrm{~m}$ in borehole 160. In general, the observed heat-pipe patterns are similar in location and extent for the measured and simulated temperatures. However, there are differences that can be attributed to local heterogeneity in the rock surrounding the DST, which is not accounted for in the DST TH model (but is explicitly accounted for in the predictive TH seepage model, using three realizations of small-scale fracture permeability variations). In borehole 158, for example, the simulated temperature consistently overestimates the measured heat-pipe signature. Borehole 159, on the other hand, exhibits a strong heat-pipe signal in the measured temperatures at 36 and 48 months of heating, a signal longer in extent than with the simulated temperature. In the assessment of the DST model results, heat-pipe signals have been analyzed for all boreholes equipped with temperature sensors. On average, the extent and location of these TH coupling signals is well represented in the temperature profiles, though the measured data show more spatial variability. In short, it can be said that there is good agreement between measured and simulated temperatures, even in the subtle signals that indicate $\mathrm{TH}$ coupling. The goodness of agreement between measured and simulated temperature data is defined more quantitatively from the results of a statistical analysis presented in Section 7.4.3.1.3. 


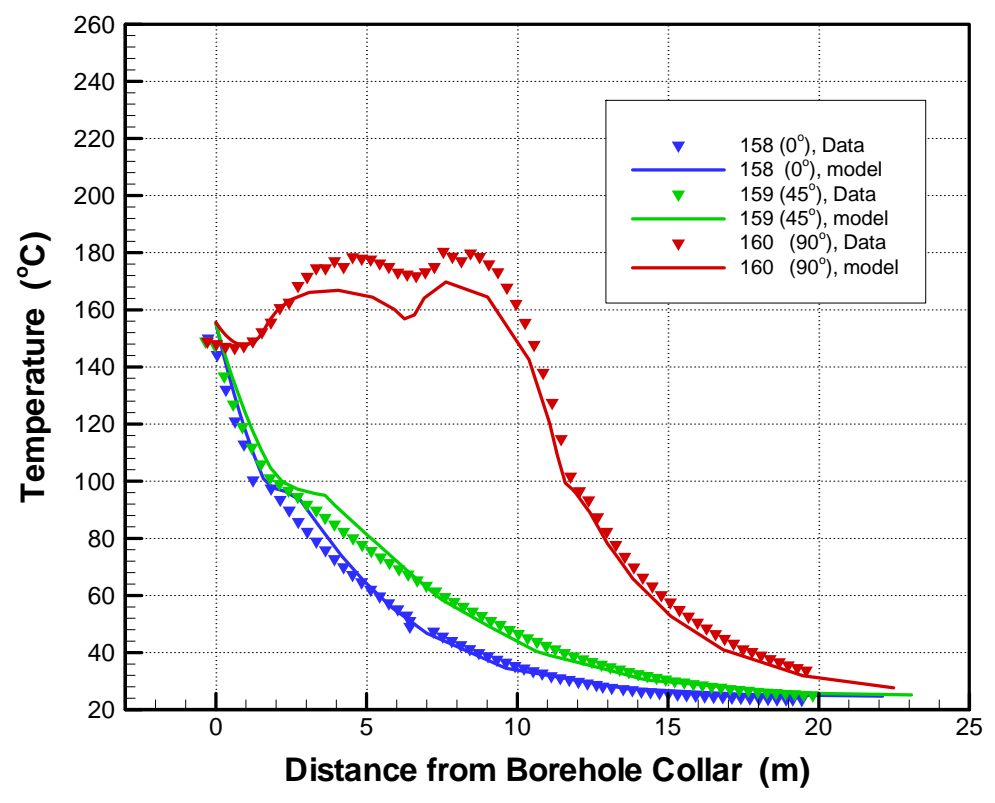

(a)

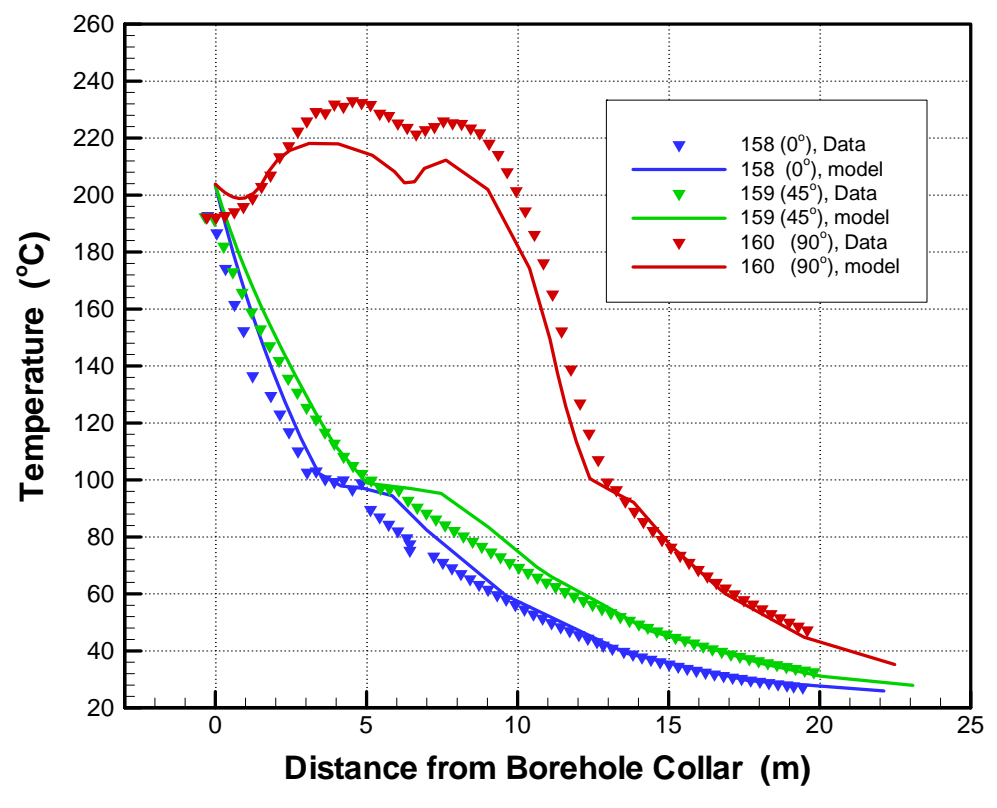

Output DTN (for Figures 7.4.3.1-1a through 1d): LB0303DSCPDSTV.001.

Input DTNs (for Figures 7.4.3.1-1a through 1d): MO9807DSTSET01.000 [DIRS 113644], MO9810DSTSET02.000 [DIRS 113662], MO9906DSTSET03.000 [DIRS 113673], MO0001SEPDSTPC.000 [DIRS 153836],

MO0007SEPDSTPC.001 [DIRS 153707], MO0012SEPDSTPC.002 [DIRS 153708], MO0107SEPDSTPC.003 [DIRS 158321], MO0202SEPDSTTV.001 [DIRS 158320].

Figure 7.4.3.1-1. Measured and Simulated Temperature Profile in Boreholes 158, 159, and 160 at Different Times of Heating: (a) 12 months, (b) 24 months, (c) 36, and (d) 48 months 


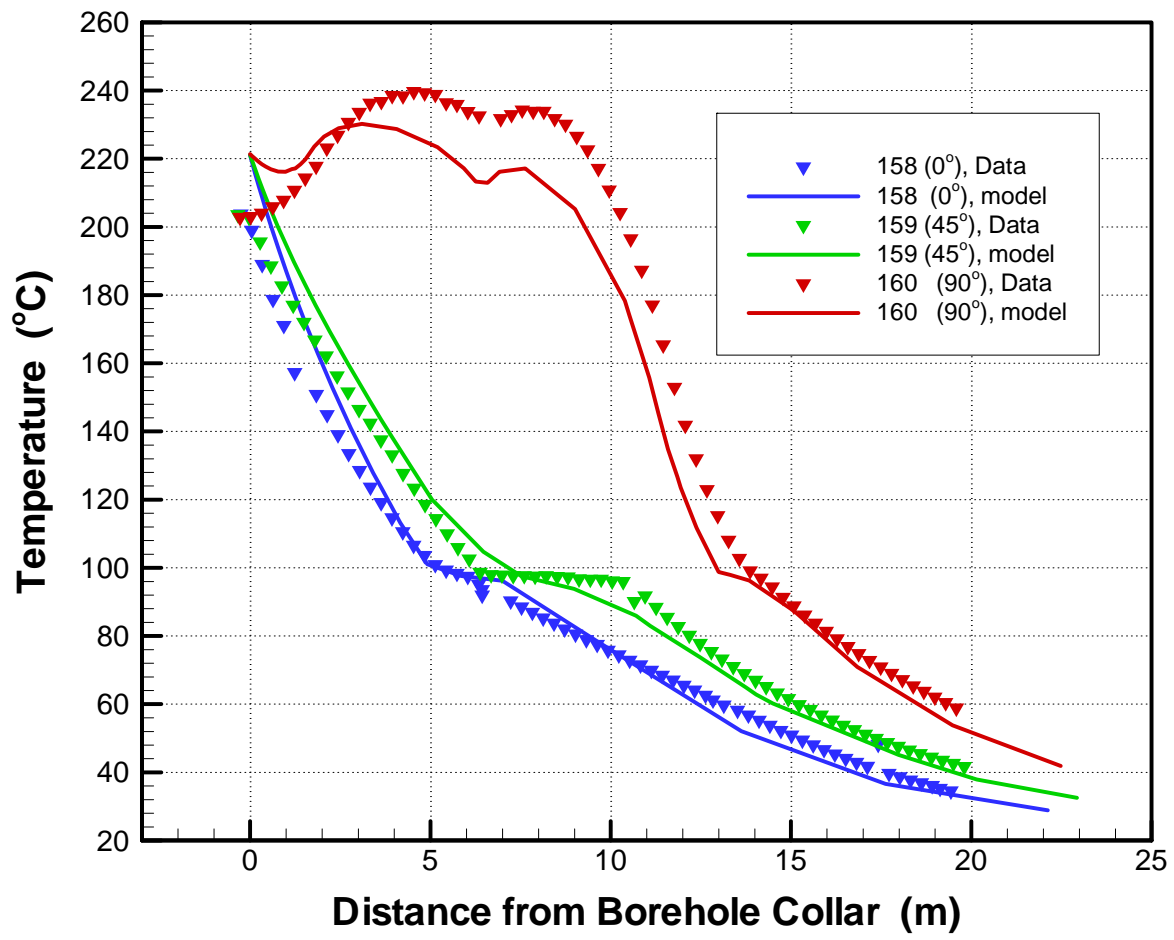

(c)

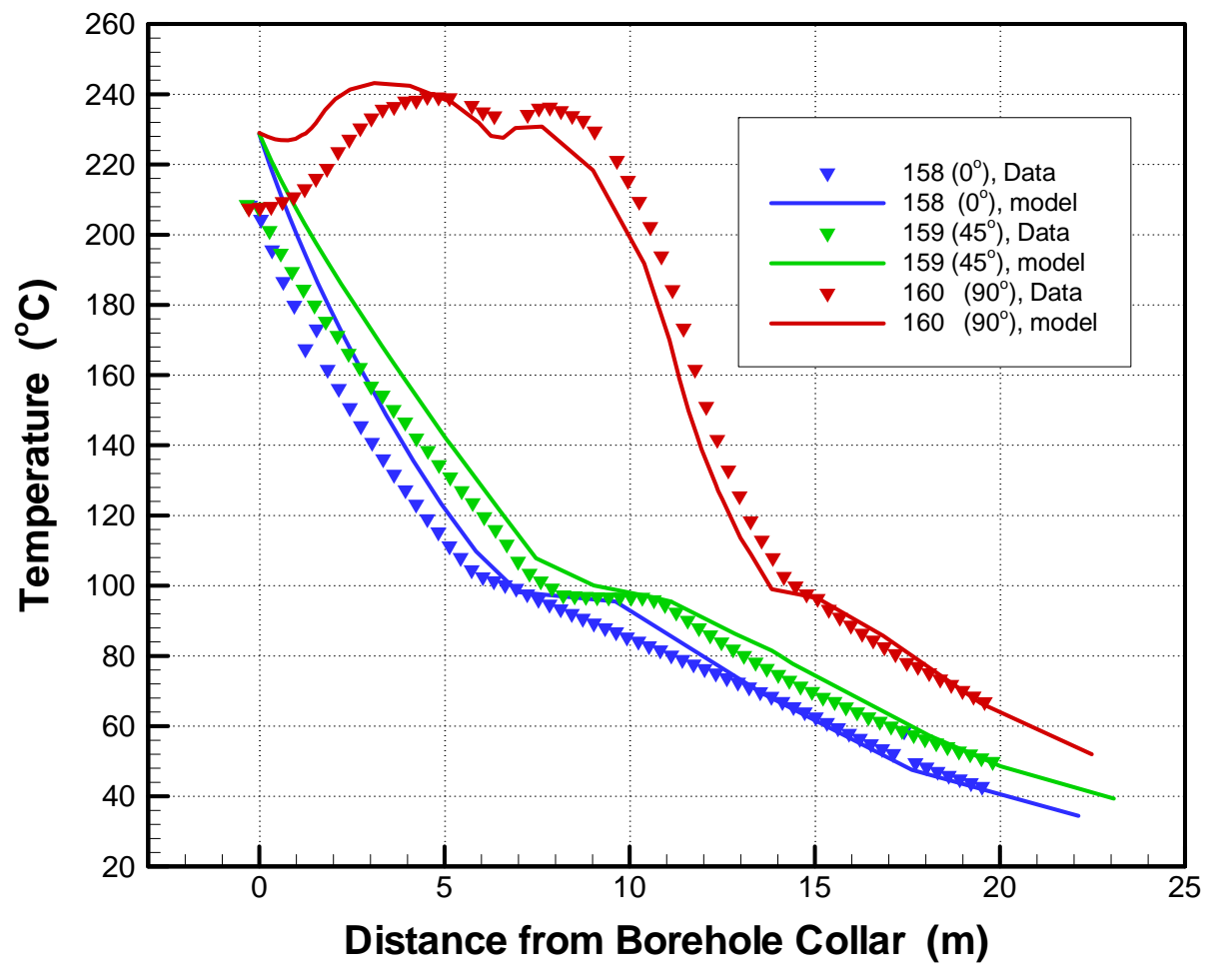

Figure 7.4.3.1-1 (continued). Measured and Simulated Temperature Profile in Boreholes 158, 159, and 160 at Different Times of Heating: (a) 12 months, (b) 24 months, (c) 36 , and (d) 48 months 
Figure 7.4.3.1-2 presents simulated and measured temperature profiles at 5 months following heater turn-off in boreholes 158, 159, and 160. (Qualified temperature data are only available through the end of June 2001; i.e., about 5 1/2 months of natural cooling in the DST rock block.) Close to the heat sources, the temperatures have significantly dropped. Note that the rock thermal gradients in the drift vicinity are directed towards the drift wall. In horizontal borehole 160 , this is mainly a result of the hotter rock region around the wing heaters, where the thermal load was particularly strong during the 4-year heating phase (compare with Figure 7.4.3.1-1d for the temperature profile close to the end of heating). In the other boreholes, the thermal gradient towards the drift wall is a result of the small heat capacity within the drift; much more energy is stored in the rock than in the drift, so that the rock cooling is slower. In general, there is reasonably good agreement between measured and simulated temperatures during cooling. Similar to the heating phase, the simulated temperatures are somewhat higher than the measured temperatures in boreholes 158 and 159. In borehole 160, they are almost identical, particularly far away from the heat sources. The absence of the "humps" in the temperature profile in borehole 160 during cooling is understood because of the absence of heat output from the wing heaters. That the simulated temperatures at the drift wall are higher than the measured temperatures has already been discussed. At the end of heating, the wall of the Heated Drift was at approximately $208^{\circ} \mathrm{C}$, whereas the simulated drift-wall temperature was close to $228^{\circ} \mathrm{C}$ (see Figure 7.4.3.1-1d), i.e., a difference of $20^{\circ} \mathrm{C}$. At 5 months of cooling, there is almost an identical difference of $20^{\circ} \mathrm{C}$ between measured and simulated temperatures. The simulated temperature drop during cooling is very similar to the measured temperature drop.

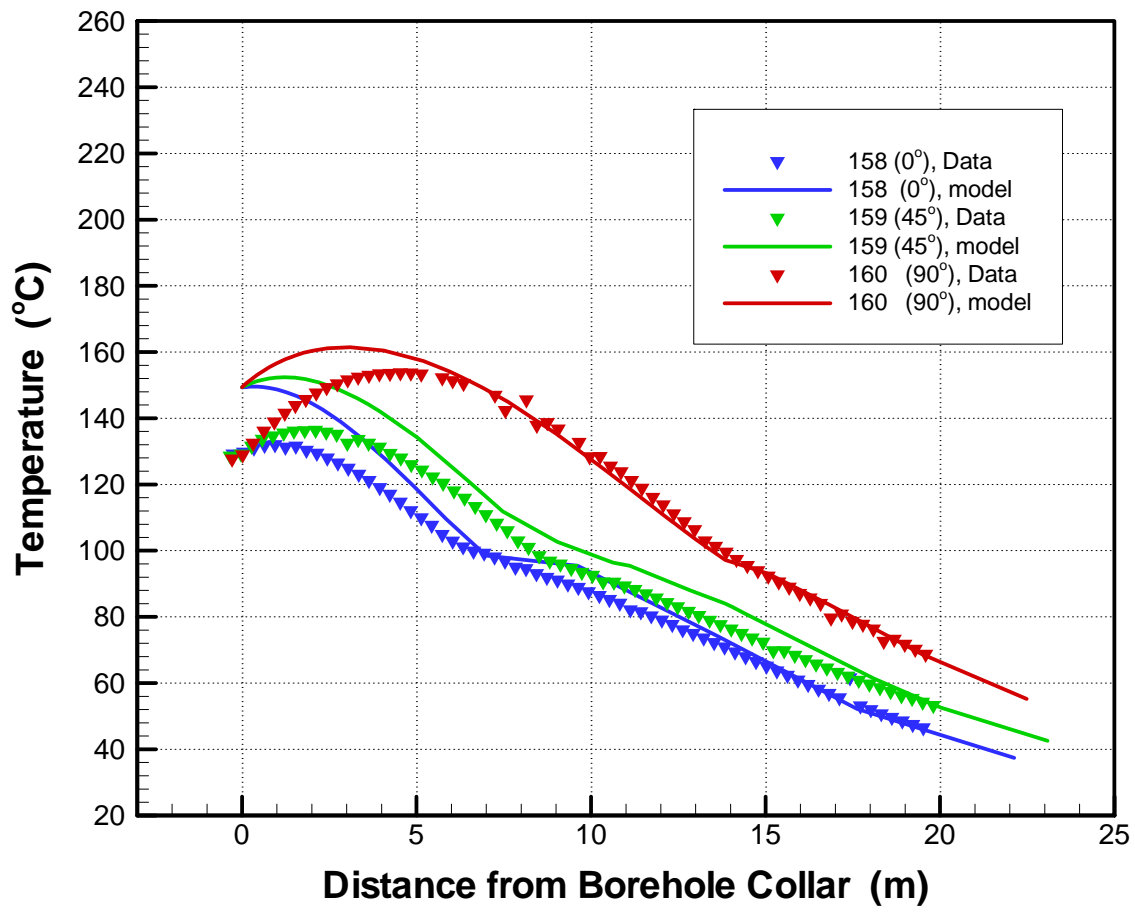

Output DTN: LB0303DSCPDSTV.001.

Input DTN: MO0208SEPDSTTD.001 [DIRS 161767].

Figure 7.4.3.1-2 Measured and Simulated Temperature Profile at 5 Months of Cooling in Boreholes 158, 159 , and 160 


\subsection{Temperature History}

The temporal evolution of measured and simulated temperatures is shown in Figures 7.4.3.1-3a through 7.4.3.1-3c, for a time period that covers 49.5 months of heating and 5.5 months of cooling. First, the temperature history is analyzed for a few selected sensors in borehole 160 . Borehole 160 is the horizontal borehole running slightly above the wing heaters that was already presented in Section 7.4.3.1.1. The sensors selected are 160-9, 160-17, 160-33, 160-44 and 160-55, located at distances of 2.13, 4.54, 9.36, 12.67, and $15.96 \mathrm{~m}$ from the borehole collar, respectively. The other boreholes shown are boreholes 59 and 60, two boreholes in the first cluster of hydrology holes (57-61) located about $10 \mathrm{~m}$ down the Heated Drift from the bulkhead. In the vertical plane of cluster 57-61, boreholes 59 and 60 are closest to the source of heat, with borehole 59 above and borehole 60 below the Heated Drift (see Figures 7.2.2-2 and 7.3.3-3). Each of these boreholes has four temperature sensors installed in them (59-1 through 59-4 and 60-1 through 60-4), with their locations indicated in Figure 7.3.3-3. All three boreholes chosen for the temperature analysis experience large changes, both in terms of temperature and moisture redistribution (to be discussed later).

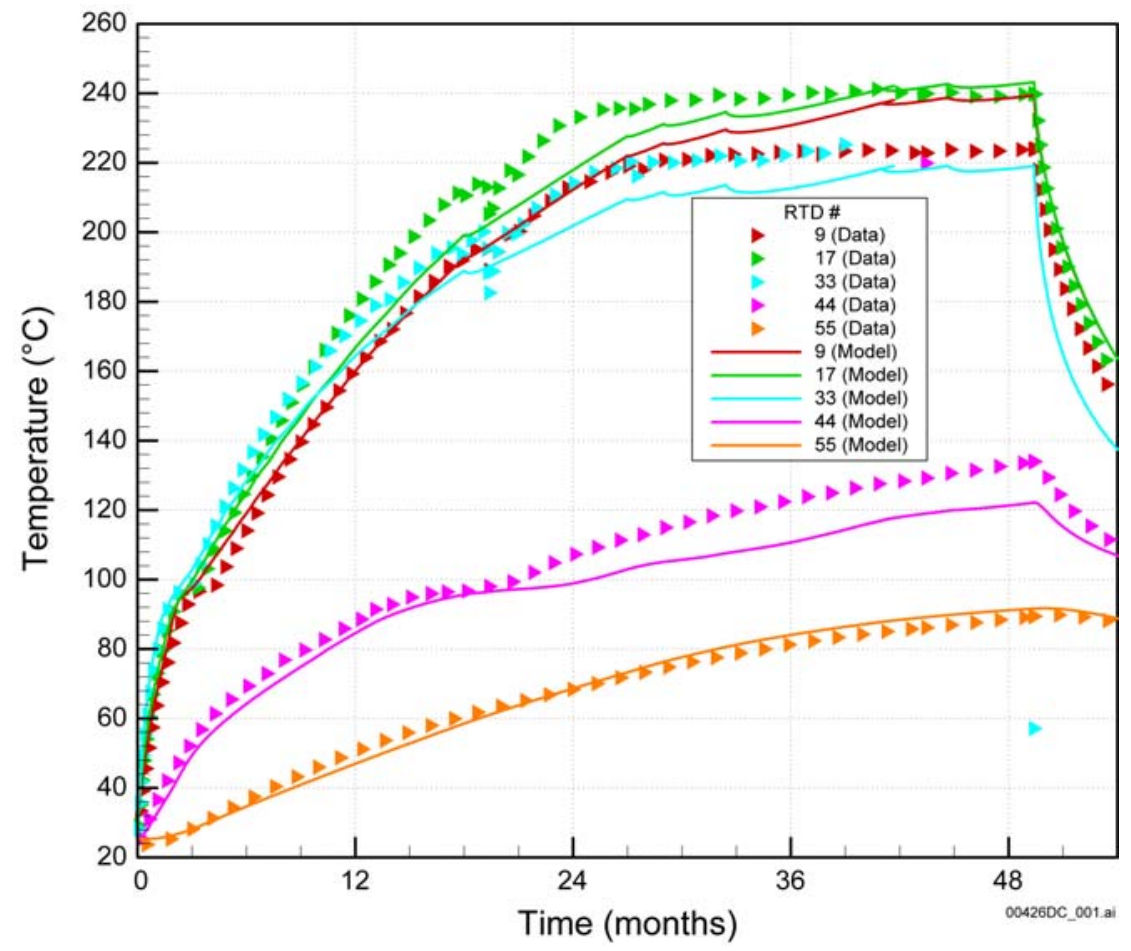

(a)

Output DTN (for Figures 7.4.3.1-3a through 3c): LB0303DSCPDSTV.001.

Input DTNs (for Figures 7.4.3.1-3a through 3c): MO9807DSTSET01.000 [DIRS 113644], MO9810DSTSET02.000 [DIRS 113662], MO9906DSTSET03.000 [DIRS 113673], MO0001SEPDSTPC.000 [DIRS 153836], MO0007SEPDSTPC.001 [DIRS 153707], MO0012SEPDSTPC.002 [DIRS 153708], M00107SEPDSTPC.003 [DIRS 158321], MO0202SEPDSTTV.001 [DIRS 158320]; MO0208SEPDSTTD.001 [DIRS 161767]

Figure 7.4.3.1-3. Temporal Evolution of Temperature in Selected Sensors of Boreholes (a) 160, (b) 59, and (c) 60 


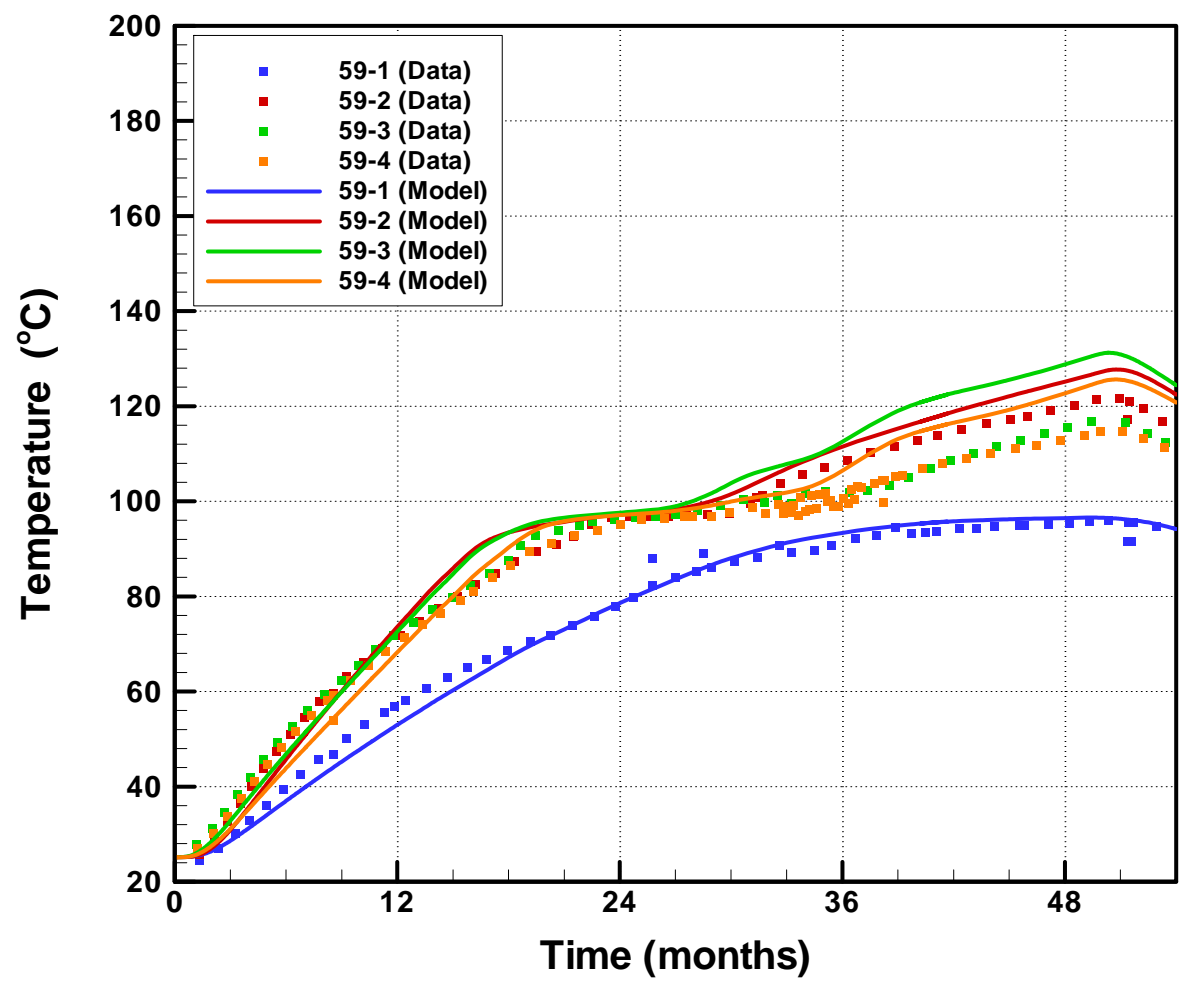

(b)

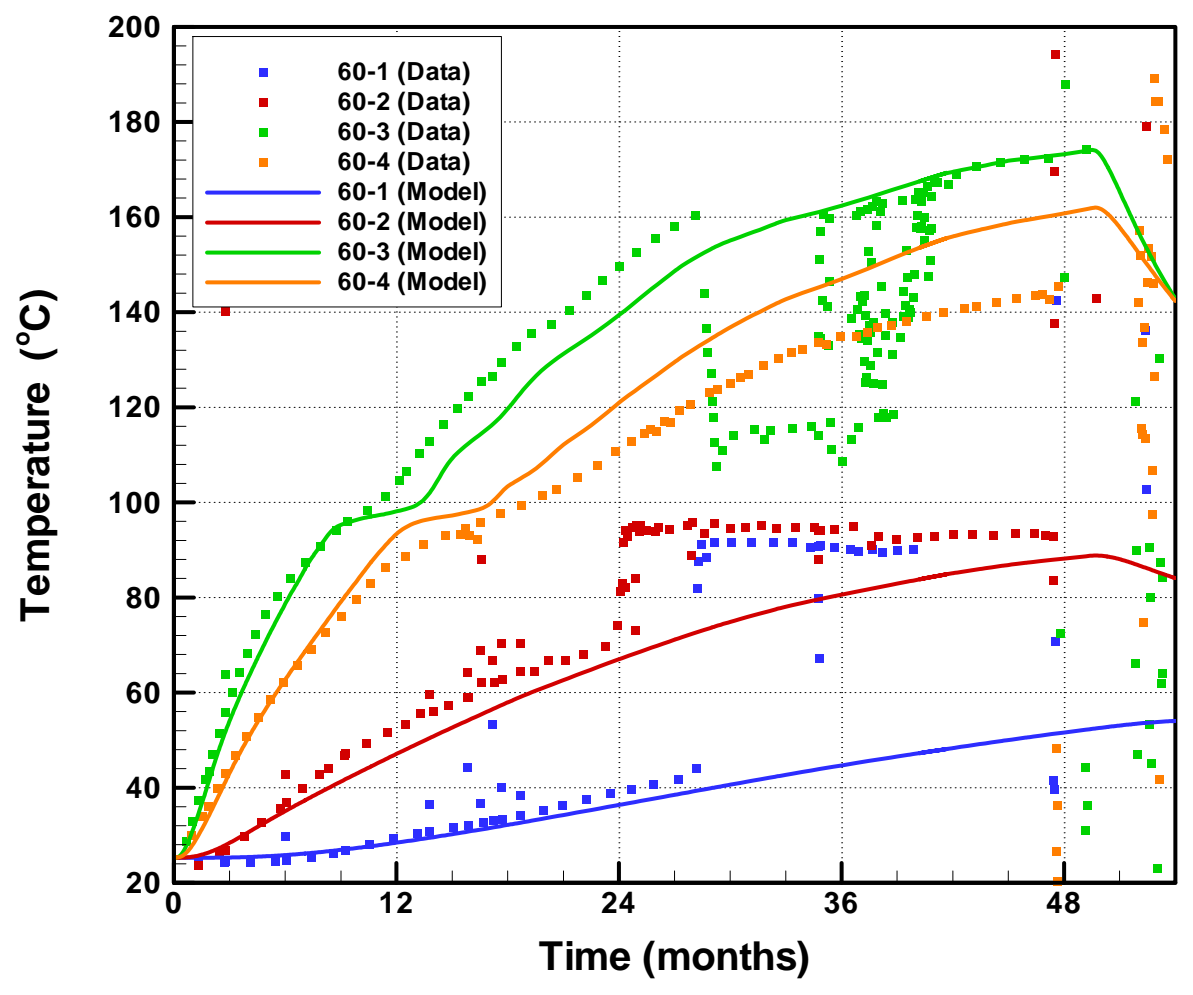

Figure 7.4.3.1-3 (Continued). Temporal Evolution of Temperature in Selected Sensors of Boreholes (a) 160, (b) 59, and (c) 60 
The sensors in borehole 160 show a wide variety of temperature responses, depending on their location with respect to the heat sources (Figure 7.4.3.1-3a). The three sensors 160-9, 160-17, and 160-33 are all located directly above wing heater segments, and thus exhibit strong thermal perturbation. Both measured and simulated curves have short heat-pipe signals, indicating that rock water is boiled off within a short time period. At later heating stages, the measured temperatures run slightly higher than the simulated ones, as discussed in the previous section. Sensors with this close proximity to the wing heaters show the effect of the smeared-out heater representation in the model. (Note that Sensor 160-33 stopped functioning at about 37 months of heating.) Sensor 160-44 measures rock temperature close to the tip of the wing heater, a few meters further into the rock. The temperature increase is slower and a heat pipe of significant duration evolves, beginning at about 15 months and lasting for 6 to 9 months. This indicates that the fractured rock at the location of this sensor remained in the two-phase boiling zone during this entire time period, and became dry afterwards as the boiling front eventually moved further away from the heater. While both curves exhibit the same starting point, the simulated temperature results show a slightly longer duration of the heat-pipe signal compared to the measured data. Finally, Sensor 160-55, with the largest distance into the rock, remains below boiling temperature for the entire heating phase. The measured and the simulated results match well for this sensor. Figure 7.4.3.1-3a also shows temperature evolution during the first 5.5 months of cooling. The higher the temperature at the end of heating, the steeper the drop in temperature when the heaters are turned off. For most sensors, the temperature decrease during cooling appears to be slightly more pronounced in the measured data compared to the simulated results. This may indicate that heat capacity is overestimated in the model. However, a longer observation period would be needed to test this hypothesis.

The maximum temperatures in borehole 59 are smaller than those recorded in borehole 160, because of the larger distance from the heat sources (Figure 7.4.3.1-3b). Sensor 59-1, closest to the borehole collar, reaches only about $88^{\circ} \mathrm{C}$ at the end of heating phase. The other sensors in borehole 59 record higher temperatures, reaching about $115^{\circ} \mathrm{C}$ towards the end of heating phase. Each of these sensors records a heat-pipe signature of considerable duration, beginning at about 19 months of heating and lasting for close to a year. The long duration of the heat-pipe signal is caused by a significant reflux of water from the condensation zone back to the boiling region, driven by gravitational and capillary forces. Notice that the agreement between measured and simulated temperatures is good in all the four sensors of borehole 59. In particular, the duration of the heat-pipe signal is accurately captured by the numerical model. Good agreement is also seen during the first 5.5 months of cooling.

Compared to borehole 59, borehole 60 is slightly closer to the heat sources, and runs below the Heated Drift instead of above it (Figure 7.4.3.1-3c). Sensors 60-1 and 60-2 record the smallest temperatures, owing to their location several meters sideways from the tip of the wing heaters. They remain below boiling temperatures during the entire test phase, and reasonably good agreement is seen between the measured and simulated curves. The other two sensors, 60-3 and 60-4, record much higher temperatures. Both sensors exhibit heat-pipe signals, though they appear earlier than those in borehole 59 and are of shorter duration. Part of this is caused by the closer proximity of the two sensors to the heat source compared to the sensors in 59. However, the main reason for the shorter duration two-phase conditions in 60 is that the borehole is below the Heated Drift. Here, most of the condensate that accumulates outside the boiling zone will drain downwards with gravity away from the DST rock. While both the measured and simulated 
temperatures exhibit short heat-pipe signals compared to borehole 59, the simulation results show more pronounced signals of longer duration. Section 7.4.4 discusses how these subtle differences lead to interesting conclusions regarding the use of the DKM model for fracture-matrix interaction versus the AFM model. Note that the distortions in measured temperature data (sudden rise in 60-1 and 60-2, sudden drop in 60-3) are caused by deflation (failure) of the packers in the borehole. The temperature sensors in boreholes 59 and 60 are not grouted; instead, they are attached to the packer string in the open borehole. Hence, once the packers are deflated, the borehole acts as an open conduit for vapor flow, and temperature in measurement intervals that were originally isolated by packers can easily equilibrate with each other. The packer strings were removed in November 2001, just prior to end of heating. Therefore, no temperature data are available from this borehole during cooling.

In general, the agreement between measured and simulated temperature history is good for all three boreholes, comparing temperature sensors that are representative of locations with fairly different $\mathrm{TH}$ behavior. In particular, the temporal evolution of heat-pipe signals has been well represented by the model. For a few sensors, namely 60-3 and 60-4, the predicted heat pipes are of longer duration than the measured heat pipes. Section 7.4.4 demonstrates that these differences can in part be explained by the conceptual model used for fracture-matrix interaction.

\subsection{Temperature Statistics}

Discussions in Sections 7.4.3.1.1 and 7.4.3.1.2 indicate qualitatively good agreement between measured and simulated temperatures. Results from the statistical analysis of measured and simulated temperatures at the DST are presented for a more quantitative validation. The two statistical measures used are the mean difference and the root mean square difference, the former revealing a systematic bias, the latter giving the overall accuracy of the simulation compared to the measured data (see Section 7.4.2).

Table 7.4.3.1-1. Statistical Comparison of Measured and Simulated Temperatures

\begin{tabular}{|c|c|c|}
\hline Time (months) & \multicolumn{2}{|c|}{ Statistical Measure } \\
\hline & Mean Difference (MD) $\left({ }^{\circ} \mathbf{C}\right)$ & $\begin{array}{c}\text { Root Mean Square Difference } \\
\left.\text { (RMSD) ( }{ }^{\circ} \mathbf{C}\right)\end{array}$ \\
\hline 6 & 0.01 & 5.63 \\
\hline 12 & -0.15 & 7.21 \\
\hline 18 & 0.90 & 8.72 \\
\hline 24 & 1.06 & 9.79 \\
\hline 30 & 1.27 & 10.49 \\
\hline 33 & 1.65 & 10.61 \\
\hline 36 & 2.01 & 11.27 \\
\hline 42 & 2.95 & 12.60 \\
\hline 48 & 3.59 & 12.80 \\
\hline 5 months cooling & 4.34 & 8.12 \\
\hline
\end{tabular}

NOTE: The following DTNs give simulated and measured temperature data that were used to calculate the statistical measures given above, as defined in Section 7.4.2. Simulated Temperature is from Output DTN: LB0303DSCPDSTV.001. Measured Temperatures are from Input DTNs: MO9807DSTSET01.000 [DIRS 113644], MO9810DSTSET02.000 [DIRS 113662], MO9906DSTSET03.000 [DIRS 113673], MO0001SEPDSTPC.000 [DIRS 153836], MO0007SEPDSTPC.001 [DIRS 153707], MO0012SEPDSTPC.002 [DIRS 153708], MO0107SEPDSTPC.003 [DIRS 158321], MO0202SEPDSTTV.001 [DIRS 158320]; MO0208SEPDSTTD.001 [DIRS 161767] 
From Table 7.4.3.1-1, the mean difference is mostly positive and increases slowly through successive months of heating. A positive mean difference implies that overall the temperatures from the DST TH model are higher than the measurements. For example, at 24 months of heating, simulated temperatures are on an average $1.06^{\circ} \mathrm{C}$ higher than measured temperatures. The difference increases with continuation of heating, reaching $3.59^{\circ} \mathrm{C}$ at the end of heating and $4.34^{\circ} \mathrm{C}$ at 5 months of cooling. That the mean difference between the simulated and the measured temperatures is always less than $5^{\circ} \mathrm{C}$, i.e., less than 2 percent of the maximum rock temperature at the end of heating and much smaller than the validation criterion of less than $10^{\circ} \mathrm{C}$ mean difference, is significant considering the complicated nature of the DST and the uncertainties involved in modeling the thermal hydrology in an open field test like the DST.

The root mean square difference, though increasing rapidly at the early phases of heating, plateaus during later phases of heating and the first 5 months of cooling. The maximum value of root mean square difference of about $12.8^{\circ} \mathrm{C}$, on the order of about 5 percent of the maximum rock temperature, indicates a reasonably good statistical fit between measured and simulated temperatures. In addition, though the RMSD increases with time, it begins to plateau towards the end of the heating period. This trend provides confidence that, even if the test were to be run for a longer period, RMSD would have been within acceptable limits (i.e., there would still be good fit between measured and predicted temperature data). These results, involving more than 1,700 sensors, together with the illustrations of the temperature profiles and the temporal evolution of temperatures shown in Section 7.4.3.1.1 and 7.4.3.1.2, indicate that the $\mathrm{TH}$ processes have been accurately captured in the DST TH model.

\subsubsection{Water Redistribution: Matrix Saturation}

TH processes of water boiling, vapor transport and subsequent condensation, drainage in fractures, and imbibition of water into the matrix result in redistribution of moisture in the DST block. As presented in Section 7.4.1, saturation changes in the rock matrix in the DST are tracked by neutron logging, ERT, and GPR. All three types of measured data show existence of dryout zones in the matrix that expand with time and build-up of condensate outside the dryout regions where matrix saturation increases from the ambient value. To validate the DST TH model, the matrix saturation predicted by the DST TH model is compared against measured geophysical-radar-tomography data. The goal is to demonstrate that the DST TH model captures the essential elements of the coupled $\mathrm{TH}$ processes expected to occur in the rock matrix. It needs to be emphasized that, because of the qualitative nature of measured geophysical data, the comparison between measured and simulated matrix saturation is also qualitative. Nevertheless, matching the patterns and time evolution of simulated and measured dryout and condensation zone does provide effective validation for the dominant TH processes. In this report, GPR data are used for comparison with simulated results.

The following sequence of Figures 7.4.3.2-1a through 7.4.3.2-3a show the contours of change in matrix water saturation from preheat ambient conditions as obtained from GPR measurements, at time snapshots of approximately 14 (January 1999), 23 (October 1999), and 49.5 (January 2002) months of heating. (Heating started on 12/03/1997 and lasted until 01/14/2002.) For comparison with the simulated saturation values, the water content data initially derived from the GPR measurements (DTN: LB0210GPRDSTHP.001 [DIRS 160895]) have been divided by the matrix porosity of the Tptpmn rock unit (0.11). The GPR measurements are obtained in a cluster 
of boreholes designated for geophysical measurements (boreholes 47 to 51), bracketing the Heated Drift at a distance of about $6 \mathrm{~m}$ from the bulkhead (see Figure 7.2.2-3). From this cluster, borehole 49 above the drift and boreholes 50 and 51 below the drift had been selected for cross-borehole GPR testing. Thus, the rock volume covered is bounded between these boreholes. For comparison with the measured results, the simulated saturation changes from the ambient conditions are plotted in Figures 7.4.3.2-1b through Figures 7.4.3.2-3b. The time snapshots selected here are 12, 24, and 48 months of heating, slightly different from the respective GPR collection times, as the full simulation output from the TOUGH2 runs was produced on a 6-month basis. 
(a)

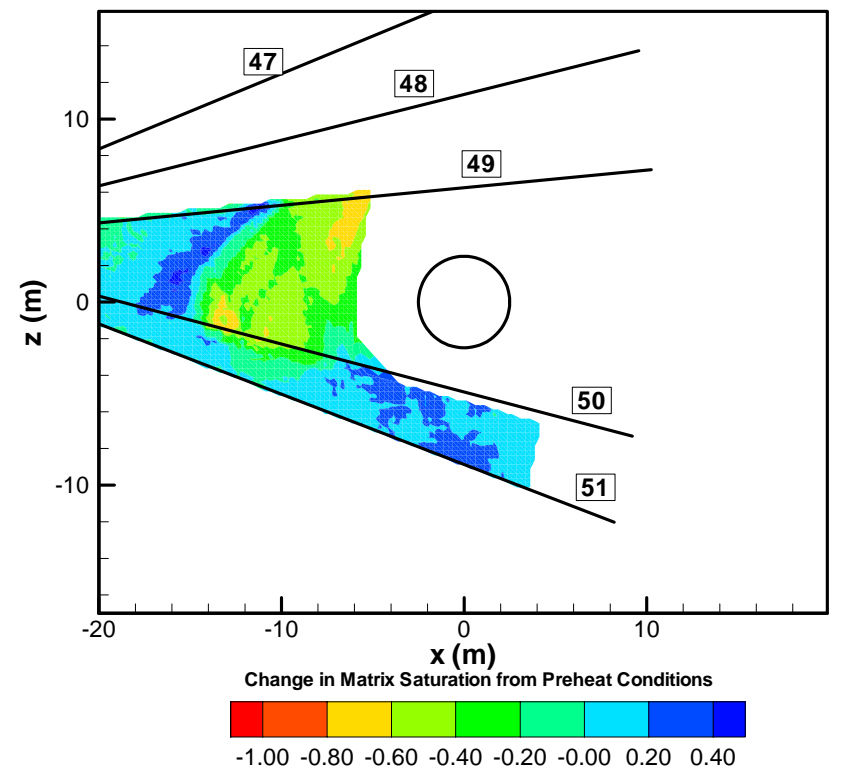

Derived from Input DTN: LB0210GPRDSTHP.001 [DIRS 160895].

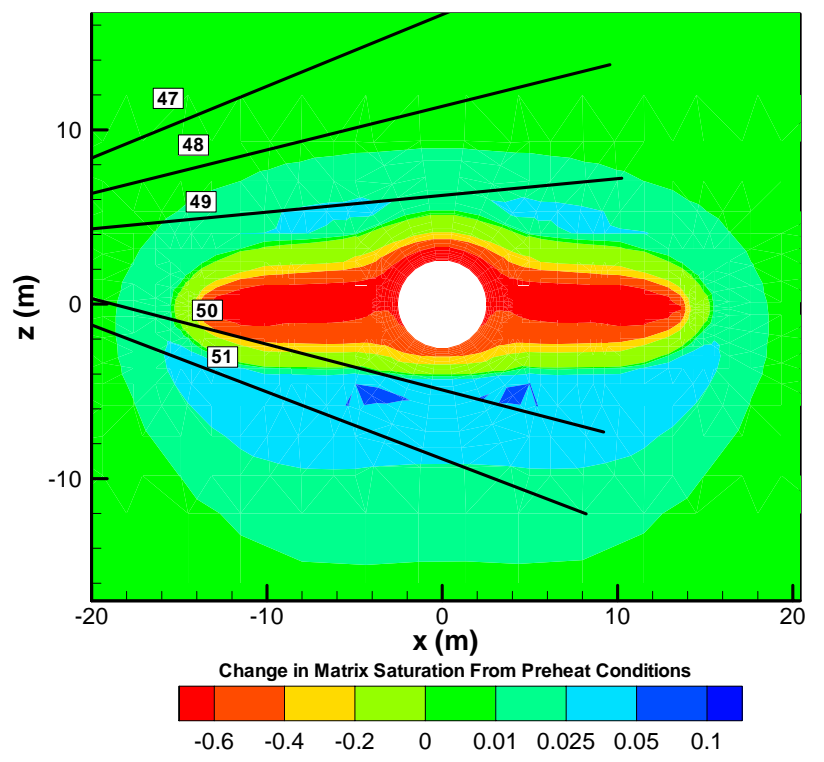

(b)

$\begin{array}{llllllll}-0.6 & -0.4 & -0.2 & 0 & 0.01 & 0.025 & 0.05 & 0.1\end{array}$

Output DTN: LB0303DSCPDSTV.001.

Figure 7.4.3.2-1 Change in Matrix Saturation from Preheat Saturation (a) Measured GPR Results in Boreholes 49 to 51 in January 1999 (Approximately 14 Months of Heating) and (b) Simulated Results at 12 Months of Heating 


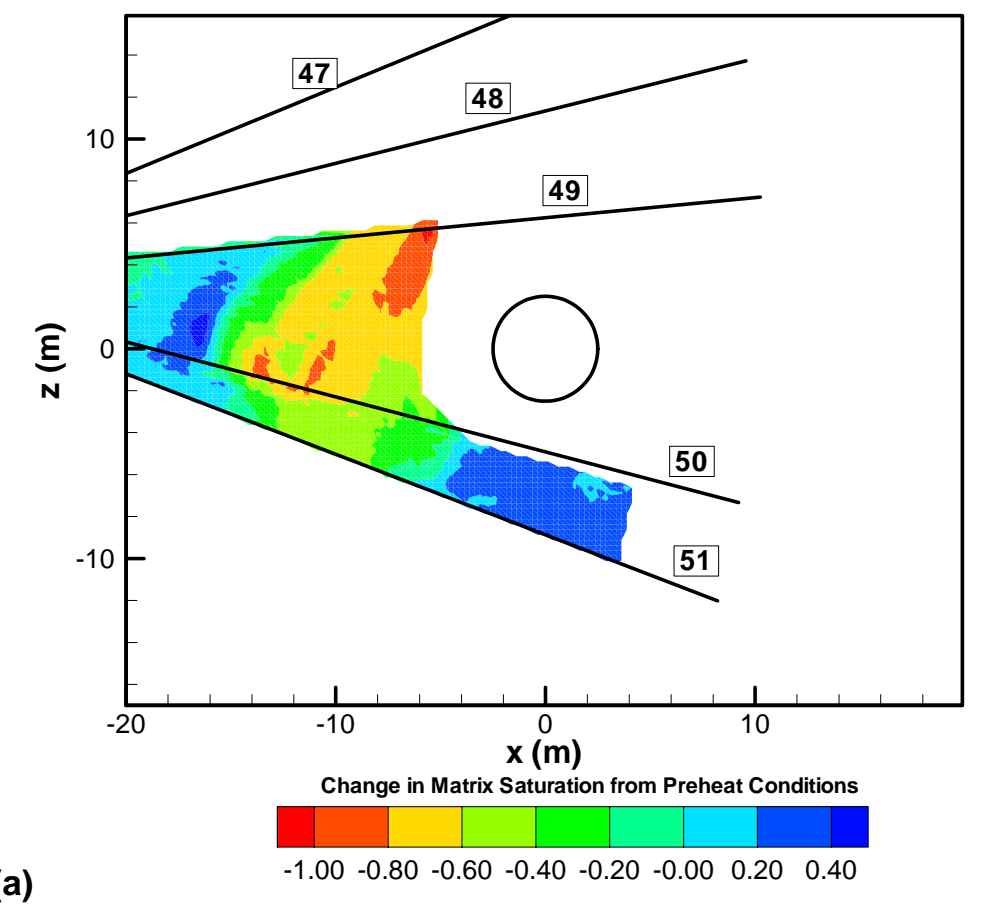

Derived from Input DTN: LB0210GPRDSTHP.001 [DIRS 160895].

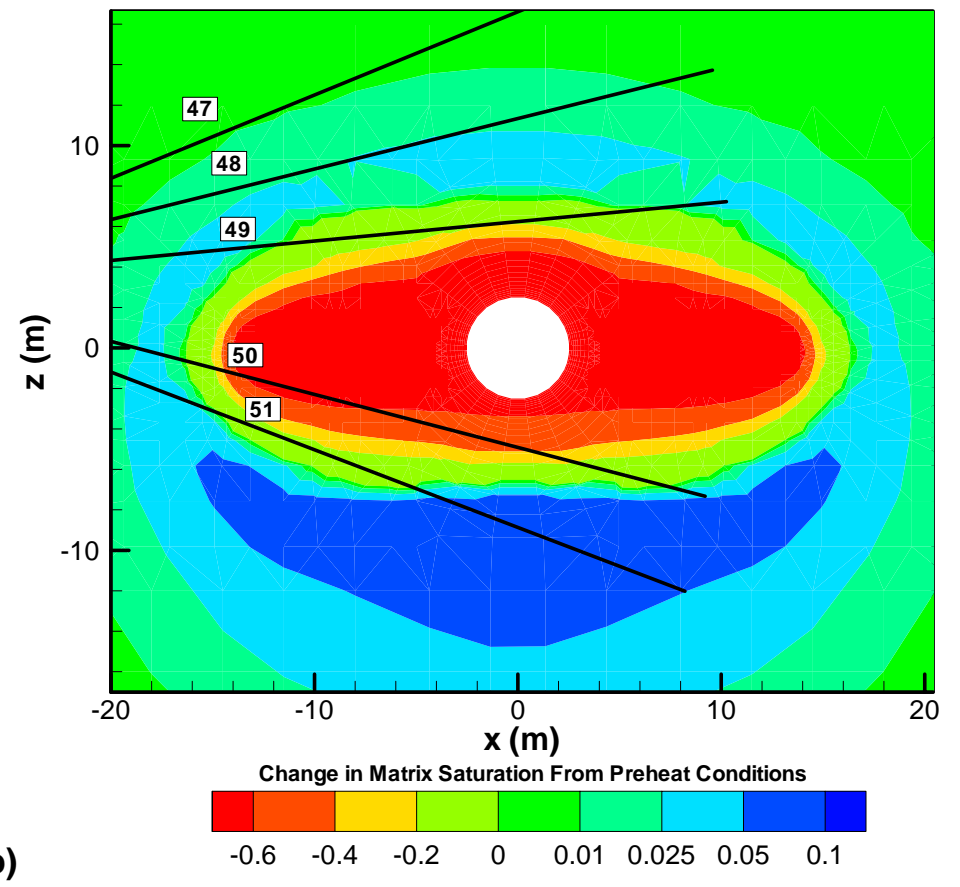

Output DTN: LB0303DSCPDSTV.001.

Figure 7.4.3.2-2. Change in Matrix Saturation from Preheat Saturation (a) Measured GPR Data in Boreholes 49 to 51 in October 1999 (Approximately 23 Months of Heating) and (b) Simulated Results at 24 Months of Heating 


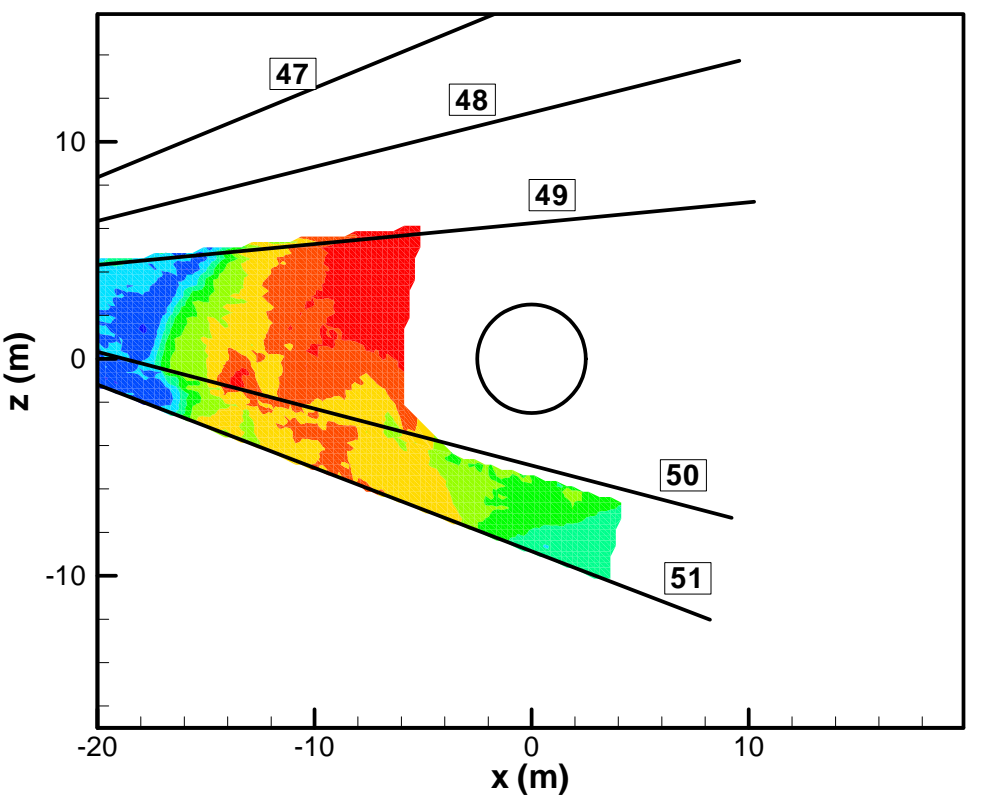

(a)

Change in Matrix Saturation from Preheat Conditions

Derived from Input DTN: LB0210GPRDSTHP.001 [DIRS 160895].

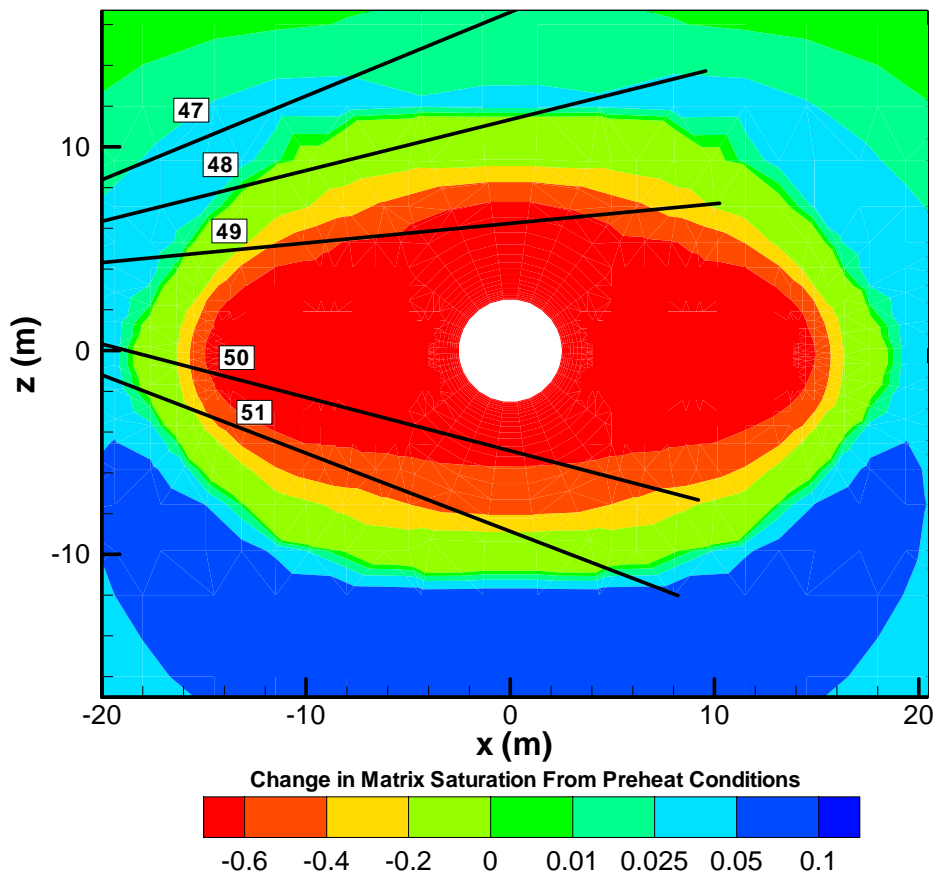

(b)

Output DTN: LB0303DSCPDSTV.001.

Figure 7.4.3.2-3. Change in Matrix Saturation from Preheat Saturation (a) Measured GPR Data in Boreholes 49 to 51 in January 2002 (Near the End of Heating) and (b) Simulated Results at End of Heating Phase 
Figure 7.4.3.2-1 shows the matrix saturation changes at approximately 1 year of heating. The measured results indicate a significant volume of rock that has saturation less than ambient. The red, yellow, and greenish colors in this figure imply decrease in saturation (or drying), while the blue colors indicate increase in saturation (wetting or condensation). The dryout zone extends mainly between boreholes 49 and 50; however, dryout is also seen at the tip of the wing heater between boreholes 50 and 51. Increase in saturation occurs below the heated area between boreholes 50 and 51, and in the rock just outside of the wing heater tip between boreholes 49 and 50. These observations are now compared with the simulation results. Here, the color map is slightly different. The red, yellow, and light green colors show drying. Increase in saturation corresponds to dark green or blue colors. Comparison indicates that there is remarkable consistency in the location of the dryout and condensation zones between the two plots (i.e., drying between boreholes 49 and 50, and also between 50 and 51 at the tip of the wing heater; condensate buildup between 50 and 51 below the heaters, also at the tip of the wing heater just outside of the heated area). The only difference in saturation pattern is seen above the heaters close to borehole 49 , where the measured data indicate that the rock may already be drying.

Similar results can be seen in Figure 7.4.3.2-2, at about 2 years of heating. In both the measured and simulated data, the dryout zone has extended and the saturation decrease in this zone has become more pronounced. Note, for example, that the area between boreholes 50 and 51, close to the tip of the wing heaters, is now fully drying in both plots. Also, signals of condensate buildup are more obvious now in both figures, in particular below the Heated Drift between boreholes 50 and 51. Finally, at the end of heating (Figure 7.4.3.2-3), most of the rock volume bracketed between the GPR boreholes has dried, except for areas outside of the tip of the wing heaters. Again, the agreement between the geophysical measurements and the simulated results is excellent.

Two GPR measurements have been performed during the cooling phase, at approximately 2.5 months of cooling (data collected on 03/25/2002; cooling started 01/14/2002) and at 5 months of cooling (data collected on 06/13/2002). However, the changes in matrix saturation compared to the conditions at the end of heating are very subtle, smaller than the measurement uncertainty related to the GPR method. This is supported by simulation results in which the saturation changes after 6 months of cooling are mostly within \pm 0.05 . Direct comparison of measured and simulated results will be meaningful only for later times when more significant processes of rewetting have occurred; therefore, no results are presented in this report.

\subsubsection{Water Redistribution: Fracture Saturation}

Wetting and drying in fractures (in other words, increase and decrease of liquid saturation) gives rise to changes in air permeability. At the beginning of the heating period, drying first occurs around the Heated Drift and the wing heaters. Just outside of this drying zone, a zone of higher than ambient saturation forms because the produced vapor condenses in cooler areas. Air-injection tests performed in this condensate zone should first exhibit a decrease in air permeability. With continued heating, the drying zone expands, and areas that were initially located in the condensate zone will now be dry. As a result, air permeabilities in these zones should rise because the fracture water content is slightly smaller than at ambient. Thus, by 
tracking air-permeability changes, the movement of drying and wetting in the fractures can be tracked.

It should be noted that THM effects in response to heating-opening and closure of fracturesalso affect air-permeability data. These processes, which are not accounted for in the DST TH model, are explicitly simulated and discussed in Drift Scale THM Model (BSC 2004 [DIRS 169864]), documenting a fully coupled THM model. (THC effects on air permeability, e.g., from mineral precipitation/dissolution, are less relevant for DST. The duration of the DST is too short to show significant effects of fracture aperture changes due to THC processes.) For the comparative interpretation of air-permeability data and $\mathrm{TH}$ simulation results conducted in this report, the expected effects of THM processes are considered in a qualitative manner. Typically, elevated temperatures lead to closure of fractures in the vicinity of the heat sources (giving rise to a decrease in air permeability) and to fracture opening in cooler regions further away from the heat source (giving rise to an increase in air permeability). The measured air permeability comprises the net effect of both TH and THM processes. For example, the TH simulation results may predict an increase in air permeability after going through a minimum as a result of fracture drying after an initial saturation increase. The measured permeability, however, may increase much later than the $\mathrm{TH}$ prediction indicates, because fracture closure continues to occur if the rock temperatures are still high.

First, to illustrate the dynamic movement of the drying and condensation fronts, the simulated contours of fracture saturation are presented in a vertical cross section containing hydrology boreholes 57 through 61. Figures 7.4.3.3-1a through 7.4.3.3-1d show fracture saturation at 12 months, 18 months, 24 months, and at end of heating, respectively. In the end of this section, the measured changes in air permeability resulting from the saturation changes are analyzed, selecting boreholes 59, 60, and 61 for illustration. These boreholes, because of their proximity to the heat sources, experience the most drying and wetting and should exhibit the most prominent changes in air permeability. The numbers along the boreholes indicate the location of injection intervals for air-permeability testing. Typically, the borehole packers used to create separate borehole sections for injection are placed right next to temperature sensors that are shown as circular symbols. Thus, the injection intervals extend roughly either between the deepest sensor in the borehole and the bottom of the hole, between two displayed sensors, or between the borehole collar and the first sensor.

As shown in Figure 7.4.3.3-1a, significant drying (red color) can be seen in the fractures extending about $2 \mathrm{~m}$ above and below the Heated Drift and around the wing heaters at 12 months of heating. (Note that the ambient fracture saturation is about 0.08 to 0.09.) Areas of saturation increase (green and blue color) begin at the boundary of the drying zone and extend to about $5 \mathrm{~m}$ above and more than $15 \mathrm{~m}$ below the Heated Drift. The asymmetric buildup of the condensate zone above and below the Heated Drift is caused by gravity drainage through the fractures. Above the heaters, condensate is draining toward the boiling zone, while condensate below the heaters drains downward away from the boiling zone. The air-permeability changes expected from this saturation field are as follows: hydrology boreholes 57 and 58 should show little change because they are still residing in almost ambient-like saturation condition. In contrast, intervals 2, 3, and 4 in boreholes 59 and 61 are entering the condensate zone at 12 months of heating. These boreholes should exhibit some decrease in air permeability at this time. In borehole 60, interval 2 is partially in the dryout zone, interval 3 is in a transition state, and 
interval 4 is in the condensate zone. In Figure 7.4.3.3-1b, which shows fracture saturation contours at 18 months, the dryout zone has expanded. For example, interval 4 in borehole 60, which was in the condensate zone at 12 months, is now partially in the dryout region. Interval 3, in a transition state earlier, is now fully dry. At 24 months (Figure 7.4.3.3-1c), the dryout zone has expanded enough to fully encompass interval 3 of borehole 59. On the other hand, wetting is possibly occurring in various intervals of borehole 58. Finally, Figure 7.4.3.3-1d shows the fracture saturation at the end of heating. Here, intervals 2, 3, and 4 of boreholes 59, 60, and 61 are mainly in dry-rock regions. Wetting signals should be observed in boreholes 57 and 58 . 


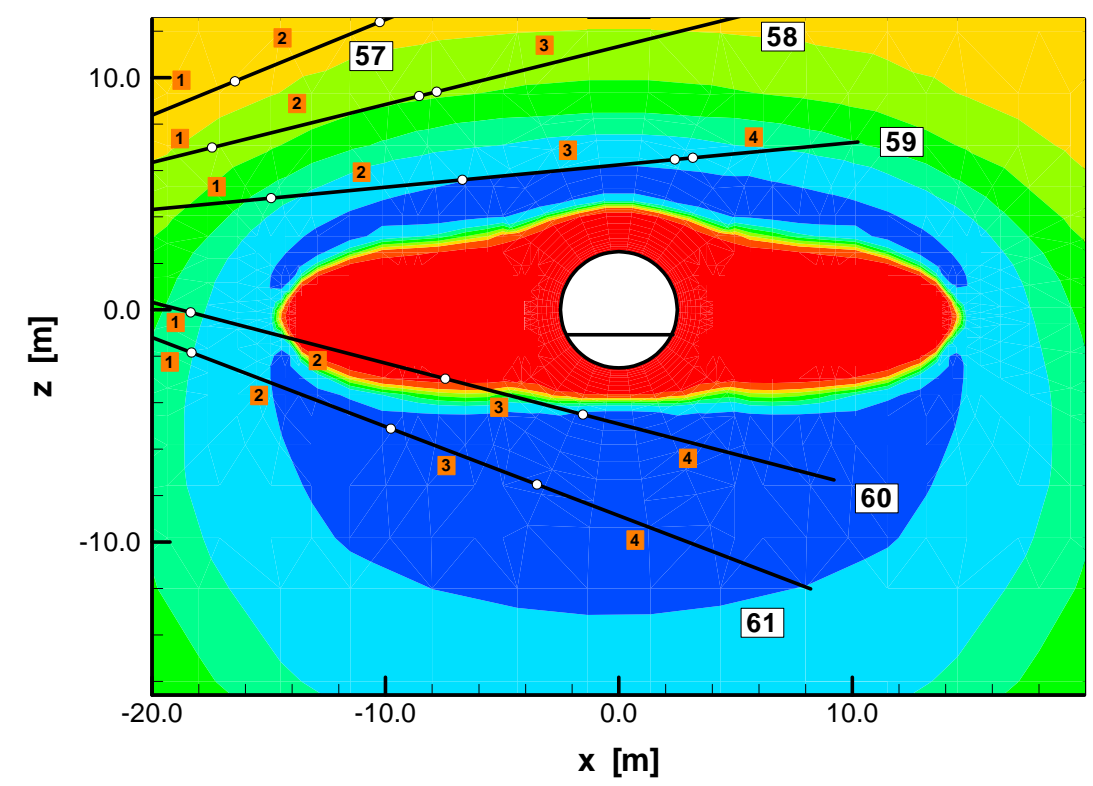

(a)

Fracture Liquid Saturation

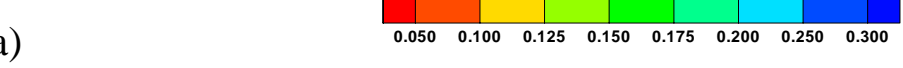

Output DTN: LB0303DSCPDSTV.001.

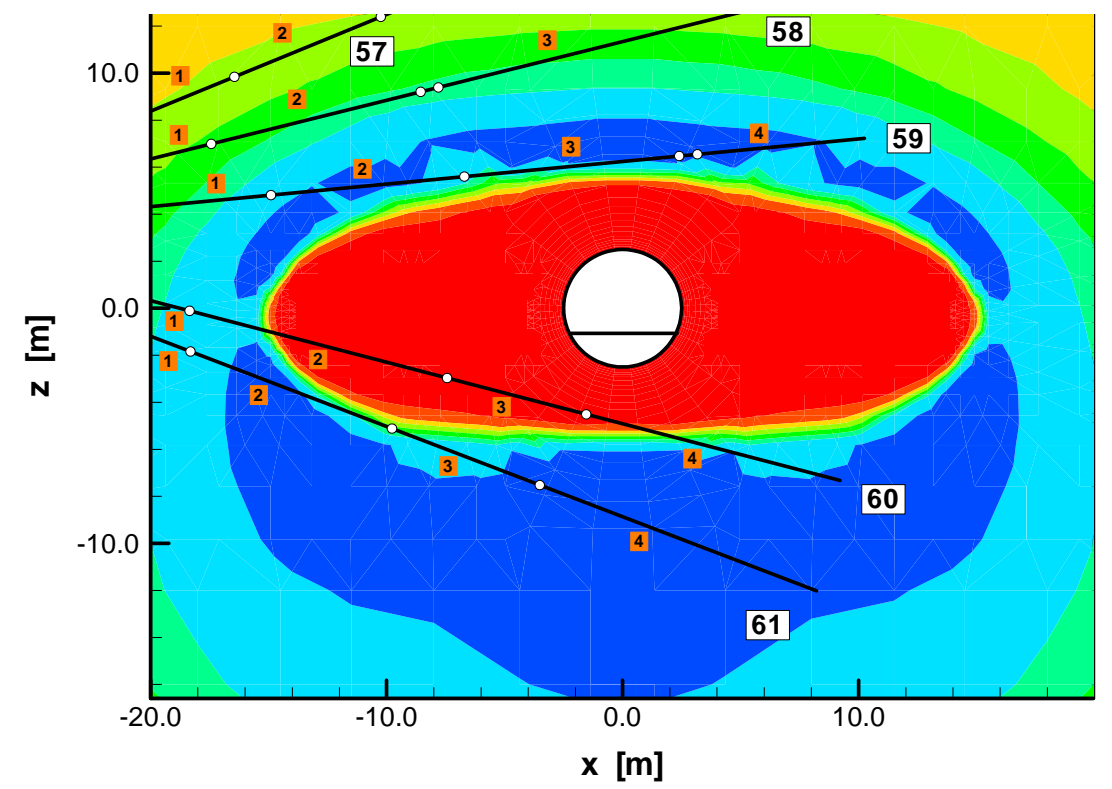

(b)

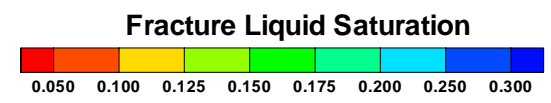

Output DTN: LB0303DSCPDSTV.001.

Figure 7.4.3.3-1. Simulated Contours of Fracture Saturation in Hydrology Boreholes 57 to 61 at Different Times of Heating (a) 12 Months, (b) 18 Months, (c) 24 Months, and (d) at End of Heating Period 


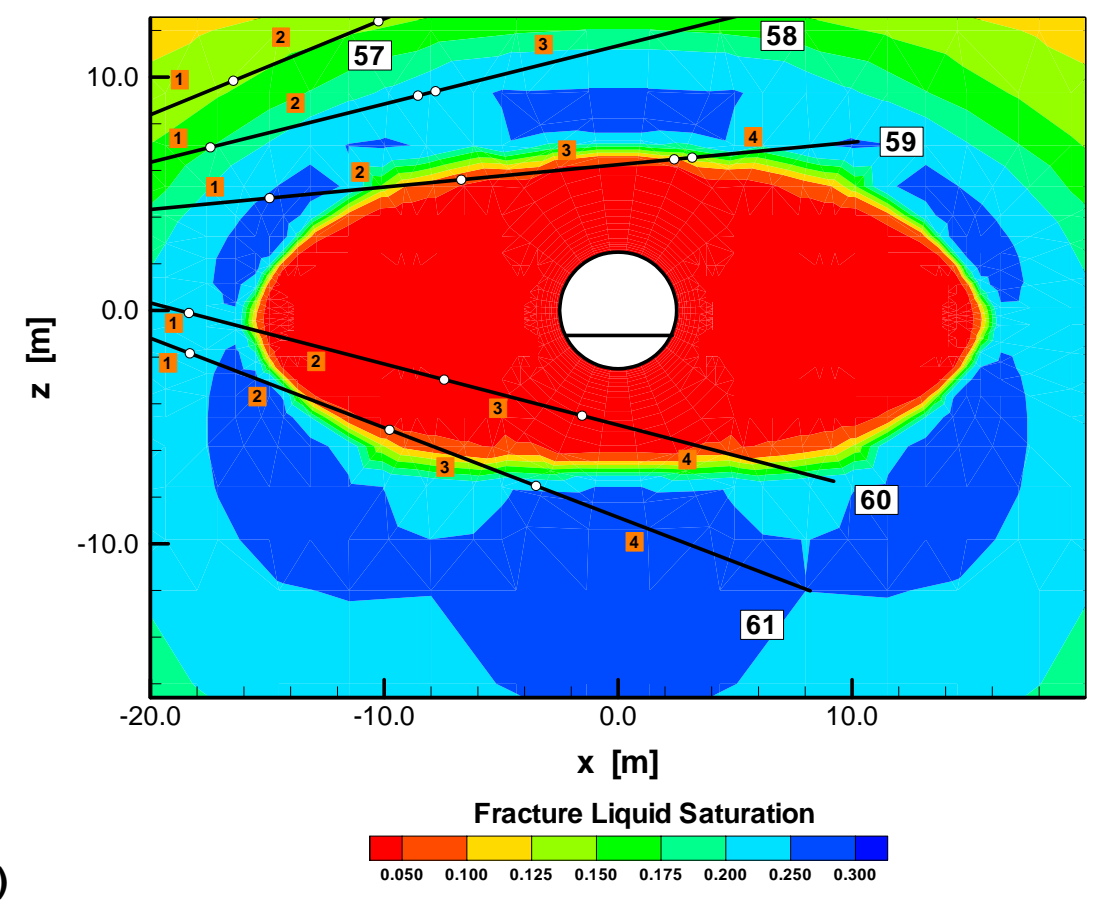

Output DTN: LB0303DSCPDSTV.001.

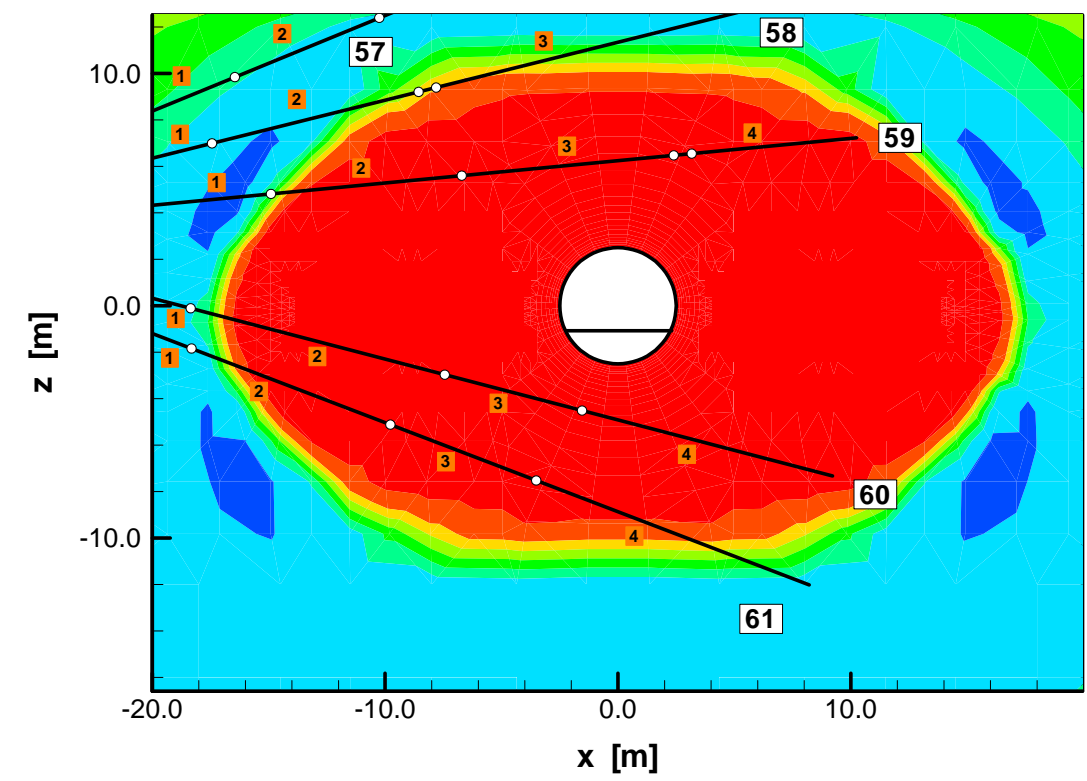

Fracture Liquid Saturation

(d)

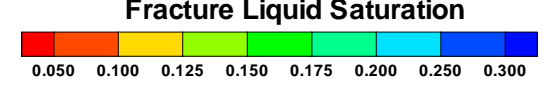

Output DTN: LB0303DSCPDSTV.001.

Figure 7.4.3.3-1 (Continued). Simulated Contours of Fracture Saturation in Hydrology Holes 57-61 at Different Times of Heating (a) 12 Months, (b) 18 Months, (c) 24 Months, and (d) at End of Heating Period 
Figures 7.4.3.3-2a through 7.4.3.3-2c show the measured and simulated air-permeability data as a function of time in boreholes 59, 60, and 61, respectively. Air-injection tests were carried out before start of heating, and preheating ambient air permeabilities were determined for each of the intervals mentioned above. The vertical axis is the ratio of the time-varying air permeability and the preheating ambient air permeability. For the simulated results, air permeabilities have been calculated from simulated water saturation using the modified Brooks-Corey formulation given in Equation 6.2.1.1-13. The saturation value is extracted from those gridblocks of the numerical discretization that are nearest to the center of the injection interval. In some cases, where the injection interval is long and may comprise areas with strongly varying saturation, this procedure may lead to a misinterpretation of the results.

Consider first Figure 7.4.3.3-2a for air-injection test data in borehole 59. Measured air-permeability data in intervals 1,2 , and 3 show a monotonically decreasing trend from preheat values through at least the first two years of heating. Afterwards, they either stabilize (interval 1) or begin to increase (intervals 2 and 3). While interval 2 remains below the pretest value, interval 3 builds up to a value higher than the pretest permeability. Interval 4 has a jump in air permeability in the first few months of heating (which is related to THM effects of fracture opening outside of the hot rock region), then exhibits a steady decline similar to the other intervals and eventually becomes fairly stable towards the very end of the heating phase. Thus, over all intervals, there is a consistent trend of air-permeability decrease, indicating saturation buildup from TH effects and fracture closure from THM effects. This is followed by a period in which air permeability either increases or at least stabilizes, showing that the injection interval measures a decrease in saturation as a result of the extending drying front. During the first heating years, the simulated trend of air-permeability decrease is reasonably consistent with the observations. That the simulated decrease is smaller than the measured change is a result of the additional effect of THM fracture closure. At later times, the simulated increase of air permeability starts too early for intervals 2,3 , and 4 . This again is attributed to continued THM effects near the heat source. While the simulated air permeabilities increase as a result of the predicted drying, the measured air permeabilities remain depressed because of fracture closure due to the still-high temperatures. Note that simulations performed with a fully coupled THM model indicate good quantitative agreement between measured and simulated air-permeability data (BSC 2004 [DIRS 169864], Section 7.4.3). Other factors contributing to differences between observation and simulation are local heterogeneity effects and misinterpretations arising from calculating the simulated air permeability at one point in space (while the measured values are integrated over the borehole interval).

The results shown in Figures 7.4.3.3-2b and 7.4.3.3-2c can be similarly explained. The trends of decrease, as observed in the measured data, are qualitatively represented by the simulation results, while the subsequent increase in the simulated air permeabilities is too early in most cases, because THM changes are not considered in the DST TH model. Note that as a result of packer failure, measurements in borehole 60 were only possible during the first two years of heating. 


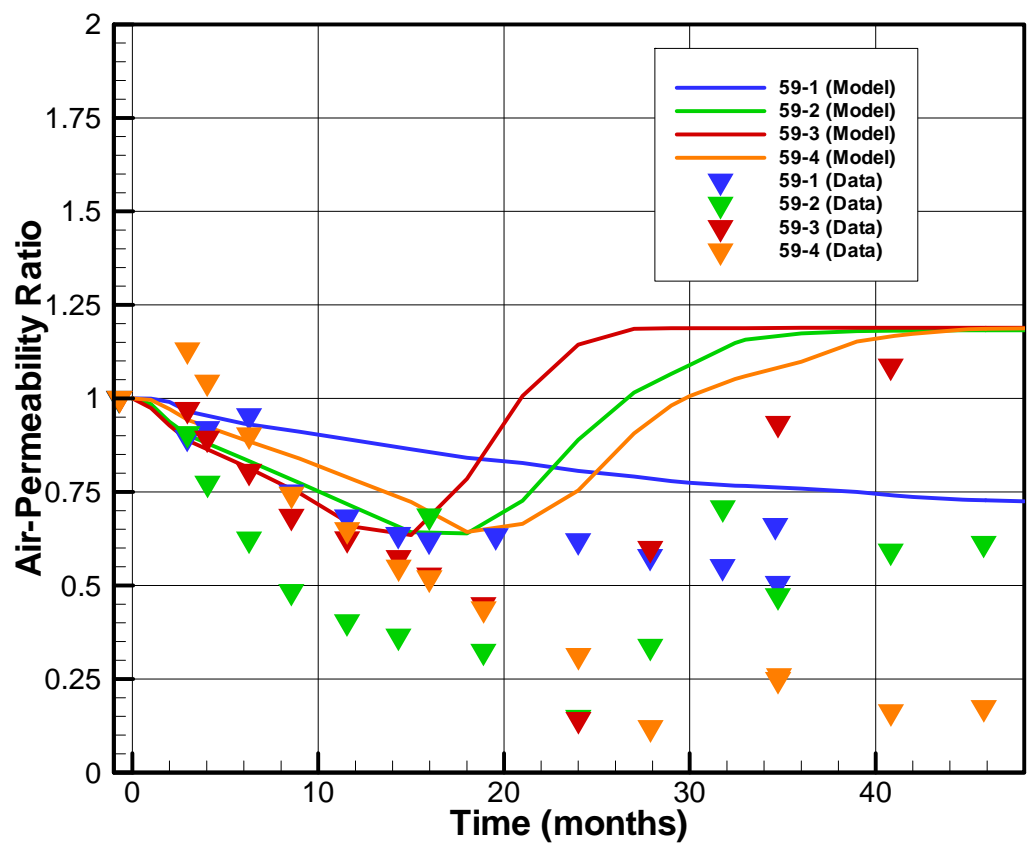

(a)

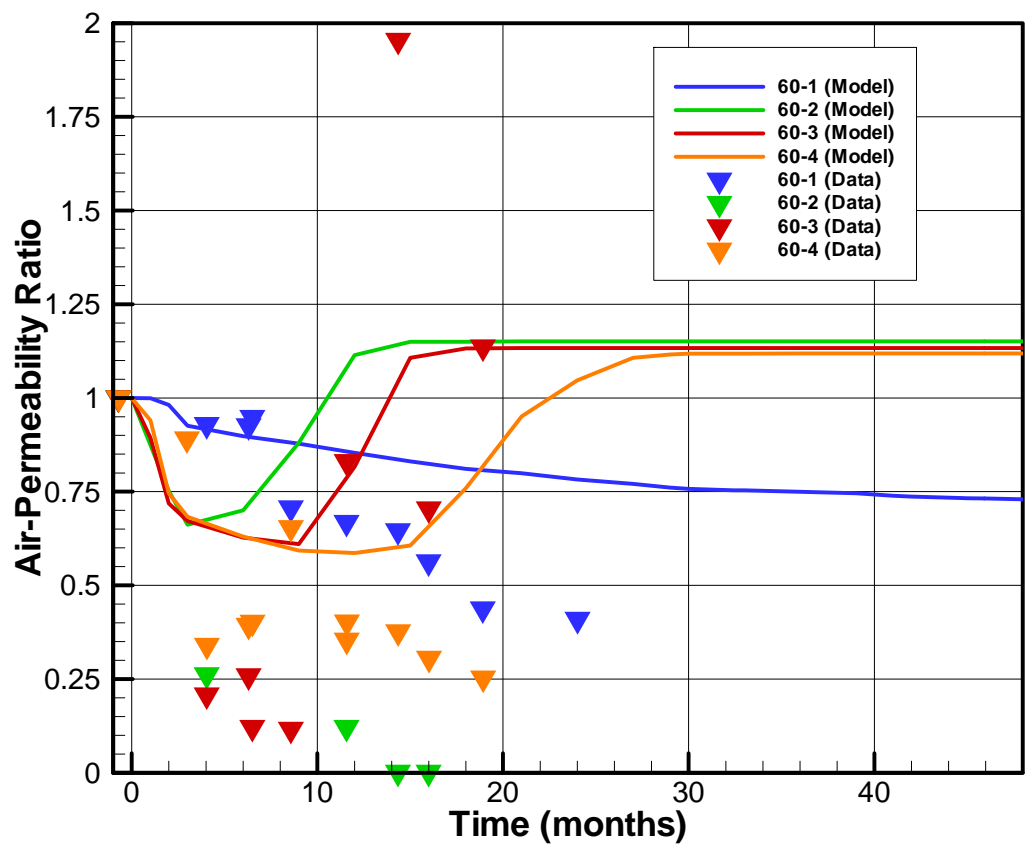

(b)

Input DTN (for Figures 7.4.3.3-2a through 2c): LB0208AIRKDSTH.001 [DIRS 160897].

Output DTN (for Figures 7.3.3.3-2a through 2c): LB0301DSCPDSTV.002.

Figure 7.4.3.3-2. Measured and Simulated Air-Permeability Ratios in Hydrology Boreholes (a) 59, (b) 60, and (c) 61 


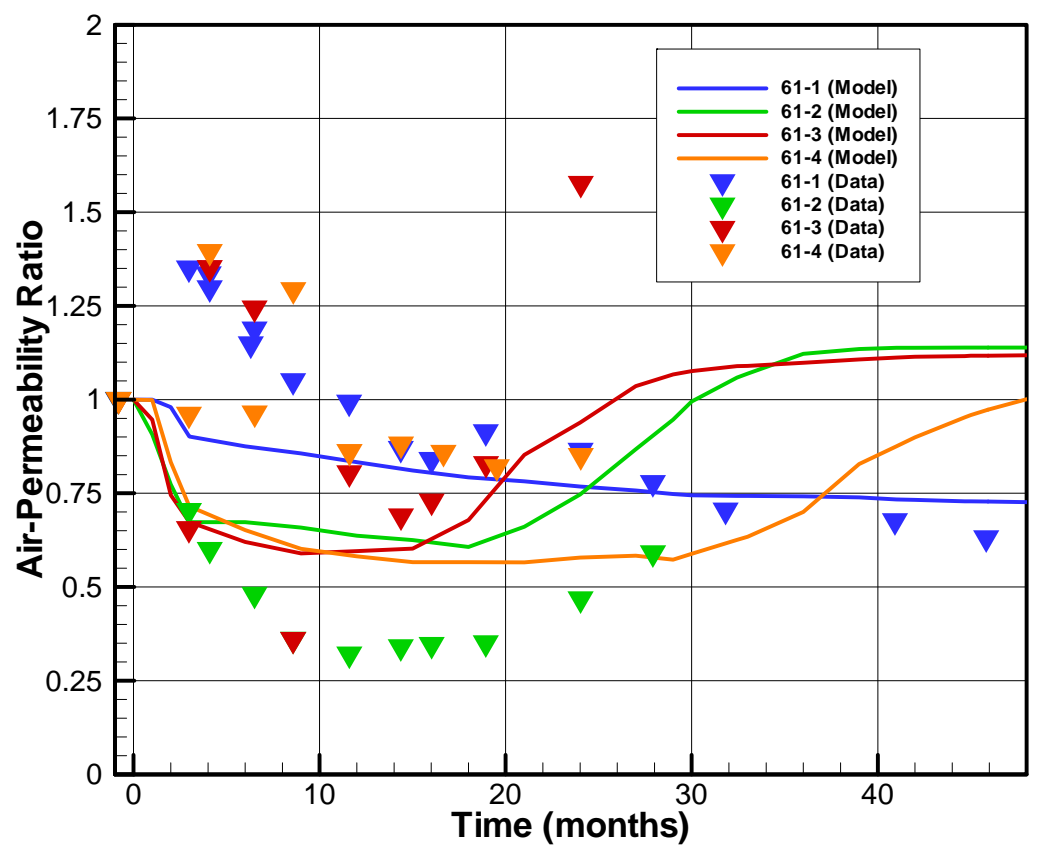

(c)

Figure 7.4.3.3-2 (Continued). Measured and Simulated Air-Permeability Ratios in Hydrology Boreholes (a) 59, (b) 60, and (c) 61

After heater turn-off in the DST, condensate water residing in the wetter zones of the rock should drain downward, away from the heated areas. Because little additional vapor is generated, the previously wetter zone should exhibit saturation decrease. This is observed from simulated contours of fracture saturation. For example, see Figure 7.4.3.3-3 for simulation results at 6 months of cooling, showing the difference in fracture saturation at this time from that at the end of heating. Some localized drying (decrease in saturation indicated by red color) is visible in the previously wet zones, just outside of the dryout region. Close to the heaters, fracture saturation remains unchanged, as rock temperature is still above boiling at 6 months of cooling. Thus, air-permeability data in most injection intervals should hardly change from the latest measurements during the heating phase. This is supported by preliminary analysis of air-injection tests conducted during cooling, indicating almost no permeability changes compared to tests performed at the end of the heating phase (Wang 2004 [DIRS 170510]). Results of these tests during cooling are therefore not presented in this report. 


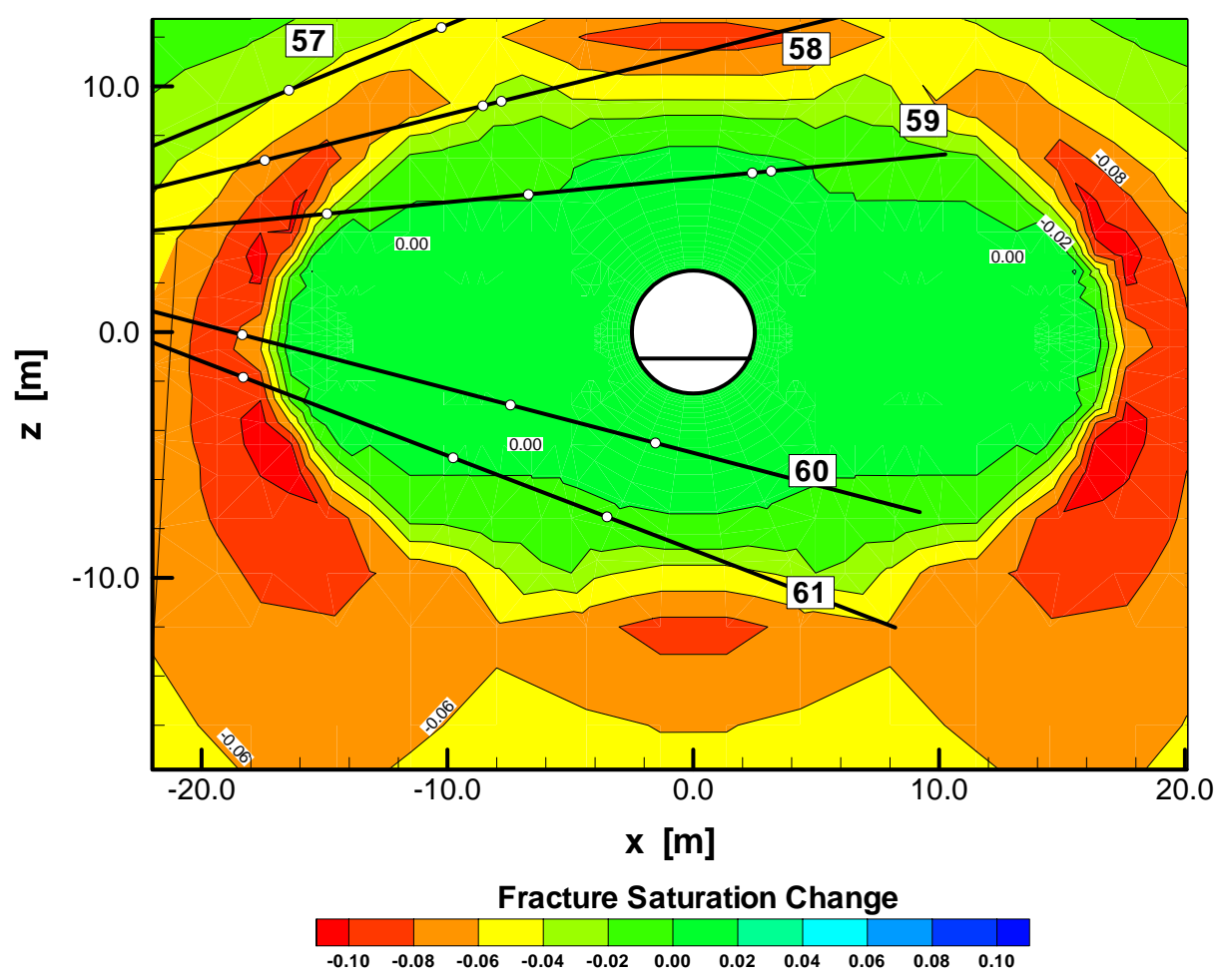

Output DTN: LB0303DSCPDSTV.001.

Figure 7.4.3.3-3. Contours of Change in Fracture Saturation from End of Heating to 6 Months of Cooling

In addition to air-permeability data, the temporal and spatial evolution of moisture buildup in fractures can also be evaluated by analysis of water collection in packed-off borehole intervals bracketing the Heated Drift. Increased liquid saturation in fractures within the condensation zone raises the plausibility of water seeping into borehole intervals residing at these locations. Water seepage into borehole intervals is typically promoted by increased water saturation, small-scale heterogeneity, and the presence of discrete fractures ending at the borehole wall. Since the numerical model does not explicitly account for these effects, it cannot predict the possibility of seepage into boreholes. Also, the specific location and rate of water flow into boreholes cannot be simulated in case seepage occurs. However, the general location of seepage into boreholes should coincide with regions of elevated fracture saturation. Thus, the water collection data can be used to analyze whether the simulated trends in fracture saturation are accurate. (This analysis is in addition to the model validation criteria established in BSC 2004 [DIRS 170236], Section 2.2.1.4.)

During the heating phase of the test, water samples were collected periodically (roughly every few months) from packed-off intervals in the three arrays of hydrology boreholes 57 to 61, 74 to 78, and 185 and 186. Water was produced in several intervals at several collection dates, as listed in Table 6.3.4.1-1 of Thermal Testing Measurements Report (BSC 2004 [DIRS 169900]). In some cases, water was collected in rock regions that were above boiling. In these cases, water vapor condensed while it was pumped through the cooler sample tubing and was collected as a sample of water. For the analysis below, these samples were not considered; i.e., only such samples were analyzed that clearly comprised water that had been in contact with the rock. 
Categorization of water samples that stem from condensation of vapor in tubes is fairly straightforward because the chemistry of such samples typically exhibits very dilute mineral concentrations, consistent with distilled water. Also, such samples are typically collected at smaller pumping flow rates than the liquid water samples and often have a very low $\mathrm{pH}$ value.

Figures 7.4.3.3-4a through 7.4.3.3-4h show the evolution of fracture saturation extracted from the simulated results at a gridblock representative of the location of borehole intervals 59-2, 59-3, 59-4, 60-2, 60-3, 76-2, 76-3, and 186-3. These are the borehole intervals that produced liquid water samples from the start of the test through January 14, 2002. The vertical lines in these figures indicate the dates at which water was pumped out of the respective borehole intervals. (Thus at all other sample times except for these dates there was either no water in the borehole or the water was identified as water that had condensed in the tubing.) In most cases, the simulated time period of elevated saturation at the borehole interval corresponds reasonably well with the water collection times. The remaining differences can be attributed to small-scale heterogeneity, effects of discrete fractures and the fact that the simulated saturation evolution is calculated from one representative point in space (while the water may enter the borehole over the entire length of the interval). Note that no water was collected in some other instrumented borehole intervals with similar predicted saturation history. This suggests that the small-scale heterogeneity and fracture geometry in borehole vicinity are similarly important to water seepage as fracture saturation. 


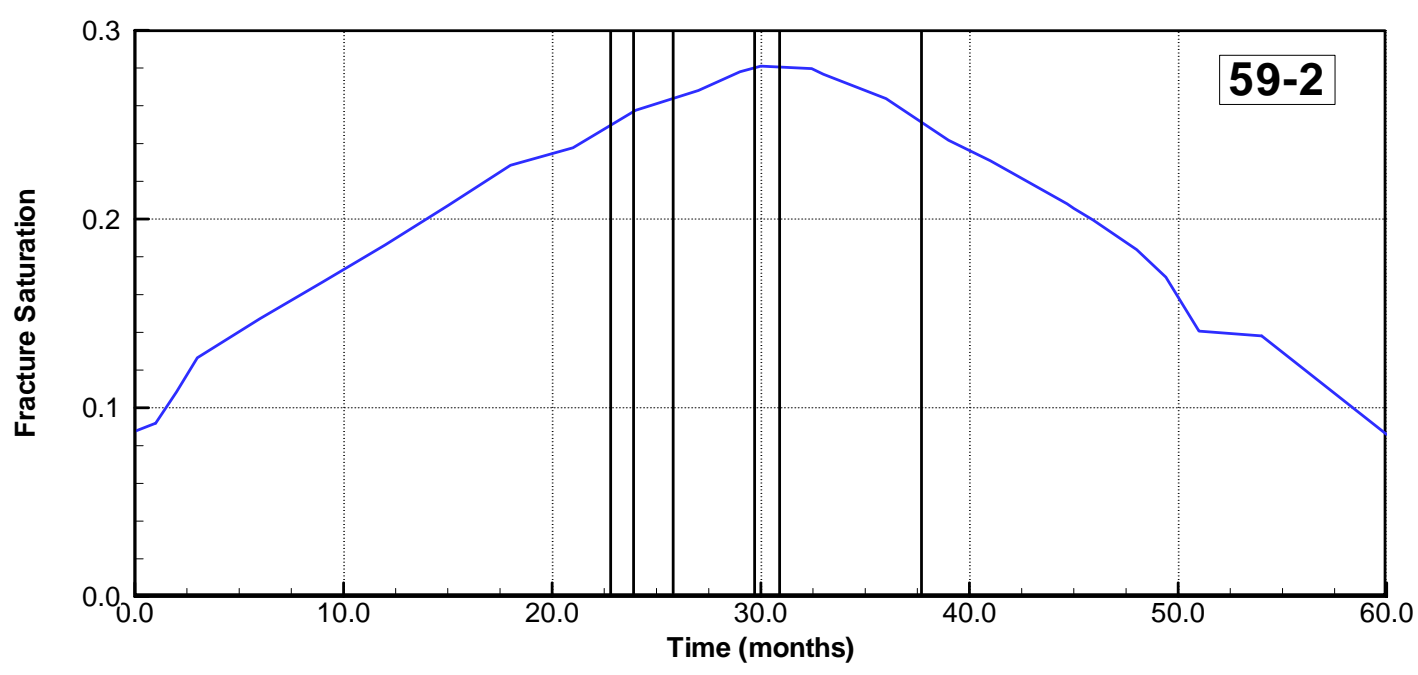

(a)

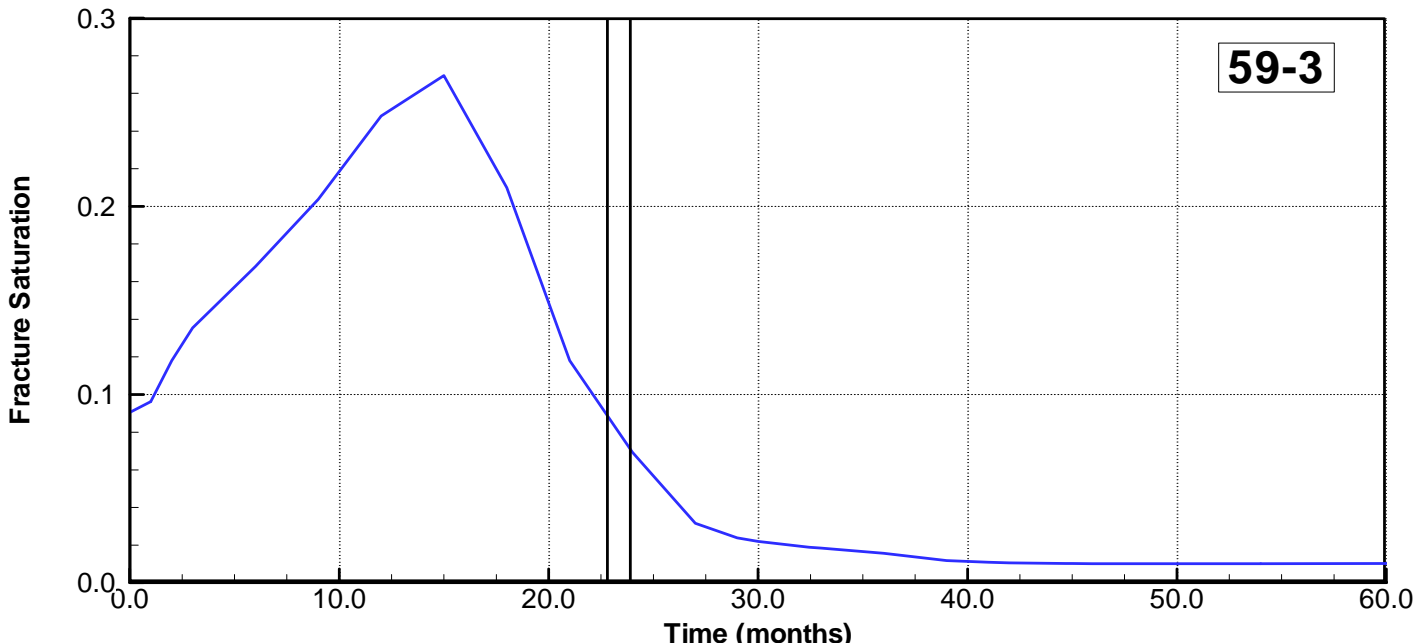

(b)

Input DTN for water collection times (for Figures 7.4.3.3-4a through 4h): SN0208F3903102.002 [DIRS 161246]. Output DTN (for Figures 7.4.3.3-4a through 4h): LB0303DSCPDSTV.001.

NOTE: Vertical lines give water collection times.

Figure 7.4.3.3-4. Simulated Fracture Saturation in Borehole Intervals (a) 59-2, (b) 59-3, (c) 59-4, (d) 60-2, (e) 60-3, (f) 76-2, (g) 76-3, and (h) 186-3 
(c)

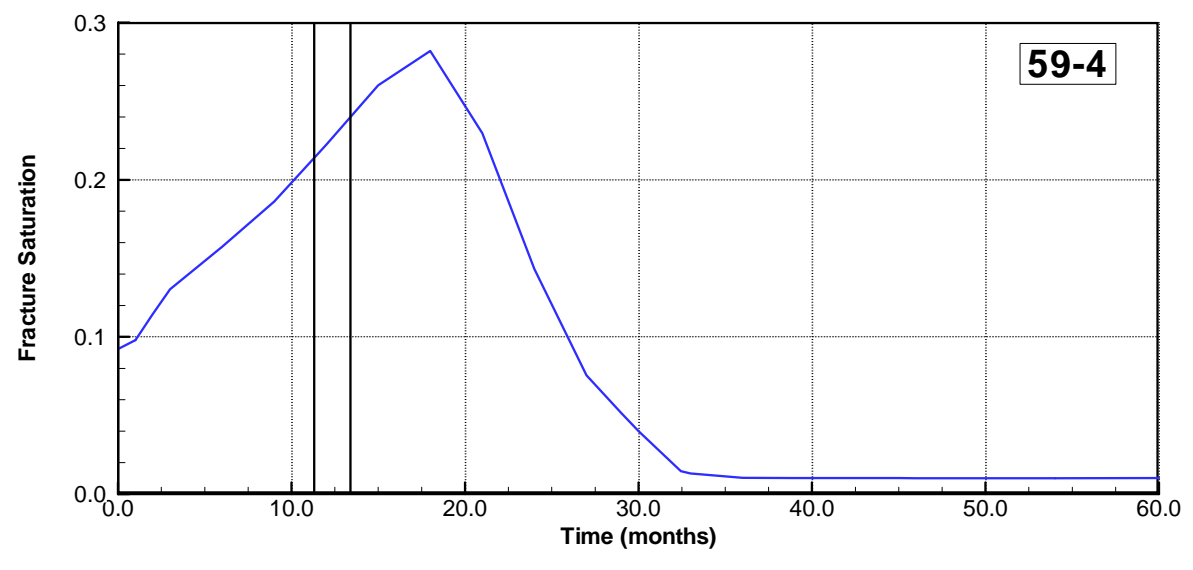

(d)

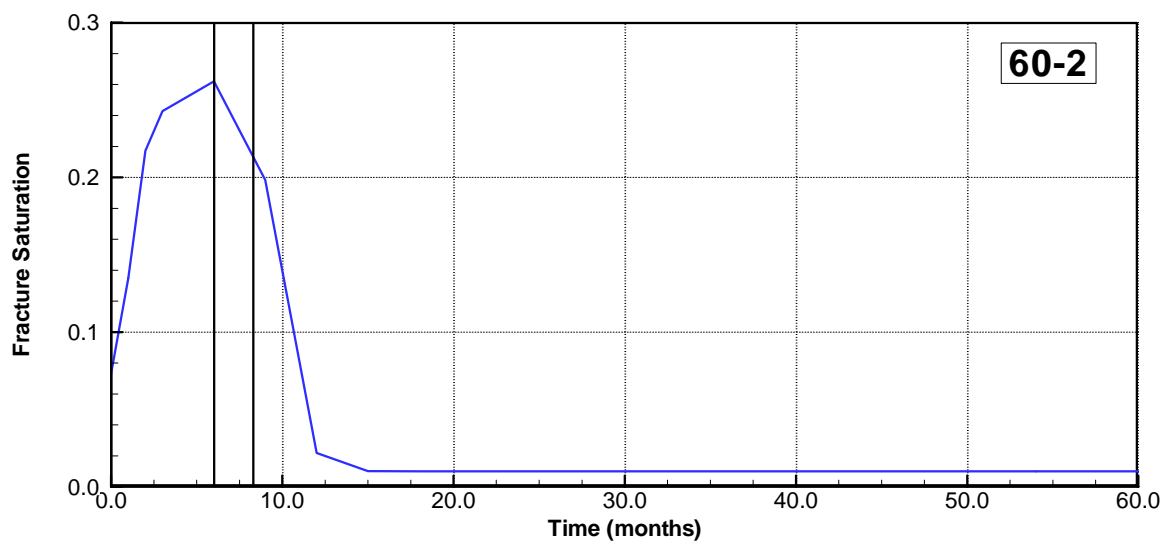

(e)

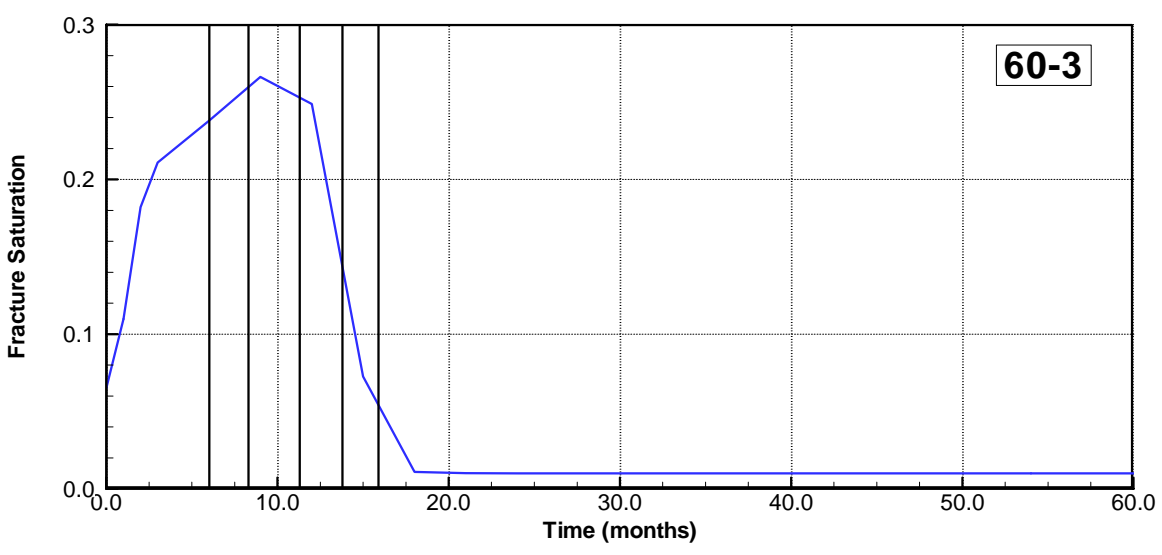

NOTE: Vertical lines give water collection times.

Figure 7.4.3.3-4 (Continued). Simulated Fracture Saturation in Borehole Intervals (a) 59-2, (b) 59-3, (c) 59-4, (d) 60-2, (e) 60-3, (f) 76-2, (g) 76-3, and (h) 186-3 


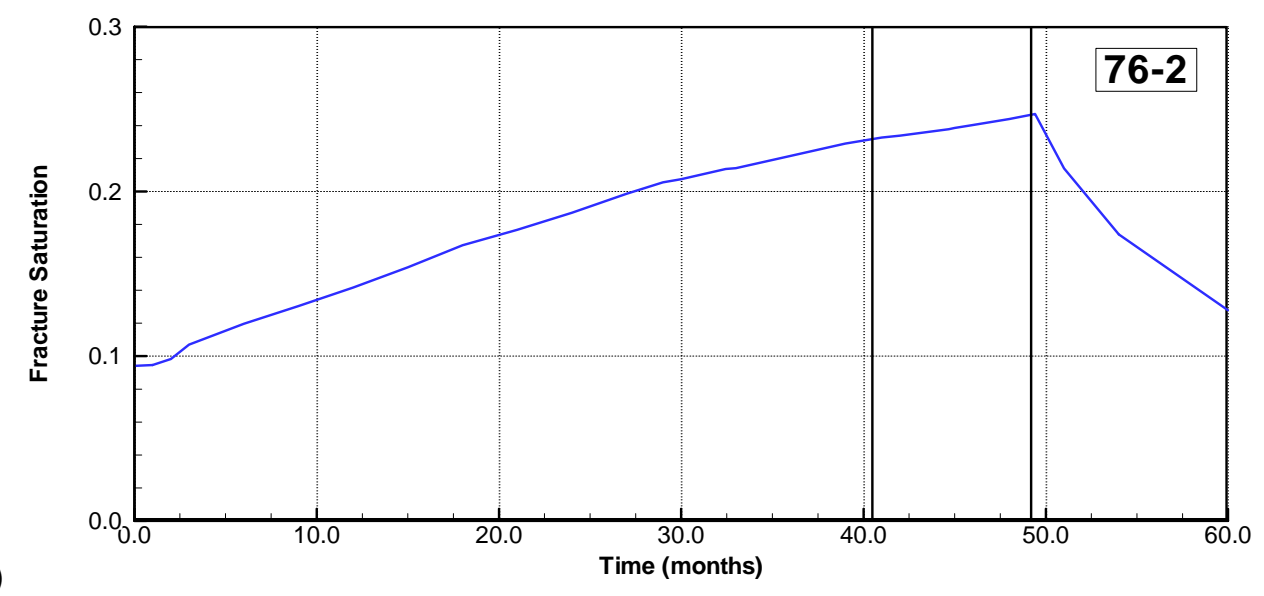

(f)

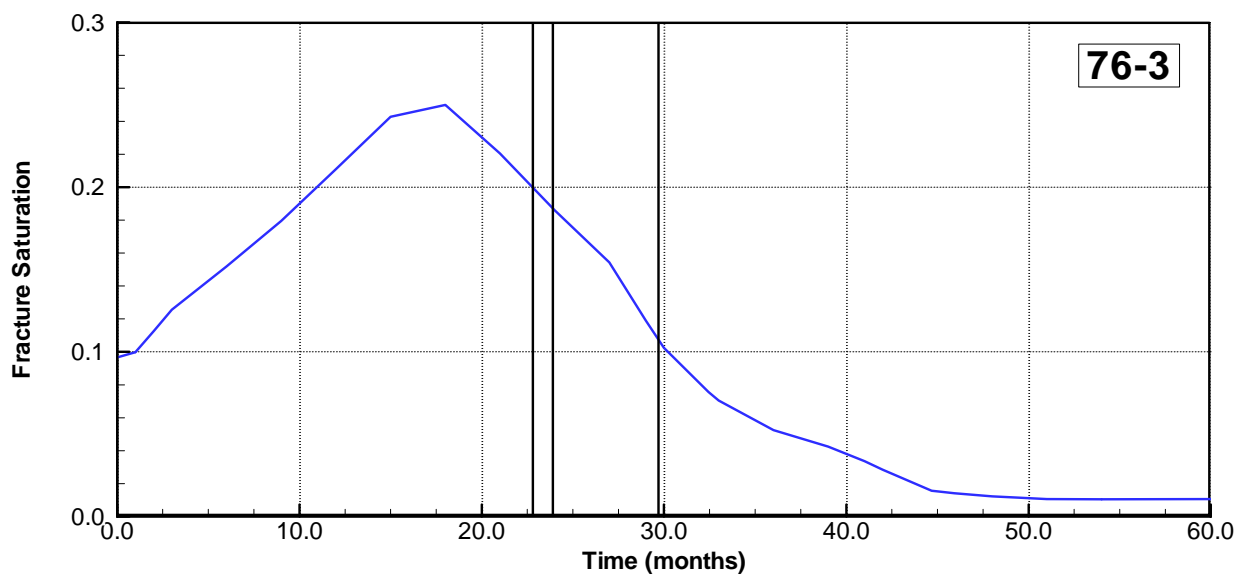

(g)

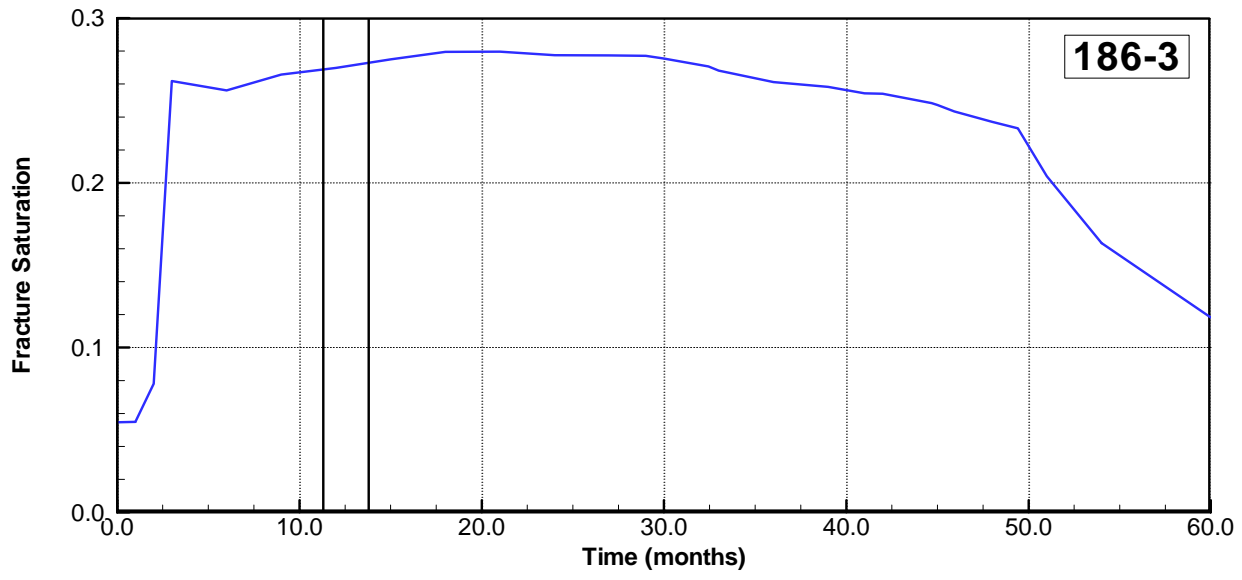

(h)

NOTE: Vertical lines give water collection times.

Figure 7.4.3.3-4 (Continued). Simulated Fracture Saturation in Borehole Intervals (a) 59-2, (b) 59-3, (c) 59-4, (d) 60-2, (e) 60-3, (f) 76-2, (g) 76-3, and (h) 186-3. Vertical lines give water collection times. 
Both the air-permeability results and the analysis of water collection data provide confidence in the model's capability to accurately represent the coupled TH processes. Though the predicted fracture saturation from the DST TH model are not always consistent with the pattern of measured air-permeability changes, the differences can be explained by THM effects that are not incorporated in the model. Also, the simulated fracture saturation evolution compares favorably with water collection in several hydrology boreholes.

\subsubsection{Comparative Analysis of the Site-Specific Property and the Calibrated Property Set}

The generally good agreement between simulated and measured results of temperature and moisture redistribution, as discussed in Section 7.4.3, indicates that the DST TH model has adequately represented the relevant TH processes in the DST. A remaining issue that needs to be addressed is that of the hydrological property set and the conceptual model for fracture-matrix interaction. The validation work in Section 7.4.3 is performed with the site-specific property set DKM-TT99 in conjunction with a standard DKM, while the predictions from the TH seepage model in Section 6 are based on the DS/AFM-UZ02-MEAN property set employing the AFM. Therefore, in this section, a comparative analysis of predictions from the DST TH model is provided with the two property sets and the two fracture-matrix interaction models. Since this comparative analysis is meant to be a sensitivity study, a two-dimensional version of the DST TH model is applied, because this considerably reduces the computational burden. This two-dimensional model is a representative vertical cross section from the three-dimensional model, identical to the three-dimensional model in every other way. Similar to Section 7.4.3, the data to be compared are temperature changes as well as matrix and fracture saturation changes, and only representative examples of these data can be presented below.

Note that a similar comparative analysis had also been conducted in the previous version of Thermal Tests Thermal-Hydrological Analyses/Model Report (BSC 2001 [DIRS 157330], Sections 6.2.2 and 6.3.2), comparing the same site-specific property set DKM-TT99 and a previous version of the mountain-scale calibrated property set. It was shown that both the property sets produce trends similar to the measured data, and that the differences in the model results represent sensitivity to the parameter values and not a disparity in the processes modeled. It was also shown that TH models based on both the AFM and the DKM produce TH results that compare well with measurements from the DST, and that the differences in the results given by the two conceptual models (AFM versus DKM) are not significant. The simulation results provided below support the conclusions of the previous report.

\subsubsection{Temperature}

Similar to Section 7.4.3.1, simulation results of temperature data are presented in two ways, using temperature profiles along boreholes and temperature history at selected sensors. The two-dimensional simulated results from the DKM-TT99 property set (with DKM) are directly compared with results from the DS/AFM-UZ02-Mean property set (with AFM). The selected boreholes and sensors are the same as those used in Section 7.4.3. 


\subsection{Temperature Profile}

Figures 7.4.4.1-1a and 7.4.4.1-1b show simulated temperature profiles in boreholes 158, 159, and 160 at 24 months and at end of heating, respectively. The solid lines represent simulations performed with site-specific properties of the DKM-TT99 data set (Section 4.1.2.1), while the dashed lines are those with the DS/AFM-UZ02-Mean property set. The temperature profiles with the two property sets are similar in pattern. However, the simulated temperatures are slightly higher with the calibrated DS/AFM-UZ02-Mean property set, in particular close to the wing heaters in borehole 160 at the end of heating. This may in part be a result of the smaller dry thermal conductivity of the DS/AFM-UZ02-Mean, which allows less heat transfer away from the heat sources (see Section 4, Table 4.1-2). Another reason is the overall slower rate of boiling using this property set, as explained in Section 7.4.4.2 below. Heat-pipe signatures are almost identical—slightly more pronounced in the DKM-TT99 property set.

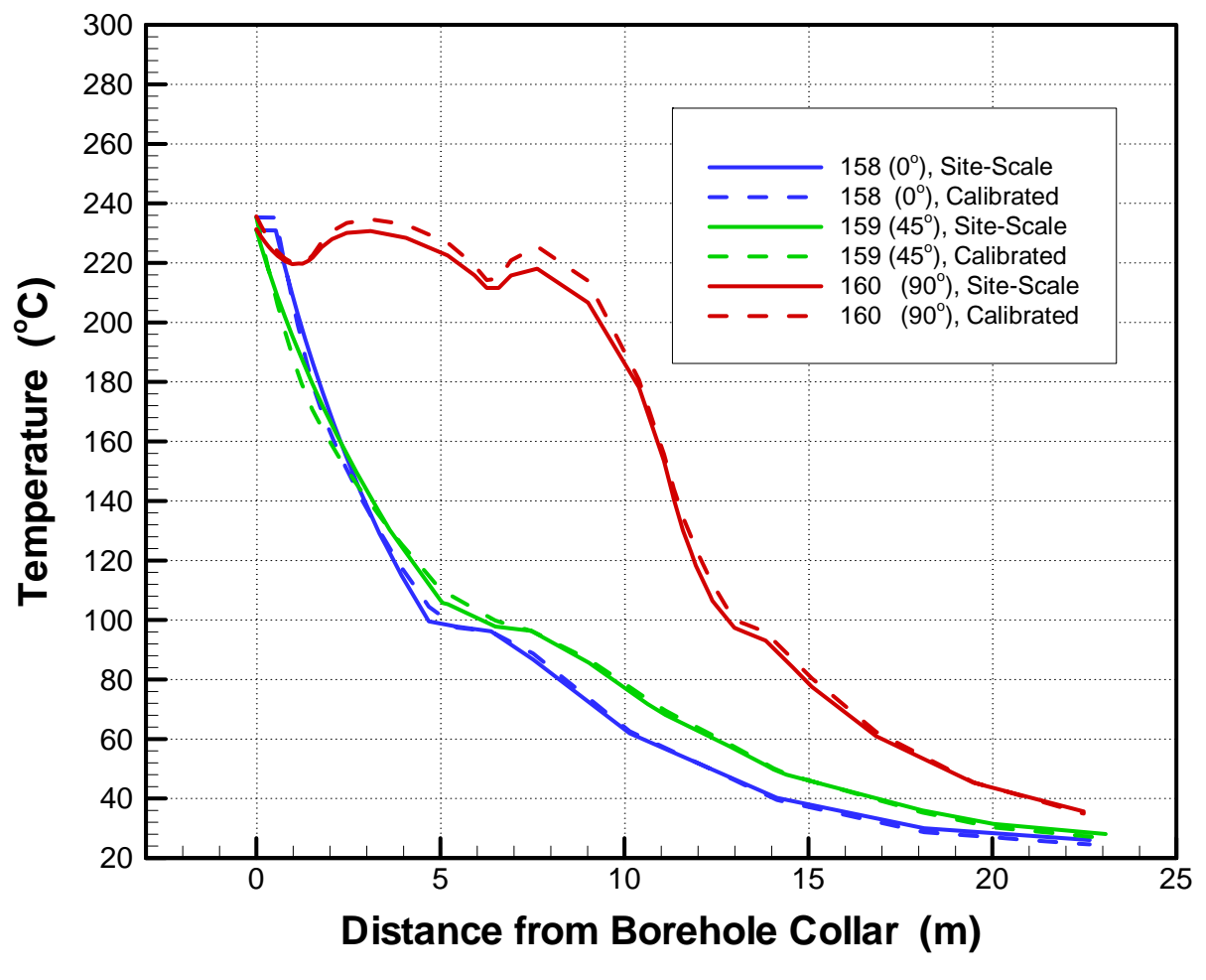

Output DTN: LB0303DSCPDSTV.001.

Figure 7.4.4.1-1. Comparison of Simulated Temperature Profiles in Boreholes 158, 159, and 160 Using the Site-Specific and DS/AFM-UZ02-Mean Property Sets at (a) 24 Months of Heating and at (b) the End of the Heating Period 


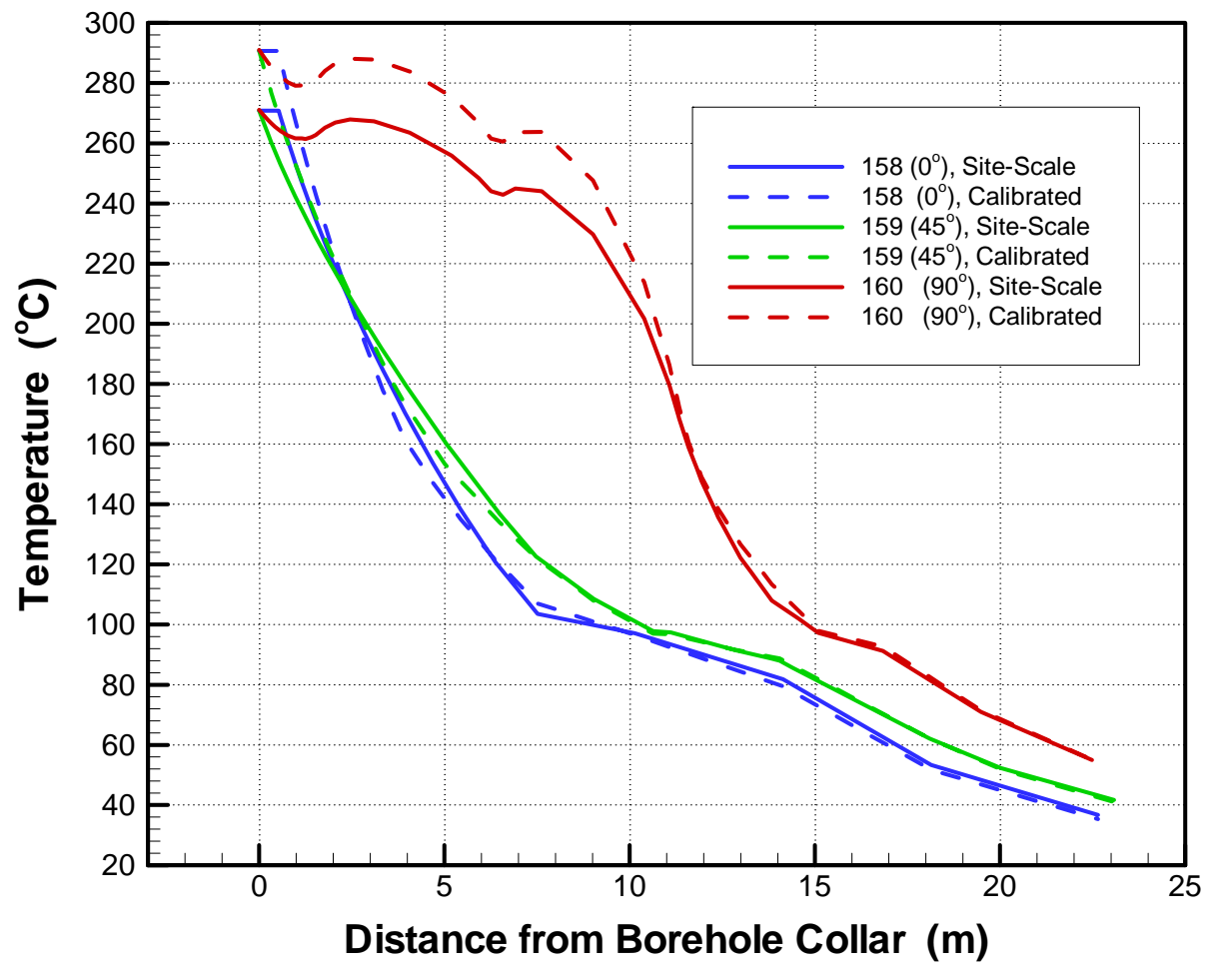

(b)

Output DTN: LB0303DSCPDSTV.001.

Figure 7.4.4.1-1 (Continued). Comparison of Simulated Temperature Profiles in Boreholes 158, 159, and 160 Using the Site-Specific and DS/AFM-UZ02-Mean Property Sets at (a) 24 Months of Heating and at (b) the End of the Heating Period

\subsection{Temperature History}

Temporal evolution of temperatures is shown in Figures 7.4.4.1-2a through 7.4.4.1-2c for selected sensors of boreholes 160,59, and 60, respectively. The solid lines are generated using the site-specific property set, and the dashed lines are generated using the DS/AFM-UZ02-Mean property set. In boreholes 160 and 59, the temperatures at above-boiling conditions are higher for the DS/AFM-UZ02-Mean property set compared to the site-specific property set. At below-boiling conditions, the temperature is similar for the two property sets. This again supports the hypothesis that the higher temperatures in the DS/AFM-UZ02-Mean results are caused by the smaller dry thermal conductivity. For the displayed sensors in boreholes 160 and 59 , the observed heat-pipe signals are similar, indicating that vapor and liquid flow processes close to the sensor locations should be similar for the two simulation runs. In contrast, Figure 7.4.4.1-2c for borehole 60 shows that, while the overall agreement between the two simulation runs is good, there is a distinct difference in the heat-pipe signatures of sensors 60-3 and 60-4. The DKM-TT99 simulation-using the DKM model-shows clear heat-pipe effects, whereas there is almost no heat pipe in the DS/AFM-UZ02-Mean results-using the AFM model. This is attributed to the fact that boreholes 160 and 59 extend above the heaters, while borehole 60 extends below the Heated Drift. Vapor condensing below the drift can partially drain downward away from the heaters, thereby reducing the potential for heat pipes. It appears that the DS/AFM-UZ02-Mean results with the AFM show no heat-pipe signals because of 
significant moisture loss from condensate drainage away from the boiling zone. Typically, the AFM features less fracture-matrix interaction compared to the DKM, so that less condensate imbibes into the rock matrix, where it would remain available for reflux back to the boiling zone as a result of capillary forces. It is shown in Section 7.4.4.3 that the fracture drainage behavior below the boiling region is indeed the main difference between simulation runs performed with the AFM and the DKM. In Figure 7.4.3.1-3c (Section 7.4.3.1.2) the measured temperature in borehole 60 is compared to the three-dimensional DST TH model results. It is noted that the measured temperatures show a minor heat-pipe signal that is clearly shorter and less pronounced than the one simulated with the DKM. It appears that the AFM model reproduces the behavior of sensors 60-3 and 60-4 somewhat better than the DKM model.

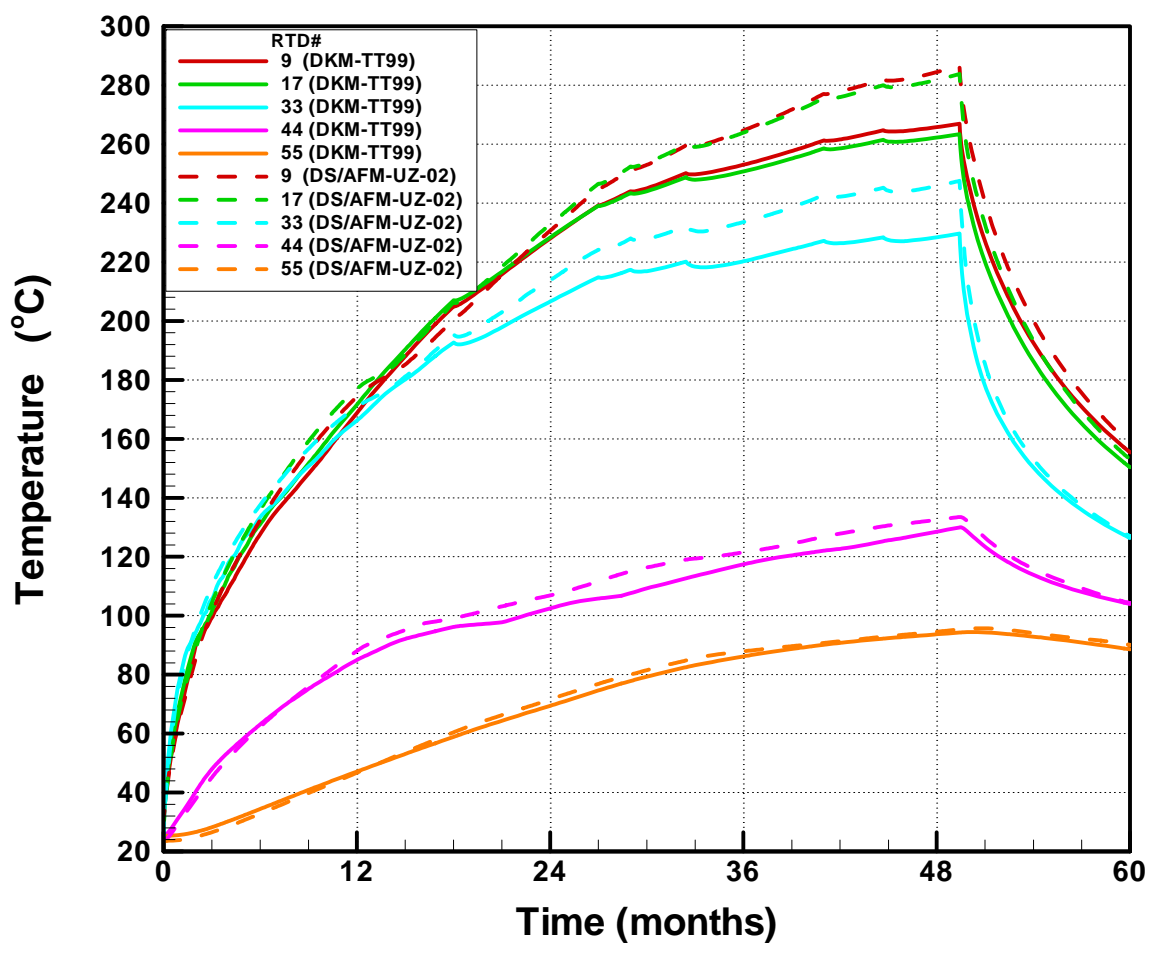

(a)

Output DTN: LB0303DSCPDSTV.001.

Figure 7.4.4.1-2. Comparison of Simulated Temporal Evolution of Temperature Using the Site-Specific and DS/AFM-UZ02-Mean Property Sets for Selected Sensors of (a) Borehole 160,

(b) Hydrology Borehole 59, and (c) Hydrology Borehole 60 


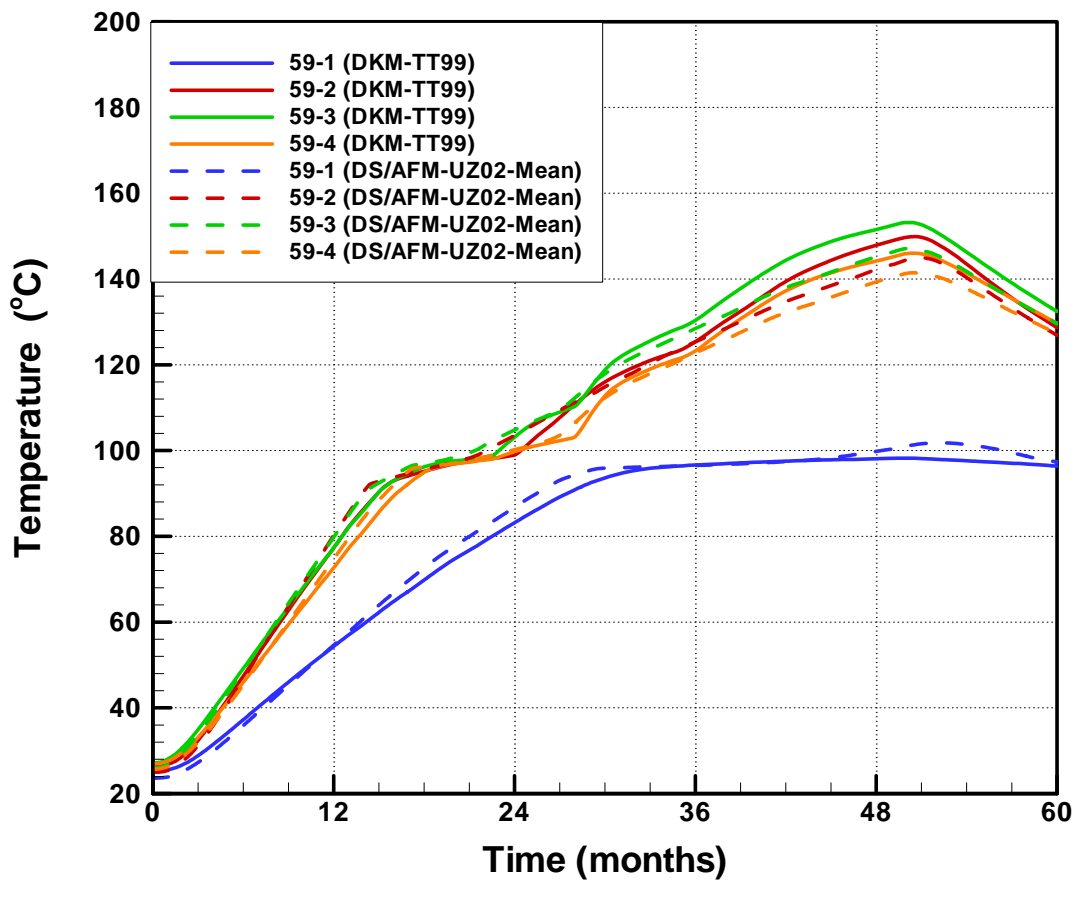

(b)

Output DTN: LB0303DSCPDSTV.001.

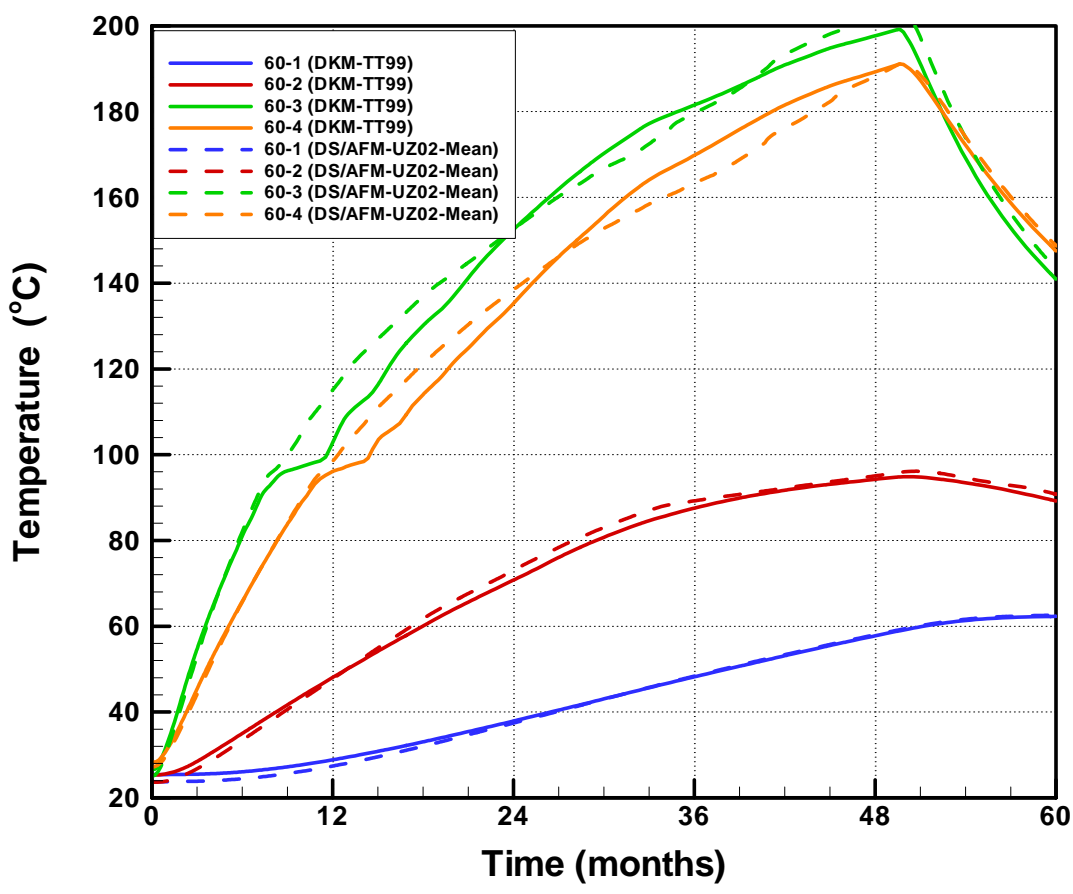

(c)

Time (months)

Output DTN: LB0303DSCPDSTV.001.

Figure 7.4.4.1-2 (Continued). Comparison of Simulated Temporal Evolution of Temperature Using the Site-Specific and DS/AFM-UZ02-Mean Property Sets for Selected Sensors of (a) Borehole 160, (b) Hydrology Borehole 59, and (c) Hydrology Borehole 60 


\subsubsection{Water Redistribution: Matrix Saturation}

For comparison of moisture redistribution in the matrix, Figures 7.4.4.2-1a and 7.4.4.2-1b, respectively, show contours of matrix saturation at the end of heating using the DS/AFM-UZ02-Mean and the DKM-TT99 property sets. Qualitatively, the two plots show similar results. The main difference lies in the smaller dryout zone for the DS/AFM-UZ02-Mean property set compared to the site-specific property set. The smaller dryout zone arises out of slower boiling of water with the DS/AFM-UZ02-Mean properties, which can be attributed to the smaller matrix permeability in this property set compared to the site-specific property set. As a result, the vapor generated from boiling cannot move out of the pore spaces easily. Subsequently, the pressure in the matrix pores tends to substantially increase, leading to an increase in the nominal boiling temperature. This, in turn, means that boiling occurs at higher temperature, which would tend to slow down the overall boiling process and would also lead to a smaller dryout rock volume. The increase in gas pressure as a result of vigorous vaporization stems from the thermal perturbation applied to the DST rock. This is not expected to occur in the repository, where the thermal load will be smaller and applied over a much longer time period. This is confirmed by simulation results from the $\mathrm{TH}$ seepage model, in which the maximum gas-pressure buildup in matrix pores is a little more than one atmosphere. Also note that matrix permeability is one of the less important parameters affecting thermal seepage, compared to, for example, the fracture permeability, capillary-strength, and the percolation flux. Thus these differences between the two data sets do not impact the predictive capabilities of the TH seepage model with respect to the magnitude and evolution of thermal seepage.

The pressure increase in the matrix pores can also account for the higher simulated temperatures seen in the DS/AFM-UZ02-Mean results compared to the DKM-TT99 simulation, as discussed in Section 7.4.4.1.1. Since less water is vaporized, less energy is consumed as latent heat of vaporization, particularly in the early phases of heating. Instead, the energy is used in increasing the temperature of superheated water. 


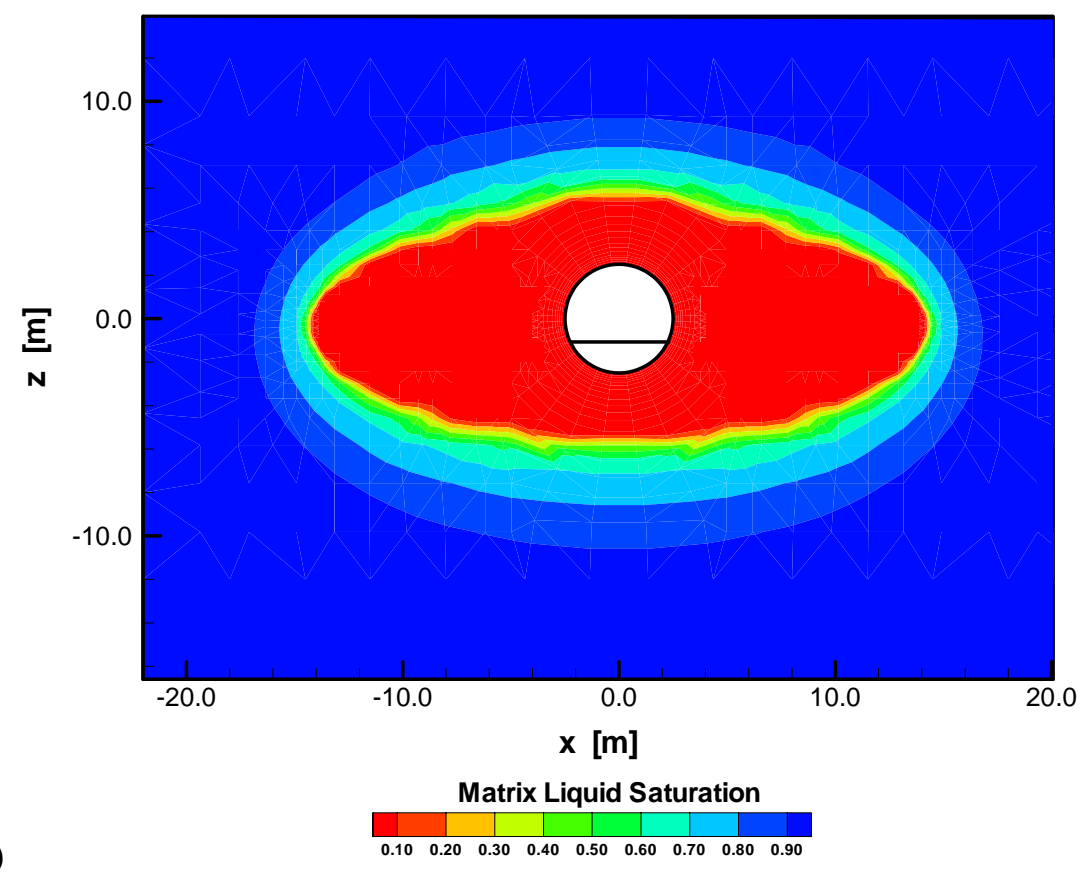

Output DTN: LB0303DSCPDSTV.001.

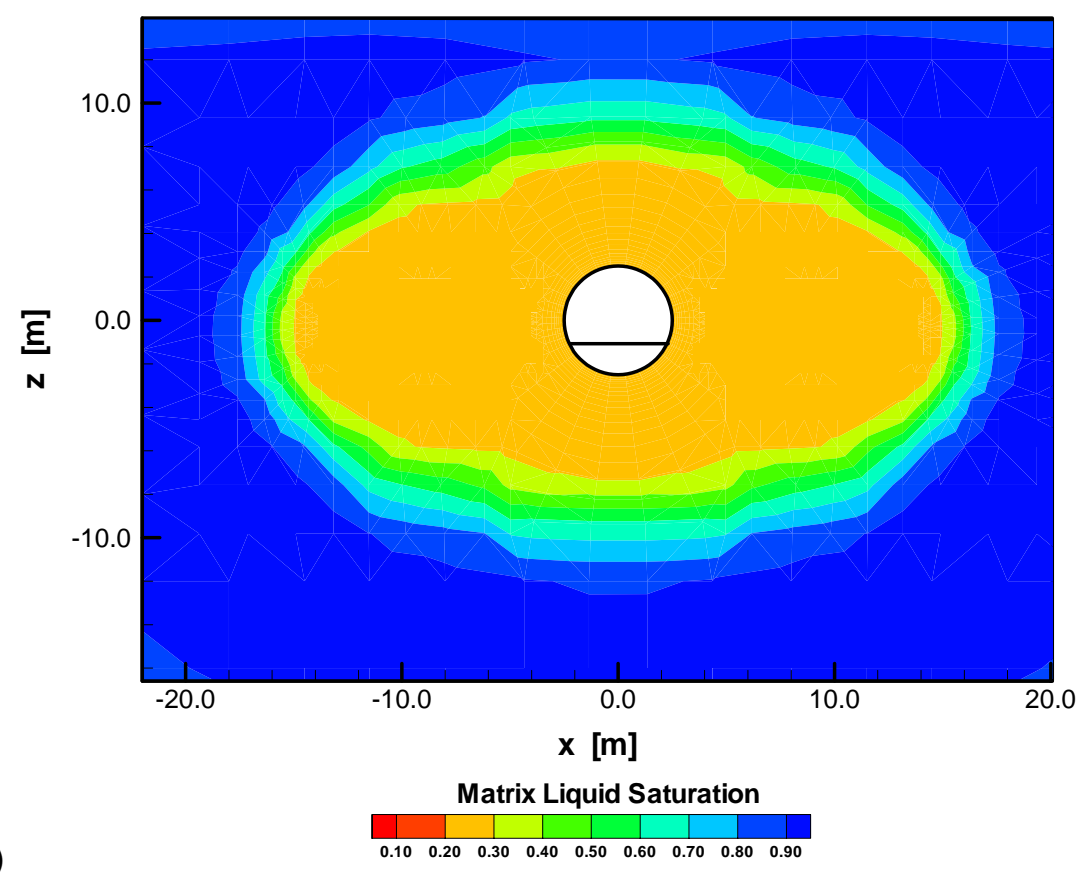

Output DTN: LB0303DSCPDSTV.001.

Figure 7.4.4.2-1. Simulated Contours of Matrix Liquid Saturation at End of Heating Using (a) the DSIAFM-UZ02-Mean Property Set and (b) the Site-Specific Property Set 


\subsubsection{Water Redistribution: Fracture Saturation and Water Flux}

Figures 7.4.4.3-1a and 7.4.4.3-1b compare contours of fracture liquid saturation at 12 months of heating using the DS/AFM-UZ02-Mean and the DKM-TT99 property sets, respectively. For better comparison between simulation results from the DKM and the AFM model, the saturation of active fractures is presented in Figure 7.4.4.3-1a, instead of using the average saturation values of all active and nonactive fractures. The relationship between average saturation and active fracture saturation is given in Equation 6.2.1.1-11. The saturation contours indicate that the two simulation results give an almost identical dryout region and fairly similar condensation patterns above and to the sides of the heaters. Below the heater, however, the effect of downward drainage away from the boiling zone is significantly stronger for the DS/AFM-UZ02-Mean runs compared to the DKM-TT99 runs. The fracture-matrix interface area is smaller when using the AFM, so that less condensate imbibes from the fractures into the matrix.

To evaluate the potential effect of these differences between the DKM and the AFM model, vectors of fracture water flux are also plotted in Figures 7.4.4.3-1a and 7.4.4.3-1b. Similar to the results of the TH seepage model presented in Section 6, the maximum fluxes can be seen above the heaters, where condensate is driven towards the boiling zone by both gravitational and capillary forces. In this region, most important for thermal seepage, the DKM and the AFM fluxes are similar in magnitude, with the maximum flux in the DKM about 50 percent higher than in the AFM. (This difference in magnitude is mainly caused by the rate of boiling being smaller in the simulation using the DS/AFM-UZ02-Mean property set. There is less water produced from boiling, so that the water fluxes are somewhat smaller.) It is below the heaters where the main qualitative and quantitative differences in water flux occur. Here, the DKM model predicts larger fluxes in upward direction (from capillary suction) back towards the boiling zone, while downward drainage is less effective. The AFM, on the other hand, produces larger downward fluxes (from gravity) away from the heaters, with relatively small reflux processes towards the boiling zone. This explains why the saturation patterns below the Heated Drift are so different. It also explains why the two simulation methods produce different heat-pipe signals in sensors 60-3 and 60-4. Both these sensors are located below the heaters in a location where strong reflux of water occurs using the DKM, but rather small reflux of water with the AFM. Comparison with the measured temperature evolution at 60-3 and 60-4 seems to indicate that the water reflux predicted by the AFM is more accurate. However, other factors such as local heterogeneity effects may also play a role. Although, the air-permeability data measured in zones 3 and 4 of borehole 61 are not conclusive in defining the more accurate model for representing fracture saturation below the drift, the data are not relevant to seepage. The main conclusion from the above is that both conceptual models produce reasonably good agreement in comparison with data, and that the main differences occur in a region below the heaters that is not important for thermal seepage. 
(a)

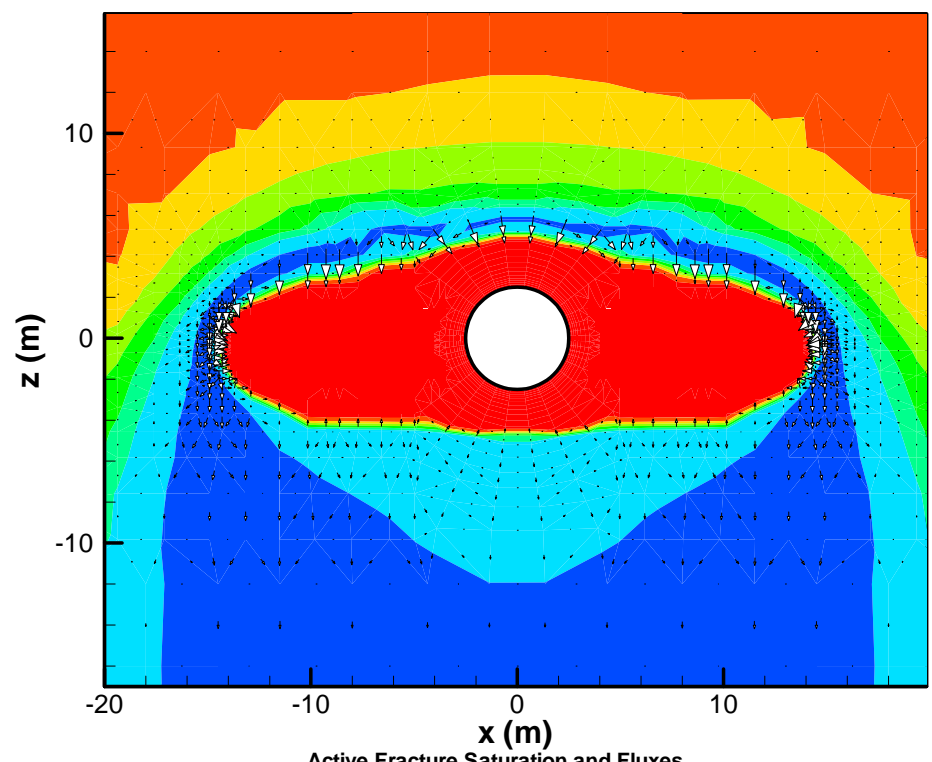

Active Fracture Saturation and Fluxes

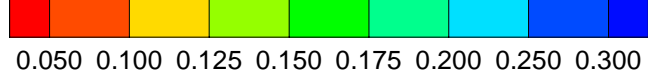

Output DTN: LB0303DSCPDSTV.001.

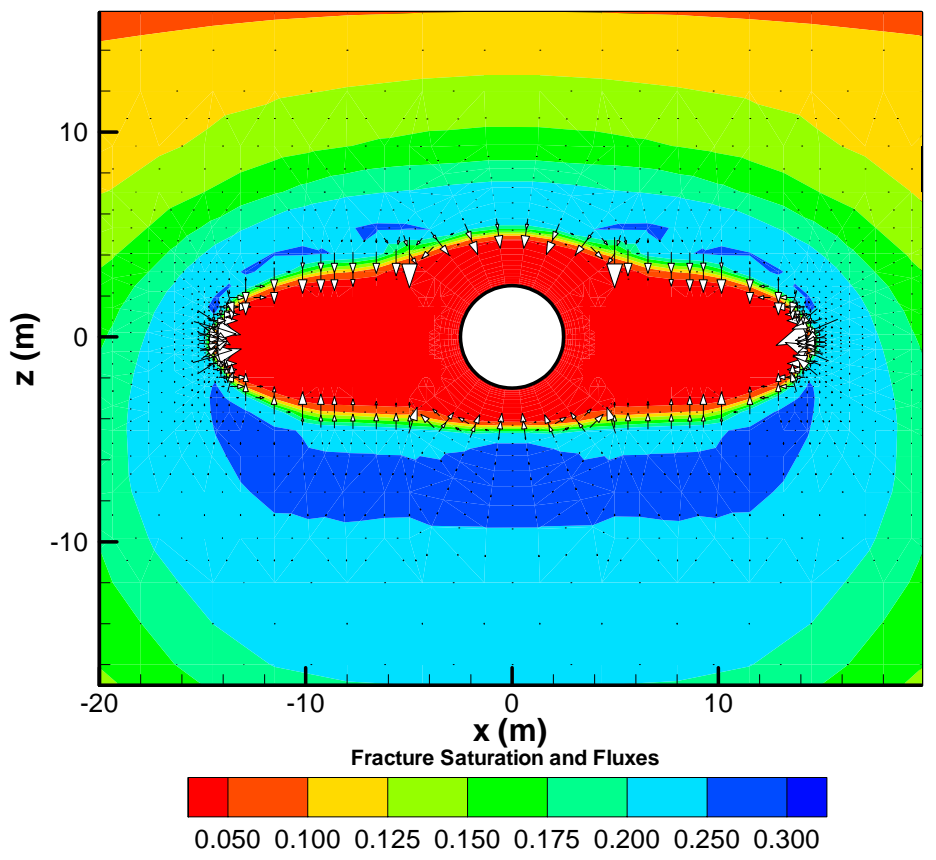

(b)

Output DTN: LB0303DSCPDSTV.001.

Figure 7.4.4.3-1. Simulated Contours of Fracture Saturation and Fracture Flux at 12 Months of Heating Using (a) the DS/AFM-UZ02-Mean Property Set and (b) the Site-Specific Property Set 


\subsection{DISCUSSION OF VALIDATION ACTIVITIES}

Validation of the TH seepage model was conducted according to the strategy outlined in the "Modeling and Scientific Analysis Activities" given in the technical work plan (BSC 2004 [DIRS 170236], Section 2.2). The TH seepage model has been validated by applying acceptance criteria based the model's intended uses and on an evaluation of the model's relative importance to the potential performance of the repository system.

The purpose of the TH seepage model is to provide findings on the evolution of thermal seepage to form the basis for thermal seepage abstraction. These qualitative findings are (1) that water is prevented from entering drifts as long as the fractured rock near the drift wall is at above-boiling temperature and (2) that the amount of thermal seepage is bounded by the respective long-term ambient seepage rate. Based on these findings, two alternative abstraction methodologies for thermal seepage are developed in Abstraction of Drift Seepage (BSC 2004 [DIRS 169131], Sections 6.5.2 and 6.5.3) for further use in the total system performance assessment (TSPA). The selected abstraction methods use upper-bound estimates of thermal seepage to account for various sources of model uncertainty.

The main method of validation is to demonstrate that the conceptual model and the $\mathrm{TH}$ properties used in Section 6 can match TH data collected from the DST. Note that the validation plan introduced in Section 7.1.3 and documented in the TWP (BSC 2004 [DIRS 170236]) established quantitative criteria for temperature data (corroboration with temperature measurements) and qualitative criteria for hydrological data (corroboration with geophysical measurements and air permeability data). The three-dimensional TH model developed for this purpose, the DST TH model, has the same conceptualization and simulates the same relevant TH processes as the TH seepage model. Model evaluation was performed in two steps: first, a site-specific property set was applied and evaluated in direct comparison with measured data; second, simulation results using the site-specific property set were compared with results from the DS/AFM-UZ02-Mean property set. The latter property set was derived to better represent average ambient conditions across various stratigraphic layers of Yucca Mountain and is the one used in Section 6.2 for predicting the TH behavior of the repository.

Comparison of measured and simulated data in the DST is first presented for temperature. The agreement is generally good, both spatially and temporally-as demonstrated in various temperature plots - as well as quantitatively_as shown by statistical measures for the goodness of fit. The validation criteria for temperature data, as defined in Section 7.4.1, have been met. The temperature profiles and temperature history plots show similar heat-pipe behavior between the measured and the simulated data, providing evidence that $\mathrm{TH}$ coupling is well understood. The criterion here is that the predicted location and duration of these two-phase signals should also be observed in the measurements, which is demonstrated in Section 7.4.3.1.1. Also, the mean difference between measured and simulated temperatures at more than 1,700 temperature sensors does not exceed 2 percent of the maximum rock temperature. The good agreement establishes the fact that the DST TH model (and hence the TH seepage model) has successfully incorporated the relevant $\mathrm{TH}$ processes as far as temperature is concerned.

Apart from temperature analyses, TH processes are also evaluated by qualitatively tracking the time-varying location of the drying and condensation front in response to heating. In the DST, 
this tracking was done using geophysical measurements, which measure saturation changes in the matrix, and by periodic air-injection tests, which measure saturation changes in the fractures. These methods are useful for estimating qualitative changes, whereas quantitative values of water saturation should be considered with caution because of measurement uncertainties. Thus the validation criterion for measurements of moisture redistribution, defined in Section 7.4.1, is a qualitative agreement between the trends and relative changes in dryout and condensation patterns, as indicated by simulated saturation changes and estimated from measurements. Comparison of geophysical data from GPR measurements with the simulated contours of matrix saturation at various times indicates that the time-varying location of the drying and condensation front is adequately represented by the model. Simulated fracture saturations-and predicted air-permeability changes calculated from these saturation changes-were compared with measured air-permeability data obtained at different times throughout the heating phase of the test. This comparison suggests that-while the main trends of air-permeability changes are captured by results of the TH model - a better agreement between simulated and measured values can only be achieved if thermal-mechanical processes are included. Since the DST TH model does not account for THM effects such as fracture closure and opening, some quantitative differences between simulated and measured air permeabilities remain. To provide additional confidence, the simulated fracture-saturation results were also compared to the location and timing of water collection from several packed-off borehole intervals. It was shown that water collection data correspond well with the predicted locations of high saturation from the model. This, and the overall good agreement of temperature and matrix saturation data, provides confidence that the relevant $\mathrm{TH}$ processes of moisture redistribution are accurately represented by the model, despite the fact that THM effects are neglected.

In Section 7.4.3, the DST TH model utilized the site-specific property set DKM-TT99 in conjunction with the DKM for fracture-matrix interaction. In Section 7.4.4, a sensitivity analysis was performed using the DS/AFM-UZ02-Mean property set and applying the AFM. Comparison of simulation results reveals minor differences in temperature and small differences in matrix saturation between the two property sets. Fracture saturation results, on the other hand, demonstrate noticeable differences in the flow patterns below the heated area, but show good agreement above and to the sides of the heaters. For the purpose of this report, both property sets and both underlying models-DKM and AFM-produced results that were within the acceptable limit around the measured data (see Section 7.4.1 for validation criteria), given that the fractured rock above the drift is most important for analysis of thermal seepage.

As mentioned in Section 7.1, the DST is only one out of three heater tests of different scales and geometry that have been conducted at Yucca Mountain. The successful modeling analyses performed for the Single Heater Test (SHT) and the Large Block Test (LBT) provide additional confidence in the TH models developed for the fractured rock at Yucca Mountain (Tsang and Birkholzer 1999 [DIRS 137577]; BSC 2001 [DIRS 157330]; Mukhopadhyay and Tsang 2002 [DIRS 160788]). In contrast to SHT and DST, which are located deep down in the ESF in an area of very small percolation, the LBT is a fractured rock block at the ground surface just southeast of Yucca Mountain. Here, a few intense rainfall events resulted in significant downward flow of water from the top of the block towards the boiling region in the center. Water was able to penetrate to the heater horizon and actually cooled the temperature below boiling for a short time. It was demonstrated that large conductive fractures connected the top of the block with the heater horizon, thereby providing a fast path for water fluxes of large 
magnitude. These processes were accurately modeled by Mukhopadhyay and Tsang (2002 [DIRS 160788], Section 5), with a process model similar to the TH seepage model, demonstrating that the model used for thermal seepage is capable of simulating fast-flow effects.

Confidence is also gained by results from the alternative conceptual model of Section 6.3 that support the prediction of the TH seepage model. The alternative conceptual model, referred to as THMEFF, considers the possibility that unsaturated fracture flow may occur in fast-flowing preferential pathways (thin fingers) that drain downward intermittently. Such conditions may promote the potential of seepage during the thermal period at Yucca Mountain, because finger flow may penetrate far into the superheated rock zone (i.e., rock temperature above boiling point of water) around waste emplacement drifts. To test the impact of such flow concepts-which can be approximated by continuum models such as the TH seepage model-the THMEFF simulations in Section 6.3 analyzed the fate of episodic preferential-flow events that originate somewhere in the condensation zone above the repository and percolate downward towards the emplacement drifts. The assumed finger-flow events are fast and intense compared to the average flow conditions generally considered in process models like the TH seepage model, and vaporization effects are limited as a result of the small cross-sectional area between the draining water and the hot rock. These conditions, along with a simplified one-dimensional finger-flow model representing continuous vertical fractures, create an unfavorable environment for the vaporization barrier above heated waste emplacement drifts. In spite of this, the THMEFF results are reasonably consistent with the process model results obtained with the TH seepage model. Most importantly, the THMEFF demonstrates that finger flow is not able to penetrate through the superheated rock during the first several hundred years of heating, when rock temperature is high and boiling conditions exist in a sufficiently large region above the drifts. These are the conditions in which the largest thermal perturbation occurs, or, in other words, when the potential for episodic finger flow is highest. Only later, when the boiling zone is small and the impact of vaporization is limited, can finger flow arrive at the drift crown. However, the strong thermal perturbation observed at early heating stages has already diminished during this time period, and the net result of water arrival at the drift-considering the combined impact of water buildup in the condensation zone and vaporization in the superheated zone-is similar to ambient percolation. Seepage of water into the drift is not expected from this water arrival, because the flow should be effectively diverted around the drift by the capillary barrier capability of the open cavity. These findings are consistent over a wide range of finger flow characteristics studied in a sensitivity analysis, covering the potential uncertainty in finger flow patterns.

In summary, it can be concluded that the validation criteria established for demonstrating corroboration of model results with experimental data have been met. Other validation requirements concerning confidence building during model have also been fulfilled, including publications in refereed professional journals and corroboration with alternative conceptual models (Sections 6.3 and 7.1.2). In addition, activities requirements for confidence building during model development have been satisfied (Section 7.1.1). Altogether, the model development activities and post-development validation activities described establish the scientific bases for the drift scale TH models. Based on this, the drift scale TH models used in this report are considered to be sufficiently accurate and adequate for the intended purpose and to the level of confidence required by the model's relative importance to the potential performance of the repository system (see Section 7.1). 


\section{INTENTIONALLY LEFT BLANK}




\section{CONCLUSIONS}

\subsection{SUMMARY AND CONCLUSIONS}

This report documents the conceptual model and results obtained from numerical simulation of the coupled thermal-hydrological $(\mathrm{TH})$ processes in the vicinity of waste emplacement drifts. Heating of rock water to above-boiling conditions induces water saturation changes and perturbed water fluxes that affect the potential of water seepage into drifts. In addition to the capillary barrier at the rock-drift interface-independent of the thermal conditions-a second barrier exists to downward percolation at above-boiling conditions, from vaporization of water in the fractured rock overlying the repository. A numerical model was developed in this report to analyze the combined effect of these two barriers (not to be construed as synonymous with regulatory definition of barriers). The $\mathrm{TH}$ seepage model is a model that accounts for all important $\mathrm{TH}$ processes in response to heating while incorporating the capillary barrier condition at the drift wall. The conceptual model for evaluating capillary barrier behavior was adopted from the simulation methods developed for ambient seepage, namely the seepage calibration model (SCM) and the seepage model for performance assessment (SMPA). The key elements in these models-fracture permeability heterogeneity, small capillary-strength parameter, and effects of discrete fractures at the drift wall-have all been included in the TH seepage model. Simulations are performed to explicitly calculate fluid flow down to the drift during the heating phase of the repository, and to directly calculate transient seepage rates into the drift. These transient rates for the thermally affected time period are compared to the respective long-term ambient seepage rates, the latter calculated from steady-state simulation runs applying the constant infiltration rates associated with the three climate periods.

Most simulations conducted with the TH seepage model consider the TH conditions near intact drifts that have not degraded or collapsed. Results from these simulations are presented in Sections 6.2.2, 6.2.3, and 6.2.4.2. Two main suites of simulation cases have been studied. The first suite of cases addresses the relevant thermal-hydrological conditions in the drift vicinity, mainly for informative purposes. The second suite of cases focuses specifically on the potential for thermal seepage for further use in seepage abstraction and TSPA, applying the specific modeling framework for seepage that was outlined above. Several sensitivity cases were conducted (see overview in Section 6.2.1.6), including:

- Different repository host rocks with the Tptpmn submodel (for a drift located in nonlithophysal rock) and the Tptpll submodel (for a drift located in lithophysal rock)

- Different thermal operating modes (including a case that never reaches boiling conditions and a case with maximum temperature as high as $143^{\circ} \mathrm{C}$ in the rock)

- Different percolation fluxes at upper boundary (considering climate changes and flow focusing, with resulting percolation fluxes as high as $2,500 \mathrm{~mm} / \mathrm{yr}$ )

- Different capillary-strength parameter values for fractures in the drift vicinity (ranging from $400 \mathrm{~Pa}$ to about 10,000 Pa) 
- Variations in key rock properties such as near-field fracture permeability and matrix thermal conductivity

- Active fracture model and standard dual-permeability method

- Different conceptual model choices for defining the interface thermal conductivity between fracture-fracture connections and matrix-fracture connections as well as in-drift properties

- Transient thermal representation and long-term ambient (steady-state) representation.

The thermal modes and the percolation fluxes considered cover a wide range of the variability and uncertainty in $\mathrm{TH}$ conditions expected in the repository. For a given set of $\mathrm{TH}$ rock properties, the predicted thermal conditions-maximum rock temperature, extent of the superheated rock zone, and duration of the boiling period-are mainly driven by the assumed heat load and the magnitude of percolation. One thermal mode, the low-temp mode, results in rock temperatures that never reach boiling conditions. It was shown that thermal effects on flow and seepage are negligible in this case, so that the potential for thermal seepage can be estimated from ambient seepage results. The other thermal modes give rise to boiling of water in the fractured rock close to waste emplacement drifts. Simulation results demonstrate that the thermal perturbation of the flow field-causing increased downward flux from the condensation zone towards the drifts - is strongest during the first few hundred years after closure, corresponding to the time period when rock temperature is highest and the vaporization barrier is most effective. Even for high percolation fluxes into the model domain, and strong flow channeling as a result of fracture heterogeneity, water cannot penetrate far into the superheated rock during the time that rock temperature is above boiling, and model results show no seepage. The majority of the vaporized (and subsequently condensed) matrix water is diverted around the dryout zone and drains away from the drift. The magnitude of percolation affects the temperature conditions in the fracture rock. For a given thermal load, high percolation fluxes tend to cool down the rock temperatures, result in a shorter boiling period, and cause more distinct heat-pipe effects compared to small percolation fluxes.

At the time when temperature has returned to below-boiling conditions and fractures start rewetting at the drift (for mean infiltration without flow focusing, this occurs around 1,000 years after emplacement), the capillary barrier at the drift wall continues to operate, reducing (or preventing) water seepage into the drift. Since the thermal and hydrological conditions in the fractured rock will be perturbed from heating for a long time, simulation of thermal seepage was performed for 4,000 years after waste emplacement. The performance of the capillary barrier during this time period was evaluated in comparison to results from long-term ambient seepage (steady-state) simulations that were conducted to provide reference values for seepage at different percolation rates. The results indicate that thermal seepage never occurs in simulation cases where the respective long-term ambient seepage is zero. In cases where long-term ambient seepage is obtained-typically, cases with high percolation fluxes, heterogeneous fracture permeability fields, small fracture-capillary strength parameter in the drift vicinity, and inclusion of the effect of discrete fractures in the immediate drift vicinity using a specific drift wall boundary condition - thermal seepage is possible. (These are cases that have been identified as promoting seepage in ambient seepage studies: e.g., Birkholzer et al. 1999 [DIRS 105170]; BSC 
2004 [DIRS 167652]) In such cases, seepage is predicted to begin several hundred to a few thousand years after rock temperature has returned below boiling, the delay caused by the slow saturation buildup in fractures; there is no seepage during the time period of above-boiling temperatures in the rock. Thermal-seepage percentages are always smaller than the respective ambient reference values, indicating that there is no enhanced seepage as a result of reflux of water (because most of the condensate has long drained down away from the drift), and that the long-term ambient seepage values provide an asymptotic upper limit for thermal seepage. Note that these general conclusions apply for all above-boiling thermal operating modes and for both the Tptpmn and the Tptpll repository horizons. Mainly because of the smaller thermal conductivity in this unit, the Tptpll submodel—for the same thermal mode-has slightly higher maximum temperatures, a larger superheated zone, and a longer boiling period than the Tptpmn submodel, giving rise to a more effective vaporization barrier. The key conclusions from the analyses for intact drifts are:

- For the low-temp thermal operating mode, thermal effects on flow and seepage are negligible, and the potential for long-term seepage can be estimated from ambient seepage results.

- For the other thermal operating modes discussed in this report, including the base case operating mode, percolation fluxes at the top of the model domain plays a significant role.

- For a given thermal load, higher percolation fluxes result in cooler rock temperatures, shorter duration of boiling, and earlier occurrence of drift seepage.

- Thermal seepage never occurs for cases where the long-term ambient seepage is zero.

- For cases where thermal seepage takes place, it is predicted to begin several hundred to a few thousand years after rock temperature has returned below boiling, the delay caused by the slow saturation buildup in fractures; there is no seepage during the time period of above-boiling temperatures in the rock.

- Thermal-seepage percentages are always smaller than the respective ambient reference values, indicating that there is no enhanced seepage as a result of reflux of water.

- Reduced fracture capillary strength parameter, reduced near-field fracture permeability, increased percolation fluxes, and the presence of discrete fractures in the vicinity of the drift wall tend to enhance both long-term ambient seepage and thermal seepage.

Additional $\mathrm{TH}$ simulations were conducted with the $\mathrm{TH}$ seepage model to analyze the $\mathrm{TH}$ conditions within and around collapsed drifts and to determine the impact on seepage abstraction. The drift collapse was assumed to occur shortly after emplacement of the radioactive waste. Results from the collapsed drift simulations can be summarized as follows:

- In contrast to open drifts, where a combined capillary and vaporization barrier at the drift crown prevents water seepage during the period of above-boiling temperatures, vaporization is not effective at the crown of collapsed drifts. 
- With ambient rock water boiling off in the rubble material, in-drift flux perturbation gives rise to moderate reflux of condensate in the upper half of collapsed drifts. However, water drainage down to the waste packages is not possible, a result of the vaporization barrier forming in the vicinity of the waste package.

- The vaporization and reflux processes cease after a few thousand years or less, and the TH conditions slowly approach steady-state (ambient) behavior. During this transition phase, the fluxes in the lower half of the collapsed drift remain zero at all times. Later, when steady-state conditions have been reached, the entire collapsed drift is characterized by zero fluxes, as the void spaces are essentially dry (at residual saturation).

- The above in-drift flow processes are largely unaffected by changes in the percolation flux because the capillary barrier at the drift crown limits water flux from the intact rock into the rubble material.

\subsection{IMPLICATIONS FOR ABSTRACTION OF THERMAL SEEPAGE IN INTACT DRIFTS}

Based on the consistent trends observed in the thermal seepage results, abstraction methods for transient seepage into intact drifts were recommended in Section 6.2.4.1. These abstraction methods use the long-term ambient seepage rate calculated for each climate period as reference values for thermal seepage. The abstraction method used for licence application (LA) is documented in Abstraction of Drift Seepage (BSC 2004 [DIRS 169131]). As a basis for the abstraction rationale, several thermal seepage simulation scenarios, including sensitivity analyses to percolation fluxes, heat loads, key rock parameters, and conceptual model choices, were presented in Sections 6.2.2, 6.2.3, and 6.2.4.2. It was demonstrated that the potential variability of boundary conditions and rock properties results in considerable differences in the $\mathrm{TH}$ conditions, e.g., in the duration of the boiling period or the predicted maximum rock temperature at the drift wall. However, the general conclusions about the magnitude and evolution of thermal seepage, and thus the recommended abstraction procedures, are valid over the required range of boundary conditions and parameter values used in TSPA (i.e., extreme percolation fluxes, different repository temperature conditions, varying near-field rock properties).

The abstraction methodologies proposed in the above paragraph utilize simplified transient thermal-seepage rates based on the long-term ambient seepage estimates. It is recommended that the long-term ambient seepage rates used for such thermal seepage abstraction are the ones provided by the SMPA. This ambient seepage model, computationally much less demanding compared to the TH seepage model, can be applied to a wide range of parameters and flux boundary conditions. Also, the SMPA results are considered quantitatively more reliable than the ones from the TH seepage model, due to the three-dimensional model representation and the large number of realizations considered. Thus, the qualitative evolution of thermal seepage relative to the long-term ambient seepage would be derived from the TH seepage model, while the quantitative magnitude of seepage would be predicted by the SMPA. 


\subsection{MODEL VALIDATION AND UNCERTAINTIES}

The validation activities conducted for the TH seepage model are described in Section 7 of this report. The TH seepage model has been validated by applying acceptance criteria based on an evaluation of the model's intended use and the model's relative importance to the potential performance of the repository system. All validation requirements defined in the TWP (BSC 2004 [DIRS 170236], Section 2.2.1) have been fulfilled, including corroboration of model results with experimental data, publications in refereed professional journals, and corroboration with an alternative conceptual model (Sections 6.3 and 7). Requirements for confidence building during model development have also been satisfied. The model development activities and postdevelopment validation activities described establish the scientific bases for the drift scale $\mathrm{TH}$ models. Based on this, the drift scale TH models used in this report are considered to be sufficiently accurate and adequate for the intended purpose and to the level of confidence required by the model's relative importance to the potential performance of the repository system.

The most important validation method in this report is corroboration with experimental data; i.e., to demonstrate a good agreement between model results and appropriate experimental data, using measurements from the Drift Scale Test (DST). The DST TH model was developed for this purpose; it is a three-dimensional drift-scale process model that has the same model conceptualization as the TH seepage model. The model was applied to the DST using the DKM-TT99 property set, specific for the DST test block, and the DS/AFM-UZ02-Mean property set, representing average properties over the repository. To test the different methods for fracture-matrix interaction, simulations were performed using the standard dual-permeability method (DKM) and the active fracture model (AFM), respectively. Comparison with measured data from the DST indicated good overall agreement for temperature values and moisture redistribution patterns, implying that the models considered are valid for the purposes of this report. Both property sets and both the DKM/AFM methods are suitable for simulating the thermally perturbed conditions in the test block of the DST. The qualitative and quantitative assessment of model agreement with data-including evaluation of subtle temperature signals showing TH coupling, comparison with geophysical measurements, air-permeability data, and occurrence of fracture flow at water collection points-indicates that uncertainty in predicting temperature, saturation, and water flux is within acceptable ranges. Though not presented in this report, the TH process models have also been applied to the Single Heater Test (SHT) and the Large Block Test (LBT) at Yucca Mountain, also resulting in good agreement between simulation and measurements (Tsang and Birkholzer 1999 [DIRS 137577]; BSC 2001 [DIRS 157330]; Mukhopadhyay and Tsang 2002 [DIRS 160788]). This provides additional confidence in the suitability of the predictive model.

Note that the geometry and the in-drift heat source setup of the DST are similar to the proposed design of waste emplacement drifts. Therefore, the TH processes measured and simulated in the DST occur on the same spatial scale as the ones predicted to occur in the repository drifts. With respect to the time scale, however, it is recognized that the DST provides observations on temperatures and water redistribution for a time frame of four years while the intended application of the thermal-hydrologic modeling prediction is for many centuries. It is not possible to perform such tests similar to the DST for time frames even approaching the intended time frame for predictions. However, the TH seepage model is considered valid for the intended 
time frame of interest beyond four years because of the following: (1) The governing TH processes leading to moisture redistribution-vaporization, vapor transport, condensation, and reflux - are the same over four years and over much longer time frames; only the duration of these processes is different. (2) The conceptual framework used for describing these processes, i.e., the energy and mass balances, are valid for all times; these principles do not change. (3) The observations from the DST for both temperatures (energy) and mass are consistent with the current understanding of these processes as demonstrated by comparison with model predictions. Furthermore, it is reasonable to expect that the scientific understanding of these processes in the intended application will not change because the state of knowledge of these processes has been developed extensively for many years, as illustrated by successful predictions for similar processes.

All three thermal tests have been conducted in the Tptpmn unit at Yucca Mountain; however, there has been no testing in the Tptpll unit. Thus, validation of the TH seepage model does not include direct comparison with measured data from the Tptpll. However, the good agreement of the model predictions with data from the Tptpmn provides confidence that the $\mathrm{TH}$ processes in the fractured rock are well captured by the model. Therefore, application of the model to the Tptpll unit is appropriate since similar TH processes will occur in that unit. Some uncertainty, however, remains about the rock properties of the Tptpll unit and the influence of lithophysal cavities. This uncertainty is propagated to TSPA by the choice of upper-bound estimates of thermal seepage in the seepage abstraction (BSC 2004 [DIRS 169131], Sections 6.5.2 and 6.5.3).

As discussed in Section 7.1, no seepage of liquid water has been observed in the Heated Drift of the DST. The DST results allow for a unique model validation with respect to the near-field TH conditions in the rock mass, but offer no seepage data (observed seepage rates) that can be used directly for thermal seepage validation purposes. Thus, validation of the seepage part of the TH seepage model is an indirect one. First, the better the overall TH behavior can be predicted by the DST TH model, the more confidence is gained for the seepage results obtained with the TH seepage model. In other words, the successful validation of the DST TH model with respect to coupled processes (i.e., saturation distribution, temperature signals) adds confidence in the seepage part of the $\mathrm{TH}$ seepage model because the thermally perturbed water fluxes are accurately represented. Second, the modeling framework for the capillary barrier treatment in the TH seepage model can already be considered validated, because the conceptual model is identical to the one validated and successfully applied in the ambient seepage studies. As described in Seepage Calibration Model and Seepage Testing Data (BSC (2004 [DIRS 171764], Section 7), the conceptual model developed in the SCM was tested by performing blind predictions of seepage rates for niche liquid release tests that had not been used for model calibration and that were conducted in a different drift section. It was demonstrated that the measured ambient seepage data (seepage threshold and seepage rate) were accurately represented by the simulated results. Validation of the coupled TH processes (using the DST data) together with validation of the ambient seepage conceptual model (using liquid-release data) provides confidence in the thermal seepage results of the TH seepage model. However, some uncertainty remains, since no direct test data on thermal seepage at extreme flux conditions are available. This uncertainty is propagated to TSPA by the choice of upper-bound estimates of thermal seepage in the seepage abstraction (BSC 2004 [DIRS 169131], Sections 6.5.2 and 6.5.3). 
Uncertainties regarding the effectiveness of the vaporization barrier have also been addressed in Section 6.3 of this report, where an alternative conceptual model of water flow in the superheated rock environment is introduced, the TH model for episodic finger flow (THMEFF). The THMEFF conceptualizes that the thermally perturbed downward flux from the condensation zone towards the superheated rock zone drains in episodic finger-flow patterns. The effectiveness of the vaporization barrier is then tested for these extreme conditions where downward flux is fast and large in magnitude compared to average flow, and where vaporization is limited by the small cross-sectional area between the narrow finger and the rock surface. Analyses were performed using finger-flow characteristics from experimental work described in the literature, applied to the thermal conditions in the Tptpmn and Tptpll units at several selected times after emplacement. It was demonstrated that results of the alternative conceptual model are consistent with the process-model results obtained with the TH seepage model. Most importantly, the THMEFF results show that finger flow is not able to penetrate through the superheated rock during the first several hundred years of heating, when rock temperature is high and boiling conditions exist in a sufficiently large region above the drifts. These are the conditions when the largest thermal perturbation occurs, or, in other words, when the potential for episodic finger flow is highest. Note that the THMEFF includes a number of limitations that are valid for a qualitative evaluation, but should not be interpreted as an exact quantitative representation of system behavior at Yucca Mountain. For example, one such limitation is that experimental data from a granite fracture at Stripa are used to represent the characteristics of episodic finger flow in fractured tuff at Yucca Mountain (remember though that the flow processes are similar).

For numerical models, the main sources of uncertainty are uncertainty in model input parameters and uncertainty in the conceptual model. As discussed in the above paragraph, uncertainty with respect to the conceptual model has been addressed in this report, building confidence in the validity of the conceptual model for thermal seepage. Remaining uncertainties are propagated to TSPA by the choice of upper-bound estimates of thermal seepage in the seepage abstraction (BSC 2004 [DIRS 169131], Sections 6.5.2 and 6.5.3). Uncertain and spatially variable model input parameters are the rock properties and the model boundary conditions. Sensitivity to all parameters relevant for thermal seepage was explicitly studied with the TH seepage model by assessing seepage in two host rock units with different thermal and hydrological properties, by varying the seepage relevant fracture capillary-strength parameter, by analyzing infiltration scenarios with different flux multiplication factors, by changing host rock thermal conductivities and fracture permeabilities, and by simulating several different thermal loads (see Section 6.2.1.6 for overview of simulation cases). In all these cases, covering a wide range of property values and conditions, the main conclusions regarding thermal seepage were similar, in that no seepage is predicted to occur during the period of above-boiling temperatures in the rock and that thermal seepage is always less in magnitude compared to the respective long-term ambient values. This confirms that these main conclusions hold for all relevant TSPA parameter cases.

\subsection{HOW THE APPLICABLE ACCEPTANCE CRITERIA ARE ADDRESSED}

The following information describes how this analysis addresses the acceptance criteria in the Yucca Mountain Review Plan (NRC 2003 [DIRS 163274], Sections 2.2.1.3.3 and 2.2.1.3.6.3). Only those acceptance criteria that are applicable to this report (see Section 4.2) are discussed. In most cases, the applicable acceptance criteria are not addressed solely by this report; rather, the 
acceptance criteria are fully addressed when this report is considered in conjunction with other analysis and model reports that describe quantity and chemistry of water contacting engineered barriers and waste forms, and flow in the unsaturated zone. Where a subcriterion includes several components, only some of those components may be addressed. How these components are addressed is summarized below. The acceptance criteria and subcriteria listed in Section 4.2 and here are consistent with those mentioned in Section 3.2.1 of Technical Work Plan for: NearField Environment and Transport: Near-Field Coupled Processes (TH Seepage and THM) Model Report Integration (BSC 2004 [DIRS 170236]), except for the following deviation. For "Quantity and Chemistry of Water Contacting Waste Packages and Waste Forms (Section 2.2.1.3.3)," Acceptance Criteria 5: Model Abstraction Output is Supported by Objective Comparisons is included here though not present in the technical work plan (BSC 2004 [DIRS 170236], Section 3.2.1).

\section{Acceptance Criteria from Section 2.2.1.3.3.3, Quantity and Chemistry of Water Contacting Engineered Barriers and Waste Forms}

\section{Acceptance Criterion 1: System Description and Model Integration Are Adequate.}

(1) The design features, physical phenomena, and couplings for this report (see Sections 5, 6.1, and 6.2.1) are consistent with those in other related model reports, see for example, Drift-Scale Coupled Processes (DST and THC Seepage) Models (BSC 2004 [DIRS 169856] and Drift-Scale THM Model (BSC 2004 [DIRS 169864]). The abstraction procedure for determining quantity of water entering the emplacement drifts is given in Abstraction of Drift Seepage (BSC 2004 [DIRS 169131], Sections 6.5 and 6.7).

(2) The abstraction of quantity of water entering the emplacement drifts is provided in Abstraction of Drift Seepage (BSC 2004 [DIRS 169131], Sections 6.5 and 6.7). The technical bases (see Sections 5, 6.1 and 6.2.1) for thermal seepage in this report are identical to those in Abstraction of Drift Seepage (BSC 2004 [DIRS 169131]).

(3) Thermal line load and decay of radioactive heat, parameters important for estimating quantity of water entering the emplacement drifts, have been obtained from controlled sources (see Section 4.1.1.3). The adopted values for these parameters are identical to those in other related model reports (see item (1) above).

(4) The physics of the coupled thermal-hydrological processes and the thermal seepage phenomenon (Section 6.1) are adequately incorporated into an appropriate process model based on a sufficient technical basis (Section 6.2.1), supported by field data (Sections 4.1 and 7) and sensitivity analyses (Sections 6.2.2, 6.2.3, and 6.2.4).

(5) The technical bases, assumptions, data, and models used in this report to determine the quantity of water entering the emplacement drifts are consistent with those used in analyzing the flow paths in the unsaturated zone. Sufficient technical bases and justifications have been provided for modeling coupled thermal-hydrological effects on seepage and flow (Sections 5, 6.1 and 6.2.1). 
(6) Seepage of water into the emplacement drifts promotes corrosion of engineered barriers and degradation of waste packages. The potential for water seepage into emplacement drifts under different thermal conditions is addressed in Section 6.2 (particularly in Section 6.2.4).

(7) The modeling approach in this report is consistent with the dimensionality of seepage abstractions (Section 6.2.1.2) and detailed information on engineered barrier design and other engineered features (Sections 4.1.1.6 and 6.2.1.2).

(8) Adequate technical bases (see Sections 6.1 and 6.2.1) have been provided for the TH seepage model in this report. The coupling of thermal and hydrological processes, which determine quantity of water entering emplacement drifts, has been elaborately discussed (see Sections 6.2.1, 6.2.2, and 6.2.3) through numerical modeling. Sensitivity studies including alternative parameter choices have been discussed in Section 6.2.4. Alternative conceptual models have been discussed in Section 6.3. Model validation of coupled TH processes against field thermal tests are provided in Section 7.

(9) Performance affecting processes that have been observed in thermal-hydrologic tests and experiments have been conceptually included in the TH seepage model (Section 6.2.1). Model validation against measured TH data (from field thermal tests) are discussed in Section 7. The approach and model is documented in a transparent and traceable manner by adopting input data from controlled sources and by thorough record keeping.

\section{Acceptance Criterion 2: Data Are Sufficient for Model Justification.}

(1) Geological, hydrological, and thermal property data used in this report are adequately justified and described (Sections 4.1, 5, and 6.2.1). Adequate description of how the data were used, interpreted, and appropriately synthesized into the parameters is provided in Sections 4.1, 5, and 6.2.1.

(2) Sufficient data (see Sections 4.1) were collected on the relevant characteristics of the natural system for conceptual models of $\mathrm{TH}$ coupled processes, that affect seepage and flow into emplacement drifts.

(3) Heater tests were designed and conducted with the objective of observing $\mathrm{TH}$ processes for the temperature ranges expected for repository conditions and making measurements for mathematical models. Section 7 provides discussion of TH data collected from the DST, the largest Yucca Mountain thermal test. Section 7 also provides validation of the conceptual TH seepage model against measured $\mathrm{TH}$ data from the DST.

(4) Sufficient data were collected for the formulation of the conceptual framework and for the validation of the $\mathrm{TH}$ process model (Section 7). Sufficient data were collected to characterize the TH properties of the natural system and to observe critical TH processes (Section 7). 


\section{Acceptance Criterion 3: Data Uncertainty Is Characterized and Propagated Through the Model Abstraction.}

(1) Parameter values, assumed ranges, probability distributions, and bounding assumptions (see Sections 4.1.1, 5, 6.1, 6.2.1, 6.2.2, and 6.2.3) used in this report are technically defensible, reasonably account for uncertainty, and do not result in an under-representation of the risk estimate (see Sections 8.1, 8.2, and 8.3).

(2) The parameters used in and the coupled processes modeled by the process model are technically defensible; they are based on and are consistent with available data from Yucca Mountain (see Section 4.1.1).

(3) Parameters used to define initial conditions (Section 6.2.1.3), boundary conditions (Sections 4.1.1.2 and 6.2.1.3), and computational domain (Sections 4.1.1.5 and 6.2.12) in sensitivity analyses (Section 6.2.4.2) involving coupled $\mathrm{TH}$ effects on seepage and flow are consistent with available data.

(4) Uncertainties and variabilities in the coupled $\mathrm{TH}$ processes are evaluated, reasonably accounted for and adequately represented (Sections 6.2, 6.3, and 8.3), providing a sufficient basis for incorporating data uncertainty in downstream reports on seepage abstraction.

(6) Where sufficient data do not exist, the definition of parameter values is based on other appropriate sources (see Section 5).

Acceptance Criterion 4: Model Uncertainty Is Characterized and Propagated Through the Model Abstraction.

(1) Alternative modeling choices have been adequately addressed (see Sections 6.2.4.2.3 through 6.2.4.2.6). Selected modeling approaches are consistent with available data and current scientific understanding.

(2) An alternative conceptual model has been developed consistent with available data and current scientific understanding (see Section 6.3). Modeling approaches have been discussed (see Sections 6.1 and 6.2). Model uncertainty is evaluated by sensitivity studies with the $\mathrm{TH}$ seepage model (Sections 6.2.4.2.3 through 6.2.4.2.6).

(3) Consideration of conceptual model uncertainty is consistent with available data, laboratory experiments, and field measurements (see Sections 6.2.4.2.3 through 6.2.4.2.6, 6.3, and 7).

(4) Adequate consideration is given to effects of $\mathrm{TH}$ coupled processes in the assessment of alternative conceptual models (Section 6.2 and 6.3).

(5) A dual-permeability model (DKM) has been adopted for the TH seepage model (see Section 6.1 and 6.2.1). 


\section{Acceptance Criterion 5: Model Abstraction Output Is Supported by Objective Comparisons.}

(1) The recommended abstraction methodologies are based on detailed process-level models (Sections 6.2.4.1 and 8.2).

(2) The assumptions and approximations are demonstrated to be appropriate for process-level models (Sections 5, 6.1.1, and 6.2.1)

(3) Accepted and well-documented procedures are used to construct and test the numerical models that simulate coupled TH effects on seepage and flow (Sections 6.1.1 and 6.2.1).

\section{Acceptance Criteria from Section 2.2.1.3.6.3, Flow Paths in the Unsaturated Zone.}

Acceptance Criterion 1: System Description and Model Integration Are Adequate.

(1) The design features, physical phenomena, and couplings for this report (see Sections 5, 6.1, and 6.2.1) are consistent with those in other related model reports; see for example, Drift-Scale Coupled Processes (DST and THC Seepage) Models (BSC 2004 [DIRS 169856]) and Drift-Scale THM Model (BSC 2004 [DIRS 169864]).

(2) The aspects of geology, hydrology, physical phenomena, and TH couplings that may affect flow paths in the unsaturated zone are adequately considered (see Sections 6.1, 6.2.1, 6.2.2, and 6.2.3)

(3) In the context of abstraction of flow paths in the unsaturated zone, the assumptions (Section 5), technical bases (Sections 6.1 and 6.2.1), data (Section 4.1.1), and models (Sections 6.1 and 6.2) in this report are consistent with other related abstractions.

(5) Sufficient technical bases have been provided to assess the degree to which features, events, and processes have been included (see Section 6).

(6) Adequate spatial and temporal variability of model parameters are employed in the TH seepage model to investigate flow paths in the unsaturated zone (Sections 6.1, 6.2.1, 6.2.2, and 6.2.3).

(7) The average parameter values used in the TH seepage model are representative of the temporal and spatial discretizations (Sections 4.1.1).

(9) Data from qualified sources have been used. Further confidence is gained through thorough record keeping. 


\section{Acceptance Criterion 2: Data Are Sufficient for Model Justification.}

(1) Hydrological and thermal property values used in this report have been adequately justified (Sections 4.1.1 and 5)

(2) Geology and hydrology data used in this report are obtained from controlled sources (Section 4.1.1).

(3) Estimates of percolation fluxes were obtained from controlled and qualified sources (Section 4.1.1.4 and Appendix B).

(4) Appropriate thermal-hydrologic tests were designed and conducted, so that critical thermal-hydrologic processes could be observed; Section 7 provides discussion of validation of the TH seepage model against measured thermal-hydrologic data from the largest thermal test at Yucca Mountain.

(5) Sensitivity and uncertainty analyses have been performed (Sections 6.2.4.2.3 through 6.2.4.2.6, and 6.3).

(6) Accepted and well-documented procedures are used to construct numerical models (Sections 4.1.1 and 6).

(7) Mathematical models (Section 6.2.1.1.3) are provided that are consistent with conceptual models (Sections 6.1 and 6.2.1.1.1). The robustness of results from different mathematical models is compared (Sections 6.2 and 6.3).

\section{Acceptance Criterion 3: Data Uncertainty Is Characterized and Propagated Through the Model Abstraction.}

(1) Parameter values, assumed ranges, probability distributions, and bounding assumptions (see Sections 4.1.1, 5, 6.1, 6.2.1, 6.2.2, and 6.2.3) used in this report are technically defensible, reasonably account for uncertainty, and do not result in an under-representation of the risk estimate (see Sections 8.1, 8.2, and 8.3).

(2) Adequate technical bases for the parameter values have been provided (Sections 4.1.1, 5, 6.2.1, and 6.2.4.2).

(3) Possible statistical correlations between parameter values have been discussed, when appropriate (Section 4.1.1).

(4) The sensitivity analyses (Sections 6.2.4.2.3 through 6.2.4.2.6) in this report are consistent with available data.

(5) Coupled TH processes have been adequately represented (Sections 6.1 and 6.2).

(6) Uncertainties in the characteristics of the natural system are considered (Sections 6.2.4.2.3 through 6.2.4.2.6). 


\section{Acceptance Criterion 4: Model Uncertainty Is Characterized and Propagated Through the Model Abstraction.}

(1) Alternative modeling choices have been adequately addressed (see Sections 6.2.4.2.3 through 6.2.4.2.6). Selected modeling approaches are consistent with available data and current scientific understanding.

(2) The bounds of uncertainty considered by the TH seepage model are considered (Sections 8.1, 8.2, and 8.3).

(3) Consideration of conceptual model uncertainty is consistent with available data, laboratory experiments, and field measurements (see Sections 6.2.4.2.3 through 6.2.4.2.6, 6.3, and 7).

\subsection{OUTPUT DTNS}

Thermal properties for the UZ model layers (see Section 4.1.1.1 and Appendix F) are developed in this report. These thermal properties for the UZ model layers have been submitted to the TDMS as output from this report. These thermal properties can be found in DTN: LB0402THRMLPRP.001.

Several of the many simulation cases presented in this model report have been selected for submittal to the Technical Data Management System (TDMS). The simulation cases that were submitted to the TDMS are those cases deemed relevant to downstream users. The rationale for selecting simulation cases for the TDMS is given below:

\section{TH Seepage Model}

- Simulation cases that mainly serve informative purposes and provide intermediary or supplementary results are not submitted to the TDMS. These are the simulation cases in Sections 6.2.2.1 and 6.2.3.1, where drift-scale $\mathrm{TH}$ conditions are presented without specific focus on thermal seepage, and in Sections 6.2.4.2.4 and 6.4.2.4.5, where different alternative model choices are tested for comparison.

- Simulation cases that are specifically intended to calculate thermal seepage and to evaluate the combined barrier effectiveness are submitted to the TDMS. These are all simulation cases presented in Sections 6.2.2.2, 6.2.3.2, and 6.2.4.2.1 through 6.2.4.2.3 of this report, and also include selected simulation cases in Appendix C. The DTNs comprise both transient thermal runs and long-term ambient (steady-state) runs. The following DTNs have been submitted:

- Thermal seepage results for intact drifts: LB0303DSCPTHSM.001 (TOUGH2 files) and LB0301DSCPTHSM.002 (developed data); LB0309DSCPTHSM.001 (TOUGH2 files) and LB0309DSCPTHSM.002 (developed data)

- TH Conditions for Collapsed Drifts: LB0310DSCPTHSM.001 (TOUGH2 files) and LB0310DSCPTHSM.002 (developed data) 
- Thermal seepage results for intact drifts with revised thermal properties (Appendix): LB0404DSCPTHSM.001 (TOUGH2 files) and LB0404DSCPTHSM.002 (developed data)

\section{THMEFF (Alternative Conceptual Model)}

- Data from the THMEFF are not submitted to the TDMS. The THMEFF is an alternative conceptual model providing corroborative information to support the TH seepage model. Specific results of this model are intermediary results and are not relevant as direct input for downstream users.

\section{DST TH Model}

- All simulation cases conducted with the DST TH model and presented in this report are submitted to the TDMS. The DTNs are: LB0303DSCPDSTV.001 (TOUGH2 files) and LB0301DSCPDSTV.002 (developed data).

For the selected simulation cases, all computer files needed to reproduce the model results were submitted to the TDMS. For both the TH seepage model and the DST TH model runs, the input files needed to perform a TOUGH2 simulation and the respective output files obtained from the respective TOUGH2 simulation have been submitted. Data developed from these simulations have been submitted in addition to the simulation files. These data comprise computer files giving the transient or steady-state seepage rates, extracted from the TH seepage model, and computer files providing predicted air-permeability results, calculated from saturation data simulated with the DST TH model. Reproducibility by an appropriately qualified individual is possible by consulting this report and the pertinent scientific notebook pages as listed in Table 6-1. 


\section{INPUTS AND REFERENCES}

The following is a list of the references cited in this document. Column 2 represents the unique six-digit numerical identifier (the Document Input Reference System [DIRS] number), which is placed in the text following the reference callout (e.g., BSC 2002 [DIRS 160780]). The purpose of these numbers is to assist the reader in locating a specific reference. Within the reference list, multiple sources by the same author (e.g., BSC 2002) are sorted alphabetically by title.

\subsection{DOCUMENTS CITED}

Ang, A.H-S. and Tang, W.H. 1975. “Basic Principles.” Volume I of Probability

160321 Concepts in Engineering Planning and Design. New York, New York: John Wiley \& Sons. TIC: 8346.

Birkholzer, J.; Li, G.; Tsang, C-F.; and Tsang, Y. 1999. “Modeling Studies and 105170 Analysis of Seepage into Drifts at Yucca Mountain.” Journal of Contaminant Hydrology, 38, (1-3), 349-384. New York, New York: Elsevier. TIC: 244160.

Birkholzer, J.T. 2002. TH_PULSE: Program for Calculating Infiltration of 160748 Episodic Liquid Fingers in Superheated Rock Fractures, Theory, User's Manual, and Sample Applications. LBNL/PUB-3277. Berkeley, California: Lawrence Berkeley National Laboratory. TIC: 253581.

Birkholzer, J.T. and Tsang, Y.W. 1997. Pretest Analysis of the ThermalHydrological Conditions of the ESF Drift Scale Test. Milestone SP9322M4. Berkeley, California: Lawrence Berkeley National Laboratory. ACC: MOL.19971201.0810.

Birkholzer, J.T. and Tsang, Y.W. 2000. "Modeling the Thermal-Hydrologic 154608 Processes in a Large-Scale Underground Heater Test in Partially Saturated Fractured Tuff.” Water Resources Research, 36, (6), 1431-1447. Washington, D.C.: American Geophysical Union. TIC: 248278.

Brooks, R.H. and Corey, A.T. 1966. "Properties of Porous Media Affecting Fluid 119392 Flow." Journal of the Irrigation and Drainage Division, Proceedings of the American Society of Civil Engineers, 92, (IR2), 61-89. Ann Arbor, Michigan: American Society of Civil Engineers. TIC: 216867.

BSC (Bechtel SAIC Company) 2001. FY 01 Supplemental Science and Performance Analyses, Volume 1: Scientific Bases and Analyses. TDR-MGR-MD000007 REV 00 ICN 01. Las Vegas, Nevada: Bechtel SAIC Company. ACC: MOL.20010801.0404; MOL.20010712.0062; MOL.20010815.0001.

BSC 2001. FY01 Supplemental Science and Performance Analyses, Volume 2: Performance Analyses. TDR-MGR-PA-000001 REV 00. Las Vegas, Nevada:

Bechtel SAIC Company. ACC: MOL.20010724.0110. 
BSC 2001. Multiscale Thermohydrologic Model. ANL-EBS-MD-000049 REV 00

158204

ICN 02. Las Vegas, Nevada: Bechtel SAIC Company.

ACC: MOL.20020123.0279.

BSC 2001. Thermal Tests Thermal-Hydrological Analyses/Model Report. ANL-

157330

NBS-TH-000001 REV 00 ICN 02. Las Vegas, Nevada: Bechtel SAIC Company.

ACC: MOL.20011116.0025.

BSC 2001. UZ Flow Models and Submodels. MDL-NBS-HS-000006 REV 00 ICN

01. Las Vegas, Nevada: Bechtel SAIC Company. ACC: MOL.20020417.0382.

BSC 2002. Geologic Framework Model (GFM2000). MDL-NBS-GS-000002

REV 01. Las Vegas, Nevada: Bechtel SAIC Company.

ACC: MOL.20020530.0078.

BSC 2002. Invert Effective Thermal Conductivity Calculation. 000-00C-WIS0-

159906 00100-000-00A. Las Vegas, Nevada: Bechtel SAIC Company.

ACC: MOL.20020828.0178.

BSC 2002. Repository Design, Repository/PA IED Subsurface Facilities Plan Sht. 1 of 5, Sht. 2 of 5, Sht. 3 of 5, Sht. 4 of 5, and Sht. 5 of 5. DWG-MGR-MD-000003 REV A. Las Vegas, Nevada: Bechtel SAIC Company.

ACC: MOL.20020601.0194.

BSC 2002. Ventilation Model. ANL-EBS-MD-000030 REV 01 ICN 01. Las Vegas, Nevada: Bechtel SAIC Company. ACC: MOL.20021106.0055.

160975

BSC 2003. Advection Versus Diffusion in the Invert. ANL-EBS-MD-000063 REV

170881

00. Las Vegas, Nevada: Bechtel SAIC Company. ACC: DOC.20040217.0004;

Replacement for 165686.

BSC 2003. Development of Numerical Grids for UZ Flow and Transport

Modeling. ANL-NBS-HS-000015 REV 01. Las Vegas, Nevada: Bechtel SAIC

Company. ACC: DOC.20030404.0005.

BSC 2003. Drift-Scale Coupled Processes (DST and THC Seepage) Models.

162050

MDL-NBS-HS-000001 REV 02. Las Vegas, Nevada: Bechtel SAIC Company.

ACC: DOC.20030804.0004.

BSC 2003. Repository Design Project, RDP/PA IED Typical Waste Package

164053

Components Assembly 1 of 9. 800-IED-WIS0-00201-000-00A. Las Vegas,

Nevada: Bechtel SAIC Company. ACC: ENG.20030702.0001.

BSC 2003. Repository Design Project, Repository/PA IED Emplacement Drift

164052

Committed Materials 1 of 2. 800-IED-WIS0-00301-000-00A. Las Vegas, Nevada:

Bechtel SAIC Company. ACC: ENG.20030627.0003. 
BSC 2003. Repository Design, Repository/PA IED Subsurface Facilities. 800-

161731 IED-EBS0-00403-000-00B. Las Vegas, Nevada: Bechtel SAIC Company.

ACC: MOL.20030109.0147.

BSC 2004. Abstraction of Drift Seepage. MDL-NBS-HS-000019, Rev. 01. Las

169131

Vegas, Nevada: Bechtel SAIC Company.

BSC 2004. Analysis of Hydrologic Properties Data. ANL-NBS-HS-000042, Rev. 00. Las Vegas, Nevada: Bechtel SAIC Company.

BSC 2004. Calibrated Properties Model. MDL-NBS-HS-000003, Rev. 02. Las

169857

Vegas, Nevada: Bechtel SAIC Company.

BSC 2004. Conceptual Model and Numerical Approaches for UZ Flow and

170035

Transport. MDL-NBS-HS-000005 REV 01. Las Vegas, Nevada: Bechtel SAIC Company.

BSC 2004. D\&E / PA/C IED Emplacement Drift Configuration and Environment. 800-IED-MGR0-00201-000-00B. Las Vegas, Nevada: Bechtel SAIC Company. ACC: ENG.20040326.0001.

BSC 2004. D\&E / PA/C IED Typical Waste Package Components Assembly. 800IED-WIS0-00204-000-00B. Las Vegas, Nevada: Bechtel SAIC Company.

ACC: ENG.20040202.0012.

BSC 2004. D\&E / PA/C IED Typical Waste Package Components Assembly. 800IED-WIS0-00205-000-00C. Las Vegas, Nevada: Bechtel SAIC Company.

ACC: ENG.20040202.0013.

BSC 2004. Data Qualification Report: Heat Capacity Values for Rock and 171504 Lithostratigraphic Layers of the Geologic Framework Model for Use on the Yucca Mountain Project. TDR-NBS-GS-000028 REV 00. Las Vegas, Nevada: Bechtel SAIC Company. ACC: DOC.20040805.0007.

BSC 2004. Design and Engineering, Drip Shield Plate - 1. 000-M00-SSE0-

168283 00601-000-00A. Las Vegas, Nevada: Bechtel SAIC Company.

ACC: ENG.20040310.0027.

BSC 2004. Development of Numerical Grids for UZ Flow and Transport Modeling. ANL-NBS-HS-000015 REV 02. Las Vegas, Nevada: Bechtel SAIC Company. ACC: DOC.20040901.0001.

BSC 2004. Drift Degradation Analysis. ANL-EBS-MD-000027, Rev. 03. Las 166107 Vegas, Nevada: Bechtel SAIC Company. ACC: DOC.20040915.0010.

BSC 2004. Drift Scale THM Model. MDL-NBS-HS-000017, Rev. 01. Las Vegas, Nevada: Bechtel SAIC Company. 
BSC 2004. Drift-Scale THC Seepage Model. MDL-NBS-HS-000001, Rev. 03.

169856

Las Vegas, Nevada: Bechtel SAIC Company.

BSC 2004. Geologic Framework Model (GFM2000). MDL-NBS-GS-000002

170029

REV 02. Las Vegas, Nevada: Bechtel SAIC Company.

ACC: DOC.20040827.0008.

BSC 2004. Heat Capacity Analysis Report. ANL-NBS-GS-000013, Rev. 01. Las

170003 Vegas, Nevada: Bechtel SAIC Company.

BSC 2004. In Situ Field Testing of Processes. ANL-NBS-HS-000005, Rev. 03.

170004

Las Vegas, Nevada: Bechtel SAIC Company.

BSC 2004. In-Drift Natural Convection and Condensation. MDL-EBS-MD-

164327

000001, Rev. 00. Las Vegas, Nevada: Bechtel SAIC Company.

BSC 2004. Multiscale Thermohydrologic Model. ANL-EBS-MD-000049, Rev. 02. Las Vegas, Nevada: Bechtel SAIC Company.

169565

BSC 2004. Q-List. 000-30R-MGR0-00500-000-000 REV 00. Las Vegas, Nevada:

168361

Bechtel SAIC Company. ACC: ENG.20040721.0007.

BSC 2004. Repository Subsurface Emplacement Drifts Steel Invert Structure Sect.

169776

\& Committed Materials. 800-SS0-SSE0-00102-000-00B. Las Vegas, Nevada:

Bechtel SAIC Company. ACC: ENG.20040520.0005.

BSC 2004. Seepage Calibration Model and Seepage Testing Data. MDL-NBS-

171764 HS-000004 REV 03. Las Vegas, Nevada: Bechtel SAIC Company.

ACC: DOC.20040922.0003.

BSC 2004. Seepage Model for PA Including Drift Collapse. MDL-NBS-HS-

167652

000002, Rev. 03. Las Vegas, Nevada: Bechtel SAIC Company.

BSC 2004. Technical Work Plan for: Near-Field Environment and Transport:

Near-Field Coupled Processes (TH Seepage and THM) Model Report Integration.

TWP-MGR-PA-000015 REV 00. Las Vegas, Nevada: Bechtel SAIC Company.

ACC: DOC.20040610.0001.

BSC 2004. Technical Work Plan for: Performance Assessment Unsaturated Zone.

167969

TWP-NBS-HS-000003 REV 02 [Errata 001]. Las Vegas, Nevada: Bechtel SAIC

Company. ACC: MOL.20030102.0108; DOC.20040121.0001.

BSC 2004. Thermal Conductivity of Non-Repository Lithostratigraphic Layers.

MDL-NBS-GS-000006, Rev. 01. Las Vegas, Nevada: Bechtel SAIC Company.

170033 
BSC 2004. Thermal Conductivity of the Potential Repository Horizon. MDL-

NBS-GS-000005, Rev. 01. Las Vegas, Nevada: Bechtel SAIC Company.

ACC: MOL.20040630.0641

BSC 2004. Thermal Testing Measurements Report. TDR-MGR-HS-000002 REV

169900

00. Las Vegas, Nevada: Bechtel SAIC Company.

BSC 2004. UZ Flow Models and Submodels. MDL-NBS-HS-000006, Rev. 02.

Las Vegas, Nevada: Bechtel SAIC Company.

BSC 2004. Ventilation Model and Analysis Report. ANL-EBS-MD-000030, Rev.

04. Las Vegas, Nevada: Bechtel SAIC Company.

Buscheck, T.A. and Nitao, J.J. 1993. "Repository-Heat-Driven Hydrothermal Flow at Yucca Mountain, Part I: Modeling and Analysis.” Nuclear Technology, 104, (3), 418-448. La Grange Park, Illinois: American Nuclear Society. TIC: 224039.

Buscheck, T.A.; Rosenberg, N.D.; Gansemer, J.; and Sun, Y. 2002.

160749

"Thermohydrologic Behavior at an Underground Nuclear Waste Repository."

Water Resources Research, 38, (3), 10-1 through 10-19. Washington, D.C.:

American Geophysical Union. TIC: 253566.

Canori, G.F. and Leitner, M.M. 2003. Project Requirements Document. TER-

MGR-MD-000001 REV 02. Las Vegas, Nevada: Bechtel SAIC Company.

ACC: DOC.20031222.0006.

Carslaw, H.S. and Jaeger, J.C. 1959. Conduction of Heat in Solids. 2nd Edition.

100968

Oxford, Great Britain: Oxford University Press. TIC: 206085.

CRWMS (Civilian Radioactive Waste Management System) M\&O (Management and Operating Contractor) 1997. Ambient Characterization of the Drift Scale Test Block. BADD00000-01717-5705-00001 REV 01. Las Vegas, Nevada: CRWMS M\&O. ACC: MOL.19980416.0689.

CRWMS M\&O 1997. Drift Scale Test Design and Forecast Results. BAB00000001717-4600-00007 REV 01. Las Vegas, Nevada: CRWMS M\&O.

ACC: MOL.19980710.0155.

CRWMS M\&O 1998. Drift Scale Test As-Built Report. BAB000000-01717-570000003 REV 01. Las Vegas, Nevada: CRWMS M\&O.

ACC: MOL.19990107.0223.

CRWMS M\&O 1998. Near-Field/Altered Zone Coupled Effects Expert Elicitation Project. Las Vegas, Nevada: CRWMS M\&O. ACC: MOL.19980729.0638. 
CRWMS M\&O 1998. Thermal Test Progress Report \#1. Las Vegas, Nevada:

159512

CRWMS M\&O. ACC: MOL.19991104.0269.

CRWMS M\&O 1999. Thermal Test Progress Report \#2. BABEAF000-01717-

154585 5700-00001 REV 00. Las Vegas, Nevada: CRWMS M\&O.

ACC: MOL.19991104.0270.

CRWMS M\&O 1999. Thermal Test Progress Report \#3. Las Vegas, Nevada: CRWMS M\&O. ACC: MOL.19991104.0271.

159513

CRWMS M\&O 1999. Thermal Test Progress Report \#4. Las Vegas, Nevada:

160806

CRWMS M\&O. ACC: MOL.20020131.0342.

CRWMS M\&O 2000. Geologic Framework Model (GFM3.1). MDL-NBS-GS-

138860 000002 REV 00 ICN 01. Las Vegas, Nevada: CRWMS M\&O.

ACC: MOL.20000121.0115.

CRWMS M\&O 2000. Seepage Model for PA Including Drift Collapse. MDLNBS-HS-000002 REV 01. Las Vegas, Nevada: CRWMS M\&O.

ACC: MOL.20010221.0147.

CRWMS M\&O 2000. Tabulated In-Drift Geometric and Thermal Properties Used in Drift-Scale Models for TSPA-SR. CAL-EBS-HS-000002 REV 00. Las Vegas, Nevada: CRWMS M\&O. ACC: MOL.20020212.0257.

CRWMS M\&O 2000. Thermal Test Progress Report \#5. Las Vegas, Nevada:

160807

CRWMS M\&O. ACC: MOL.20020131.0308.

CRWMS M\&O 2000. Total System Performance Assessment for the Site

153246

Recommendation. TDR-WIS-PA-000001 REV 00 ICN 01. Las Vegas, Nevada: CRWMS M\&O. ACC: MOL.20001220.0045.

CRWMS M\&O 2000. Unsaturated Zone Flow and Transport Model Process Model Report. TDR-NBS-HS-000002 REV 00 ICN 02. Las Vegas, Nevada:

CRWMS M\&O. ACC: MOL.20000831.0280.

CRWMS M\&O 2001. Seepage Calibration Model and Seepage Testing Data. MDL-NBS-HS-000004 REV 01. Las Vegas, Nevada: CRWMS M\&O.

ACC: MOL.20010122.0093.

CRWMS M\&O 2001. Water Distribution and Removal Model. ANL-EBS-MD000032 REV 01. Las Vegas, Nevada: CRWMS M\&O.

ACC: MOL.20010214.0031.

de Marsily, G. 1986. Quantitative Hydrogeology: Groundwater Hydrology for 100439 Engineers. San Diego, California: Academic Press. TIC: 208450. 
Doughty, C. 1999. "Investigation of Conceptual and Numerical Approaches for

Evaluating Moisture, Gas, Chemical, and Heat Transport in Fractured Unsaturated Rock.” Journal of Contaminant Hydrology, 38, (1-3), 69-106. New York, New York: Elsevier. TIC: 244160.

Edlefsen, N.E. and Anderson, A.B.C. 1943. “Thermodynamics of Soil Moisture.” 138932 Hilgardia, 15, (2), 31-298. Berkeley, California: California Agricultural Experiment Station. TIC: 235679.

Finsterle, S. 2000. "Using the Continuum Approach to Model Unsaturated Flow in Fractured Rock.” Water Resources Research, 36, (8), 2055-2066. Washington, D.C.: American Geophysical Union. TIC: 248769.

Francis, N.D. 1997. “The Base-Case Thermal Properties for TSPA-VA Modeling." 127326 Memorandum from N.D. Francis (SNL) to Distribution, April 16, 1997. ACC: MOL.19980518.0229.

Glass, R.J. 1993. “Modeling Gravity-Driven Fingering in Rough-Walled Fractures Using Modified Percolation Theory." High Level Radioactive Waste Management, Proceedings of the Fourth Annual International Conference, Las Vegas, Nevada, April 26-30, 1993. 2, 2042-2052. La Grange Park, Illinois: American Nuclear Society. TIC: 208542.

Grant, S.A. 2003. "Extension of a Temperature Effects Model for Capillary Pressure Saturation Relations.” Water Resources Research, 39, (1), SBH 1-1 SBH 1-10. Washington, D.C.: American Geophysical Union. TIC: 56355.

Hakami, E. 1995. Aperture Distribution of Rock Fractures. Doctoral thesis. Stockholm, Sweden: Royal Institute of Technology, Department of Civil and Environmental Engineering. TIC: 253610.

Hakami, E. and Barton, N. 1990. "Aperture Measurements and Flow Experiments 160754 Using Transparent Replicas of Rock Joints.” Rock Joints, Proceedings of the International Symposium on Rock Joints, Loen, Norway, 4-6 June 1990. Barton, N. and Stephansson, O., eds. Pages 383-390. Brookfield, Vermont: A.A. Balkema. TIC: 103532.

IFC (International Formulation Committee) 1967. The 1967 IFC Formulation for 156448 Industrial Use, A Formulation of the Thermodynamic Properties of Ordinary Water Substance. Düsseldorf, Germany: International Formulation Committee of the Sixth International Conference on the Properties of Steam. TIC: 224838.

Kneafsey, T.J. and Pruess, K. 1998. “Laboratory Experiments on Heat-Driven Two-Phase Flows in Natural and Artificial Rock Fractures." Water Resources Research, 34, (12), 3349-3367. Washington, D.C.: American Geophysical Union. TIC: 247468. 
LeCain, G.D. 1995. Pneumatic Testing in 45-Degree-Inclined Boreholes in Ash-

101700

Flow Tuff Near Superior, Arizona. Water-Resources Investigations Report 95-

4073. Denver, Colorado: U.S. Geological Survey. ACC: MOL.19960715.0083.

Lichtner, P.C. and Walton, J.C. 1994. Near-Field Liquid-Vapor Transport in a

152609

Partially Saturated High-Level Nuclear Waste Repository. CNWRA 94-022. San

Antonio, Texas: Center for Nuclear Waste Regulatory Analyses. TIC: 216007.

Lin, W.; Blair, S.C.; Wilder, D.; Carlson, S.; Wagoner, J.; DeLoach, L.; Danko, G.;

159069

Ramirez, A.L.; and Lee, K. 2001. Large Block Test Final Report. UCRL-ID-

132246, Rev. 2. Livermore, California: Lawrence Livermore National Laboratory.

TIC: 252918.

Liu, H.H.; Doughty, C.; and Bodvarsson, G.S. 1998. “An Active Fracture Model

105729 for Unsaturated Flow and Transport in Fractured Rocks.” Water Resources Research, 34, (10), 2633-2646. Washington, D.C.: American Geophysical Union. TIC: 243012.

Mualem, Y. 1976. “A New Model for Predicting the Hydraulic Conductivity of Unsaturated Porous Media.” Water Resources Research, 12, (3), 513-522.

Washington, D.C.: American Geophysical Union. TIC: 217339.

Mukhopadhyay, S. and Tsang, Y.W. 2002. "Understanding the Anomalous Temperature Data from the Large Block Test at Yucca Mountain, Nevada.” Water Resources Research, 38, (10), 28-1 through 28-12. Washington, D.C.: American Geophysical Union. TIC: 253867.

Mukhopadhyay, S. and Tsang, Y.W. 2003. "Uncertainties in Coupled ThermalHydrological Processes Associated with the Drift Scale Test at Yucca Mountain, Nevada.” Journal of Contaminant Hydrology, 62-63, 595-612. New York, New York: Elsevier. TIC: 254205.

Nicholl, M.J.; Glass, R.J.; and Nguyen, H.A. 1993. "Small-Scale Behavior of Single Gravity-Driven Fingers in an Initially Dry Fracture.” High Level Radioactive Waste Management, Proceedings of the Fourth Annual International Conference, Las Vegas, Nevada, April 26-30, 1993. 2, 2023-2032. La Grange Park, Illinois: American Nuclear Society. TIC: 208542.

Nicholl, M.J.; Glass, R.J.; and Wheatcraft, S.W. 1994. "Gravity-Driven Infiltration Instability in Initially Dry Nonhorizontal Fractures.” Water Resources Research, 30, (9), 2533-2546. Washington, D.C.: American Geophysical Union.

TIC: 243493.

Nitao, J.J. 2000. Documentation of the Thermal Energy Balance Equation Used in the USNT Module of the NUFT Flow and Transport Code. UCRL-ID-139836. Livermore, California: Lawrence Livermore National Laboratory. ACC: MOL.20020711.0161. 
NRC (U.S. Nuclear Regulatory Commission) 2003. Yucca Mountain Review Plan, 163274 Final Report. NUREG-1804, Rev. 2. Washington, D.C.: U.S. Nuclear Regulatory Commission, Office of Nuclear Material Safety and Safeguards. TIC: 254568.

Oldenburg, C.M. and Pruess, K. 1993. “On Numerical Modeling of Capillary Barriers.” Water Resources Research, 29, (4), 1045-1056. Washington, D.C.: American Geophysical Union. TIC: 238834.

Perry, R.H.; Green, D.W.; and Maloney, J.O., eds. 1984. Perry's Chemical 125806 Engineers' Handbook. 6th Edition. New York, New York: McGraw-Hill. TIC: 246473.

Persoff, P. and Pruess, K. 1995. “Two-Phase Flow Visualization and Relative 160758 Permeability Measurement in Natural Rough-Walled Rock Fractures.” Water Resources Research, 31, (5), 1175-1186. Washington, D.C.: American Geophysical Union. TIC: 229697.

Philip, J.R.; Knight, J.H.; and Waechter, R.T. 1989. "Unsaturated Seepage and 105743 Subterranean Holes: Conspectus, and Exclusion Problem for Circular Cylindrical Cavities.” Water Resources Research, 25, (1), 16-28. Washington, D.C.: American Geophysical Union. TIC: 239117.

Phillips, O.M. 1996. "Infiltration of a Liquid Finger Down a Fracture into 152005 Superheated Rock.” Water Resources Research, 32, (6), 1665-1670. Washington, D.C.: American Geophysical Union. TIC: 239025.

Pruess, K. 1987. TOUGH User's Guide. NUREG/CR-4645. Washington, D.C.: U.S. Nuclear Regulatory Commission. TIC: 217275.

Pruess, K. 1991. TOUGH2-A General-Purpose Numerical Simulator for Multiphase Fluid and Heat Flow. LBL-29400. Berkeley, California: Lawrence Berkeley Laboratory. ACC: NNA.19940202.0088.

Pruess, K. 1997. “On Vaporizing Water Flow in Hot Sub-Vertical Rock Fractures.” 144794 Transport in Porous Media, 28, (3), 335-372. Boston, Massachusetts: Kluwer Academic Publishers. TIC: 238922.

Pruess, K. 1998. “On Water Seepage and Fast Preferential Flow in Heterogeneous, Unsaturated Rock Fractures.” Journal of Contaminant Hydrology, 30, 333-362. New York, New York: Elsevier. TIC: 238921.

Pruess, K.; Oldenburg, C.; and Moridis, G. 1999. TOUGH2 User's Guide, Version 160778 2.0. LBNL-43134. Berkeley, California: Lawrence Berkeley National Laboratory. TIC: 253038. 
Pruess, K.; Tsang, Y.W.; and Wang, J.S.Y. 1984. Numerical Studies of Fluid and 144801 Heat Flow Near High-Level Nuclear Waste Packages Emplaced in Partially Saturated Fractured Tuff. LBL-18552. Berkeley, California: Lawrence Berkeley Laboratory. TIC: 211033.

Pruess, K.; Wang, J.S.Y.; and Tsang, Y.W. 1990. “On Thermohydrologic Conditions Near High-Level Nuclear Wastes Emplaced in Partially Saturated Fractured Tuff, 2. Effective Continuum Approximation.” Water Resources Research, 26, (6), 1249-1261. Washington, D.C.: American Geophysical Union. TIC: 224854.

Ross, B. 1990. “The Diversion Capacity of Capillary Barriers.” Water Resources 141790 Research, 26, (10), 2625-2629. Washington, D.C.: American Geophysical Union. TIC: 225235.

Su, G.W.; Geller, J.T.; Pruess, K.; and Wen, F. 1999. "Experimental Studies of Water Seepage and Intermittent Flow in Unsaturated, Rough-Walled Fractures.” Water Resources Research, 35, (4), 1019-1037. Washington, D.C.: American Geophysical Union. TIC: 245798.

Tsang, Y.W. and Birkholzer, J.T. 1999. "Predictions and Observations of the Thermal-Hydrological Conditions in the Single Heater Test.” Journal of Contaminant Hydrology, 38, (1-3), 385-425. New York, New York: Elsevier. TIC: 244160.

Tsang, Y.W.; Birkholzer, J.T.; Sonnenthal, E.; Spycher, N.; Apps, J.; Peterson, J.E., 144941 Jr.; and Williams, K.H. 1998. Drift Scale Test Progress Report Lawrence Berkeley National Laboratory, Version 0.0. Milestone SP2930M4. Berkeley, California: Lawrence Berkeley National Laboratory. ACC: MOL.19980825.0268.

USGS (U.S. Geological Survey) 2003. Simulation of Net Infiltration for Modern and Potential Future Climates, with Errata. ANL-NBS-HS-000032 REV 00 ICN 02. Denver, Colorado: U.S. Geological Survey. ACC: MOL.20011119.0334; DOC.20031014.0004; DOC.20031015.0001.

van Genuchten, M.T. 1980. “A Closed-Form Equation for Predicting the Hydraulic Conductivity of Unsaturated Soils.” Soil Science Society of America Journal, 44, (5), 892-898. Madison, Wisconsin: Soil Science Society of America. TIC: 217327.

Wang, J. 2004. Scientific Notebooks Referenced in Model Report U0240 Drift-Scale Coupled Processes Model, MDL-NBS-HS-000015 REV 01 "Memorandum from J.S. Wang (BSC) to File, July 17, 2004, with attachment. ACC: MOL.20040809.0113. 
Wang, J.S. 2003. "Scientific Notebooks Referenced in Model Report U0240,

Drift-Scale Coupled Processes (DST and TH Seepage) Models, MDL-NBS-HS000015 REV 00.” Interoffice correspondence from J.S. Wang (BSC) to File, March 25, 2003, with attachments. ACC: MOL.20030407.0010.

Williams, N.H. 2001. “Contract \#: DE-AC08-01RW12101--Thermal Test 160809 Progress Report \#7.” Letter from N.H. Williams (BSC) to S.P. Mellington (DOE/YMSCO), November 9, 2001, NHW:TJV:bm-1025010261, with enclosure. ACC: MOL.20011207.0060.

Williams, N.H. 2001. “Contract \#: DE-AC08-01NV12101 -- Thermal Test 156323 Progress Report \#6.” Letter from N.H. Williams (BSC) to S.P. Mellington (DOE/YMSCO), April 19, 2001, PROJ.04/01.030, with enclosure.

ACC: MOL.20010612.0531.

Williams, N. H. 2002. Contract No. DE-AC28-01RW12101 - Key Technical Issue (KTI) Agreement Item Thermal Effects on Flow (TEF) 2.01.

ACC: MOL.20030213.0147.

\subsection{CODES, STANDARDS, REGULATIONS, AND PROCEDURES}

10 CFR 63. Energy: Disposal of High-Level Radioactive Wastes in a Geologic

Repository at Yucca Mountain, Nevada. Readily available

AP-2.22Q, Rev. 1, ICN 1. Classification Analyses and Maintenance of the Q-List. Washington, D.C.: U.S. Department of Energy, Office of Civilian Radioactive Waste Management. ACC: DOC.20040714.0002.

AP-2.27Q, Rev. 1, ICN 4. Planning for Science Activities. Washington, D.C.: U.S. Department of Energy, Office of Civilian Radioactive Waste Management. ACC: DOC.20040610.0006

AP-SIII.2Q, Rev. 1, ICN 2. Qualification of Unqualified Data. Washington, D.C.: U.S. Department of Energy, Office of Civilian Radioactive Waste Management. ACC: DOC.20040127.0008.

AP-SIII.3Q, Rev. 2 ICN 1. Submittal and Incorporation of Data to the Technical Data Management System. Washington, D.C.: U.S. Department of Energy, Office of Civilian Radioactive Waste Management. ACC: DOC.20040226.0001.

AP-SIII.9Q, Rev. 1, ICN 7. Scientific Analyses. Washington, D.C.: U.S. Department of Energy, Office of Civilian Radioactive Waste Management. ACC: DOC.20040920.0001.

AP-SIII.10Q, Rev. 2, ICN 7. Models. Washington, D.C.: U.S. Department of Energy, Office of Civilian Radioactive Waste Management.

ACC: DOC.20040920.0002. 
AP-SV.1Q, Rev. 1, ICN 1. Control of the Electronic Management of Information. Washington, D.C.: U.S. Department of Energy, Office of Civilian Radioactive Waste Management. ACC: DOC.20030929.0004.

LP-SI.11Q-BSC, Rev. 0, ICN 0. Software Management. Washington, D.C.: U.S. Department of Energy, Office of Civilian Radioactive Waste Management.

ACC: DOC.20040225.0007.

YMP-LBNL-QIP-SV.0, Rev. 2, Mod. 1. Management of LBNL Electronic Data. Berkeley, California: Lawrence Berkeley National Laboratory.

ACC: MOL.20020717.0319.

\subsection{SOURCE DATA, LISTED BY DATA TRACKING NUMBER}

GS000308311221.005. Net Infiltration Modeling Results for 3 Climate Scenarios 147613 for FY99. Submittal date: 03/01/2000.

GS000483351030.003. Thermal Properties Measured 12/01/99 to 12/02/99 Using 152932 the Thermolink Soil Multimeter and Thermal Properties Sensor on Selected Potential Candidate Backfill Materials Used in the Engineered Barrier System. Submittal date: 11/09/2000.

LB000300123142.001. Thermal-Hydrological Simulations of the Drift Scale Test. AMR N0000, Thermal Tests Thermal Hydrological Analysis/Model Report.

Submittal date: 03/24/2000.

LB0205REVUZPRP.001. Fracture Properties for UZ Model Layers Developed 159525 from Field Data. Submittal date: 05/14/2002.

LB0208AIRKDSTH.001. Air Permeability Data for the Heating Phase of the DST. 160897 Submittal date: 08/09/2002.

LB0208UZDSCPMI.002. Drift-Scale Calibrated Property Sets: Mean Infiltration 161243 Data Summary. Submittal date: 08/26/2002.

LB0210GPRDSTCP.001. DST GPR Monitoring of Water Content Over Time 160896 (Cooling Phase). Submittal date: 10/31/2002.

LB0210GPRDSTHP.001. DST GPR Monitoring of Water Content Over Time (Heating Phase). Submittal date: 10/31/2002.

160895

LB0210THRMLPRP.001. Thermal Properties of UZ Model Layers: Data 160799 Summary. Submittal date: 10/25/2002.

LB03023DKMGRID.001. UZ 3-D Site Scale Model Grids. Submittal date:

162354 02/26/2003. 
LB0302SCMREV02.002. Seepage-Related Model Parameters K and 1/A: Data

162273

Summary. Submittal date: 02/28/2003.

LB0303THERMSIM.001. UZ Thermal Modeling: Simulations. Submittal date:

165167

03/28/2003.

LB0310AMRU0120.001. Supporting Calculations and Analysis for Seepage

166409

Abstraction and Summary of Abstraction Results. Submittal date: 10/23/2003.

LB990501233129.004. 3-D UZ Model Calibration Grids for AMR U0000,

111475

"Development of Numerical Grids of UZ Flow and Transport Modeling".

Submittal date: 09/24/1999.

LB991131233129.004. Modeling of Thermo-Hydrological Data to Simulate Flow,

162183

Transport, and Geothermal Conditions of the UZ Model. AMR U0050, "UZ Flow Models and Submodels”. Submittal date: 03/11/2000.

LL000114004242.090. TSPA-SR Mean Calculations. Submittal date: 01/28/2000.

142884

MO0001SEPDSTPC.000. Drift Scale Test (DST) Temperature, Power, Current, 153836 and Voltage Data for June 1, 1999 through October 31, 1999. Submittal date: 01/12/2000.

MO0002ABBLSLDS.000. As-Built Borehole Locations and Sensor Locations for 147304 the Drift Scale Test Given in Local (DST) Coordinates. Submittal date: 02/01/2000.

MO0003RIB00071.000. Physical and Chemical Characteristics of Alloy 22.

148850

Submittal date: 03/13/2000.

MO0007SEPDSTPC.001. Drift Scale Test (DST) Temperature, Power, Current, 153707 and Voltage Data for November 1, 1999 through May 31, 2000. Submittal date: 07/13/2000.

MO0012SEPDSTPC.002. Drift Scale Test (DST) Temperature, Power, Current, and Voltage Data for June 1, 2000 through November 30, 2000. Submittal date: 12/19/2000.

MO0107SEPDSTPC.003. Drift Scale Test (DST) Temperature, Power, Current, 158321 and Voltage Data for December 1, 2000 through May 31, 2001. Submittal date: 07/06/2001.

MO0202SEPDSTTV.001. Drift Scale Test (DST) Temperature, Power, Current, 158320 and Voltage Data for June 1, 2001 through January 14, 2002. Submittal date: 02/28/2002. 
MO0208SEPDSTTD.001. Drift Scale Test (DST) Temperature Data for January 15, 2002 through June 30, 2002. Submittal date: 08/29/2002.

161767

MO0307MWDAC8MV.000. Analytical-La-Coarse-800M Ventilation. Submittal

165395 date: $07 / 15 / 2003$.

MO0307MWDAC8VD.000. Analytical-LA-Coarse-800M Ventilation with the 167396 Delta Method Analysis. Submittal date: 07/15/2003.

MO0407SEPFEPLA.000. LA FEP List. Submittal date: 07/20/2004.

170760

MO9807DSTSET01.000. Drift Scale Test (DST) Temperature, Power, Current, 113644 Voltage Data for November 7, 1997 through May 31, 1998. Submittal date: 07/09/1998.

MO9810DSTSET02.000. Drift Scale Test (DST) Temperature, Power, Current, Voltage Data for June 1 through August 31, 1998. Submittal date: 10/09/1998.

MO9901MWDGFM31.000. Geologic Framework Model. Submittal date: 01/06/1999.

MO9906DSTSET03.000. Drift Scale Test (DST) Temperature, Power, Current, Voltage Data for September 1, 1998 through May 31, 1999. Submittal date: 06/08/1999.

SN0206T0503102.005. Thermal Conductivity of the Non-Repository Layers of Yucca Mountain. Submittal date: 06/27/02.

160258

SN0208F3903102.002. Summary of Thermal Test Water Samples and Field 161246 Measurements through 1/14/2002. Submittal date: 08/16/2002.

SN0208T0503102.007. Thermal Conductivity of the Potential Repository Horizon 160257 Rev 3. Submittal date: 08/26/2002.

SN0303T0503102.008. Revised Thermal Conductivity of the Non-Repository Layers of Yucca Mountain. Submittal date: 03/19/2003.

162401

SN0307T0510902.003. Updated Heat Capacity of Yucca Mountain Stratigraphic 164196 Units. Submittal date: 07/15/2003.

SN0402T0503102.010. Heat Capacity Values for Lithostratigraphic Layers of 170993 Yucca Mountain. Submittal date: 02/24/2004.

SN0404T0503102.011. Thermal Conductivity of the Potential Repository Horizon Rev 3. Submittal date: 04/27/2004.

169129 
SN9908T0872799.004. Tabulated In-Drift Geometric and Thermal Properties Used

108437 in Drift-Scale Models for TSPA-SR (Total System Performance Assessment-Site Recommendation). Submittal date: 08/30/1999.

\subsection{OUTPUT DATA, LISTED BY DATA TRACKING NUMBER}

LB0301DSCPDSTV.002. Drift-Scale Coupled Process Model Validation: Data Summary.

LB0301DSCPTHSM.002. Drift-Scale Coupled Process Model for Thermohydrologic Seepage: Data Summary. Submittal date: 01/29/2003.

LB0303DSCPDSTV.001. Drift-Scale Coupled Process Model Validation: Simulation Files. Submittal date: 03/20/2003.

LB0303DSCPTHSM.001. Drift-Scale Coupled Process Model for Thermohydrologic Seepage: Simulation Files. Submittal date: 03/20/2003.

LB0309DSCPTHSM.001. Drift-Scale Coupled Process Model For Thermohydrologic Seepage: Simulation Files for Additional Simulation Scenarios. Submittal date: 09/19/2003.

LB0309DSCPTHSM.002. Drift-Scale Coupled Process Model for Thermohydrologic Seepage: Data Summary for Additional Simulation Scenarios. Submittal date: 09/19/2003.

LB0310DSCPTHSM.001. Drift-Scale Coupled Process Model for Thermohydrologic Seepage: Simulation Files for Collapsed Drift Scenarios. Submittal date: 10/21/2003.

LB0310DSCPTHSM.002. Drift-Scale Coupled Process Model for Thermohydrologic Seepage: Data Summary for Collapsed Drift Scenarios. Submittal date: 10/21/2003.

LB0402THRMLPRP.001. Thermal Properties of UZ Model Layers: Data Summary. Submittal date: $02 / 20 / 2004$.

LB0404DSCPTHSM.001. Drift-Scale Coupled Process Model for Thermohydrologic Seepage: Simulation Files for Additional Simulation Scenarios. Submittal Date: 04/14/2004.

LB0404DSCPTHSM.002. Drift-Scale Coupled Process Model for Thermohydrologic Seepage: Data Summary for Additional Simulation Scenarios. Submittal Date: 04/14/2004.

\subsection{SOFTWARE CODES}

LBNL (Lawrence Berkeley National Laboratory) 1999. Software Code: AMESH. 147561

V1.0. Sun, DEC O.S. 5.5.1, V4.0. 10045-1.0-00.

LBNL 1999. Software Code: EXT. V1.0. Sun Ultra Sparc, Sun OS 5.5.1.

147562 10047-1.0-00.

LBNL 1999. Software Code: EXT. V1.1. Sun, UNIX. 10005-1.1-00.

160768 
LBNL 1999. Software code: TOUGH2. V1.3MEOS4V1.0. SUN, DEC ALPHA,

147569 SUN O.S. 5.5.1, OSF1 V4.0. 10062-1.3MEOS4V1.0-00.

LBNL 2000. Software Routine: 2KGRIDV1.F. V1.0. SUN Ultra Sparc, SUN OS

147553

5.5.1. 10244-1.0-00.

LBNL 2000. Software Routine: 2kgridv1a.for. V1.0. PC, DOS Emulation. 10382-

153067 $1.0-00$.

LBNL 2000. Software Routine: assign.f. V1.0. SUN, SUN O.S. 5.5.1.

153090 10315-1.0-00.

LBNL 2000. Software Routine: exclude.f. V1.0. SUN, SUN O.S. 5.5.1.

153089 10316-1.0-00.

LBNL 2000. Software Routine: merggrid.f. V1.0. SUN, SUN O.S. 5.5.1.

148352

10230-1.0-00.

LBNL 2000. Software Routine: MK_3DINTER*.F. V1.0. Sun, SUN O.S. 5.5.1.

147550 10241-1.0-00.

LBNL 2000. Software Routine: MK_3DSLIZE.F. V1.0. Sun, SUN O.S. 5.5.1.

147539 10232-1.0-00.

LBNL 2000. Software Routine: MK_CAN_POWER.F. V1.0. Sun, SUN O.S. 5.5.1. 147557 10247-1.0-00.

LBNL 2000. Software Routine: mk_circ.f. V1.0. Sun, SUN O.S. 5.5.1.

148349 10229-1.0-00.

LBNL 2000. Software Routine: MK_CLUSTER*.F. V1.0. Sun, SUN O.S. 5.5.1.

147548 10240-1.0-00.

LBNL 2000. Software Routine: MK_DUAL.F. V1.0. Sun, SUN O.S. 5.5.1.

147544 10236-1.0-00.

LBNL 2000. Software Routine: MK_EVALUATE_*.F. V1.0. Sun, SUN O.S. 5.5.1. 147552 10243-1.0-00.

LBNL 2000. Software Routine: MK_GENER.F. V1.0. Sun, SUN O.S. 5.5.1.

147542 10234-1.0-00.

LBNL 2000. Software Routine: mk_grav2.f. V1.0. SUN, SUN O.S. 5.5.1.

153068 10379-1.0-00.

LBNL 2000. Software Routine: MK_GRAV2D.F. V1.0. Sun, SUN O.S. 5.5.1. 147538 10231-1.0-00. 
LBNL 2000. Software Routine: MK_GRAV3D.F. V1.0. Sun, SUN O.S. 5.5.1.

147540 10233-1.0-00.

LBNL 2000. Software Routine: MK_INCON_3D_DUAL.F. V1.0.Sun, SUN O.S. 147560 5.5.1. 10250-1.0-00.

LBNL 2000. Software Routine: MK_OBS3D.F. V1.0. Sun, SUN O.S. 5.5.1.

147546

10238-1.0-00.

LBNL 2000. Software Routine: MK_OBSERV.F. V1.0. Sun, SUN O.S. 5.5.1.

147543 10235-1.0-00.

LBNL 2000. Software Routine: mk_rect.f. V1.0. Sun, SUN O.S. 5.5.1.

148351 10228-1.0-00.

LBNL 2000. Software Routine: MK_TEC*.F. V1.0. Sun, SUN O.S. 5.5.1.

147547

10239-1.0-00.

LBNL 2000. Software Routine: MK_TEMP3D_ALL.F. V1.0. Sun, SUN O.S.

147551

5.5.1. 10242-1.0-00.

LBNL 2000. Software Routine: MK_TIME*.F. V1.0. Sun , SUN O.S. 5.5.1.

147545 10237-1.0-00.

LBNL 2000. Software Routine: MK_WING_POWER.F. V1.0. Sun , SUN O.S.

147558

5.5.1. 10248-1.0-00.

LBNL 2000. Software Routine: MK_YSW_CONNE.F. V1.0. Sun, SUN O.S. 5.5.1. 147556 10246-1.0-00.

LBNL 2000. Software Routine: MK_YSW_ELEME.F. V1.0. Sun, SUN O.S.5.5.1.

147554 10245-1.0-00.

LBNL 2000. Software Routine: mrgdrift.f. V1.0. SUN, SUN O.S. 5.5.1.

153082 10380-1.0-00.

LBNL 2002. Software Code: TH_PULSE.F. V1.0. Sun, SUN O.S. 5.5.1.

160767 10851-1.0-00.

LBNL 2003. Software Code: TOUGH2. V1.6. PC/MS-DOS Windows 98, Sun

161491 UltraSparc/Sun OS 5.5.1, DEC-Alpha OSF1 V4.0. 10007-1.6-01. 


\section{INTENTIONALLY LEFT BLANK}


APPENDIX A

RANDOM PERMEABILITY FIELDS GENERATED WITH EXCEL 
The heterogeneous fracture permeability fields for the drift scale $\mathrm{TH}$ seepage model were generated using Excel 97 SR-1. Four different realizations of the heterogeneous fracture permeability field were generated, three for the Tptpmn submodel and one for the Tptpll submodel. All realizations of the Tptpmn submodel have a mean permeability of $3.3 \times 10^{-13} \mathrm{~m}^{2}$ (see Table 4.1-2) and a standard deviation (in $\log 10$ space) of 0.84 (see Section 6.2.2.2.2). The mean fracture permeability for the Tptpll submodel is $9.1 \times 10^{-13} \mathrm{~m}^{2}$ (see Table $4.1-2$ ). The standard deviation for the Tptpll submodel is assumed to be the same as that for the Tptpmn submodel (see Section 6.2.3.2.1).

To generate random permeability fields, a workbook was opened in Excel. Under the "Tools" drawdown menu, the option "Data Analysis"a was used and "Random Number Generation" was selected. Then the following input information was entered to the algorithm:

1. Number of Variables: 1

2. Number of Random Numbers: 440 (for the number of heterogeneous elements)

3. Distribution: From the drawdown menu, "normal” was selected

4. Mean: Since lognormal distribution was desired, the mean was provided as $\ln (10) x$ $\log \left(3.3 \times 10^{-13}\right) \sim-28.74$ for the Tptpmn submodel. The mean for the Tptpll submodel was similarly $\ln (10) \times \log \left(9.1 \times 10^{-13}\right) \sim-27.72$

5. The standard deviation was provided in the natural log space as $0.84 \times \ln (10) \sim 1.934$

6. Random Seed: A random seed was provided

Once the distributions were generated in natural log space, they were converted into permeability values using the "EXP" function. The resulting distributions were saved in four different output Excel files with the following names:

1. liste_rel1_tptpmn.xls: First realization for the Tptpmn submodel

2. liste_rel2_tptpmn.xls: Second realization for the Tptpmn submodel

3. liste_rel3_tptpmn.xls: Third realization for the Tptpmn submodel

4. liste_rel1_tptpll.xls: First realization for the Tptpll submodel

These four files have been submitted to the TDMS (Output DTN: LB0303DSCPTHSM.001). Note that the random seeds required for generating the permeability fields in Excel were not recorded. Thus, it may not be possible to reproduce the individual numbers in the distributions. However, what is more important from a statistical standpoint is that the distribution itself is reproduced statistically (rather than the individual numbers). As proof of the fact that the desired

a If the Data Analysis command is not on the Tools menu, the Analysis ToolPak in Microsoft Excel needs to be installed. To install the Analysis ToolPak: 1) On the Tools menu, click Add-Ins; 2) Select the Analysis

ToolPak check box. 
statistical distribution has been generated, the actual mean and standard deviation of the numbers generated is calculated in each of the above submitted files. These are consistent with the desired mean and standard deviation of the respective distribution. The slight mismatch occurs because of the finite sample number used in generating the distributions.

The dates, times, and file sizes of the four Excel data files, as included in the TDMS are listed below.

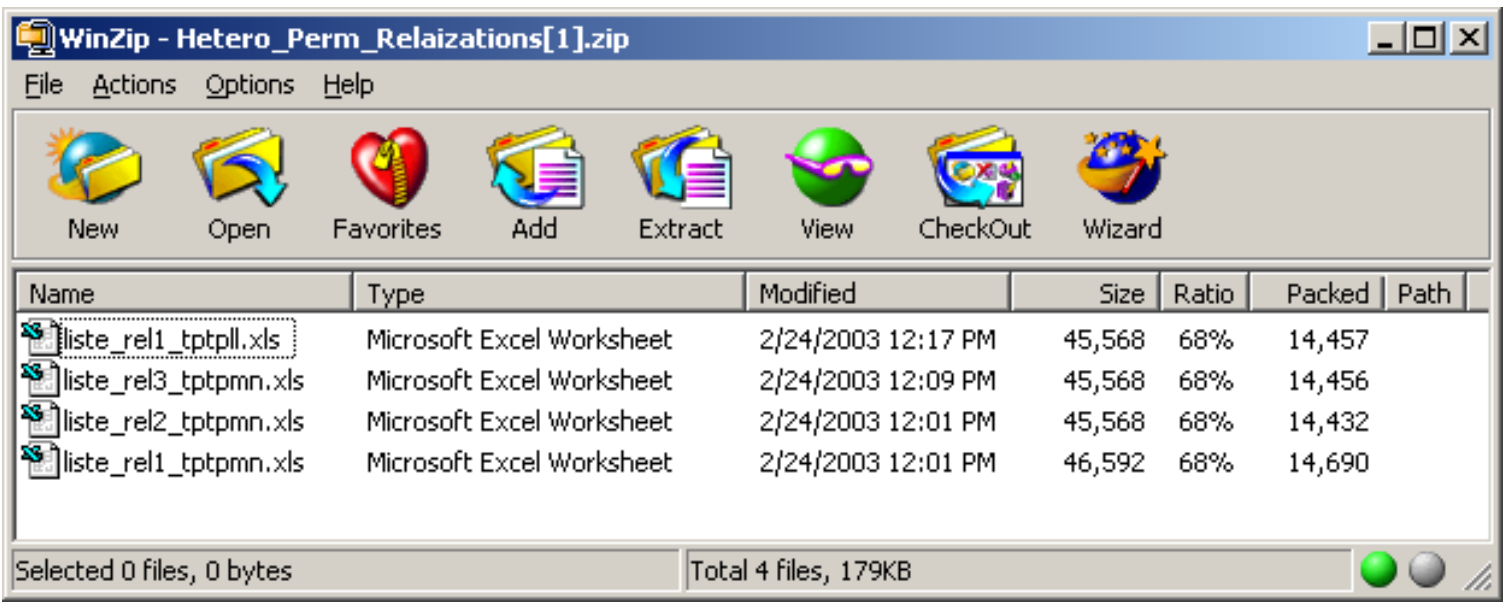




\section{APPENDIX B}

\section{ARITHMETIC AVERAGE FOR INFILTRATION VALUES}


The infiltration values $(6,16$, and $25 \mathrm{~mm} /$ year for the present-day, monsoon, and glacial transition periods, respectively) represent repository-wide averages of percolation; the values are calculated as an arithmetic average of the 31 repository locations considered in Multiscale Thermohydrologic Model (BSC 2001 [DIRS 158204], Section 6.3.1). The infiltration values at 31 locations are provided in DTN: LL000114004242.090 [DIRS 142884] (file “chimney_infiltration_fluxes," median infiltration cases) (see Section 4.1.1.5). The calculation for deriving the repository-wide averages is conducted in an Excel spreadsheet as listed below. The first column gives the 31 locations, the other three columns give infiltration values in $\mathrm{mm} / \mathrm{yr}$ for the present-day, the monsoon, and the glacial transition climate periods as extracted from the DTN. The calculated averages have been rounded to $6 \mathrm{~mm} / \mathrm{yr}, 16 \mathrm{~mm} / \mathrm{yr}$, and $25 \mathrm{~mm} / \mathrm{yr}$, respectively, for further use in this report.

Table B-1. Average Infiltration Values for Different Climate Periods

\begin{tabular}{|c|c|c|c|}
\hline Column & Present Day & Monsoon & Glacial \\
\hline $17 \mathrm{c} 4$ & 1.493 & 3.252 & 5.211 \\
\hline $17 c 3$ & 4.677 & 10.71 & 18.418 \\
\hline $17 c 2$ & 5.554 & 13.726 & 22.42 \\
\hline 17c1 & 1.7 & 4.588 & 7.013 \\
\hline $16 c 5$ & 9.41 & 17.746 & 30.732 \\
\hline $16 \mathrm{c} 4$ & 11.302 & 32.651 & 47.872 \\
\hline $16 c 3$ & 4.18 & 10.303 & 16.574 \\
\hline $16 c 2$ & 3.147 & 7.163 & 10.986 \\
\hline $16 \mathrm{c} 1$ & 3.879 & 9.432 & 15.079 \\
\hline $15 c 5$ & 8.428 & 17.265 & 29.872 \\
\hline $15 c 4$ & 14.412 & 40.972 & 60.237 \\
\hline $15 c 3$ & 5.68 & 13.12 & 19.949 \\
\hline $15 \mathrm{c} 2$ & 7.395 & 17.707 & 27.097 \\
\hline $15 \mathrm{c} 1$ & 0.663 & 0.436 & 0.816 \\
\hline $14 c 5$ & 5.449 & 14.472 & 20.214 \\
\hline $14 \mathrm{c} 4$ & 10.132 & 28.876 & 41.998 \\
\hline $14 c 3$ & 10.144 & 24.091 & 38.66 \\
\hline $14 c 2$ & 6.909 & 16.9 & 27.923 \\
\hline $14 \mathrm{c} 1$ & 4.794 & 12.093 & 18.881 \\
\hline $13 c 4$ & 15.877 & 43.993 & 65.028 \\
\hline 13c3 & 1.304 & 2.637 & 4.194 \\
\hline $13 \mathrm{c} 2$ & 0.485 & 0.492 & 1.271 \\
\hline
\end{tabular}


Table B-1. Average Infiltration Values for Different Climate Periods (Continued)

\begin{tabular}{|c|c|c|c|}
\hline Column & Present Day & Monsoon & Glacial \\
\hline $13 c 1$ & 6.335 & 18.869 & 27.005 \\
\hline 12c4 & 15.998 & 42.285 & 58.627 \\
\hline 12c3 & 12.011 & 40.749 & 63.168 \\
\hline 12c2 & 1.416 & 9.154 & 23.399 \\
\hline 12c1 & 0.406 & 0.25 & 0.733 \\
\hline I1c4 & 3.015 & 11.575 & 19.057 \\
\hline I1c3 & 7.809 & 21.854 & 32.439 \\
\hline 11c2 & 0.877 & 0.94 & 2.13 \\
\hline \multirow[t]{3}{*}{ |1c1 } & 0.574 & 10.004 & 13.523 \\
\hline & Average & Average & Average \\
\hline & 5.941625 & 16.07435 & 24.85568 \\
\hline
\end{tabular}




\section{APPENDIX C}

SENSITIVITY TO REVISED MATRIX POROSITY AND THERMAL PROPERTIES 
This appendix provides a description of additional simulation runs that were conducted using revised thermal property data for the various stratigraphic layers in the UZ at Yucca Mountain. Some of the DTNs providing input parameters in Section 4 were changed after the simulation runs in Section 6.2 had been completed. The simulation results in this appendix demonstrate that the impact of these parameter changes on the near-field TH response is negligible, and that all the conclusions regarding thermal seepage summarized in Section 8.1 still hold, even when using the revised properties. The following provides a comparative analysis of selected simulation runs with the new property set (given in DTN: LB0402THRMLPRP.001) and the previous property set (given in DTN: LB0210THRMLPRP.001 [DIRS 160799]).

\section{C.1 INPUT DATA}

The revised thermal properties used here are given in DTN: LB0402THRMLPRP.001 (see Appendix F). As noted in Section 4.1.1.1, the original thermal properties were provided in DTN: LB0210THRMLPRP.001 [DIRS 160799]. The simulation runs in this appendix use the following properties from these DTNs: matrix porosity, matrix rock grain density, matrix specific heat capacity, bulk dry thermal conductivity, and bulk wet thermal conductivity. The revisions to the properties affected only the matrix porosity, the rock grain density, and the dry and wet heat conductivities; minor changes in heat capacity stem from rounding-off differences. Only the nonrepository units were affected by these changes (Table C-1). The properties of the repository units remain essentially unchanged (shaded data on Table C-1). Thus, it can be expected that the impact of these property changes on the TH conditions near emplacement drifts is small (see Sections C.3 and C.4 for the comparative analysis); most emplacement drifts are separated from the affected nonrepository units by thick layers of rock.

Adjustments in DTN: LB0210THRMLPRP.001 [DIRS 160799] became necessary because a new revision of Thermal Conductivity of Non-Repository Lithostratigraphic Layers (BSC 2004 [DIRS 170033]) became available, providing a new DTN: SN0303T0503102.008 [DIRS 162401] with revised porosity, density and thermal conductivity values for all nonrepository layers (different from those used for the simulations presented in Section 6.2). The revised values were used to derive DTN: LB0402THRMLPRP.001, which contain adjustments from the source data provided in DTN: SN0303T0503102.008 [DIRS 162401]. The source data are defined for the stratigraphic units of the geologic framework model (BSC 2002 [DIRS 159124]), while the thermal seepage model uses the slightly different layering of the UZ model (e.g., BSC 2003 [DIRS 160109], Table 11). When UZ layers comprise two or more GFM layers, the thermal properties were averaged. The procedures followed in developing these revised thermal properties can be found in Appendix F.

For the simulations in this appendix, the same heat capacity values as those presented in Section 6.2 are used. However, an alternative set of heat capacity and grain density values are also provided in Heat Capacity and Thermal Expansion Coefficients Analysis Report (BSC 2004 [DIRS 170003]), as contained in DTN: SN0307T0510902.003 [DIRS 164196]. The alternative values were derived from a mineral summation method, based on the mineral composition of the grain. Heat capacity and grain density are calculated as the sum of heat capacities and grain densities of the minerals weighted by their abundance. For thermal modeling purposes, the product of heat capacity and grain density define the thermal storage capacity in a given volume of rock. It can be shown that the product of heat capacity and grain density calculated from this 
alternative set is similar (less than a few percent) to that used in Section 6.2 and in this appendix. Considering that the thermal response of the near-field environment is rather insensitive to heat capacity (BSC 2001 [DIRS 155950], Sections 5.3.1.2.3 and 5.3.1.4.9), the impact of using these slightly different alternative values is expected to be negligibly small. While not documented in this report, a selected simulation case was conducted using the alternative values for heat capacity and grain density, giving $\mathrm{TH}$ results that were virtually identical to those presented in Section 6.2.

\section{C.2 MODELING PROCEDURE AND SIMULATION CASES}

Except for using the revised property set, the modeling procedures of the simulation runs in this appendix are identical to those described in Section 6.2.1. A subset of the suite of simulations conducted in Section 6.2 was repeated in this appendix using the revised properties. It was not necessary to repeat all original simulation runs because the impact of the property changes was expected (and turned out) to be very small. The selected simulation cases are listed in Table C-2.

Similar to Section 6.2.1.6, each new simulation case is denoted by a specific name code as follows. The first two letters are either MN (for the Tptpmn submodel) or LL (for the Tptpll submodel), followed by HOM (for homogeneous representation of permeability) or HET (for heterogeneous representation of permeability), followed by NEW (indicating the use of revised properties), followed by a two-digit number. For example, a simulation name MN-HET-NEW01 denotes the first simulation case with the Tptpmn submodel using a heterogeneous permeability field and revised thermal properties. Results from this simulation case can be directly compared with the original simulation MN-HET-01.

The rationale for selecting simulation cases is as follows: Simulation Case MN-HOM-NEW-01 was chosen because it corresponds to the primary simulation case (base case) for studying the drift-scale TH processes in Section 6.2.1.1. Simulation Cases MN-HET-NEW-01 through -04 were selected as representative of the many cases presented in Sections 6.2.2.2 and 6.2.4.2 that focus on the potential for thermal seepage with related sensitivities. With flux multiplication factors of 1, 5, 10, and 20, they cover sufficient variation of the most important parameter for thermal seepage, i.e., percolation flux. All the above cases use the Tptpmn submodel, i.e., where the emplacement drift is located in the Tptpmn stratigraphic unit. As it turned out, the impact of adjusting properties in nonrepository units was negligibly small for all the Tptpmn simulation cases, in particular when considering the primary focus of this report, which is the evolution of thermal seepage. Due to the small impact, only one additional simulation was selected for the Tptpll submodel (LL-HOM-NEW-01). The reason for analyzing both submodels is that, depending on the stratigraphy and the vertical location of the drifts, the Tptpmn and the Tptpll submodel may be slightly more or slightly less affected from parameter changes in nonrepository units. 
Table C-1. Summary of Revised and Original Rock Matrix Properties

\begin{tabular}{|c|c|c|c|c|c|c|c|c|c|c|}
\hline \multirow[t]{2}{*}{$\begin{array}{l}\text { UZ Model } \\
\text { Layer }\end{array}$} & \multicolumn{2}{|c|}{ Matrix Porosity } & \multicolumn{2}{|c|}{$\begin{array}{c}\text { Grain Density } \\
\left(\mathrm{kg} / \mathrm{m}^{3}\right)\end{array}$} & \multicolumn{2}{|c|}{$\begin{array}{c}\text { Heat Capacity } \\
(\mathrm{J} / \mathrm{Kg}-\mathrm{K})\end{array}$} & \multicolumn{2}{|c|}{$\begin{array}{l}\text { Bulk Dry Conductivity } \\
(\mathrm{W} / \mathrm{m}-\mathrm{K})\end{array}$} & \multicolumn{2}{|c|}{$\begin{array}{l}\text { Bulk Wet Conductivity } \\
(\mathrm{W} / \mathrm{m}-\mathrm{K})\end{array}$} \\
\hline & Revised & Original & Revised & Original & Revised & Original & Revised & Original & Revised & Original \\
\hline tcw11 & 0.119 & 0.118 & 2486 & 2514 & 985.0 & 985.0 & 1.30 & 1.30 & 1.81 & 1.80 \\
\hline tcw12 & 0.119 & 0.118 & 2486 & 2514 & 985.0 & 985.0 & 1.30 & 1.30 & 1.81 & 1.80 \\
\hline tcw13 & 0.211 & 0.0457 & 2385 & 2274 & 1040 & 1040 & 0.572 & 0.670 & 0.909 & 0.794 \\
\hline ptn21 & 0.385 & 0.354 & 2374 & 2288 & 1040 & 1040 & 0.490 & 0.489 & 1.06 & 1.07 \\
\hline ptn22 & 0.385 & 0.354 & 2374 & 2288 & 1040 & 1040 & 0.490 & 0.489 & 1.06 & 1.07 \\
\hline ptn23 & 0.385 & 0.354 & 2374 & 2288 & 1040 & 1040 & 0.490 & 0.489 & 1.06 & 1.07 \\
\hline ptn24 & 0.385 & 0.354 & 2374 & 2288 & 1040 & 1040 & 0.490 & 0.489 & 1.06 & 1.07 \\
\hline ptn25 & 0.385 & 0.354 & 2374 & 2288 & 1040 & 1040 & 0.490 & 0.489 & 1.06 & 1.07 \\
\hline ptn26 & 0.385 & 0.251 & 2374 & 2283 & 1040 & 1040 & 0.490 & 0.537 & 1.06 & 0.957 \\
\hline tsw31 & 0.0775 & 0.0457 & 2441 & 2274 & 1012 & 1040 & 0.900 & 0.670 & 1.11 & 0.794 \\
\hline tsw32 & 0.119 & 0.118 & 2486 & 2514 & 985.0 & 985.0 & 1.30 & 1.30 & 1.81 & 1.80 \\
\hline tsw33 & 0.143 & 0.143 & 2344 & 2358 & 985.0 & 985.0 & 1.16 & 1.16 & 1.68 & 1.68 \\
\hline tsw34 & 0.129 & 0.129 & 2466 & 2466 & 985.0 & 985.0 & 1.42 & 1.42 & 2.07 & 2.07 \\
\hline tsw35 & 0.149 & 0.149 & 2325 & 2325 & 985.0 & 985.0 & 1.28 & 1.28 & 1.89 & 1.89 \\
\hline tsw36 & 0.106 & 0.106 & 2473 & 2473 & 985.0 & 985.0 & 1.49 & 1.49 & 2.13 & 2.13 \\
\hline tsw37 & 0.106 & 0.106 & 2473 & 2473 & 985.0 & 985.0 & 1.54 & 1.49 & 2.20 & 2.13 \\
\hline tsw38 & 0.0360 & 0.046 & 2396 & 2274 & 1040 & 1040 & 0.688 & 0.670 & 0.796 & 0.794 \\
\hline tsw39 & 0.385 & 0.046 & 2374 & 2274 & 1040 & 1040 & 0.490 & 0.670 & 1.06 & 0.794 \\
\hline $\operatorname{ch} 1(\mathrm{v}, \mathrm{z})$ & 0.385 & 0.354 & 2374 & 2288 & 1040 & 1040 & 0.490 & 0.489 & 1.06 & 1.07 \\
\hline $\operatorname{ch} 2(\mathrm{v}, \mathrm{z})$ & 0.333 & 0.328 & 2504 & 2256 & 1038 & 1038 & 0.595 & 0.600 & 1.26 & 1.27 \\
\hline $\operatorname{ch} 3(v, z)$ & 0.333 & 0.328 & 2504 & 2256 & 1038 & 1038 & 0.595 & 0.600 & 1.26 & 1.27 \\
\hline $\operatorname{ch} 4(\mathrm{v}, \mathrm{z})$ & 0.333 & 0.328 & 2504 & 2256 & 1038 & 1038 & 0.595 & 0.600 & 1.26 & 1.27 \\
\hline $\operatorname{ch} 5(v, z)$ & 0.333 & 0.328 & 2504 & 2256 & 1038 & 1038 & 0.595 & 0.600 & 1.26 & 1.27 \\
\hline $\operatorname{ch} 6(\mathrm{v}, \mathrm{z})$ & 0.333 & 0.328 & 2504 & 2256 & 1038 & 1038 & 0.595 & 0.600 & 1.26 & 1.27 \\
\hline pp4 & 0.300 & 0.297 & 2557 & 2103 & 1040 & 1040 & 0.569 & 0.538 & 1.13 & 1.11 \\
\hline pp3 & 0.300 & 0.297 & 2557 & 2103 & 1040 & 1040 & 0.569 & 0.538 & 1.13 & 1.11 \\
\hline pp2 & 0.255 & 0.233 & 2587 & 2385 & 1012 & 1009 & 0.741 & 0.733 & 1.33 & 1.34 \\
\hline pp1 & 0.277 & 0.273 & 2519 & 2038 & 1040 & 1040 & 0.596 & 0.564 & 1.15 & 1.13 \\
\hline bf3 & 0.194 & 0.188 & 2485 & 2106 & 1021 & 1018 & 0.788 & 0.757 & 1.34 & 1.33 \\
\hline bf2 & 0.264 & 0.262 & 2506 & 2012 & 1040 & 1040 & 0.611 & 0.576 & 1.16 & 1.14 \\
\hline
\end{tabular}

NOTES: Revised data are from DTN: LB0402THRMLPRP.001 (rounded to the number of significant digit shown).

Original data are from DTN: LB0210THRMLPRP.001 (rounded to the number of significant digit shown).

Fracture thermal properties are derived using matrix properties as discussed in Section 6.2.1.1.3. Other rock properties data are identical to those listed in Table 6.1-2. The data for repository units are shaded. 
Table C-2. List of Simulation Cases Using Revised Properties

\begin{tabular}{|c|c|c|c|c|c|c|c|c|}
\hline $\begin{array}{l}\text { New Simulation } \\
\text { Case }\end{array}$ & $\begin{array}{l}\text { Thermal } \\
\text { Load }\end{array}$ & $\begin{array}{c}\text { Flux } \\
\text { multiplication } \\
\text { factor }\end{array}$ & Property Set & $\begin{array}{l}\text { Permeability in } \\
\text { Drift Vicinity }\end{array}$ & $\begin{array}{l}\text { Capillary Strength } \\
\text { in Drift Vicinity }\end{array}$ & $\begin{array}{l}\text { Previous } \\
\text { Simulation } \\
\text { Case }\end{array}$ & $\begin{array}{c}\text { Previous } \\
\text { Case Shown } \\
\text { in Section }\end{array}$ & $\begin{array}{l}\text { Output DTN for New } \\
\text { Simulation }\end{array}$ \\
\hline \multicolumn{9}{|c|}{ Tptpmn Submodel } \\
\hline MN-HOM-NEW-01 & $\begin{array}{l}\text { Referenc } \\
\text { e Mode }\end{array}$ & 1 & $\begin{array}{l}\text { DS/AFM-UZO2- } \\
\text { Mean }\end{array}$ & Homogeneous & $\begin{array}{l}\text { From DS-AFM- } \\
\text { UZ02-Mean }\end{array}$ & MN-HOM -01 & 6.2.2.1.1 & NA (see Section 8.5) \\
\hline MN-HET-NEW-01 & $\begin{array}{l}\text { Referenc } \\
\text { e Mode }\end{array}$ & 1 & $\begin{array}{l}\text { DS/AFM-UZ02- } \\
\text { Mean }\end{array}$ & $\begin{array}{l}\text { Heterogeneous } \\
\text { (Realization 1) }\end{array}$ & $\begin{array}{l}\text { From SCM } \\
(1 / \alpha=589 \mathrm{~Pa})\end{array}$ & MN-HET-01 & 6.2 .2 .2 .3 & LB0404DSCPTHSM.001 \\
\hline MN-HET-NEW-02 & $\begin{array}{l}\text { Referenc } \\
\text { e Mode }\end{array}$ & 5 & $\begin{array}{l}\text { DS/AFM-UZ02- } \\
\text { Mean }\end{array}$ & $\begin{array}{l}\text { Heterogeneous } \\
\text { (Realization 1) }\end{array}$ & $\begin{array}{l}\text { From SCM } \\
(1 / \alpha=589 \mathrm{~Pa})\end{array}$ & MN-HET-02 & 6.2.2.2.4 & $\begin{array}{l}\text { LB0404DSCPTHSM.001 } \\
\text { LB04041DSCPTHSM.002 }\end{array}$ \\
\hline MN-HET-NEW-03 & $\begin{array}{l}\text { Referenc } \\
\text { e Mode }\end{array}$ & 10 & $\begin{array}{l}\text { DS/AFM-UZ02- } \\
\text { Mean }\end{array}$ & $\begin{array}{l}\text { Heterogeneous } \\
\text { (Realization 1) }\end{array}$ & $\begin{array}{l}\text { From SCM } \\
(1 / \alpha=589 \mathrm{~Pa})\end{array}$ & MN-HET-03 & 6.2 .2 .2 .4 & $\begin{array}{l}\text { LB0404DSCPTHSM.001 } \\
\text { LB0404DSCPTHSM.002 }\end{array}$ \\
\hline MN-HET-NEW-04 & $\begin{array}{l}\text { Referenc } \\
\text { e Mode }\end{array}$ & 20 & $\begin{array}{l}\text { DS/AFM-UZ02- } \\
\text { Mean }\end{array}$ & $\begin{array}{l}\text { Heterogeneous } \\
\text { (Realization 1) }\end{array}$ & $\begin{array}{l}\text { From SCM } \\
(1 / \alpha=589 \mathrm{~Pa})\end{array}$ & MN-HET-04 & 6.2 .4 .2 & $\begin{array}{l}\text { LB0404DSCPTHSM.001 } \\
\text { LB04041DSCPTHSM.002 }\end{array}$ \\
\hline \multicolumn{9}{|c|}{ Tptpll Submodel } \\
\hline LL-HOM-NEW-01 & $\begin{array}{l}\text { Referenc } \\
\text { e Mode }\end{array}$ & 1 & $\begin{array}{l}\text { DS/AFM-UZ02- } \\
\text { Mean }\end{array}$ & Homogeneous & $\begin{array}{l}\text { From DS-AFM- } \\
\text { UZ02-Mean }\end{array}$ & LL-HOM-01 & 6.2.3.1 & NA (see Section 8.5) \\
\hline
\end{tabular}

NOTE: The steady-state ambient simulation cases that are required to compare the thermal seepage results to their steady-state ambient counterparts were not repeated. This is not necessary because the steady-state ambient situation is not affected by changes in porosity, density, or thermal conductivity. 


\section{C.3 SIMULATION RESULTS - REVISED VERSUS ORIGINAL PROPERTIES (TPTPMN SUBMODEL)}

The first simulation case that is analyzed for the impact of thermal property changes is the base case simulation MN-HOM-NEW-01. This simulation assumes a drift emplaced in the Tptpmn stratigraphic unit, uses homogeneous properties, applies a thermal load representative of average conditions (reference mode, see Section 6.2.1.3.3), and uses the mean infiltration scenario without flow focusing (see Section 6.2.1.4). Except for the property changes, this simulation case is similar to simulation case MN-HET-01 presented in Section 6.2.2.1.1. Figures C-1, C-2, and C-3 show the evolution of matrix temperature, matrix saturation, and fractures saturation, respectively, for both property sets. It is evident that the differences between the two simulations are negligibly small. Temperatures at the drift crown differ by less than one degree between the original and revised simulation results, the revised results showing a minor temperature decrease. Rewetting of matrix and fractures at the drift crown is predicted to occur at around the same time for the two simulation cases. The small impact of changes in thermal properties on $\mathrm{TH}$ conditions is also demonstrated in Figure C-4, where fracture saturations and downward fluxes are plotted along a vertical line above the drift crown. Again, the simulated results are virtually identical. No seepage occurs in either case.

The following simulation cases for the Tptpmn submodel focus on the potential for thermal seepage. According to the conceptual model introduced in Section 6.2.1.1.2, they incorporate a heterogeneous fracture permeability field (using Realization 1 of the heterogeneous field) and apply the fracture capillary-strength parameter suggested from the SCM. Again, the reference mode thermal load is applied. The cases studied have flux multiplication factors of $1,5,10$, and 20. Consistent with the original simulation described in Section 6.2.2.2.3, there is no seepage in the first case (MN-HET-NEW-01), where the imposed percolation fluxes are relatively small (i.e., $6 \mathrm{~mm} /$ year during present-day climate, $16 \mathrm{~mm} / \mathrm{yr}$ during the monsoon climate, and 25 $\mathrm{mm} /$ year during glacial transition climate). Figures C-5 and C-6 demonstrate that the temperature and fractures saturation histories for this case are almost identical to the original simulation results (MN-HET-01). For higher percolation flux cases, seepage was predicted to occur in the original simulation runs (flux multiplication factors of 5 and 10 in Section 6.2.2.4 and flux multiplication factor 20 in Section 6.2.4.2), and the same result is obtained with the revised property set. For the first case with flux multiplication factor 5, the temperature and saturation plots in Figures C-7 and C-8 confirm that the TH conditions close to the drift wall are not affected by the property changes. Since the saturation pattern at the drift wall is directly linked to the onset and the evolution of seepage, there is also no difference in the predicted seepage rates. Figure C-8 shows virtually identical seepage rates resulted from simulations with the revised and previous property sets. Figures C-9 and C-10 give a comparison of seepage rates obtained for the simulation cases with flux multiplication factors of 10 and 20, demonstrating that the "no-impact" conclusion holds for rather high percolation flux cases too.

\section{C.4 SIMULATION RESULTS - REVISED VERSUS ORIGINAL PROPERTIES (TPTPLL SUBMODEL)}

Because of the negligible impact of the revised property set on TH conditions in the Tptpmn submodel (see Section C.3), only one simulation was performed for the Tptpll submodel. The selected simulation case is the base case simulation LL-HOM-NEW-01. This simulation 
assumes a drift emplaced in the Tptpll stratigraphy unit, uses homogeneous properties, applies a thermal load representative of average conditions (reference mode), and uses the mean infiltration scenario without flow focusing. Except for the property changes, this simulation case is identical to simulation case LL-HET-01 presented in Section 6.2.3.1. Figures C-11, C-12, and C-13 show the evolution of matrix temperature, matrix saturation, and fractures saturation, respectively, for the revised and the original property set. The differences between the two property sets are small, yet slightly larger than those obtained for the Tptpmn submodel. Temperatures differ by a little more than one degree between the original and revised simulation results, the revised results showing a small temperature decrease. As a result, the onset of rewetting in the fractures at the drift crown is predicted to occur about 50 years earlier using the revised properties. However, the differences in fracture saturation vanish soon after initiation of rewetting; except for a time period of about 50 years (at about 1,200 years after waste emplacement), the saturation evolution of the two cases is identical. The slightly earlier rewetting can also be seen in Figure C-14, where fracture saturations and fluxes are plotted along a vertical line above the drift crown. While the saturation profiles are very similar for time steps of 100 years, 500 years, and 2,000 years, the 1,000-year profiles indicate a slightly smaller dryout zone compared to the previous property set. No seepage is predicted to occur in both cases.

The observed differences between the two property sets are slightly larger using the Tptpll submodel compared to those predicted for the Tptpmn submodel. This finding can be explained when analyzing the vertical distance between the emplacement drifts and the stratigraphic units that have been affected by thermal property changes. Table C-1 suggests that the tsw31 layer is the first unit above the repository with thermal conductivity changes, while the tsw37 layer is the first unit below the repository with such changes. As explained in Section 6.2.1.2, the Tptpmn submodel stratigraphy is adopted from a location close to borehole USW SD-9. Here, the center of the emplacement drift (located in the tsw34 unit) is roughly $150 \mathrm{~m}$ below the tsw31 layer, and roughly $150 \mathrm{~m}$ above the tsw37 unit. ${ }^{\mathrm{b}}$ The Tptpll submodel uses a stratigraphy near the center of the repository, close to the area of the proposed Cross-Drift Thermal Test. Here, the center of the emplacement drift (located in the tsw35 unit) is roughly $200 \mathrm{~m}$ below the tsw31 layer, but only about $90 \mathrm{~m}$ above the tsw37 unit. ${ }^{1}$ That the Tptpll submodel is more sensitive to the property changes than the Tptpmn submodel is a result of the relatively smaller distance between the drift and the underlying tsw37 unit.

While the observed differences between the two property sets are slightly larger than those predicted for the Tptpmn submodel, they are much smaller than differences stemming from the spatial variability of input parameters and boundary conditions for the thermal seepage model.

\footnotetext{
${ }^{\mathrm{b}}$ This calculation is conducted using the simulation MESH files for the Tptpmn and Tptpll submodels, respectively, as given in DTN: LB0404DSCPTHSM.001. Using a MESH file for the Tptpmn submodel from one of the respective data directories, one can extract the vertical distances as follows: The distance between the center of the repository and the tsw31/tsw32 interface is given by the average vertical coordinates of elements F 610 (tsw31) and F 603 (tsw32), respectively. The distance between the center of the repository and the tsw36/tsw37 interface is given by the average vertical coordinates of elements F1004 (tsw36) and F1006 (tsw37), respectively. Using a MESH file for the Tptpll submodel from one of the respective data directories, one can extract the vertical distances as follows: The distance between the center of the repository and the tsw31/tsw32 interface is given by the average vertical coordinates of elements F 584 (tsw31) and F 579 (tsw32), respectively. The distance between the center of the repository and the tsw36/tsw37 interface is given by the average vertical coordinates of elements F 773 (tsw36) and F 781 (tsw37), respectively. The vertical distances are given in the MESH file in the ELEMENT block, in the last column to the right.
} 
Figures 6.2.4.2-1 through 6.2.4.2-4, for example, demonstrate the bandwidth of temperature and thermal seepage responses for simulation cases with different thermal loads or different percolation fluxes. Compared to this, the discrepancies occurring from the property revision are negligibly small.

\section{C.5 CONCLUSIONS REGARDING THE ABSTRACTION OF THERMAL SEEPAGE}

The model results shown in Sections C.3 and C.4 demonstrate that the differences between TH conditions predicted with revised thermal properties vs. original thermal properties are either almost undetectable (for the Tptpmn submodel) or very small (for the Tptpll submodel). In the latter case, rewetting occurs somewhat earlier using the revised properties, as a result of the small temperature decrease, compared to the original properties. However, these differences are not large enough to change the main output generated in REV 00 of this report. The main output of the report is the consistent result that (1) seepage during the thermal period does not occur at above-boiling temperatures, and (2) that, in case seepage occurs at later times, the thermal seepage rate is always smaller than the respective long-term ambient seepage rate for the considered time period (see Section 6.2.4.1). This consistency in thermal seepage results over many simulation cases is utilized in Abstraction of Drift Seepage (BSC 2004 [DIRS 169131]) to develop an abstraction methodology for thermal seepage.

Two alternative abstraction methodologies for thermal seepage are proposed in Section 6.5.2 of Abstraction of Drift Seepage (BSC 2004 [DIRS 169131]). Both are based on the qualitative results of the thermal seepage model given in Section 6.2, and also incorporate quantitative results from other sources. These quantitative results are (1) the ambient seepage rates with related spatial variability over the repository provided by the SMPA (BSC 2004 [DIRS 167652]), and (2) the duration of the boiling period near emplacement drifts with related spatial variability over the repository provided by the multiscale thermohydrologic model (BSC 2004 [DIRS 169565]). Therefore, as long as the main outputs from the thermal seepage model remain unchanged in a qualitative sense, the abstraction of drift seepage and the seepage calculation in TSPA are unaffected. This is clearly true for the small differences obtained using the revised vs. the previous property sets. As a result, there is no impact on the proposed abstraction methodology for thermal seepage. 


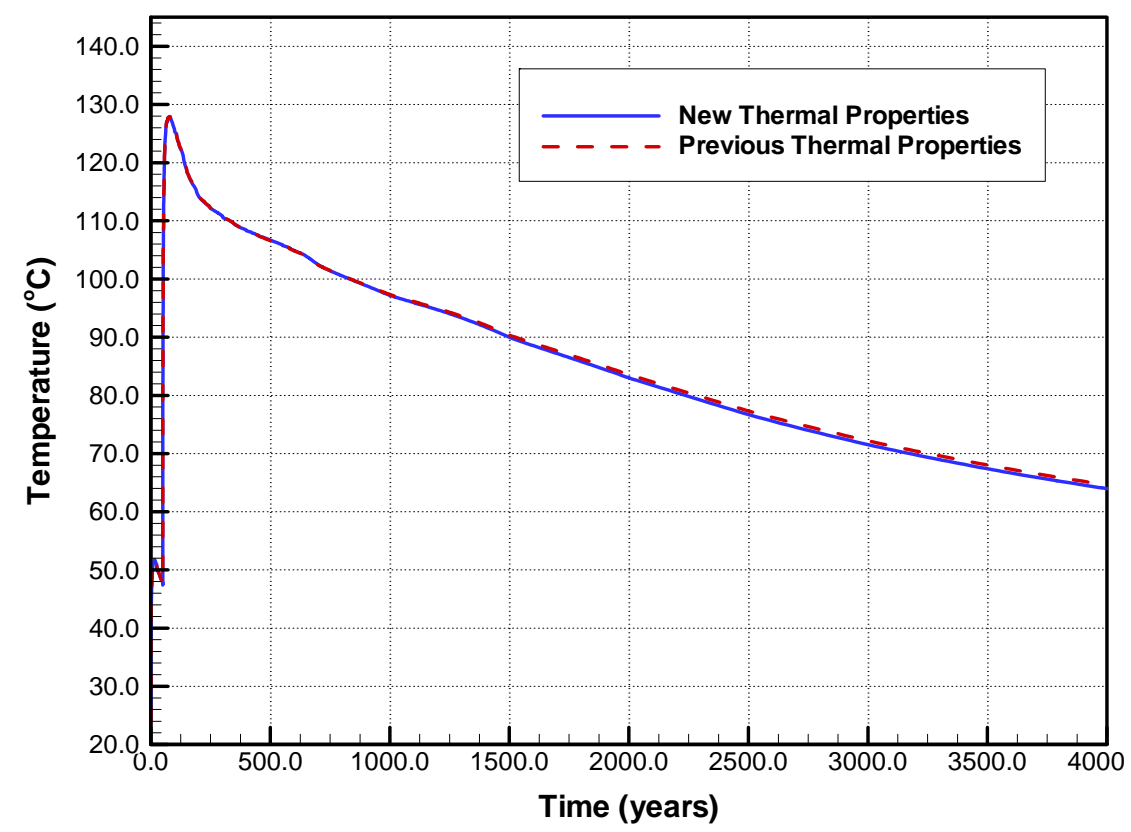

Output DTN: NA (See Section 8.5).

Figure C-1. Evolution of Rock Temperature at the Drift Crown for Tptpmn Submodel, Comparing New vs. Previous Thermal Properties (Simulation Cases MN-HOM-NEW-01 vs. MN-HOM-01)

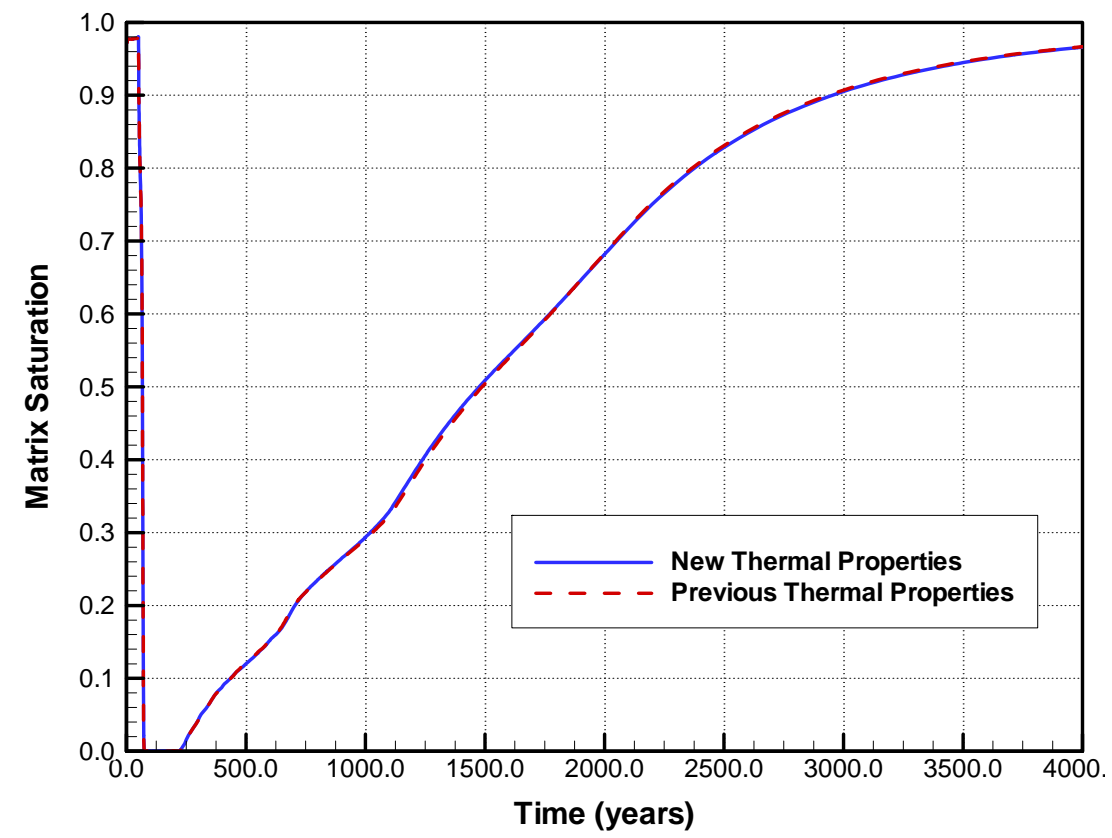

Output DTN: NA (See Section 8.5).

Figure C-2. Evolution of Matrix Saturation at the Drift Crown for Tptpmn Submodel, Comparing New vs. Previous Thermal Properties (Simulation Cases MN-HOM-NEW-01 vs. MN-HOM-01) 


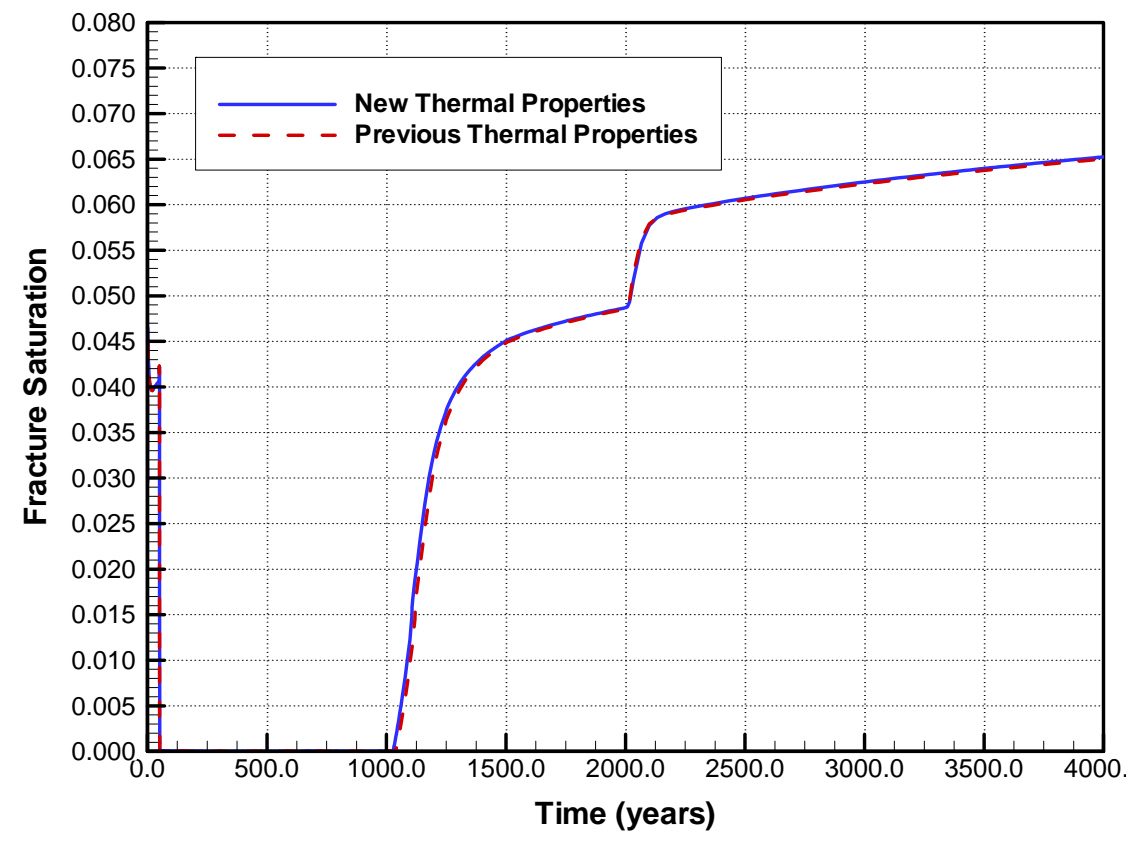

Output DTN: NA (See Section 8.5).

Figure C-3. Evolution of Fracture Saturation at the Drift Crown for Tptpmn Submodel, Comparing New vs. Previous Thermal Properties (Simulation Cases MN-HOM-NEW-01 vs. MN-HOM-01) 


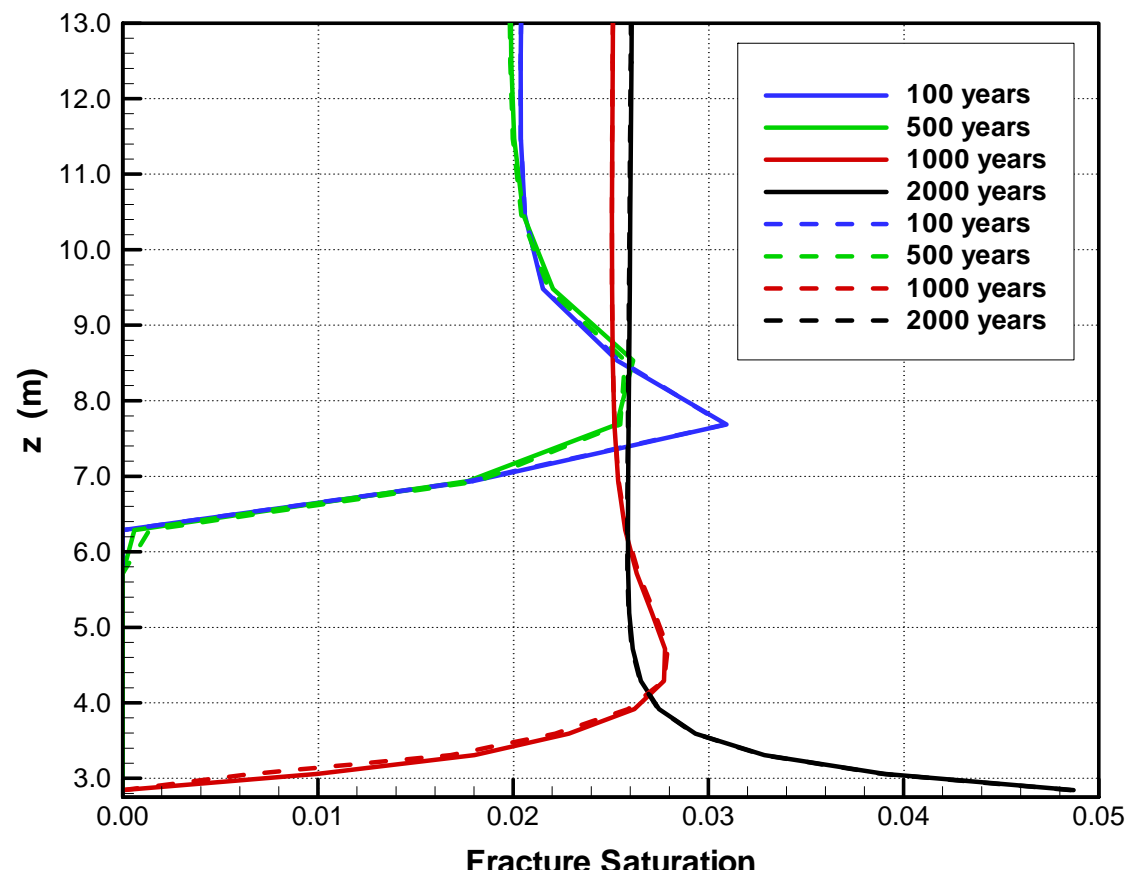

(a)

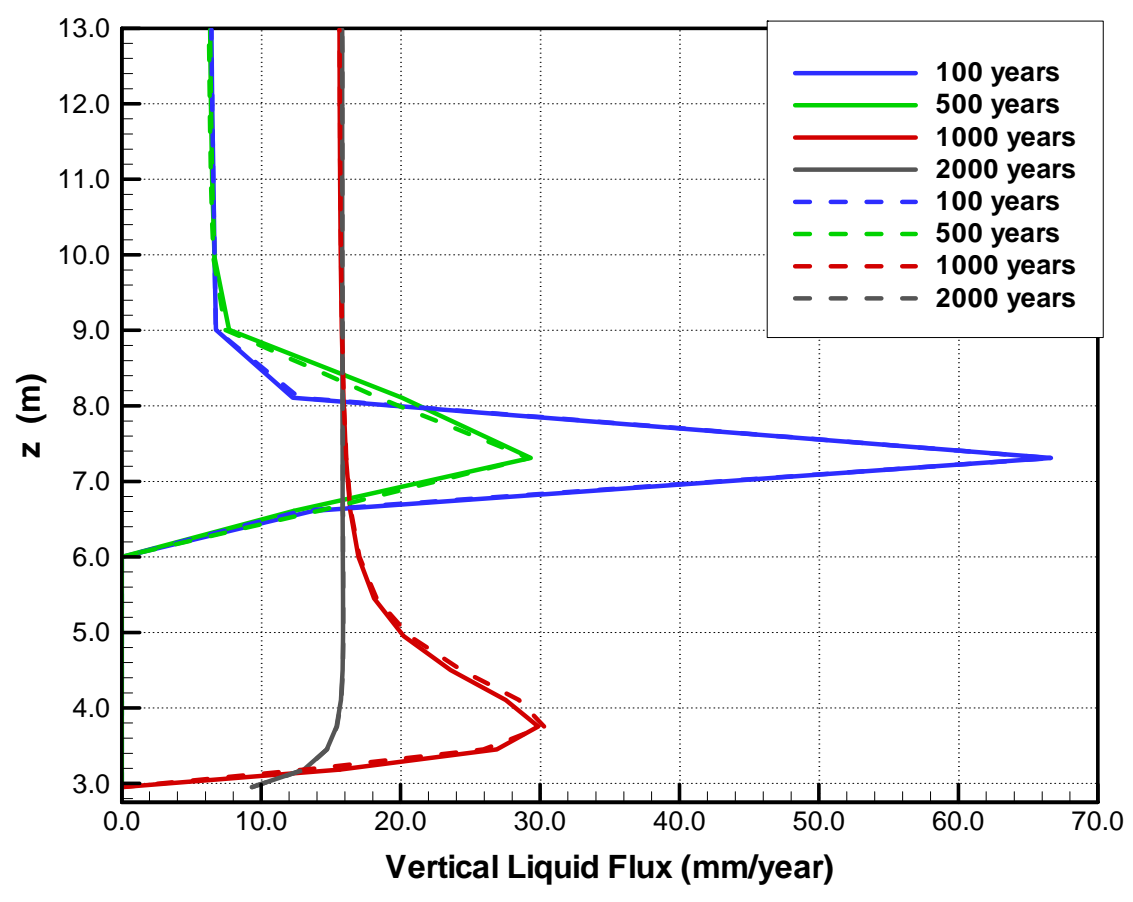

(b)

Output DTN: NA (See Section 8.5).

NOTE: The solid blue line represents new thermal properties; the dashed red line represents previous thermal properties.

Figure C-4. (a) Fracture Saturation and (b) Vertical Liquid Flux in a Vertical Cross Section above Drift Crown for Tptpmn Submodel, Comparing New vs. Previous Thermal Properties (Simulation Cases MN-HOM-NEW-01 vs. MN-HOM-01) 


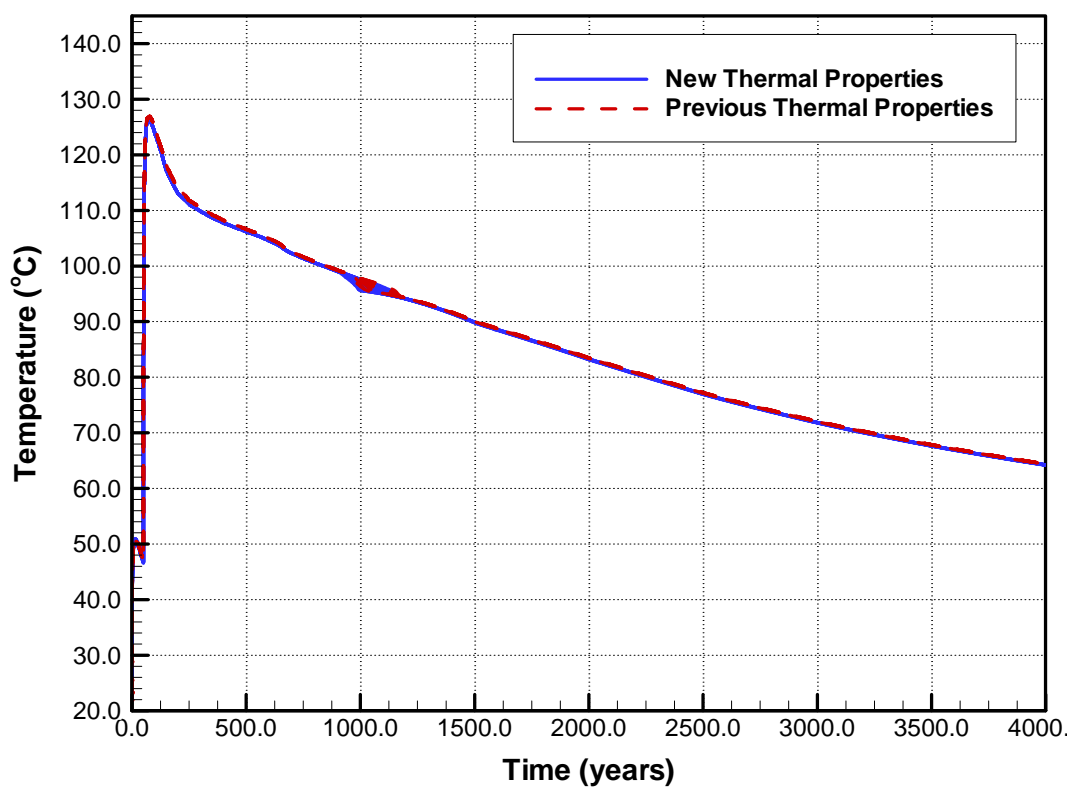

Output DTN: LB0404DSCPTHSM.001.

NOTE: Figure shows all rock discretization elements along the drift periphery from the crown to the springline.

Figure C-5. Evolution of Rock Temperature for Tptpmn Submodel with Flux Multiplication Factor 1 (Realization 1), Comparing New vs. Previous Thermal Properties (Simulation Cases MN-HET-NEW-01 vs. MN-HET-01)

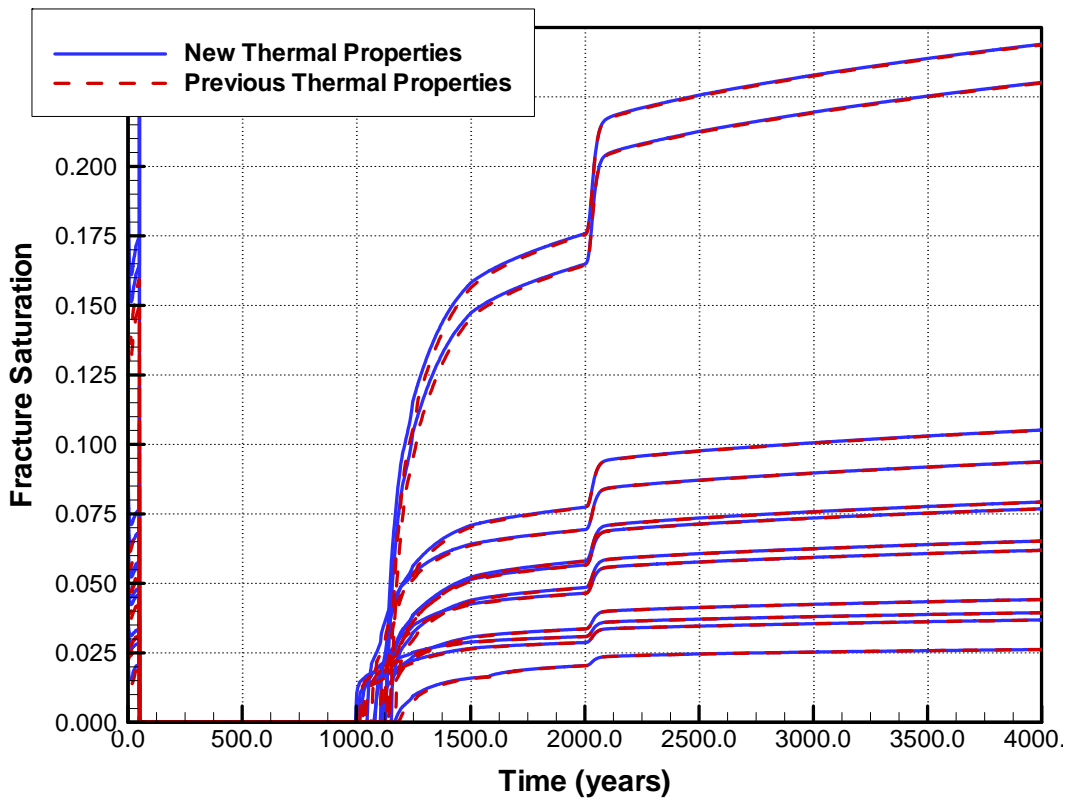

Output DTN: LB0404DSCPTHSM.001.

NOTE: Figure shows all rock discretization elements along the drift periphery from the crown to the springline.

Figure C-6. Evolution of Fracture Saturation for Tptpmn Submodel with Flux Multiplication Factor 1 (Realization 1), Comparing New vs. Previous Thermal Properties (Simulation Cases MN-HET-NEW-01 vs. MN-HET-01) 


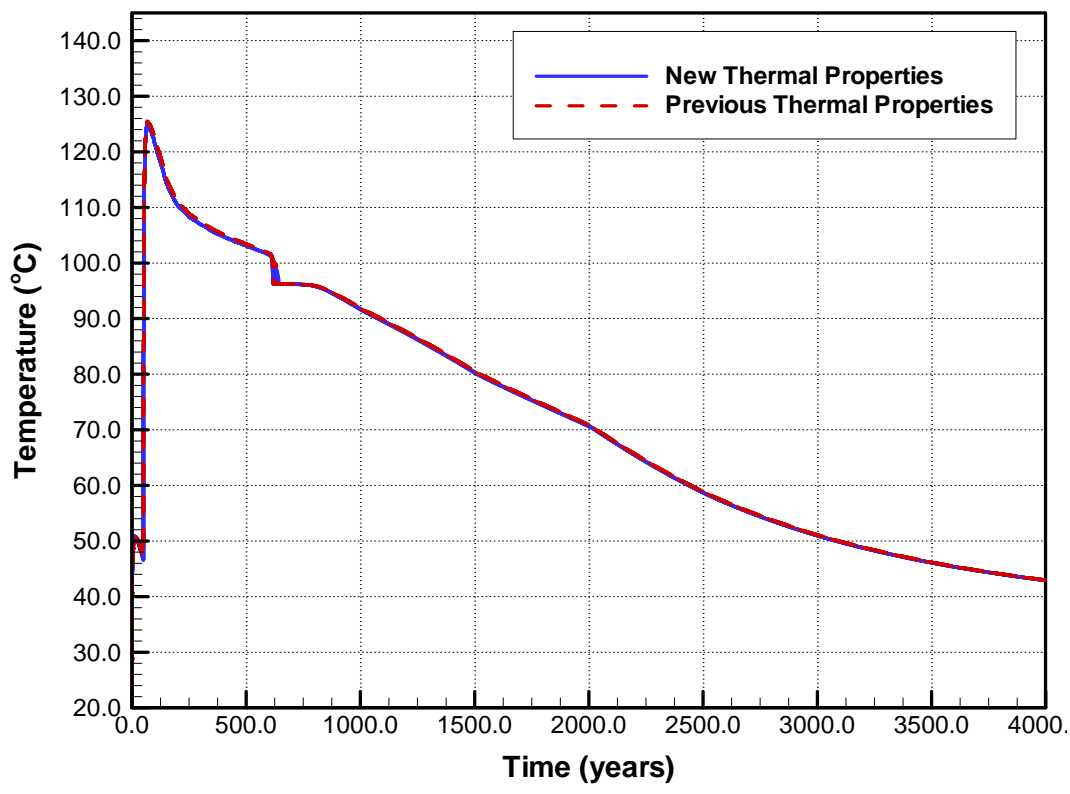

Output DTN: LB0404DSCPTHSM.001.

NOTE: Figure shows all rock discretization elements along the drift periphery from the crown to the springline.

Figure C-7. Evolution of Rock Temperature for Tptpmn Submodel with Flux Multiplication Factor 5 (Realization 1), Comparing New vs. Previous Thermal Properties (Simulation Cases MN-HET-NEW-02 vs. MN-HET-02)

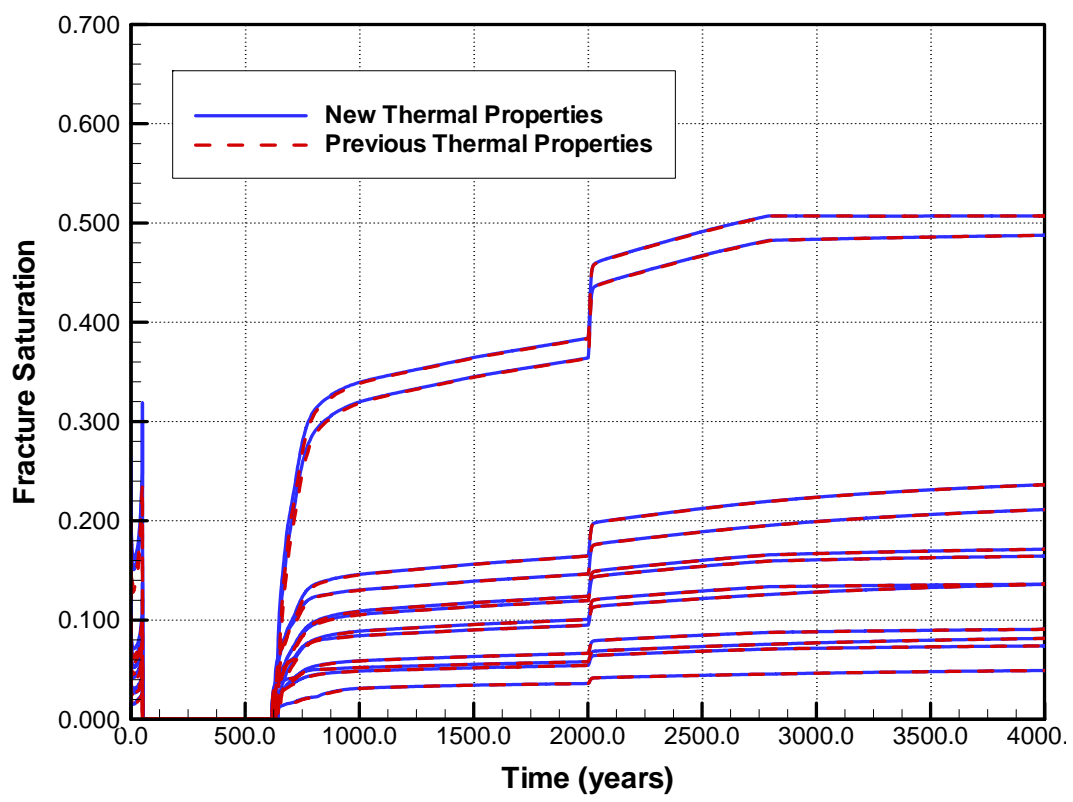

Output DTN: LB0404DSCPTHSM.001.

NOTE: $\quad$ Figure shows all rock discretization elements along the drift periphery from the crown to the springline.

Figure C-8. Evolution of Fracture Saturation for Tptpmn Submodel with Flux Multiplication Factor 5 (Realization 1), Comparing New vs. Previous Thermal Properties (Simulation Cases MN-HET-NEW-02 vs. MN-HET-02) 


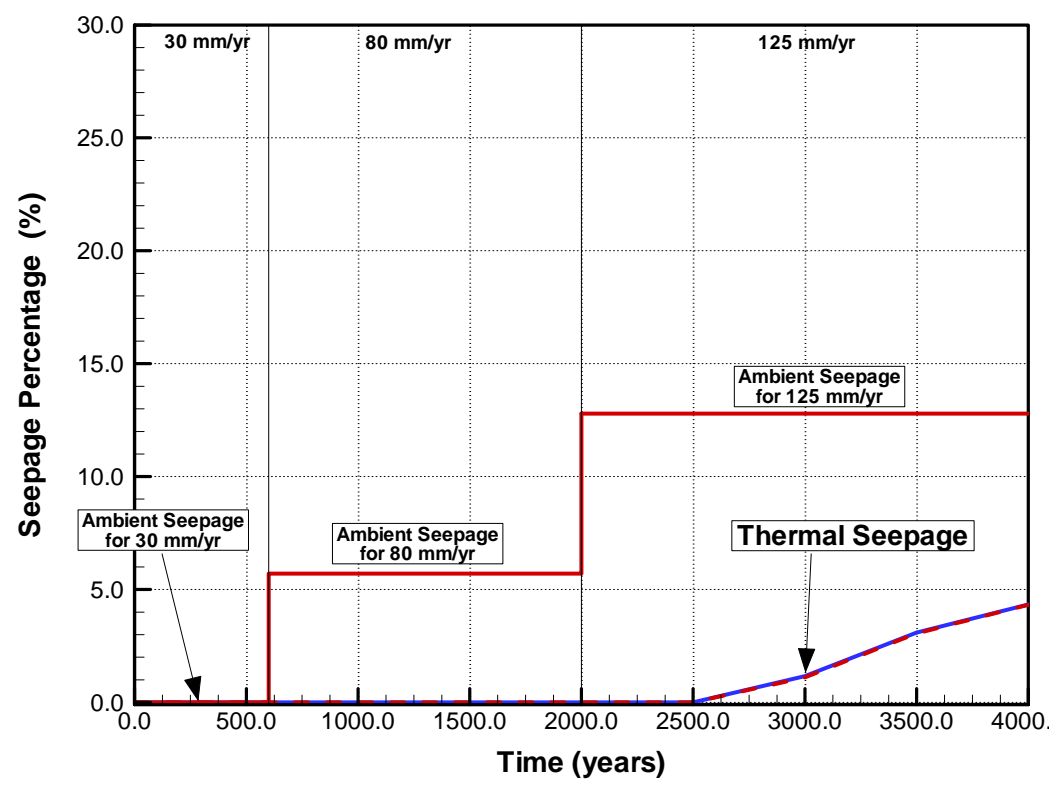

Output DTN: LB0404DSCPTHSM.001.

NOTE: The solid blue line represents new thermal properties; the dashed red line represents previous thermal properties.

Figure C-8. Evolution of Thermal Seepage for Tptpmn Submodel with Flux Multiplication Factor 5 (Realization 1), Comparing New vs. Previous Thermal Properties (Simulation Cases MN-HET-NEW-02 vs. MN-HET-02).

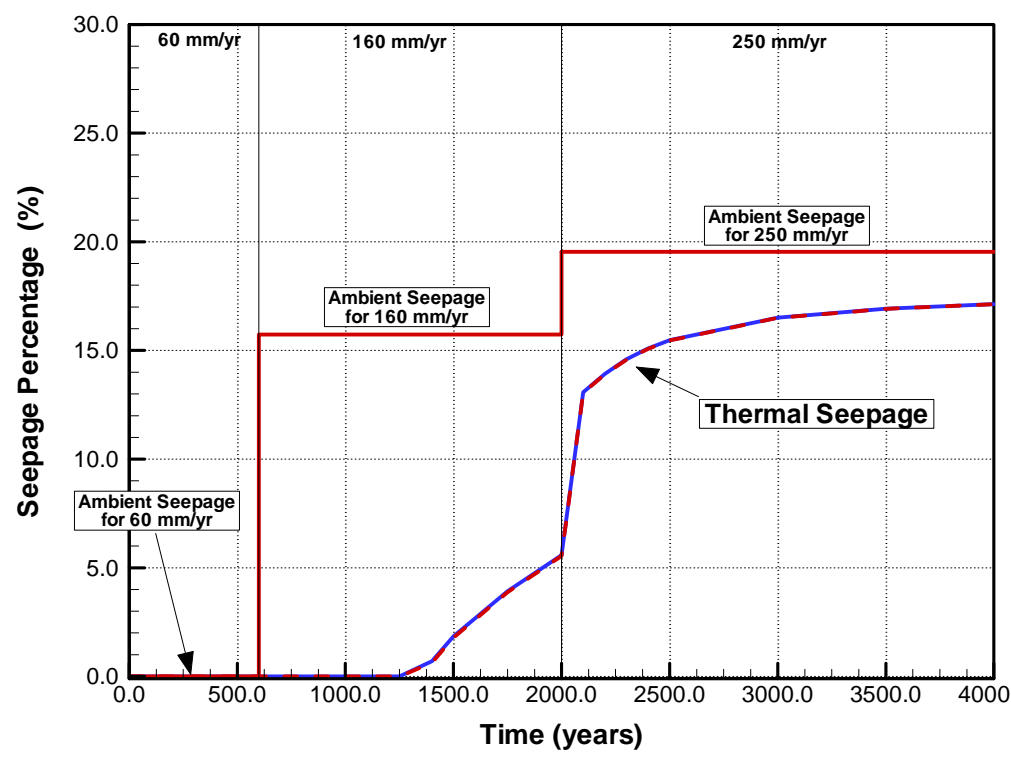

Output DTN: LB0404DSCPTHSM.001.

NOTE: The solid blue line represents new thermal properties; the dashed red line represents previous thermal properties.

Figure C-9. Evolution of Thermal Seepage for Tptpmn Submodel with Flux Multiplication Factor 10 (Realization 1), Comparing New vs. Previous Thermal Properties (Simulation Cases MN-HET-NEW-03 vs. MN-HET-03) 


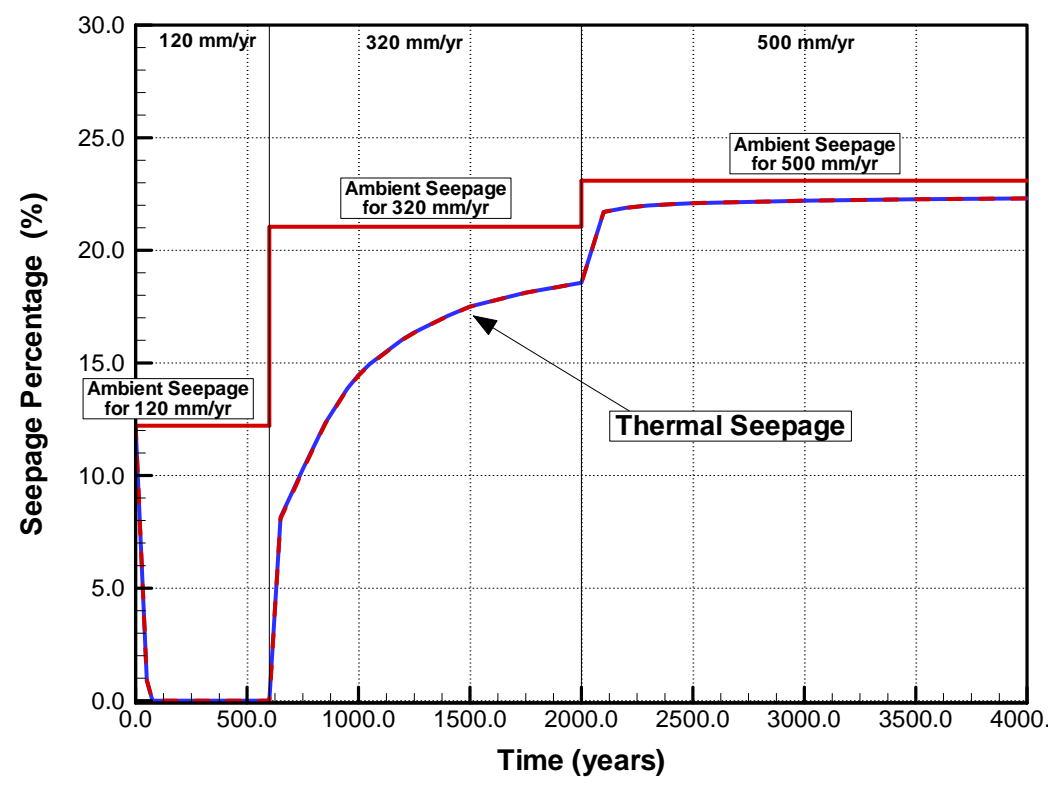

Output DTN: LB0404DSCPTHSM.001.

NOTE: The solid blue line represents new thermal properties; the dashed red line represents previous thermal properties.

Figure C-10. Evolution of Thermal Seepage for Tptpmn Submodel with Flux Multiplication Factor 10 (Realization 1), Comparing New vs. Previous Thermal Properties (Simulation Cases MN-HET-NEW-03 vs. MN-HET-03)

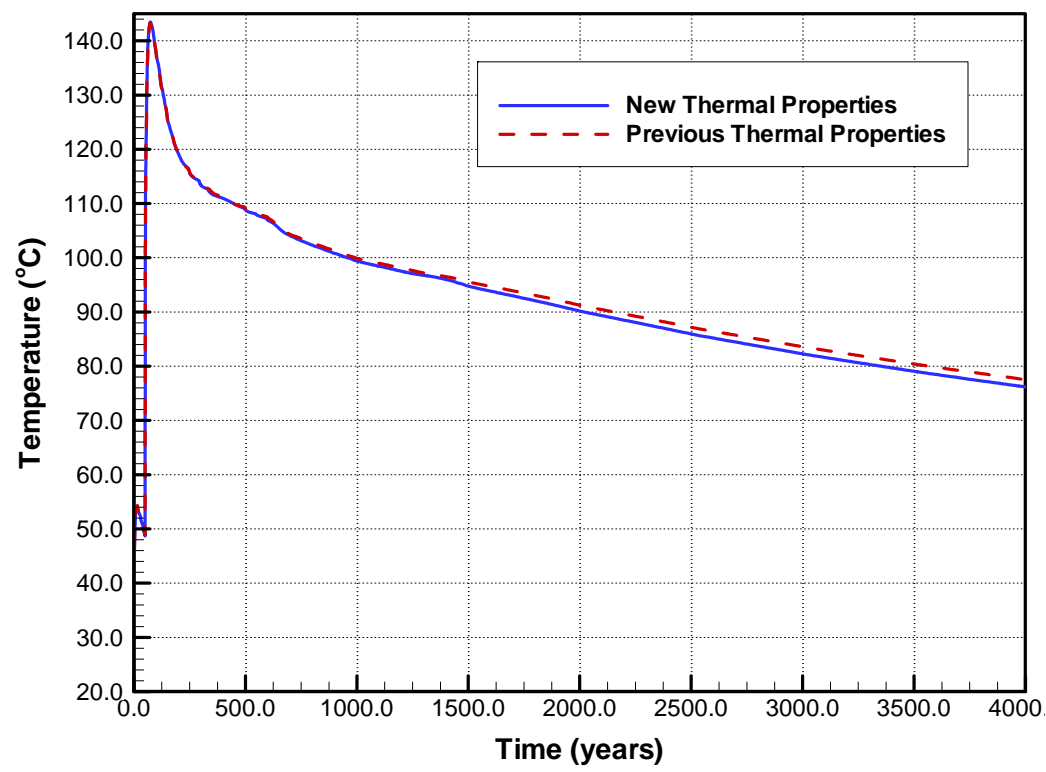

Output DTN: NA (See Section 8.5).

Figure C-11. Evolution of Rock Temperature at the Drift Crown for Tptpll Submodel, Comparing New vs. Previous Thermal Properties (Simulation Cases LL-HOM-NEW-01 vs. LL-HOM-01) 


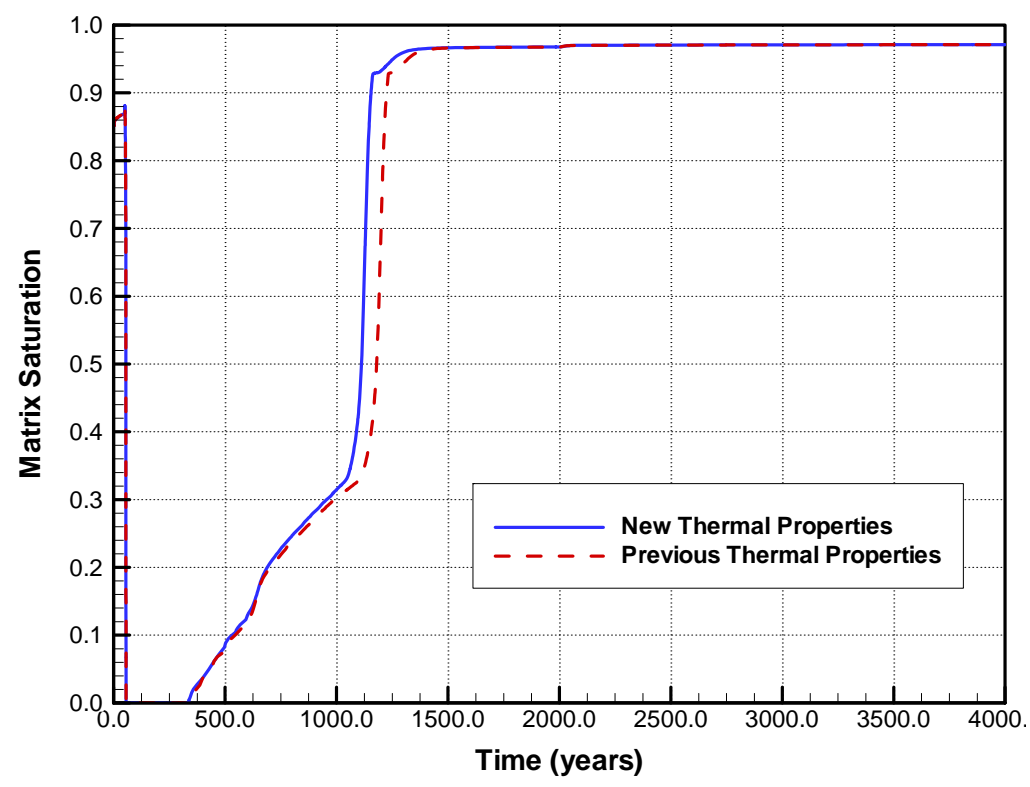

Output DTN: NA (See Section 8.5).

Figure C-12. Evolution of Matrix Saturation at the Drift Crown for Tptpll Submodel, Comparing New vs. Previous Thermal Properties (Simulation Cases LL-HOM-NEW-01 vs. LL-HOM-01)

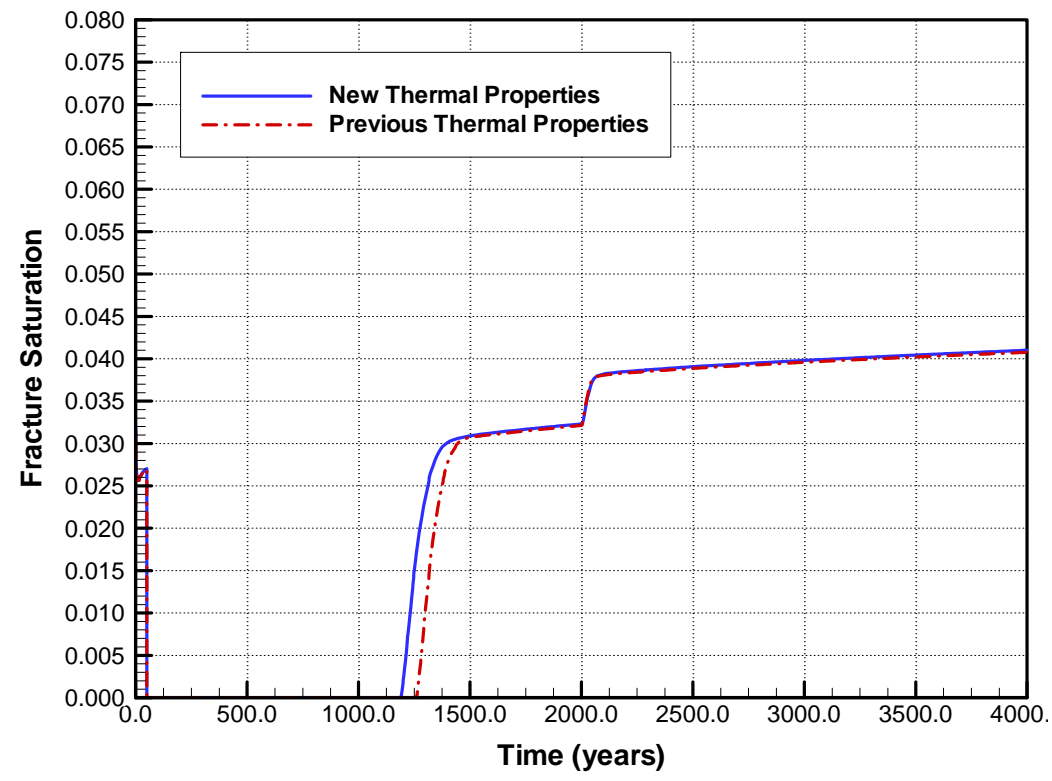

Output DTN: NA (See Section 8.5).

Figure C-13. Evolution of Fracture Saturation at the Drift Crown for Tptpll Submodel, Comparing New vs. Previous Thermal Properties (Simulation Cases LL-HOM-NEW-01 vs. LL-HOM-01) 


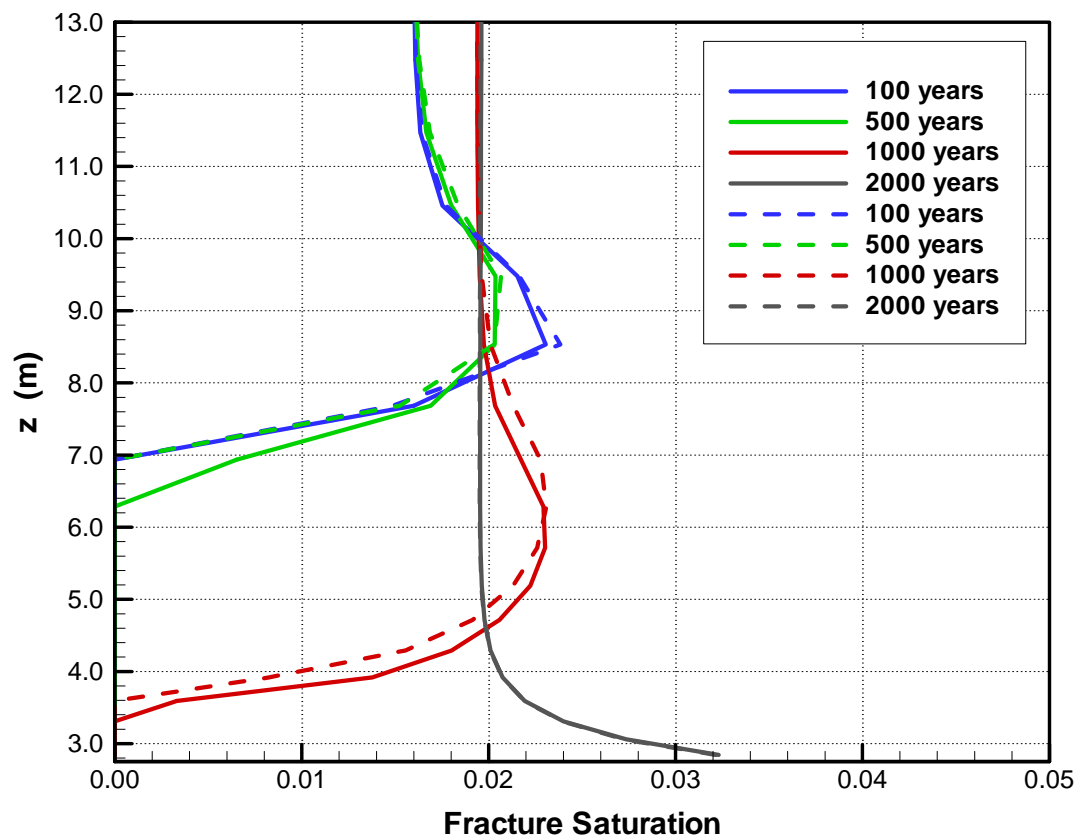

(a)

Fracture Saturation

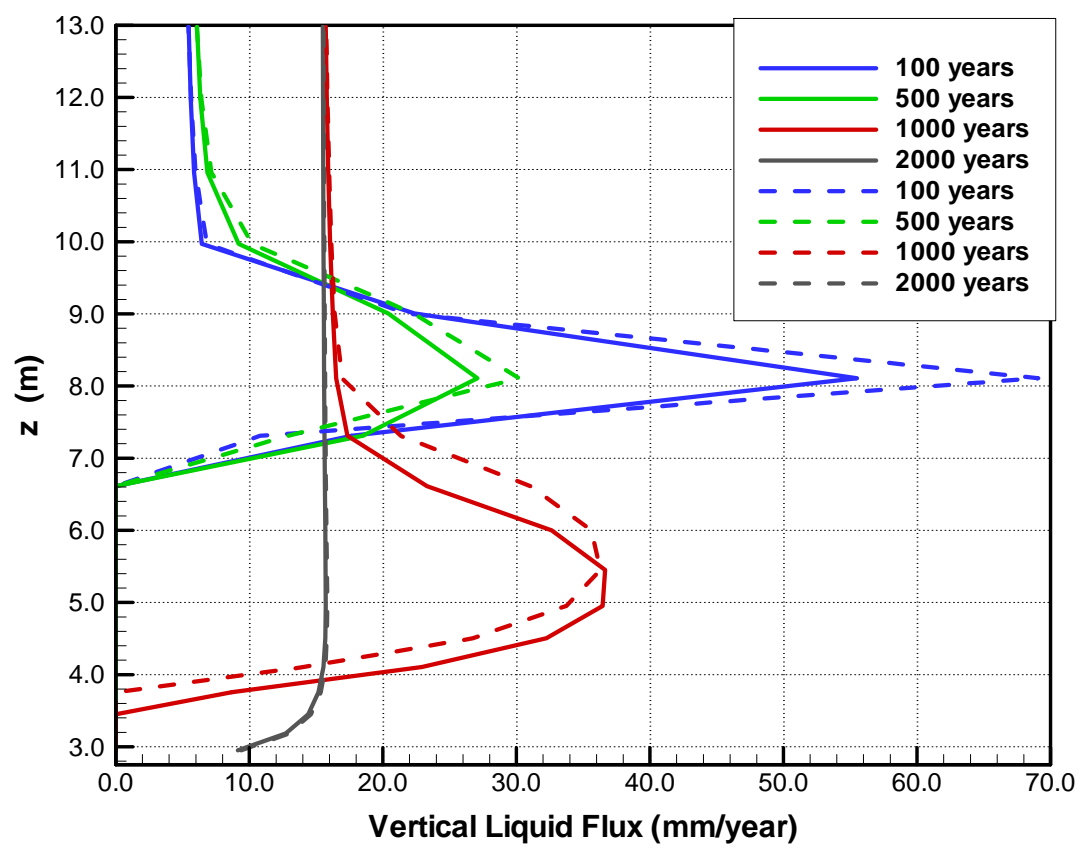

(b)

Output DTN: NA (See Section 8.5).

NOTE: The solid blue line represents new thermal properties; the dashed red line represents previous thermal properties.

Figure C-14. (a) Fracture Saturation and (b) Vertical Liquid Flux in a Vertical Cross Section above Drift Crown for Tptpll Submodel, Comparing New vs. Previous Thermal Properties (Simulation) 
APPENDIX D

TOP AND BOTTOM MODEL BOUNDARY CONDITIONS 
1. Extracting Top and Bottom Boundary Conditions from DTN: LB0303THERMSIM.001 [DIRS 165167]

a. Download the contents of the DTN from the TDMS.

b. Locate the folder "LB0303THERMSIM.001.zip." On a PC, open the DTN with the help of WinZip (double click on the folder).

c. Locate the file SAVE_2_20_03_as_final_calibrated and open it (double click to open).

d. Using the 'Find' facility under 'Edit', first find 'Tp Tph74'. The first number in the line immediately following 'Tp Tph74' is the pressure (in Pa), the second number is gas saturation plus ten (gas saturation is dimensionless), and the third number is temperature (in degrees centigrade). Since 'Tp Tph74' is at the top of Column ' $h 74$ ', the top boundary condition at the top of Column ' $h 74$ ' is

i. Pressure: $86304 \mathrm{~Pa}$ (rounded off)

ii. Gas Saturation: $10.9899999-10=0.99$ (rounded off)

iii. Temperature: $17.33^{\circ} \mathrm{C}$ (rounded off)

These numbers are given in the 4th row and 3rd column of Table 4.1-6 as the top boundary conditions.

e. Repeat step (d) for "Bt Bth74" for bottom boundary conditions in column ' $h 74$ '

f. Repeat step (d) for 'Tp Tph28' for top boundary conditions in Column 'h28', which represents the top boundary condition for the Tptpmn submodel.

g. Repeat step (d) for 'Bt Bth28' for bottom boundary condition at Column 'h28' (or bottom boundary condition in the Tptpmn submodel).

2. Extracting Top and Bottom Boundary Conditions from DTN: LB991131233129.004 [DIRS 162183]

a. Download the contents of the DTN from the TDMS.

b. Locate the folder “LB991131233129.004.zip.” On a PC, open the DTN with the help of WinZip (double click on the file name).

c. Locate the file "pa99cal_ecm.out" and open it by double clicking on it.

d. Using the 'Find' facility under 'Edit', first find 'Tpj34'. The second number in the same line with 'Tpj34' is the pressure (in Pa), the third number is temperature (in degrees centigrade), and the fourth number is gas saturation (gas saturation is dimensionless). Since 'Tpj34' is at the top of Column ' $\mathrm{j} 34$ ', the top boundary condition at the top of Column ' $\mathrm{j} 344$ ' is

i. Pressure: $84765 \mathrm{~Pa}$

ii. Gas Saturation: 0.99 (rounded off)

iii. Temperature: $16.08^{\circ} \mathrm{C}$ (rounded off)

These numbers are given in the 4th row and 2nd column of Table 4.1-6 as the top boundary conditions.

e. Repeat step (d) for "Btj34” for bottom boundary conditions in column ' $\mathrm{j} 34$ '

f. Repeat step (d) for 'Tpi64' for top boundary conditions in Column 'i64', which represents the top boundary condition for the Tptpmn submodel.

g. Repeat step (d) for 'Bti64' for bottom boundary condition at Column 'i64' (or bottom boundary condition in the Tptpmn submodel). 


\section{INTENTIONALLY LEFT BLANK}




\section{APPENDIX E \\ EXTRACTION OF CONTACT ELEVATION FROM THREE-DIMENSIONAL UZ NUMERICAL GRIDS}


The procedures for extraction of contact elevation between various stratigraphic layers in selected vertical columns from three-dimensional UZ numerical grids are provided below. Procedures are also provided for calculating the thicknesses of the various stratigraphic layers in those selected columns. The procedures below are explained for the vertical columns (adopted and revised) utilized for the Tptpll submodel. Contact elevations and thicknesses of the stratigraphic layers in selected columns (adopted and revised) of the Tptpmn submodel can also be obtained following similar procedures.

\section{Extraction of Column Data From DTN: LB03023DKMGRID.001 [DIRS 162354]}

a. Download DTN: LB03023DKMGRID.001 from the TDMS. Unzip the contents of LB03023DKMGRID.001 using WinZip on a PC.

b. Transfer the file 'mesh_3dn.dkm' to a Unix platform.

c. Execute the following commands on a Unix machine (for Column ' $h 74$ '): $>>$ grep 'h74' mesh_3dn.dkm > mesh_h74

$>>$ grep $-\mathrm{v}$ ' $\mathrm{F}$ ' mesh_h74 >> mesh_mat_h74

d. Use an editor to open file "mesh_mat_h74" and use the editor to remove all element connections for which the cosine vector is not $-.1000 \mathrm{E}+01$. This will ensure that one has only vertical connections between elements. Save this file.

e. The last column in 'mesh_mat_h74' gives the elevation of the center of the various elements in Column 'h74' (element names are given in the first column of 'mesh_mat_h74', the second and third column provide the rock type and the volume of the elements. The fifth and sixth columns give the $\mathrm{x}$ - and $\mathrm{y}$-coordinates of the center of the elements.

f. Now use the interface distances in the connection section of the elements in conjunction with the elevations of the center of the elements to calculate the elevations at the top of each element. Repeat this for the first element of each rock type; the result is the elevation of the top of each geological layer. These results are given in the second column of Table 4.1-9

g. Example: Locate element M0003h74 in file 'mesh_mat_h74.' This is the only element in rock type tcw13 (noted as 'tcwM3'to indicate that it is a matrix element not a fracture). Its grid center elevation is $1321.4 \mathrm{~m}$. This element is connected to element M002Dh74, which is the last element in tcw12, and its center is located at $1333.7 \mathrm{~m}$. To find the elevation of the interface between elements M002Dh74 and M0003h74, do the following:

Check the vertical connection between these elements. Their vertical connection is the sixth connection in the list of connections. The distance of the interface between those two elements is 2.662 from the center of M0003h74 or $9.670 \mathrm{~m}$ from the center of M002Dh74. Either way, the elevation of their interface is $1324.1 \mathrm{~m}$ ( 1321.4+2.662 or 1333.7-9.670). Since M002Dh74 is the last element in tcw12 and M0003h74 is the first element in tcw13, this is the elevation at the top of tcw13. This is noted in the second column of Table 4.1-9.

h. The thickness of each layer is calculated by taking a difference of the successive layers. These results are given in the third column of Table 4.1-9.

Example: The thickness (= $34.5 \mathrm{~m}$ ) of the 'tsw34' stratigraphic layer is calculated by subtracting the elevation of the top of 'tsw35' $(=1129.7 \mathrm{~m})$ from the elevation of the top of the 'tsw34' layer (= $1164.2 \mathrm{~m})$. 
2. Extraction of Column Data From DTN: LB990501233129.004 [DIRS 111475]

a. Download DTN: LB990501233129.004 from the TDMS. Unzip the contents of LB990501233129.004 using WinZip on a PC.

b. Transfer the files to a Unix platform. Then go into the directory 3-D_Grid_Calib. Find the file 3d2kcalib_pc1.mesh.

c. Execute the following commands on a Unix machine (for Column ' $\mathrm{j} 34$ '):

$>$ grep ‘j34' 3d2kcalib_pc1.mesh > mesh_j34

$>>$ grep $-v$ 'F' mesh_j34>> mesh_mat_j34

d. Use an editor to open file "mesh_mat_j34" and use the editor to remove all element connections for which the cosine vector is not $-.1000 \mathrm{E}+01$. This will ensure that one has only vertical connections between elements. Save this file.

i. The last column in 'mesh_mat_j34' gives the elevation of the center of the various elements in Column ' $\mathrm{j} 34$ ' (element names are given in the first column of 'mesh_mat_j34', the second and third column provide the rock type and the volume of the elements. The fifth and sixth columns give the $\mathrm{x}$ - and $\mathrm{y}$-coordinates of the center of the elements.

j. Now take an average of the elevations of the center of the elements to calculate the elevations at the top of each element. Repeat this for the first element of each rock type, the result is the elevation of the top of each geological layer. These elevations (in meters) are given in the second column of Table 4.1-9.

k. Example: Locate element Mdj34 in file 'mesh_mat_j34.' This is the only element in rock type tcw13 (noted as 'tcwM3'to indicate that it is a matrix element not a fracture). Its grid center elevation is $1328.7494 \mathrm{~m}$. This element is connected to element Mcj34, which is the last element in tcw12, and its center is located at $1355.3887 \mathrm{~m}$. To find the elevation of the interface between elements Mcj34 and Mdj34, calculate the arithmetic average of $1355.3887 \mathrm{~m}$ and $1328.7494 \mathrm{~m}$. The result is an elevation of $1342.1 \mathrm{~m}$ (rounded off) at the top of 'tcw13.' This is noted in the second column in Table 4.1-8 (check for 'tcw13').

1. The thickness of each layer is calculated by subtracting the elevations of successive layers. The resultant thicknesses are provided in the third column of Table 4.1-9. Example: For the 'tsw34' stratigraphic layer, its top elevation is at $1164.2 \mathrm{~m}$. The top elevation of the 'tsw35' layer is at $1129.7 \mathrm{~m}$. Thus, the thickness of the 'tsw34' layer is $1169.2-1132.0=37.2 \mathrm{~m}$. This result is provided in the third column of Table 4.1-9 (check value for 'tsw34'). 


\section{APPENDIX F \\ DERIVATION OF THERMAL PROPERTIES FOR UZ MODEL LAYERS IN DTN: LB0402THRMLPRP.001}


Thermal properties include rock grain density, dry and wet rock thermal conductivities, rock grain specific heat capacity, matrix porosity, lithophysae porosity, and fracture porosity. These properties are basic inputs into model studies involving heat flow.

Thermal properties for the UZ model layers in DTN: LB0210THRMLPRP.001 [DIRS 160799] were developed from the thermal-property data for the various lithostratigraphic layers (DTNs: SN0206T0503102.005 [DIRS 160258] and SN0208T0503102.007 [DIRS 160257]). The first of these two DTNs supplies thermal properties for most of the lithostratigraphic layers except the geological layers at the repository horizon. The second DTN deals with thermal properties of the geological layers in the repository horizon, namely the upper lithophysal, the middle nonlithophysal, the lower lithophysal, and the lower nonlithophysal stratigraphic units of Topopah Spring welded tuff.

Wet and dry thermal conductivity, matrix porosity, and bulk density data for the nonrepository lithostratigraphic layers have been updated. The most recent qualified data for these parameters can be found in DTN: SN0303T0503102.008 [DIRS 162401]. The heat capacity values of the lithostratigraphic layers are taken from DTN: SN0402T0503102.010 [DIRS 170993]. The thermal properties of the UZ model layers have thus been updated based on data available in three DTNs: SN0208T0503102.007 [DIRS 160257], SN0402T0503102.010 [DIRS 170993], and SN0303T05030102.008 [DIRS 162401].

In most cases, a UZ model layer directly corresponds to a unique lithostratigraphic unit. In such instances, the thermal properties are adopted directly from their corresponding stratigraphic unit without alteration. On the other hand, when a UZ model layer is composed of two or more adjacent lithostratigraphic units, the averaging technique of Francis (1997 [DIRS 127326], pp. 5 to 7) is used for estimating the properties while assuming an equal thickness for all the relevant units. The conceptual model underlying this technique is that heat flow is one-dimensional and in a direction normal to interfaces between the units under consideration. This is appropriate considering that heat flow in the ambient system and in the disturbed system (during repository heating) at Yucca Mountain is predominantly vertical. (This is because the horizontal dimensions of the repository horizon are much larger than the vertical dimension.) The corresponding equivalent thermal conductivity ( $\left.\lambda_{\text {wet or } d r y, ~ e q}\right)$, grain density $\left(\rho_{g, e q}\right)$, and heat capacity $\left(C_{p, \text { eq }}\right)$ are calculated using the following equations which were derived from those of Francis (1997 [DIRS 127326], pp. 5 to 7) assigning a uniform thickness for different geologic units within each model layer containing more than one geologic units:

$$
\begin{gathered}
\lambda_{k, e q}=\frac{n \prod_{i=1}^{n} \lambda_{k, i}}{\sum_{j=1}^{n}\left(\prod_{i=1, i \neq j}^{n} \lambda_{i}\right)}(\mathrm{k}=\text { wet or dry }) \\
\rho_{g, e q}=\frac{\sum_{i=1}^{n} \rho_{g, i}}{n}
\end{gathered}
$$




$$
C_{p, e q}=\frac{\sum_{i=1}^{n} C_{p, i} \rho_{g, i}}{n \rho_{g, e q}}
$$

where $n$ is the total number of the involved lithostratigraphic units, and $\lambda_{g, i}, \rho_{g, i}$ and $C_{p, i}$ are heat conductivity, grain density, and heat capacity, respectively, for a lithostratigraphic unit $i$. Note that the use of an equal thickness for all the relevant units within a model layer is adequate here because differences between thermal properties for these units (within a model layer) are not significant. Additionally, resultant matrix porosities are the simple arithmetic mean of the porosities for the constituent stratigraphic units. The calculated thermal properties for the UZ model layers are given in Table F-1. The determination of the properties is described in scientific notebooks (Wang 2003 [DIRS 161123], pp. 69 to 79; Wang 2004 [DIRS 170510], pp. 30 to 33).

The thermal conductivities listed in Table F-1 are matrix thermal conductivities. For lithophysal stratigraphic units and corresponding UZ model layers, it is often necessary to use the bulk thermal conductivities instead of the matrix thermal conductivities. For stratigraphic units Tptpul, Tptpmn, Tptpll and Tptpln (or UZ model layers tsw33, tsw34, tsw35 and tsw36), lithophysal porosities are listed in Table F-1 (from DTN: SN0208T0503102.007 [DIRS 160257]). For these stratigraphic units, the bulk thermal conductivities are also listed in DTN: SN0208T0503102.007 [DIRS 160257]. The bulk thermal conductivities of the corresponding UZ model layers are listed in Table F-2. For further details, refer to the Scientific Notebooks (Wang 2004 [DIRS 161123], pp. 69 to 79; Wang 2004 [DIRS 170510], pp. 30 to 33).

The thermal properties of the faults are developed using the averaging techniques discussed above (Francis 1997 [DIRS 127326]). The UZ model represents faults as having four layers that are defined by the major hydrogeologic units (HGU), TCw, PTn, TSw, and CHn/Cfu. For each of these units, averages are taken across all the stratigraphic subunits. For example, to obtain the matrix thermal properties of tcwf, averages were taken over Tpcr, Tpcp, Tpcpv3, and Tpcpv2. The details of the calculations can again be found in scientific notebooks (Wang 2003 [DIRS 161123], pp. 76 to 79; Wang 2004 [DIRS 170510], pp. 30 to 33). The calculated fault thermal properties are listed in Table F-3.

The data reported in Tables F-1, F-2, and F-3 have been compiled and submitted to the TDMS under output DTN: LB0402THRMLPRP.001. 
Table F-1. Matrix Thermal Properties for the UZ Model Layers

\begin{tabular}{|c|c|c|c|c|c|c|}
\hline Model Layer & $\begin{array}{l}\text { Grain Density } \\
\left(\mathrm{kg} / \mathrm{m}^{3}\right)\end{array}$ & $\begin{array}{c}\text { Grain Specific } \\
\text { Heat Capacity } \\
(\mathrm{J} / \mathrm{kg}-\mathrm{K})\end{array}$ & $\begin{array}{c}\text { Dry Thermal } \\
\text { Conductivity } \\
(\mathrm{W} / \mathrm{m}-\mathrm{K})\end{array}$ & $\begin{array}{l}\text { Wet Thermal } \\
\text { Conductivity } \\
\text { (W/m-K) }\end{array}$ & $\begin{array}{c}\text { Matrix } \\
\text { Porosity } \\
(-)\end{array}$ & $\begin{array}{c}\text { Lithophysae } \\
\text { Porosity } \\
(-)\end{array}$ \\
\hline tcw11 & 2486 & 985.0 & 1.3000 & 1.8100 & 0.1190 & N/A \\
\hline tcw12 & 2486 & 985.0 & 1.3000 & 1.8100 & 0.1190 & N/A \\
\hline tcw13 & 2385 & 1040.1 & 0.5724 & 0.9092 & 0.2105 & N/A \\
\hline ptn21 & 2374 & 1040.1 & 0.4900 & 1.0600 & 0.3850 & $N / A$ \\
\hline ptn22 & 2374 & 1040.1 & 0.4900 & 1.0600 & 0.3850 & $N / A$ \\
\hline ptn23 & 2374 & 1040.1 & 0.4900 & 1.0600 & 0.3850 & $N / A$ \\
\hline ptn24 & 2374 & 1040.1 & 0.4900 & 1.0600 & 0.3850 & N/A \\
\hline ptn25 & 2374 & 1040.1 & 0.4900 & 1.0600 & 0.3850 & N/A \\
\hline ptn26 & 2374 & 1040.1 & 0.4900 & 1.0600 & 0.3850 & N/A \\
\hline tsw31 & 2441 & 1012.0 & 0.8998 & 1.1057 & 0.0775 & N/A \\
\hline tsw32 & 2486 & 985.0 & 1.3000 & 1.8100 & 0.1190 & N/A \\
\hline tsw33 & 2344 & 985.0 & 1.3223 & 1.9093 & 0.1429 & 0.123 \\
\hline tsw34 & 2466 & 985.0 & 1.4553 & 2.1276 & 0.1287 & 0.025 \\
\hline tsw35 & 2325 & 985.0 & 1.3998 & 2.0707 & 0.1486 & 0.088 \\
\hline tsw36 & 2473 & 985.0 & 1.5356 & 2.1958 & 0.1058 & 0.03 \\
\hline tsw37 & 2473 & 985.0 & 1.5356 & 2.1958 & 0.1058 & 0.03 \\
\hline tsw38 & 2396 & 1040.1 & 0.6880 & 0.7960 & 0.0360 & N/A \\
\hline tsw39 & 2374 & 1040.1 & 0.4900 & 1.0600 & 0.3850 & N/A \\
\hline $\operatorname{ch} 1[v, z]$ & 2374 & 1040.1 & 0.4900 & 1.0600 & 0.3850 & N/A \\
\hline $\operatorname{ch} 2[v, z]$ & 2504 & 1037.5 & 0.5950 & 1.2600 & 0.3330 & N/A \\
\hline $\operatorname{ch} 3[v, z]$ & 2504 & 1037.5 & 0.5950 & 1.2600 & 0.3330 & N/A \\
\hline $\operatorname{ch} 4[v, z]$ & 2504 & 1037.5 & 0.5950 & 1.2600 & 0.3330 & N/A \\
\hline $\operatorname{ch} 5[v, z]$ & 2504 & 1037.5 & 0.5950 & 1.2600 & 0.3330 & N/A \\
\hline $\operatorname{ch6}[v, z]$ & 2504 & 1037.5 & 0.5950 & 1.2600 & 0.3330 & N/A \\
\hline pp4 & 2557 & 1040.1 & 0.5690 & 1.1300 & 0.3000 & N/A \\
\hline pp3 & 2557 & 1040.1 & 0.5690 & 1.1300 & 0.3000 & N/A \\
\hline pp2 & 2587 & 1012.2 & 0.7405 & 1.3347 & 0.2545 & N/A \\
\hline pp1 & 2519 & 1040.1 & 0.5959 & 1.1493 & 0.2767 & N/A \\
\hline bf3 & 2485 & 1021.1 & 0.7877 & 1.3434 & 0.1937 & N/A \\
\hline bf2 & 2506 & 1040.1 & 0.6112 & 1.1584 & 0.2640 & N/A \\
\hline tr3 & 2658 & 1021.4 & 0.6408 & 1.2337 & 0.2910 & N/A \\
\hline tr2 & 2635 & 1040.1 & 0.5350 & 1.1000 & 0.3320 & $N / A$ \\
\hline
\end{tabular}

Output DTN: LB0402THRMLPRP.001. 
Table F-2. Bulk Thermal Conductivities of Repository Model Layers

\begin{tabular}{|l|l|l|}
\hline \multicolumn{1}{|c|}{ Model Layer } & Dry Thermal Conductivity (W/m-K) & Wet Thermal Conductivity (W/m-K) \\
\hline tsw33 & 1.1636 & 1.6785 \\
\hline tsw34 & 1.4191 & 2.0743 \\
\hline tsw35 & 1.2788 & 1.8905 \\
\hline tsw36 & 1.4901 & 2.1304 \\
\hline tsw37 & 1.4901 & 2.1304 \\
\hline
\end{tabular}

Output DTN: LB0402THRMLPRP.001.

Table F-3. Fault Thermal Properties

\begin{tabular}{|l|l|l|l|l|l|l|}
\hline Major Unit & $\begin{array}{c}\text { Fault } \\
\text { Layer }\end{array}$ & $\begin{array}{c}\text { Grain } \\
\text { Density } \\
\left(\mathrm{kg} / \mathrm{m}^{3}\right)\end{array}$ & $\begin{array}{c}\text { Grain Specific } \\
\text { Heat Capacity } \\
(\mathrm{J} / \mathrm{kg}-\mathrm{K})\end{array}$ & $\begin{array}{c}\text { Dry Thermal } \\
\text { Conductivity } \\
(\mathrm{W} / \mathrm{m}-\mathrm{K})\end{array}$ & $\begin{array}{c}\text { Wet Thermal } \\
\text { Conductivity } \\
(\mathrm{W} / \mathrm{m}-\mathrm{K})\end{array}$ & $\begin{array}{c}\text { Matrix } \\
\text { Porosity }(-\end{array}$ \\
\hline TCw & tcwf & 2435 & 1012.0 & 0.7948 & 1.2104 & 0.1648 \\
\hline PTn & ptnf & 2374 & 1040.1 & 0.4900 & 1.0600 & 0.3850 \\
\hline TSw & tswf & 2400 & 1003.3 & 0.9696 & 1.3923 & 0.1383 \\
\hline CHn & chnf & 2509 & 1034.4 & 0.5884 & 1.1761 & 0.3068 \\
\hline CFu & cfuf & 2565 & 1029.8 & 0.6419 & 1.2124 & 0.2645 \\
\hline
\end{tabular}

Output DTN: LB0402THRMLPRP.001. 


\section{APPENDIX G \\ QUALIFICATION OF DATA FROM DTN：SN9908T0872799.004 FOR INTENDED USE IN THIS REPORT}




\section{G.1 PURPOSE OF DATA QUALIFICATION}

Although DTN: SN9908T0872799.004 [DIRS 108437] is the technical output of the calculation presented in Tabulated In-Drift Geometric and Thermal Properties Used in Drift-Scale Models for TSPA-SR (CRWMS M\&O 2000 [DIRS 171790], Table 2), unqualifed inputs were used in the development of those results, which were thus identified by that report as requiring further verification. The purpose of this data qualification effort is to qualify the values derived from DTN: SN9908T0872799.004 [DIRS 108437], for the parameters shown in Table G-1, as adequate for their intended use in the drift-scale modeling of TH seepage in this report. Some of the data from SN9908T0872799.004 [DIRS 108437], which have been used to develop the predictions in this report, have since been superceded. Even though these data have been superceded, the data are shown below to be qualified as adequate for their intended use in this report. This qualification is done following AP-SIII.2Q, Qualification of Unqualified Data, and in accordance with the Data Qualification Plan included in Section G.8.

Table G-1. Parameters and Values from DTN: SN9908T0872799.004 [DIRS 108437] to be Qualified

\begin{tabular}{|l|l|}
\hline \multicolumn{1}{|c|}{ Parameter } & \multicolumn{1}{c|}{ Value } \\
\hline Waste Package and Drip Shield Dimensions and Attributes & $1.945 \mathrm{~m}$ \\
\hline Location of waste package center above bottom of drift & $0.805 \mathrm{~m}$ \\
\hline Location of waste package center below the drift springline & $0.396 \mathrm{~m}$ \\
\hline $\begin{array}{l}\text { Air gap between waste package surface and the inside of drip shield (only } \\
\text { used for collapsed drift scenarios in Section 6.2.5) }\end{array}$ & $1.231 \mathrm{~m}$ \\
\hline Inside radius of drip shield & $8189.2 \mathrm{~kg} / \mathrm{m}^{3}$ \\
\hline Waste package shell density & $488.86 \mathrm{~J} / \mathrm{kg} / \mathrm{K}$ \\
\hline Waste package specific heat & \\
\hline & \\
\hline Invert Properties & $6.152 \times 10^{-10} \mathrm{~m}^{2}$ \\
\hline Invert intrinsic permeability & 0.545 \\
\hline Invert porosity & $2530 \mathrm{~kg} / \mathrm{m}^{3}$ \\
\hline Invert grain density & $948 \mathrm{~J} / \mathrm{kg} / \mathrm{K}$ \\
\hline Invert specific heat
\end{tabular}

\section{G.2 PURPOSE OF DATA BEING QUALIFIED}

The data being qualified in this appendix relates to dimensions, configuration, and properties of the in-drift materials for a typical emplacement drift. These data were needed to enable the development of the TH seepage model (based on the TOUGH2 simulator). The primary purpose (see Section 1) of the TH seepage model is to estimate the quantity of seepage that could enter a repository drift; hence, the configuration and properties that are assigned to the in-drift components (such as the waste packages and the invert) have little impact on the predictions of seepage by the model. Consequently, the data evaluation criteria presented below are based on reasonableness of the input data, both in terms of design changes, as well as in the scientific sense, rather than actual input requirements of the model. 


\section{G.3 QUALIFICATION METHODS}

Consistent with AP-SIII.2Q, the method selected to qualify the data in Table G-2 is adopted from Method 2 in Attachment 3 of the qualification procedure:

- Corroborating Data - The data to be qualified are compared with either more recent project data, or with similar data developed by duplicate or independent calculations since DTN: SN9908T0872799.004 [DIRS 108437] was developed. A comparison is made with current controlled YMP documentation or data in the TDMS for corroboration.

\section{G.4 QUALIFICATION PROCESS ATTRIBUTES}

Consistent with AP-SIII.2Q from Attachment 4, the attributes associated with this data qualification include:

3. The extent to which the data demonstrate the properties of interest (e.g., physical, chemical, geologic, mechanical).

This attribute is justified for application here because the data being qualified were developed specifically for the repository waste emplacement drifts.

10. Extent and quality of corroborating data or confirmatory testing results.

This attribute is appropriate because of the availability of the newer project data that supersedes the data directly used in this report and can corroborate the values in DTN: SN9908T0872799.004 [DIRS 108437].

\section{G.5 DATA EVALUATION CRITERIA}

Consistent with AP-SIII.2Q, criteria have been established to evaluate the adequacy of the data being qualified. In general terms, the data selected to represent the in-drift environment must be reasonably consistent with either (1) the dimensions, geometry, and configuration with the current repository layout, or (2) the results of comparable calculations.

(1) The dimensions and properties associated with the waste package and drip shield should be within a factor of 25 percent of the most recent values (if a single value is available), or within the range from the most recent source;

(2) Because the properties of the invert have little impact on the model, the values that were used should be scientifically reasonable, and thus values of porosity, specific heat, and density should be within 25 percent of the most recent values, if a single value is available for them or they should be located within the range of values obtained from the most recent source. The value of permeability should be within one order of magnitude of the most recent value. 


\section{G.6 EVALUATION OF DATA TO BE QUALIFIED}

Table G-2 contains the input model data that is to be qualified. The model input value can be compared to the values given in the corroborative information.

Table G-2. In-Drift Geometry and Property Choices for TH Seepage Model

\begin{tabular}{|c|c|c|c|c|}
\hline \multirow{2}{*}{ Parameter } & \multicolumn{2}{|l|}{ Model Input } & \multicolumn{2}{|c|}{ Corroborative Information } \\
\hline & Source & Value & Value & Source \\
\hline \multicolumn{5}{|c|}{ Waste Package and Drip Shield Dimensions and Attributes } \\
\hline $\begin{array}{l}\text { Location of waste } \\
\text { package center above } \\
\text { bottom of drift }\end{array}$ & $\begin{array}{l}\text { DTN: } \\
\text { SN9908T0872799.004 } \\
\text { [DIRS 108437] }\end{array}$ & $1.945 \mathrm{~m}$ & $1.750-2.150 \mathrm{~m}$ & $\begin{array}{l}\text { BSC } 2004 \text { [DIRS 168489] } \\
\text { (center line of waste package } \\
\text { height above invert from } \\
\text { Figure 1) and BSC } 2004 \\
\text { [DIRS 169776] (invert } \\
\text { thickness) }\end{array}$ \\
\hline $\begin{array}{l}\text { Location of waste } \\
\text { package center below } \\
\text { the drift springline }\end{array}$ & $\begin{array}{l}\text { DTN: } \\
\text { SN9908T0872799.004 } \\
\text { [DIRS 108437] }\end{array}$ & $0.805 \mathrm{~m}$ & $0.6-1.0 \mathrm{~m}$ & $\begin{array}{l}\text { BSC } 2004 \text { [DIRS 168489] } \\
\text { (drift diameter and center line } \\
\text { of waste package height } \\
\text { above invert from Figure 1) } \\
\text { and BSC } 2004 \text { [DIRS 169776] } \\
\text { (invert thickness) }\end{array}$ \\
\hline $\begin{array}{l}\text { Air gap between } \\
\text { waste package } \\
\text { surface and the inside } \\
\text { of drip shield (only } \\
\text { used for collapsed } \\
\text { drift scenarios in } \\
\text { Section } 6.2 .5 \text { ) }\end{array}$ & $\begin{array}{l}\text { DTN: } \\
\text { SN9908T0872799.004 } \\
\text { [DIRS 108437] }\end{array}$ & $0.396 \mathrm{~m}$ & $0.367-1.132 \mathrm{~m}$ & $\begin{array}{l}\text { BSC } 2004 \text { [DIRS 168489]), } \\
\text { Figure } 1\end{array}$ \\
\hline $\begin{array}{l}\text { Inside radius of drip } \\
\text { shield }\end{array}$ & $\begin{array}{l}\text { DTN: } \\
\text { SN9908T0872799.004 } \\
\text { [DIRS 108437] }\end{array}$ & $1.231 \mathrm{~m}$ & $1.285 \mathrm{~m}$ & BSC 2004 [DIRS 168283] \\
\hline $\begin{array}{l}\text { Waste package shell } \\
\text { density (see also } \\
\text { Section } 4.1 .1 .6 \text { ) }\end{array}$ & $\begin{array}{l}\text { DTN: } \\
\text { SN9908T0872799.004 } \\
\text { [DIRS 108437] }\end{array}$ & $8189.2 \mathrm{~kg} / \mathrm{m}^{3}$ & $8690 \mathrm{~kg} / \mathrm{m}^{3}$ & $\begin{array}{l}\text { DTN: } \\
\text { MO0003RIB00071.000 } \\
\text { [DIRS 148850] } \\
\text { Mass density of Alloy } 22 \\
\text { (N06022), which is the outer } \\
\text { barrier of the following WPs: } \\
\text { 21-PWR AP, 44-BWR, } \\
5 \text { DHLW/DOE SNF-SHORT, } \\
5 \text { DHLW/DOE SNF-LONG. } \\
\text { The density of the waste } \\
\text { package internal cylinder is } \\
2,175-3,495 \mathrm{~kg} / \mathrm{m}^{3} \text { (BSC } \\
2004 \text { [DIRS } 167758]) .\end{array}$ \\
\hline $\begin{array}{l}\text { Waste package } \\
\text { specific heat }\end{array}$ & $\begin{array}{l}\text { DTN: } \\
\text { SN9908T0872799.004 } \\
\text { [DIRS 108437] }\end{array}$ & $488.86 \mathrm{~J} / \mathrm{kg} / \mathrm{K}$ & $378-731 \mathrm{~J} / \mathrm{kg} / \mathrm{K}$ & $\begin{array}{l}\text { BSC } 2004 \text { [DIRS 167758], } \\
\text { Table } 20 .\end{array}$ \\
\hline
\end{tabular}


Table G-2. In-Drift Geometry and Property Choices for TH Seepage Model (Continued)

\begin{tabular}{|c|c|c|c|c|}
\hline \multirow{2}{*}{ Parameter } & \multicolumn{2}{|l|}{ Model Input } & \multicolumn{2}{|c|}{ Corroborative Information } \\
\hline & Source & Value & Value & Source \\
\hline \multicolumn{5}{|c|}{ Invert Properties (Continued) } \\
\hline $\begin{array}{l}\text { Invert intrinsic } \\
\text { permeability }\end{array}$ & $\begin{array}{l}\text { DTN: } \\
\text { SN9908T0872799.004 } \\
\text { [DIRS 108437] }\end{array}$ & $\begin{array}{l}6.152 \times 10^{-10} \\
\mathrm{~m}^{2} \\
(2 \text { to } 4.75 \mathrm{~mm} \\
\text { particles })\end{array}$ & $\begin{array}{l}6.0 \times 10^{-10} \mathrm{~m}^{2} \\
(3 \mathrm{~mm} \text { particle) } \\
(\text { a) }\end{array}$ & $\begin{array}{l}\text { BSC } 2003 \text { [DIRS 170881], } \\
\text { Section 6.4 and Attachment } \\
\text { XI; CRWMS M\&O } 2001 \\
\text { [152016], Attachment XV }\end{array}$ \\
\hline Invert porosity & $\begin{array}{l}\text { DTN: } \\
\text { SN9908T0872799.004 } \\
\text { [DIRS 108437] }\end{array}$ & 0.545 & $0.55^{(b)}$ & $\begin{array}{l}\text { BSC } 2003 \text { [DIRS 170881], } \\
\text { Attachment XI; CRWMS } \\
\text { M\&O } 2001 \text { [DIRS 152016], } \\
\text { Attachment XIV }\end{array}$ \\
\hline Invert grain density & $\begin{array}{l}\text { DTN: } \\
\text { SN9908T0872799.004 } \\
\text { [DIRS 108437] }\end{array}$ & $2530 \mathrm{~kg} / \mathrm{m}^{3}$ & $2530 \mathrm{~kg} / \mathrm{m}^{3}$ (c) & $\begin{array}{l}\text { BSC } 2003 \text { [DIRS 170881], } \\
\text { Attachment XI; CRWMS } \\
\text { M\&O } 2001 \text { [DIRS 152016], } \\
\text { Attachment XIV }\end{array}$ \\
\hline Invert specific heat & $\begin{array}{l}\text { DTN: } \\
\text { SN9908T0872799.004 } \\
\text { [DIRS 108437] }\end{array}$ & $948 \mathrm{~J} / \mathrm{kg} / \mathrm{K}$ & $930 \mathrm{~J} / \mathrm{kg} / \mathrm{K}^{(\mathrm{d})}$ & $\begin{array}{l}\text { BSC } 2003 \text { [DIRS 170881], } \\
\text { Attachment XI }\end{array}$ \\
\hline \multicolumn{5}{|c|}{$\begin{array}{l}\text { a The permeability of the invert is estimated from the curve fitting analysis presented in CRWMS M\&O } 2001 \text { [DIRS } \\
\text { 152016]. } \\
\text { b The porosity of the invert is calculated using measured data (from the sources cited) for grain density }\left(2530 \mathrm{~kg} / \mathrm{m}^{3}\right) \text { and } \\
\text { bulk density }\left(1150 \mathrm{~kg} / \mathrm{m}^{3}\right) \text { of crushed tuff sieved between } 2.00 \text { to } 4.75 \mathrm{~mm} \text {. } \\
\text { c The grain density of invert material is the measured (from the source cited) grain density of crushed tuff sieved } \\
\text { between } 2.00 \text { and } 4.75 \mathrm{~mm} \text {. } \\
\text { d The specific heat of invert material is the average of the } 11 \text { ( } 4-10 \text { crushed tuff) samples listed in DTN: } \\
\text { GS000483351030.003 [DIRS 152932]. }\end{array}$} \\
\hline
\end{tabular}

\section{G.7 FINDINGS OF DATA QUALIFICATION EFFORT}

The parameters grouped under "Waste Package and Drip Shield Dimensions and Attributes" in Table G.2 are repository design information that has evolved since the current $\mathrm{TH}$ seepage models were developed. The comparison of these model input data with the more recent values shows that all of the model input values are within 25 percent of the current values or that they reside within the range of current values, and thus meet the criteria of acceptability for use in this model report. The model input data are therefore demonstrated to be qualified for their application.

The input values for the parameters grouped under "Invert Properties" in Table G-2 can be corroborated by either the duplication of the calculations used in Tabulated In-Drift Geometric and Thermal Properties Used in Drift-Scale Models for TSPA-SR (CRWMS M\&O 2000 [DIRS 171790]) to generate the values used in the TH seepage modeling, or by comparable derivations of values. For the parameters of intrinsic permeability, porosity, grain density, and heat capacity of the invert, Advection Versus Diffusion in the Invert (BSC 2003 [DIRS 170881]), as well as Water Distribution and Removal Model (CRWMS M\&O 2001 [DIRS 152016]), reproduced the same or similar calculations as those that were used as input to DTN: SN9908T0872799.004 [DIRS 108437]. Both of these reports were developed, checked and approved under the current post-PVAR YMP QA procedures (BSC 2003 [DIRS 170881] was developed under AP-SIII.9Q and CRWMS M\&O 2001 [DIRS 152016] was developed under AP-3.10Q). The comparison of 
the model input data for invert properties with the more recent values shows that all of the model input values meet the criteria of acceptability for use in the TH seepage model.

Based on the above assessment, the data shown on Table G-1 have been demonstrated to be qualified for their application as input to the TH seepage models.

\section{G.8 DATA QUALIFICATION PLAN}

A Data Qualification Plan was developed for the above qualification effort, in accordance with Attachment 2 of AP.SIII.2Q. A facsimile of this plan is provided below.

\begin{tabular}{|c|c|c|}
\hline \multirow{2}{*}{ BSC } & \multirow{2}{*}{ Data Qualification Plan } & QA: QA \\
\hline & & Page 1 of 1 \\
\hline \multicolumn{3}{|c|}{ Section I. Organizational Information } \\
\hline \multicolumn{3}{|l|}{ Qualification Title } \\
\hline \multicolumn{3}{|c|}{ Qualification of In-drift Configuration, Dimensions, and Component Properties for MDL-NBS-HS-000015. } \\
\hline \multicolumn{3}{|c|}{ Requesting Organization } \\
\hline \multicolumn{3}{|c|}{ Near Field Environment and Transport } \\
\hline \multicolumn{3}{|c|}{ Section II. Process Planning Requirements } \\
\hline \multicolumn{3}{|c|}{ 1. List of Unqualified Data to be Evaluated } \\
\hline \multicolumn{3}{|c|}{$\begin{array}{l}\text { See Table G-1 (of MDL-NBS-HS-000015 REV01), Parameters and Values from DTN: SN9908T0872799.004 [DIRS 108437] to be } \\
\text { Qualified. }\end{array}$} \\
\hline \multicolumn{3}{|c|}{$\begin{array}{l}\text { This is data relating to dimensions, configuration, and properties of in-drift materials for a typical emplacement drift. These data were } \\
\text { needed to develop the Thermal-Hydrology (TH) Seepage Model (based on the TOUGH2 simulator). The primary purpose of this } \\
\text { model is to estimate the quantity of seepage that could enter a repository drift and not to model the flow behavior of seepage water } \\
\text { inside the emplacement drift. Hence the configuration and properties that are assigned to the in-drift components have little or no } \\
\text { impact on these seepage predictions. }\end{array}$} \\
\hline \multicolumn{3}{|c|}{ 2. Type of Data Qualification Method(s) [Including rationale for selection of method(s) (Attachment 3) and qualification attributes (Attachment 4)] } \\
\hline \multicolumn{3}{|c|}{$\begin{array}{l}\text { Attributes used from Attachment } 4 \text { of AP-SIII.2Q: Item 3) The extent to which data demonstrate properties of interest; and Item 10) } \\
\text { Extent and quality of corroborating data. }\end{array}$} \\
\hline \multicolumn{3}{|c|}{ 3. Data Qualification Team and Additional Support Staff Required } \\
\hline \multicolumn{3}{|c|}{$\begin{array}{l}\text { Chairperson: Jens Birkholzer, Lawrence Berkeley National Laboratory } \\
\text { Technically competent individual: Sumit Mukhopadhyay, Lawrence Berkeley National Laboratory }\end{array}$} \\
\hline \multicolumn{3}{|c|}{ 4. Data Evaluation Criteria } \\
\hline \multicolumn{3}{|c|}{$\begin{array}{l}\text { The TH Seepage Model (based on TOUGH } 2 \text { simulator) model is created such that all of the heat generated inside an emplacement } \\
\text { drift is transmitted to the host rock. Thus the criteria for having acceptable data is: } \\
\text { 1. In total, the data selected to represent the in-drift environment must be reasonably consistent with either the dimensions, geometry, } \\
\text { and configuration with the repository layout; or with the results of comparable calculations. } \\
\text { 2. The selection of the in-drift component dimensions should be within a factor of } 25 \text { percent of the most recent values or, if a single } \\
\text { value is not appropriate, should reside within the suggested range from the most recent source. The same criteria should apply for } \\
\text { values of porosity, specific heat and density. The value of permeability should be within one order of magnitude of the most recent } \\
\text { value. }\end{array}$} \\
\hline \multicolumn{3}{|c|}{ 5. Identification of Procedures Used } \\
\hline \multicolumn{3}{|c|}{$\begin{array}{l}\text { AP-SIII.10Q, Models } \\
\text { AP-SIII.2Q, Qualification of Unqualified Data }\end{array}$} \\
\hline \multicolumn{3}{|c|}{ Section III. Approval } \\
\hline $\begin{array}{l}\text { Qualification Chairperson Printed Name } \\
\text { Jens Birkholzer }\end{array}$ & Qualification Chairperson Signature & $-16-04$ \\
\hline $\begin{array}{l}\text { Responsible Manager Printed Name } \\
\text { Near Field Environment and Transport }\end{array}$ & Respobsiole Manager Signature & $8 / 16 / 04$ \\
\hline
\end{tabular}


INTENTIONALLY LEFT BLANK 


\section{APPENDIX H \\ DATA QUALIFICATION PLAN FOR QUALIFICATION OF VENTILATION EFFICIENCY VALUE}


The ventilation efficiency value used as direct input to the TH seepage model was calculated using unqualified software. The value has been qualified for use in this report in Section 4.1.1.3, in accordance with the data qualification plan presented below. The original of this plan is included in the records package for this model report.

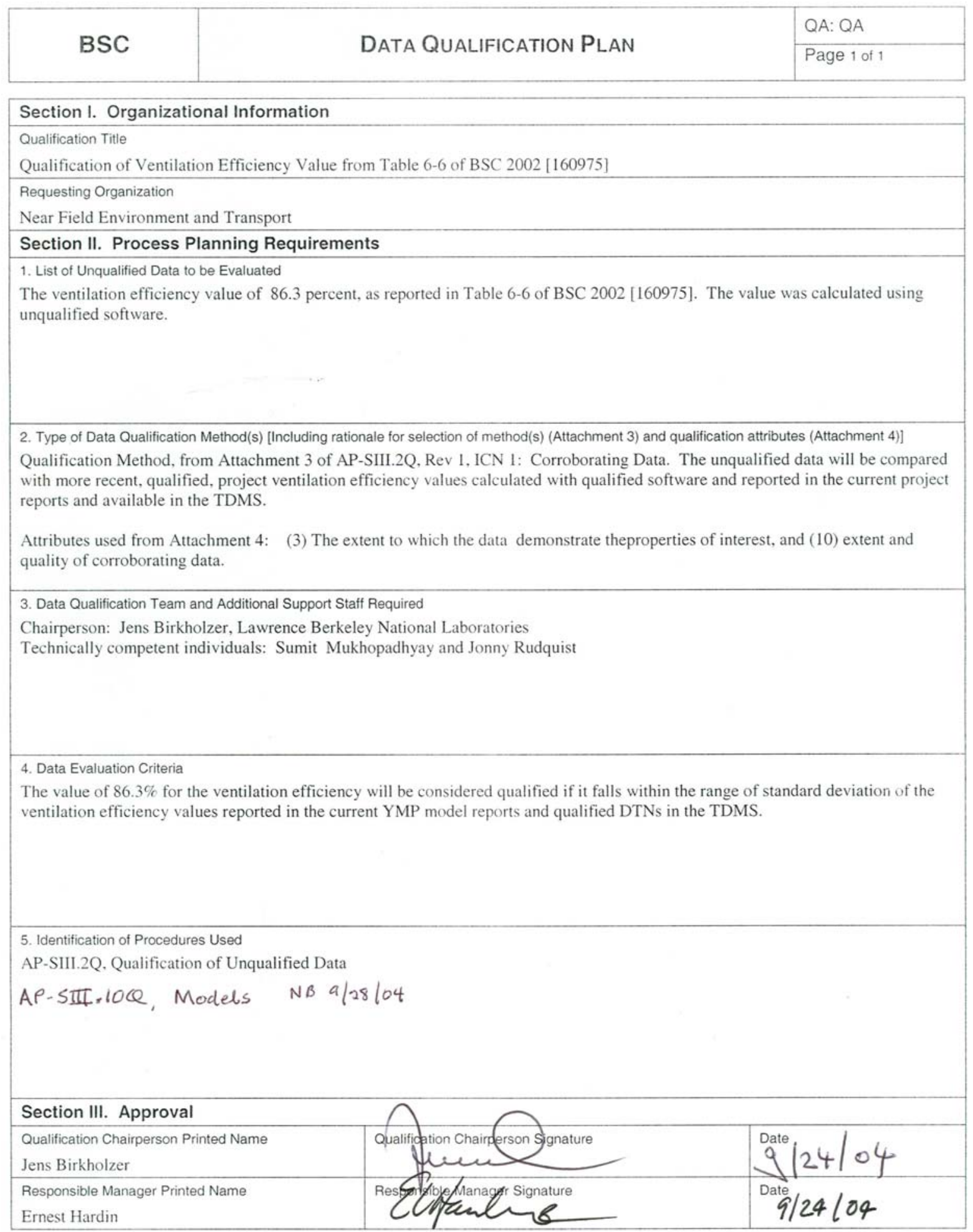




\section{INTENTIONALLY LEFT BLANK}

